\title{
THE STEUBENVILLE COMPREHENSIVE AIR MONITORING PROGRAM (SCAMP)
}

\author{
Final Report
}

For the Period February 1, 1999, through June 30, 2006

Daniel P. Connell, Stephen E. Winter

CONSOL Energy Inc. Research \& Development 4000 Brownsville Road

South Park, PA 15129

412-854-6600

Helen Suh, Stefanie Sarnat, James Sullivan, Robert Canales, Pablo Ruiz Harvard School of Public Health

401 Park Drive

Boston, MA 02215

Report Issued: March 2007

DOE Cooperative Agreement DE-FC26-00NT40771

OCDO Grant Agreement CDO/D-98-2 


\section{DISCLAIMER}

This report was prepared as an account of work sponsored by an agency of the United States Government. Neither the United States Government nor any agency thereof, nor any of their employees, makes any warranty, express or implied, or assumes any legal liability or responsibility for the accuracy, completeness, or usefulness of any information, apparatus, product, or process disclosed, or represents that its use would not infringe privately owned rights. Reference herein to any specific commercial product, process, or service by trade name, trademark, manufacturer, or otherwise does not necessarily constitute or imply its endorsement, recommendation, or favoring by the United States Government or any agency thereof. The views and opinions of authors expressed herein do not necessarily state or reflect those of the United States Government or any agency thereof.

This report was prepared by CONSOL Energy Inc. Research \& Development with support in part by a grant from the Ohio Coal Development Office (OCDO) within the Ohio Air Quality Development Authority (OAQDA). Neither the State of Ohio nor any of its agencies, nor any person acting on behalf of the State:

1. Make any warranty or representation, express or implied, with respect to the accuracy, completeness, or usefulness of the information contained in this report, or that the use of any information, apparatus, method, or process disclosed in this report may not infringe privately-owned rights; or

2. Assume any liabilities with respect to the use of, or for damages resulting from the use of, any information, apparatus, method or process disclosed in this report.

Reference herein to any specific commercial product, process, or service by trade name, trademark, manufacturer, or otherwise, does not necessarily constitute or imply its endorsement, recommendation, or favoring; nor do the view and opinions of authors expressed herein necessarily state or reflect those of the State of Ohio or its agencies.

NOTICE TO JOURNALISTS AND PUBLISHERS: Please feel free to quote and borrow from this report; however, please include a statement noting the Ohio Coal Development Office's support for the project. 


\section{ABSTRACT}

In 1999, CONSOL Energy Inc. Research \& Development (CONSOL R\&D), in cooperation with the research partners and funding agencies acknowledged below, launched the Steubenville Comprehensive Air Monitoring Program (SCAMP) to clarify uncertainties regarding fine particulate matter $\left(\mathrm{PM}_{2.5}\right)$ concentration, composition, and exposure. The study was conducted in Steubenville, Ohio, a small but heavily industrialized city located in the Upper Ohio River Valley that historically has had elevated particulate matter (PM) concentrations and been a key location for PM health effects research. In addition to providing a much-needed current assessment of $\mathrm{PM}_{2.5}$ in Steubenville, which had been studied previously during the late 1970s and 1980s as part of the Harvard Six Cities Study, SCAMP helped to fulfill a number of $\mathrm{PM}_{2.5}$ research needs that remained after the U.S. Environmental Protection Agency (EPA) promulgated a new National Ambient Air Quality Standard (NAAQS) for PM $_{2.5}$ in 1997. These included the need for better estimates of the relationship between ambient concentrations of $\mathrm{PM}_{2.5}$ and its components and actual human exposures to these species, the need to characterize the potential for confounding by gaseous pollutants in $\mathrm{PM}_{2.5}$ epidemiology studies, the need for better characterization of individual chemical components of $\mathrm{PM}_{2.5}$, and the need for data to develop State Implementation Plans (SIPs) in response to the $\mathrm{PM}_{2.5}$ NAAQS.

SCAMP included two major interrelated components. As part of the ambient air monitoring program, which was led by CONSOL R\&D, $\mathrm{PM}_{2.5}, \mathrm{PM}_{2.5}$ components, co-pollutants, and meteorological conditions were monitored from May 2000 through May 2002 at a central ambient air monitoring station in Steubenville, and $\mathrm{PM}_{2.5}$ and its components were simultaneously monitored at four comparatively remote satellite sites in the surrounding region. As part of the indoor and personal exposure program, which was led by the Harvard School of Public Health (HSPH) under subcontract to CONSOL R\&D, personal, indoor, and outdoor exposures to $\mathrm{PM}_{2.5}, \mathrm{PM}_{2.5}$ components, and gaseous pollutants were characterized during the summer and fall of 2000 for a panel of older adults and during the winter and summer of 2001 for a panel of children living in Steubenville. Smaller studies conducted as part of SCAMP included methods development and validation activities and a concurrent evaluation of the effects of $\mathrm{PM}_{2.5}$ and gases on the cardiac health of the older adult panel.

Results from SCAMP reveal the importance of distinct regional- and local-source mechanisms that contribute to ambient $\mathrm{PM}_{2.5}$ concentrations in Steubenville. Regional, secondary-sulfate-dominated $\mathrm{PM}_{2.5}$, likely originating from coal-fired power plants to the west and southwest of Steubenville, is the largest contributor to $\mathrm{PM}_{2.5}$ mass, accounting for about $40 \%$ of the total. Local sources in the immediate Steubenville vicinity, including motor vehicles and iron and steel facilities, account for about $30 \%$ of the total $\mathrm{PM}_{2.5}$ mass observed in the city. $\mathrm{PM}_{2.5}$ from these local sources tends to be enriched in $\mathrm{Fe}, \mathrm{Mn}, \mathrm{Zn}$, and carbon species and to correlate strongly with primary gaseous pollutants, especially during nocturnal inversion-driven episodes. Results also indicate that central-site ambient $\mathrm{PM}_{2.5}$ concentrations are strong proxies of corresponding personal exposures for older adults and, to a lesser extent, for children in Steubenville. The ability of ambient concentrations to reflect personal exposures differed by particle component; for example, ambient concentrations of $\mathrm{SO}_{4}{ }^{2-}$, a predominantly regional pollutant, were better proxies of corresponding personal exposures than were ambient concentrations of elemental carbon, a predominantly local pollutant. Home ventilation conditions also significantly modified personal-ambient associations. Finally, ambient concentration and personal exposure results suggest that time-series health studies based on 24-hour ambient concentrations may not be able to separate the independent effects of particles and gases.

Funding for SCAMP was provided by the U.S. Department of Energy's National Energy Technology Laboratory, Ohio Coal Development Office within the Ohio Air Quality Development Authority, Electric Power Research Institute, American Petroleum Institute, National Mining Association, American Iron and Steel Institute, Edison Electric Institute, National Institute of Environmental Health Sciences, U.S. EPA, and CONSOL Energy Inc. Additional research participants included Ohio University, Franciscan University of Steubenville, Saint Vincent College, Wheeling Jesuit University, Optimal Technologies, Air Quality Sciences, Inc., and Control Analytics, Inc. 


\section{TABLE OF CONTENTS}

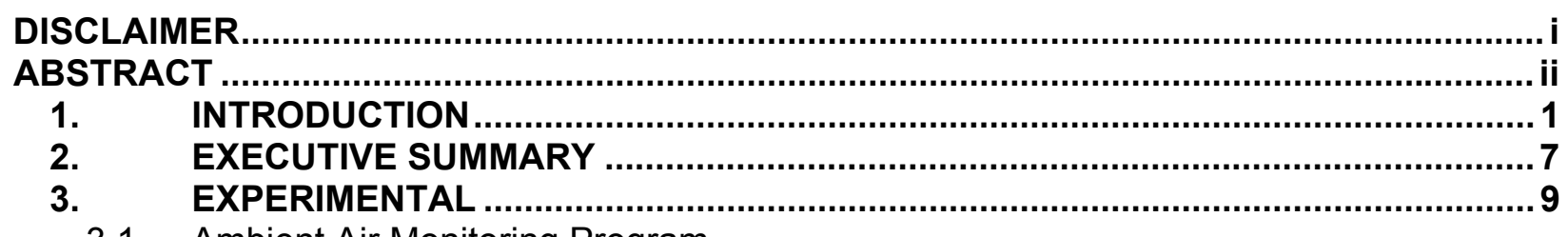

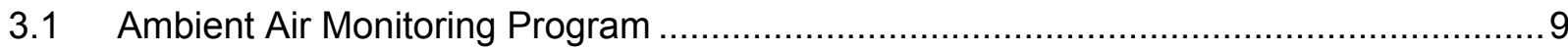

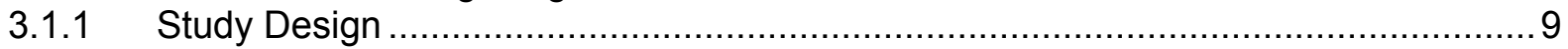

3.1.2 Sampling and Analytical Methods ......................................................... 12

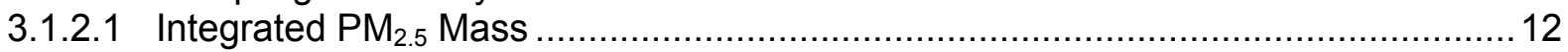

3.1.2.2 $\mathrm{PM}_{2.5}$ Water-Extractable Ions and Elements ............................................. 12

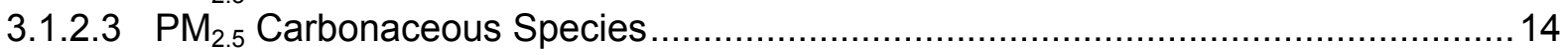

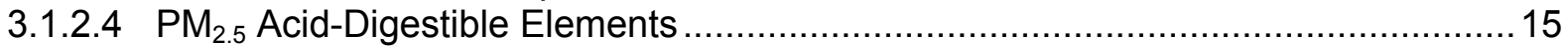

3.1.2.5 Integrated $\mathrm{PM}_{10}$ Mass and Composition .................................................... 16

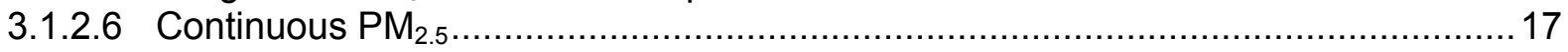

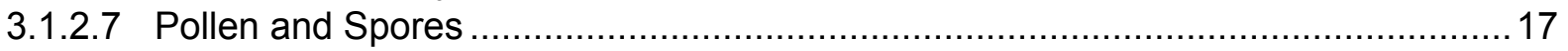

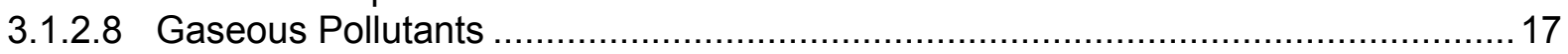

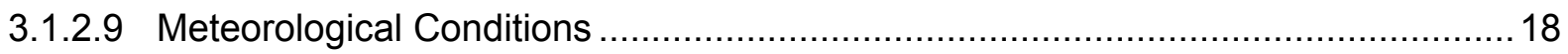

3.1.3 Quality Assurance and Quality Control.................................................. 18

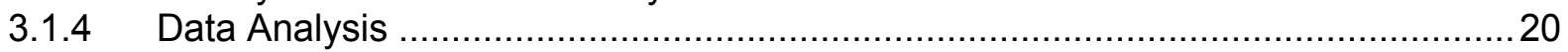

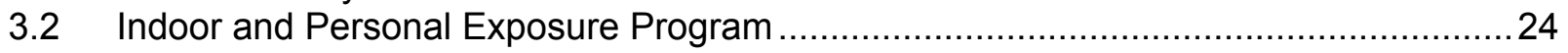

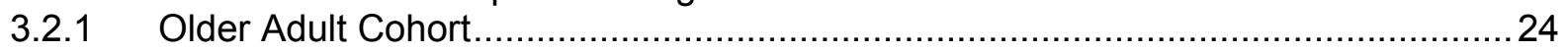

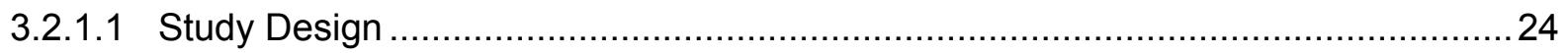

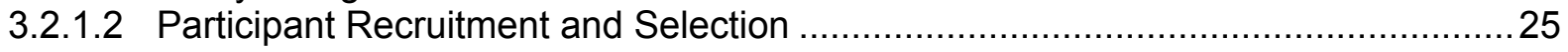

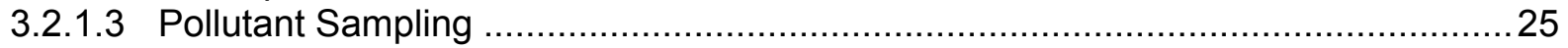

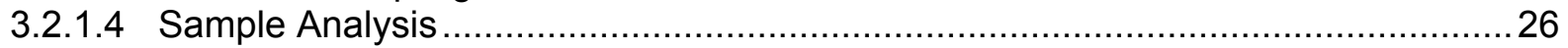

3.2.1.5 Housing Characteristics Questionnaire .......................................................... 26

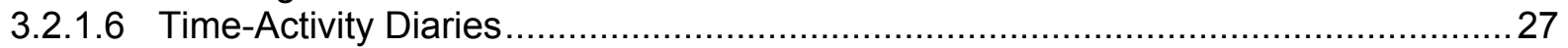

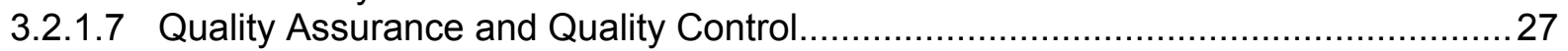

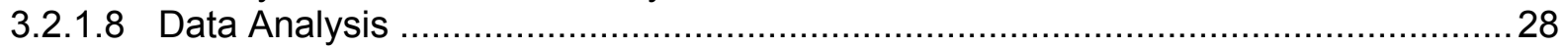

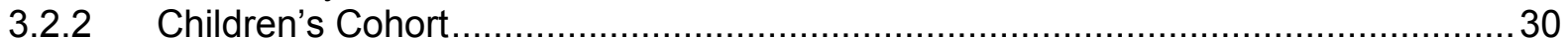

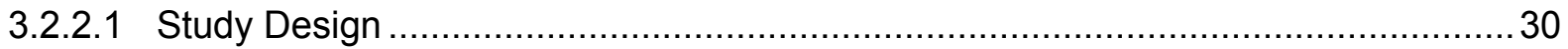

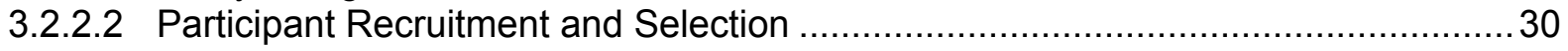

3.2.2.3 Air Pollution and Air Exchange Rate Sampling ............................................. 30

3.2.2.4 Housing Characteristics Questionnaire .......................................................... 31

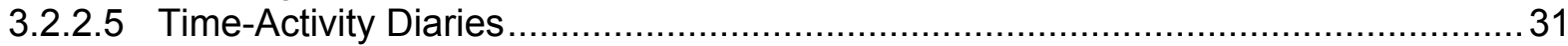

3.2.2.6 Quality Assurance and Quality Control........................................................ 31

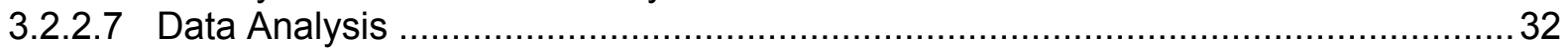

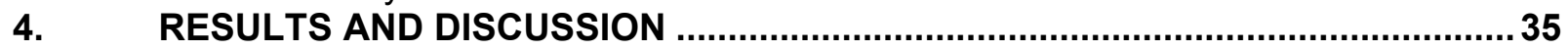

4.1 Methods Development and Validation............................................................ 35

4.1.1 Evaluation of the Performance of the Harvard Multi-Pollutant Sampler vs.

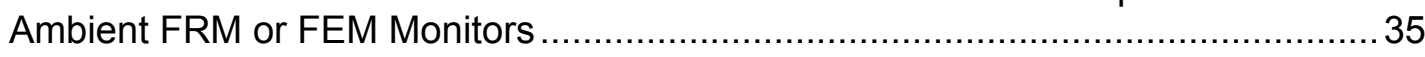

4.1.2 Development and Evaluation of Methods for Determining Elements in $\mathrm{PM}_{2.5}$

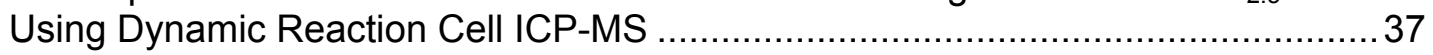

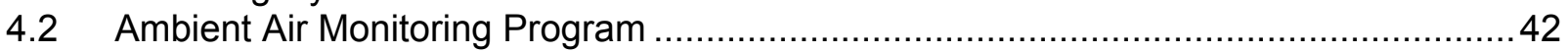

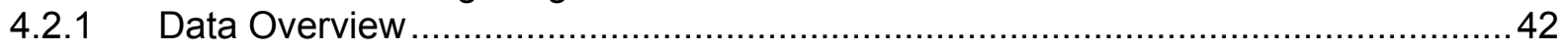

4.2.2 $\quad \mathrm{PM}_{2.5}$ and Co-Pollutant Concentrations at Steubenville ................................... 48

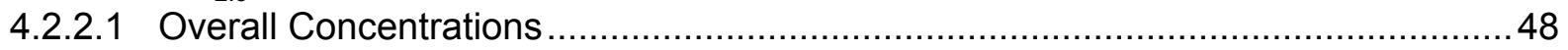

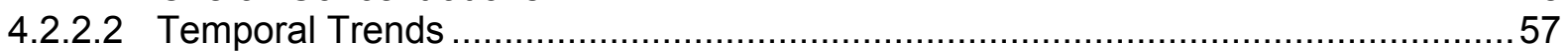


4.2.2.3 Comparison with Benchmark Values............................................................... 71

4.2.3 Spatial Variability of $\mathrm{PM}_{2.5}$ in the Steubenville Region...................................... 75

4.2.3.1 Spatial Variability in the Magnitude of $\mathrm{PM}_{2.5}$ and $\mathrm{PM}_{2.5}$ Component

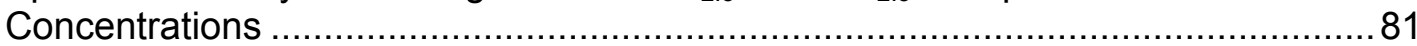

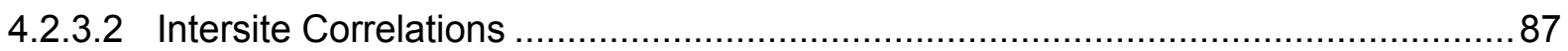

4.2.4 Associations of $\mathrm{PM}_{2.5}$ and $\mathrm{PM}_{10}$ with Co-Pollutants and Meteorological

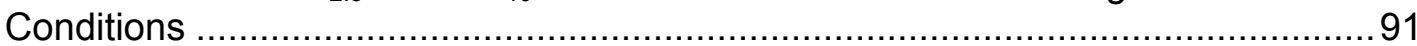

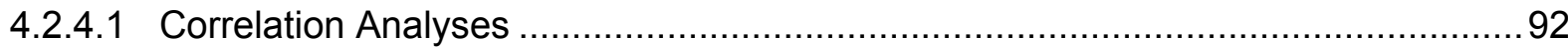

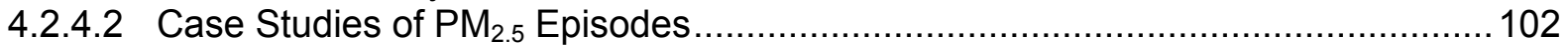

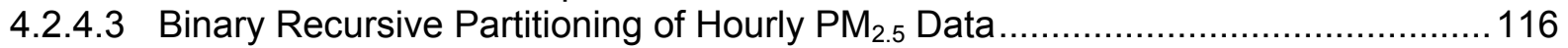

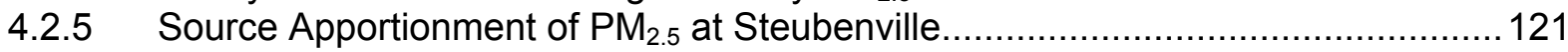

4.2.5.1 Positive Matrix Factorization Results.......................................................... 121

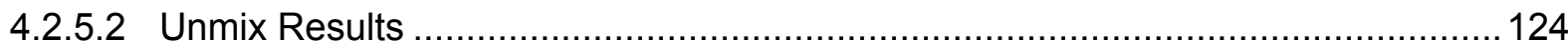

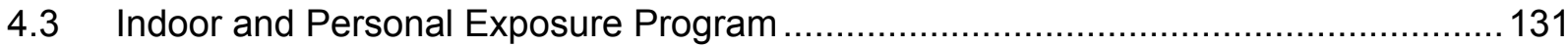

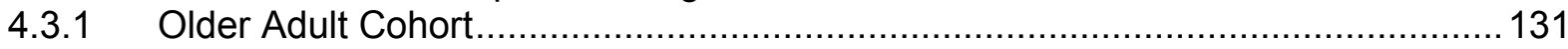

4.3.1.1 Participant Summary and Characteristics .................................................. 131

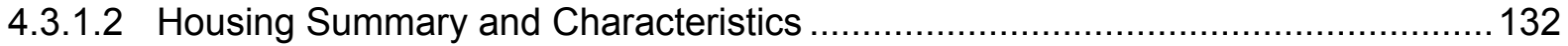

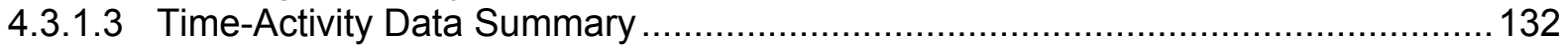

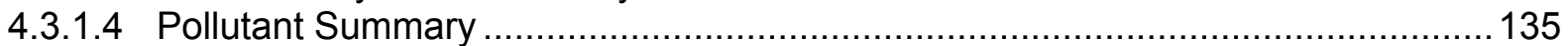

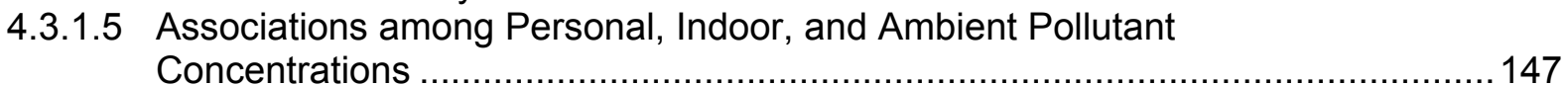

4.3.1.6 Factors Affecting Relationships .......................................................... 152

4.3.1.7 Summary of Elemental Data................................................................... 162

4.3.1.8 Associations Among Personal, Indoor, and Ambient Elemental

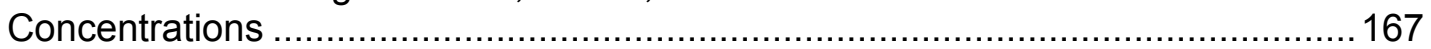

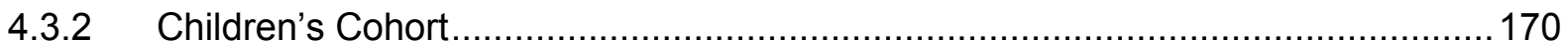

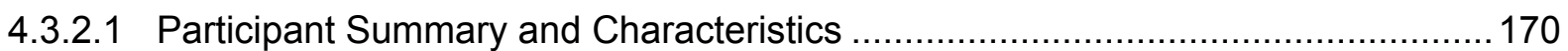

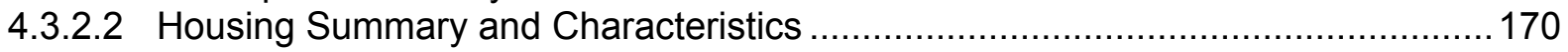

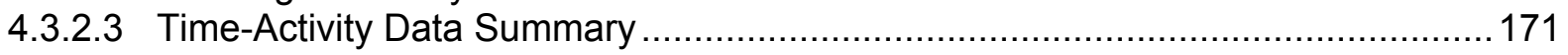

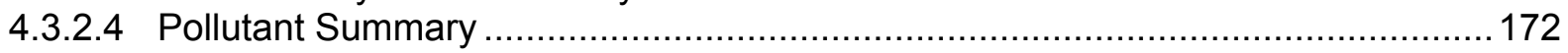

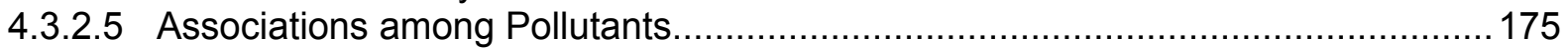

4.3.2.6 Associations among Personal, Outdoor, Indoor, and Ambient Pollutant

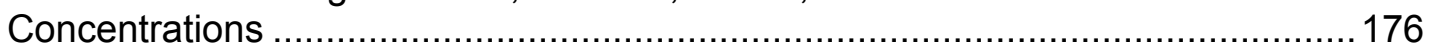

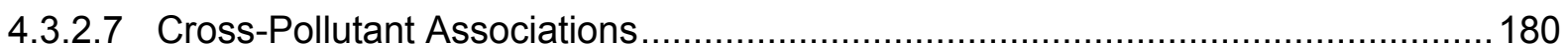

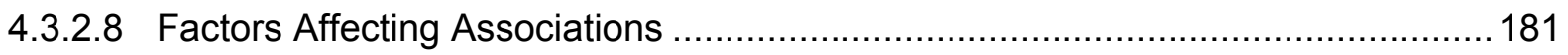

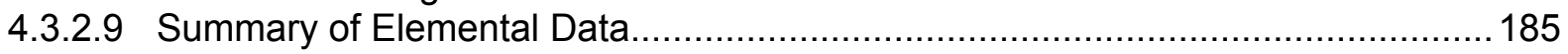

4.3.2.10 Associations between Personal Exposures, Indoor Concentrations, and Ambient Concentrations for Selected Elements ..............................................189

4.3.2.11 Associations between $\mathrm{PM}_{2.5}$ Source Factors at the Central Site and Outdoor, Indoor, and Personal $\mathrm{PM}_{2.5}$ Concentrations …………....................................193

4.3.3 Discussion of Results from the Older Adult and Children's Cohorts ....................199

4.4 Associations between Air Pollution and Cardiac Health Effects................................202

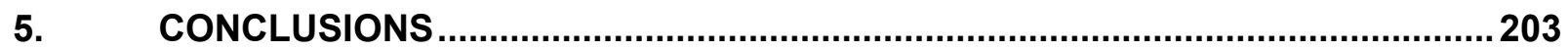

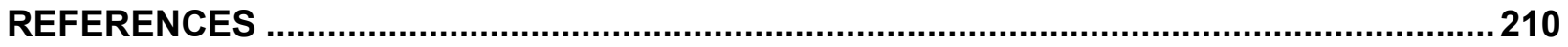

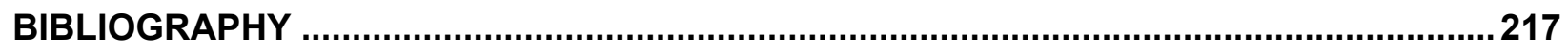

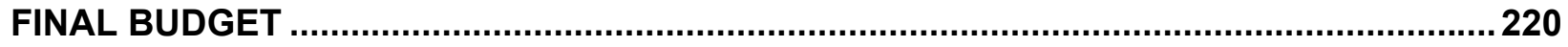

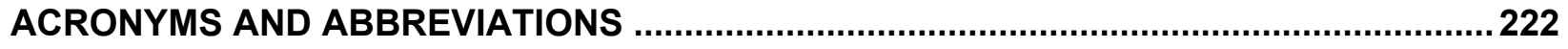




\title{
LIST OF APPENDICES
}

\author{
Appendix A. Ambient Air Monitoring Program, Supplemental QA/QC Information \\ Appendix B. Indoor and Personal Exposure Program, Questionnaire and Time Activity \\ Diary Forms
}

Appendix C. Data (Separate Compact Disc Containing Air Monitoring and Exposure Data)

Appendix D. The Steubenville Comprehensive Air Monitoring Program (SCAMP): Concentrations and Solubilities of $\mathrm{PM}_{2.5}$ Trace Elements and their Implications for Source Apportionment and Health Research

Appendix E. Ambient Particulate Air Pollution and Cardiac Arrhythmia in a Panel of Older Adults in Steubenville, Ohio

Appendix F. Short-term Effects of Air Pollution on Heart Rate Variability in Senior Adults in Steubenville, $\mathrm{OH}$

\section{LIST OF TABLES}

Table 1. SCAMP sponsors and research participants. 5

Table 2. Sampling regimen for SCAMP ambient air monitoring sites. 11

Table 3. Strategy and detection limits for the determination of elements in the watersoluble fraction of $\mathrm{PM}_{2.5}$ using DRC ICP-MS.

Table 4. Strategy and detection limits for the determination of elements in the aciddigestible fraction of $\mathrm{PM}_{2.5}$ using DRC ICP-MS.

Table 5. Standard Operating Procedures followed by the SCAMP ambient air monitoring program.

Table 6. Imprecision estimates for the Harvard multi-pollutant monitor and FRM or FEM $\mathrm{PM}_{2.5}$ and gas monitors.

Table 7. Estimated bias of the Harvard multi-pollutant monitor relative to the $F R M P_{2.5}$

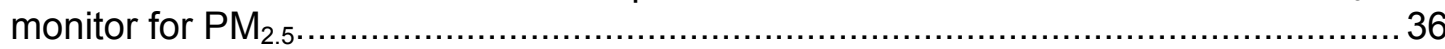

Table 8. Estimated bias of the Harvard multi-pollutant monitor relative to the $F R M P M_{2.5}$

Table 9. Estimated bias of the Harvard multi-pollutant monitor relative to the FRM or FEM gas analyzers...................................................................................... 36

Table 10. Estimated limits of detection for the Harvard multi-pollutant monitor and FRM or

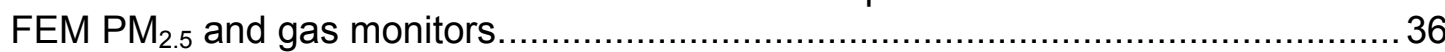

Table 11. Issues explored during the development of methods for determining trace

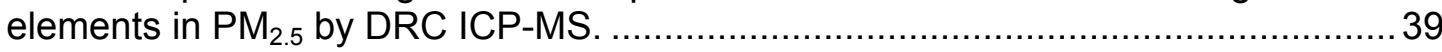

Table 12. Concentrations and uncertainties of various elements determined in three sets of duplicate $\mathrm{PM}_{2.5}$ samples by XRF and DRC ICP-MS.

Table 13. Data completeness for 24-hr integrated PM and PM component measurements at the SCAMP ambient air monitoring sites.

Table 14. Data completeness for continuous $\mathrm{PM}_{2.5}$, gaseous pollutants, meteorological conditions, and pollen and spores measured at the central Steubenville site. Summary of the percentage of valid PM and PM component observations at each of the SCAMP ambient air monitoring sites that were below the limits of detection. 
Table 16. Quality indicators for the determination of elements in the water-extractable fraction of $\mathrm{PM}_{2.5}$ via DRC ICP-MS.

Table 17. Quality indicators for the determination of elements in the acid-digestible fraction of $\mathrm{PM}_{2.5}$ via DRC ICP-MS.

Table 18. Summary statistics for 24-hr average $\mathrm{PM}_{2.5}$ and $\mathrm{PM}_{2.5}$ component mass concentrations $\left(\mu \mathrm{g} / \mathrm{m}^{3}\right)$ at the central Steubenville site.

Table 19. Summary statistics for $1-\mathrm{hr}$ and 24-hr average $\mathrm{PM}_{2.5}$ mass concentrations $\left(\mu \mathrm{g} / \mathrm{m}^{3}\right)$ measured at the central Steubenville site using a TEOM

Table 20. Overall composition of $\mathrm{PM}_{2.5}$ at Steubenville, based on 109 days with complete or nearly complete $\mathrm{PM}_{2.5}$ speciation data.

Table 21. Summary statistics for 24-hr average mass concentrations of $P_{10}$ and waterextractable $\mathrm{PM}_{10}$ components $\left(\mu \mathrm{g} / \mathrm{m}^{3}\right)$ at the central Steubenville site. Also shown are quartiles summarizing the distribution of daily ratios of the mass of $\mathrm{PM}$ and water-soluble PM components in the $\mathrm{PM}_{2.5}$ fraction to the mass of these species in the $\mathrm{PM}_{10}$ fraction.

Table 22. Summary statistics for $1-\mathrm{hr}$ and $24-\mathrm{hr}$ average gas concentrations measured at the central Steubenville site.

Table 23. Summary statistics for 24-hr average spore counts (number/m ${ }^{3}$ ) at the central Steubenville site.

Table 24. Summary statistics for 24-hr average pollen counts (number $/ \mathrm{m}^{3}$ ) at the central Steubenville site.

Table 25. Median 24-hr average meteorological conditions at Steubenville during the warm (April-September) and cool (October-March) seasons.

Table 26. Summary of primary National Ambient Air Quality Standards (U.S. EPA, 2006) ...... 71

Table 27. Comparison of mean pollutant concentrations observed at the SCAMP central Steubenville site (2000-2002) with mean pollutant concentrations observed in Steubenville during the Six Cities Study. $\mathrm{PM}_{2.5}$ total mass concentrations are in $\mu \mathrm{g} / \mathrm{m}^{3} ; \mathrm{PM}_{2.5}$ component concentrations are in $\mathrm{ng} / \mathrm{m}^{3}$, and gas concentrations are in $\mathrm{ppb}$. ....

Table 28. Comparison of mean ambient air HAP concentrations in $\mathrm{PM}_{2.5}$ at Steubenville during SCAMP with non-cancer chronic inhalation RfCs, MRLs and RELs....

Table 29. Summary statistics for 24-hr average mass concentrations of $P_{2.5}$ and waterextractable $\mathrm{PM}_{2.5}$ components $\left(\mu \mathrm{g} / \mathrm{m}^{3}\right)$ at the five SCAMP ambient air monitoring sites, 2000-2002.

Table 30. Spearman correlation coefficients between ambient concentrations of various $P M$ measures (i.e., hourly $\mathrm{PM}_{2.5}$, daily $\mathrm{PM}_{2.5}$, daily $\mathrm{PM}_{10}$, and daily $\mathrm{PM}_{10-2.5}$ ) and ambient concentrations of various gaseous pollutants at the central Steubenville site, both overall and by astronomical season.

Table 31. Spearman correlation coefficients between daily ambient concentrations of $\mathrm{PM}_{2.5}, \mathrm{PM}_{10}$, and $\mathrm{PM}_{10-2.5}$ and daily ambient pollen and spore counts at the central Steubenville site, both overall and by astronomical season.

Table 32. Spearman correlation coefficients between ambient concentrations of various $P M$ measures (i.e., hourly $\mathrm{PM}_{2.5}$, daily $\mathrm{PM}_{2.5}$, daily $\mathrm{PM}_{10}$, and daily $\mathrm{PM}_{10-2.5}$ ) and meteorological conditions at the central Steubenville site, both overall and by astronomical season.

Table 33. Spearman correlations between concentrations of $\mathrm{PM}_{2.5}$ ionic, carbonaceous, and acid-digestible elemental components and concentrations of $\mathrm{PM}_{2.5}, \mathrm{PM}_{10}$, and $\mathrm{PM}_{10-2.5}$ total mass measured at the central Steubenville site during SCAMP. 
Table 34. Matrix of Spearman correlations computed for pairwise concentrations of $\mathrm{PM}_{2.5}$ ionic, carbonaceous, and acid-digestible elemental components measured at the central Steubenville site during SCAMP.

Table 35. Spearman correlations between concentrations of $\mathrm{PM}_{2.5}$ ionic, carbonaceous, and acid-digestible elemental components and gaseous co-pollutant concentrations and meteorological conditions measured at the central Steubenville site during SCAMP.

Table 36. Spearman correlation coefficients between 24-hr $\mathrm{PM}_{2.5}$ chemical component (i.e., ion, carbon, and acid-digestible element) concentrations at the central Steubenville site and measures of the intraday timing of $\mathrm{PM}_{2.5}$ episodes and the impact of local versus regional sources on $\mathrm{PM}_{2.5}$ concentrations in Steubenville... 116

Table 37. Summary of terminal nodes of the binary recursive partitioning tree shown in Figure 52.

Table 38. Source profile $\left(\mathrm{ng} / \mathrm{m}^{3}\right)$ for the seven-source PMF model run using $\mathrm{PM}_{2.5}$ total mass, ion, carbon, and acid-digestible element data collected at the central Steubenville site during SCAMP. Estimated concentrations with magnitudes at least twice as great as their standard deviations are highlighted in bold.

Table 39. Summary of results of the seven-source PMF model run using $\mathrm{PM}_{2.5}$ total mass, ion, carbon, and acid-digestible element data collected at the central Steubenville site during SCAMP.

Table 40. Model specifications and diagnostics for the three best five-source Unmix model runs using $\mathrm{PM}_{2.5}$ total mass, ion, carbon, and acid-digestible element data collected at the central Steubenville site during SCAMP.

Table 41. Source profiles $\left(\mathrm{ng} / \mathrm{m}^{3}\right)$ for the three best five-source Unmix model runs using $\mathrm{PM}_{2.5}$ total mass, ion, carbon, and acid-digestible element data collected at the central Steubenville site during SCAMP. Estimated concentrations with magnitudes at least twice as great as their uncertainties are highlighted in bold.... 126

Table 42. Spearman correlation coefficients comparing estimated daily source contributions (to total $\mathrm{PM}_{2.5}$ mass at Steubenville) for the three best five-source Unmix solutions with estimated daily source contributions for the seven-source PMF model.

Table 43. Spearman correlation coefficients comparing estimated daily source contributions (to total $\mathrm{PM}_{2.5}$ mass at Steubenville) for the three best five-source Unmix solutions with daily average gaseous pollutant concentrations and meteorological conditions

Table 44. Spearman correlation coefficients between estimated daily source contributions (to total $\mathrm{PM}_{2.5}$ mass at Steubenville) for the three best five-source Unmix solutions and estimates of the impact of local versus regional sources on $\mathrm{PM}_{2.5}$ concentrations in Steubenville.

Table 45. Housing characteristics for the older adult cohort.

Table 46. Average number of 30-minute segments per day spent in various locations for the older adult cohort.*

Table 47. Average number of 30-minute segments per day spent doing various activities for the older adult cohort.*

Table 48. Proximity to sources/ventilation, average count of 30 -minute segments per day for the older adult cohort.*....

Table 49. Average duration (min/day) in transit and outdoors $(n=10)$

Table 50. Quality assurance parameters for pollutant data collected for the older adult cohort.

Table 51. Ambient and outdoor concentrations by season for the older adult cohort.* 
Table 52. Associations (analyzed via mixed models) among ambient pollutants measured at the central Steubenville site during the summer and fall of 2000 using Harvard multi-pollutant monitors. *

Table 53 Correlations between ambient pollutant concentrations at the SCAMP central site and outdoor concentrations measured at apartment complexes in Steubenville using Harvard multi-pollutant monitors in Summer and Fall of 2000.*.

Table 54. Personal and indoor pollutant concentrations by season for the older adult cohort.

Table 55. Associations between personal particle concentrations and personal gas concentrations, by season, for the older adult cohort.*

Table 56. Associations between indoor particle concentrations and indoor gas concentrations, by season, for the older adult cohort.*

Table 57. Comparison of personal-ambient, personal-indoor, and indoor-ambient relationships (by season) for the older adult cohort via mixed models. ${ }^{*}$

Table 58. Associations between personal gas exposures and ambient particle concentrations for the older adult cohort, by season. *

Table 59. Associations between personal particle exposures and ambient gas concentrations for the older adult cohort, by season. ${ }^{*}$........................................ 152

Table 60. Personal vs. ambient $\mathrm{PM}_{2.5}$ concentrations by activity and proximity to ventilation for the older adult cohort.*

Table 61. Personal vs. ambient $\mathrm{SO}_{4}{ }^{2-}$ concentrations by activity and proximity to ventilation for the older adult cohort.*

Table 62. Personal vs. ambient EC $\left(>N^{* *}\right)$ concentrations by activity and proximity to ventilation for the older adult cohort.*

Table 63. Personal vs. ambient $\mathrm{O}_{3}$ concentrations by activity and proximity to ventilation for the older adult cohort.*

Table 64. Personal vs. ambient $\mathrm{SO}_{2}$ concentrations by activity and proximity to ventilation for the older adult cohort.*

Table 65. Personal vs. ambient $\mathrm{SO}_{2}\left(>\mathrm{ND}^{* *}\right)$ concentrations by activity and proximity to ventilation for the older adult cohort.*

Table 66. Personal vs. ambient $\mathrm{NO}_{2}$ concentrations by activity and proximity to ventilation for the older adult cohort.*

Table 67. Personal vs. ambient $\mathrm{NO}_{2}$ concentrations by activity and proximity to ventilation for individuals without gas stoves for the older adult cohort.*

Table 68. Indoor vs. ambient $\mathrm{PM}_{2.5}$ concentrations by ventilation conditions for the older adult cohort.*

Table 69. Indoor vs. ambient $\mathrm{SO}_{4}{ }^{2-}$ concentrations by ventilation conditions for the older adult cohort.*

Table 70. Indoor vs. ambient EC ( $>\mathrm{ND}^{* *}$ ) concentrations by ventilation conditions for the older adult cohort.*

Table 71. Indoor vs. ambient $\mathrm{O}_{3}$ concentrations by ventilation conditions for the older adult cohort.*.

Table 72. Indoor vs. ambient $\mathrm{SO}_{2}$ concentrations by ventilation conditions for the older adult cohort.*

Table 73. Indoor vs. ambient $\mathrm{SO}_{2}\left(>\mathrm{ND}^{* *}\right)$ concentrations by ventilation conditions for the older adult cohort. ${ }^{*}$

Table 74. Indoor vs. ambient $\mathrm{NO}_{2}$ concentrations by ventilation conditions for the older adult cohort.*

Table 75. Indoor vs. ambient $\mathrm{NO}_{2}$ concentrations by ventilation conditions for homes without gas stoves for the older adult cohort.* 
Table 76. Indoor vs. ambient pollutant concentrations by stove type for the older adult cohort.*

Table 77. Personal vs. ambient pollutant concentrations by stove type for the older adult cohort. *

Table 78. Water-extractable elements concentrations $\left(\mathrm{ng} / \mathrm{m}^{3}\right)$ measured in personal, indoor, outdoor, and ambient environments for the older adult cohort.

Table 79. Water-extractable elements concentrations $\left(\mathrm{ng} / \mathrm{m}^{3}\right)$ measured in personal, indoor, outdoor, and ambient environments for the older adult cohort.....

Table 80. Personal vs. indoor concentrations of select elements (acid-digestible) for the older adult cohort.*

Table 81. Personal vs. indoor concentrations of select elements (water-extractable) for the older adult cohort.*

Table 82. Indoor vs. ambient concentrations of select elements (acid-digestible) for the older adult cohort.*

Table 83. Indoor vs. ambient concentrations of select elements (water-extractable) for the older adult cohort.*

Table 84. Personal vs. ambient concentrations of select elements (acid-digestible) for the older adult cohort.*

Table 85. Personal vs. ambient concentrations of select elements (water-extractable) for the older adult cohort.*

Table 86. Housing characteristics of the children's cohort.

Table 87. Fraction of time spent in various locations, in transit, and near sources for the children's cohort.

Table 88. Quality assurance parameters - children's cohort.*

Table 89. Personal, indoor, outdoor, and ambient pollutant concentrations by season for the children's cohort.*

Table 90. Correlations among outdoor and ambient $\mathrm{PM}_{2.5}, \mathrm{SO}_{4}{ }^{2-}, \mathrm{EC}, \mathrm{O}_{3}$, and $\mathrm{NO}_{2}$

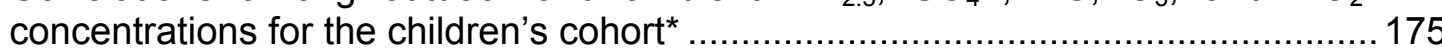

Table 91. Correlations among indoor $\mathrm{PM}_{2.5}, \mathrm{SO}_{4}{ }^{2-}, \mathrm{EC}, \mathrm{O}_{3}$, and $\mathrm{NO}_{2}$ concentrations for the children's cohort.*....

Table 92. Correlations among personal $\mathrm{PM}_{2.5}, \mathrm{SO}_{4}{ }^{2-}, \mathrm{EC}, \mathrm{O}_{3}$, and $\mathrm{NO}_{2}$ exposures for the children's cohort.*...

Table 93. Mixed model results describing associations among particle and gas concentrations measured in the indoor, personal, and outdoor microenvironments for the children's cohort*

Table 94. Associations between personal exposures and ambient concentrations of particle and gaseous pollutants monitored for the children's cohort.

Table 95. Cross-pollutant associations between ambient particle and gas concentrations and personal gas and particle exposures for the children's cohort.

Table 96. Effect of ventilation on indoor-ambient associations in the summer season for the children's cohort.*

Table 97. Indoor vs. ambient concentrations by stove type for the children's cohort. ${ }^{*}$........... 182

Table 98. Personal vs. ambient concentrations by stove type for the children's cohort. ${ }^{*}$....... 183

Table 99. Personal vs. ambient concentrations by fraction of time spent outdoors for the children's cohort.*

Table 100.Personal vs. ambient concentrations by fraction of time spent indoors near open windows for the children's cohort.*....

Table 101.Personal vs. ambient concentrations by fraction of time spent traveling by car for the children's cohort.*....

Table 102. Water-extractable element concentrations $\left(\mathrm{ng} / \mathrm{m}^{3}\right)$ measured in personal, indoor, outdoor, and ambient environments for the children's cohort. 
Table 103. Acid-digestible element concentrations $\left(\mathrm{ng} / \mathrm{m}^{3}\right)$ measured in personal, indoor, outdoor, and ambient environments for the children's cohort.

Table 104. Associations between personal exposures and ambient concentrations for select water-extractable elements for the children's cohort.

Table 105. Associations between personal exposures and ambient concentrations for select acid-digestible elements for the children's cohort.

Table 106. Associations between indoor and ambient concentrations for select waterextractable elements for the children's cohort.

Table 107. Associations between indoor and ambient concentrations for select aciddigestible elements for the children's cohort.

Table 108. Summary statistics for central site data considered for use in factor analysis. ....... 194

Table 109. Parameters from the regression of $\mathrm{PM}_{2.5}$ vs. daily source scores

Table 110. Average source contributions (in $\mathrm{ng} / \mathrm{m}^{3}$ ) for the four-source factor analysis model.

Table 111. Source profiles (species mass per total mass associated with the source factor, expressed as a percentage) for the four-source factor analysis model.................. 196

Table 112. Comparison of results from two different models of indoor $\mathrm{PM}_{2.5}$ concentrations vs. $\mathrm{PM}_{2.5}$ factors from the central ambient air monitoring site.

Table 113. Regression results describing the ability of central site factors to predict 24-hr outdoor, indoor, or personal $\mathrm{PM}_{2.5}$ concentrations for the children's cohort.

\section{LIST OF FIGURES}

Figure 1. SCAMP ambient air monitoring sites.

Figure 2. Autocorrelation function (ACF) plots for (a) the time series of 24-hour $\mathrm{PM}_{2.5}$ concentrations measured at the central Steubenville site using the FRM monitor, (b) the time series of 24-hour $\mathrm{NO}_{3}{ }^{-}$concentrations measured at the central Steubenville site, (c) the time series of paired differences between 24hour $\mathrm{PM}_{2.5}$ concentrations measured at the central Steubenville site and at the northern satellite site, and (d) the time series of residuals from a simple linear regression analysis of 24-hour $\mathrm{PM}_{2.5}$ concentrations as a function of 24-hour $\mathrm{CO}$ concentrations at the central Steubenville site. Lines extending beyond the dashed blue interval indicate statistically significant autocorrelation. Lags are in units of 1 day for subplots (a), (c), and (d), and in units of 4 days for subplot (b)....22

Figure 3. Histogram (a) and quantile-quantile plot (b) showing the distribution of 24-hour average $\mathrm{PM}_{2.5}$ concentrations measured at the central Steubenville site during SCAMP using the FRM.

Figure 4. Scatterplot of 24-hr average NO concentrations versus 24-hr average CO concentrations measured at the Central Steubenville site, with linear least squares line.

Figure 5. Precision of the DRC ICP-MS and XRF for various elements as a function of the mass of the element present in the $\mathrm{PM}_{2.5}$ sample.

Figure 6. CONSOL R\&D (DRC ICP-MS) and Columbia (high-resolution ICP-MS) recoveries of elements in NIST SRM 1648 for digestion \#1.

Figure 7. CONSOL R\&D (DRC ICP-MS) and Columbia (high-resolution ICP-MS) recoveries of elements in NIST SRM 1648 for digestion \#2.

Figure 8. Bias of the TEOM monitor relative to the FRM monitor at the central Steubenville site, as a function of the FRM-determined $\mathrm{PM}_{2.5}$ concentration. The blue line represents bias in $\mu \mathrm{g} / \mathrm{m}^{3}$; the red line represents bias in $\%$.

Figure 9. Time series of 24-hr average $\mathrm{PM}_{2.5}$ concentrations measured by the FRM at Steubenville. 
Figure 10. Case study showing two days at Steubenville with similar 24-hr average $\mathrm{PM}_{2.5}$ concentrations but different hourly $\mathrm{PM}_{2.5}$ concentration profiles, based on TEOM data from the central site. The blue line shows hourly average concentrations; the red line shows the 24-hr mean.

Figure 11. Distribution of daily fractional solubilities (defined in text) computed using 24-hr average $\mathrm{PM}_{2.5}$ water-extractable and acid-digestible element concentrations measured at the central Steubenville site.

Figure 12. Daily $\mathrm{PM}_{2.5}$ mass balance closures at the central Steubenville site, overall and by season.

Figure 13. Time series of 24-hr average $\mathrm{PM}_{10}$ concentrations measured by the $\mathrm{FRM}$ at Steubenville.

Figure 14. Boxplots summarizing the distributions of 24-hr average $\mathrm{PM}_{2.5}, \mathrm{PM}_{10}$, and $\mathrm{PM}_{10 \text { - }}$ 2.5 concentrations measured at the central Steubenville site by month, based on data collected between May 2000 and May 2002

Figure 15. Ratios of warm-to-cool season median concentrations for PM and gaseous pollutants at the central Steubenville site. Solid points indicate statistically significant seasonal differences.

Figure 16. Boxplots summarizing the distributions of 24-hr average pollen and spore number concentrations measured at the central Steubenville site by month, based on data collected between June 2000 and May 2002.

Figure 17. Ratios of warm-to-cool season median concentrations for $\mathrm{PM}_{2.5}$ and $\mathrm{PM}_{10}$ waterextractable components at the central Steubenville site. Solid symbols indicate statistically significant seasonal differences.

Figure 18. Ratios of warm-to-cool season median concentrations for $\mathrm{PM}_{2.5}$ carbonaceous and acid-digestible elemental components at the central Steubenville site. Solid symbols indicate statistically significant seasonal differences.

Figure 19. Overall average $\mathrm{PM}_{2.5}$ composition by season at the central Steubenville site, based on the application of a mass balance (described earlier) to 109 days with complete or near-complete $\mathrm{PM}_{2.5}$ speciation data.

Figure 20. Boxplots summarizing the distributions of 24-hr average $\mathrm{PM}_{2.5}, \mathrm{PM}_{10}$, and $\mathrm{PM}_{10-}$ 2.5 concentrations measured at the central Steubenville site by day of week, based on data collected between May 2000 and May 2002.

Figure 21. Ratios of weekday-to-weekend median concentrations for PM and gaseous pollutants at the central Steubenville site. Solid points indicate statistically significant weekday/weekend differences.

Figure 22. Ratios of weekday-to-weekend median concentrations for $\mathrm{PM}_{2.5}$ and $\mathrm{PM}_{10}$ water-extractable components at the central Steubenville site. Solid symbols indicate statistically significant weekday/weekend differences.

Figure 23. Ratios of weekday-to-weekend median concentrations for $\mathrm{PM}_{2.5}$ carbonaceous and acid-digestible elemental components at the central Steubenville site. Solid points indicate statistically significant weekday/weekend differences.

Figure 24. Diurnal profiles of $\mathrm{PM}_{2.5}$ at Steubenville: (a) boxplot showing distribution of $\mathrm{PM}_{2.5}$ concentrations by hour of day, and (b) mean $\mathrm{PM}_{2.5}$ concentrations by hour of day and season.

Figure 25. Concentrations of $\mathrm{SO}_{2}, \mathrm{NO}_{x}, \mathrm{CO}$, and $\mathrm{O}_{3}$ by hour of day and season at the central Steubenville site.

Figure 26. Al-normalized enrichment factors for elements in $\mathrm{PM}_{2.5}$ at Steubenville ................. 75

Figure 27. Ratios of warm-to-cool season median concentrations for $\mathrm{PM}_{2.5}$ at the SCAMP ambient air monitoring sites. Solid points indicate statistically significant seasonal differences. 
Figure 28. Ratios of warm-to-cool season median concentrations for $\mathrm{PM}_{2.5}$ waterextractable ionic and elemental components at the SCAMP ambient air monitoring sites. Solid points indicate statistically significant seasonal differences, based on the results of Wilcoxon rank sum tests at $\alpha=0.05$.

Figure 29. Ratios of weekday-to-weekend median concentrations for $\mathrm{PM}_{2.5}$ at the SCAMP ambient air monitoring sites. Solid points indicate statistically significant weekday/weekend differences. .....

Figure 30. Ratios of weekday-to-weekend median concentrations for $\mathrm{PM}_{2.5}$ waterextractable ionic and elemental components at the SCAMP ambient air monitoring sites. Solid points indicate statistically significant weekday/weekend differences, based on the results of Wilcoxon rank sum tests at $\alpha=0.05$.

Figure 31. Parity plots showing 24-hr average $\mathrm{PM}_{2.5}$ concentrations measured at each of the SCAMP satellite sites versus 24-hr average $\mathrm{PM}_{2.5}$ concentrations measured simultaneously at the Steubenville site.

Figure 32. Percentage of days for which 24-hr average $\mathrm{PM}_{2.5}$ and water-extractable $\mathrm{PM}_{2.5}$ component concentrations measured at each SCAMP satellite site were greater than corresponding concentrations measured at the central Steubenville site.

Figure 33. Median daily ratios of $\mathrm{PM}_{2.5}$ and water-extractable $\mathrm{PM}_{2.5}$ component concentrations measured at the central Steubenville site to corresponding concentrations measured at each SCAMP satellite site.

Figure 34. Intersite coefficients of divergence for all possible SCAMP site pairsbased on mean concentrations of 22 water-extractable $\mathrm{PM}_{2.5}$ components.

Figure 35. Estimated contribution of local sources to concentrations of $\mathrm{PM}_{2.5}$ and its major ionic components at Steubenville during SCAMP.

Figure 36. Intersite Spearman correlation coefficients for $\mathrm{PM}_{2.5}$ and its water-extractable components in the Steubenville region. Ten correlations are plotted for each variable, corresponding to the ten possible SCAMP site pairs.

Figure 37. Scatterplot illustrating the association between intersite distance and the strength of association between $\mathrm{PM}_{2.5}$ and $\mathrm{PM}_{2.5}$ component concentrations measured at SCAMP site pairs. Plotted are the $25^{\text {th }}, 50^{\text {th }}$, and $75^{\text {th }}$ percentile Spearman correlation coefficients for each site pair, with linear least squares lines.

Figure 38. Intersite Spearman correlation coefficients for $\mathrm{PM}_{2.5}$ and its water-extractable components in the Steubenville region during the warm season (red; AprilSeptember) and the cool season (blue; October-March). Ten correlations are plotted for each variable, corresponding to the ten possible SCAMP site pairs........90

Figure 39. Scatterplots showing the association between log-transformed daily $\mathrm{PM}_{2.5}$ concentrations and log-transformed daily $\mathrm{NO}_{2}$ concentrations measured at the central Steubenville site during SCAMP, with linear least squares lines. The leftmost plot shows all data collected during SCAMP; the center and rightmost plots show only those data that were collected during the winter and summer, respectively.

Figure 40. Scatterplots showing the association between log-transformed daily $\mathrm{PM}_{2.5}$ concentrations and daily temperatures measured at the central Steubenville site during SCAMP, with linear least squares lines. The leftmost plot shows all data collected during SCAMP; the center and rightmost plots show only those data that were collected during the winter and summer, respectively.

Figure 41. Scatterplots showing 1-hr average $\mathrm{PM}_{2.5}$ concentrations versus 1-hr average wind speeds and barometric pressures measured at the central Steubenville site during SCAMP. 
Figure 42. Scatterplot showing 1-hr average $\mathrm{PM}_{2.5}$ concentrations versus 1-hr rainfall at the central Steubenville site during SCAMP.

Figure 43. Time series of hourly $\mathrm{PM}_{2.5}$ concentrations measured by the TEOM monitor at the central Steubenville site during a warm season episode of elevated $\mathrm{PM}_{2.5}$ concentrations, which occurred between September 5 and September 11, 2001, and a cool season episode of elevated $\mathrm{PM}_{2.5}$ concentrations, which occurred between November 30 and December 6, 2001.

Figure 44. Time series of 1-hr $\mathrm{PM}_{2.5}$ concentrations (blue) and gaseous pollutant concentrations (red) observed at the central Steubenville site on September 5$11,2001$.

Figure 45. Time series of $1-\mathrm{hr} \quad \mathrm{PM}_{2.5}$ concentrations (blue) and gaseous pollutant concentrations(red) observed at the central Steubenville site on November 30 December 6, 2001.

Figure 46. Time series of 1-hr $\mathrm{PM}_{2.5}$ concentrations (blue) and meteorological conditions (red) observed at the central Steubenville site on September 5-11, 2001............108

Figure 47. Time series of 1-hr $\mathrm{PM}_{2.5}$ concentrations (blue) and meteorological conditions (red) observed at the central Steubenville site on November 30 - December 6, 2001.

Figure 48. Vertical temperature soundings taken at 7:00 a.m. EST at the Moon Township, PA, National Weather Service station on each day of the September 5-11, 2001, "warm season" $\mathrm{PM}_{2.5}$ episode and the November 30-December 6, 2001, "cool season" $\mathrm{PM}_{2.5}$ episode.

Figure 49. Normalized $\mathrm{PM}_{2.5}$ composition (expressed as a "compositional enrichment factor" per the definition given in the text) at Steubenville during the 24-hr period from 9:00 a.m. on 9/8/01 to 9:00 a.m. on 9/9/01 and the 24-hr period from 9:00 a.m. on $12 / 5 / 01$ to $9: 00$ a.m. on $12 / 6 / 01$.

Figure 50. Time series of 24-hr average $\mathrm{PM}_{2.5}$ concentrations measured at the five SCAMP monitoring sites from September 5 through September 11, 2001, and from November 30 through December 6, 2001.

Figure 51. Time series of 24-hr average $\mathrm{PM}_{2.5}$ and $\mathrm{PM}_{10-2.5}$ concentrations observed at the central Steubenville site from September 5 through September 11, 2001, and from November 30 through December 6, 2001.

Figure 52. Binary recursive partitioning classification tree constructed using all valid 1-hr average $\mathrm{PM}_{2.5}$ concentrations measured at Steubenville during SCAMP. For each splitting node, observations satisfying the splitting criterion are sent to the left; all other observations are sent to the right. Each terminal node is labeled with its predicted class as well as an identification number. Units are ppm for $\mathrm{CO}, \mathrm{ppb}$ for all other gases, ${ }^{\circ} \mathrm{C}$ for temperature (Temp), \% for relative humidity $(\mathrm{RH})$, mph for wind speed (WS), $\mathrm{kW} / \mathrm{m}^{2}$ for solar radiation (Rad), and inches of $\mathrm{Hg}$ for barometric pressure (BP). For a splitting variable $\mathrm{V}, \mathrm{VmN}$ represents the 1-hr average value of that variable observed $\mathrm{N}$ hours earlier; dVN represents the N-hr change in that variable's value. Seas is season; Fa is Fall, and Su is Summer.

Figure 53. Boxplot showing the distribution of actual $\mathrm{PM}_{2.5}$ concentrations $\left(\mu \mathrm{g} / \mathrm{m}^{3}\right)$ falling in each terminal node of the classification tree presented in Figure 42. Nodes are sorted by increasing median concentration. Regions corresponding to classes A through $D$ are labeled.

Figure 54. Boxplots showing the distributions of estimated source contributions $\left(\mu \mathrm{g} / \mathrm{m}^{3}\right)$ by astronomical season for each of the seven sources resolved by PMF for the central Steubenville site. 
Figure 55. $\mathrm{PM}_{2.5}$ concentrations at Steubenville predicted by each of the three best fivesource Unmix model runs vs. corresponding $\mathrm{PM}_{2.5}$ concentrations measured at the central Steubenville site.

Figure 56. Boxplots showing the distributions of estimated source contributions $\left(\mu \mathrm{g} / \mathrm{m}^{3}\right)$ by astronomical season for each of the source factors resolved by the three best five-source Unmix solutions.

Figure 57. Locations of the apartment complexes where many of the older adult participants resided ("G", "K", "E") and the central ambient air monitoring site ("C") in Steubenville, OH. "G" represents the location of the Gaylord apartment building, "K" the Kennedy apartment building, "E" the Elmer White apartment building, and " $\mathrm{C}$ " the central ambient site located at the Franciscan University of Steubenville.

Figure 58. Ambient and outdoor $\mathrm{PM}_{2.5}$ concentrations in Steubenville measured using Harvard multi-pollutant monitors in the summer and fall of 2000.

Figure 59. Ambient and outdoor $\mathrm{O}_{3}$ concentrations in Steubenville measured using Harvard multi-pollutant monitors in the summer and fall of 2000.

Figure 60. Ambient and outdoor EC concentrations in Steubenville measured using Harvard multi-pollutant monitors in the summer and fall of 2000.

Figure 61. Ambient and outdoor $\mathrm{NO}_{2}$ concentrations in Steubenville measured using Harvard multi-pollutant monitors in the summer and fall of 2000.

Figure 62. Ambient and outdoor $\mathrm{SO}_{4}{ }^{2-}$ concentrations in Steubenville measured using Harvard multi-pollutant monitors in the summer and fall of 2000.

Figure 63. Ambient and outdoor $\mathrm{SO}_{2}$ concentrations in Steubenville measured using Harvard multi-pollutant monitors in the summer and fall of 2000.

Figure 64. Locations of the residences of participants in the children's cohort. The central ambient air monitoring site was located at the Franciscan University of Steubenville.

Figure 65. Individual-specific $\mathrm{R}^{2}$ values for associations among personal, indoor, and outdoor $\mathrm{PM}_{2.5}$ concentrations measured for the children's cohort.

Figure 66. Individual-specific $\mathrm{R}^{2}$ values for associations among personal, indoor, and outdoor $\mathrm{SO}_{4}{ }^{2-}$ concentrations measured for the children's cohort.

Figure 67. Individual-specific $\mathrm{R}^{2}$ values for associations among personal, indoor, and outdoor EC concentrations measured for the children's cohort.

Figure 68. $\mathrm{PM}_{2.5}$ concentrations observed at the central Steubenville site vs. $\mathrm{PM}_{2.5}$ concentrations predicted by the factor analysis model. 


\section{INTRODUCTION}

Fine particulate matter $\left(\mathrm{PM}_{2.5}\right)$, an air pollutant class nominally comprising airborne particles with aerodynamic diameters less than $2.5 \mu \mathrm{m}$, has garnered substantial attention from the scientific and regulatory communities because of concerns about its possible effects on human health. Driven largely by epidemiology studies that reported associations between fine particulate air pollution and mortality (e.g., Dockery et al., 1993; Pope et al., 1995) or morbidity, especially for susceptible subpopulations such as older adults (e.g., Delfino et al., 1997) and children (e.g., Dockery et al., 1996), the U.S. Environmental Protection Agency (EPA) announced a new National Ambient Air Quality Standard (NAAQS) for $\mathrm{PM}_{2.5}$ in July 1997. The standard limits annual mean outdoor $\mathrm{PM}_{2.5}$ concentrations to $15 \mu \mathrm{g} / \mathrm{m}^{3}$ (averaged over three years) and 24-hr mean outdoor $\mathrm{PM}_{2.5}$ concentrations to $65 \mu \mathrm{g} / \mathrm{m}^{3}$ (3-year average of annual $98^{\text {th }}$ percentile 24-hr concentration). More recently, in December 2005, the U.S. EPA proposed reducing the 24-hr standard from $65 \mu \mathrm{g} / \mathrm{m}^{3}$ to $35 \mu \mathrm{g} / \mathrm{m}^{3}$, citing "increased protection against health effects associated with short-term exposure (including premature mortality and increased hospital admissions and emergency room visits)," and retaining the annual standard of $15 \mu \mathrm{g} / \mathrm{m}^{3}$ for "continuing protection against health effects associated with long-term exposure (including premature mortality and development of chronic respiratory disease)" (71 FR 2620).

However, in spite of these epidemiological findings and regulatory actions, substantial uncertainties remain regarding the actual relationship between $\mathrm{PM}_{2.5}$ and human health and the best means for reducing ambient $\mathrm{PM}_{2.5}$ concentrations to attain regulatory compliance. These uncertainties stem in large part from the fact that $\mathrm{PM}_{2.5}$ is a broad class of chemically and physically diverse substances that originate from a variety of natural and anthropogenic sources. Fine particles can be emitted directly to the atmosphere as primary emissions or formed secondarily from gaseous precursors. Primary particles typically include crustal material, elemental carbon (EC), certain organic compounds, fly ash, and trace metal species, whereas secondary particles typically include ammonium sulfate, ammonium nitrate, and secondary organic aerosols; the amounts of these particle components can vary appreciably in time and space. Ambient particles and their precursors are emitted by a variety of sources, such as fossil-fuel-fired power plants, automobiles, diesel engines, metal smelting and processing plants, incinerators, kilns, various industrial facilities, wood burning, forest fires, fugitive dust and soil, and sea salt. $\mathrm{PM}_{2.5}$ and $\mathrm{PM}_{10}$ (particles with aerodynamic diameters less than $10 \mu \mathrm{m}$ ), are the only pollutants regulated under the NAAQS that do not comprise a specific chemical composition. Hence, in order to develop State Implementation Plans (SIPs) to reduce ambient mass concentrations of $\mathrm{PM}_{2.5}$ in nonattainment areas under the $\mathrm{PM}_{2.5}$ NAAQS, it is first important to identify the extents to which various chemical components contribute to $\mathrm{PM}_{2.5}$ mass concentrations in these areas and to identify the sources that emit these components or their precursors. Other factors, such as meteorology, that control the effects of these sources, must also be understood.

Moreover, it is still uncertain whether some or all of the health effects that have been attributed to $\mathrm{PM}_{2.5}$ in epidemiology studies result from the mass of fine particles in general, or whether they instead result from a specific physically- or chemically-defined type of fine particle or another pollutant that correlates to some extent with total $\mathrm{PM}_{2.5}$ mass concentrations. Toxicological evidence suggests that certain chemical components of $\mathrm{PM}_{2.5}$ are likely to be more harmful to human health than others. For example, Gurgueira et al. (2002) reported that inhalation of residual oil fly ash (ROFA) particles triggered oxidative stress in rats, whereas inhalation of carbon black aerosols did not, and Medeiros et al. (2004) studied the effects of nasal instillation of various particle surrogates in mice and concluded that acute inflammatory changes were modulated more significantly by particle composition than by particle mass. A 
number of toxicology studies (e.g., Ghio et al., 1999a; Zelikoff et al, 2002; Gavett et al., 2003) have reported associations between adverse health effects and the transition metal content of particulate matter (PM). The solubility of compounds containing these transition metals may be of importance; for example, Fernandez et al. (2005) recently reported that lung permeability in mice increased significantly when the mice were exposed to soluble $\mathrm{ZnSO}_{4}$ aerosol, but not when they were exposed to insoluble $\mathrm{ZnO}$ aerosol. In a recent review of toxicological and epidemiological evidence regarding the health risks of PM components, Grahame and Schlesinger (2005) concluded that "toxicology studies have identified mechanisms by which specific components of vehicular, industrial, or urban emissions might be harmful, but find that secondary sulfates and nitrates appear not to be harmful at ambient concentrations." These authors also reported that recent innovative epidemiological studies that were able to differentiate among the effects of urban and rural air masses generally yielded similar conclusions. Indeed, several epidemiology studies (e.g., Peters et al., 1997; Burnett et al., 2000; Mar et al., 2000; Laden et al., 2000) have discovered associations between particular components, source classes, or size fractions of $\mathrm{PM}_{2.5}$ and adverse health effects. However, because of the paucity of ambient $\mathrm{PM}_{2.5}$ composition data relative to $\mathrm{PM}_{2.5}$ total mass concentration data, many of the epidemiological studies conducted to date have not assessed the acute health risks posed by specific particle components. (Only within the last five years have EPA monitoring sites begun routine monitoring of $\mathrm{PM}_{2.5}$ component concentrations on a 1in-3 or 1-in-6 day frequency). Hence, there is a need to enhance the quantity and quality of data concerning $\mathrm{PM}_{2.5}$ chemical composition, especially for components such as trace metals that are difficult to measure but may have important health implications, so that the health risks posed by individual fine particle constituents can be better understood.

It is also possible that the health effects ascribed to $\mathrm{PM}_{2.5}$ may instead result to some extent from co-pollutants that vary collinearly with $\mathrm{PM}_{2.5}$ concentrations and therefore have the potential to confound the results of $\mathrm{PM}_{2.5}$ epidemiology studies. Gaseous pollutants such as $\mathrm{CO}, \mathrm{NO}_{2}, \mathrm{SO}_{2}$, and $\mathrm{O}_{3}$ are known to pose risks to human health; research (Jakab et al., 1996; Kleinman et al., 2000) has also suggested that synergistic toxicological interactions between gaseous and particle pollutants may be important. A number of early particulate matter epidemiology studies, many of which were instrumental in the promulgation of the $\mathrm{PM}_{2.5}$ NAAQS, have been criticized (Moolgavkar and Luebeck, 1996; Lipfert and Wyzga, 1997) for not adequately considering the potential confounding effects of gases such as $\mathrm{CO}$ and $\mathrm{NO}_{2}$. Several recent studies (Moolgavkar, 2003; Villeneuve et al., 2003; Klemm et al., 2004) that considered both particulate matter and gaseous pollutants reported that gases were more strongly associated with health effects than was particulate matter. Stieb et al. (2002) conducted a meta-analysis incorporating the results of 109 time-series studies of air pollution and mortality from around the world and concluded that " $\mathrm{PM}_{10}, \mathrm{CO}, \mathrm{NO}_{2}, \mathrm{O}_{3}$, and $\mathrm{SO}_{2}$ were all positively and significantly associated with all-cause mortality." However, it remains uncertain whether one or several of the particle or gaseous pollutants, or some other unaccounted factor, is responsible for the observed health effects. Pollen and spores are also generally copollutants rather than components of $\mathrm{PM}_{2.5}$, because they typically have diameters on the order of $10 \mu \mathrm{m}$ to $200 \mu \mathrm{m}$ (U.S. Geological Survey, 2003). These bioaerosols have been epidemiologically associated with respiratory health effects including asthma (Stieb et al., 2000), although the literature contains mixed conclusions regarding the ability of pollen and spores to confound the results of air pollution epidemiology studies (Neas et al., 1996; Rosas et al., 1998). Possible effects of other particle species with diameters greater than $2.5 \mu \mathrm{m}$ must also be clarified; coarse particles $\left(\mathrm{PM}_{10-2.5}\right)$ have been significantly associated with mortality in several studies exploring both $\mathrm{PM}_{2.5}$ and $\mathrm{PM}_{10-2.5}$ (Mar et al., 2000; Ostro et al., 2000). Hence, there is a need to better elucidate the possibility for confounding by gases and other co-pollutants in $\mathrm{PM}_{2.5}$ epidemiology studies. 
A further complicating factor in establishing the relationship between $\mathrm{PM}_{2.5}$ and human health is the fact that concentrations of $\mathrm{PM}_{2.5}$ and co-pollutants measured at centrally-located outdoor ambient air monitoring stations, which have typically been used in epidemiological studies, do not represent actual human exposures to these species. Outdoor pollutant concentrations vary spatially to some extent, depending upon factors like meteorology, topography, proximity to sources, etc., such that concentrations outside of a person's home, for example, may differ appreciably from those measured at a centrally located ambient air monitoring site. Moreover, people in modern urban societies spend a majority of their time in indoor microenvironments; hence, their exposure to particles of outdoor origin is dependent upon these particles' ability to penetrate indoors without depositing or chemically reacting. Because ambient concentrations are only proxies of actual air pollutant exposures, their use in epidemiology studies to represent such exposures introduces error, potentially biasing the results of these studies (Zeger et al., 2000; Meng et al., 2005). Studies that have reported associations between ambient $\mathrm{PM}_{2.5}$ concentrations and health effects based solely on central site exposure data have often relied on large sample sizes to compensate for the potential bias to the null that can result from exposure misclassification when central site measurements are used to reflect exposures. However, for epidemiologic panel studies, which include a smaller number of participants, more accurate and precise exposure estimates are needed to provide sufficient power to examine the associations between ambient particle concentrations and health effects. Exposures can be estimated more precisely using personal monitoring and/or home-specific assessment of indoor and outdoor concentrations.

Several studies have suggested that the spatial variability of particle concentrations and the relationship between personal particle exposures and ambient particle concentrations vary appreciably by particle component. Studies conducted in Philadelphia, PA, and Washington, D.C., found that summer $\mathrm{PM}_{10}$ and $\mathrm{PM}_{2.5}$ concentrations were relatively uniform across these urban areas (Burton et al., 1996). Correlations among various sites' summer PM levels were strong in each city, particularly for $\mathrm{PM}_{2.5}$, suggesting that the sources of $\mathrm{PM}_{2.5}$ in the summer are regional in nature, which is not surprising given the cities' high summer concentrations of $\mathrm{SO}_{4}{ }^{2-}$, a known regional pollutant. In contrast, in a study conducted in inner-city Boston, MA (Levy et al., 2000), personal exposures to $\mathrm{PM}_{2.5}$ and traffic particles varied considerably, with this variation related to proximity to a bus depot and to diesel traffic. These findings are consistent with findings from several other exposure studies, which also suggest that whereas ambient concentrations of regional $\mathrm{PM}_{2.5}$ components such as $\mathrm{SO}_{4}{ }^{2-}$ measured at centrally-located air monitoring sites are strong predictors on average of personal exposures for panels of individuals living nearby (Sarnat et al., 2000; Sarnat et al., 2002), the ability of a single centrallylocated ambient monitoring site to reflect exposures for locally-generated particle components such as EC is poor (Janssen et al., 1997; Chang et al., 2000; Koutrakis et al., 1992; Tolocka et al., 2001; Sarnat et al., 2001). In light of the aforementioned need for further research to clarify the link between specific chemical components of ambient $\mathrm{PM}_{2.5}$ and human health, additional elucidation of the associations between ambient concentrations of these components and human exposures to them is warranted.

Home ventilation conditions are also suggested to have a significant effect on the relationship between ambient $\mathrm{PM}_{2.5}$ concentrations and personal exposures to $\mathrm{PM}_{2.5}$. In a panel study of senior citizens in Baltimore, MD (Abt et al., 2000), repeated measurements of personal air pollutant exposures, home ventilation, and ambient air pollutant concentrations were used to investigate the influence of home ventilation on the personal-ambient $\mathrm{PM}_{2.5}$ association. Results showed that ventilation (as determined using self-reported information about the fraction of time spent indoors with open windows) was a significant predictor of the personal-ambient 
$\mathrm{PM}_{2.5}$ relationship, which was strongest for individuals spending most of their time in wellventilated environments and weakest for individuals spending their time in poorly ventilated environments. Further research is needed to confirm and supplement these findings.

Finally, personal exposure measurements of $\mathrm{PM}_{2.5}$ and gaseous pollutants can provide valuable information regarding the potential for confounding in air pollution epidemiology studies. For confounding to occur in studies employing central site measurements as proxies of exposure, ambient concentrations of a given pollutant of interest (e.g., $\mathrm{PM}_{2.5}$ ) must correlate with personal exposures to concentrations of the possible confounders (e.g., gases and other co-pollutants). Sarnat et al. (2001) examined the potential for confounding of particle health effect results by gaseous pollutants in a study of senior citizens living in Baltimore, MD, and found that although ambient $\mathrm{PM}_{2.5}$ concentrations were strongly associated with ambient concentrations of several gaseous pollutants, including $\mathrm{O}_{3}$, only ambient $\mathrm{PM}_{2.5}$ concentrations (and not ambient gaseous pollutant concentrations) were strong indicators of respective personal exposures, suggesting that the gaseous pollutants can not confound observed $\mathrm{PM}_{2.5}$-associated health effects for individuals with similar exposure profiles and living in similar urban locations. There is a need for additional assessments of this type to permit an evaluation of the applicability of these Baltimore results to different locations.

Resolution of the numerous $\mathrm{PM}_{2.5}$ research needs identified above is essential to ensure that the regulations written and money spent to control fine particulate matter produce the greatest possible benefits to public health and the environment. For example, if the health effects that have been associated with fine particulate matter are caused by specific chemical components of the particles rather than by total $\mathrm{PM}_{2.5}$ mass, then money spent to control $\mathrm{PM}_{2.5}$ mass by reducing ambient levels of its most prevalent, but benign, constituents may yield little improvement in public health.

Thus, in response to these $\mathrm{PM}_{2.5}$ research needs, CONSOL Energy Inc. Research \& Development (CONSOL R\&D), in collaboration with the funding agencies and participating groups listed in Table 1, launched the Steubenville Comprehensive Air Monitoring Program (SCAMP) in 1999. As its name suggests, SCAMP focused on characterizing $\mathrm{PM}_{2.5}$ and gaseous pollutant concentrations and exposures in Steubenville, $\mathrm{OH}$, a city of $\sim 19,000$ people located in a heavily industrialized area along the Ohio River in eastern Ohio. The city is part of the larger Steubenville-Weirton Metropolitan Statistical Area (MSA), which has a population of $\sim 132,000$. Despite its small population relative to major U.S. cities, Steubenville is an important location for $\mathrm{PM}_{2.5}$ research. Steubenville had the greatest concentrations of $\mathrm{PM}_{2.5}$, total suspended particulate (TSP), inhalable particles, $\mathrm{SO}_{4}{ }^{2-}, \mathrm{SO}_{2}$, and $\mathrm{NO}_{2}$ of the cities examined by the landmark Harvard Six Cities Study (Dockery et al., 1993), which reported an association between $\mathrm{PM}_{2.5}$ and mortality and was one of the "core studies" used by the U.S. EPA to establish the NAAQS for $\mathrm{PM}_{2.5}$. Although ambient $\mathrm{PM}_{2.5}$ concentrations in Steubenville have declined appreciably (Connell et al., 2005a) since the Six Cities Study was conducted in the 1970s and 1980s, likely owing to declines in the city's population (U.S. Census Bureau, 2000) and industrial activity (West Virginia University Bureau of Business and Economic Research, 2001) and advances in the application of air pollution control equipment, Jefferson County, $\mathrm{OH}$, where Steubenville is situated, is a nonattainment area under the $\mathrm{PM}_{2.5}$ NAAQS and is one of 18 counties projected by the U.S. EPA to remain in nonattainment in 2015 after the implementation of the Clean Air Interstate Rule (CAIR) (U.S. EPA, 2005a). Steubenville remains an ideal location for examining the impact of coal-fired power plant emissions on ambient $\mathrm{PM}_{2.5}$, as it is situated within $\sim 20 \mathrm{~km}$ of two major coal-fired power plants and within $200 \mathrm{~km}$ of numerous others located in the Ohio River Valley region. Mass-based $\mathrm{PM}_{2.5}$ regulations have particularly large implications for these plants, as sulfate, which results largely 
from $\mathrm{SO}_{2}$ emitted by coal combustion, is the largest contributor to $\mathrm{PM}_{2.5}$ mass in many eastern U.S. locations (Frank, 2006). Steubenville also permits an analysis of the effects of iron, steel, and coke facilities on ambient $\mathrm{PM}_{2.5}$ concentrations and compositions, as such facilities are located within a few kilometers of the city. Hence, the current assessment of $\mathrm{PM}_{2.5}$ concentration, composition, and exposure in Steubenville provided by SCAMP is particularly relevant for aiding implementation plan development and supplementing the results of previous landmark epidemiology studies conducted in that city.

Table 1. SCAMP sponsors and research participants.

\begin{tabular}{|c|c|}
\hline Sponsors & Research Participants \\
\hline $\begin{array}{c}\text { Ohio Coal Development Office within the Ohio Air } \\
\text { Quality Development Authority }\end{array}$ & Harvard School of Public Health \\
Electric Power Research Institute & Ohio University \\
American Petroleum Institute & Franciscan University of Steubenville \\
National Mining Association & Saint Vincent College \\
American Iron and Steel Institute & Wheeling Jesuit University \\
Edison Electric Institute & Optimal Technologies \\
National Institute of Environmental Health Sciences & Air Quality Sciences, Inc. \\
U.S. Environmental Protection Agency & Control Analytics, Inc. \\
CONSOL Energy Inc. & \\
\hline
\end{tabular}

SCAMP included two interrelated major components: the ambient air monitoring program and the indoor and personal exposure program. As part of the ambient air monitoring program, which was led by CONSOL R\&D, $\mathrm{PM}_{2.5}$ and $\mathrm{PM}_{10}$ mass, $\mathrm{PM}_{2.5}$ and $\mathrm{PM}_{10}$ composition, gaseous pollutant concentrations, pollen and spore counts, and meteorological conditions were measured from May 2000 through May 2002 at a central outdoor monitoring site in Steubenville. $\mathrm{PM}_{2.5}$ mass and composition were also determined during this period at four surrounding satellite sites. As part of the indoor and personal exposure program, which was led by the Harvard School of Public Health (HSPH) under subcontract to CONSOL R\&D, personal, indoor, and outdoor exposures to $\mathrm{PM}_{2.5}, \mathrm{PM}_{2.5}$ components, and gaseous pollutants were characterized during the summer and fall of 2000 for a panel of older adults and during the winter and summer of 2001 for a panel of children living in Steubenville. The ambient air monitoring program and the outdoor monitoring portion of the indoor and personal exposure program were funded by the U.S. Department of Energy's National Energy Technology Laboratory (DOE-NETL) and CONSOL Energy Inc. The indoor and personal air sampling portions of the indoor and personal exposure program were funded by the consortium of non-DOE sources listed in Table 1, led by the Ohio Coal Development Office (OCDO) within the Ohio Air Quality Development Authority (OAQDA).

The SCAMP ambient air monitoring and indoor and personal exposure programs were designed to provide information to help resolve several of the specific $\mathrm{PM}_{2.5}$ research needs identified in the discussion above, including the need for better estimates of the relationship between 
ambient concentrations of $\mathrm{PM}_{2.5}$ and its components and actual human exposures to these species, the need for better characterization of the potential for confounding by gaseous pollutants in $\mathrm{PM}_{2.5}$ epidemiology studies, the need for better characterization of individual chemical components of $\mathrm{PM}_{2.5}$, and the need for data for development of SIPs in response to the $\mathrm{PM}_{2.5}$ NAAQS. In addition to its two major components, SCAMP included several smaller studies designed to validate personal sampling methodologies, develop more sensitive analytical methods for determining trace elements in $\mathrm{PM}_{2.5}$, and examine associations between pollutant concentrations and heart rate variability for the older adult panel. Major objectives of the overall project were as follows:

1. To measure $\mathrm{PM}_{2.5}, \mathrm{PM}_{10}$, and co-pollutant concentrations and collect hourly meteorological data and daily pollen and spore counts at a central urban site in Steubenville,

2. To measure $\mathrm{PM}_{2.5}$ concentrations at four remote sites in the Steubenville region,

3. To measure $\mathrm{PM}_{2.5}$ and co-pollutant concentrations outside the homes of participating individuals in Steubenville,

4. To measure indoor $\mathrm{PM}_{2.5}$ and co-pollutant concentrations in the living environment of participating individuals in Steubenville,

5. To measure $\mathrm{PM}_{2.5}$ and co-pollutant concentrations in the "personal" environment of participating individuals in Steubenville,

6. To characterize the chemical and physical nature of indoor, outdoor, and personal $\mathrm{PM}_{2.5}$,

7. To evaluate the relationships between ambient concentrations and personal exposure to $\mathrm{PM}_{2.5}$ and co-pollutants,

8. To evaluate the relationships among indoor, outdoor, and personal $\mathrm{PM}_{2.5}$ concentrations and indoor, outdoor, and personal co-pollutants,

9. To compare $\mathrm{PM}_{2.5}$ collected at urban and remote sites,

10. To determine whether heart rate variability correlates with any or all of the pollutants monitored, and

11. To provide a comprehensive database for use in epidemiological studies, long-range transport studies, and SIP development.

Results from the SCAMP ambient air monitoring program, the SCAMP indoor and personal exposure program, and the various smaller studies conducted as part of the project have been disseminated via a number of publications and presentations, which are listed in the Bibliography included with this report. This final report integrates and summarizes these results and discusses their implications for $\mathrm{PM}_{2.5}$ research and policymaking. 


\section{EXECUTIVE SUMMARY}

The Steubenville Comprehensive Air Monitoring Program (SCAMP) was conducted to clarify uncertainties regarding fine particulate matter $\left(\mathrm{PM}_{2.5}\right)$ concentration, composition, and exposure. As part of the program, $\mathrm{PM}_{2.5}, \mathrm{PM}_{2.5}$ components, co-pollutants, and meteorological conditions were monitored from May 2000 through May 2002 at a central ambient air monitoring station in Steubenville, $\mathrm{OH}$, and $\mathrm{PM}_{2.5}$ and its components were simultaneously monitored at four comparatively remote satellite sites in the surrounding region. Additionally, personal, indoor, and outdoor exposures to $\mathrm{PM}_{2.5}, \mathrm{PM}_{2.5}$ components, and gaseous pollutants were characterized during the summer and fall of 2000 for a panel of older adults and during the winter and summer of 2001 for a panel of children living in Steubenville. The program also included the successful development of a method for determining $\mathrm{PM}_{2.5}$ trace elements by dynamic reaction cell ICP-MS, a study to validate personal sampling methodologies, and a concurrent evaluation of the effects of $\mathrm{PM}_{2.5}$ and gases on the cardiac health of the older adult panel. SCAMP succeeded in generating a powerful database of information concerning ambient, outdoor, indoor, and personalbreathing-space concentrations of $\mathrm{PM}_{2.5}$, its components, and co-pollutants in Steubenville and in helping to address a number of $\mathrm{PM}_{2.5}$ research needs, including the need for better estimates of the relationship between ambient concentrations of $\mathrm{PM}_{2.5}$ and its components and actual human exposures to these species, the need for better characterization of the potential for confounding by gaseous pollutants in $\mathrm{PM}_{2.5}$ epidemiology studies, the need for better characterization of individual chemical components of $\mathrm{PM}_{2.5}$, and the need for data for development of State Implementation Plans (SIPs) in response to the $\mathrm{PM}_{2.5}$ National Ambient Air Quality Standards (NAAQS). Major conclusions of the program are as follows:

- Average concentrations of $\mathrm{PM}_{2.5}$, as well as those of many $\mathrm{PM}_{2.5}$ components and gaseous pollutants, in Steubenville have decreased appreciably since the Harvard Six Cities Study was conducted in the late 1970 s and 1980 s, but remain elevated relative to the annual $\mathrm{PM}_{2.5}$ NAAQS. The mean $\mathrm{PM}_{2.5}$ concentration measured during SCAMP $\left(18.4 \mu \mathrm{g} / \mathrm{m}^{3}\right)$ was $40 \%$ less than that measured during the Six Cities Study, but remained more than $3 \mu \mathrm{g} / \mathrm{m}^{3}$ above the $\mathrm{PM}_{2.5} \mathrm{NAAQS}$. Hence, further reductions in $\mathrm{PM}_{2.5}$ concentrations in Steubenville will be required; data collected as part of SCAMP are particularly relevant for informing the development of an appropriate $\mathrm{PM}_{2.5}$ implementation plan for Steubenville.

- Secondary-sulfate-dominated regional $\mathrm{PM}_{2.5}$, likely resulting from coal-fired power plants to the west and southwest of Steubenville, is the largest contributor to ambient $\mathrm{PM}_{2.5}$ in Steubenville, accounting for about $40 \%$ of the total mass. Primary $\mathrm{PM}_{2.5}$ emissions from coal-fired power plants, on the other hand, appear to contribute relatively little (i.e., $<5 \%$ ) to the total mass of ambient $\mathrm{PM}_{2.5}$. Hence, whereas reductions in secondary sulfates originating from coal-fired power plants (as required under the Clean Air Interstate Rule) will almost certainly be needed if Steubenville is to attain compliance with the $\mathrm{PM}_{2.5}$ NAAQS, further reductions in primary particulate emissions from coal-fired power plants would be of relatively little aid in attaining a mass-based standard.

- Local sources in the immediate Steubenville vicinity, including motor vehicles, iron and steel facilities, and possibly other point and area sources, contribute an estimated $5 \mu \mathrm{g} / \mathrm{m}^{3}(\sim 30 \%)$ to the total mass of ambient $\mathrm{PM}_{2.5}$ in Steubenville.

- Distinct mechanisms cause local- and regional-scale episodes of elevated $\mathrm{PM}_{2.5}$ concentrations in Steubenville. Regional-scale episodes typically occurred during warmer periods of the year and were often characterized by multiple-day periods of consistently and moderately elevated concentrations of secondary-sulfate-dominated $\mathrm{PM}_{2.5}$. Conversely, local-scale episodes typically occurred during cooler portions of the year and were characterized by shorter overnight periods of more acutely elevated concentrations of $\mathrm{PM}_{2.5}$ resulting from the buildup of primary particles enriched in trace metals and carbonaceous species during nocturnal temperature inversions. Both of the $\mathrm{PM}_{2.5}$ episode types identified during SCAMP must be considered when developing an implementation plan to reduce concentrations of $\mathrm{PM}_{2.5}$ in Steubenville.

- Concentrations of certain transition metals, including Fe, Mn, and $\mathrm{Zn}$, observed at Steubenville are appreciably elevated relative to concentrations observed in the surrounding region and in other larger U.S. cities. Further research should be conducted to better elucidate whether these metals play any role in the health effects previously associated with $\mathrm{PM}_{2.5}$ in Steubenville. 
- Ambient fine particle concentration is a strong proxy of corresponding personal exposure for older adults and, to a lesser extent, for children in Steubenville. Mixed model results indicated that, for every $10 \mu \mathrm{g} / \mathrm{m}^{3}$ increase in corresponding ambient $\mathrm{PM}_{2.5}$ concentrations, personal exposures of the older adults increased an average of $7.3 \pm 0.5 \mu \mathrm{g} / \mathrm{m}^{3}$ during the summer and $6.3 \pm 0.5 \mu \mathrm{g} / \mathrm{m}^{3}$ during the fall. For the children, for every $10 \mu \mathrm{g} / \mathrm{m}^{3}$ increase in corresponding ambient concentrations, personal $\mathrm{PM}_{2.5}$ exposures increased an average of $5.8 \pm 0.8$ during the summer and $2.5 \pm 1.4 \mu \mathrm{g} / \mathrm{m}^{3}$ during the winter. Overall, results of SCAMP confirm the results of previous studies showing that ambient $\mathrm{PM}_{2.5}$ concentrations are strong proxies of corresponding personal exposures, especially for older adults.

- The ability of ambient fine particle concentrations to reflect personal exposures differs by particle component, and is greater for $\mathrm{SO}_{4}{ }^{2-}$, a predominantly regional fine particle, than for elemental carbon (EC), a predominantly locally-emitted fine particle. Personal-ambient associations for $\mathrm{SO}_{4}{ }^{2-}$, like those for $\mathrm{PM}_{2.5}$, were stronger in summer than in fall or winter, whereas personal-ambient associations for EC followed an opposite seasonal pattern. Again, personal-ambient associations were stronger for the older adults than for the children. Findings are consistent with those of previous studies and provide additional justification for the use of ambient $\mathrm{SO}_{4}{ }^{2-}$, and to a lesser extent $\mathrm{EC}$, to represent corresponding mean personal exposures in epidemiologic analyses. Future exposure studies should examine factors contributing to the observed differences in pollutant exposures for older adults and children. Further improvements in methods for measuring personal exposures to $\mathrm{PM}_{2.5}$ components (and to gases such as $\mathrm{SO}_{2}$ ) are also needed, particularly for trace elements, which often exhibited poor precision or could not be quantified in personal exposure samples during SCAMP, and for organic carbon, which was the second largest component of ambient $\mathrm{PM}_{2.5}$ mass in Steubenville during SCAMP but was not measured in personal exposure samples because of methodological limitations.

- Home ventilation was the primary factor affecting the ability of ambient pollutant concentrations to reflect the personal exposures of older adults and children to these pollutants. For both cohorts, slopes describing the increase in indoor or personal pollutant concentrations for a corresponding increase in ambient concentrations were generally greater when windows were open or when participants spent more time near open windows. Results from SCAMP are the first to show the impact of home ventilation as a modifier of personal-ambient gas associations, and suggest that ventilation may be an important modifier of the magnitude of effect in time-series health studies.

- Time-series health studies based on 24-hour ambient concentrations may not be able to separate the independent effects of particles and gases in Steubenville. Analyses of ambient air monitoring data from the central site suggest that gaseous pollutants such as $\mathrm{CO}, \mathrm{NO}_{2}$, and to a lesser extent $\mathrm{O}_{3}$, may cause seasonally-dependent collinearity problems in $\mathrm{PM}_{2.5}$ time series epidemiology studies focusing on Steubenville. Furthermore, comparisons of central site data with personal exposure data indicate statistically significant associations between ambient particle concentrations and personal $\mathrm{O}_{3}$ and $\mathrm{NO}_{2}$ exposures, suggesting that the effects of these pollutants may be difficult to differentiate. It is important to note, however, that ambient particle concentrations were generally better proxies of exposures to the particles themselves rather than the gases. Nevertheless, future epidemiology studies focusing on $\mathrm{PM}_{2.5}$ should carefully consider the possibility for confounding by gaseous copollutants such as $\mathrm{CO}, \mathrm{NO}_{2}$, and $\mathrm{O}_{3}$, as well as the possibility that the associations among and effects of these pollutants may be significantly modified by season or by home ventilation status. Previous studies that did not adequately consider these possibilities should be interpreted cautiously.

- Health effect studies conducted using $\mathrm{PM}_{2.5}$ and gaseous pollutant data collected at the SCAMP central monitoring site in Steubenville found that fine particulate sulfate, but not elemental carbon, was significantly associated with decreased heart rate variability and increased odds of supraventricular arrhythmia among members of the older adult cohort. Although these studies were based on a fairly small cohort and did not consider all major chemical components of $\mathrm{PM}_{2.5}$ in Steubenville (e.g., organic carbon, the second largest contributor to $\mathrm{PM}_{2.5}$ mass in Steubenville, was not included in the analyses), they provide evidence that increased levels of ambient fine particulate pollution from non-traffic sources (e.g., sulfate particles) may adversely affect cardiac health in the elderly. 


\section{EXPERIMENTAL}

As discussed in the introduction, the Steubenville Comprehensive Air Monitoring Program included two major complementary components: the ambient air monitoring program and the indoor and personal exposure program. As part of the ambient air monitoring program, which was designed to permit a characterization of $\mathrm{PM}_{2.5}$ concentration and composition in Steubenville, $\mathrm{OH}$, and the surrounding region and an assessment of factors that affect $\mathrm{PM}_{2.5}$ in Steubenville, $\mathrm{PM}_{2.5}, \mathrm{PM}_{2.5}$ speciation, $\mathrm{PM}_{10}, \mathrm{PM}_{10}$ speciation, gaseous pollutants, meteorological conditions, and pollen and spores were measured at a central ambient air monitoring site in Steubenville between May 2000 and May 2002, and $\mathrm{PM}_{2.5}$ and $\mathrm{PM}_{2.5}$ speciation were simultaneously measured at four satellite sites in Ohio, Pennsylvania, and West Virginia. As part of the indoor and personal exposure program, which was designed to assess how indoor and personal exposures to $\mathrm{PM}_{2.5}, \mathrm{PM}_{2.5}$ components, and gaseous pollutants relate to outdoor concentrations of these species in Steubenville for potentially sensitive populations, personal, indoor, and outdoor exposures to $\mathrm{PM}_{2.5}, \mathrm{PM}_{2.5}$ components, and gaseous pollutants were characterized for a panel of older adults and a panel of children living in Steubenville. Each panel was monitored in two distinct seasons during 2000-2001. This section summarizes the experimental methods employed by the SCAMP ambient air monitoring and indoor and personal exposure programs.

SCAMP also included several smaller components designed to supplement the ambient air monitoring and indoor and personal exposure programs. These included a study focused on the development and validation of sampling and analytical methodologies for measuring personal, indoor, and outdoor concentrations of $\mathrm{PM}_{2.5}$ and its components, as well as a study exploring associations between pollutant concentrations and heart rate variability for the older adult panel. Summaries of these smaller components of SCAMP, including both methods and key findings, are provided in the Results section of this report.

\subsection{Ambient Air Monitoring Program}

\subsubsection{Study Design}

Figure 1 shows the locations of the five sites constituting the SCAMP ambient air monitoring network. The central ambient air monitoring station in Steubenville was located on the campus of Franciscan University of Steubenville $\sim 500 \mathrm{~m}$ northeast of where the Harvard Six Cities Study central monitoring site in Steubenville had been located. The SCAMP site was situated atop a bluff overlooking the western bank of the Ohio River from a height of $\sim 110 \mathrm{~m}$. The river runs from approximately due north to due south in the Steubenville vicinity; the monitoring site was located within a few kilometers of several major industrial facilities and vehicular thoroughfares located along the river. A long-term parking lot near the monitoring station was usually full but experienced only infrequent traffic. Hence, the SCAMP central site was expected to capture the effect of local source emissions in the immediate Steubenville vicinity on ambient air $\mathrm{PM}_{2.5}$ and co-pollutant concentrations in the city, without being unduly influenced by any one particular source.

The four satellite monitoring sites were positioned to provide information about $\mathrm{PM}_{2.5}$ concentrations and compositions observed in less-industrialized areas surrounding Steubenville for comparison with those observed in Steubenville, and to permit an assessment of the effects of distance and direction on $\mathrm{PM}_{2.5}$ concentration and composition in the Steubenville region. Relative to Steubenville, the satellite sites, which were situated approximately at the cardinal compass points around Steubenville, were located about $19 \mathrm{~km}$ to the north $(\mathrm{N})$ in Tomlinson 
Run State Park near New Manchester, WV; $33 \mathrm{~km}$ to the south (S) on the campus of Wheeling Jesuit University in Wheeling, WV; $108 \mathrm{~km}$ to the east (E) on the campus of Saint Vincent College in Latrobe, PA; and $22 \mathrm{~km}$ to the west (W) in Hopedale, $\mathrm{OH}$. Among the satellite sites, the southern site was most similar to the Steubenville site, as it was located $\sim 3 \mathrm{~km}$ from the center of Wheeling, a city of $\sim 30,000$ people located along the Ohio River.

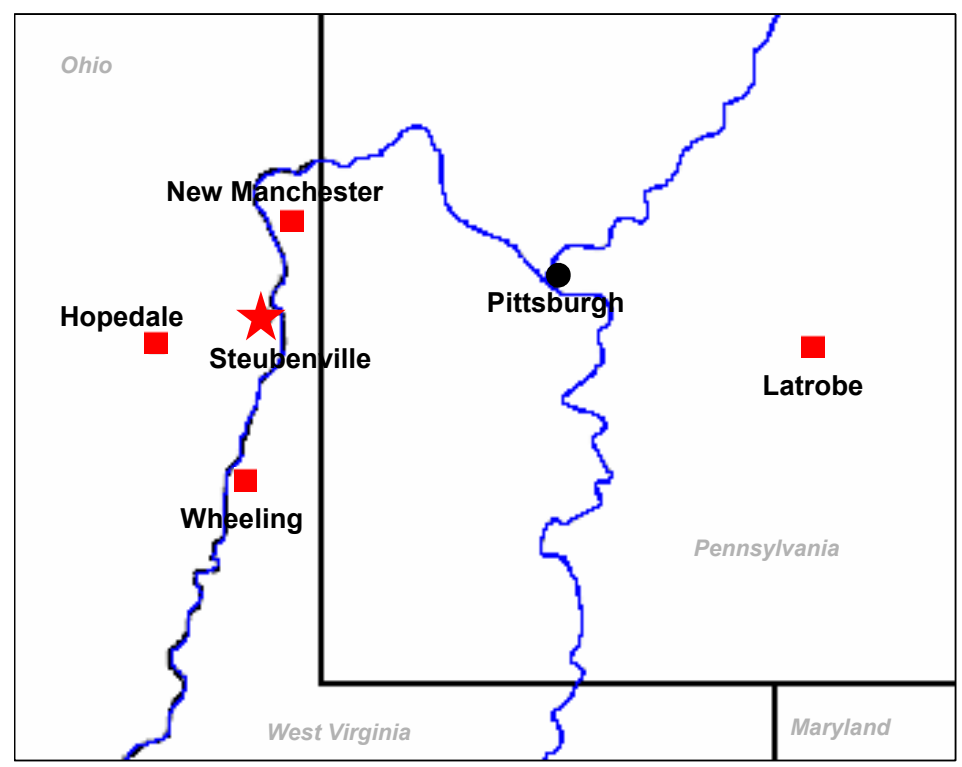

Figure 1. SCAMP ambient air monitoring sites.

Table 2 summarizes the sampling regimen followed by the SCAMP ambient air monitoring sites. The central monitoring station in Steubenville served as the ambient air monitoring "supersite" for the program. There, 24-hr average $\mathrm{PM}_{2.5}$ mass concentrations were determined daily using the Federal Reference Method (FRM) for $\mathrm{PM}_{2.5}$, and $\mathrm{PM}_{2.5}$ component concentrations were determined from 24-hr integrated samples collected every fourth day using the FRM monitor and a speciation sampler. The measured components of $\mathrm{PM}_{2.5}$ included sulfate $\left(\mathrm{SO}_{4}{ }^{2-}\right)$, nitrate $\left(\mathrm{NO}_{3}{ }^{-}\right)$, chloride $\left(\mathrm{Cl}^{-}\right)$, ammonium $\left(\mathrm{NH}_{4}{ }^{+}\right)$, elemental carbon (EC), organic carbon (OC), a suite of elements in the water-extractable $\mathrm{PM}_{2.5}$ fraction, and a suite of elements in the acid-digestible $\mathrm{PM}_{2.5}$ fraction. Twenty-four-hour average $\mathrm{PM}_{10}$ concentrations were also determined each day at the central Steubenville site using the FRM for $\mathrm{PM}_{10}$; the $\mathrm{PM}_{10}$ samples collected every fourth day were further analyzed to determine concentrations of $\mathrm{SO}_{4}{ }^{2-}, \mathrm{NO}_{3}{ }^{-}, \mathrm{Cl}^{-}, \mathrm{NH}_{4}{ }^{+}$, and a suite of water-extractable elements. In addition to these 24-hr integrated $\mathrm{PM}_{2.5}$ and $\mathrm{PM}_{10}$ measures, hourly $\mathrm{PM}_{2.5}$ mass concentrations were measured using a tapered element oscillating microbalance (TEOM), daily pollen and spore counts were determined from samples collected using a Burkard volumetric spore trap, and hourly gas $\left(\mathrm{SO}_{2}, \mathrm{O}_{3}, \mathrm{NO}_{\mathrm{x}}\right.$, and $\left.\mathrm{CO}\right)$ concentrations and meteorological conditions were monitored.

At each of the four satellite sites, 24-hr average $\mathrm{PM}_{2.5}$ mass concentrations were determined daily using the FRM for $\mathrm{PM}_{2.5}$, and water extracts from the FRM $\mathrm{PM}_{2.5}$ samples collected every fourth day were analyzed for ions $\left(\mathrm{SO}_{4}{ }^{2-}, \mathrm{NO}_{3}{ }^{-}, \mathrm{Cl}^{-}, \mathrm{NH}_{4}{ }^{+}\right)$and a suite of elements.

For all five sites, the 24-hr sampling period for a given day occurred from 9:00 a.m. Eastern Standard Time (EST) on that day until 9:00 a.m. EST on the following day in order to be consistent with the sampling schedule followed by the SCAMP indoor and personal exposure program. (On every third day from June 30, 2001 - August 2, 2001 and from January 8, 2002 - 
Table 2. Sampling regimen for SCAMP ambient air monitoring sites.

\begin{tabular}{|c|c|c|c|c|c|c|}
\hline Variable & Locations $^{a}$ & $\begin{array}{l}\text { Sampling } \\
\text { Period }\end{array}$ & $\begin{array}{l}\text { Frequency } \\
\left(\text { days }^{-1}\right)\end{array}$ & $\begin{array}{l}\text { Resolution } \\
\text { (hours) }\end{array}$ & Sampling Method ${ }^{b}$ & Analytical Method \\
\hline $\mathrm{PM}_{2.5}$ & $\begin{array}{l}\text { ST, N, S, E, } \\
\text { W }\end{array}$ & $5 / 13 / 00-5 / 14 / 02$ & $1 / 1$ & 24 & $\begin{array}{l}\mathrm{PM}_{2.5} \text { FRM Sampler, Teflon } \\
\text { Filter }\end{array}$ & Gravimetry (FRM) \\
\hline $\begin{array}{l}\text { lons }\left(\mathrm{SO}_{4}{ }^{2-}, \mathrm{NO}_{3}^{-}\right. \\
\left.\mathrm{Cl}^{-}, \mathrm{NH}_{4}^{+}\right)\end{array}$ & $\begin{array}{l}\text { ST, N, S, E, } \\
\text { W }\end{array}$ & $5 / 16 / 00-5 / 14 / 02$ & $1 / 4$ & 24 & $\begin{array}{l}\mathrm{PM}_{2.5} \text { FRM Sampler, Teflon } \\
\text { Filter }\end{array}$ & Ion Chromatography \\
\hline $\begin{array}{l}\text { Carbon (EC, } \\
\mathrm{OC})\end{array}$ & ST & $8 / 12 / 00-5 / 14 / 02$ & $1 / 4$ & 24 & $\begin{array}{l}\mathrm{PM}_{2.5} \text { Speciation Sampler, } \\
\text { Quartz Filter }\end{array}$ & Thermal Optical Transmittance \\
\hline $\begin{array}{l}\text { Water- } \\
\text { Extractable } \\
\text { Elements }\end{array}$ & $\begin{array}{l}\mathrm{ST}, \mathrm{N}, \mathrm{S}, \mathrm{E}, \\
\mathrm{W}\end{array}$ & $5 / 16 / 00-5 / 14 / 02$ & $1 / 4$ & 24 & $\begin{array}{l}\mathrm{PM}_{2.5} \text { FRM Sampler, Teflon } \\
\text { Filter }\end{array}$ & $\begin{array}{l}\text { Dynamic Reaction Cell ICP- } \\
\text { MS }\end{array}$ \\
\hline $\begin{array}{l}\text { Acid-Digestible } \\
\text { Elements }\end{array}$ & ST & $8 / 12 / 00-5 / 14 / 02$ & $1 / 4$ & 24 & $\begin{array}{l}\mathrm{PM}_{2.5} \text { Speciation Sampler, } \\
\text { Teflon Filter }\end{array}$ & $\begin{array}{l}\text { Dynamic Reaction Cell ICP- } \\
\text { MS }\end{array}$ \\
\hline $\mathrm{PM}_{10}$ & ST & $5 / 13 / 00-5 / 14 / 02$ & $1 / 1$ & 24 & $\begin{array}{l}\mathrm{PM}_{10} \text { FRM Sampler, Teflon } \\
\text { Filter }\end{array}$ & Gravimetry \\
\hline $\begin{array}{l}\text { lons }\left(\mathrm{SO}_{4}{ }^{2-}, \mathrm{NO}_{3}{ }^{-}\right. \\
\left.\mathrm{Cl}^{-}, \mathrm{NH}_{4}{ }^{+}\right)\end{array}$ & ST & $5 / 16 / 00-5 / 14 / 02$ & $1 / 4$ & 24 & $\begin{array}{l}\mathrm{PM}_{10} \text { FRM Sampler, Teflon } \\
\text { Filter }\end{array}$ & Ion Chromatography \\
\hline $\begin{array}{l}\text { Water- } \\
\text { Extractable } \\
\text { Elements }\end{array}$ & ST & $5 / 16 / 00-5 / 14 / 02$ & $1 / 4$ & 24 & $\begin{array}{l}\mathrm{PM}_{10} \text { FRM Sampler, Teflon } \\
\text { Filter }\end{array}$ & $\begin{array}{l}\text { Dynamic Reaction Cell ICP- } \\
\text { MS }\end{array}$ \\
\hline $\mathrm{PM}_{2.5}$ & ST & $6 / 14 / 00-5 / 14 / 02$ & $1 / 1$ & $1,24^{d}$ & TEOM & $\mathrm{N} / \mathrm{A}$ \\
\hline $\mathrm{SO}_{2}$ & ST & $5 / 16 / 00-5 / 14 / 02$ & $1 / 1$ & $1,24^{d}$ & FEM, UV Fluorescence & N/A \\
\hline $\mathrm{NO} / \mathrm{NO}_{2} / \mathrm{NO}_{\mathrm{x}}$ & ST & $5 / 16 / 00-5 / 14 / 02$ & $1 / 1$ & $1,24^{d}$ & FRM, Chemiluminescence & $\mathrm{N} / \mathrm{A}$ \\
\hline $\mathrm{CO}$ & ST & $5 / 16 / 00-5 / 14 / 02$ & $1 / 1$ & $1,24^{d}$ & FRM, Gas Filter Correlation & $\mathrm{N} / \mathrm{A}$ \\
\hline $\mathrm{O}_{3}$ & ST & $5 / 16 / 00-5 / 14 / 02$ & $1 / 1$ & $1,24^{d}$ & FEM, UV & N/A \\
\hline $\begin{array}{l}\text { Weather } \\
\text { Conditions }^{c}\end{array}$ & ST & $5 / 16 / 00-5 / 14 / 02$ & $1 / 1$ & $1,24^{d}$ & $\begin{array}{l}\text { 10-meter Meteorological } \\
\text { Tower }\end{array}$ & N/A \\
\hline Pollen and Spores & ST & $6 / 21 / 00-5 / 13 / 02$ & $1 / 1$ & 24 & $\begin{array}{l}\text { 7-Day Burkard Volumetric } \\
\text { Spore Trap }\end{array}$ & Optical Microscopy \\
\hline
\end{tabular}

${ }^{\mathrm{a}} \mathrm{ST}$ is Steubenville; N, S, E, and W are the northern, southern, eastern, and western satellite sites, respectively. ${ }^{\mathrm{b}} \mathrm{FRM}=\mathrm{Federal}$ Reference Method, FEM = Federal Equivalent Method. 'Includes wind speed, temperature, relative humidity, solar radiation, rainfall, and barometric pressure. ${ }^{\mathrm{d}}$ Monitored continuously; 1-hr and 24-hr averages were computed. 
January 20, 2002, the $\mathrm{PM}_{2.5}$ speciation sampler at the central Steubenville site was operated from 12:00 a.m. EST to 12:00 a.m. EST as part of a sampling program being conducted by the U.S. EPA. When these EPA sampling days fell on regularly scheduled SCAMP speciation sampling days, the EPA sampling schedule was followed for the speciation sampler. Speciation sampler results from these EPA sampling days are not included in the analyses presented in this report).

\subsubsection{Sampling and Analytical Methods}

\subsubsection{Integrated $\mathrm{PM}_{2.5}$ Mass}

Twenty-four-hour average $\mathrm{PM}_{2.5}$ mass concentrations were determined daily at the central Steubenville site and each of the four satellite sites according to the Federal Reference Method for $\mathrm{PM}_{2.5}$. Each 24-hr integrated $\mathrm{PM}_{2.5}$ sample was collected on a 47-mm Teflon filter using a Thermo Andersen $\mathrm{PM}_{2.5}$ Sequential Sampler (RAAS2.5-300, U.S. EPA Designation RFPS0598-120) operating at a flow rate of $\sim 16.67 \mathrm{~L} / \mathrm{min}$. Filters were conditioned before and after exposure, and the mass of sampled $\mathrm{PM}_{2.5}$ was determined gravimetrically using a Cahn C-33 microbalance in a clean weighing room that was controlled for temperature, humidity, and vibration. Daily average concentrations were determined based upon the mass of sample collected and the volume of air sampled.

\subsubsection{2 $\mathrm{PM}_{2.5}$ Water-Extractable lons and Elements}

The 24-hr integrated $\mathrm{PM}_{2.5}$ FRM samples from every fourth day at each of the five SCAMP monitoring sites were submitted for ionic and water-extractable elemental analyses. The Teflon filters containing these samples were transferred into rinsed polypropylene digestion tubes using Teflon-coated forceps and covered with $25 \mathrm{~mL}$ of $18-\mathrm{M} \Omega$ deionized water containing $0.2 \%$ isopropanol as a wetting agent. The tubes were then sonicated for 30 minutes, and the resulting leachate from each sample was divided into separate aliquots for anionic, cationic, and elemental analyses.

\subsubsection{1 lons}

$\mathrm{SO}_{4}{ }^{2-}, \mathrm{NO}_{3}{ }^{-}, \mathrm{Cl}^{-}$, and $\mathrm{NH}_{4}{ }^{+}$were determined by ion chromatography (IC). Anionic species were separated by an anion exchange resin using a sodium carbonate-sodium bicarbonate eluent in a Dionex DX-100 ion chromatograph. Ammonium was separated by a cation exchange resin using a nitric acid-EDTA eluent in a Waters ion chromatograph. Both instruments use a conductivity meter to detect the concentrations of the ionic species in solution, which are then converted to 24-hr average ambient air values. Analytical detection limits, expressed in units of $\mu \mathrm{g} / \mathrm{m}^{3}$ of sampled ambient air for ease of comparison with the ambient air concentration data presented later, were approximately $0.02 \mu \mathrm{g} / \mathrm{m}^{3}$ for $\mathrm{Cl}^{-}, 0.06 \mu \mathrm{g} / \mathrm{m}^{3}$ for $\mathrm{NO}_{3}^{-}$, and $0.1 \mu \mathrm{g} / \mathrm{m}^{3}$ for $\mathrm{NH}_{4}{ }^{+}$and $\mathrm{SO}_{4}{ }^{2-}$.

\subsection{Water-Extractable Elements}

Concentrations of 21 water-extractable elemental components of $\mathrm{PM}_{2.5}$ (Al, As, Ba, Ca, Cd, Co, $\mathrm{Cr}, \mathrm{Cu}, \mathrm{Fe}, \mathrm{K}, \mathrm{Mg}, \mathrm{Mn}, \mathrm{Na}, \mathrm{Ni}, \mathrm{Pb}, \mathrm{Se}, \mathrm{Si}, \mathrm{Sn}, \mathrm{Ti}, \mathrm{V}, \mathrm{Zn}$ ) were determined by dynamic reaction cell (DRC) inductively coupled plasma-mass spectrometry (ICP-MS). Prior to analysis, an internal standard solution containing $\mathrm{Ge}$ and In was added to each sample so that instrument drift could be monitored and corrected. 
All elemental determinations were performed using a PerkinElmer ELAN 6100 DRC ICP-MS. Aside from the DRC, the instrument is a conventional quadrupole ICP-MS. The liquid sample to be analyzed is nebulized and passed through an argon plasma, which converts the analyte atoms into primarily singly charged ions. These ions are focused by a lens system and fed to a quadrupole mass spectrometer, which filters the ions according to their mass-to-charge ratio $(\mathrm{m} / \mathrm{z})$, allowing only those with a specific $\mathrm{m} / \mathrm{z}$ to pass through. A discrete dynode detector is used to count the ions passing through the quadrupole.

Interferences limit the ability of conventional ICP-MS to determine certain isotopes (e.g., ${ }^{39} \mathrm{~K}$, ${ }^{40} \mathrm{Ca},{ }^{51} \mathrm{~V},{ }^{52} \mathrm{Cr},{ }^{56} \mathrm{Fe},{ }^{75} \mathrm{As}$, and ${ }^{80} \mathrm{Se}$ ) that are of interest to $\mathrm{PM}_{2.5}$ researchers. These interferences may result from isobaric species (e.g., ${ }^{40} \mathrm{Ar}^{+}$, which interferes with the determination of ${ }^{40} \mathrm{Ca}$ ) or polyatomic species (e.g., ${ }^{40} \mathrm{Ar}^{16} \mathrm{O}^{+}$, which interferes with the determination of ${ }^{56} \mathrm{Fe}$ ) that have the same $\mathrm{m} / \mathrm{z}$ as the desired analyte. Certain sample matrices can increase the potential for interferences. For example, if the sample contains $\mathrm{Cl}^{-},{ }^{40} \mathrm{Ar}^{35} \mathrm{Cl}^{+}$ can interfere with the determination of ${ }^{75} \mathrm{As}$, and ${ }^{35} \mathrm{Cl}^{16} \mathrm{O}^{+}$can interfere with the determination of ${ }^{51} \mathrm{~V}$.

The DRC is employed to minimize these interferences. Prior to entering the analyzing quadrupole, ionic species generated in the plasma pass through a reaction cell that also contains an active quadrupole. A gas such as $\mathrm{CH}_{4}$ or $\mathrm{NH}_{3}$ that readily reacts with the interfering species but not with the desired analyte is introduced into the reaction cell. The reaction gas converts interfering species to uncharged species or species with masses that differ from that of the analyte. For example, $\mathrm{NH}_{3}$ reacts with ${ }^{40} \mathrm{Ar}^{+}$to form neutral ${ }^{40} \mathrm{Ar}$ according to the following electron transfer reaction, which has a rate constant of $1.7 \times 10^{-9} \mathrm{~cm}^{3}$ molecule $^{-1} \mathrm{~s}^{-1}$ (Tanner and Baranov, 1999):

$$
{ }^{40} \mathrm{Ar}^{+}+\mathrm{NH}_{3} \rightarrow{ }^{40} \mathrm{Ar}+\mathrm{NH}_{3}^{+}
$$

The electron transfer reaction between ${ }^{40} \mathrm{Ca}^{+}$and $\mathrm{NH}_{3}$ is comparatively slow, having a rate constant of less than $10^{-13} \mathrm{~cm}^{3}$ molecule $\mathrm{e}^{-1} \mathrm{~s}^{-1}$, and therefore does not occur to any appreciable extent. (Tanner and Baranov, 1999). Hence, $\mathrm{NH}_{3}$ can be used to minimize the ${ }^{40} \mathrm{Ar}^{+}$ interference on the determination of ${ }^{40} \mathrm{Ca}$. The quadrupole present in the reaction cell is used to control the $\mathrm{m} / \mathrm{z}$ characteristics of the ion beam that is sent to the analyzing quadrupole. Species falling outside of a specific mass bandpass window are ejected from the cell, preventing the formation of new interfering species. Hence, the reaction gas and active quadrupole present in the DRC work together to substantially reduce many of the interferences that limit the capabilities of conventional ICP-MS.

As part of SCAMP, methods for applying DRC ICP-MS to the determination of elements in filterbased $\mathrm{PM}_{2.5}$ samples were developed and validated. The results of this method development are described in the Section 4.1.2 of this report. Table 3 outlines the strategy that was ultimately used as part of SCAMP to determine each of the 21 targeted elements in the waterextractable $\mathrm{PM}_{2.5}$ fraction by DRC ICP-MS. As the table indicates, the method included multiple determinations of many elements, including determinations of different isotopes of the element, determinations of the same isotope using different reaction gases (or no reaction gas), and determinations of the same isotope using different flow rates of the same reaction gas. Because of this strategy, multiple detection limits were obtained for several elements. Detection limits shown in Table 3 were converted to units of $\mathrm{ng} / \mathrm{m}^{3}$ of sampled ambient air for ease of comparison with the ambient air concentration data presented later. 
Table 3. Strategy and detection limits for the determination of elements in the water-soluble fraction of $\mathrm{PM}_{2.5}$ using DRC ICP-MS.

\begin{tabular}{|c|c|c|c|}
\hline Element & Isotope & Reaction Gas & Detection Limits ( $\mathrm{ng} / \mathrm{m}^{3}$ of sampled air) \\
\hline $\mathrm{Al}$ & 27 & $\mathrm{NH}_{3}$ & 0.1 \\
\hline As & 75 & $\mathrm{CH}_{4}$ & 0.04 \\
\hline $\mathrm{Ba}$ & 138 & None & 0.01 \\
\hline \multirow{3}{*}{$\mathrm{Ca}$} & 40 & $\mathrm{CH}_{4}$ & 12 \\
\hline & 40 & $\mathrm{NH}_{3}$ & 3,1 \\
\hline & 44 & None & 27 \\
\hline \multirow{2}{*}{$\mathrm{Cd}$} & 111 & None & 0.01 \\
\hline & 114 & None & 0.01 \\
\hline Co & 59 & None & 0.002 \\
\hline \multirow{2}{*}{$\mathrm{Cr}$} & 52 & $\mathrm{CH}_{4}$ & 0.03 \\
\hline & 53 & $\mathrm{CH}_{4}$ & 2.16 \\
\hline $\mathrm{Cu}$ & 63 & None & 0.04 \\
\hline \multirow{2}{*}{$\mathrm{Fe}$} & 54 & $\mathrm{CH}_{4}$ & $5.2,1.8$ \\
\hline & 56 & $\mathrm{CH}_{4}$ & 0.2 \\
\hline \multirow{2}{*}{ K } & 39 & $\mathrm{CH}_{4}$ & 69 \\
\hline & 39 & $\mathrm{NH}_{3}$ & $0.5,0.4,0.3$ \\
\hline \multirow{2}{*}{$\mathrm{Mg}$} & 24 & None & 0.1 \\
\hline & 25 & None & 0.2 \\
\hline $\mathrm{Mn}$ & 55 & $\mathrm{CH}_{4}$ & 0.8 \\
\hline \multirow{2}{*}{$\mathrm{Na}$} & 23 & $\mathrm{NH}_{3}$ & 1 \\
\hline & 23 & None & 2 \\
\hline \multirow{2}{*}{$\mathrm{Ni}$} & 58 & None & 0.1 \\
\hline & 60 & None & 0.2 \\
\hline $\mathrm{Pb}$ & 208 & None & 0.1 \\
\hline \multirow{2}{*}{ Se } & 80 & $\mathrm{CH}_{4}$ & 0.05 \\
\hline & 82 & None & 0.26 \\
\hline Si & 28 & $\mathrm{NH}_{3}$ & $25,7,6$ \\
\hline Sn & 118 & None & 0.021 \\
\hline $\mathrm{Ti}$ & 48 & None & 0.07 \\
\hline $\mathrm{V}$ & 51 & $\mathrm{CH}_{4}$ & 0.08 \\
\hline \multirow{2}{*}{$\mathrm{Zn}$} & 66 & None & 0.2 \\
\hline & 68 & None & 0.2 \\
\hline
\end{tabular}

${ }^{\mathrm{a} S o m e}$ isotopes were determined under more than one reaction gas flow rate, resulting in multiple detection limits corresponding to the different flow rates.

\subsubsection{3 $\mathrm{PM}_{2.5}$ Carbonaceous Species}

On every fourth day at the central Steubenville site from August 12, 2000, through May 14, 2002, a 24-hr integrated $\mathrm{PM}_{2.5}$ sample was collected on a quartz filter using a Thermo Andersen $\mathrm{PM}_{2.5}$ speciation sampler (RAAS2.5-400) with the quartz channel operating at a flow rate of 7.5 to $8.5 \mathrm{~L} / \mathrm{min}$. No denuder was used in series with the quartz filter. Prior to use, the quartz filters were prepared by firing to $600{ }^{\circ} \mathrm{C}$ for $4 \mathrm{hr}$ to remove carbon background. Filters were sealed and refrigerated during periods of storage. Field blanks were used on each sampling day to assess the carbon background experienced during handling and storage. To determine the 24hr average ambient concentration of elemental and organic carbon, a square of known area was punched from the exposed filter and analyzed using a Sunset Laboratory Thermal Optical 
Transmittance (TOT) Analyzer. The instrument used a thermal program similar to that currently being followed by the U.S. EPA Speciation Trends Network (Research Triangle Institute, 2003), but it was modified slightly in accordance with the instrument manufacturer's recommendations. All results were adjusted to account for background carbon by blank subtraction, and the blankcorrected masses were converted to 24-hr average ambient air values by dividing by the volume of air sampled. Detection limits for EC and OC, expressed in ambient air concentration units, were approximately $0.04 \mu \mathrm{g} / \mathrm{m}^{3}$ and $0.25 \mu \mathrm{g} / \mathrm{m}^{3}$, respectively.

\subsubsection{4 $\mathrm{PM}_{2.5}$ Acid-Digestible Elements}

The $\mathrm{PM}_{2.5}$ speciation sampler at the central Steubenville site was also used to collect 24-hr integrated $\mathrm{PM}_{2.5}$ samples for acid-digestible elemental analysis on a 1-in-4 day frequency from August 12, 2000, through May 14, 2002. All acid-digestible elemental analyses were performed using DRC ICP-MS. To facilitate DRC ICP-MS method development and allow for possible reanalyses required during this process, $\mathrm{PM}_{2.5}$ samples were collected in duplicate on Teflon filters using separate channels of the speciation sampler. Both channels operated at volumetric sampling rates of about $16.67 \mathrm{~L} / \mathrm{min}$.

Filters were digested and analyzed via DRC ICP-MS in two sequences. All filters from the primary speciation sampler channel were digested and analyzed during the first sequence. Because of several method-related issues encountered during this first succession of analyses, filters from the secondary speciation sampler channel were digested and analyzed in a second sequence in order to improve valid data capture. In cases where valid results for an element were obtained from both the primary filter and the secondary filter for a given day, the results were arithmetically averaged, and this average concentration value is reported. If a valid result was obtained from only one of the two filters collected on a given day, this result is likewise reported.

To prepare the $\mathrm{PM}_{2.5}$ samples for elemental analysis, each exposed filter was placed in a cleaned, disposable polypropylene vessel and digested for 16-18 hr in a dilute mixture of $\mathrm{HNO}_{3}$, $\mathrm{HF}$, and $\mathrm{HCl}$. Although it is hazardous and requires careful handling, HF is required to allow more complete digestion of elements contained in the siliceous matrices commonly encountered in $\mathrm{PM}_{2.5}$. After cooling, a boric acid solution was added to each digestate to complex the HF, and an internal standard solution containing $\mathrm{Ge}$ and In was added so that instrument drift could be monitored and corrected. (Isopropyl alcohol, a wetting agent, was also added to each digestate during the second sequence of analyses). The digestates were then heated for an additional hour before submittal for elemental analysis.

All acid-digestible elemental determinations during SCAMP were performed using a PerkinElmer ELAN 6100 DRC ICP-MS. The method was designed to determine 21 elements (i.e., Al, As, Ba, Ca, Cd, Co, Cr, Cu, Fe, K, Mg, Mn, Na, Ni, Pb, Se, Si, Sn, Ti, V, Zn) that are of interest to $\mathrm{PM}_{2.5}$ researchers. However, two of the 21 elements, Si and $\mathrm{Na}$, routinely failed to meet quality control criteria and will not be discussed further in this report. Table 4 shows the remaining 19 elements and outlines the general strategy used to determine each of them by DRC ICP-MS.

As the table indicates, the method included multiple determinations of many elements, including determinations of different isotopes of the element, determinations of the same isotope using different reaction gases (or no reaction gas), and determinations of the same isotope using different flow rates of the same reaction gas. Because of this strategy, multiple analytical detection limits were obtained for most elements. Detection limits shown in Table 4 have been 
converted to units of $\mathrm{ng} / \mathrm{m}^{3}$ of sampled ambient air for ease of comparison with the ambient air concentration data presented later.

Table 4. Strategy and detection limits for the determination of elements in the acid-digestible fraction of $\mathrm{PM}_{2.5}$ using DRC ICP-MS.

\begin{tabular}{|c|c|c|c|}
\hline Element & Isotopes & $\begin{array}{c}\text { Reaction } \\
\text { Gases }\end{array}$ & Detection Limits ( $\mathrm{ng} / \mathrm{m}^{3}$ of sampled air) \\
\hline $\mathrm{Al}$ & 27 & $\mathrm{NH}_{3}$ & $13.5,15.1,15.9$ \\
\hline As & 75 & $\mathrm{CH}_{4}, \mathrm{NH}_{3}$, None & $0.19,0.34,0.37,0.43$ \\
\hline $\mathrm{Ba}$ & 138 & None & $0.1,0.6$ \\
\hline \multirow{2}{*}{$\mathrm{Ca}$} & 40 & $\mathrm{CH}_{4}$ & 15 \\
\hline & 44 & None & 92 \\
\hline \multirow{2}{*}{$\mathrm{Cd}$} & 111 & None & 0.03 \\
\hline & 114 & None & 0.07 \\
\hline Co & 59 & None & $0.025,0.027$ \\
\hline \multirow{2}{*}{$\mathrm{Cr}$} & 52 & $\mathrm{CH}_{4}$ & 0.11 \\
\hline & 53 & $\mathrm{NH}_{3}$ & 0.38 \\
\hline \multirow{2}{*}{$\mathrm{Cu}$} & 63 & $\mathrm{CH}_{4}, \mathrm{NH}_{3}$ & $0.6,0.8$ \\
\hline & 65 & $\mathrm{CH}_{4}$ & 0.6 \\
\hline \multirow{2}{*}{$\mathrm{Fe}$} & 54 & $\mathrm{CH}_{4}$ & $2.8,3.4$ \\
\hline & 56 & $\mathrm{CH}_{4}, \mathrm{NH}_{3}$ & $1.1,10.5$ \\
\hline $\mathrm{K}$ & 39 & $\mathrm{CH}_{4}, \mathrm{NH}_{3}$ & $1,4,60$ \\
\hline \multirow{2}{*}{$\mathrm{Mg}$} & 24 & None & 2 \\
\hline & 25 & None & 2 \\
\hline $\mathrm{Mn}$ & 55 & $\mathrm{CH}_{4}, \mathrm{NH}_{3}$ & $0.4,0.7$ \\
\hline \multirow{2}{*}{$\mathrm{Ni}$} & 58 & $\mathrm{NH}_{3}$, None & $0.2,0.3$ \\
\hline & 60 & $\mathrm{CH}_{4}$ & 0.3 \\
\hline \multirow{2}{*}{$\mathrm{Pb}$} & 207 & None & 0.2 \\
\hline & 208 & None & $0.1,0.2$ \\
\hline \multirow{2}{*}{$\mathrm{Se}$} & 78 & $\mathrm{CH}_{4}$ & 0.17 \\
\hline & 80 & $\mathrm{CH}_{4}$ & 0.09 \\
\hline \multirow{2}{*}{ Sn } & 118 & None & 0.073 \\
\hline & 120 & None & $0.058,0.283$ \\
\hline $\mathrm{Ti}$ & 48 & None & $1.48,4.23$ \\
\hline $\mathrm{V}$ & 51 & $\mathrm{NH}_{3}$ & 0.14 \\
\hline \multirow{3}{*}{$\mathrm{Zn}$} & 64 & $\mathrm{NH}_{3}$ & 1.1 \\
\hline & 66 & None & $0.9,1.4$ \\
\hline & 68 & None & 2 \\
\hline
\end{tabular}

${ }^{a}$ Some isotopes were determined under more than one reaction gas, reaction gas flow rate, etc., resulting in multiple detection limits corresponding to the different instrument conditions.

\subsubsection{Integrated $\mathrm{PM}_{10}$ Mass and Composition}

Twenty-four-hour average $\mathrm{PM}_{10}$ mass concentrations were determined daily at the central Steubenville site according to the Federal Reference Method for $\mathrm{PM}_{10}$. Each 24-hr integrated $\mathrm{PM}_{10}$ sample was collected on a 47-mm Teflon filter using a Thermo Andersen $\mathrm{PM}_{10}$ Sequential Sampler (RAAS10-300, U.S. EPA Designation RFPS-0699-0132) operating at a flow rate of 16.67 L/min. Filters were conditioned before and after exposure, and the mass of $\mathrm{PM}_{10}$ was determined gravimetrically using a Cahn C-33 microbalance in a clean weighing room that was 
controlled for temperature, humidity, and vibration. Daily average ambient air concentrations were determined based upon the mass of sample collected and the volume of air sampled.

The 24-hr integrated $\mathrm{PM}_{10}$ FRM samples from every fourth day were submitted for ionic and water-extractable elemental analyses. Ions $\left(\mathrm{SO}_{4}{ }^{2-}, \mathrm{NO}_{3}{ }^{-}, \mathrm{Cl}^{-}\right.$, and $\left.\mathrm{NH}_{4}{ }^{+}\right)$and 21 waterextractable elements (Al, As, Ba, Ca, Cd, Co, Cr, Cu, Fe, K, Mg, Mn, Na, Ni, Pb, Se, Si, Sn, Ti, $\mathrm{V}, \mathrm{Zn}$ ) were determined by ion chromatography and DRC ICP-MS, respectively, according to the same procedures described in Section 3.1.2.2 above for $\mathrm{PM}_{2.5}$.

\subsubsection{Continuous $\mathrm{PM}_{2.5}$}

Ambient $\mathrm{PM}_{2.5}$ mass concentrations were measured continuously from June 14,2000 , through May 14, 2002, at the central Steubenville site using a Rupprecht \& Patashnick Series 1400a tapered element oscillating microbalance (TEOM) equipped with a sharp cut inlet for $\mathrm{PM}_{2.5}$. The instrument was configured in the standard way to collect $\mathrm{PM}_{2.5}$ from a $3.0 \mathrm{~L} / \mathrm{min}$ sample stream on a Teflon-coated glass fiber filter. The TEOM filter and sample stream were maintained at 50 ${ }^{\circ} \mathrm{C}$ to remove moisture from the sampled air and prevent condensation on the filter. However, operation at this temperature may also cause the loss of some semi-volatile particulate matter (e.g., ammonium nitrate, semi-volatile organic compounds, and particle-bound water), resulting in an underestimation of total $\mathrm{PM}_{2.5}$ mass (Allen et al., 1997). The magnitude of this artifact is dependent upon the composition of the sampled $\mathrm{PM}_{2.5}$, and therefore varies with location and time. TEOMs can be equipped with Nafion diffusion dryers for moisture removal and operated at $30{ }^{\circ} \mathrm{C}$ to reduce the loss of semi-volatile material; however, this was not common practice at the time of SCAMP. All TEOM data collected during SCAMP were validated against operational performance criteria established by the instrument manufacturer.

\subsubsection{Pollen and Spores}

Pollen and spores were collected daily at the central Steubenville site between June 21, 2000, and May 13, 2002, using a 7-day Burkard volumetric spore trap. Ambient air was sampled at a constant volumetric flow rate, and pollen and spores in the sampled stream impacted onto an adhesive plastic tape, which rotated once at a constant rate during the course of each weekly sampling interval. Exposed tapes were analyzed by a certified environmental microbiology laboratory (Air Quality Sciences, Marietta, GA), which used optical microscopy counting procedures to determine speciated daily average pollen and spore counts.

\subsubsection{Gaseous Pollutants}

Ambient concentrations of gaseous priority pollutants, including $\mathrm{SO}_{2}, \mathrm{NO}_{\mathrm{x}}, \mathrm{CO}$, and $\mathrm{O}_{3}$, were measured continuously using an Advanced Pollution Instruments Model 900 turnkey ambient air sampling system. The system consisted of individual rack-mounted gaseous pollutant analyzers, which were housed in a mobile trailer and integrated into a dedicated sampling manifold. Gaseous pollutants were collected through a typical glass "candy cane" at a sampling height of approximately $3.5 \mathrm{~m}$ above ground level. The gas analyzers were all Advanced Pollution Instruments models, and included an automated federal equivalent method (FEM) ultraviolet fluorescence $\mathrm{SO}_{2}$ analyzer (Model 100, EQSA-0990-077), an automated FRM chemiluminescence $\mathrm{NO}_{x}$ analyzer (Model 200A, RFNA-1194-099), an automated FEM ultraviolet absorption $\mathrm{O}_{3}$ analyzer (Model 400, EQOA-0992-087), and an automated FRM gas filter correlation $\mathrm{CO}$ analyzer (Model 300, RFCA-1093-093). The $\mathrm{NO}_{x}$ analyzer determined concentrations of $\mathrm{NO}_{x}$ and $\mathrm{NO}$; concentrations of $\mathrm{NO}_{2}$ were computed by difference. 


\subsubsection{Meteorological Conditions}

Meteorological conditions, including wind speed (WS), temperature (Temp), relative humidity $(\mathrm{RH})$, solar radiation (Rad), rainfall (Rain), and barometric pressure (BP), were monitored continuously at the central Steubenville site using standard instrumentation (Met One) atop a $10-\mathrm{m}$ tower. Wind direction was also monitored, but no valid data were obtained because of a data logging error.

\subsubsection{Quality Assurance and Quality Control}

All sampling activities and laboratory analyses conducted as part of the SCAMP ambient air monitoring program were carried out in accordance with the CONSOL R\&D Quality Assurance Guidelines for the Steubenville Comprehensive Air Monitoring Program (April 2000) and with applicable standard operating procedures (SOPs), as listed in Table 5.

Table 5. Standard Operating Procedures followed by the SCAMP ambient air monitoring program.

\begin{tabular}{|c|c|}
\hline Title & Source \\
\hline SOP for the RAAS FRM $\mathrm{PM}_{2.5}$ and $\mathrm{PM}_{10}$ Samplers & Optimal Technologies \\
\hline SOP for Downloading Data off of the FRM PM 2.5 and $\mathrm{PM}_{10}$ RAAS Samplers & Optimal Technologies \\
\hline SOP for the RAAS PM 2.5 Speciation Sampler & Optimal Technologies \\
\hline SOP for Auditing and Calibrating Flow on the Speciation Sampler & Optimal Technologies \\
\hline SOP for the R\&P TEOM Sampler (Continuous PM) & Optimal Technologies \\
\hline SOP for Continuous Gas Analyzers & Optimal Technologies \\
\hline SOP for the Burkard Pollen/Spore Sampler & Optimal Technologies \\
\hline Guidelines for Determining Calibration & Optimal Technologies \\
\hline Particulate Sampling Instrumentation Field Quality Assurance Schedule & Optimal Technologies \\
\hline $\begin{array}{l}\text { Real Time Pollutant and Meteorological Instrumentation Field Quality } \\
\text { Assurance Schedule }\end{array}$ & Optimal Technologies \\
\hline Mass Flow Calibrator Preventative Maintenance Schedule & Optimal Technologies \\
\hline Zero Air System Preventative Maintenance Schedule & Optimal Technologies \\
\hline Ozone Analyzer Preventative Maintenance Schedule & Optimal Technologies \\
\hline $\mathrm{NO}_{2}$ and $\mathrm{NH}_{3}$ Analyzers Preventative Maintenance Schedule & Optimal Technologies \\
\hline $\mathrm{SO}_{2}$ Analyzer Preventative Maintenance Schedule & Optimal Technologies \\
\hline CO Analyzer Preventative Maintenance Schedule & Optimal Technologies \\
\hline Meteorological Tower Maintenance Schedule & Optimal Technologies \\
\hline $\begin{array}{l}\text { Standard Method for Analyzing Teflon Filters for Anions by lon } \\
\text { Chromatography }\end{array}$ & CONSOL R\&D \\
\hline $\begin{array}{l}\text { Standard Method for Analyzing Teflon Filters for Ammonium by lon } \\
\text { Chromatography }\end{array}$ & CONSOL R\&D \\
\hline $\begin{array}{l}\text { Standard Method for Analyzing Teflon Filters for } \mathrm{H} 2 \mathrm{O} \text { Soluble Elements by } \\
\text { DRC ICP-MS }\end{array}$ & CONSOL R\&D \\
\hline $\begin{array}{l}\text { Standard Method for Analyzing Teflon Filters for Total Elements by DRC } \\
\text { ICP-MS }\end{array}$ & CONSOL R\&D \\
\hline Carbon Analysis of Aerosol Filter Samples for the Pittsburgh PM Supersite & $\begin{array}{l}\text { Carnegie Mellon } \\
\text { University }\end{array}$ \\
\hline
\end{tabular}


Site operators were trained in sampling methodologies and quality assurance and quality control (QA/QC) protocols during a seminar hosted by CONSOL R\&D in April 2000. Logbooks were maintained for each monitoring site and participating laboratory to document observations, exceptions, maintenance activities, and QA/QC items. CONSOL R\&D periodically audited each monitoring site and participating laboratory to assess instrument performance, review logbooks, and ensure compliance with QA/QC guidelines. Moreover, performance audits of FRM and FEM analyzers were periodically conducted by the Ohio EPA during the program. Corrective actions were taken where necessary. An end-of-program audit of all PM samplers, gas analyzers, and meteorological instruments used during the SCAMP ambient air monitoring program was performed by Optimal Technologies in May 2002; no significant instrument performance issues were detected. Gravimetric determinations of PM mass collected at the five SCAMP monitoring sites were performed by laboratories at CONSOL R\&D and Ohio University; both of these laboratories demonstrated acceptable performance for gravimetric analysis of PM filters in an inter-laboratory round robin program conducted by the Harvard School of Public Health in 2000 and 2001. In addition, CONSOL R\&D, which performed all PM speciation analyses conducted as part of the SCAMP ambient air monitoring program, demonstrated proficiency for performing IC on filter extracts in an external quality assurance program that was conducted by the Harvard School of Public Health in 2000 and 2001, and demonstrated proficiency for performing carbon analyses in a mini round robin carried out with Desert Research Institute in 2002.

Table A.1 in Appendix A summarizes the QA/QC and maintenance schedule followed for ambient pollutant samplers during the SCAMP ambient air monitoring program. All filter-based PM samples were collected in accordance with the guidelines outlined in EPA Quality Assurance Guidance Document 2.12 (U.S. EPA, 1998). The guidelines outlined in 40 CFR Parts 50, 53, and 58 and in the Guideline on Speciated Particulate Monitoring (Chow and Watson, 1998) were also followed where applicable. Field blanks were routinely collected for all integrated PM samplers to permit an assessment of background levels of PM and PM components experienced during filter handling, transport, and storage. At each of the five SCAMP ambient air monitoring sites, one field blank was included with every batch of four FRM filters. Moreover, Teflon and quartz field blanks were collected for every day of $\mathrm{PM}_{2.5}$ speciation sampling at the central Steubenville site.

All gas measurements were made in accordance with quality assurance guidelines outlined by the U.S. EPA (U.S. EPA, 1994; 40 CFR 58.61). The performance of each analyzer was monitored by taking daily (shortly after midnight) calibration readings for zero and span concentrations of appropriate certified gas standards. Zero and span control charts were used to determine the validity of measured data, and to determine when physical adjustments to the instruments were required. For each gaseous pollutant, prior to data analysis, hourly average concentrations recorded by the system's data logger were corrected to track instrument performance by linear interpolation between adjacent daily calibration readings.

Table A.2 in Appendix A summarizes the laboratory QA/QC procedures that were followed for the gravimetric analysis of filter-based $\mathrm{PM}_{2.5}$ and $\mathrm{PM}_{10}$ samples collected during SCAMP. QA/QC measures were also taken to ensure the quality of ion, carbon, and element concentrations determined from filter-based PM samples. Ion chromatographs were calibrated using serially diluted standards prepared from commercially available stock solutions (Environmental Resource Associates). Analyses were only conducted if a linear or quadratic calibration line having an $\mathrm{R}^{2}>0.9995$ was obtained and recovery of a serially diluted quality control standard (Environmental Resource Associates) was 100 $10 \%$. This quality control 
standard was further analyzed every tenth sample; again, recoveries of $100 \pm 10 \%$ were required. Duplicate analyses were performed on every tenth filter sample extract. A solution blank was also analyzed with each batch of samples to ensure low background concentrations.

For carbon species, prior to each batch of routine analyses, the TOT analyzer's internal calibration was verified using a sucrose solution containing a known amount of total carbon. Recovery was required to be $100 \pm 10 \%$. Duplicate analyses were performed on every tenth $\mathrm{PM}_{2.5}$ sample. In addition, an instrument blank was run with each batch of samples to ensure a low carbon background, and was required to contain $<0.2 \mu \mathrm{g}$ of carbon.

Prior to each batch of elemental analyses, the DRC ICP-MS was calibrated using a solution blank consisting of deionized water and internal standards plus three solutions prepared from commercially available stock solutions that covered the concentration range of the elements to be determined. Calibrations were verified by analyzing a tenfold dilution of National Institute of Standards and Technology (NIST) Standard Reference Material (SRM) 1640 (natural water) or $1643 d$ (trace elements in water) for water-extractable elemental analyses or an acid-digestion of NIST SRM 1648 (urban particulate) for acid-digestible elemental analyses. Results were considered to be valid only if these SRM determinations fell within pre-established, isotopespecific acceptable ranges around the NIST-certified values. A quality control solution was analyzed after every ten samples to re-verify calibration; recovery of this quality control sample was required to be $100 \pm 20 \%$.

Prior to data analysis, all measurements were qualified as being "valid", "flagged", or "invalid" based on the validation schedule detailed in Table A.3 in Appendix A and the analytical criteria described above. Invalid data were excluded from data analyses. All valid and flagged data underwent a second level of quality control checks, in which they were systematically examined using descriptive statistics and graphs. Anomalous data points identified via this procedure were investigated using site and instrument logs and data validation notes (for flagged data), and were invalidated or retained based on an assessment of the available evidence. All actions taken as a result of these second-level checks were logged electronically.

\subsubsection{Data Analysis}

All data collected as part of the SCAMP ambient air monitoring program were analyzed using descriptive statistics, regression and correlation analyses, and graphs. The statistical significance of seasonal, weekday/weekend, and spatial differences in pollutant concentrations was determined using independent sample t-tests, paired t-tests, or their nonparametric equivalents (i.e., Wilcoxon rank sum tests and Wilcoxon signed rank tests, respectively), as discussed below. Speciated $\mathrm{PM}_{2.5}$ data were further analyzed using reconstructed fine mass calculations (to compare measured masses of $\mathrm{PM}_{2.5}$ chemical components with total measured $\mathrm{PM}_{2.5}$ mass), enrichment factors (to compare the observed abundances of elements in ambient $\mathrm{PM}_{2.5}$ with average crustal abundances of these elements), and coefficients of divergence (to quantify the degree of spatial homogeneity in $\mathrm{PM}_{2.5}$ component concentrations observed across the SCAMP ambient air monitoring sites). In addition, binary recursive partitioning was employed to search for associations between hourly $\mathrm{PM}_{2.5}$ concentrations and hourly gaseous pollutant concentrations and meteorological conditions, and source apportionment techniques including Positive Matrix Factorization (PMF), Unmix, and potential source contribution function (PSCF) modeling were used to estimate the contributions of various emission sources to $\mathrm{PM}_{2.5}$ concentrations at the Steubenville site. All of these data analysis techniques are described or referenced, as appropriate, in the Results and Discussion section of this report. 
Where possible, actual instrument readings for determinations below the analytical limits of detection (LOD) were used in the statistical analyses presented in this paper in order to prevent the introduction of bias (Gilbert, 1987). However, for ionic and carbonaceous species, the laboratory reported only censored data; hence, determinations below the analytical LOD were set equal to half of the LOD value for these species. For analyses requiring 24-hr average values of variables that were monitored continuously (i.e., gaseous pollutants, meteorological conditions, continuous $\mathrm{PM}_{2.5}$ ), arithmetic means were computed from hourly concentrations recorded by the data logger and were considered to be valid only if at least 19 out of 24 valid hourly average values were available for the 24-hr time period of interest.

When analyzing data from the SCAMP ambient air monitoring program, special attention was given to statistical issues that are relevant to air monitoring time series data, but have generally not been adequately considered in the $\mathrm{PM}_{2.5}$ literature. Specifically, statistical tests commonly applied to air monitoring data, including simple linear regression analyses, t-tests, and Pearson correlation analyses, only provide meaningful results if the assumptions on which they are based are reasonably satisfied. Several common characteristics of air monitoring data that can violate these assumptions are as follows:

1. Autocorrelation - Simple linear regression analysis assumes that the error component of the model is statistically independent (random); independent sample t-tests assume that samples are randomly drawn from two independent populations, and paired t-tests assume that the paired differences between the two variables under consideration represent a random sample. However, time series of $\mathrm{PM}_{2.5}$ (and other air pollutants and meteorological conditions) are frequently autocorrelated, meaning that the concentration at a given time, $t$, can be predicted to some extent by the concentrations observed at previous times (e.g., for daily data, $t-1$ for 1 -day lags; $t-7$ for day-of-week trends; $t-365$ for seasonal trends, etc.). Hence, these time series are not statistically random. The autocorrelated nature of air monitoring data is demonstrated in Figure 2. Figure 2a presents an autocorrelation function (ACF) plot (i.e., a plot showing the correlation of a time series with various lags of itself) for the time series of 24-hr average $\mathrm{PM}_{2.5}$ mass concentrations measured daily at the central Steubenville site using the FRM monitor, and illustrates that this time series exhibited statistically significant autocorrelation, especially at a 1-day lag. Figure $2 \mathrm{~b}$ shows an ACF plot for the time series of $\mathrm{NO}_{3}{ }^{-}$ concentrations measured every fourth day at the central Steubenville site, demonstrating that significant autocorrelation can affect even those variables that are measured on a less-than-daily frequency. Figures $2 c$ and $2 d$, which present ACF plots for the time series of differences between $\mathrm{PM}_{2.5}$ concentrations measured at the central Steubenville site and the northern satellite site and the time series of residuals from simple linear regression of $\mathrm{PM}_{2.5}$ as a function of $\mathrm{CO}$ at the central Steubenville site, respectively, show how the autocorrelated nature of air monitoring data can cause the assumption of randomness to be violated for paired t-tests and simple linear regression analyses.

2. Non-Normal Distributions - Simple linear regression analyses, independent sample ttests, and paired t-tests assume that residuals, sample means, and paired differences, respectively, are normally distributed. However, air pollutant concentration data typically are not normally distributed. Rather, these data, which physically must be greater than or equal to zero, often exhibit lognormal distributions, as illustrated in Figure 3 for 24hour average $\mathrm{PM}_{2.5}$ concentrations at the central Steubenville site. Deviations from normality are of greatest concern when sample sizes are small (the central limit theorem applies to larger sample sizes).

3. Outliers - Air pollutant time series often contain outliers resulting from abnormally elevated concentrations observed during air pollution episodes. These outliers can 
substantially influence the results of linear regression and Pearson correlation analyses. Moreover, t-tests are not robust to outliers, because outliers have an effect on sample means and sample standard deviations.

4. Heteroscedasticity - Linear regression analysis assumes that the error component of the model is homoscedastic (i.e., has a constant variance at all points along the linear relationship). However, air pollutant data frequently fail to meet this assumption. This is exemplified by the fan-like shape of the scatterplot of $\mathrm{NO}$ versus $\mathrm{CO}$ concentrations shown in Figure 4.

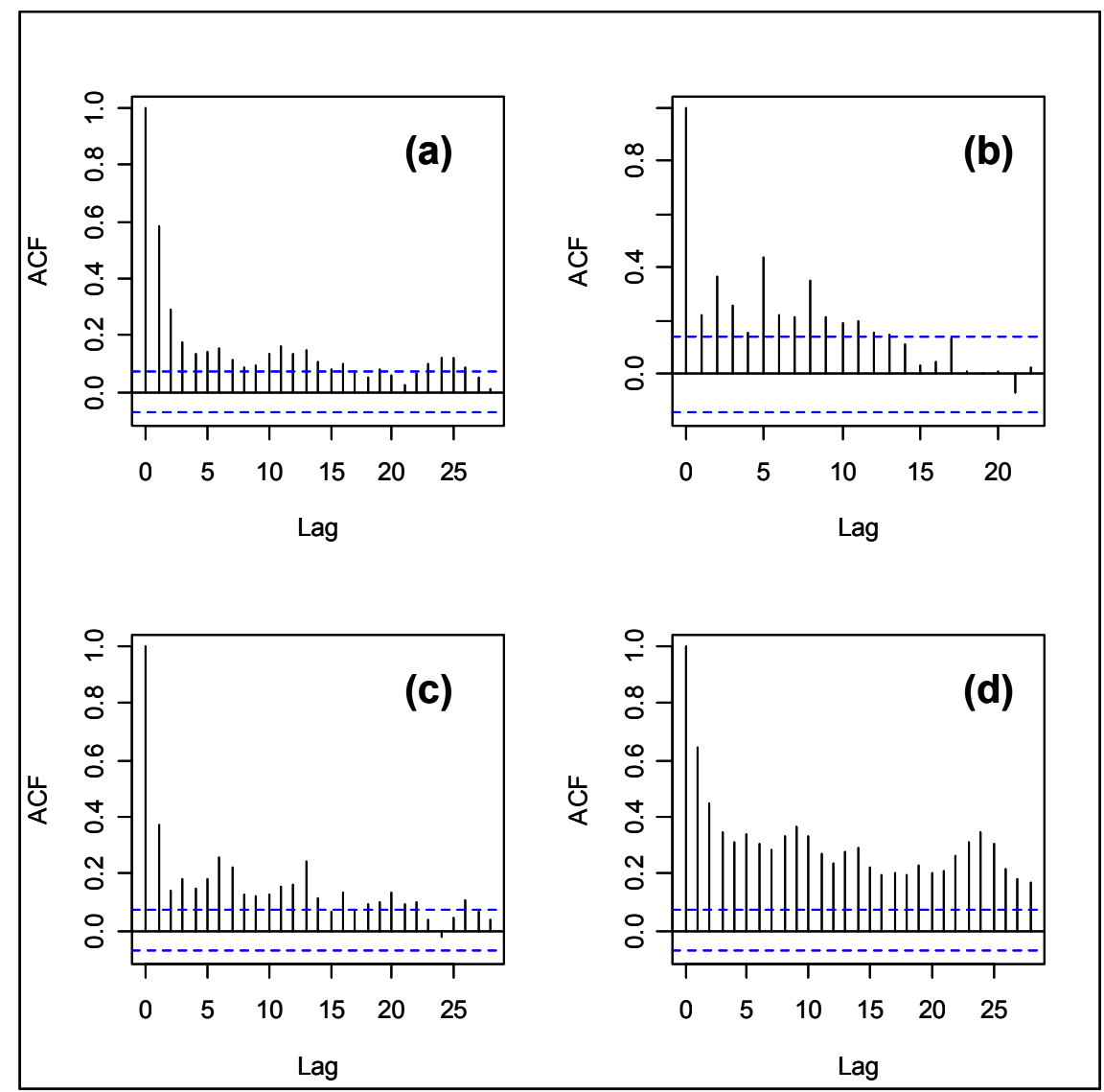

Figure 2. Autocorrelation function (ACF) plots for (a) the time series of 24-hour $\mathrm{PM}_{2.5}$ concentrations measured at the central Steubenville site using the FRM monitor, (b) the time series of 24hour $\mathrm{NO}_{3}{ }^{-}$concentrations measured at the central Steubenville site, (c) the time series of paired differences between 24-hour $\mathrm{PM}_{2.5}$ concentrations measured at the central Steubenville site and at the northern satellite site, and (d) the time series of residuals from a simple linear regression analysis of 24hour $\mathrm{PM}_{2.5}$ concentrations as a function of 24-hour $\mathrm{CO}$ concentrations at the central Steubenville site. Lines extending beyond the dashed blue interval indicate statistically significant autocorrelation. Lags are in units of 1 day for subplots (a), (c), and (d), and in units of 4 days for subplot (b).

The SCAMP ambient air monitoring program included an exploration of the applicability of autoregressive integrated moving average (ARIMA) models (Box and Jenkins, 1976) to time series of daily $\mathrm{PM}_{2.5}, \mathrm{PM}_{2.5}$ ionic and carbonaceous component, gaseous pollutant, and meteorological data as a means for overcoming these statistical limitations of air monitoring data. For select comparisons, prior to performing linear regression analyses or t-tests, data were transformed (e.g., by application of a natural logarithm, square root, fourth root, etc.) to render their distributions more normal, improve homoscedasticity, and reduce the impact of outliers. Autocorrelation was identified by examining ACF and partial autocorrelation function 
(PACF) plots, and where statistically significant autocorrelation was discovered, it was modeled by fitting an appropriate ARIMA model. The general form of an ARIMA(p,d,q) model representing a time series, $\mathrm{X}$, of appropriately transformed air pollutant concentrations is:

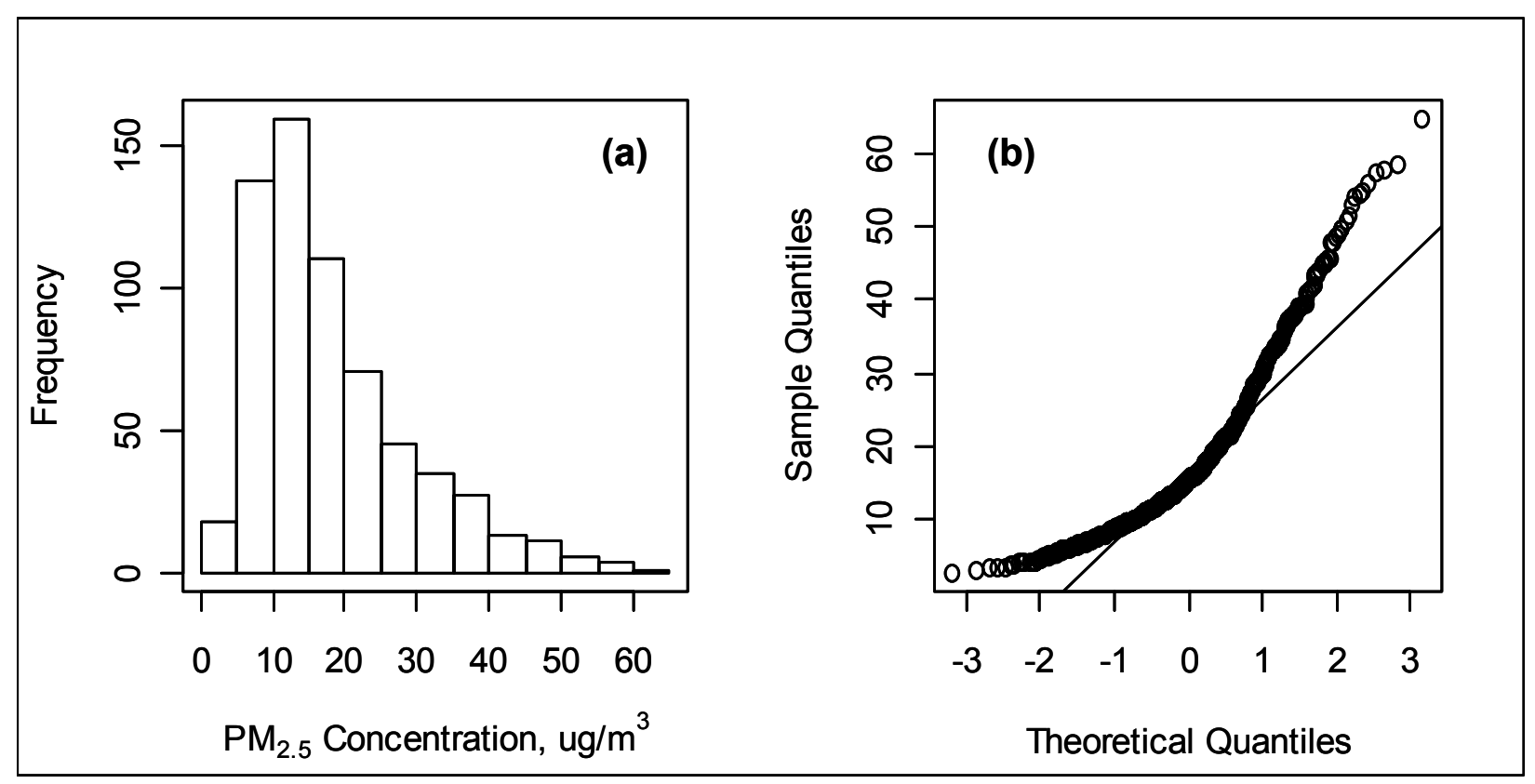

Figure 3. Histogram (a) and quantile-quantile plot (b) showing the distribution of 24-hour average $\mathrm{PM}_{2.5}$ concentrations measured at the central Steubenville site during SCAMP using the FRM.

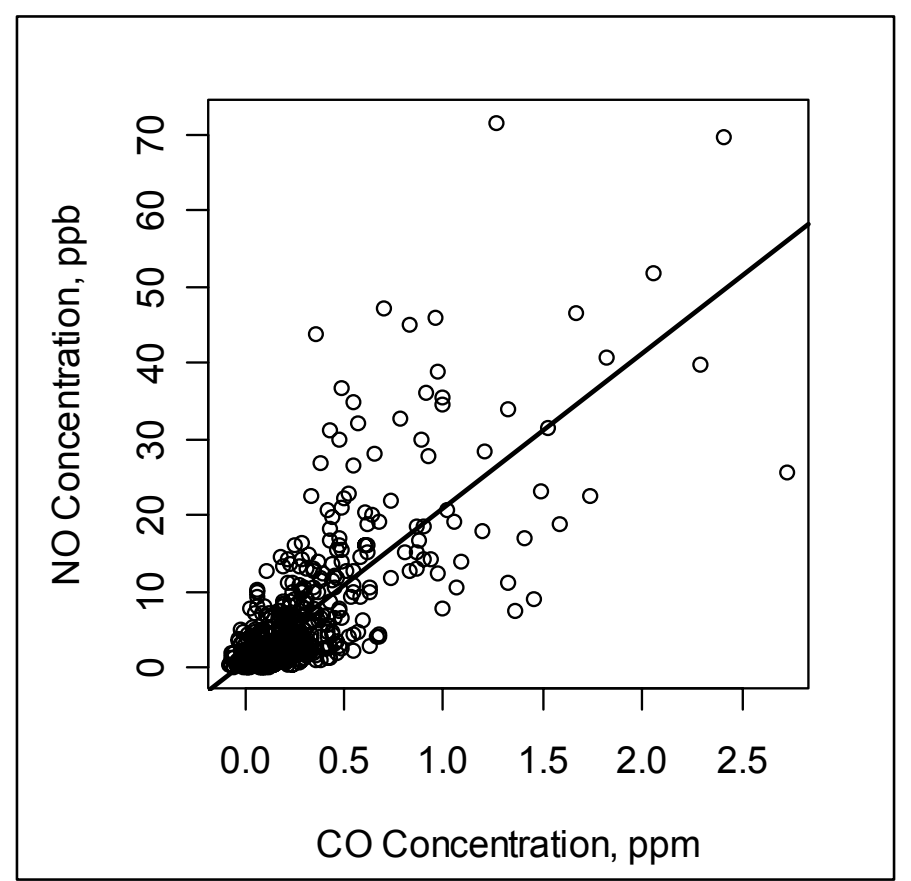

Figure 4. Scatterplot of 24-hr average NO concentrations versus 24-hr average $\mathrm{CO}$ concentrations measured at the Central Steubenville site, with linear least squares line. 
where

$$
\mathrm{W}_{\mathrm{t}}=\eta+\phi_{1} \mathrm{~W}_{\mathrm{t}-1}+\phi_{2} \mathrm{~W}_{\mathrm{t}-2}+\ldots+\phi_{\mathrm{p}} \mathrm{W}_{\mathrm{t}-\mathrm{p}}+\varepsilon_{\mathrm{t}}+\theta_{1} \varepsilon_{\mathrm{t}-1}+\theta_{2} \varepsilon_{\mathrm{t}-2}+\ldots+\theta_{\mathrm{q}} \varepsilon_{\mathrm{t}-\mathrm{q}}
$$

$$
W_{t}=\nabla^{d} X_{t}
$$

Here, $\nabla$ is the difference operator and $d$ is the order of differencing such that for $d=0, W_{t}=X_{t}$, and for $\mathrm{d}=1, \mathrm{~W}_{\mathrm{t}}=\mathrm{X}_{\mathrm{t}}-\mathrm{X}_{\mathrm{t}-1} . \quad \mathrm{X}_{\mathrm{t}}$ and $\varepsilon_{\mathrm{t}}$ are the transformed air pollutant concentration and random error term, respectively, at time $t ; \phi_{1}, \phi_{2}, \ldots, \phi_{\mathrm{p}}$ are the autoregressive parameters; $\theta_{1}$, $\theta_{2}, \ldots, \theta_{\mathrm{q}}$ are the moving average parameters, and $\eta$ is the intercept term. Seasonal patterns were removed from the datasets by the inclusion of first-order differencing in the ARIMA model or by subtracting out a 3-month moving average before modeling, when appropriate. The residuals of the ARIMA model (or the transformed pollutant concentration values, for cases in which ARIMA modeling was not required) were then used in the regression analyses and $t$ tests.

Further details of the ARIMA modeling procedure used in SCAMP and of the results of its application to data from the ambient air monitoring program are reported by Connell et al. (2005a, 2005b). These results are also referenced as appropriate throughout the Results and Discussion section of this report. The authors demonstrated that, although trends observed in SCAMP were generally similar regardless of whether autocorrelation was accounted for, " $p$ values can change by several orders of magnitude upon properly accounting for autocorrelation" (Connell et al., 2005a). Because of practical limitations, ARIMA modeling was not incorporated into all of the analyses presented in this report. Hence, these analyses, especially those assessing statistical significance, must be interpreted with some caution. Nevertheless, nonparametric statistics, including Spearman correlation coefficients, Wilcoxon rank sum tests, and Wilcoxon signed rank tests, were used in place of their parametric equivalents where appropriate in a number of the analyses presented in this paper in order to account for skewed distributions, outliers, etc. All other things being equal, such nonparametric tests are generally less powerful (i.e., less likely to reject the null hypothesis when it is false), and hence more conservative, than their parametric counterparts.

\subsection{Indoor and Personal Exposure Program}

As discussed earlier, the indoor and personal exposure program consisted of two parts focusing on the characterization of exposures to $\mathrm{PM}_{2.5}$ and pollutant gases for older adults and children, respectively. The study design was reviewed and approved by the Human Subjects Committees of the Harvard School of Public Health and the Brigham and Women's Hospital.

\subsubsection{Older Adult Cohort}

\subsubsection{Study Design}

Exposure monitoring for the older adult cohort was conducted over two 3-month sessions, spanning the summer (June 4 - August 18) and fall (September 25 - December 15) of 2000 in Steubenville, $\mathrm{OH}$. In both seasons, 25 older adults participated in exposure monitoring. These participants also participated in a companion study (described later in Section 4.4 of this report) in which repeated cardiovascular and other health measurements were made.

Air pollutant samples were collected for each participant over 24-hr periods, beginning at 9:00 a.m. ( \pm 2 hours). Indoor samples were collected for all 25 subjects; personal air pollutant 
exposures were also collected for 10 of these participants. Each participant was sampled on two consecutive days each week, resulting in up to 24 repeated measures per subject per season. These two weekly sampling days for each participant began on the day prior to the participant's weekly scheduled health measurement. In general, samples were collected for five to ten individuals each day. For the subset of subjects for which personal exposure monitoring was performed, all personal monitoring was conducted simultaneously with monitoring inside of the subjects' homes. Outdoor measurements were additionally collected on up to six days per week on the rooftops of two of the apartment buildings in which many of the subjects resided, and ambient measurements were made at the SCAMP central ambient air monitoring site in Steubenville (described in Section 3.1.1). The overall study area was small, with not greater than $3 \mathrm{~km}$ between sampling locations.

\subsubsection{Participant Recruitment and Selection}

The Jefferson County Housing Authority helped identify apartment buildings for our recruitment effort. Access was granted to the J. F. Kennedy (K), Elmer White (E), and Gaylord (G) apartment complexes. Posters, door-to-door solicitation, and group meetings were used to introduce the study and initiate interest. Inclusion criteria for this study included being a nonsmoker, over the age of 65 , and meeting criteria for the companion health study. Potential participants signed up for screening appointments.

Overall, 53 people were screened for inclusion in the study. Thirty-two of these (29 female, 3 male) were deemed eligible. The majority of the cohort resided in one of three governmentsubsidized apartment buildings located in Steubenville: Kennedy $(n=16)$, Gaylord $(n=5)$, and Elmer White $(n=5)$. Other participants lived in freestanding houses $(n=5)$ or a townhouse $(n=1)$.

Of these participants, 25 were recruited for the exposure assessment portion of the study. Twenty-two subjects took part in both the summer and fall sessions. Air pollutant sampling was performed inside the homes of all participants; personal air pollutant sampling was also performed for a subset of individuals ( $n=9$ for the summer, $n=10$ for the fall). Each participant gave written informed consent prior to their participation in the study.

\subsubsection{Pollutant Sampling}

All pollutant samples were collected using Harvard multi-pollutant monitors, which were developed to sample $\mathrm{PM}_{2.5}, \mathrm{PM}_{2.5}$ components, and gaseous pollutants simultaneously (Demokritou et al., 2001). Each monitor is comprised of an aluminum elutriator designed to hold six individual samplers. The configuration used in Steubenville included four active and two passive badge samplers. The active samplers were outfitted with $\mathrm{PM}_{2.5}$ size-selective inlets for measuring fine particles and their components, and included two (duplicate) personal exposure monitors (PEMs) loaded with Teflon filters (37-mm Teflo ${ }^{T M}$, Gelman Sciences) for determination of $\mathrm{PM}_{2.5}$ mass by gravimetric analysis and of water-extractable and acid-digestible elements by DRC ICP-MS; a mini-PEM loaded with a 15-mm Fluoropore filter, which was analyzed for $\mathrm{SO}_{4}{ }^{2-}$ by ion chromatography; and a second mini-PEM loaded with a 15-mm quartz filter, which was analyzed for EC using thermal optical transmittance.

Vacuum grease was used as the impaction medium for these four samplers. During sampling, air was pulled through the filters by use of a single vacuum pump located upstream of the inlets; flow restrictors were used to split the inlet air stream into four separate streams with adjustable flow rates. The overall flow rate through the four samplers was $5.2 \mathrm{~L} / \mathrm{min}(1.8 \mathrm{~L} / \mathrm{min}$ for PEMs 
and $0.8 \mathrm{~L} / \mathrm{min}$ for mini-PEMs) for personal exposure sampling and $9.6 \mathrm{~L} / \mathrm{min}(4.0 \mathrm{~L} / \mathrm{min}$ for PEMs and $0.8 \mathrm{~L} / \mathrm{min}$ for mini-PEMs) for indoor and outdoor sampling.

The passive badge samplers were used to measure $\mathrm{O}_{3}, \mathrm{SO}_{2}$, and $\mathrm{NO}_{2}$. They were placed in the sides of the elutriator downstream of the PEMs such that the air being pulled through the PEMs moved past the passive badges. This ensured a constant face velocity across the filters to minimize problems that result from variable wind speeds and have previously hindered measurements involving passive methods (Liu et al., 1993; Liu et al., 1994). Each sampler contained a cellulose filter, coated with either nitrite for the collection of $\mathrm{O}_{3}$ (Koutrakis et al., 1993) or triethanolamine for the collection of $\mathrm{NO}_{2}$ and $\mathrm{SO}_{2}$ (Ogawa, 1998).

For indoor and outdoor sampling, the multi-pollutant monitor was affixed to a lab stand (indoors) or a tripod (outdoors). The monitors were connected to Gast pumps running on AC power via amber-colored tubing. For indoor sampling, the set-up was placed in the room where the subject spent most of his or her time, typically the living room, at a height of approximately 1 meter above the floor. The outdoor locations included the rooftops of the Kennedy and Gaylord apartment buildings, as well as the central Steubenville ambient air monitoring site (C). All sampling flow rates were measured before and after sampling with pre-calibrated rotameters (Matheson 603 and 406).

For measuring personal exposures, the multi-pollutant monitor was affixed to the shoulder strap of a small bag used to carry a personal sampling pump (BGI Model 400), battery, and motion sensor. The entire sampling set-up weighed approximately $3 \mathrm{~kg}$. Subjects were asked to wear the sampler over their shoulder for as much time as possible during each monitoring session. Because the personal sampling pump had limited power, the PEMs were sampled at flow rates of $1.8 \mathrm{~L} / \mathrm{min}$ rather than $4 \mathrm{~L} / \mathrm{min}$ as used by the indoor and outdoor multi-pollutant monitors. To accommodate this lower flow rate, a specially designed inlet was used. All flow rates were measured in duplicate pre- and post-sampling using a $\mathrm{BUCK}^{\mathrm{TM}}$ flow meter. Averages of two consecutive measurements within $10 \mathrm{~mL} / \mathrm{min}$ of each other were used in air volume calculations.

\subsubsection{Sample Analysis}

A chemistry lab at the Franciscan University of Steubenville was used for the assembly, disassembly, cleaning, and temporary storage of filter samples. Gravimetric analyses of Teflon filters were conducted at the Harvard School of Public Health; all other lab analyses were conducted by CONSOL R\&D according to the general analytical procedures described in Section 3.1. Teflon filters were analyzed for the following elements in the water-extractable and acid-digestible $\mathrm{PM}_{2.5}$ fractions: Al, As, Ba, Ca, Cd, Co, Cr, Cu, Fe, K, Mg, Mn, Na, Ni, Pb, Se, Si, $\mathrm{Sn}, \mathrm{Ti}, \mathrm{V}$, and $\mathrm{Zn}$.

\subsubsection{Housing Characteristics Questionnaire}

Technicians administered a one-time dwelling questionnaire (included in Appendix B to this report) to study participants prior to the first week of monitoring. This questionnaire asked for information on the location of the apartment, general apartment characteristics, ventilation characteristics (e.g., number of windows, air conditioning units, heating sources, fans), and cooking and fuel characteristics. On days when sampling occurred, an indoor follow-up questionnaire was also given. This follow-up questionnaire was intended to identify indoor pollutant sources and included nine questions on cleaning and cooking; use of candles, 
incense, cigars, and cigarettes; and the extent and duration for which doors and windows were open to the outside.

\subsubsection{Time-Activity Diaries}

Subjects who participated in personal exposure monitoring were asked to complete time-activity diaries (TADs) during each 24-hour sampling session. The format for these diaries is provided in Appendix B to this report. Each participant was asked to record information about his or her location, activity, and proximity to pollutant sources in 30-minute time intervals. The diaries were reviewed and verified by field technicians after each sampling period and cross-checked with corresponding motion sensor data.

\subsubsection{Quality Assurance and Quality Control}

Flags were assigned to each sample according to the validity of airflows, sample durations and comments recorded during weigh sessions, assembly/disassembly stages, and field operations. Invalid samples were excluded from all analyses, as were samples $(n=10)$ for subjects who withdrew from the study. Five extreme $\mathrm{NO}_{2}$ samples were additionally excluded due to presumable lab or field contamination.

The multi-pollutant monitor was configured with two $\mathrm{PM}_{2.5}$ samplers; thus, duplicate samples were obtained for each subject-day, and they were used for active sample validation purposes prior to averaging for use in data analyses. A precision criterion of $\leq 0.50$ relative difference (RD) between the duplicates was established above which both $\mathrm{PM}_{2.5}$ samples and any corresponding $\mathrm{SO}_{4}{ }^{2-}$ or EC samples were invalidated (samples with $>0.50 \mathrm{RD}$ were assumed to have been adversely affected at some stage of sampling; e.g., by kinked tubing). After all invalidations, data completeness was calculated as follows: \% Completeness $=$ (total valid/total sampled) $\times 100 \%$.

Field blanks comprised $11-15 \%$ of outdoor, indoor, and personal field samples. Blank corrections were not deemed necessary for $\mathrm{PM}_{2.5}$ mass. For the other pollutants, blank corrections were applied by season and by microenvironment in cases where the median blank value was greater than its analytical limit of detection. Data below the analytical LOD for $\mathrm{SO}_{4}{ }^{2-}$, $\mathrm{EC}, \mathrm{O}_{3}, \mathrm{SO}_{2}, \mathrm{NO}_{2}$, and the 21 acid-digestible and water-extractable elements were reported as non-detect (ND) by the laboratory. The field LOD for $\mathrm{PM}_{2.5}$ mass was calculated as two times the standard deviation of the field blanks. For the other pollutants, because many blanks were $\mathrm{ND}$, field LODs were calculated by using the $95^{\text {th }}$ percentile of field blanks by season (and by microenvironment if they differed sufficiently). Concentration LODs in $\mu \mathrm{g} / \mathrm{m}^{3}$ and $\mathrm{ppb}$ were further calculated based on a 24-hr sampling period and the target sample flow rate (for active samplers) or the predetermined collection rate (for passive samplers). Collection rates were 11 $\mathrm{cc} / \mathrm{min}$ for $\mathrm{O}_{3}$ (Chang et al., 1999), $13.3 \mathrm{cc} / \mathrm{min}$ for $\mathrm{NO}_{2}$ (Chang et al., 1999) and $9.9 \mathrm{cc} / \mathrm{min}$ for $\mathrm{SO}_{2}$ (Chang - personal communication).

Imprecision for $\mathrm{PM}_{2.5}$ samplers was determined by regression analyses applied to the duplicate filter-based samples collected by the multi-pollutant monitors; for the other pollutants, co-located multi-pollutant monitors ( $A$ and $B$ ) at the central Steubenville site were used to estimate imprecision. Valid samples greater than the field LOD were paired by date $(n=69,22$, and 44 sample pairs for $\mathrm{O}_{3}, \mathrm{SO}_{2}$ and $\mathrm{NO}_{2}$, respectively), and precision was calculated using: $100 \% \mathrm{x}$ $[S D(|\operatorname{diff}|) /$ Mean(A,B)] / $\sqrt{2}$ (Kinney and Thurston, 1993). 
Accuracy was determined by comparing the multi-pollutant monitor measurements made at the central Steubenville site with 24-hr average FRM or FEM measurements made there (reference measurements were not available for $\mathrm{SO}_{4}{ }^{2-}, \mathrm{EC}$, or the elements). For the gases, only data above the field LOD were analyzed, resulting in 91, 31 and 30 sample pairs for $\mathrm{O}_{3}, \mathrm{SO}_{2}$ and $\mathrm{NO}_{2}$, respectively. Accuracy was calculated as the ratio of mean concentrations from the two methods: $100 \%$ x (multi-pollutant value / reference value). Regression slopes between the passive and FRM or FEM values were low, suggesting that the collection rates we used were overestimated for field use. However, accuracy of the $\mathrm{O}_{3}$ and $\mathrm{NO}_{2}$ concentrations was thought to be sufficient, and use of different estimated collection rates in the calculations did not improve regression fits significantly for these gases. For $\mathrm{SO}_{2}$, because so much data were < LOD, only few samples were in effect underestimated.

\subsubsection{Data Analysis}

Prior to statistical analyses, several data points were removed from the dataset, including data for subjects $(n=10)$ who withdrew early from the study, as discussed above. In addition, three indoor samples with extremely high concentrations of $\mathrm{PM}_{2.5}$ and $\mathrm{SO}_{4}{ }^{2-}$ were excluded from all data analyses, as were $27 \mathrm{PM}_{2.5}$ and $\mathrm{NO}_{2}$ indoor samples collected on days during which indoor questionnaires indicated the presence of environmental tobacco smoke (ETS). For personal exposure data, samples for which participants indicated ETS exposure on their TAD (68 persondays) were left in the data set due to their high number; models using personal $\mathrm{PM}_{2.5}$ and $\mathrm{NO}_{2}$ gave similar results when these samples were removed. Because concentrations for many of the analyzed elements were extremely low, only those pollutants with at least $50 \%$ of values above their respective LODs were included in the data analyses. These included the waterextractable concentrations of $\mathrm{As}, \mathrm{Ba}, \mathrm{Cd}, \mathrm{K}, \mathrm{Mg}, \mathrm{Pb}$, Se, and $\mathrm{V}$, and the acid-digestible concentrations of $\mathrm{Al}, \mathrm{Fe}, \mathrm{K}, \mathrm{Mg}, \mathrm{Mn}, \mathrm{Pb}, \mathrm{Se}, \mathrm{V}$, and $\mathrm{Zn}$. Due to the generally poor precision of these elemental data, however, data analyses were limited to summary statistics and correlation analyses between water-extractable and acid-digestible concentrations.

All data analyses were performed using Excel 2000, SAS Release 8.02 (SAS Institute, Cary, NC) and S-PLUS 2000 Professional Release 3 (Insightful Corporation). Pollutants were first characterized by season and by microenvironment using graphical displays and descriptive statistics, including means, medians, standard deviations (SD), and maximum concentrations. Relationships between ambient $\mathrm{PM}_{2.5}$ concentrations and corresponding personal pollutant exposures were subsequently examined. The effects of ventilation and activities on these relationships were also investigated. Similar analyses were performed using ambient $\mathrm{SO}_{4}{ }^{2-}$ and EC concentrations to determine whether the relationships between ambient concentrations and personal exposures differ for ambient regional $\mathrm{PM}_{2.5}$ pollution and ambient local $\mathrm{PM}_{2.5}$ pollution, respectively. The ambient concentrations used in the analyses were those measured at the central Steubenville site, because these data were the most complete and correspond best to the type of central site data typically used in epidemiologic analyses.

Personal-ambient relationships were examined using general linear mixed-effect models for longitudinal data (PROC MIXED in SAS), which are designed to handle data from multiple subjects and allow subjects to serve as their own controls, and are able to handle unequallyspaced data and to model the covariance structure of the data. Subjects were modeled as random effects using a compound symmetry covariance structure, which generally yielded the lowest Akaike Information Criteria (AIC). All models included a building effect in order to control for differences in building characteristics and pollutant levels where subjects resided. Missing data were assumed to be missing completely at random (MCAR) and thus not likely to affect the maximum likelihood estimates. A Tobit model (Tobin, 1958) was also used to examine 
associations with personal and indoor $\mathrm{O}_{3}$ in the fall and with $\mathrm{SO}_{2}$ in both seasons, because these pollutants had a large percentage of samples with non-detect values. Tobit models use a linear model to examine data above the pollutant detection limit and a logistic model for data below the detection limit (e.g., $y_{i}^{*}=x_{i}^{\prime} B+e_{i}$, where $y_{i}=\left(y_{i}^{*}\right.$ if $\left.y_{i}^{*}>n d\right)$ or $\left(0\right.$ if $\left.y_{i}^{*}<=n d\right)$ ). For these models, both fixed effects and random subject effects were specified in S-PLUS using the survReg object.

The dwelling questionnaires provided information about the presence of gas stoves in subjects' apartments. From the indoor questionnaires, we obtained a cleaning factor, a cooking factor, and two ventilation variables using information regarding the hours of $A C$ use and the duration of open windows/doors. All factors were 0/1 variables indicating "none" versus "any," with the exception of the TAD AC use and indoor questionnaire windows use variables. For the TAD AC data (summer only), sample numbers were very unbalanced if categorized as 0/1 (with 16 out of 187 samples falling in the "none" category). Therefore we modified the summer grouping such that "none" represented subjects spending $0-33 \%$ of time indoors with AC, and "any" represented subjects spending $33-100 \%$ of their time in this environment. For information on windows usage obtained from the indoor questionnaire, a three-level variable was created by summing the number of hours of open windows and/or doors during the sampling period and categorizing by approximate tertiles as follows: "Lo" = no windows/doors open, "Med" = the sum of open windows/doors is $>0 \mathrm{but} \leq 24 \mathrm{hr}$, and "Hi" = the sum of open windows/doors is $>24 \mathrm{hr}$.

Finally, models using indoor pollutant data were evaluated for three "subsets" of our study population. "Subset 10" included all subjects for whom personal monitoring data were available, which allowed for direct comparisons between models using personal exposure and indoor concentration data. "Subset 15 " included those subjects for whom no personal monitoring data were available. "Subset 25" was the full cohort.

On the basis of previous studies, time spent outdoors and time spent in transit were of particular interest in our analyses of exposure relationships, as were variables assessing ventilation conditions, including time spent indoors with air conditioning (AC) and time spent indoors with open windows/doors. Therefore, nine variables (i.e., presence of gas stoves, cooking, cleaning, AC use, open windows/doors, time spent outdoors, time spent in transit, time spent indoors with $\mathrm{AC}$, and time spent indoors with open windows/doors) from the dwelling questionnaires, indoor questionnaires, and time-activity diaries were included as categorical variables in statistical models.

The impact of home ventilation was examined by including home ventilation variables (VENT) in the mixed effect models as main effects and as interaction terms with ambient concentrations:

$$
(E)_{i j}=\beta_{0}+\beta_{1}\left(C_{0}\right)_{i j}+\beta_{2}(\text { BUILDING })_{i j}+\beta_{3}(\text { VENT })_{i j}+\beta_{4}\left(C_{0}{ }^{*} \text { VENT }\right)_{i j}+b_{i}+\varepsilon_{i j}
$$

Home ventilation data were included in models as categorical variables. For open window usage, a value of " 1 " indicated that the individual spent time in indoor environments with open windows, whereas a value of " 0 " indicated that the individual spent all of his/her time in indoor environments with closed windows. Similarly, for air conditioning use, values of " 1 " and "0" indicated that individuals spent time in air conditioned and non-air conditioned environments, respectively. Similar models were also constructed to examine the impact of specific activities, such as cooking and cleaning. Ventilation and activity data were obtained from the time-activity diaries for models of personal exposures and were obtained from housing questionnaires for models of indoor concentrations. Models of indoor concentrations only included data for the 
ten subjects for whom personal monitoring data were available to allow results to be compared to those for personal exposures.

All models were stratified by season. Analyses using indoor or personal $\mathrm{NO}_{2}$ as either dependent or independent variables were stratified by gas stove presence to examine whether the presence of gas stoves would affect observed relationships. Analyses evaluating the effects of ambient $\mathrm{SO}_{2}$ as the independent variable were run with and without data below the laboratory LOD since these values were replaced with random numbers during data processing stages. For most analyses, results using the full data set and the restricted data set were comparable, with some loss of significance for the restricted data set likely due to the smaller sample size. As a result, only results using the restricted data set are presented. Regression results presented for each relationship include dependent and independent variables, parameter estimates $(\beta)$, standard errors (SE), t-statistics, and intercepts.

\subsubsection{Children's Cohort}

\subsubsection{Study Design}

Exposure monitoring for the children's cohort was conducted in Steubenville during the winter (January 20 - March 4) and summer (June 1 - July 3) of 2001. Simultaneous measurements of personal exposures and indoor and outdoor concentrations of $\mathrm{PM}_{2.5}, \mathrm{EC}, \mathrm{SO}_{4}{ }^{2-}, \mathrm{NO}_{2}, \mathrm{O}_{3}$, and $\mathrm{SO}_{2}$ were made for 15 children in each season. Monitoring for each child was performed for seven consecutive 24-hr periods. In general, three subjects were sampled simultaneously each week. Corresponding 24-hr air pollutant samples were also collected at the central ambient air monitoring site in Steubenville.

\subsubsection{Participant Recruitment and Selection}

Children between the ages of 9 and 13 were recruited through local community contacts for participation in the study. The children who were identified by these contacts were contacted via telephone. Children who lived in non-smoking households and were willing to participate were included in the study. In all, sixteen children participated in the winter monitoring session. Twelve of these children again participated in the summer monitoring session, as did 3 newly recruited children, for a total of 15 subjects in the summer session. Each participant gave written informed consent prior to his or her participation in the study.

\subsubsection{Air Pollution and Air Exchange Rate Sampling}

As for the older cohort, all air pollutant concentrations for the children's cohort were measured using Harvard multi-pollutant monitors (Demokritou et al., 2001). As described above, the monitor samples fine particles, fine particle components, and gaseous pollutants simultaneously. The personal, indoor, and outdoor monitors used for the children's cohort were configured and operated identically to those used for the older adult cohort, and samples collected by these monitors were analyzed according to the same analytical procedures (see Section 3.2.1.3). In short, the monitors each included two active samplers to measure $\mathrm{PM}_{2.5}$ and water-extractable and acid-digestible elements, a mini-sampler to measure $\mathrm{SO}_{4}{ }^{2-}$, a minisampler to measure $\mathrm{EC}$, and two passive samplers to measure $\mathrm{O}_{3}$ and $\mathrm{NO}_{2}$ and $\mathrm{SO}_{2}$.

A chemistry lab at the Franciscan University of Steubenville was used for the assembly, disassembly, cleaning, and temporary storage of filter samples. Gravimetric analyses of Teflon filters were conducted at the Harvard School of Public Health; all other lab analyses were 
conducted by CONSOL R\&D according to the general analytical procedures described in Section 3.1. Teflon filters were analyzed for the following elements in the water-extractable and acid-digestible $\mathrm{PM}_{2.5}$ fractions: Al, As, Ba, Ca, Cd, Co, Cr, Cu, Fe, K, Mg, Mn, Na, Ni, Pb, Se, Si, Sn, Ti, V, and Zn.

In addition to air pollutant sampling, daily air exchange rates (AER) were measured in each home on each monitoring day. Air exchange rates were measured using a tracer gas source (perfluorocarbon tracer gas, PFT) and passive samplers (capillary adsorption tubes, CATs). PFT gas was released at a controlled rate from multiple sources within each home, with the sources placed inside the home approximately 24 hours prior to sampling to allow for equilibrium (Dietz et al., 1986). CATs were used for sample collection and were generally placed in the living room, bedroom, and kitchen. In general, 3 to 4 CATs were collected for each house. Additionally, collocated and field blank CAT samples were collected for quality assurance. After sampling, CATs were shipped to HSPH for analysis using a gas chromatograph with electron capture detector (GC/ECD). Due to a problem with sample storage, collected CATs could not be analyzed properly. As a result, air exchange rates could not be determined. Information on home ventilation, however, was captured via questionnaire data (i.e., use of fans and air conditioners, extent of open doors and windows) and was used in place of air exchange rates in our analyses. Open window information has been shown to be a better proxy of home ventilation than air exchange rates (Brown, 2006), suggesting that the lack of air exchange rate data would not impair our ability to achieve study objectives.

\subsubsection{Housing Characteristics Questionnaire}

Information about each subject's home was collected from the subject's parents using a technician-administered questionnaire (Appendix B), which asked for information on heating sources, ventilation sources, cleaning products, cleaning frequency, pets, tobacco usage, occupant information, and proximity to busy roads or other external pollutant sources.

After each 24-hr sampling period, the technician again queried the parents about activities that occurred during that period (see the Daily Follow-up Questionnaire in Appendix B). This included information on tobacco usage, cleaning activities, cooking activities, candle/incense burning, exhaust fan usage, open windows, air conditioner usage, and humidifier usage.

\subsubsection{Time-Activity Diaries}

During each sampling period, subjects kept daily time-activity diaries to record their activity patterns. Each TAD allowed for the entry of activities in half-hour intervals over the course of a waking day $(6: 30 \mathrm{am}$ to $12: 30 \mathrm{am})$. Technicians trained the subjects in the use of the diaries, and reviewed the completed diaries after each 24 -hr sampling period. The diaries documented the locations of the subjects (indoor, outdoor, in transit, type of transit) and the specific activities the subjects were engaged in during each half-hour interval. They also were used to record information that could bias the exposure results, including whether the subject was near a window or near a smoker.

\subsubsection{Quality Assurance and Quality Control}

Flags were assigned to each sample according to the validity of airflows, sample durations, and comments recorded during weigh sessions, assembly/disassembly stages, and field operations. Invalid samples were excluded from all analyses, as were samples for subjects who withdrew 
from the study. Extreme $\mathrm{NO}_{2}$ samples were additionally excluded due to presumable lab or field contamination.

The multi-pollutant monitor was configured with two $\mathrm{PM}_{2.5}$ samplers; thus, duplicate samples were obtained for each subject-day and were used for active sample validation purposes prior to averaging for use in data analyses. A precision criterion of $\leq 0.50$ relative difference (RD) between the duplicates was established above which both $\mathrm{PM}_{2.5}$ samples and any corresponding $\mathrm{SO}_{4}{ }^{2-}$ or $\mathrm{EC}$ samples were invalidated (samples with $>0.50 \mathrm{RD}$ were assumed to have been adversely affected at some stage of sampling - e.g., by kinked tubing). After all invalidations, data completeness was calculated as follows: $\%$ Completeness $=$ (total valid/total sampled) $\times 100 \%$.

Field blanks comprised $10 \%$ of outdoor, indoor and personal field samples. Based on a t-test for significance, blanks for all pollutants were found to be significantly greater than zero, and thus all samples were blank corrected. Data below the analytical LOD for $\mathrm{SO}_{4}{ }^{2-}, \mathrm{EC}, \mathrm{O}_{3}, \mathrm{SO}_{2}$, $\mathrm{NO}_{2}$, and the 21 acid-digestible and water-extractable elements were reported as non-detect (ND) by the laboratory. The field LOD for $\mathrm{PM}_{2.5}$ mass was calculated as two times the standard deviation of the field blanks. For the other pollutants, because many blanks were ND, field LODs were calculated by using the $95^{\text {th }}$ percentile of field blanks by season (and by microenvironment if they differed sufficiently). Concentration LODs in $\mu \mathrm{g} / \mathrm{m}^{3}$ and ppb were further calculated based on a 24-hr sampling period and the target sample flow rate (for active samplers) or the predetermined collection rate (for passive samplers). Collection rates were 11 $\mathrm{cc} / \mathrm{min}$ for $\mathrm{O}_{3}$ (Chang et al., 1999), $13.3 \mathrm{cc} / \mathrm{min}$ for $\mathrm{NO}_{2}$ (Chang et al., 1999) and $9.9 \mathrm{cc} / \mathrm{min}$ for $\mathrm{SO}_{2}$ (Chang - personal communication). Because a large proportion of $\mathrm{SO}_{2}$ concentrations were below the LOD, these values are not discussed.

Imprecision for $\mathrm{PM}_{2.5}$ samplers was determined by regression analyses applied to the duplicate filter-based samples collected by the multi-pollutant monitors; for the other pollutants, co-located multi-pollutant monitors ( $A$ and $B$ ) at the central Steubenville site were used to estimate imprecision. Valid samples greater than the field LOD were paired by date $(n=51$ sample pairs for both $\mathrm{O}_{3}$ and $\left.\mathrm{NO}_{2}\right)$, and precision was calculated using: $100 \% \times[\mathrm{SD}(|\operatorname{diff}|) / \mathrm{Mean}(\mathrm{A}, \mathrm{B})] / \sqrt{2}$ (Kinney and Thurston, 1993).

Accuracy was determined by comparing the multi-pollutant monitor measurements made at the central Steubenville site with 24-hr average FRM or FEM measurements made there (reference measurements were not available for $\mathrm{SO}_{4}{ }^{2-}, \mathrm{EC}$, or the elements). For the gases, only data above the field LOD were analyzed, resulting in 444 and 211 sample pairs for $\mathrm{O}_{3}$ and $\mathrm{NO}_{2}$, respectively. Accuracy was calculated as the ratio of mean concentrations from the two methods: $100 \%$ x (multi-pollutant value / reference value).

\subsubsection{Data Analysis}

All data analyses were performed using Excel 2000, SAS Release 8.02 (SAS Institute, Cary, NC) and S-PLUS 2000 Professional Release 3 (Insightful Corporation). Pollutants were first characterized by season and by microenvironment using descriptive statistics. Relationships between ambient $\mathrm{PM}_{2.5}$ concentrations and corresponding indoor, outdoor, and personal pollutant levels were subsequently examined. The effect of ventilation on these relationships was also investigated. Similar analyses were performed using ambient $\mathrm{SO}_{4}{ }^{2-}$ and $\mathrm{EC}$ concentrations to determine whether relationships differ for ambient regional PM pollution and ambient local PM pollution, respectively. The ambient concentrations used in the analyses were those measured at the central Steubenville site. 
As for the older adult cohort, relationships among personal, indoor, outdoor, and ambient concentrations for the children's cohort were examined using general linear mixed-effect models for longitudinal data (PROC MIXED in SAS), which are designed to handle data from multiple subjects and allow subjects to serve as their own controls, and are able to handle unequallyspaced data and to model the covariance structure of the data. Subjects were modeled as random effects using a compound symmetry covariance structure, which generally yielded the lowest Akaike Information Criteria (AIC). All models included a building effect in order to control for differences in building characteristics and pollutant levels where subjects resided. Missing data were assumed to be missing completely at random (MCAR) and thus not likely to affect the maximum likelihood estimates.

On the basis of previous studies, time spent outdoors and time spent in transit were of particular interest in our analyses of exposure relationships, as were variables assessing ventilation conditions, including time spent indoors with air conditioning (AC) and time spent indoors with open windows/doors. As with the older adult cohort, nine variables (i.e., presence of gas stoves, cooking, cleaning, $A C$ use, open windows/doors, time spent outdoors, time spent in transit, time spent indoors with $A C$, and time spent indoors with open windows/doors) from the dwelling questionnaires, daily follow-up questionnaires, and time-activity diaries were included as categorical variables in statistical models for the children's cohort.

The impact of home ventilation was examined by including home ventilation variables (VENT) in the mixed effect models as main effects and as interaction terms with ambient concentrations:

$$
(E)_{i j}=\beta_{0}+\beta_{1}\left(C_{0}\right)_{i j}+\beta_{3}(V E N T)_{i j}+\beta_{4}\left(C_{0}^{*} V E N T\right)_{i j}+b_{i}+\varepsilon_{i j}
$$

Home ventilation data were included in the models as categorical variables. From the indoor questionnaires, we obtained two ventilation variables using information regarding the hours of AC use and the duration of open windows/doors. For window/door usage, a three-level variable was created by summing the number of hours of open windows and/or doors during the sampling period and categorizing by approximate tertiles as follows: "Lo" = no windows/doors open, "Med" = the sum of open windows/doors is $>0$ but $\leq 24 \mathrm{hr}$, and "Hi" = the sum of open windows/doors is $>24 \mathrm{hr}$. An AC variable was created where "Any" indicated any use of air conditioning and "None" indicated no air conditioning use. Similar models were also constructed to examine the impact of specific activities, such as cooking and cleaning.

All models were stratified by season. Regression results presented for each relationship include dependent and independent variables, parameter estimates ( $\beta$ ), standard errors (SE), tstatistics, and intercepts. Element concentrations were less than their respective LOD in a number of cases; however, a subgroup of elements selected on the basis of their average values and reproducibility were analyzed using summary statistics, correlation analyses among water-extractable and acid-digestible concentrations, mixed effect models, and factor analysis techniques, as described below.

Factor analysis was applied to $\mathrm{PM}_{2.5}, \mathrm{SO}_{4}{ }^{2-}, \mathrm{EC}$, and certain elemental (either water-extractable or acid-digestible) data collected using the multi-pollutant monitors at the central Steubenville site so that the associations between these central site factors and the exposures of subjects in the children's cohort could be assessed. The subgroup of elements included in the factor analyses was selected based on the completeness and reproducibility of the measurements. For completeness, elements for which at least $80 \%$ of the samples collected produced valid determinations were included. For reproducibility, elements were included if their collocated 
measurements (at the central Steubenville site) produced a linear regression $R^{2}$ value of at least 0.60 . For some elements, both the water-extractable and acid-digestible concentrations met these criteria. In these cases, the factor analyses included concentrations for the method for which (1) the sample size or percent completeness was greatest, and (2) the $\mathrm{R}^{2}$ value for the collocated comparison was greatest. As a result of these criteria, 15 elements were selected for inclusion in the factor analyses: the water-extractable concentrations of $\mathrm{As}, \mathrm{Ba}, \mathrm{Ca}, \mathrm{Cd}, \mathrm{Fe}, \mathrm{K}$, $\mathrm{Mg}, \mathrm{Mn}, \mathrm{Na}, \mathrm{Ni}, \mathrm{Sn}$, and $\mathrm{V}$, and the acid-digestible concentrations of $\mathrm{Fe}, \mathrm{Pb}$, and $\mathrm{Ti}$.

The factor analysis method used by the SCAMP indoor and personal exposure program to apportion $\mathrm{PM}_{2.5}$ source contributions was described previously (Thurston and Spengler, 1985). This method is based on the premise that daily $\mathrm{PM}_{2.5}$ component concentrations can be reduced to a few factors with defined compositional profiles that explain most of the variability in the observed concentrations. For example, for a given day, the concentrations of a total of $m$ components can be explain by $p$ factors, where $p<m$.

Daily factor scores were calculated as:

$$
[F S]=[W][Z]
$$

where $F S$ are the factor scores, $W$ is the scoring coefficient matrix, and $Z$ consists of standardized concentrations of $\mathrm{PM}_{2.5}$ components. The SAS statistical package (PROC FACTOR) was used to solve for $W$. The initial solution usually has no physical interpretation. To give a physical interpretation, the vectors of the matrices were rotated (i.e., orthogonal rotation) to maximize the loading of each component and establish independent daily scores. This procedure makes each component more strongly associated with one factor rather than spread between several factors.

To derive absolute factor scores, an extra day with zero $\mathrm{PM}_{2.5}$ component concentrations was calculated and subtracted from these derived factors as follows:

$$
[A F S]=[F S]-\left[F S^{0}\right]
$$

where the AFS matrix consists of the absolute factor scores and $F S^{0}$ are the factor scores for the day with zero concentrations.

By regressing the daily factor scores (AFS) against the daily $\mathrm{PM}_{2.5}$ mass or component concentrations, we can estimate the source contributions from the slopes given by $\beta$. The regression equation is as follows:

$$
M_{k}=\text { Intercept }+\sum_{j=1}^{p} \beta_{j} A F S_{j k}
$$

where $M_{k}$ is the mass or component concentration for day $k, \beta$ is the estimate of the regression of daily factor scores for source $j$, and AFS are daily factor scores for factor $j$ for day $k$. The average source contribution to $\mathrm{PM}_{2.5}$ or its components for a given factor was calculated by multiplying the average of the factor scores and the $\beta$ estimates obtained above. Source profiles (\% of $\mathrm{PM}_{2.5}$ component mass per total $\mathrm{PM}_{2.5}$ mass) were calculated by dividing the average $\mathrm{PM}_{2.5}$ component contributions for each factor by the average total mass contribution of the factor. 


\section{RESULTS AND DISCUSSION}

All valid data collected as part of the SCAMP ambient air monitoring program and the SCAMP indoor and personal exposure program are included in Appendix $\mathrm{C}$ to this report. This section presents and discusses findings resulting from an analysis of these data. Results from the methods development and validation and cardiovascular health studies conducted as part of SCAMP are also summarized.

\subsection{Methods Development and Validation}

As mentioned earlier in the Introduction and Experimental sections, a small sub-component of SCAMP involved the development and validation of sampling and analytical methodologies for measuring personal, indoor, and outdoor concentrations of $\mathrm{PM}_{2.5}, \mathrm{PM}_{2.5}$ chemical constituents, and gaseous pollutants. Specifically, this component included a 20-week field comparison of the performance of the Harvard multi-pollutant monitor with the performance of FRM and FEM particle and gas monitors, as well as the development and validation of a method for determining trace elements in ambient, outdoor, indoor, and personal filter-based $\mathrm{PM}_{2.5}$ samples by dynamic reaction cell ICP-MS. Results from both of these activities are relevant to assessing the quality of data produced by the SCAMP ambient air monitoring program and indoor and personal exposure program; hence, they are presented first.

\subsubsection{Evaluation of the Performance of the Harvard Multi-Pollutant Sampler vs. Ambient FRM or FEM Monitors}

One of the research priorities for $\mathrm{PM}_{2.5}$ set forth by the National Research Council (NRC) in 1998 was to determine whether $\mathrm{PM}_{2.5}$ concentrations measured at a central ambient air monitoring station accurately reflect the breathing zone exposures of individuals to $\mathrm{PM}_{2.5}$. However, different sampling equipment and methodologies are typically used to monitor personal exposures to $\mathrm{PM}_{2.5}$ than are used to measure ambient concentrations of this pollutant. Therefore, it is important to quantify the comparability of ambient and personal monitoring methods so that possible effects of measurement error on observed differences between personal and ambient concentrations can be understood.

During the summer and fall of 2000 , a 20 -week study was conducted at the SCAMP central ambient air monitoring site to compare the ambient and personal exposure monitors used by the program. Two Harvard multi-pollutant monitors were collocated with the FRM $\mathrm{PM}_{2.5}$ sampler and FRM or FEM SO $2, \mathrm{NO}_{2}$, and $\mathrm{O}_{3}$ gaseous pollutant analyzers used by the SCAMP ambient air monitoring program. Various performance metrics, including relative bias, precision, and LODs, were quantified and compared for the various sampling techniques. Sampling, analytical, and statistical methods employed by the sampler comparison study are detailed by Winter et al. (2004).

Estimates of imprecision and limits of detection for the multi-pollutant monitors and the various FRM/FEM ambient air monitors, as well as estimates of the bias of the multi-pollutant monitors relative to the FRM/FEM monitors, are summarized in Tables 6-10. Because the relative biases of the multi-pollutant monitors were in some cases dependent upon the concentrations of the pollutants being measured, these relative biases are shown as a function of ambient pollutant concentration. For each of the pollutants being studied, the shaded cell highlights the bias of the multi-pollutant monitor relative to the FRM or FEM monitor at approximately the mean concentration observed during the 20-week study. For measurements of $\mathrm{O}_{3}$ and $\mathrm{NO}_{2}$ made using the multi-pollutant monitor, separate LODs were computed for the summer and fall 
seasons because of seasonal differences in the reactivity of the chemically-coated filters used for passive sampling.

Table 6. Imprecision estimates for the Harvard multi-pollutant monitor and FRM or FEM $\mathrm{PM}_{2.5}$ and gas monitors.

\begin{tabular}{|c|c|c|c|c|c|}
\hline \multirow[t]{2}{*}{ 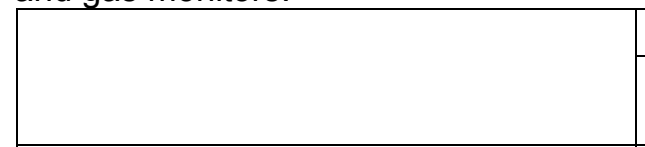 } & \multicolumn{5}{|c|}{ Estimated Imprecision } \\
\hline & $\begin{array}{c}\mathrm{PM}_{2.5} \\
\left(\mu \mathrm{g} / \mathrm{m}^{3}\right)\end{array}$ & $\begin{array}{c}\mathrm{SO}_{4}{ }^{2-} \\
\left(\mu \mathrm{g} / \mathrm{m}^{3}\right)\end{array}$ & $\begin{array}{c}\mathrm{SO}_{2} \\
\text { (ppbv) }\end{array}$ & $\begin{array}{c}\mathrm{O}_{3} \\
\text { (ppbv) }\end{array}$ & $\begin{array}{c}\mathrm{NO}_{2} \\
\text { (ppbv) }\end{array}$ \\
\hline FRM PM $_{2.5}$ Monitor & 2.6 & 0.9 & ------ & ------- & ------- \\
\hline FRM or FEM Gas Analyzer & ------ & ------ & 4.5 & 4.1 & 3.9 \\
\hline Multi-Pollutant Monitor & 1.9 & 0.6 & 2.5 & 5.7 & 7.0 \\
\hline
\end{tabular}

Table 7. Estimated bias of the Harvard multi-pollutant monitor relative to the FRM $\mathrm{PM}_{2.5}$ monitor for $\mathrm{PM}_{2.5}$.

\begin{tabular}{|l|c|c|c|c|c|}
\hline Ambient Concentration of $\mathrm{PM}_{2.5}\left(\mu \mathrm{g} / \mathrm{m}^{3}\right)$ & 5.0 & 10.0 & 20.0 & 30.0 & 50.0 \\
\hline Bias $\left(\mu \mathrm{g} / \mathrm{m}^{3}\right)$ & -0.8 & 0.2 & 2.0 & 4.5 & 8.7 \\
\hline
\end{tabular}

Table 8. Estimated bias of the Harvard multi-pollutant monitor relative to the FRM PM 2.5 monitor for $\mathrm{SO}_{4}{ }^{2-}$.

\begin{tabular}{|l|c|c|c|c|c|}
\hline Ambient Concentration of $\mathrm{SO}_{4}{ }^{2-}\left(\mu \mathrm{g} / \mathrm{m}^{3}\right)$ & 2.0 & 4.0 & 6.0 & 8.0 & 10.0 \\
\hline Bias $\left(\mu \mathrm{g} / \mathrm{m}^{3}\right)$ & -0.7 & -0.4 & 0.0 & 0.3 & 0.6 \\
\hline
\end{tabular}

Table 9. Estimated bias of the Harvard multi-pollutant monitor relative to the FRM or FEM gas analyzers.

\begin{tabular}{|l|c|c|c|c|c|}
\hline Ambient Concentration of Gas (ppbv) & 5.0 & 10.0 & 25.0 & 45.0 & 70.0 \\
\hline Bias for $\mathrm{O}_{3}(\mathrm{ppbv})$ & -0.4 & 0.2 & 2.2 & 4.8 & 9.4 \\
\hline Bias for $\mathrm{NO}_{2}$ (ppbv) & 2.0 & 2.0 & 2.0 & ------ & ------ \\
\hline Bias for $\mathrm{SO}_{2}$ (ppbv) & 6.0 & 7.9 & 13.4 & 20.7 & ------- \\
\hline
\end{tabular}

Table 10. Estimated limits of detection for the Harvard multi-pollutant monitor and FRM or FEM $\mathrm{PM}_{2.5}$ and gas monitors.

\begin{tabular}{|c|c|c|c|c|c|}
\hline \multirow[t]{2}{*}{ 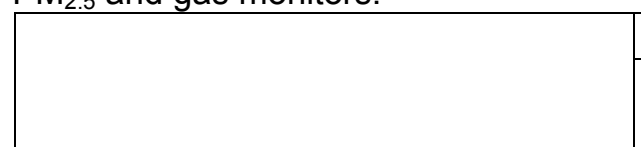 } & \multicolumn{5}{|c|}{ Estimated Limit of Detection } \\
\hline & $\begin{array}{c}\mathrm{PM}_{2.5} \\
\left(\mu \mathrm{g} / \mathrm{m}^{3}\right)\end{array}$ & $\begin{array}{c}\mathrm{SO}_{4}{ }^{2-} \\
\left(\mu \mathrm{g} / \mathrm{m}^{3}\right)\end{array}$ & $\begin{array}{c}\mathrm{SO}_{2} \\
\text { (ppbv) }\end{array}$ & $\begin{array}{c}\mathrm{O}_{3} \\
\text { (ppbv) }\end{array}$ & $\begin{array}{c}\mathrm{NO}_{2} \\
(\mathrm{ppbv})\end{array}$ \\
\hline FRM $\mathrm{PM}_{2.5}$ Monitor & 1.2 & 0.1 & ------ & ------ & ------ \\
\hline FRM or FEM Gas Analyzer & 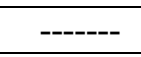 & $\begin{array}{ll}----- \\
-\end{array}$ & 2.4 & 2.1 & 1.2 \\
\hline Multi-Pollutant Monitor $^{\mathrm{a}}$ & 3.0 & 0.2 & 6.4 & $12.7,10.7$ & $10.8,6.1$ \\
\hline
\end{tabular}

${ }^{\mathrm{a}}$ For $\mathrm{O}_{3}$ and $\mathrm{NO}_{2}$, the first LOD shown is for the summer, and the second is for the fall.

The Harvard multi-pollutant monitors and the FRM $\mathrm{PM}_{2.5}$ monitor performed comparably for measurements of both total $\mathrm{PM}_{2.5}$ mass concentrations and fine particulate $\mathrm{SO}_{4}{ }^{2-}$ mass concentrations. The biases of the multi-pollutant monitor relative to the FRM sampler were approximately $10 \%$ for $\mathrm{PM}_{2.5}$ and $5 \%$ for $\mathrm{SO}_{4}{ }^{2-}$ at the mean ambient concentrations of these species. Relative biases increased slightly with increasing concentration but remained less than $20 \%$ for $\mathrm{PM}_{2.5}$ and less than $10 \%$ for $\mathrm{SO}_{4}{ }^{2-}$ at the largest ambient concentrations observed during the study. The imprecisions and LODs of the two monitors for $\mathrm{PM}_{2.5}$ and $\mathrm{SO}_{4}{ }^{2-}$ were similar.

Results were less consistent for gaseous pollutant measurements. For $\mathrm{O}_{3}$ and $\mathrm{NO}_{2}$ at their average concentrations, the multi-pollutant monitors exhibited biases of approximately $10 \%$ and $20 \%$, respectively, relative to the FRM/FEM gas analyzers. The imprecisions of the methods 
were also fairly comparable for these two gases. (The imprecisions of the multi-pollutant monitors and the FRM analyzer for $\mathrm{NO}_{2}$ were large relative to the mean $\mathrm{NO}_{2}$ concentration measured during the sampler comparison program, but the imprecision of both monitors decreased to approximately 2 ppbv when 4 discordant data points were removed). However, the multi-pollutant monitors' LODs for $\mathrm{O}_{3}$ and $\mathrm{NO}_{2}$ were 5-10 times greater than the FRM/FEM gas analyzers' LODs and about $40-110 \%$ as great as the mean ambient concentrations observed during the sampler comparison study. The differences in detection limits between the multi-pollutant monitor and the FRM/FEM monitors are likely attributable to the former's large filter blank concentrations for $\mathrm{O}_{3}$ and $\mathrm{NO}_{2}$ and its use of passive sampling technology. Concentrations of $\mathrm{SO}_{2}$ determined by the multi-pollutant monitor exhibited a large bias relative to those determined by the $\mathrm{FEM} \mathrm{SO} 2$ analyzer; this relative bias was $80 \%$ at the mean concentration measured during the sampler comparison study. Moreover, although the estimated imprecision for the multi-pollutant monitor was slightly better than that for the FEM analyzer for $\mathrm{SO}_{2}$, the $\mathrm{SO}_{2}$ detection limit estimated for the multi-pollutant monitor was more than 2.5 times as great as that for the FEM gas analyzer. The detection limits calculated for the multi-pollutant monitor for $\mathrm{SO}_{2}$ and $\mathrm{O}_{3}$ were greater than many of the indoor and personal concentrations of these gases measured during SCAMP. Consequently, the interpretation of such data is primarily limited to averages and trends (with appropriate statistical considerations, as discussed in the section describing results from the SCAMP indoor and personal exposure program) and not to single day or individual $\mathrm{SO}_{2}$ and $\mathrm{O}_{3}$ measurements.

In summary, the comparison of personal and ambient sampling methodologies conducted as part of SCAMP concluded that the Harvard multi-pollutant monitor performs well in measuring concentrations of $\mathrm{PM}_{2.5}$ and fine particulate sulfate, but that its ability to determine concentrations of gaseous pollutants is limited by bias (for $\mathrm{SO}_{2}$ ) and high detection limits (for $\mathrm{SO}_{2}, \mathrm{O}_{3}$, and $\mathrm{NO}_{2}$ ). Hence, results for these gaseous pollutants, although generally suitable for use in statistical analyses, must be interpreted with caution.

\subsubsection{Development and Evaluation of Methods for Determining Elements in $\mathrm{PM}_{2.5}$ Using Dynamic Reaction Cell ICP-MS}

An objective of SCAMP was to develop improved methodology for determining trace elements in $\mathrm{PM}_{2.5}$. Although they constitute only a very small portion of total $\mathrm{PM}_{2.5}$ mass, trace elements are important for use as tracers in source apportionment analyses of $\mathrm{PM}_{2.5}$ and may also play a role in the toxicity of fine particles. Hence, it is important that methods be developed to enable their concentrations to be determined accurately and precisely, even when these concentrations are very low (i.e., $<10 \mathrm{ng} / \mathrm{m}^{3}$ of ambient air).

A majority of the $\mathrm{PM}_{2.5}$ trace element determinations to date, including those carried out previously in Steubenville as part of the Six Cities Study and those currently being carried out by the U.S. EPA's Speciation Trends Network, have been performed using X-ray fluorescence spectrometry (XRF). An advantage of this technique is that it is nondestructive, meaning that sample preparation procedures such as dissolution or digestion are not required, and that the $\mathrm{PM}_{2.5}$ sample is preserved for future analyses. However, the widespread use of speciation samplers, which simultaneously collect multiple filter-based $\mathrm{PM}_{2.5}$ samples for analysis, has made destructive techniques relevant. Moreover, while XRF performs adequately for determining the more abundant elemental components of $\mathrm{PM}_{2.5}$, including many common crustal elements, it lacks the sensitivity required to determine a number of trace elements that are typically present in filter-based $P_{2.5}$ samples in quantities less than $50-100 \mathrm{ng}$. This limitation becomes magnified for a program such as SCAMP that includes personal exposure monitoring, because personal samplers operate at $\sim 1 / 10$ the volumetric flow rate of ambient 
monitors (assuming a standard FRM flow rate of $16.67 \mathrm{~L} / \mathrm{min}$ ), and therefore collect substantially less $\mathrm{PM}_{2.5}$. Finally, SCAMP sought to quantify elements in both the acid-digestible and water-extractable fractions of $\mathrm{PM}_{2.5}$, as these fractions each provide unique information that is useful for drawing inferences about sources and potential health effects of $\mathrm{PM}_{2.5}$. However, given XRF's limited sensitivity for direct analyses, the technique was not considered to be applicable to the analysis of water extracts of $\mathrm{PM}_{2.5}$.

After considering the strengths and weaknesses of the various candidate methods, CONSOL R\&D selected dynamic reaction cell ICP-MS for determining $\mathrm{PM}_{2.5}$ trace elements as part of SCAMP. DRC ICP-MS exhibited better sensitivity than X-ray techniques such as XRF and proton induced X-ray emission (PIXE), and included measures (i.e., the DRC) to help to overcome the isobaric and polyatomic interferences that limit the capability of conventional ICPMS to determine isotopes like ${ }^{39} \mathrm{~K},{ }^{40} \mathrm{Ca},{ }^{51} \mathrm{~V},{ }^{52} \mathrm{Cr},{ }^{56} \mathrm{Fe},{ }^{75} \mathrm{As}$, and ${ }^{80} \mathrm{Se}$. Another candidate technology, neutron activation analysis, exhibited sensitivities that were similar to or better than those exhibited by DRC ICP-MS; however, this technology was comparably expensive and did not lend itself to the high sample throughput (approximately 5000 filters) required by SCAMP.

The general principles of DRC ICP-MS and the specific methods ultimately employed by SCAMP for $\mathrm{PM}_{2.5}$ elemental analyses were described earlier in sections 3.1.2.2 and 3.1.2.4 of this report. This section summarizes the work that was performed to develop and validate those methods.

Prior to the start of the sampling components of SCAMP, CONSOL R\&D began to develop methodology for determining elements in both the acid-digestible and water-extractable fractions of $\mathrm{PM}_{2.5}$ by DRC ICP-MS. This work, which was conducted from the summer of 1999 through May 2000, focused on evaluating and optimizing sample preparation procedures and analysis parameters. Table 11 lists some of the items that were explored.

Once these and other items were thoroughly evaluated, a comparative study was conducted in 2000 to evaluate the performance of DRC ICP-MS versus that of XRF. The study involved collecting 20 matched pairs of collocated $\mathrm{PM}_{2.5}$ filters. The matched pairs included 5 sets of filters collected from personal exposure samplers and 15 sets collected from $F R M P_{2.5}$ samplers. CONSOL R\&D completed the DRC ICP-MS analyses on one filter from each pair, and the collocated filters were sent to a well-respected contract laboratory for XRF analysis. Results of CONSOL R\&D's determination of elements in the acid-digestible $\mathrm{PM}_{2.5}$ fraction by DRC ICP-MS were then compared with the XRF results, and the relative bias, precision, and sensitivity of the methods were evaluated. The accuracy of the DRC ICP-MS methods for determining acid-digestible and water-extractable elements was also investigated by analyzing NIST Standard Reference Material (SRM) 1648 (urban particulate) and NIST SRM 1643d (trace elements in water).

The results of the study demonstrated the sensitivity advantages that DRC ICP-MS has over XRF. For example, precisions of the XRF and DRC ICP-MS results were evaluated by calculating the percent difference between duplicate analyses of the same sample (for XRF, duplicate analyses were performed on filter-based $\mathrm{PM}_{2.5}$ samples; for DRC ICP-MS, analyses were performed on duplicate digestions of NIST SRM 1648, because digesting a filter-based sample in duplicate was not feasible). Figure 5 illustrates the precision of each method, expressed as relative percent difference, as a function of the total mass of element present in the $\mathrm{PM}_{2.5}$ sample. The XRF method exhibited good precision for elements that were present in large quantities in the $\mathrm{PM}_{2.5}$ samples; however, precision declined markedly for elements that were present in smaller amounts. On average, the relative percent differences for duplicate 
XRF determinations of elements present in amounts less than 50 ng were $50 \%$ or greater. Elements such as $\mathrm{As}, \mathrm{Cd}, \mathrm{Co}, \mathrm{Cr}, \mathrm{Ni}, \mathrm{V}$, and Se are typically present in amounts less than 50 ng, especially in personal exposure filter samples. The DRC ICP-MS procedure was able to repeat the analyses of all 21 study elements in two different digestions of NIST SRM 1648 to within 50\%. Figure 5 suggests that the precision of DRC ICP-MS does not depend strongly on the quantity of element present in the sample, as it does for XRF.

Table 11. Issues explored during the development of methods for determining trace elements in $\mathrm{PM}_{2.5}$ by DRC ICP-MS.

Examined background levels in the digestion. Determined the contribution of elements from various items in the digestion, including acids, DI water, reagents, filters, digestion tubes, and laboratory environment. As a result, used trace grade acids, $18 \mathrm{M} \Omega \mathrm{DI}$ water, and certified cleaned digestion tubes (Environmental Express) in the method, and used the cleaner chromatography and PM laboratories for sample preparation.

Assessed the degree of isobaric and polyatomic interferences in the MS resulting from variations in the amounts of $\mathrm{HF}$ and $\mathrm{HCl}$ used in the acid digestion method. Results were used to refine the analytical protocol.

Investigated the effects of varying acid concentrations on digestion efficiency, chloride interferences, and torch bleed. Results were used to refine the analytical protocol.

Examined whether acid-induced corrosion to the electronic pipette's piston was a point of concern for routine sample preparation for the acid-digestible method. Corrosion was determined to be negligible. Analyzed multi-pollutant sampler filter blanks to determine if washing had a significant effect on the cleanliness of 37-mm Teflon and Fluoropore filters, both of which would be used in the personal exposure samplers. As a result, pre-washing was not employed, and Fluoropore filters were used for sulfate collection.

Optimized the volume of solution required for efficient filter digestion for the acid-digestible method. Digestion volume was selected to be $1.5 \mathrm{ml}$ of a concentrated acid mixture. The volume was sufficient for filter wetting and refluxing.

Explored whether a $\mathrm{HNO}_{3}$-only digestion was adequate for the acid-digestible method. $\mathrm{A}^{\mathrm{HNO}_{3}}$ digestion was not adequate, as it produced low recoveries for most elements. It was believed that HF was required to release elements from siliceous particulate matrices. In addition, $\mathrm{HCl}$ was required for sufficient recovery of certain elements such as Fe and V.

Examined whether it was possible to analyze directly from the digestion tubes, rather than using autosampler tubes, in order to help minimize sample preparation and cost. This was determined to be impractical, and the autosampler tubes were sufficiently clean to present no contamination concerns. Investigated the addition of high-purity boric acid to stop torch bleed resulting from HF used in the digestion. Torch bleed causes high silicon background concentrations in the analysis. Decided to use a commercially available boron standard made from high-purity boric acid to complex the HF prior to analysis. In addition, an HF-resistant torch and sample introduction system was purchased for routine analysis.

The SCAMP method comparison study concluded that XRF had adequate sensitivity to determine $\mathrm{Al}, \mathrm{Ca}, \mathrm{Fe}, \mathrm{K}, \mathrm{Pb}, \mathrm{Si}$, and $\mathrm{Zn}$ in $\mathrm{PM}_{2.5}$. DRC ICP-MS displayed adequate sensitivity to determine all 21 study elements with the exception of $\mathrm{Si}$, for which uncertainties often exceeded $20 \%$. The XRF and DRC ICP-MS results consistently agreed within $20 \%$ for only Se and $\mathrm{Pb}$. Fe and $\mathrm{Mn}$ concentrations determined by the two methods generally agreed within $30 \% ; \mathrm{Al}, \mathrm{Ca}, \mathrm{K}$, and $\mathrm{Zn}$ concentrations typically differed by $30 \%-70 \%$, and Si concentrations typically differed by a factor of 5-10. In almost all instances, concentrations determined by XRF were lower than those determined by DRC ICP-MS. A sampling of the data is included in Table 12. Results are discussed in greater detail by Conrad et al. (2000). 


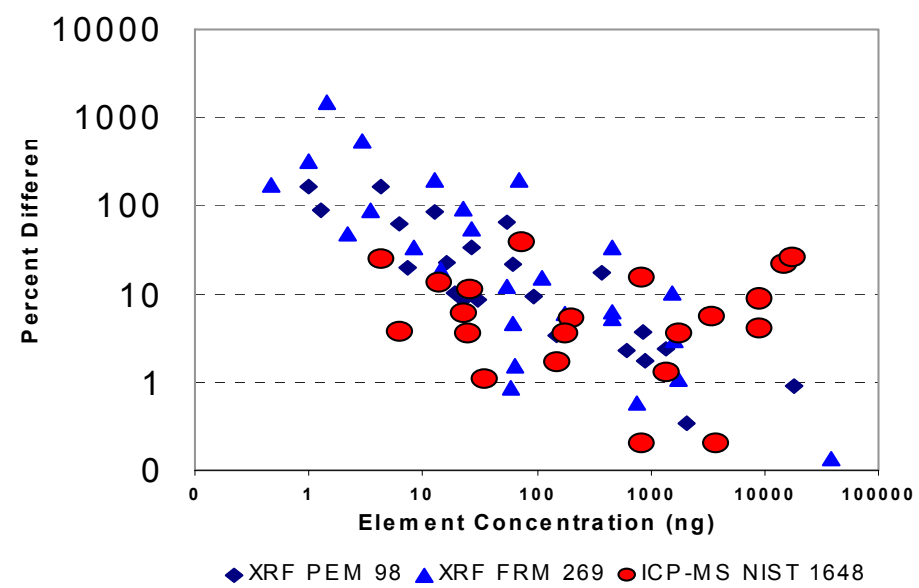

Figure 5. Precision of the DRC ICP-MS and XRF for various elements as a function of the mass of the element present in the $\mathrm{PM}_{2.5}$ sample.

Table 12. Concentrations and uncertainties of various elements determined in three sets of duplicate $\mathrm{PM}_{2.5}$ samples by XRF and DRC ICP-MS.

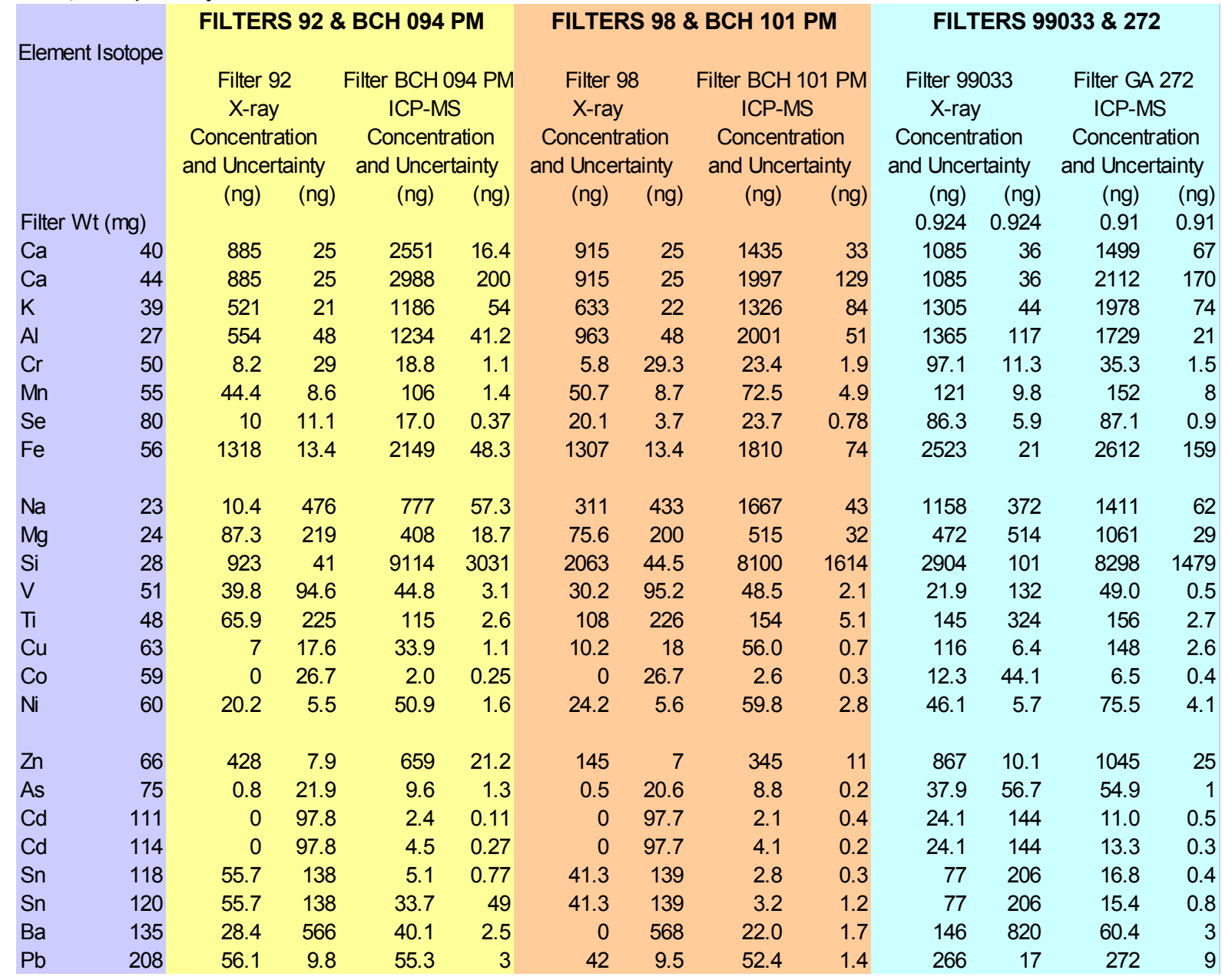


Additional DRC ICP-MS method validation work was completed in late 2000. Acid digestates produced as part of the XRF/DRC ICP-MS comparison study described above were analyzed by Columbia University using a high-resolution ICP-MS. Because high-resolution ICP-MS employs a different technique to resolve interferences than DRC ICP-MS, it served as an independent check on the accuracy of the DRC ICP-MS. Results of the comparison were presented by Winter et al. (2002). In general, element concentrations determined by the two ICP-MS methods agreed well. (DRC ICP-MS performed most poorly for $\mathrm{Cu}$ and $\mathrm{K}$; highresolution ICP-MS performed most poorly for $\mathrm{Cu}, \mathrm{Cr}$, and $\mathrm{Si}$ ). Moreover, as shown in Figures 6 and 7 , the methods generally agreed very well for elemental determinations in two different digestions of NIST SRM 1648 (100 $\mu$ g loaded onto a Teflon filter, as would typically be encountered for $\mathrm{PM}_{2.5}$ personal exposure samples).

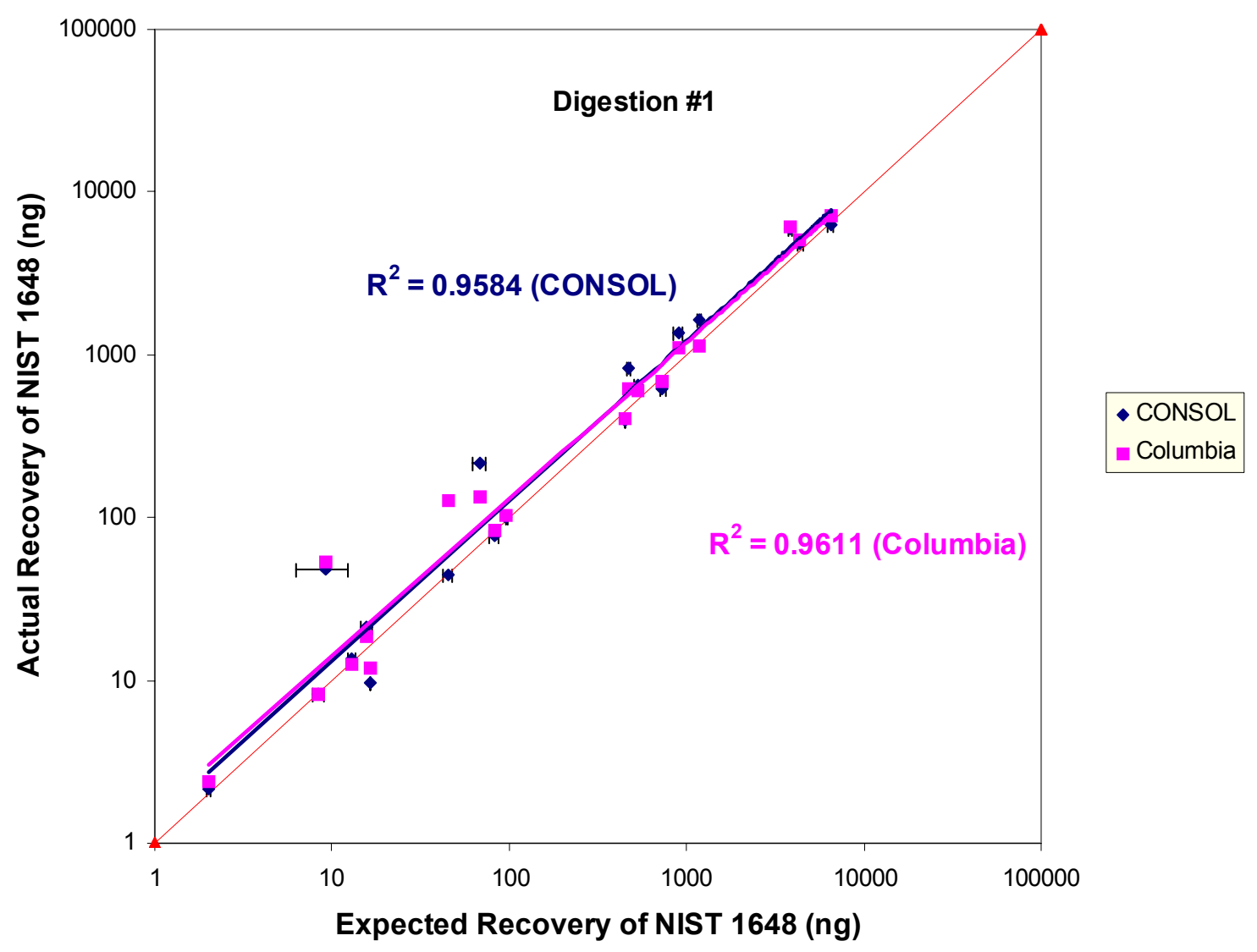

Figure 6. CONSOL R\&D (DRC ICP-MS) and Columbia (high-resolution ICP-MS) recoveries of elements in NIST SRM 1648 for digestion \#1. 


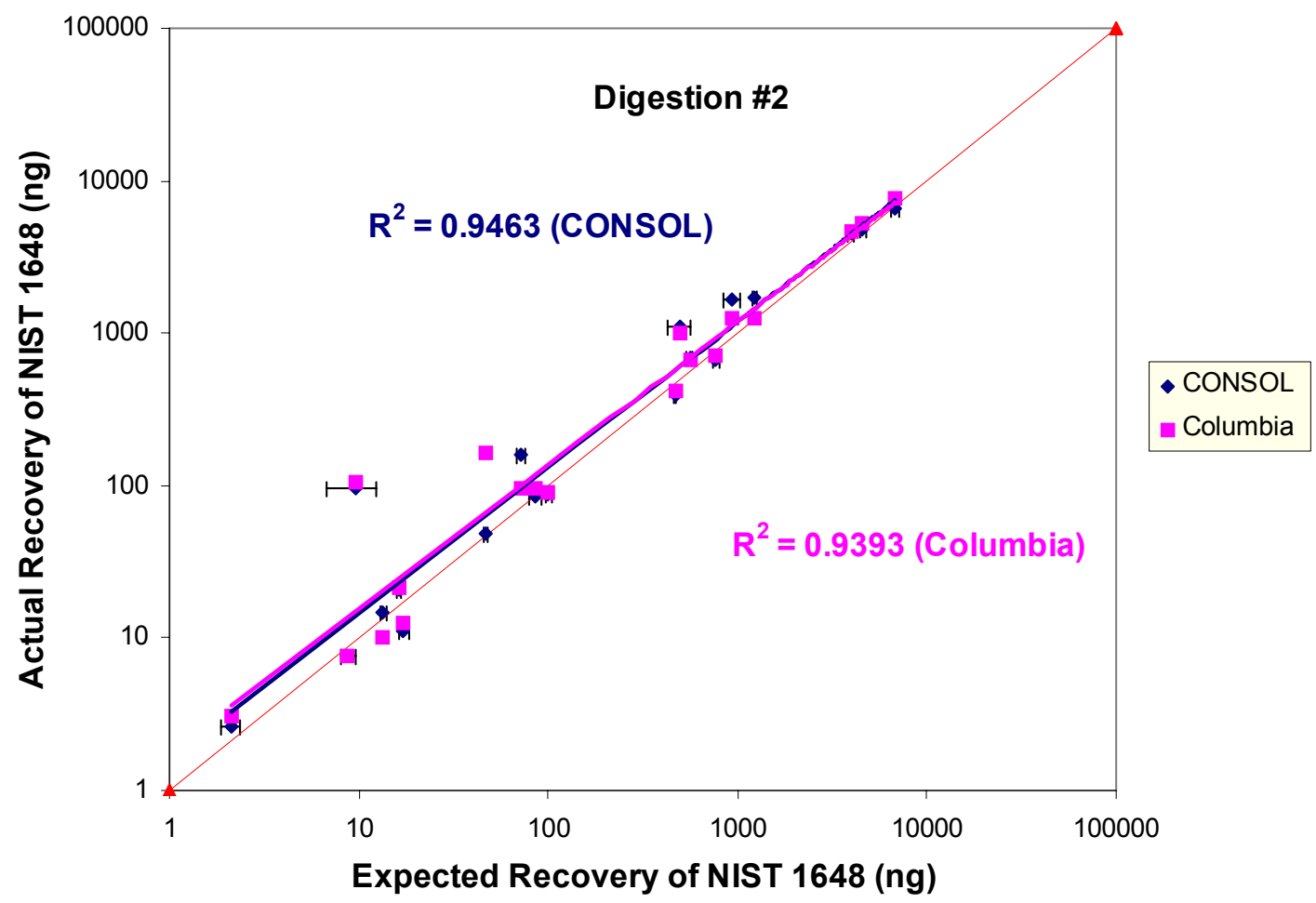

Figure 7. CONSOL R\&D (DRC ICP-MS) and Columbia (high-resolution ICP-MS) recoveries of elements in NIST SRM 1648 for digestion \#2.

In summary, the comparisons of DRC ICP-MS with XRF and high-resolution ICP-MS confirmed that DRC ICP-MS performs adequately for determining elements in $\mathrm{PM}_{2.5}$ samples and that it offers improved sensitivity over XRF for a number of trace elements that are of interest to $\mathrm{PM}_{2.5}$ researchers. Additional performance metrics for DRC ICP-MS are presented later in the sections describing results from the SCAMP ambient air monitoring program and indoor and personal exposure program.

\subsection{Ambient Air Monitoring Program}

\subsubsection{Data Overview}

The sampling schedule for the five sites comprising the SCAMP ambient air monitoring network was described earlier in section 3.1.1 of this report. Tables 13 and 14, which summarize the data completeness for each parameter monitored at each site, indicate the extents to which the sites were successful in producing valid data. 
Table 13. Data completeness for 24-hr integrated PM and PM component measurements at the SCAMP ambient air monitoring sites.

\begin{tabular}{|c|c|c|c|c|c|c|c|c|c|}
\hline \multirow[b]{2}{*}{ Parameter } & \multirow{2}{*}{\multicolumn{2}{|c|}{$\begin{array}{l}\text { No. of } \\
\text { Planned } \\
\text { Sampling } \\
\text { Days }\end{array}$}} & \multicolumn{7}{|c|}{ Data Completeness (\%) ${ }^{a}$} \\
\hline & & & \multicolumn{2}{|c|}{$\begin{array}{c}\text { Steubenville } \\
\mathrm{PM}_{2.5}\end{array}$} & $\begin{array}{c}\text { Steubenville } \\
\mathrm{PM}_{10}\end{array}$ & $\begin{array}{l}\text { North } \\
\mathrm{PM}_{2.5}\end{array}$ & $\begin{array}{l}\text { South } \\
\mathrm{PM}_{2.5}\end{array}$ & $\begin{array}{l}\text { East } \\
\mathrm{PM}_{2.5}\end{array}$ & $\begin{array}{l}\text { West } \\
\text { PM }_{2.5}\end{array}$ \\
\hline $\mathrm{PM}_{2.5} / \mathrm{PM}_{10}$ & \multicolumn{2}{|c|}{732} & \multicolumn{2}{|c|}{87} & 92 & 91 & 57 & 92 & 80 \\
\hline $\mathrm{SO}_{4}^{2-}$ & \multicolumn{2}{|c|}{183} & \multicolumn{2}{|c|}{83} & 88 & 88 & 52 & 86 & 70 \\
\hline $\mathrm{NO}_{3}^{-}$ & \multicolumn{2}{|c|}{183} & \multicolumn{2}{|c|}{83} & 88 & 88 & 52 & 85 & 70 \\
\hline $\mathrm{Cl}^{-}$ & \multicolumn{2}{|c|}{183} & \multicolumn{2}{|c|}{83} & 88 & 88 & 52 & 85 & 70 \\
\hline $\mathrm{NH}_{4}^{+}$ & \multicolumn{2}{|c|}{183} & \multicolumn{2}{|c|}{83} & 88 & 88 & 52 & 85 & 70 \\
\hline EC & \multicolumn{2}{|c|}{161} & \multicolumn{2}{|c|}{88} & NA & NA & NA & NA & $\mathrm{NA}$ \\
\hline \multirow[t]{2}{*}{ OM } & \multicolumn{2}{|c|}{161} & \multicolumn{2}{|c|}{88} & NA & NA & NA & NA & NA \\
\hline & water $^{b}$ & acid $^{\mathrm{c}}$ & water $^{b}$ & $\operatorname{acid}^{d}$ & water $^{b}$ & water $^{b}$ & water $^{b}$ & water $^{b}$ & water $^{\mathrm{b}}$ \\
\hline $\mathrm{Al}$ & 183 & 161 & 70 & 84 & 69 & 48 & 27 & 74 & 50 \\
\hline As & 183 & 161 & 77 & 86 & 78 & 75 & 36 & 79 & 61 \\
\hline $\mathrm{Ba}$ & 183 & 161 & 77 & 77 & 79 & 75 & 37 & 78 & 55 \\
\hline $\mathrm{Ca}$ & 183 & 161 & 61 & 85 & 58 & 64 & 28 & 67 & 40 \\
\hline $\mathrm{Cd}$ & 183 & 161 & 77 & 86 & 79 & 75 & 37 & 77 & 55 \\
\hline Co & 183 & 161 & 78 & 76 & 79 & 77 & 38 & 78 & 60 \\
\hline $\mathrm{Cr}$ & 183 & 161 & 70 & 84 & 70 & 67 & 33 & 69 & 52 \\
\hline $\mathrm{Cu}$ & 183 & 161 & 68 & 81 & 62 & 64 & 33 & 67 & 54 \\
\hline $\mathrm{Fe}$ & 183 & 161 & 68 & 86 & 69 & 66 & 31 & 65 & 43 \\
\hline $\mathrm{K}$ & 183 & 161 & 69 & 83 & 68 & 64 & 27 & 70 & 52 \\
\hline $\mathrm{Mg}$ & 183 & 161 & 78 & 86 & 79 & 78 & 39 & 79 & 61 \\
\hline $\mathrm{Mn}$ & 183 & 161 & 73 & 86 & 74 & 72 & 35 & 75 & 51 \\
\hline $\mathrm{Na}$ & 183 & 161 & 63 & NA & 62 & 65 & 35 & 69 & 51 \\
\hline $\mathrm{Ni}$ & 183 & 161 & 76 & 75 & 75 & 75 & 39 & 77 & 57 \\
\hline $\mathrm{Pb}$ & 183 & 161 & 74 & 86 & 75 & 72 & 35 & 73 & 51 \\
\hline $\mathrm{Se}$ & 183 & 161 & 75 & 82 & 75 & 73 & 37 & 72 & 56 \\
\hline $\mathrm{Si}$ & 183 & 161 & 66 & NA & 65 & 64 & 26 & 68 & 48 \\
\hline Sn & 183 & 161 & 78 & 85 & 79 & 76 & 37 & 78 & 55 \\
\hline $\mathrm{Ti}$ & 183 & 161 & 28 & 75 & 45 & 20 & 11 & 19 & 11 \\
\hline $\mathrm{V}$ & 183 & 161 & 78 & 82 & 79 & 78 & 39 & 79 & 61 \\
\hline $\mathrm{Zn}$ & 183 & 161 & 78 & 86 & 79 & 78 & 39 & 78 & 61 \\
\hline
\end{tabular}

Notes: NA = not applicable; ${ }^{a}$ Computed as $100 \% \times$ number of valid observations / number of planned observations; ${ }^{b}$ Measured in water-extractable $\mathrm{PM}_{2.5}$ fraction; ${ }^{\mathrm{c}}$ Measured in acid-digestible $\mathrm{PM}_{2.5}$ fraction.

The data completeness value shown in the tables for a given parameter at a given site is the number of valid daily or hourly determinations of that parameter as a percentage of the total number of planned daily or hourly determinations (based on the sampling regimen presented in Table 2). Hence, days for which sampling was planned but did not occur (e.g., due to an instrument problem) or for which sampling did occur but data were invalidated because of sampling, analytical, or level 2 quality control checks both count against data completeness. As shown in Table 8, valid FRM-determined $\mathrm{PM}_{2.5}$ concentrations were obtained for $\geq 80 \%$ of the 732 planned sampling days at all of the SCAMP monitoring sites except for the southern satellite site. This FRM sampler at this site experienced a variety of problems that prevented sampling on a number of days. In many cases, data completeness for $\mathrm{PM}_{2.5}$ components was less than that for $\mathrm{PM}_{2.5}$ mass because some samples failed to pass $\mathrm{QC}$ criteria for laboratory 
analyses. With the exception of rainfall, data completeness was $\geq 70 \%$ for gaseous pollutants, meteorological conditions, continuous $\mathrm{PM}_{2.5}$ mass, and pollen and spores measured at the central Steubenville site. The rain gauge malfunctioned during the first half of the program, and only produced valid data from April 24, 2001, until the end of the program.

Table 14. Data completeness for continuous $\mathrm{PM}_{2.5}$, gaseous pollutants, meteorological conditions, and pollen and spores measured at the central Steubenville site.

\begin{tabular}{|c|c|c|}
\hline Parameter & $\begin{array}{c}\text { No. of Planned Sampling } \\
\text { Periods }\end{array}$ & Data Completeness (\%) $^{\mathbf{a}}$ \\
\hline $\mathrm{TEOM} \mathrm{PM}_{2.5}$ Mass & 16,800 & 87 \\
\hline $\mathrm{SO}_{2}$ & 17,496 & 86 \\
\hline $\mathrm{NO}_{2}$ & 17,496 & 79 \\
\hline $\mathrm{NO}_{\mathrm{x}}$ & 17,496 & 72 \\
\hline $\mathrm{CO}$ & 17,496 & 74 \\
\hline $\mathrm{O}_{3}$ & 17,496 & 85 \\
\hline Wind Speed & 17,496 & 77 \\
\hline Temperature & 17,496 & 96 \\
\hline Relative Humidity & 17,496 & 96 \\
\hline Solar Radiation & 17,496 & 96 \\
\hline Barometric Pressure & 17,496 & 84 \\
\hline Rainfall & 17,496 & 96 \\
\hline Pollen & 17,496 & 52 \\
\hline Spores & 692 & 85 \\
\hline
\end{tabular}

Notes: NA = not applicable; ${ }^{a}$ Computed as $100 \%$ x number of valid observations / number of planned observations.

All of the 24-hr average $\mathrm{PM}_{2.5}$ and $\mathrm{PM}_{10}$ mass concentrations determined at the SCAMP ambient air monitoring sites using the FRMs for these species were greater than the detection limits of the methods. Table 15 summarizes the percentage of valid observations that were below the respective analytical LODs for each $\mathrm{PM}_{2.5}$ or $\mathrm{PM}_{10}$ chemical component measured at each SCAMP monitoring site. As shown in the table, a majority of components had only a small percentage (i.e. $<15 \%$ ) of non-detects. Noteworthy exceptions included $\mathrm{Cl}^{-}, \mathrm{Cr}$, and $\mathrm{Ti}$ in the water-extractable $\mathrm{PM}_{2.5}$ fraction. $\mathrm{PM}_{2.5}$ and $\mathrm{PM}_{10} \mathrm{Cl}^{-}$concentrations are presented in this report; however, results should be interpreted with caution because of the large number of observations below the LOD. Water-extractable $\mathrm{Cr}$, for which an overwhelming majority of observations were below the LOD, and water-extractable Ti, for which data completeness was poor and a substantial percentage of the few valid determinations were below the LOD, are not included in the analyses presented here.

Because SCAMP included the novel application of dynamic reaction cell ICP-MS to $\mathrm{PM}_{2.5}$ elemental analysis, the quality of the resulting elemental data is of particular interest. Quality indicators for the performance of the DRC ICP-MS in determining water-extractable element concentrations are shown in Table 16. As discussed above, water-extractable $\mathrm{Cr}$ and $\mathrm{Ti}$ were excluded from the analyses presented in this report because of poor data completeness and/or a large number of observations below the LOD. Water-extractable Si was also excluded from the analyses presented here because of high background concentrations, as shown in Table 16. For the remaining 18 elements, the method exhibited good short-term precision (<10\% relative standard deviation (RSD) among replicate determinations), acceptable long-term precision (< $25 \%$ RSD among replicate determinations), good accuracy (recovery of NIST 1643d was 
$100 \pm 10 \%$ for 15 elements), and small background concentrations (median solution blank $\leq 20 \%$ of median exposed filter determination).

Table 15. Summary of the percentage of valid PM and PM component observations at each of the SCAMP ambient air monitoring sites that were below the limits of detection.

\begin{tabular}{|c|c|c|c|c|c|c|c|}
\hline \multirow[b]{2}{*}{ Parameter } & \multicolumn{7}{|c|}{$\%$ of Valid Observations Below LOD } \\
\hline & \multicolumn{2}{|c|}{$\begin{array}{c}\text { Steubenville } \\
\mathrm{PM}_{2.5}\end{array}$} & $\begin{array}{c}\text { Steubenville } \\
\mathrm{PM}_{10}\end{array}$ & $\begin{array}{l}\text { North } \\
\mathrm{PM}_{2.5}\end{array}$ & $\begin{array}{l}\text { South } \\
\mathrm{PM}_{2.5}\end{array}$ & $\begin{array}{l}\text { East } \\
\mathrm{PM}_{2.5}\end{array}$ & $\begin{array}{l}\text { West } \\
\text { PM }_{2.5}\end{array}$ \\
\hline $\mathrm{SO}_{4}{ }^{2-}$ & \multicolumn{2}{|c|}{0} & 0 & 0 & 0 & 0 & 0 \\
\hline $\mathrm{NO}_{3}^{-}$ & \multicolumn{2}{|c|}{2} & 2 & 11 & 6 & 6 & 12 \\
\hline $\mathrm{Cl}^{-}$ & \multicolumn{2}{|c|}{40} & 16 & 60 & 40 & 60 & 55 \\
\hline $\mathrm{NH}_{4}^{+}$ & \multicolumn{2}{|c|}{1} & 1 & 0 & 0 & 0 & 0 \\
\hline EC & \multicolumn{2}{|c|}{1} & NA & NA & NA & NA & NA \\
\hline \multirow[t]{2}{*}{ OM } & \multicolumn{2}{|c|}{1} & NA & NA & NA & NA & NA \\
\hline & water $^{\mathrm{a}}$ & acid $^{b}$ & water $^{\mathrm{a}}$ & water $^{a}$ & water $^{\mathrm{a}}$ & water $^{a}$ & water $^{2}$ \\
\hline $\mathrm{Al}$ & 0 & 0 & 0 & 0 & 0 & 0 & 0 \\
\hline As & 0 & 7 & 0 & 0 & 0 & 1 & 0 \\
\hline $\mathrm{Ba}$ & 0 & 1 & 0 & 0 & 0 & 0 & 0 \\
\hline $\mathrm{Ca}$ & 0 & 6 & 0 & 0 & 0 & 0 & 0 \\
\hline $\mathrm{Cd}$ & 0 & 1 & 0 & 0 & 0 & 1 & 1 \\
\hline Co & 1 & 22 & 1 & 3 & 0 & 1 & 0 \\
\hline $\mathrm{Cr}$ & 75 & 0 & 73 & 73 & 90 & 76 & 90 \\
\hline $\mathrm{Cu}$ & 1 & 2 & 0 & 0 & 0 & 1 & 0 \\
\hline $\mathrm{Fe}$ & 4 & 0 & 8 & 8 & 4 & 3 & 4 \\
\hline $\mathrm{K}$ & 5 & 1 & 6 & 4 & 4 & 5 & 8 \\
\hline $\mathrm{Mg}$ & 0 & 0 & 0 & 0 & 0 & 0 & 0 \\
\hline $\mathrm{Mn}$ & 7 & 1 & 1 & 10 & 13 & 7 & 14 \\
\hline $\mathrm{Na}$ & 0 & NA & 0 & 0 & 0 & 0 & 0 \\
\hline $\mathrm{Ni}$ & 2 & 27 & 0 & 1 & 1 & 2 & 1 \\
\hline $\mathrm{Pb}$ & 0 & 0 & 1 & 0 & 0 & 2 & 1 \\
\hline $\mathrm{Se}$ & 0 & 1 & 0 & 0 & 0 & 2 & 1 \\
\hline $\mathrm{Si}$ & 2 & NA & 2 & 4 & 0 & 5 & 0 \\
\hline $\mathrm{Sn}$ & 5 & 1 & 17 & 9 & 2 & 6 & 1 \\
\hline $\mathrm{Ti}$ & 25 & 2 & 6 & 38 & 10 & 31 & 38 \\
\hline $\mathrm{V}$ & 3 & 1 & 5 & 2 & 1 & 4 & 5 \\
\hline $\mathrm{Zn}$ & 0 & 0 & 0 & 0 & 0 & 1 & 0 \\
\hline
\end{tabular}

Notes: NA = not applicable; ${ }^{a}$ Water-extractable $\mathrm{PM}_{2.5}$ fraction; ${ }^{\mathrm{b}}$ Acid-digestible $\mathrm{PM}_{2.5}$ fraction.

Table 16 presents data regarding the performance of the DRC ICP-MS method in determining acid-digestible element concentrations. Included among these data are estimates of the relative imprecision of the overall method (i.e., accounting for filter handling, digestion, and instrumental analysis) per element based on pairwise comparisons of determinations from duplicate filters, as well as estimates of the accuracy of the method, which was measured as the average recovery of elements in NIST SRM 2783 (air particulate on filter media). Imprecision data are not available for $\mathrm{Ba}, \mathrm{Co}$, and $\mathrm{Ni}$, because valid results were not obtained for these elements during the first sequence of analyses. Accuracy data are not available for $\mathrm{Cd}$, Se, and Sn, because no certified or reference values were provided by NIST for these elements. Based on the quality indicators shown in Table 16, Cr was excluded from the analyses presented in the remainder of this paper because of high field blank loadings (relative to exposed filter loadings) 
and poor accuracy (evidenced by an abnormally high recovery of SRM 2783). Performance of the DRC ICP-MS method for the remaining 18 elements was considered acceptable, especially given the low concentrations being measured. The method performed particularly well for As, $\mathrm{Cd}, \mathrm{Fe}, \mathrm{K}, \mathrm{Mg}, \mathrm{Mn}, \mathrm{Pb}, \mathrm{Se}$, and $\mathrm{Sn}$; these elements were characterized by few observations (< $10 \%$ ) below the analytical LOD (Table 4 ), low relative imprecisions $(<25 \%)$, low background concentrations (mean field blank loading $<25 \%$ of mean sample loading), and good accuracy where data were available (recovery of NIST SRM $2783=100 \pm 10 \%$ ). Aluminum also met these criteria; however, the elevated standard deviation for recovery of Al in the SRM indicates that results for this element tended to vary across instrument runs and reaction gas conditions.

Table 16. Quality indicators for the determination of elements in the water-extractable fraction of $\mathrm{PM}_{2.5}$ via DRC ICP-MS.

\begin{tabular}{|c|c|c|c|c|}
\hline Element & $\begin{array}{l}\text { Solution Blank as \% of } \\
\text { Exposed Filter } \\
\text { Determination (Based } \\
\text { on Median Values) }\end{array}$ & $\begin{array}{l}\text { Short-Term } \\
\text { Precision }^{\mathrm{a}} \\
\text { (\% RSD) }\end{array}$ & $\begin{array}{l}\text { Long-Term } \\
\text { Precision } \\
\text { (\% RSD) }\end{array}$ & $\begin{array}{c}\text { Accuracy }^{a} \\
\text { (\% Recovery of } \\
\text { NIST Water 1643d) }\end{array}$ \\
\hline $\mathrm{Al}$ & 2 & 4 & 4 & 95 \\
\hline As & 3 & 4 & 10 & 95 \\
\hline $\mathrm{Ba}$ & 3 & 3 & 4 & 101 \\
\hline $\mathrm{Ca}$ & 3 & 7 & 24 & 91 \\
\hline $\mathrm{Cd}$ & 2 & 3 & 1 & 96 \\
\hline Co & 17 & 2 & 2 & 99 \\
\hline $\mathrm{Cr}$ & 8 & 7 & 6 & 99 \\
\hline $\mathrm{Cu}$ & 11 & 3 & 11 & 98 \\
\hline $\mathrm{Fe}$ & 2 & 8 & 15 & 129 \\
\hline $\mathrm{K}$ & 2 & 6 & 11 & 107 \\
\hline $\mathrm{Mg}$ & 3 & 4 & 9 & 101 \\
\hline $\mathrm{Mn}$ & 1 & 5 & 6 & 106 \\
\hline $\mathrm{Na}$ & 7 & 2 & 21 & 103 \\
\hline $\mathrm{Ni}$ & 17 & 4 & 4 & 97 \\
\hline $\mathrm{Pb}$ & 1 & 3 & 5 & 98 \\
\hline $\mathrm{Se}$ & 0 & 8 & 9 & 86 \\
\hline $\mathrm{Si}$ & 110 & 3 & 4 & 102 \\
\hline $\mathrm{Sn}$ & 5 & NA & NA & NA \\
\hline $\mathrm{Ti}$ & NA & NA & NA & NA \\
\hline $\mathrm{V}$ & 1 & 6 & 9 & 95 \\
\hline $\mathrm{Zn}$ & 1 & 7 & 6 & 102 \\
\hline
\end{tabular}

Notes: NA = Not applicable; ${ }^{\mathrm{a}}$ Based upon replicate determinations of a 10x dilution of NIST Water 1643d over a period of 2 hours; ${ }^{b}$ Based upon replicate determinations of a 10x dilution of NIST Water 1643d on 3 different days.

FRM and TEOM monitors for measuring $\mathrm{PM}_{2.5}$ mass concentrations were collocated at the central Steubenville site throughout SCAMP, permitting an assessment of the performance of the TEOM relative to the FRM. The results of such a comparison were detailed by Connell et al. (2005c). For purposes of the comparison, hourly TEOM data were averaged over 24-hr periods corresponding to the FRM sampling schedule; 515 pairs of collocated measurements were included in the analysis. Both methods exhibited similar imprecisions, ranging from 0.0 to 4.2 $\mu \mathrm{g} / \mathrm{m}^{3}$ for the FRM sampler and from 1.7 to $4.0 \mu \mathrm{g} / \mathrm{m}^{3}$ for the TEOM monitor for FRMdetermined ambient $\mathrm{PM}_{2.5}$ concentrations of 6.6 to $43.2 \mu \mathrm{g} / \mathrm{m}^{3}$. (The FRM imprecisions estimated here from the comparison of the FRM sampler with the TEOM sampler are consistent 
with the FRM imprecision of $2.6 \mu \mathrm{g} / \mathrm{m}^{3}$ estimated above from the comparison of the FRM sampler with the multi-pollutant sampler). However, as shown in Figure 8, $\mathrm{PM}_{2.5}$ mass concentrations determined by the TEOM were substantially biased in the negative direction relative to those determined by the FRM. As discussed in Section 3.1.2.6, such a negative bias is expected when the TEOM is operated at $50^{\circ} \mathrm{C}$, because this temperature is sufficiently high to promote the loss of some semi-volatile material from the mass of $\mathrm{PM}_{2.5}$ that has accumulated on the TEOM filter. TEOM data collected as part of SCAMP were used for trending rather than for determining compliance with mass-based standards, and therefore were not corrected to account for this bias. Nevertheless, the bias should be considered when interpreting the results presented in this report; hourly average $\mathrm{PM}_{2.5}$ concentrations presented here are likely lower than true ambient concentrations.

Table 17. Quality indicators for the determination of elements in the acid-digestible fraction of $\mathrm{PM}_{2.5}$ via DRC ICP-MS.

\begin{tabular}{|c|c|c|c|c|}
\hline Element & $\begin{array}{l}\text { Field Blank as \% of } \\
\text { Exposed Filter } \\
\text { Determination }^{\mathrm{a}} \\
\end{array}$ & $\begin{array}{c}\text { Relative } \\
\text { Imprecision }^{\text {b }} \\
(\%) \\
\end{array}$ & $\begin{array}{c}\text { Recovery (S.D.) of } \\
\text { NIST SRM } 2783^{\mathrm{C}} \\
(\%) \\
\end{array}$ & \begin{tabular}{|c|} 
SRM 2783 \\
Blank as \% of Loaded \\
Filter Determination $^{\mathrm{a}}$ \\
\end{tabular} \\
\hline $\mathrm{Al}$ & 23.0 & 20.8 & $99 \quad(34)$ & 2 \\
\hline As & 6.6 & 21.9 & $110 \quad(7)$ & 9 \\
\hline $\mathrm{Ba}$ & 9.1 & NA & $104 \quad(11)$ & 2 \\
\hline $\mathrm{Ca}$ & 53.6 & 24.2 & $104 \quad(6)$ & 11 \\
\hline $\mathrm{Cd}$ & 4.2 & 21.5 & NA & NA \\
\hline Co & 51.5 & NA & $115 \quad(12)$ & -3 \\
\hline $\mathrm{Cr}$ & 84.8 & 26.2 & $163 \quad(4)$ & 50 \\
\hline $\mathrm{Cu}$ & 42.6 & 17.9 & $79 \quad(21)$ & 4 \\
\hline $\mathrm{Fe}$ & 7.2 & 19.2 & $97 \quad(12)$ & 0 \\
\hline $\mathrm{K}$ & 12.8 & 15.1 & $99 \quad(11)$ & 4 \\
\hline $\mathrm{Mg}$ & 16.5 & 22.1 & (5) & 2 \\
\hline $\mathrm{Mn}$ & 1.6 & 22.6 & 106 (NA) & 3 \\
\hline $\mathrm{Ni}$ & 9.5 & NA & $119 \quad(20)$ & 0 \\
\hline $\mathrm{Pb}$ & 21.9 & 21.8 & $101 \quad(5)$ & -1 \\
\hline $\mathrm{Se}$ & 14.5 & 16.8 & NA & NA \\
\hline Sn & 5.3 & 24.0 & NA & NA \\
\hline $\mathrm{Ti}$ & 52.8 & 21.3 & 71 (14) & 3 \\
\hline V & 35.0 & 33.6 & 84 (10) & 13 \\
\hline $\mathrm{Zn}$ & 28.9 & 18.7 & $108 \quad(8)$ & 4 \\
\hline
\end{tabular}

Notes: NA = Not available; ${ }^{\mathrm{a} B a s e d}$ on mean values; ${ }^{\mathrm{b}}$ Relative imprecision $=100 \cdot(\mathrm{RMSD} / \sqrt{2}) / \mathrm{mean}$, where RMSD is the root mean square difference between duplicate determinations (i.e., from separate analyses of co-collected primary and secondary filters) of a given element, and mean is the overall mean concentration of that element measured at Steubenville during SCAMP; 'Standard deviation values represent the variability among determinations of the same SRM 2783 digestate across different runs, isotopes, and/or reaction gas conditions. 


\subsection{2 $\mathrm{PM}_{2.5}$ and Co-Pollutant Concentrations at Steubenville}

\subsubsection{Overall Concentrations}

\subsubsection{1 $P M_{2.5}$ and $P M_{2.5}$ Chemical Components}

Table 18 presents summary statistics for 24-hr average $\mathrm{PM}_{2.5}$ mass concentrations measured using the Federal Reference Method monitor at the central Steubenville site, as well as for 24-hr average mass concentrations of $\mathrm{PM}_{2.5}$ chemical components determined at the central site. The overall mean $\mathrm{PM}_{2.5}$ mass concentration measured at Steubenville during SCAMP was 18.4 $\mu \mathrm{g} / \mathrm{m}^{3}$. Sulfate and organic material $(\mathrm{OM})$, which is estimated by multiplying the measured organic carbon mass concentration by a factor of 1.4 to account for the mass of elements such as $\mathrm{H}, \mathrm{O}$, and $\mathrm{N}$ that are associated with carbon in organic compounds, on average collectively accounted for over half of the total $\mathrm{PM}_{2.5}$ mass. Mean ambient air concentrations of these species were 5.8 and $4.5 \mu \mathrm{g} / \mathrm{m}^{3}$, respectively. Mean concentrations of fine particulate ammonium and nitrate were 2.3 and $1.16 \mu \mathrm{g} / \mathrm{m}^{3}$, respectively; all of the other measured $\mathrm{PM}_{2.5}$ components had average ambient air concentrations less than $1 \mu \mathrm{g} / \mathrm{m}^{3}$.

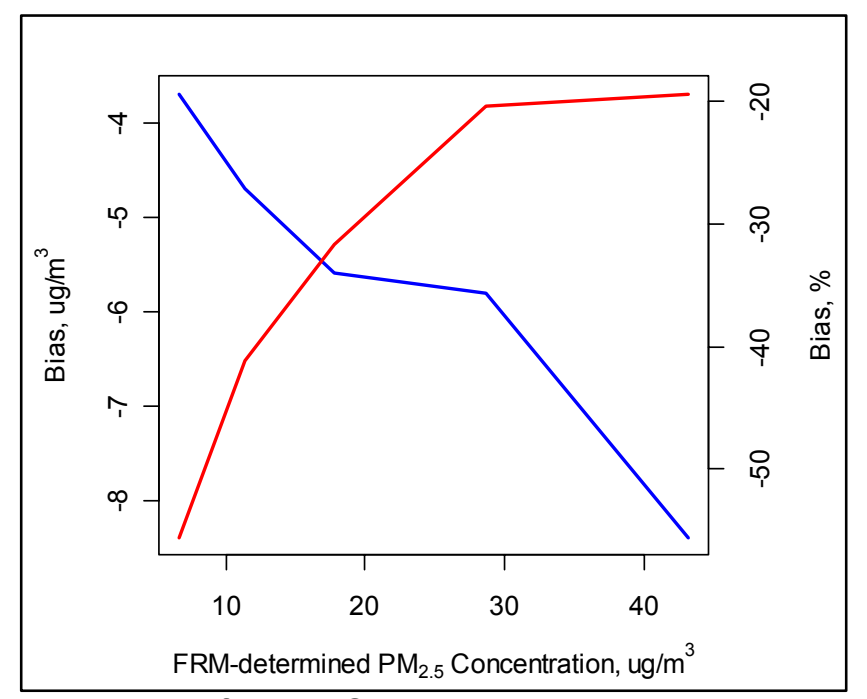

Figure 8. Bias of the TEOM monitor relative to the FRM monitor at the central Steubenville site, as a function of the FRM-determined $\mathrm{PM}_{2.5}$ concentration. The blue line represents bias in $\mu \mathrm{g} / \mathrm{m}^{3}$; the red line represents bias in \%.

It is important to note that mass concentrations of nitrate reported in Table 18 and throughout this report, which were determined from $\mathrm{PM}_{2.5}$ (or $\mathrm{PM}_{10}$ ) samples collected on Teflon filters using the FRM monitor, are likely lower than true ambient air concentrations. Biases for $\mathrm{NO}_{3}{ }^{-}$, as well as for other semi-volatile species such as $\mathrm{OC}$ and $\mathrm{NH}_{4}{ }^{+}$, have been described in the literature (Jansen et al., 2002). As reported by Connell et al. (2005a), $\mathrm{NO}_{3}^{-}$concentrations determined from FRM samples at Steubenville were on average $0.79 \mu \mathrm{g} / \mathrm{m}^{3}$ less than $\mathrm{NO}_{3}{ }^{-}$ concentrations determined from samples collected on nylon filters using a collocated speciation sampler equipped with a magnesium oxide denuder. However, because compliance with the NAAQS for $\mathrm{PM}_{2.5}$ is based upon measurements made using the FRM, concentrations determined using this method are of greater interest than true ambient concentrations when assessing the impact of $\mathrm{PM}_{2.5}$ components on a location's attainment status. Hence, the $\mathrm{NO}_{3}{ }^{-}$ concentrations determined from FRM samples are reported and used in the statistical analyses 
presented throughout this report. All of the other $\mathrm{PM}_{2.5}$ components presented here except for elemental and organic carbon were similarly determined from undenuded Teflon-filter-based samples. The carbonaceous species cannot be determined accurately from samples collected on Teflon filters; however, as stated the Experimental section, these species were collected without a denuder to better approximate FRM sampling conditions.

As evidenced by the standard deviations and ranges shown in Table 18, mass concentrations of $\mathrm{PM}_{2.5}$ and its components exhibited appreciable day-to-day variability at Steubenville during SCAMP. This variability is visually evident in Figure 9, which is a plot of the time series of daily $\mathrm{PM}_{2.5}$ concentrations at the central site. Twenty-four-hour average $\mathrm{PM}_{2.5}$ concentrations ranged from 2.7 to $64.8 \mu \mathrm{g} / \mathrm{m}^{3}$, with a coefficient of variation (100\% x standard deviation / mean) of $61 \%$. All but five of the $\mathrm{PM}_{2.5}$ components determined at the central site had coefficients of variation greater than this; the coefficients of variation ranged from $45 \%$ for acid-digestible Ca to $242 \%$ for $\mathrm{Cl}^{-}$. Mean concentrations were greater than median concentrations for $\mathrm{PM}_{2.5}$ and each of its components, reflecting the positively skewed distribution of these air pollutant concentrations and the effect of episodic occurrences of high concentrations on the means.

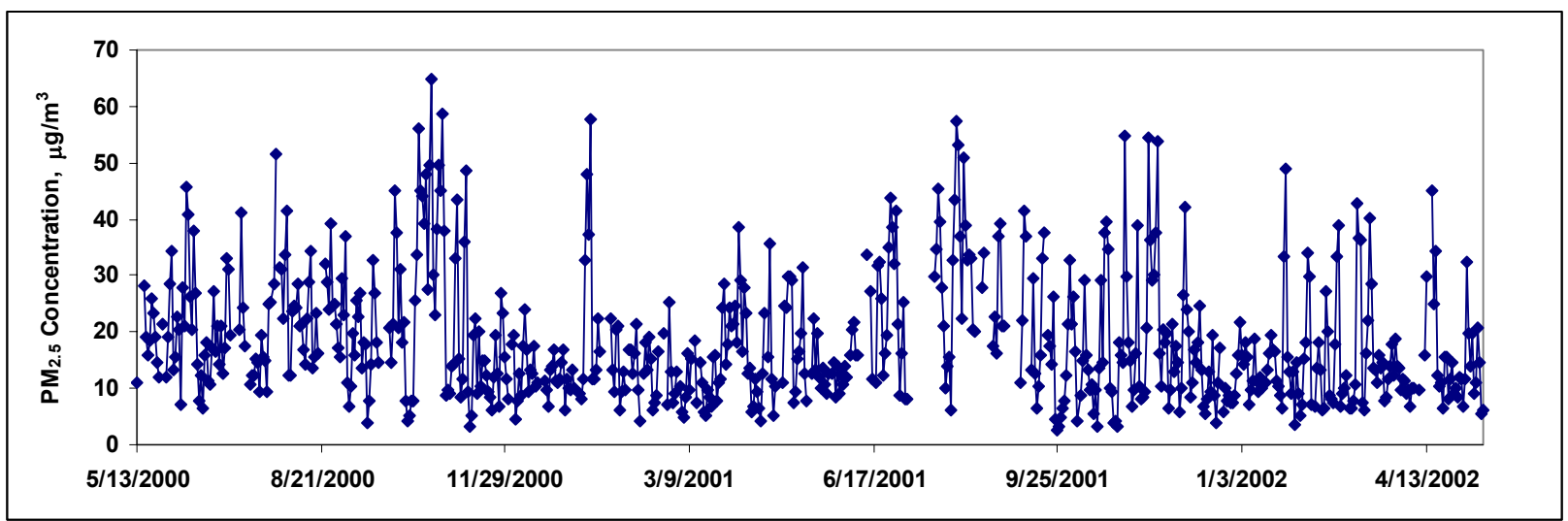

Figure 9. Time series of 24-hr average $\mathrm{PM}_{2.5}$ concentrations measured by the FRM at Steubenville.

In addition to measurements made using the FRM monitor, total $\mathrm{PM}_{2.5}$ mass concentrations were monitored continuously at the Steubenville site using a TEOM. Table 19 summarizes 1-hr and 24-hr average mass concentrations computed from these continuous measurements. As discussed earlier, $\mathrm{PM}_{2.5}$ concentrations measured using the TEOM exhibited an appreciable negative bias relative to those measured using the FRM because of losses of semi-volatile material from the TEOM. Hence, the $\mathrm{PM}_{2.5}$ concentrations reported in Table 19 are substantially lower than those reported in Table 18. Hourly $\mathrm{PM}_{2.5}$ concentrations measured using the TEOM ranged from $-9.0 \mu \mathrm{g} / \mathrm{m}^{3}$ to $139.6 \mu \mathrm{g} / \mathrm{m}^{3}$, with a mean of $12.7 \mu \mathrm{g} / \mathrm{m}^{3}$. Some valid $1-\mathrm{hr}$ average $\mathrm{PM}_{2.5}$ concentrations measured using the TEOM were negative, likely because the mass of accumulated $\mathrm{PM}_{2.5}$ lost from the filter due to volatilization exceeded the mass of newly collected $\mathrm{PM}_{2.5}$ during those measurement periods. Although negative concentrations clearly do not represent physical reality, they are consistent with the known bias of the TEOM, and were used in the analyses presented in this report, as removing them or forcing them to zero would bias the statistical results. Because hourly $\mathrm{PM}_{2.5}$ measurements capture intraday as well as interday variability, the coefficient of variation for the hourly measurements (98\%) was appreciably greater than that for the daily measurements at Steubenville. 
Table 18. Summary statistics for 24 -hr average $\mathrm{PM}_{2.5}$ and $\mathrm{PM}_{2.5}$ component mass concentrations $\left(\mu \mathrm{g} / \mathrm{m}^{3}\right)$ at the central Steubenville site.

\begin{tabular}{|c|c|c|c|c|c|c|c|c|c|}
\hline & $\mathbf{N}$ & Mean & S.D. & Min & Q25 & Q50 & Q75 & Max \\
\hline \multicolumn{2}{|c|}{$\mathrm{PM}_{2.5}$} & 640 & 18.4 & 11.2 & 2.7 & 10.1 & 15.3 & 23.3 & 64.8 \\
\hline \multicolumn{2}{|c|}{$\mathrm{NH}_{4}^{+}$} & 151 & 2.3 & 1.5 & 0.0 & 1.3 & 1.8 & 3.1 & 7.2 \\
\hline \multicolumn{2}{|c|}{$\mathrm{SO}_{4}{ }^{2-}$} & 151 & 5.8 & 4.1 & 1.0 & 2.8 & 4.4 & 7.3 & 23.4 \\
\hline \multicolumn{2}{|c|}{$\mathrm{NO}_{3}^{-}$} & 151 & 1.16 & 1.16 & 0.03 & 0.35 & 0.71 & 1.60 & 5.34 \\
\hline \multicolumn{2}{|l|}{$\mathrm{Cl}^{-}$} & 151 & 0.21 & 0.51 & 0.01 & 0.01 & 0.05 & 0.14 & 3.76 \\
\hline \multicolumn{2}{|l|}{ EC } & 142 & 0.84 & 0.75 & 0.00 & 0.37 & 0.67 & 1.02 & 4.62 \\
\hline \multicolumn{2}{|l|}{ OM } & 142 & 4.5 & 3.1 & 0.2 & 2.6 & 3.7 & 5.8 & 15.3 \\
\hline \multirow{2}{*}{ Al } & tot & 135 & 0.0977 & 0.0566 & 0.0297 & 0.0622 & 0.0808 & 0.1233 & 0.4117 \\
\hline & ws & 128 & 0.0187 & 0.0185 & 0.0013 & 0.0061 & 0.0132 & 0.0254 & 0.1243 \\
\hline \multirow{2}{*}{ As } & tot & 139 & 0.00164 & 0.00164 & 0.00016 & 0.00067 & 0.00120 & 0.00188 & 0.01056 \\
\hline & ws & 140 & 0.00259 & 0.00284 & 0.00030 & 0.00105 & 0.00195 & 0.00304 & 0.02227 \\
\hline \multirow{2}{*}{$\mathrm{Ba}$} & tot & 124 & 0.0023 & 0.0015 & 0.0003 & 0.0011 & 0.0020 & 0.0032 & 0.0085 \\
\hline & ws & 141 & 0.0019 & 0.0013 & 0.0004 & 0.0010 & 0.0016 & 0.0024 & 0.0086 \\
\hline \multirow{2}{*}{$\mathrm{Ca}$} & tot & 137 & 0.136 & 0.061 & 0.045 & 0.093 & 0.118 & 0.167 & 0.310 \\
\hline & ws & 111 & 0.078 & 0.051 & 0.010 & 0.044 & 0.061 & 0.105 & 0.241 \\
\hline \multirow{2}{*}{ Cd } & tot & 139 & 0.00046 & 0.00058 & 0.00001 & 0.00019 & 0.00030 & 0.00051 & 0.00589 \\
\hline & ws & 141 & 0.00051 & 0.00067 & 0.00004 & 0.00019 & 0.00036 & 0.00065 & 0.00716 \\
\hline \multirow{2}{*}{ Co } & tot & 122 & 0.000065 & 0.000047 & -0.000023 & 0.000031 & 0.000061 & 0.000091 & 0.000209 \\
\hline & ws & 142 & 0.000037 & 0.000021 & -0.000002 & 0.000024 & 0.000035 & 0.000049 & 0.000132 \\
\hline \multirow{2}{*}{$\mathrm{Cu}$} & tot & 130 & 0.0032 & 0.0018 & 0.0002 & 0.0019 & 0.0028 & 0.0040 & 0.0098 \\
\hline & ws & 124 & 0.0028 & 0.0027 & 0.0000 & 0.0013 & 0.0020 & 0.0036 & 0.0217 \\
\hline \multirow{2}{*}{$\mathrm{Fe}$} & tot & 139 & 0.272 & 0.308 & 0.024 & 0.087 & 0.173 & 0.294 & 1.530 \\
\hline & ws & 125 & 0.019 & 0.023 & 0.000 & 0.005 & 0.012 & 0.024 & 0.136 \\
\hline \multirow{2}{*}{ K } & tot & 134 & 0.091 & 0.055 & 0.022 & 0.055 & 0.073 & 0.114 & 0.261 \\
\hline & ws & 126 & 0.099 & 0.062 & 0.017 & 0.059 & 0.080 & 0.119 & 0.314 \\
\hline \multirow{2}{*}{ Mg } & tot & 138 & 0.047 & 0.048 & 0.009 & 0.020 & 0.032 & 0.057 & 0.389 \\
\hline & ws & 142 & 0.029 & 0.036 & 0.003 & 0.010 & 0.019 & 0.032 & 0.321 \\
\hline \multirow{2}{*}{ Mn } & tot & 139 & 0.0146 & 0.0154 & 0.0007 & 0.0050 & 0.0096 & 0.0174 & 0.0905 \\
\hline & ws & 133 & 0.0078 & 0.0080 & -0.0002 & 0.0025 & 0.0053 & 0.0098 & 0.0413 \\
\hline \multirow{2}{*}{$\mathrm{Na}$} & tot & NA & NA & NA & NA & NA & NA & NA & NA \\
\hline & ws & 115 & 0.090 & 0.074 & 0.016 & 0.045 & 0.069 & 0.108 & 0.501 \\
\hline \multirow{2}{*}{$\mathrm{Ni}$} & tot & 121 & 0.0011 & 0.0015 & -0.0003 & 0.0003 & 0.0007 & 0.0015 & 0.0081 \\
\hline & ws & 139 & 0.0006 & 0.0006 & 0.0000 & 0.0003 & 0.0005 & 0.0007 & 0.0045 \\
\hline \multirow{2}{*}{$\mathrm{Pb}$} & tot & 139 & 0.0153 & 0.0207 & 0.0021 & 0.0070 & 0.0105 & 0.0162 & 0.2183 \\
\hline & ws & 136 & 0.0090 & 0.0128 & 0.0004 & 0.0026 & 0.0053 & 0.0098 & 0.1216 \\
\hline So & tot & 132 & 0.00330 & 0.00321 & 0.00005 & 0.00149 & 0.00240 & 0.00420 & 0.02469 \\
\hline Se & ws & 137 & 0.00473 & 0.00493 & 0.00034 & 0.00194 & 0.00343 & 0.00573 & 0.03391 \\
\hline Sn & tot & 137 & 0.00136 & 0.00119 & 0.00015 & 0.00062 & 0.00097 & 0.00155 & 0.00597 \\
\hline SI & ws & 142 & 0.00022 & 0.00031 & -0.00002 & 0.00006 & 0.00011 & 0.00025 & 0.00235 \\
\hline $\mathrm{Ti}$ & tot & 121 & 0.0169 & 0.0206 & 0.0000 & 0.0089 & 0.0116 & 0.0177 & 0.1590 \\
\hline$\pi$ & ws & NA & NA & NA & NA & NA & NA & NA & NA \\
\hline & tot & 132 & 0.00150 & 0.00149 & 0.00009 & 0.00057 & 0.00106 & 0.00199 & 0.01102 \\
\hline V & ws & 143 & 0.00105 & 0.00133 & 0.00004 & 0.00025 & 0.00066 & 0.00117 & 0.00780 \\
\hline & tot & 139 & 0.0844 & 0.0814 & 0.0199 & 0.0409 & 0.0576 & 0.0898 & 0.4486 \\
\hline 2 & ws & 143 & 0.0555 & 0.0745 & 0.0029 & 0.0150 & 0.0280 & 0.0601 & 0.4355 \\
\hline
\end{tabular}

NOTE: tot $=$ concentration in the acid-digestible $\mathrm{PM}_{2.5}$ fraction, ws $=$ concentration in the water-soluble $\mathrm{PM}_{2.5}$ fraction 
Table 19. Summary statistics for 1 -hr and 24 -hr average $P M_{2.5}$ mass concentrations $\left(\mu \mathrm{g} / \mathrm{m}^{3}\right)$ measured at the central Steubenville site using a TEOM.

\begin{tabular}{|l|c|c|c|c|c|c|c|c|}
\hline & N & Mean & S.D. & Min & Q25 & Q50 & Q75 & Max \\
\hline 1-hr PM $_{\mathbf{2 . 5}}$ & 14682 & 12.7 & 12.5 & -9.0 & 4.3 & 8.6 & 17.0 & 139.6 \\
\hline 24-hr $\mathbf{P M}_{\mathbf{2 . 5}}$ & 590 & 12.6 & 9.7 & -0.1 & 5.7 & 9.6 & 16.6 & 53.9 \\
\hline
\end{tabular}

In light of recent findings suggesting that health effects, including asthma (Delfino et al, 1998) and myocardial infarction (Peters et al., 2001), are associated with short-term transient exposure to $\mathrm{PM}$, it is important to determine whether the 24-hr $\mathrm{PM}_{2.5}$ concentrations commonly used in epidemiology studies can serve as surrogates for shorter-term exposures. Chuersuwan et al. (2000) and Weber et al. (2003) reported that in Newark, NJ, and Atlanta, GA, respectively, short-term episodes of elevated $\mathrm{PM}_{2.5}$ concentrations were at times masked by the use of 24-hr average data. Connell et al. (2005c) analyzed the potential for such masking to occur at Steubenville using SCAMP data from the central site, and reported that 24-hr average concentrations generally indicated the potential for exposure to high 1-hr average concentrations, although there were some exceptions. For example, 5 days with 24-hr average $\mathrm{PM}_{2.5}$ concentrations $<30 \mu \mathrm{g} / \mathrm{m}^{3}$ had 1-hr maximum $\mathrm{PM}_{2.5}$ concentrations $>65 \mu \mathrm{g} / \mathrm{m}^{3}$. Figure 10 graphically illustrates another such exception by showing two days with very similar 24-hr average $\mathrm{PM}_{2.5}$ concentrations but very different hourly concentration profiles. Although such exceptions did not occur frequently at Steubenville, they should be considered when designing studies to differentiate among the effects of daily and shorter-term exposures to $\mathrm{PM}_{2.5}$.

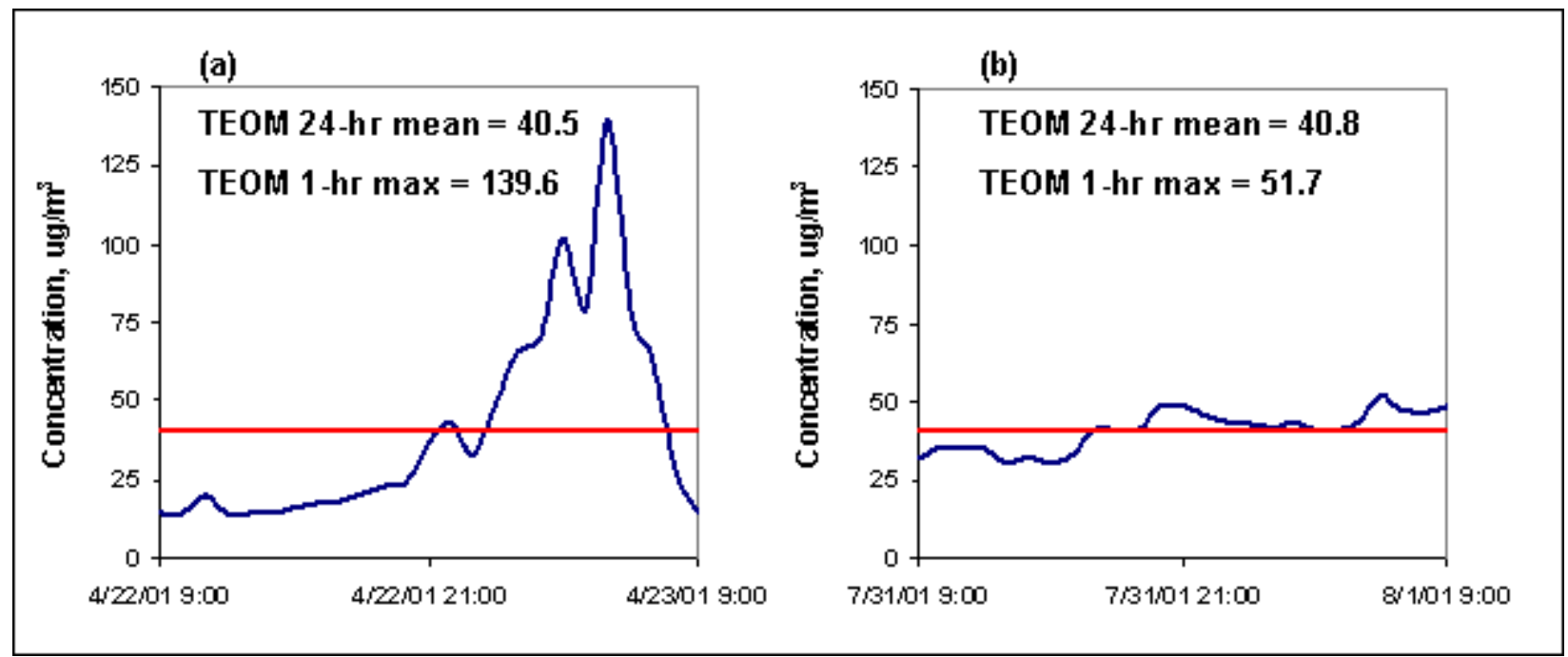

Figure 10. $\quad$ Case study showing two days at Steubenville with similar 24-hr average $\mathrm{PM}_{2.5}$ concentrations but different hourly $\mathrm{PM}_{2.5}$ concentration profiles, based on TEOM data from the central site. The blue line shows hourly average concentrations; the red line shows the 24-hr mean.

As described earlier and shown in Table 18, ambient air concentrations of a suite of trace and crustal elements were determined for both the acid-digestible and water-extractable fractions of $\mathrm{PM}_{2.5}$ samples collected at the Steubenville site. The water-extractability of $\mathrm{PM}_{2.5}$ trace elements is of interest to health effects researchers, because it provides some indication of their bioavailability. A number of recent PM toxicology studies (e.g., Fernandez et al., 2005; Frampton et al., 1999; Huang et al., 2003; Zelikoff et al., 2002) have reported associations between soluble transition metals and pulmonary health endpoints. Figure 11 summarizes the distribution of daily fractional solubilities (computed as the concentration determined in the 
water-extractable $\mathrm{PM}_{2.5}$ fraction divided by the concentration determined in the acid-digestible $\mathrm{PM}_{2.5}$ fraction on a given day) observed at Steubenville for the 17 elements for which valid concentrations were determined in both $\mathrm{PM}_{2.5}$ fractions during SCAMP. Fe was the most abundant but least water-extractable of the $\mathrm{PM}_{2.5}$ elements determined at Steubenville, having a mean ambient air concentration of $272 \mathrm{ng} / \mathrm{m}^{3}$ and a median fractional solubility of $6 \%$. Al and Sn were also largely insoluble, having median fractional solubilities of less than 0.2. Conversely, As, Ba, Cd, K, and Se were largely water-extractable from $\mathrm{PM}_{2.5}$ collected at Steubenville; these elements each had a median fractional solubility of greater than 0.8 . The data presented in Table 18 and Figure 11 indicate that concentrations of As and Se determined in the water-extractable fraction were frequently greater than concentrations determined in the acid-digestible fraction of $\mathrm{PM}_{2.5}$. This physical incongruity is likely due to a sampling or analytical error; however, as noted by Connell et al. (2006), pairwise concentrations measured in the water-extractable and acid-digestible fractions were well-correlated for each of these elements, suggesting that they are suitable for use in trending and source apportionment analyses.

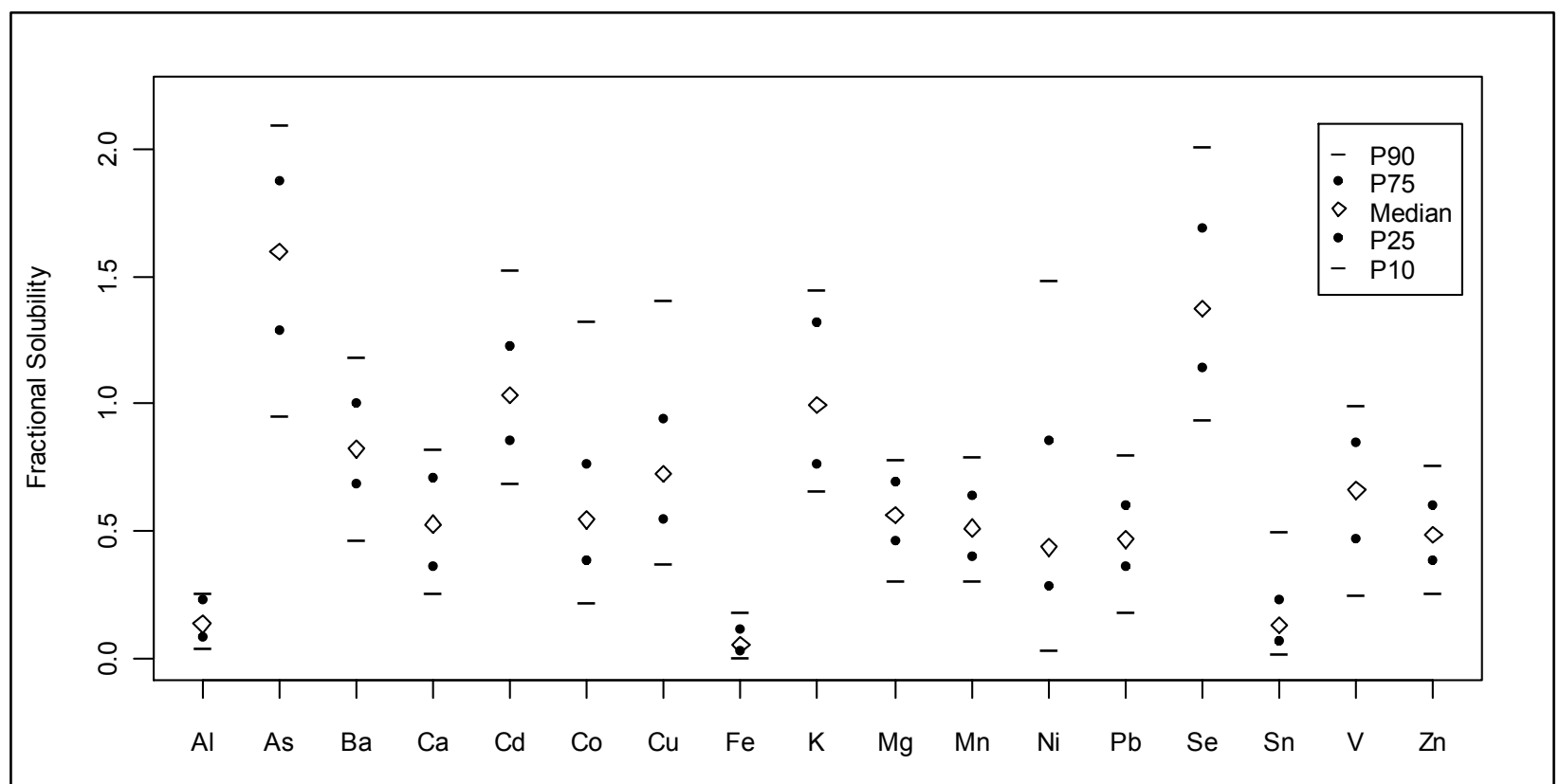

Figure 11. Distribution of daily fractional solubilities (defined in text) computed using 24-hr average $\mathrm{PM}_{2.5}$ water-extractable and acid-digestible element concentrations measured at the central Steubenville site.

Because 24-hr average $\mathrm{PM}_{2.5}$ chemical component mass concentrations at Steubenville were determined using several different sampling and analytical techniques, mass balances were performed to assess the extent to which these measurements accounted for the total $\mathrm{PM}_{2.5}$ mass determined by the FRM. In addition to providing an assessment of the quality of the $\mathrm{PM}_{2.5}$ speciation measurements made at the Steubenville site, the mass reconstruction process also provided a means for better evaluating the composition of $\mathrm{PM}_{2.5}$ on a percentage basis. (Because of missing values and variations in the sampling schedules for total $\mathrm{PM}_{2.5}$ mass concentrations and the mass concentrations of its chemical components, percentages computed using the means shown in Table 18 are only approximate). $\mathrm{PM}_{2.5}$ mass balances were performed using a modified version of the reconstructed fine mass (RCFM) formula 
commonly employed by Desert Research Institute (Tropp et al., 2003); the formula used in SCAMP is given by:

$\mathrm{RCFM}=\mathrm{SO}_{4}{ }^{2-}+\mathrm{NO}_{3}{ }^{-}+\mathrm{NH}_{4}{ }^{+}+\mathrm{OM}+\mathrm{EC}+(\mathrm{Na}+\mathrm{Cl})+$ Geological + Trace Elements,

where $\mathrm{OM}=1.4 \cdot \mathrm{OC}$, as discussed previously; $\mathrm{Na}+\mathrm{Cl}$ was computed as the sum of the measured masses of water-extractable $\mathrm{Na}$ and $\mathrm{Cl}^{-}$if data were available for water-extractable $\mathrm{Na}$, and as $1.6 \cdot \mathrm{Cl}^{-}$if water-extractable $\mathrm{Na}$ data were not available; Geological was computed as $1.89 \cdot \mathrm{Al}+2.14 \cdot \mathrm{Si}+1.4 \cdot \mathrm{Ca}+1.43 \cdot \mathrm{Fe}$ (the multipliers are used to account for the mass of oxides of these elements), and Trace Elements was computed as the sum of the masses of the 15 species other than $\mathrm{Al}, \mathrm{Ca}$, and Fe that were determined by DRC ICP-MS. Because Si data were not available from the central Steubenville site, the mass of Si was estimated as 1.52 . Al, where 1.52 is the ratio of the mass of fine particulate Si to the mass of fine particulate Al measured in Steubenville during the Six Cities Study (Laden et al., 2000).

There were 109 days for which valid data were available for all of the $\mathrm{PM}_{2.5}$ components required to compute RCFM. (Because their contribution to total $P_{2.5}$ mass is very small, it was not required that all trace element species be present). Table 20 summarizes the overall $P_{2.5}$ composition at Steubenville during these days. Figure 12 shows the distribution of daily mass balance closures (computed as 100\% - RCFM / FRM Mass), both overall and by astronomical season. The median daily mass balance closure was $90.3 \%$, with minimum and maximum values of 63.0 and $119.6 \%$, and $25^{\text {th }}$ and $75^{\text {th }}$ percentiles of $85.0 \%$ and $96.1 \%$. The underestimation of total $\mathrm{PM}_{2.5}$ mass on average is expected and is likely due in part to the presence of species such as particle-bound water and compounds of trace elements that were not measured. Moreover, the multipliers used to estimate OM from OC and Si from Al for inclusion in the RCFM formula may be low. Turpin and Lim (2001) suggest a factor of 1.4-1.8 for estimating the average molecular weight per carbon weight for urban organic aerosols, and an even greater factor for non-urban aerosols. If a factor of 1.8 is used in the RCFM formula for SCAMP, the median daily mass balance closure increases to $97.7 \%$. In addition, the Si/Al ratio of 1.52 derived from the Laden et al. (2000) data is substantially less than the ratio of 3.41 derived from crustal averages reported by Mason (1966). Use of this larger ratio further increases the median mass balance closure to $100.3 \%$.

Table 20. Overall composition of $\mathrm{PM}_{2.5}$ at Steubenville, based on 109 days with complete or nearly complete $\mathrm{PM}_{2.5}$ speciation data.

\begin{tabular}{|c|c|}
\hline Component & Percent $(\mathbf{w} / \mathbf{w})$ of Total $\mathbf{P M}_{\mathbf{2 . 5}}$ Mass \\
\hline Sulfate & 30.4 \\
\hline Nitrate & 6.7 \\
\hline Ammonium & 12.5 \\
\hline Organic Material $^{-1}$ & 25.7 \\
\hline Elemental Carbon & 4.8 \\
\hline $\mathrm{Na}^{-} \mathrm{Cl}^{-}$ & 1.9 \\
\hline Geological & 6.3 \\
\hline Trace Elements & 1.6 \\
\hline Unidentified & 10.0 \\
\hline
\end{tabular}




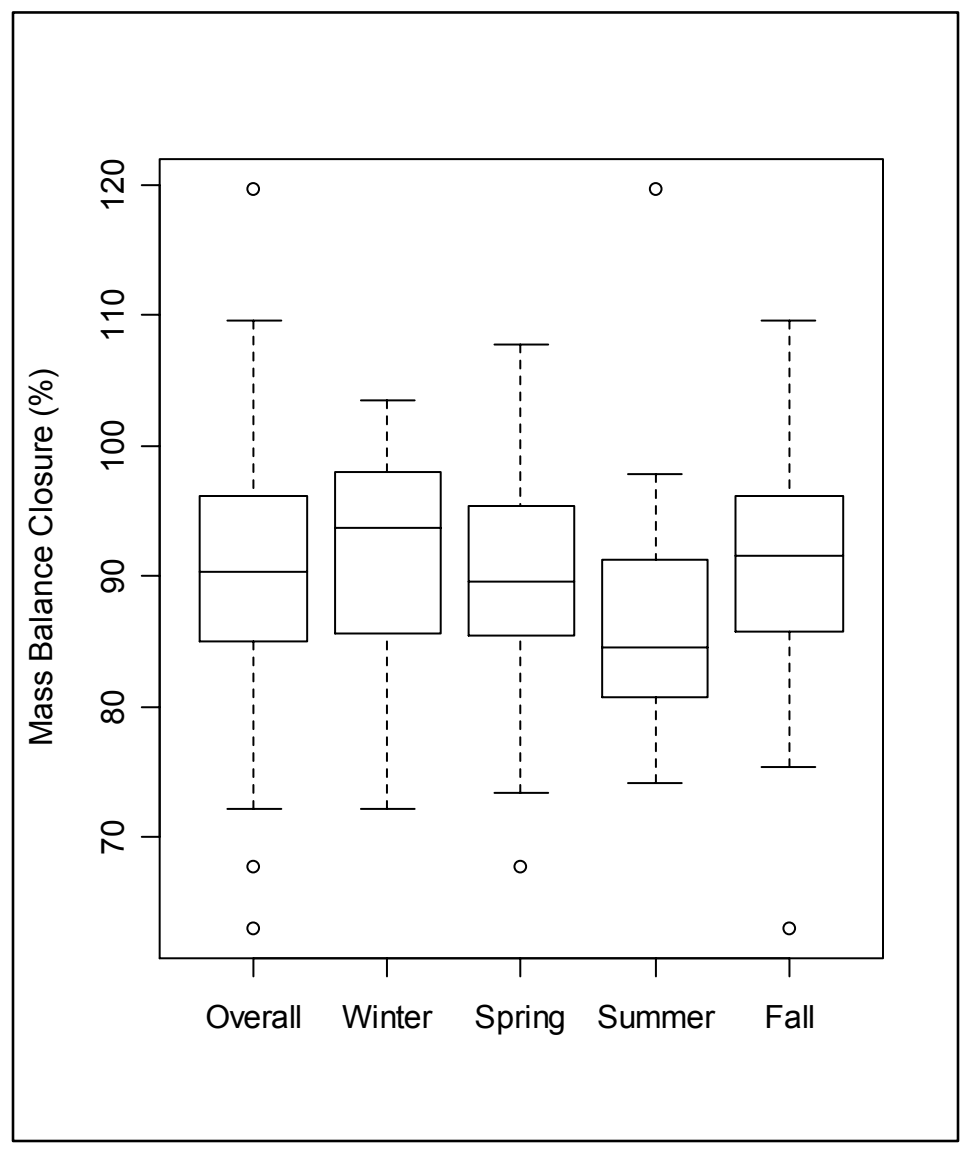

Figure 12. Daily $\mathrm{PM}_{2.5}$ mass balance closures at the central Steubenville site, overall and by season.

\subsubsection{2 $P M_{10}$ and $P M_{10}$ Chemical Components}

Table 21 presents summary statistics for 24-hr average mass concentrations of $\mathrm{PM}_{10}$ and its chemical components determined at the central Steubenville site. Figure 13 shows the time series of daily $\mathrm{PM}_{10}$ mass concentrations measured during SCAMP. The overall mean $\mathrm{PM}_{10}$ mass concentration observed between May 2000 and May 2002 as part of SCAMP was 27.4 $\mu \mathrm{g} / \mathrm{m}^{3}$. Daily average $\mathrm{PM}_{10}$ concentrations ranged from 4.9 to $102.2 \mu \mathrm{g} / \mathrm{m}^{3}$, with a coefficient of variation of $58 \%$. Sulfate was the most abundant of the $\mathrm{PM}_{10}$ chemical components that were measured $\left(\mathrm{OM}\right.$, the second most abundant component of $\mathrm{PM}_{2.5}$, was not measured for $\mathrm{PM}_{10}$ as part of SCAMP), having a mean ambient air concentration of $6.2 \mu \mathrm{g} / \mathrm{m}^{3}$ (about $22.6 \%$ of the total $\mathrm{PM}_{10}$ mass concentration). Coefficients of variation for $\mathrm{PM}_{10}$ components ranged from $49 \%$ for water-soluble $\mathrm{K}$ to $194 \%$ for water-soluble $\mathrm{Pb}$. 


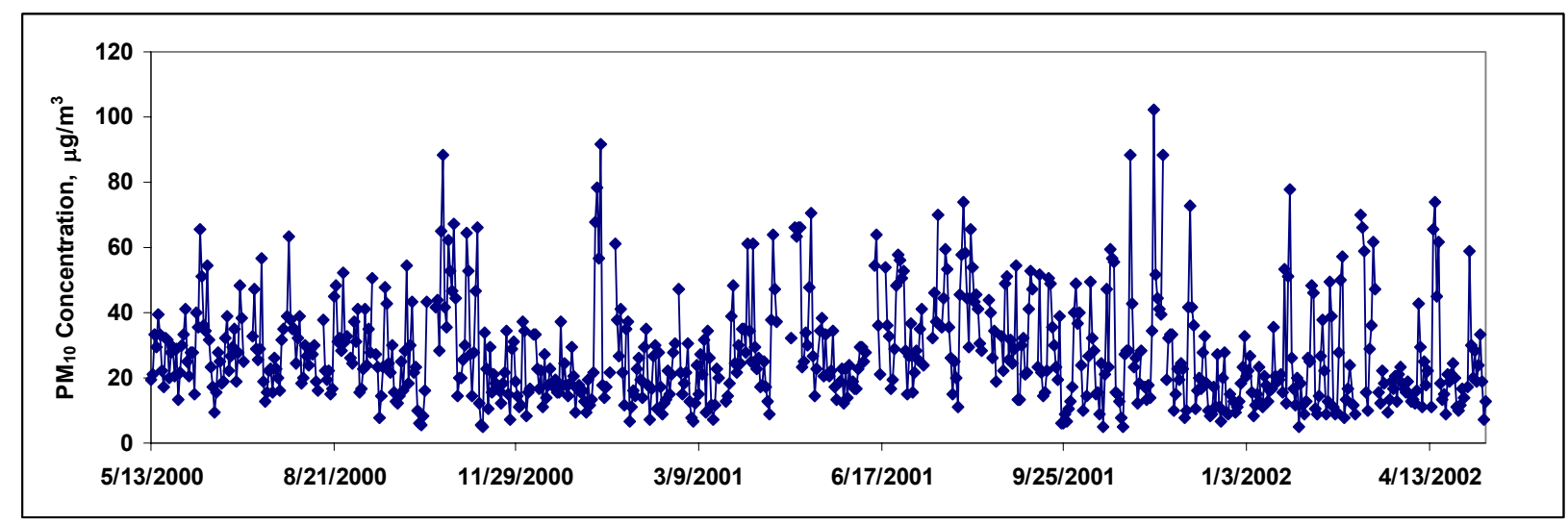

Figure 13. Time series of 24-hr average $\mathrm{PM}_{10}$ concentrations measured by the FRM at Steubenville.

$\mathrm{PM}_{10}$ includes $\mathrm{PM}_{2.5}$, as well as coarser particles with diameters between about 2.5 and $10 \mu \mathrm{m}$. Hence, in order to permit an assessment of the extent to which the mass and composition of $\mathrm{PM}_{10}$ at Steubenville is attributable to $\mathrm{PM}_{2.5}$, Table 21 includes quartiles summarizing the daily ratios of the masses of $P M$ and $P M$ components in the $P_{2.5}$ fraction to those in the $P M_{10}$ fraction. $\mathrm{PM}_{2.5}$ typically accounted for $58-77 \%$ (interquartile range) of the mass of $\mathrm{PM}_{10}$ at Steubenville. Median ratios of concentrations of $\mathrm{NH}_{4}{ }^{+}, \mathrm{SO}_{4}{ }^{2-}$, and water-extractable $\mathrm{As}, \mathrm{Cd}, \mathrm{Cu}$, Se, and $V$ in $\mathrm{PM}_{2.5}$ to concentrations of these species in $\mathrm{PM}_{10}$ were $1 \pm 0.1$, suggesting that they are predominantly present in the fine fraction. Water-extractable $\mathrm{Pb}$ and $\mathrm{Sn}$ had median daily $\mathrm{PM}_{2.5} / \mathrm{PM}_{10}$ ratios substantially greater than 1 , likely because of sampling or analytical error. Conversely, median $\mathrm{PM}_{2.5} / \mathrm{PM}_{10}$ ratios for $\mathrm{Cl}^{-}$and water-extractable $\mathrm{Ba}, \mathrm{Ca}, \mathrm{Co}, \mathrm{Mg}$, and $\mathrm{Mn}$ were $<0.5$, suggesting that at least half of their total concentration in $\mathrm{PM}_{10}$ is contributed by the coarse fraction.

\subsection{Co-Pollutants}

Table 22 summarizes $1-\mathrm{hr}$ and 24-hr gaseous pollutant concentrations computed from continuous monitoring data collected at the central Steubenville site. Mean gaseous pollutant concentrations ranged from $6.8 \mathrm{ppb}$ for $\mathrm{NO}$ to $0.30 \mathrm{ppm}$ for $\mathrm{CO}$. Coefficients of variation were $45 \%\left(\mathrm{O}_{3}\right)$ to $137 \%$ (NO) for daily data, and $69 \%\left(\mathrm{O}_{3}\right)$ to $219 \%(\mathrm{NO})$ for hourly data. As with $\mathrm{PM}_{2.5}$ and $\mathrm{PM}_{10}$, mean concentrations were greater than median concentrations, reflecting the effect of episodic occurrences of high concentrations on the mean. Negative values were obtained for several gas observations that otherwise met all validation criteria, indicating that ambient concentrations were smaller than instrument noise during the periods in which these measurements were made. As with $\mathrm{PM}_{2.5}$ TEOM data, these negative values were used in the analyses presented in this report, because adjusting them would introduce bias. 
Table 21. Summary statistics for 24-hr average mass concentrations of $\mathrm{PM}_{10}$ and water-extractable $\mathrm{PM}_{10}$ components $\left(\mu \mathrm{g} / \mathrm{m}^{3}\right)$ at the central

Steubenville site. Also shown are quartiles summarizing the distribution of daily ratios of the mass of PM and water-soluble PM components in the $\mathrm{PM}_{2.5}$ fraction to the mass of these species in the $\mathrm{PM}_{10}$ fraction.

\begin{tabular}{|c|c|c|c|c|c|c|c|c|c|c|c|c|}
\hline & \multicolumn{8}{|c|}{$\mathrm{PM}_{10}$ Summary Statistics } & \multicolumn{4}{|c|}{$\mathrm{PM}_{2.5} / \mathrm{PM}_{10}$ Summary Statistics } \\
\hline & $\mathbf{N}$ & Mean & S.D. & Min & Q25 & Q50 & Q75 & Max & $\mathbf{N}$ & Q25 & Q50 & Q75 \\
\hline $\mathbf{P M}_{10}$ & 676 & 27.4 & 15.9 & 4.9 & 15.8 & 23.1 & 34.7 & 102.2 & 610 & 0.58 & 0.68 & 0.77 \\
\hline $\mathrm{NH}_{4}^{+}$ & 161 & 2.2 & 1.4 & 0.0 & 1.2 & 1.9 & 2.8 & 8.5 & 141 & 0.94 & 1.03 & 1.11 \\
\hline $\mathrm{SO}_{4}{ }^{2-}$ & 161 & 6.2 & 4.5 & 1.2 & 3.1 & 5.2 & 7.8 & 31.8 & 141 & 0.86 & 0.94 & 1.00 \\
\hline $\mathrm{NO}_{3}^{-}$ & 161 & 1.76 & 1.45 & 0.03 & 0.68 & 1.25 & 2.42 & 6.55 & 141 & 0.42 & 0.61 & 0.76 \\
\hline $\mathrm{Cl}^{-}$ & 161 & 0.38 & 0.64 & 0.01 & 0.06 & 0.16 & 0.38 & 4.67 & 141 & 0.20 & 0.49 & 1.00 \\
\hline $\mathrm{Al}$ & 126 & 0.0280 & 0.0266 & 0.0017 & 0.0098 & 0.0184 & 0.0351 & 0.1446 & 116 & 0.34 & 0.51 & 1.00 \\
\hline As & 142 & 0.00222 & 0.00182 & 0.00017 & 0.00113 & 0.00176 & 0.00266 & 0.01242 & 129 & 0.93 & 1.06 & 1.27 \\
\hline $\mathrm{Ba}$ & 144 & 0.0064 & 0.0045 & 0.0008 & 0.0033 & 0.0052 & 0.0079 & 0.0247 & 130 & 0.26 & 0.30 & 0.36 \\
\hline $\mathrm{Ca}$ & 106 & 0.517 & 0.327 & 0.036 & 0.284 & 0.508 & 0.655 & 1.744 & 95 & 0.11 & 0.13 & 0.20 \\
\hline $\mathrm{Cd}$ & 144 & 0.00054 & 0.00079 & 0.00004 & 0.00021 & 0.00037 & 0.00064 & 0.00861 & 130 & 0.81 & 0.96 & 1.09 \\
\hline Co & 144 & 0.000079 & 0.000048 & -0.000002 & 0.000044 & 0.000071 & 0.000106 & 0.000271 & 131 & 0.40 & 0.49 & 0.58 \\
\hline $\mathrm{Cu}$ & 114 & 0.0030 & 0.0035 & 0.0000 & 0.0013 & 0.0022 & 0.0039 & 0.0315 & 108 & 0.66 & 0.93 & 1.26 \\
\hline $\mathrm{Fe}$ & 127 & 0.023 & 0.038 & 0.000 & 0.005 & 0.011 & 0.023 & 0.300 & 112 & 0.55 & 0.82 & 1.52 \\
\hline $\mathrm{K}$ & 124 & 0.106 & 0.052 & 0.016 & 0.070 & 0.100 & 0.133 & 0.309 & 113 & 0.70 & 0.87 & 1.10 \\
\hline Mg & 144 & 0.124 & 0.108 & 0.005 & 0.057 & 0.097 & 0.149 & 0.735 & 131 & 0.15 & 0.21 & 0.29 \\
\hline$M n$ & 135 & 0.0214 & 0.0216 & 0.0004 & 0.0080 & 0.0145 & 0.0305 & 0.1660 & 120 & 0.25 & 0.39 & 0.51 \\
\hline $\mathrm{Na}$ & 113 & 0.237 & 0.314 & 0.019 & 0.073 & 0.107 & 0.234 & 1.689 & 104 & 0.39 & 0.58 & 0.78 \\
\hline $\mathrm{Ni}$ & 138 & 0.0010 & 0.0015 & 0.0001 & 0.0004 & 0.0007 & 0.0011 & 0.0141 & 126 & 0.50 & 0.71 & 1.00 \\
\hline $\mathbf{P b}$ & 137 & 0.0057 & 0.0111 & 0.0000 & 0.0011 & 0.0028 & 0.0063 & 0.1147 & 125 & 1.07 & 1.49 & 3.20 \\
\hline Se & 137 & 0.00453 & 0.00468 & 0.00033 & 0.00182 & 0.00324 & 0.00551 & 0.02885 & 124 & 0.95 & 1.08 & 1.24 \\
\hline Sn & 144 & 0.00015 & 0.00022 & 0.00000 & 0.00003 & 0.00008 & 0.00018 & 0.00143 & 130 & 1.00 & 1.57 & 2.51 \\
\hline $\mathbf{v}$ & 145 & 0.00118 & 0.00148 & 0.00003 & 0.00031 & 0.00068 & 0.00156 & 0.01135 & 132 & 0.61 & 0.93 & 1.11 \\
\hline$Z n$ & 145 & 0.0623 & 0.0732 & 0.0039 & 0.0203 & 0.0374 & 0.0699 & 0.4601 & 132 & 0.71 & 0.84 & 0.94 \\
\hline
\end{tabular}


Table 22. Summary statistics for $1-\mathrm{hr}$ and $24-\mathrm{hr}$ average gas concentrations measured at the central Steubenville site.

\begin{tabular}{|c|c|c|c|c|c|c|c|c|c|}
\hline & & $\mathbf{N}$ & Mean & S.D. & Min & Q25 & Q50 & Q75 & Max \\
\hline \multirow{2}{*}{$\begin{array}{l}\mathrm{SO}_{2} \\
(\mathrm{ppb})\end{array}$} & 1-hr & 14969 & 10.6 & 14.0 & 0.4 & 2.9 & 6.0 & 12.4 & 233.9 \\
\hline & 24-hr & 624 & 10.5 & 8.4 & 1.3 & 5.0 & 8.2 & 12.9 & 60.1 \\
\hline \multirow{2}{*}{$\begin{array}{l}\text { NO } \\
(p p b)\end{array}$} & 1-hr & 13857 & 6.8 & 14.9 & -1.4 & 0.3 & 1.2 & 4.9 & 215.3 \\
\hline & 24-hr & 569 & 6.8 & 9.3 & 0.1 & 1.3 & 3.3 & 8.1 & 71.5 \\
\hline \multirow{2}{*}{$\begin{array}{l}\mathrm{NO}_{2}{ }^{\mathrm{a}} \\
(\mathrm{ppb})\end{array}$} & 1-hr & 12562 & 12.7 & 8.9 & -0.5 & 5.6 & 10.1 & 18.0 & 52.9 \\
\hline & 24-hr & 504 & 12.7 & 5.8 & 1.9 & 8.3 & 11.8 & 16.4 & 33.1 \\
\hline \multirow{2}{*}{$\begin{array}{l}\mathrm{NO}_{\mathrm{x}} \\
(\mathrm{ppb})\end{array}$} & 1-hr & 12952 & 18.8 & 19.8 & -0.8 & 6.4 & 11.5 & 23.5 & 196.9 \\
\hline & 24-hr & 525 & 18.8 & 12.8 & 2.4 & 9.9 & 15.3 & 23.4 & 102.6 \\
\hline \multirow{2}{*}{$\begin{array}{l}\text { CO } \\
\text { (ppm) }\end{array}$} & 1-hr & 14881 & 0.30 & 0.58 & -0.19 & 0.05 & 0.13 & 0.29 & 8.09 \\
\hline & 24-hr & 620 & 0.30 & 0.35 & -0.08 & 0.10 & 0.20 & 0.36 & 2.73 \\
\hline \multirow{2}{*}{$\begin{array}{l}\mathrm{O}_{3} \\
\text { (ppb) }\end{array}$} & 1-hr & 13482 & 27.9 & 19.2 & -0.4 & 12.1 & 25.7 & 39.5 & 104.3 \\
\hline & 24-hr & 580 & 28.0 & 12.6 & 2.4 & 19.3 & 26.6 & 35.5 & 77.0 \\
\hline
\end{tabular}

${ }^{\mathrm{a}}$ Computed by differencing measured $\mathrm{NO}_{\mathrm{x}}$ and $\mathrm{NO}$ concentrations.

Tables 23 and 24 summarize daily counts of spores and pollen, respectively, from the central site. For each type of pollen and spore, the tables show both the total number of daily observations and the number of daily observations with nonzero counts, as there were a considerable number of days for which certain types were not found on the tape from the Burkard sampler. Only four of the spore types (ascospores, basidiospores, cladosporium, and smut/myxo/periconia) were present on greater than $75 \%$ of the days studied; each of the specific pollen types was observed in $30 \%$ of the samples or less. Hence, because of statistical limitations related to the presence of large numbers of non-detects, the trending and correlation analyses presented in the rest of this paper will be limited to the four prevalent spore types, total spores, and total pollen.

\subsubsection{Temporal Trends}

Temporal trends in ambient concentrations of $\mathrm{PM}_{2.5}$ and co-pollutants are induced by temporal trends in factors, such as anthropogenic activities, biogenic activities, and meteorological conditions, that affect these concentrations. Hence, characterizing seasonal, day-of-week, and diurnal trends can provide insight into factors that influence ambient pollutant concentrations, which can prove valuable when developing ways to reduce these concentrations. Moreover, the characterization of temporal trends in pollutant concentrations is important for health effects research, as epidemiological models must be designed to appropriately account for these trends (e.g., to prevent confounding by season), and the potential for exposure to elevated concentrations of ambient pollutants is dependent upon the interaction between the temporal patterns exhibited by these pollutants and temporal patterns of human activity. This section characterizes seasonal, day-of-week, and diurnal trends exhibited by $\mathrm{PM}_{2.5}$ and co-pollutants at the central ambient air monitoring site in Steubenville during SCAMP. 
Table 23. Summary statistics for $24-\mathrm{hr}$ average spore counts $\left(\right.$ number $/ \mathrm{m}^{3}$ ) at the central Steubenville site.

\begin{tabular}{|l|l|r|r|r|r|r|r|r|r|}
\hline Species & $\mathbf{N}$ & $\mathbf{N}_{\text {nonzero }}$ & Mean & S.D. & Min & Q25 & Q50 & Q75 & Max \\
\hline Alternaria & 599 & 386 & 52.6 & 84.9 & 0 & 0 & 11 & 75 & 652 \\
\hline Ascospores & 599 & 557 & 1482.1 & 2794.7 & 0 & 64 & 417 & 1551 & 22929 \\
\hline Basidiospores & 599 & 591 & 3200.7 & 4646.4 & 0 & 139 & 1059 & 4663 & 35784 \\
\hline Botrytis & 599 & 146 & 9.9 & 27.5 & 0 & 0 & 0 & 0 & 278 \\
\hline Cercospora & 599 & 23 & 0.9 & 5.6 & 0 & 0 & 0 & 0 & 75 \\
\hline Chaetomium & 599 & 39 & 0.8 & 3.6 & 0 & 0 & 0 & 0 & 53 \\
\hline Cladosporium & 599 & 583 & 1372.7 & 1843.7 & 0 & 128 & 567 & 2091 & 12598 \\
\hline Curvularia & 599 & 80 & 2.1 & 6.3 & 0 & 0 & 0 & 0 & 64 \\
\hline Drechs/Helminth/Bipolaris & 599 & 79 & 1.7 & 5.0 & 0 & 0 & 0 & 0 & 32 \\
\hline Epicoccum & 599 & 367 & 34.0 & 65.8 & 0 & 0 & 11 & 43 & 674 \\
\hline Fusarium & 599 & 5 & 0.2 & 3.4 & 0 & 0 & 0 & 0 & 75 \\
\hline Hyaline Conidia & 599 & 365 & 84.6 & 154.3 & 0 & 0 & 21 & 107 & 1283 \\
\hline Penicillium/Aspergillus & 599 & 6 & 1.5 & 21.7 & 0 & 0 & 0 & 0 & 493 \\
\hline Peronospora & 599 & 13 & 0.6 & 6.5 & 0 & 0 & 0 & 0 & 118 \\
\hline Pestalotia & 599 & 88 & 2.6 & 7.9 & 0 & 0 & 0 & 0 & 75 \\
\hline Pithomyces & 599 & 182 & 10.9 & 27.7 & 0 & 0 & 0 & 11 & 332 \\
\hline Polythrincium & 599 & 141 & 5.7 & 14.4 & 0 & 0 & 0 & 0 & 139 \\
\hline Rusts & 599 & 161 & 10.3 & 30.2 & 0 & 0 & 0 & 11 & 353 \\
\hline Smut/Myxo/Periconia & 599 & 463 & 82.2 & 146.7 & 0 & 11 & 32 & 91 & 1208 \\
\hline Stachybotrys & 599 & 1 & 0.1 & 1.3 & 0 & 0 & 0 & 0 & 32 \\
\hline Torula & 599 & 65 & 2.7 & 14.4 & 0 & 0 & 0 & 0 & 267 \\
\hline Ulocladium & 599 & 7 & 0.3 & 3.1 & 0 & 0 & 0 & 0 & 64 \\
\hline Unidentified Spores & 599 & 37 & 1.8 & 9.5 & 0 & 0 & 0 & 0 & 131 \\
\hline Hyphal Fragments & 599 & 6 & 0.4 & 4.5 & 0 & 0 & 0 & 0 & 87 \\
\hline Other Spores & 599 & 240 & 12.3 & 49.8 & 0 & 0 & 0 & 11 & 898 \\
\hline Total Spores & 599 & 599 & 6373.5 & 7832.2 & 32 & 551 & 3101 & 9711 & 44596 \\
\hline & & & & & & & & & \\
\hline
\end{tabular}


Table 24. Summary statistics for $24-\mathrm{hr}$ average pollen counts (number $/ \mathrm{m}^{3}$ ) at the central Steubenville site.

\begin{tabular}{|l|l|r|r|r|r|r|r|r|r|}
\hline Species & $\mathbf{N}$ & $\mathbf{N}_{\text {nonzero }}$ & Mean & S.D. & Min & Q25 & Q50 & Q75 & Max \\
\hline Ambrosia/Franseria & 586 & 140 & 6.3 & 20.4 & 0 & 0 & 0 & 0 & 171 \\
\hline Betulaceae & 586 & 73 & 2.7 & 20.0 & 0 & 0 & 0 & 0 & 441 \\
\hline Carya & 586 & 65 & 1.1 & 4.5 & 0 & 0 & 0 & 0 & 70 \\
\hline Chenopod/Amaranth & 586 & 36 & 0.2 & 1.0 & 0 & 0 & 0 & 0 & 13 \\
\hline Compositae & 586 & 3 & 0.0 & 0.2 & 0 & 0 & 0 & 0 & 3 \\
\hline Cupressaceae & 586 & 88 & 1.8 & 12.1 & 0 & 0 & 0 & 0 & 243 \\
\hline Cyperaceae & 586 & 0 & 0.0 & 0.0 & 0 & 0 & 0 & 0 & 0 \\
\hline Fagus & 586 & 7 & 0.1 & 0.6 & 0 & 0 & 0 & 0 & 11 \\
\hline Fraxinus & 586 & 60 & 6.8 & 65.3 & 0 & 0 & 0 & 0 & 1294 \\
\hline Gramineae & 586 & 178 & 4.2 & 12.5 & 0 & 0 & 0 & 3 & 120 \\
\hline Juglans & 586 & 24 & 0.3 & 2.4 & 0 & 0 & 0 & 0 & 32 \\
\hline Liquidambar & 586 & 18 & 0.2 & 1.5 & 0 & 0 & 0 & 0 & 21 \\
\hline Morus & 586 & 56 & 2.5 & 13.1 & 0 & 0 & 0 & 0 & 152 \\
\hline Pinus & 586 & 135 & 6.7 & 30.9 & 0 & 0 & 0 & 0 & 537 \\
\hline Plantago & 586 & 125 & 1.2 & 2.9 & 0 & 0 & 0 & 0 & 21 \\
\hline Platanus & 586 & 76 & 4.6 & 19.9 & 0 & 0 & 0 & 0 & 286 \\
\hline Populus & 586 & 86 & 2.1 & 7.8 & 0 & 0 & 0 & 0 & 78 \\
\hline Quercus & 586 & 93 & 25.4 & 137.2 & 0 & 0 & 0 & 0 & 2505 \\
\hline Rumex & 586 & 15 & 0.2 & 1.7 & 0 & 0 & 0 & 0 & 37 \\
\hline Salix & 586 & 36 & 0.5 & 2.2 & 0 & 0 & 0 & 0 & 24 \\
\hline Tilia & 586 & 3 & 0.0 & 0.6 & 0 & 0 & 0 & 0 & 13 \\
\hline Typha & 586 & 13 & 0.1 & 1.1 & 0 & 0 & 0 & 0 & 21 \\
\hline Ulmus & 586 & 60 & 5.5 & 42.0 & 0 & 0 & 0 & 0 & 636 \\
\hline Urtica & 586 & 20 & 0.1 & 0.8 & 0 & 0 & 0 & 0 & 11 \\
\hline Unidentified Pollen & 586 & 210 & 6.4 & 20.7 & 0 & 0 & 0 & 3 & 238 \\
\hline Other Pollen & 586 & 445 & 83.0 & 241.0 & 0 & 3 & 13 & 55 & 3478 \\
\hline Total Pollen & & & & & & & & 0 & \\
\hline
\end{tabular}




\subsection{Seasonal Variability}

Figure 14 presents boxplots showing $\mathrm{PM}_{2.5}, \mathrm{PM}_{10}$, and $\mathrm{PM}_{10-2.5}$ concentrations at the central Steubenville site by month. Both $\mathrm{PM}_{2.5}$ and $\mathrm{PM}_{10}$ exhibited a trend of higher summertime and lower wintertime concentrations. Median monthly $\mathrm{PM}_{2.5}$ concentrations ranged from $24.0 \mu \mathrm{g} / \mathrm{m}^{3}$ in August to $11.3 \mu \mathrm{g} / \mathrm{m}^{3}$ in December, and median monthly $\mathrm{PM}_{10}$ concentrations ranged from $30.2 \mu \mathrm{g} / \mathrm{m}^{3}$ in August to $17.3 \mu \mathrm{g} / \mathrm{m}^{3}$ in December. The lowest monthly median $\mathrm{PM}_{10-2.5}$ concentration $\left(5.3 \mu \mathrm{g} / \mathrm{m}^{3}\right)$ also occurred during December; however, the greatest monthly median $\left(9.4 \mu \mathrm{g} / \mathrm{m}^{3}\right)$ occurred during May rather than August. Despite the seasonal pattern exhibited by $\mathrm{PM}_{2.5}$ and $\mathrm{PM}_{10}$ concentrations on average, episodically high daily concentrations (i.e., those greater than the $90^{\text {th }}$ percentile concentrations of 34.7 and $50.5 \mu \mathrm{g} / \mathrm{m}^{3}$ for $\mathrm{PM}_{2.5}$ and $\mathrm{PM}_{10}$, respectively) were observed in all seasons, and the maximum 24-hr average concentrations observed during SCAMP for both of these particulate matter measures occurred during autumn rather than during summer. The maximum $\mathrm{PM}_{10-2.5}$ concentration observed during summer was $23.5 \mu \mathrm{g} / \mathrm{m}^{3}$, whereas maxima during the other three seasons were all greater than $40 \mu \mathrm{g} / \mathrm{m}^{3}$.
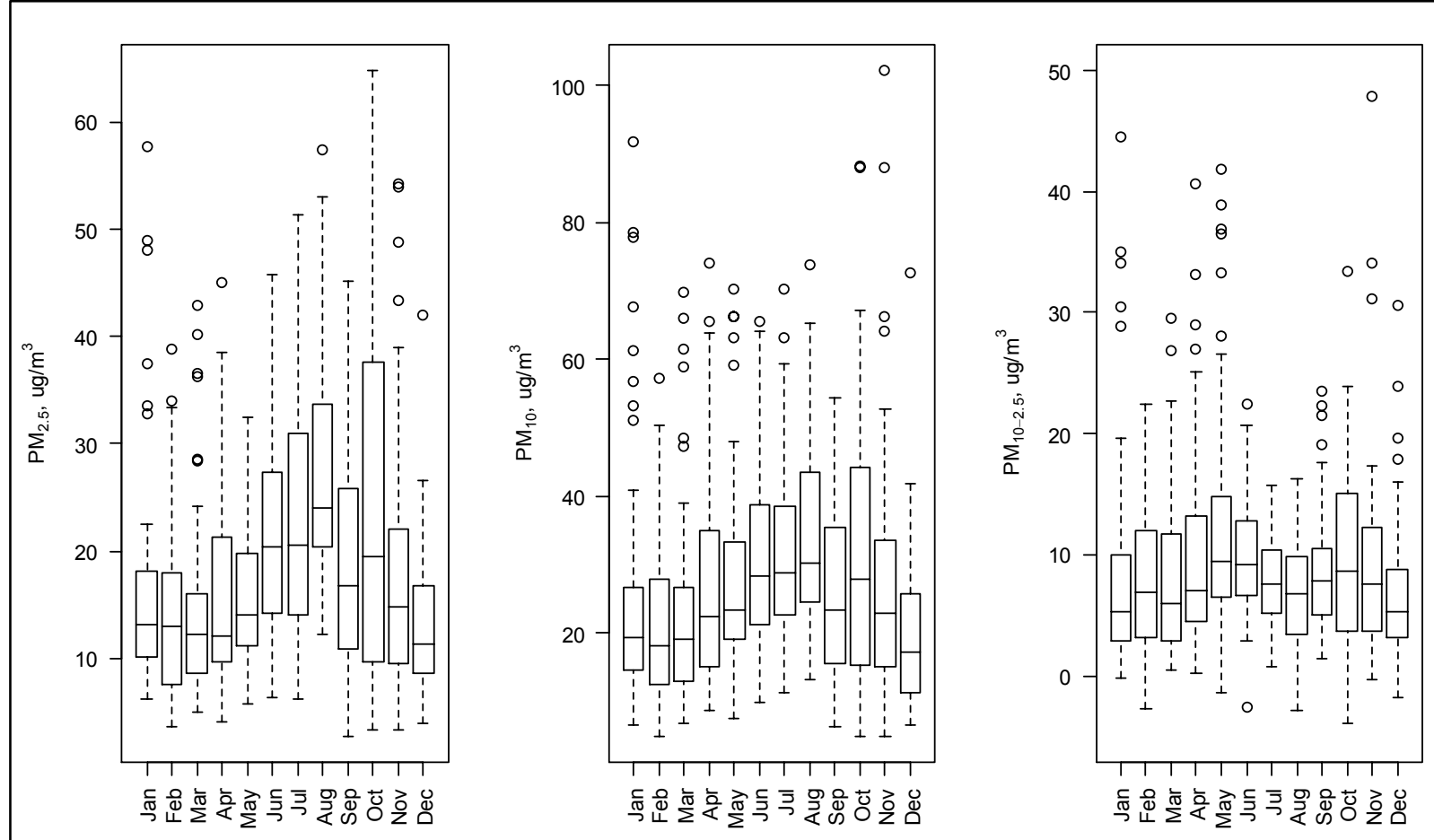

Figure 14. Boxplots summarizing the distributions of 24-hr average $\mathrm{PM}_{2.5}, \mathrm{PM}_{10}$, and $\mathrm{PM}_{10-2.5}$ concentrations measured at the central Steubenville site by month, based on data collected between May 2000 and May 2002.

To further examine seasonal trends in concentrations of PM, PM components, and co-pollutants at the Steubenville site, median 24-hr average concentrations observed during the "warm season" were compared with median 24-hr average concentrations observed during the "cool season." For the purposes of this comparison, the "warm season" was defined as April through September, and the "cool season" was defined as October through March. Median values were used because they provide an indication of typical concentration levels, but are not inflated by high-concentration outliers. Table 25 summarizes the average meteorological conditions observed at Steubenville during these seasons. 
Table 25. Median 24-hr average meteorological conditions at Steubenville during the warm (AprilSeptember) and cool (October-March) seasons.

\begin{tabular}{|c|c|c|}
\hline Parameter & Warm Season Median & Cool Season Median \\
\hline Wind Speed $(\mathrm{m} / \mathrm{s})$ & 1.99 & 2.83 \\
\hline Temperature $\left({ }^{\circ} \mathrm{C}\right)$ & 18.9 & 3.6 \\
\hline Relative Humidity $(\%)$ & 75.19 & 70.78 \\
\hline Solar Radiation $\left(\mathrm{W} / \mathrm{m}^{2}\right)$ & 230 & 80 \\
\hline Barometric Pressure $(\mathrm{mm} \mathrm{Hg})$ & 734.3 & 732.8 \\
\hline
\end{tabular}

Figure 15 is a plot of the ratios of median warm season concentrations to median cool season concentrations for PM and gaseous pollutant variables that were measured on a daily frequency during SCAMP. For each variable, a nonparametric Wilcoxon rank sum test was applied to test whether the locations of the distributions of 24-hr average concentrations observed during the warm and cool seasons differed significantly (i.e., at a statistical significance level of $\alpha=0.05$ ). (It should be noted that because of the autocorrelated nature of $\mathrm{PM}_{2.5}$ data, the results of the statistical significance tests presented here may be subject to bias, as the tests assume independent, random samples). Concentrations of $\mathrm{PM}_{2.5}, \mathrm{PM}_{10}$, and $\mathrm{PM}_{10-2.5}$ were significantly higher during the warm season than during the cool season, although the difference was more pronounced for $\mathrm{PM}_{2.5}$ and $\mathrm{PM}_{10}$ than for $\mathrm{PM}_{10-2.5}$. These results are consistent with the conclusions drawn above from Figure $15 . \mathrm{O}_{3}$ concentrations similarly were significantly greater during the warm season than during the cool season, reflecting the influence of seasonal variations in sunlight on concentrations of this photochemically-produced pollutant. Conversely, concentrations of $\mathrm{SO}_{2}, \mathrm{NO}$, and $\mathrm{CO}$ were significantly greater during the cool season than during the warm season. These gases are primary pollutants; hence, the seasonal variation in their concentrations may be attributable to seasonal variations in emissions or to seasonal variations in meteorological conditions such as wind direction and mixing height that affect transport and accumulation. Concentrations of $\mathrm{NO}_{2}$ and $\mathrm{NO}_{\mathrm{x}}$ (which includes $\mathrm{NO}$ and $\mathrm{NO}_{2}$ ) did not vary significantly by season.

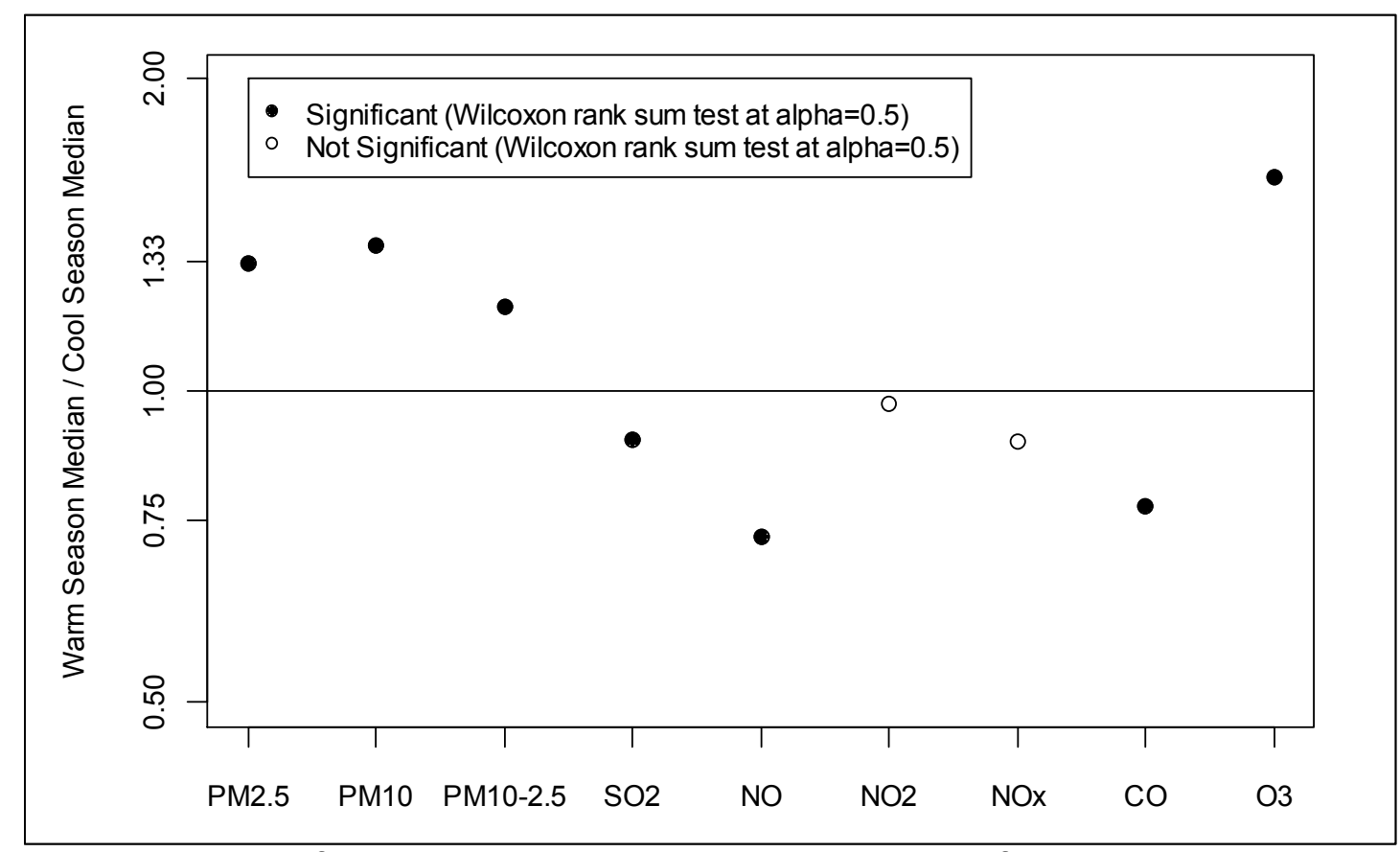

Figure 15. Ratios of warm-to-cool season median concentrations for PM and gaseous pollutants at the central Steubenville site. Solid points indicate statistically significant seasonal differences. 
In order to preserve reasonable y-axis limits, pollen and spores are not shown in Figure 16; however, their concentrations were substantially and significantly higher during the warm season than during the cool season. The boxplots in Figure 16 show total pollen and spore counts by month at Steubenville. Pollen counts were greatest in April and May, when many trees and grasses in the region pollinate. A less pronounced local maximum is also evident during weed pollination season in August and September. Spore counts were greatest in August and lowest in January.

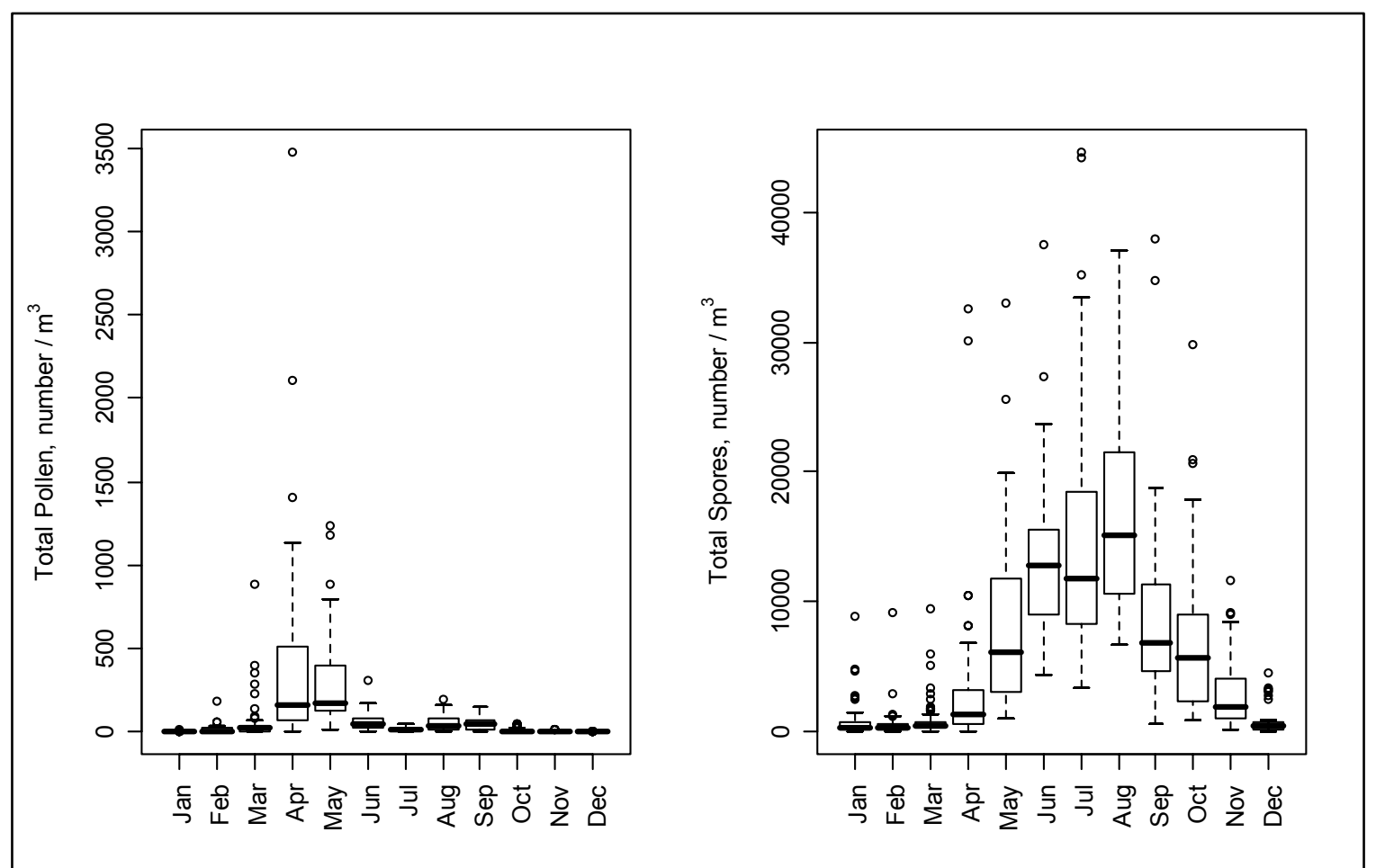

Figure 16. Boxplots summarizing the distributions of 24-hr average pollen and spore number concentrations measured at the central Steubenville site by month, based on data collected between June 2000 and May 2002.

Figure 17 shows ratios of median warm season concentrations to median cool season concentrations for $\mathrm{PM}_{2.5}$ and $\mathrm{PM}_{10}$ ions and water-soluble elemental components that were measured every fourth day during SCAMP. Figure 18 shows these ratios for fine particulate EC, OM, and acid-digestible elements, which were also measured on a 1-in-4 day frequency. As is typical for the northeastern United States (Sickles, 1999), sulfate concentrations were significantly greater during the warm season than during the cool season at Steubenville, whereas nitrate concentrations were significantly greater during the cool season than during the warm season. The seasonal trend exhibited by sulfate (which is expected to be present primarily as $\left(\mathrm{NH}_{4}\right)_{2} \mathrm{SO}_{4}$ or as $\left.\mathrm{NH}_{4} \mathrm{HSO}_{4}\right)$ is likely due to the effect of increased summertime photochemical activity on concentrations of this predominantly secondary pollutant (Faust, 1994). Formation of particulate nitrate (which is expected to be present primarily as $\mathrm{NH}_{4} \mathrm{NO}_{3}$ ) is thermodynamically favored by low temperatures and high relative humidity and depends upon the availability of $\mathrm{NH}_{3}$ (Pittsburgh Air Quality Study, 2003), explaining why $\mathrm{NO}_{3}{ }^{-}$concentrations are elevated during the cool season, when temperatures favor $\mathrm{NH}_{4} \mathrm{NO}_{3}$ formation and less $\mathrm{NH}_{3}$ has reacted to form $\left(\mathrm{NH}_{4}\right)_{2} \mathrm{SO}_{4}$. 


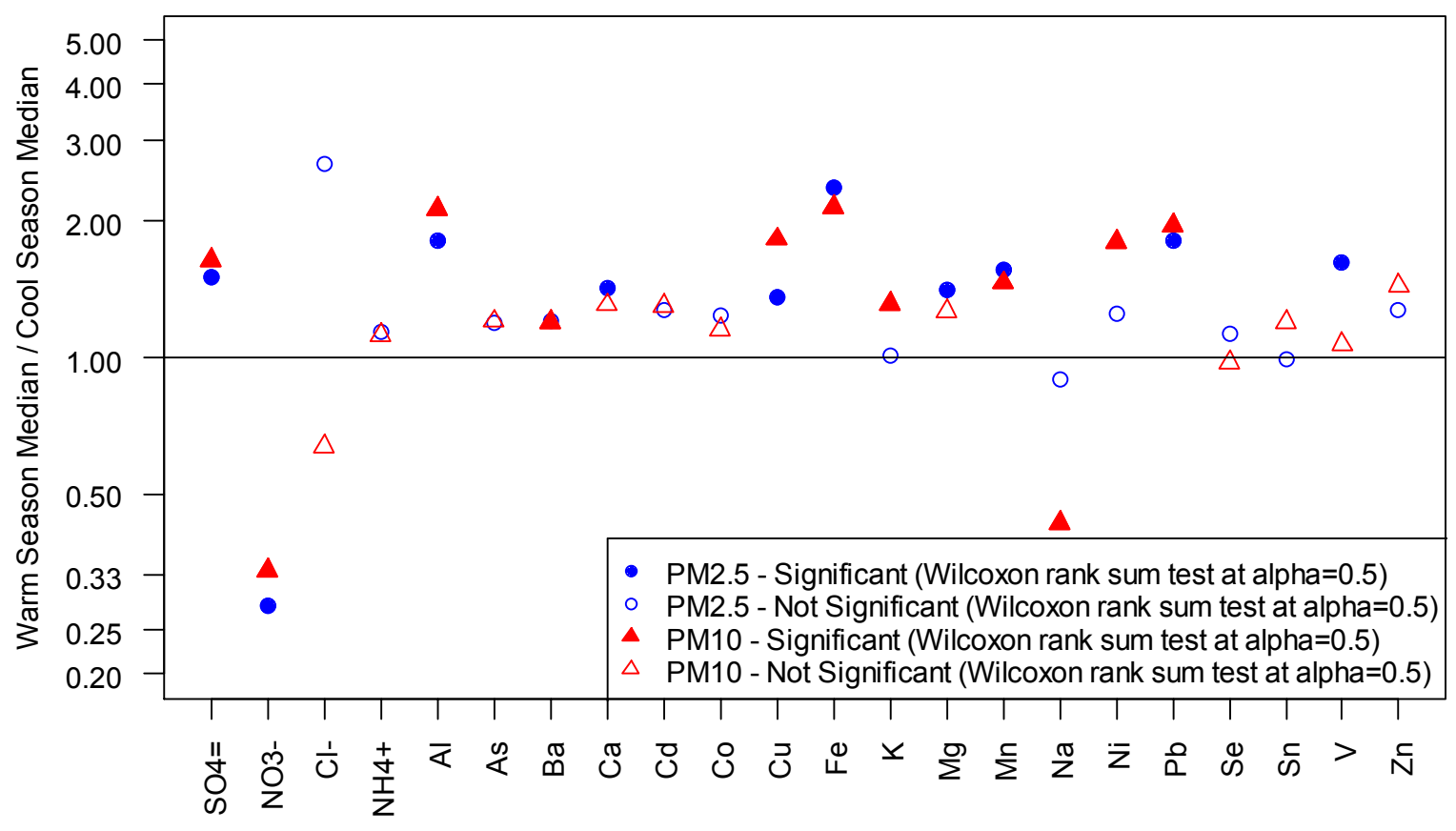

Figure 17. Ratios of warm-to-cool season median concentrations for $\mathrm{PM}_{2.5}$ and $\mathrm{PM}_{10}$ waterextractable components at the central Steubenville site. Solid symbols indicate statistically significant seasonal differences.

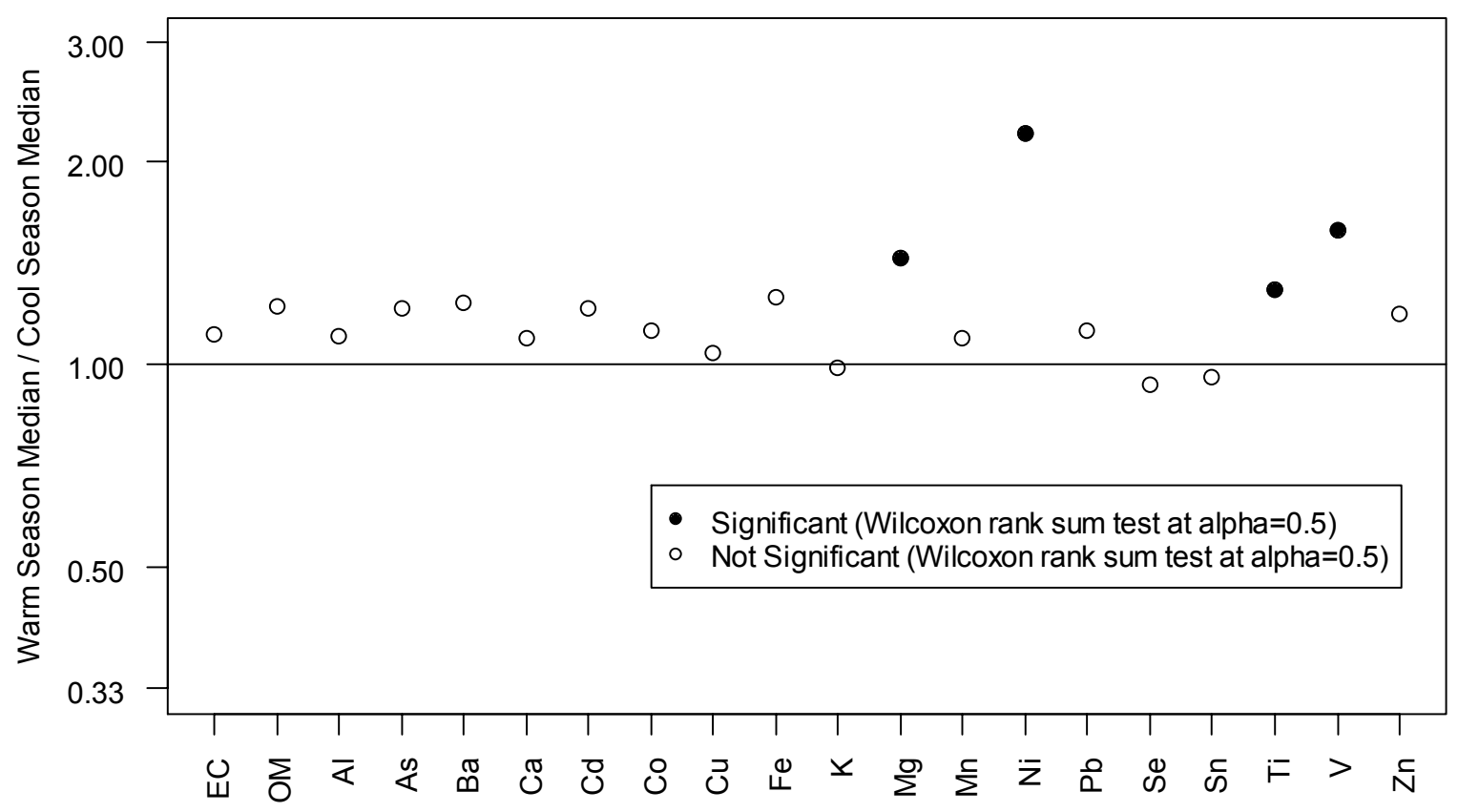

Figure 18. Ratios of warm-to-cool season median concentrations for $\mathrm{PM}_{2.5}$ carbonaceous and aciddigestible elemental components at the central Steubenville site. Solid symbols indicate statistically significant seasonal differences. 
As a result of seasonal variability in the mass concentrations of its components, the composition of $\mathrm{PM}_{2.5}$ (measured on a percentage basis) exhibited similar seasonal variability. Figure 19 shows average $\mathrm{PM}_{2.5}$ composition at Steubenville by astronomical season. Calculations were performed using the mass balance procedure and 109-day dataset described earlier in Section 4.2.2.1. Sulfate and the unidentified components of $\mathrm{PM}_{2.5}$ showed a pronounced trend of accounting for a greater portion of total $\mathrm{PM}_{2.5}$ mass during summer and a lesser portion during winter, whereas nitrate showed the opposite trend. The trends displayed by $\mathrm{SO}_{4}{ }^{2-}$ and $\mathrm{NO}_{3}{ }^{-}$are explained by the physical mechanisms described above that cause seasonal variations in the mass concentrations of these pollutants. The trend shown by the unidentified components likely reflects the increased contribution of particle-bound water to $\mathrm{FRM}$-determined $\mathrm{PM}_{2.5}$ mass in Steubenville during summertime. Ammonium accounted for a slightly larger percentage of $\mathrm{PM}_{2.5}$ mass in summer than in the other three seasons, reflecting its association with $\mathrm{SO}_{4}{ }^{2-}$ in ambient $\mathrm{PM}_{2.5}$. The remaining major $\mathrm{PM}_{2.5}$ components each exhibited minimum percent contributions to total $\mathrm{PM}_{2.5}$ mass during summer. However, as shown in Figures 17 and 18, mass concentrations of these components did not vary significantly by season; hence, the observed compositional trend is instead attributable to increased total $\mathrm{PM}_{2.5}$ mass resulting from elevated contributions of sulfate, ammonium, and unidentified components in summertime. Sulfate was by far the most prevalent $\mathrm{PM}_{2.5}$ component in summer, when average $\mathrm{PM}_{2.5}$ mass concentrations were greatest, accounting for $38.4 \%$ of the total $\mathrm{PM}_{2.5}$ mass. The second largest contributor in this season was organic material, which accounted for $21.7 \%$ of the total mass. Conversely, in winter, when average $\mathrm{PM}_{2.5}$ concentrations were lowest, $\mathrm{OM}$ accounted for a greater percentage of $\mathrm{PM}_{2.5}$ mass $(27.5 \%)$ than did $\mathrm{SO}_{4}{ }^{2-}(24.8 \%)$.

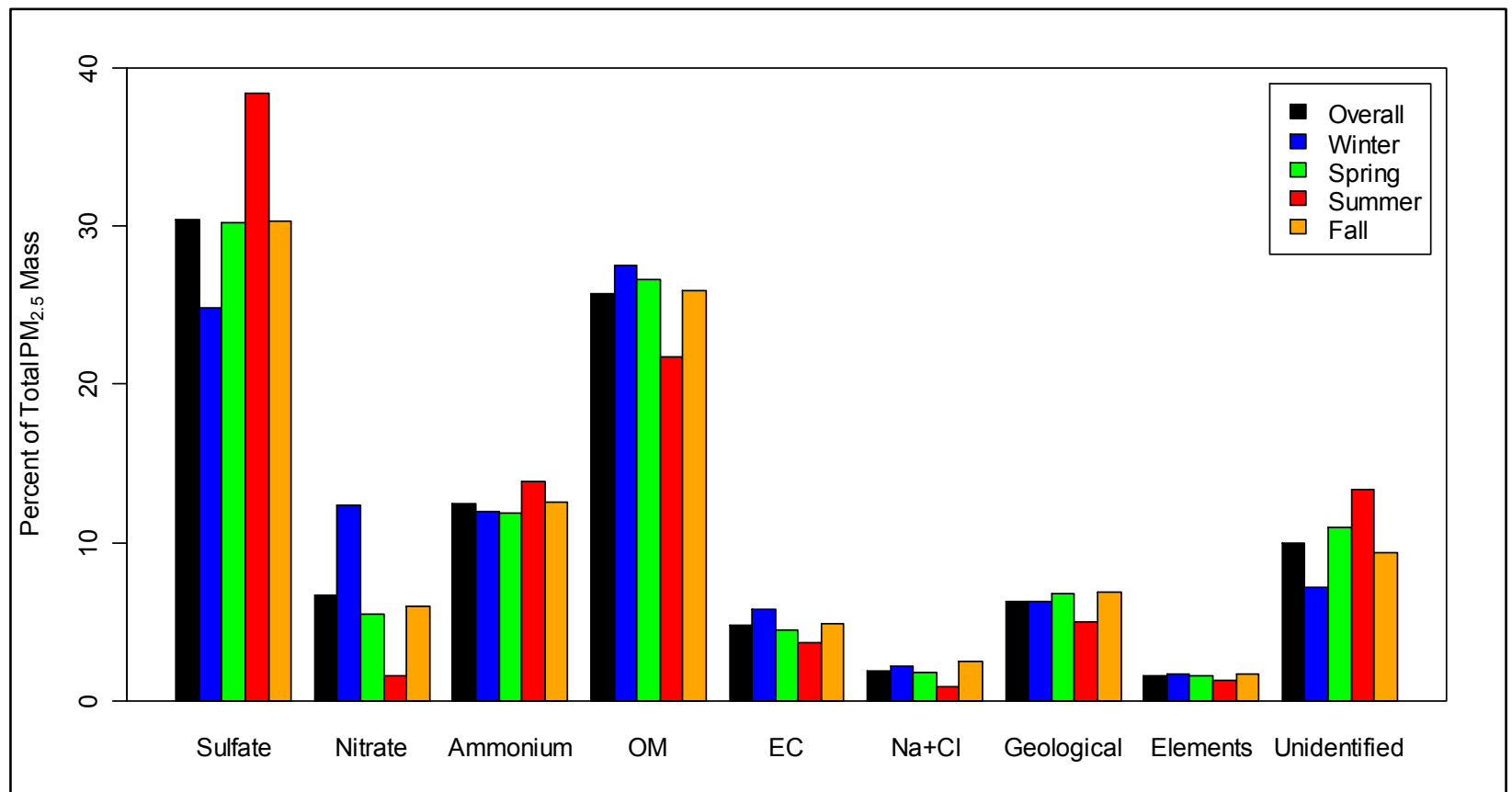

Figure 19. Overall average $\mathrm{PM}_{2.5}$ composition by season at the central Steubenville site, based on the application of a mass balance (described earlier) to 109 days with complete or near-complete $\mathrm{PM}_{2.5}$ speciation data.

As shown in Figures 17 and 18, concentrations of a number of elemental components of $\mathrm{PM}_{2.5}$ and $\mathrm{PM}_{10}$, including $\mathrm{Al}, \mathrm{Ba}, \mathrm{Ca}, \mathrm{Cu}, \mathrm{Fe}, \mathrm{Mg}, \mathrm{Mn}, \mathrm{Pb}$, and $\mathrm{V}$ in the water-extractable $\mathrm{PM}_{2.5}$ fraction, $\mathrm{Al}, \mathrm{Ba}, \mathrm{Cu}, \mathrm{Fe}, \mathrm{K}, \mathrm{Mn}, \mathrm{Ni}$, and $\mathrm{Pb}$ in the water-extractable $\mathrm{PM}_{10}$ fraction, and $\mathrm{Mg}, \mathrm{Ni}, \mathrm{Ti}$, and $\mathrm{V}$ in the acid-digestible $\mathrm{PM}_{2.5}$ fraction, were significantly greater during the warm season 
than during the cool season at Steubenville. This trend may be attributable to seasonal variations in primary emissions of these elements, although it is observed for a diverse array of elements that likely originate from different sources. Alternatively, it may result from seasonal variations in ventilation conditions or transport direction that cause variations in the extent to which one or more source regions impact the monitoring site. For elements in the water-soluble PM fraction, another plausible explanation is that certain $\mathrm{PM}_{2.5}$ constituents (e.g., secondary sulfates) that are more prevalent during summertime than during wintertime interact with ambient metals to increase their solubility. Connell et al. (2006) examined seasonal variations in trace element fractional solubilities observed at the Steubenville site during SCAMP, and reported that fractional solubilities of $\mathrm{Al}, \mathrm{Fe}$, and $\mathrm{Pb}$ were significantly greater during the warm season than during the cool season. Moreover, the fractional solubility of $\mathrm{Fe}$ exhibited moderate, positive correlations $\left(r_{s}=0.66-0.72\right)$ with $\mathrm{SO}_{4}{ }^{2-}$ and temperature during the summertime, when photochemical activity and secondary $\mathrm{SO}_{4}{ }^{2-}$ concentrations are maximal, whereas correlations between $\mathrm{Fe}$ fractional solubility and temperature and $\mathrm{SO}_{4}{ }^{2-}$ were comparatively weak $\left(r_{s}=-0.21-0.17\right)$ during wintertime. Ghio et al. (1999b) reported that in controlled laboratory experiments, aqueous $\mathrm{SO}_{4}{ }^{2-}$ was capable of mobilizing soluble $\mathrm{Fe}$ from $\mathrm{Fe}_{2} \mathrm{O}_{3}$, but only in the presence of light. Results from SCAMP are consistent with the possibility that fine particulate $\mathrm{Fe}$ in Steubenville may be solubilized to some extent by interaction with sulfates under suitable photochemical conditions, and reinforce Grahame and Schlesinger's (2005) recommendation for further research to examine the effect of secondary sulfates on the solubility of $\mathrm{PM}_{2.5}$ metals.

Aside from $\mathrm{NO}_{3}^{-}$, the only $\mathrm{PM}$ component with significantly greater ambient concentrations during the cool season than during the warm season at Steubenville was $\mathrm{Na}$ in the watersoluble $\mathrm{PM}_{10}$ fraction. This difference may reflect the use of $\mathrm{NaCl}$ to treat icy roads in Steubenville during winter. The median ambient $\mathrm{PM}_{10} \mathrm{Cl}^{-}$concentration was also greater during the cool season than during the warm season in Steubenville, consistent with this hypothesis, although the seasonal difference in $\mathrm{Cl}^{-}$concentrations was not statistically significant. Ambient concentrations of water-soluble $\mathrm{Na}$ and $\mathrm{Cl}^{-}$in $\mathrm{PM}_{2.5}$ at Steubenville showed a less-pronounced or different seasonal trend, suggesting that different sources account for the presence of these species in the fine and coarse particle fractions.

\subsection{Day-of-Week Variability}

Figure 20 presents boxplots showing $\mathrm{PM}_{2.5}, \mathrm{PM}_{10}$, and $\mathrm{PM}_{10-2.5}$ concentrations at the central Steubenville site by day-of-week. $\mathrm{PM}_{2.5}$ concentrations did not exhibit a pronounced day-ofweek trend during SCAMP; the greatest median concentration by day-of-week was $16.4 \mu \mathrm{g} / \mathrm{m}^{3}$ on Monday, and the lowest was $13.9 \mu \mathrm{g} / \mathrm{m}^{3}$ on Friday. Conversely, $\mathrm{PM}_{10}$ and $\mathrm{PM}_{10-2.5}$ concentrations exhibited a trend of higher weekday (i.e., Monday-Friday) and lower weekend (i.e., Saturday-Sunday) concentrations. Median Saturday and Sunday concentrations ranged from 19.0-19.9 $\mathrm{\mu g} / \mathrm{m}^{3}$ for $\mathrm{PM}_{10}$ and from 5.8-5.9 $\mu \mathrm{g} / \mathrm{m}^{3}$ for $\mathrm{PM}_{10-2.5}$, whereas median weekday concentrations ranged from 22.3-26.8 $\mu \mathrm{g} / \mathrm{m}^{3}$ for $\mathrm{PM}_{10}$ and from 7.6-8.6 $\mu \mathrm{g} / \mathrm{m}^{3}$ for $\mathrm{PM}_{10-2.5}$.

Figure 21, which shows ratios of weekday median concentrations to weekend median concentrations for variables that were measured on a daily frequency during SCAMP, echoes these observations. Concentrations of $\mathrm{PM}_{10}$ and $\mathrm{PM}_{10-2.5}$, as well as those of $\mathrm{NO}$ and $\mathrm{NO}_{\mathrm{x}}$, were significantly greater on weekdays than on weekends during SCAMP (based on the results of Wilcoxon rank sum tests), whereas concentrations of $\mathrm{PM}_{2.5}, \mathrm{SO}_{2}, \mathrm{NO}_{2}, \mathrm{CO}, \mathrm{O}_{3}$, total spores, and total pollen did not show significant weekday/weekend differences. Figure 22 shows ratios of median weekday concentrations to median weekend concentrations for $\mathrm{PM}_{2.5}$ and $\mathrm{PM}_{10}$ ions and water-soluble elemental components that were measured every fourth day 

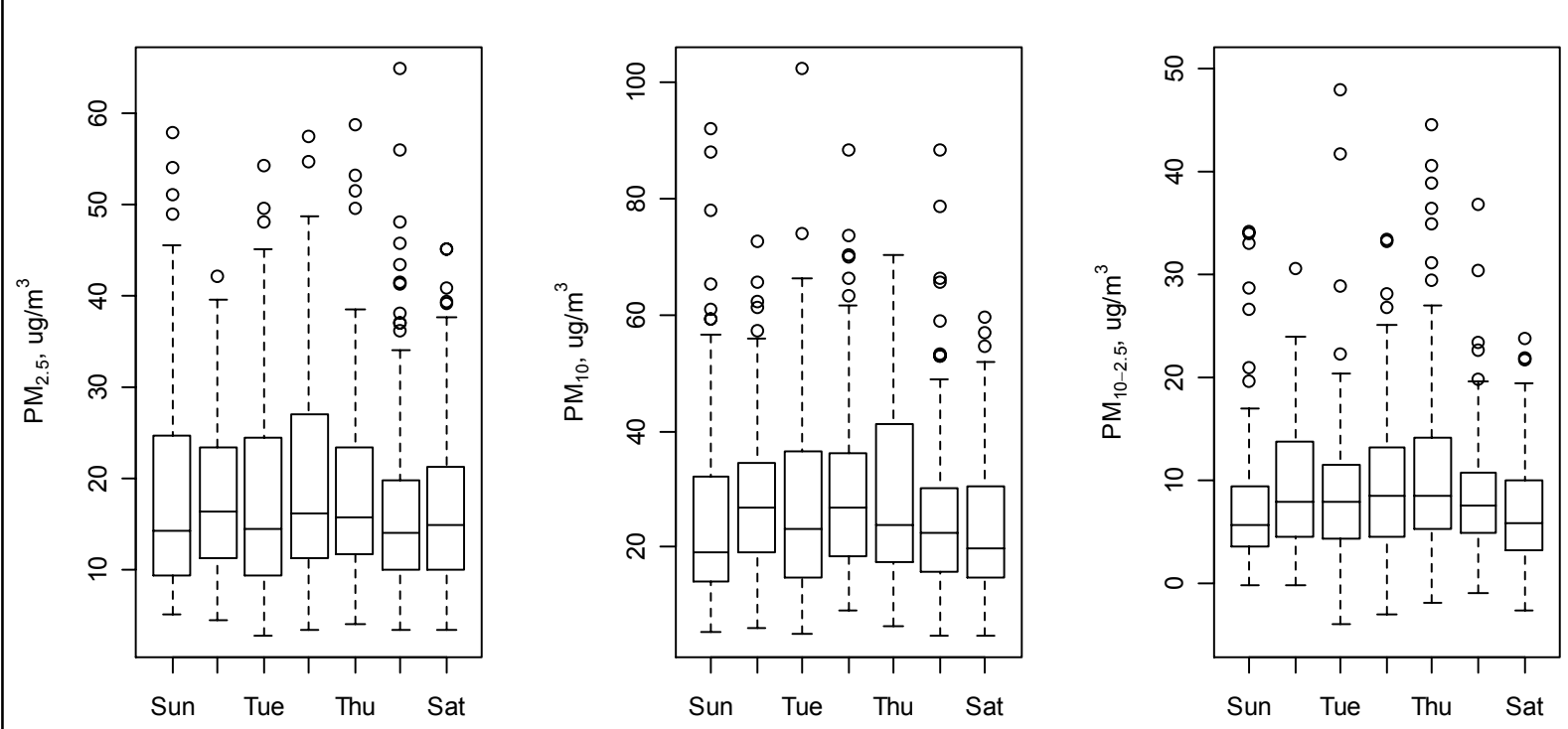

Figure 20. Boxplots summarizing the distributions of 24-hr average $\mathrm{PM}_{25}, \mathrm{PM}_{10}$, and $\mathrm{PM}_{10-25}$ concentrations measured at the central Steubenville site by day of week, based on data collected between May 2000 and May 2002.

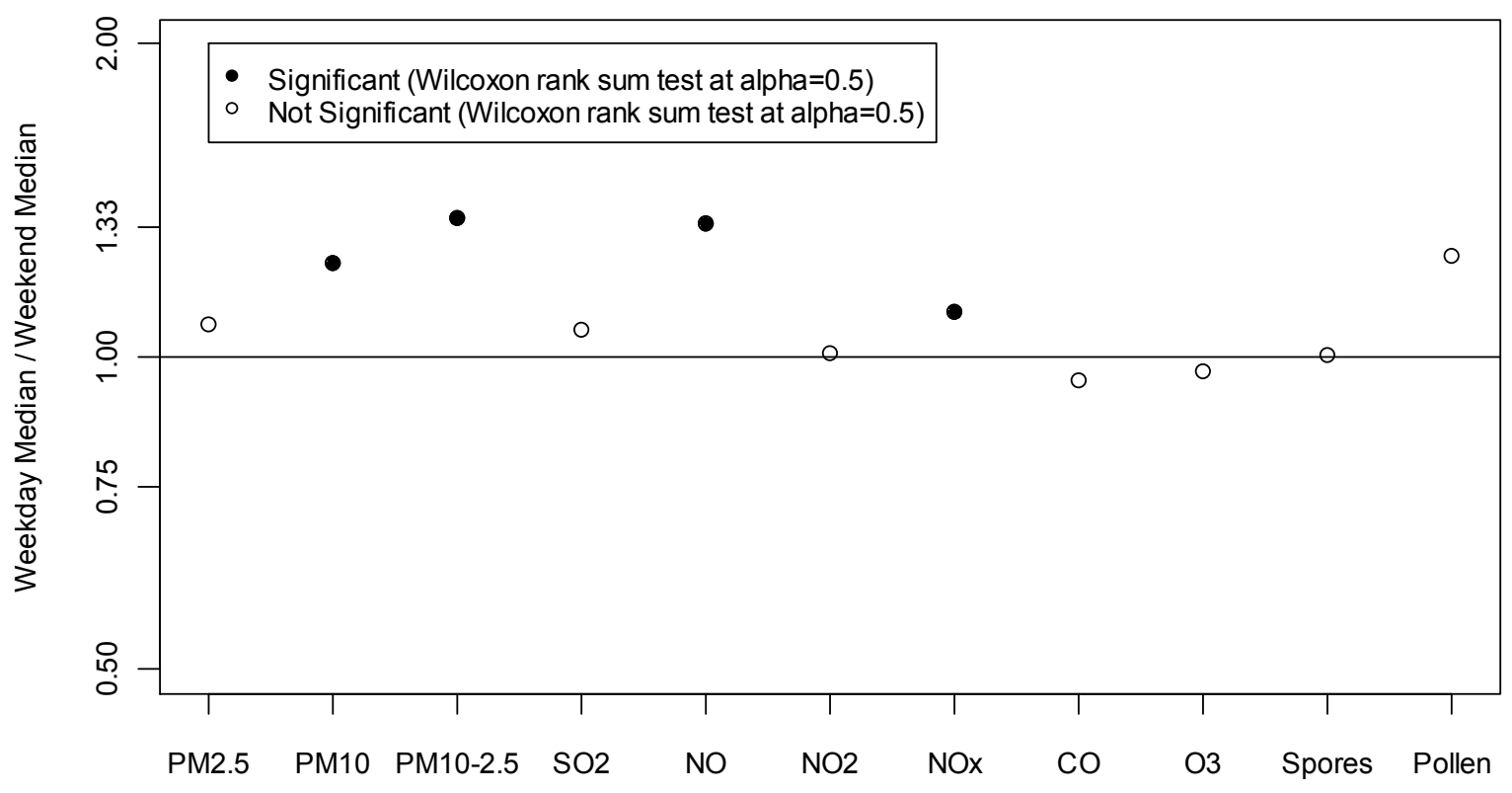

Figure 21. Ratios of weekday-to-weekend median concentrations for PM and gaseous pollutants at the central Steubenville site. Solid points indicate statistically significant weekday/weekend differences. 


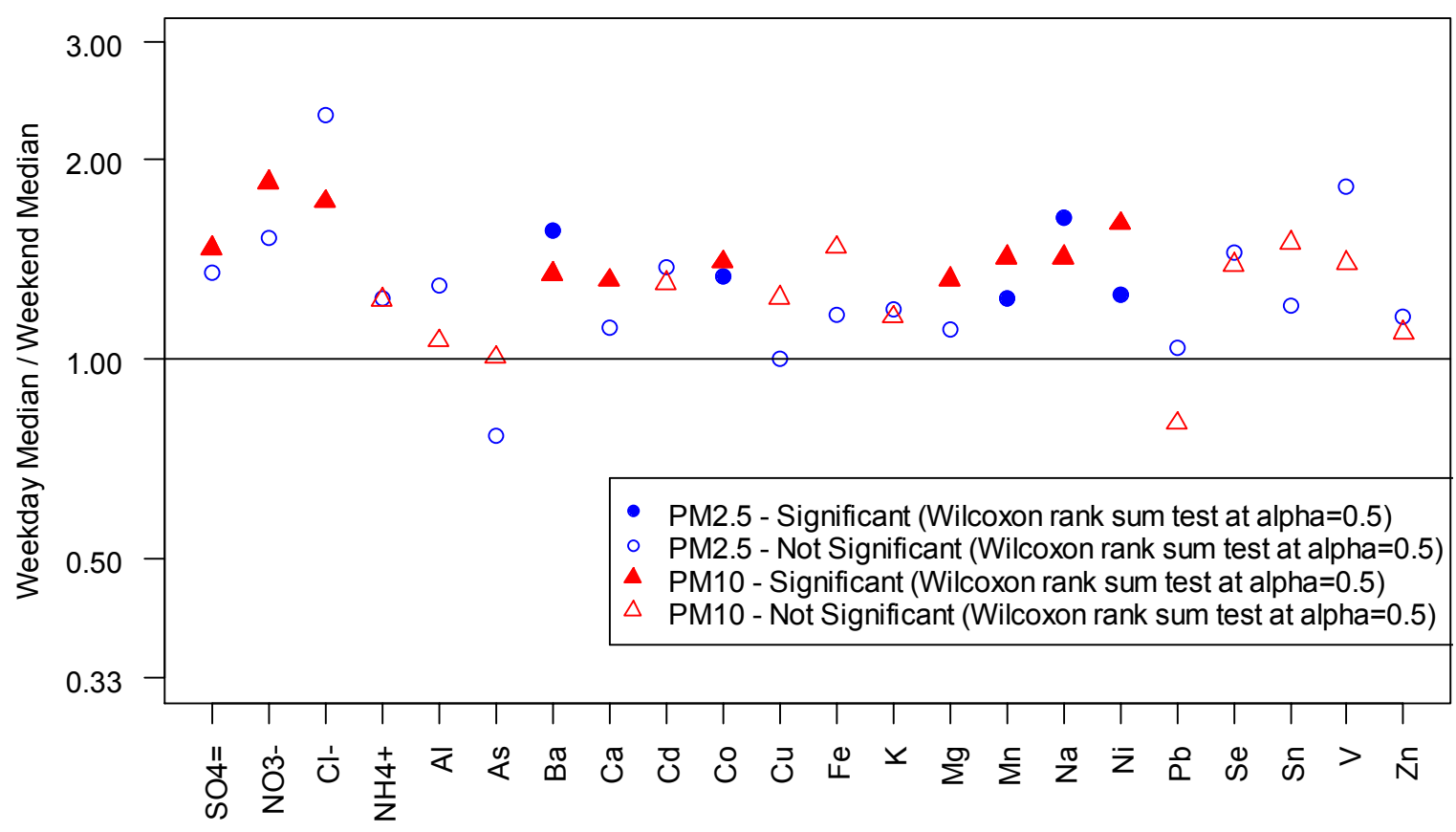

Figure 22. Ratios of weekday-to-weekend median concentrations for $\mathrm{PM}_{2.5}$ and $\mathrm{PM}_{10}$ waterextractable components at the central Steubenville site. Solid symbols indicate statistically significant weekday/weekend differences.

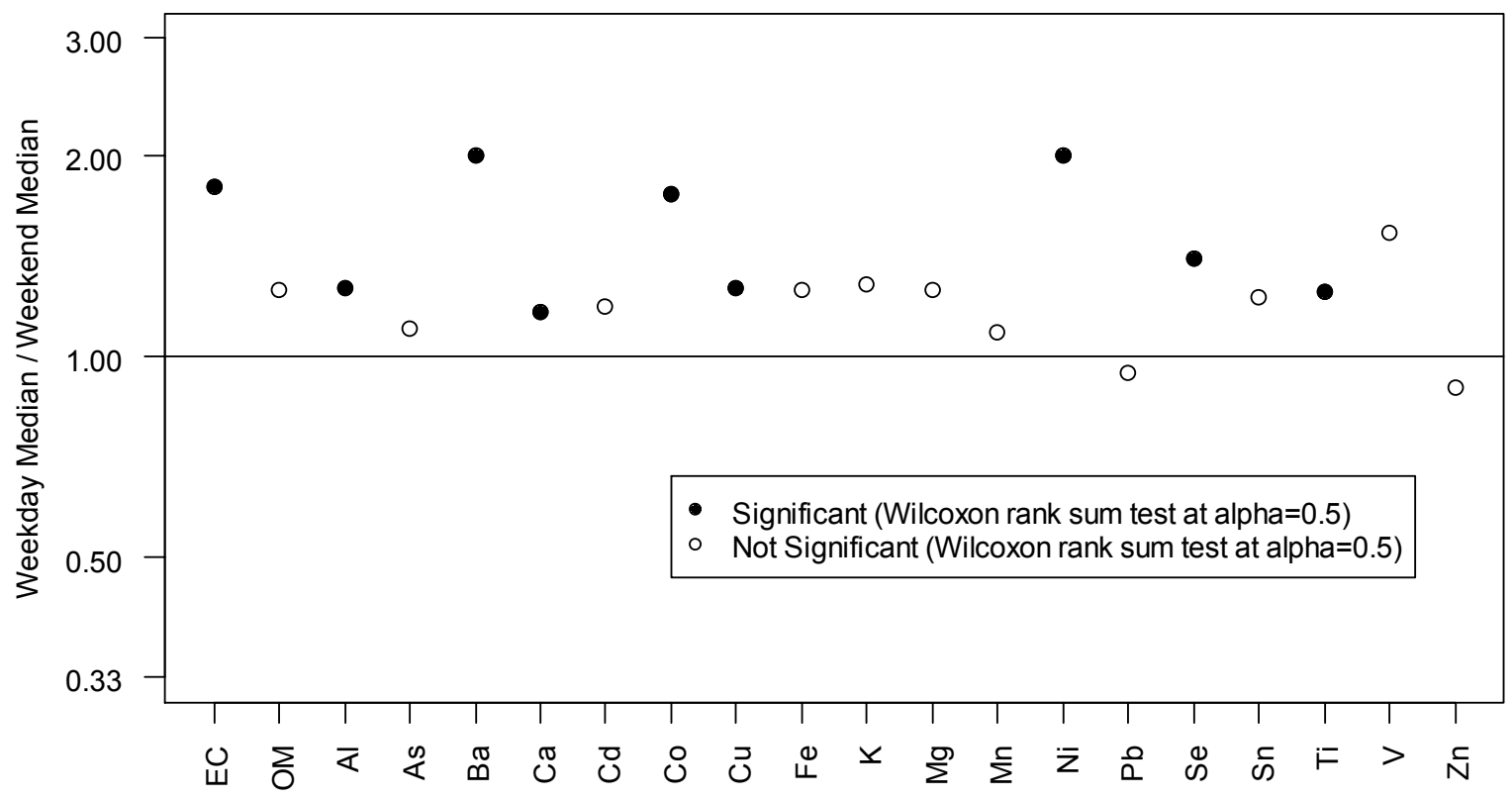

Figure 23. Ratios of weekday-to-weekend median concentrations for $\mathrm{PM}_{2.5}$ carbonaceous and aciddigestible elemental components at the central Steubenville site. Solid points indicate statistically significant weekday/weekend differences. 
during SCAMP, and Figure 23 shows these ratios for fine particulate EC, OM, and aciddigestible elements, which were also measured on a 1-in-4 day frequency. A majority of the $\mathrm{PM}_{2.5}$ and $\mathrm{PM}_{10}$ components measured during SCAMP exhibited greater median concentrations during weekdays than during weekends; these weekday/weekend differences were statistically significant in a number of cases. Because of the relatively small number of samples collected for variables that were sampled on a 1-in-4 day frequency, the observed weekend/weekday differences may be an anomaly of the subset of days sampled in some cases. (For example, weekday/weekend differences for $\mathrm{PM}_{2.5}, \mathrm{SO}_{2}$, and $\mathrm{NO}_{2}$, which were not statistically significant when all daily data collected during SCAMP were used in the analyses, became statistically significant when only data collected every fourth day were used). Nevertheless, the trend of higher weekday and lower weekend concentrations is likely real for some of the parameters (e.g., for $\mathrm{PM}_{10}, \mathrm{PM}_{10-2.5}$, and $\mathrm{NO}_{\mathrm{x}}$, which exhibited this trend regardless of whether 1-in-1 or 1-in4 day data were used), and the direction of this trend was consistent in all cases in which a significant difference was found (i.e., no parameter exhibited significantly greater concentrations during weekends than during weekdays). Unlike seasonal trends, day-of-week trends are not expected to result from variations in meteorology. Weekday and weekend values did not differ significantly for any of the meteorological parameters monitored during SCAMP, regardless of whether daily or 1-in-4 day data were used. Rather, the day-of-week trends observed during SCAMP likely resulted from increased anthropogenic emissions (e.g., vehicular or industrial) during the weekdays.

\subsection{Diurnal Variability}

As discussed earlier, $\mathrm{PM}_{2.5}$ total mass and gaseous pollutant concentrations were monitored continuously at the central site in Steubenville, permitting their diurnal variability to be explored. Figure 24 includes a boxplot showing the distribution of $\mathrm{PM}_{2.5}$ concentrations observed at Steubenville for each hour of the day during SCAMP, as well as a line plot showing mean $\mathrm{PM}_{2.5}$ concentrations by time-of-day and season. Figure 25 shows mean gaseous pollutant concentrations observed at the central Steubenville site by time-of-day and season.

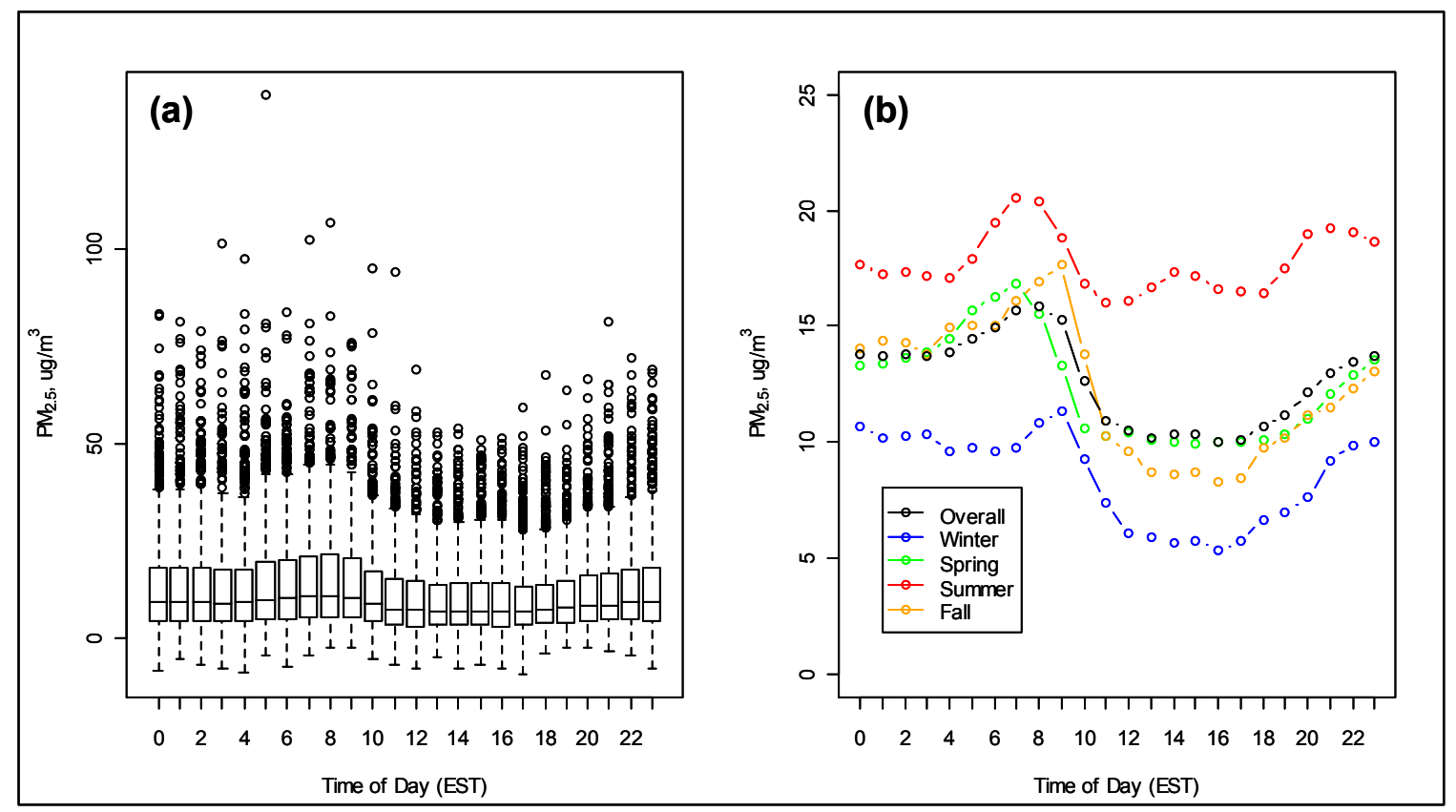

Figure 24. Diurnal profiles of $\mathrm{PM}_{2.5}$ at Steubenville: (a) boxplot showing distribution of $\mathrm{PM}_{2.5}$ concentrations by hour of day, and (b) mean $\mathrm{PM}_{2.5}$ concentrations by hour of day and season. 

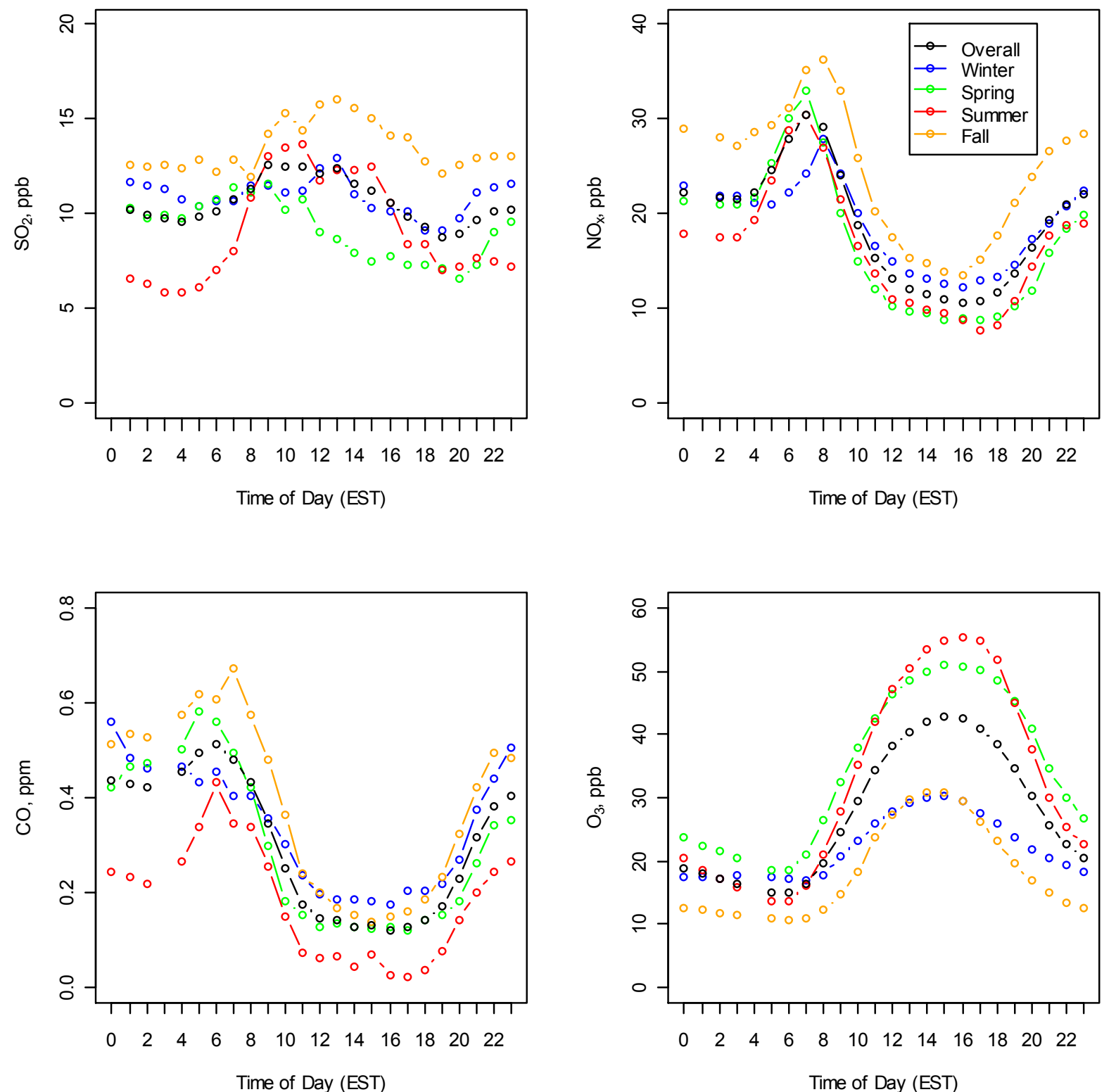

Figure 25. Concentrations of $\mathrm{SO}_{2}, \mathrm{NO}_{x}, \mathrm{CO}$, and $\mathrm{O}_{3}$ by hour of day and season at the central Steubenville site.

Although the diurnal profile of $\mathrm{PM}_{2.5}$ concentration was highly variable, as evidenced in Figure 24, on average it exhibited a trend of moderate overnight concentrations building up to a peak concentration of $15.8 \mu \mathrm{g} / \mathrm{m}^{3}$ (measured using the TEOM) at 8:00 a.m. EST, and then declining to a minimum concentration of $10.0 \mu \mathrm{g} / \mathrm{m}^{3}$ at 4:00 p.m. EST. (The shift in the timing of the morning maximum in spring and summer relative to fall and winter evident in Figure 24(b) likely reflects Steubenville's shift from Eastern Standard Time to Eastern Daylight Time during most of spring and all of summer). This trend is similar to the diurnal profiles exhibited by $\mathrm{NO}_{\mathrm{x}}$ and $\mathrm{CO}$, which on average reached maximum concentrations at 7:00 a.m. and 6:00 a.m. EST, respectively, and minimum concentrations at 4:00 p.m. EST. $\mathrm{O}_{3}$, a photochemically-produced secondary pollutant, exhibited an opposite diurnal pattern of maximal concentrations during midafternoon, when photochemical activity peaks, and minimal concentrations during early 
morning, when photochemical production ceases and $\mathrm{O}_{3}$ depletion by deposition and reaction with freshly-emitted pollutants such as $\mathrm{NO}$ occurs rapidly. Even though a large portion of $\mathrm{PM}_{2.5}$ mass during summer in Steubenville is expected to result from secondary sulfates, $\mathrm{PM}_{2.5}$ mass concentrations during that season still exhibited a diurnal trend characterized by an early morning peak in concentration; although the minimum concentration occurred during late morning (11:00 a.m. EST) rather than late afternoon, and a small local maximum was observed during mid-afternoon, likely reflecting the photochemical formation of secondary aerosol.

The diurnal behavior exhibited by $\mathrm{PM}_{2.5}$ in Steubenville likely results from diurnal variability in both emissions and meteorology. The close semblance between the average diurnal profiles of $\mathrm{PM}_{2.5}, \mathrm{NO}_{\mathrm{x}}$, and $\mathrm{CO}$ likely reflects the influence of a common emission source of these pollutants. Motor vehicles are one known source of $\mathrm{CO}, \mathrm{NO}_{\mathrm{x}}$, and $\mathrm{PM}_{2.5}$ emissions; Chuersuwan et al. (2000) attributed an average morning (6:00 a.m. to 9:30 a.m. EST) peak in $\mathrm{PM}_{2.5}$ concentrations in New Jersey to the influence of local motor vehicle traffic. Statewide average traffic count data from the Ohio Department of Transportation (2004) suggest that automobile traffic on urban principal arterial roadways increases drastically from about 5:00 a.m. to about 7:00 a.m., similar to the timing of the build-up in concentration leading to the early morning maxima in $\mathrm{PM}_{2.5}, \mathrm{CO}$, and $\mathrm{NO}_{\mathrm{x}}$ concentrations. Hence, it is likely that automotive emissions contribute at least in part to the average morning peak in $\mathrm{PM}_{2.5}$ concentration. However, unlike traffic counts, which remain elevated throughout midday and reach an even greater maximum during late afternoon rush hour before declining dramatically overnight, $\mathrm{PM}_{2.5}$, $\mathrm{CO}$, and $\mathrm{NO}_{x}$ concentrations on average exhibit minima during afternoon and more elevated concentrations overnight. This suggests that factors other than motor vehicles also influence their diurnal profiles. Based on 2001 estimates from the U.S. EPA (2001), the primary metals industry and electric and industrial fossil fuel combustion sources are the largest sources of $\mathrm{CO}$ and $\mathrm{NO}_{\mathrm{x}}$, respectively, in Jefferson County, $\mathrm{OH}$, where Steubenville is located. Hence, these sources, which also emit $\mathrm{PM}_{2.5}$, likely influence the diurnal behavior of these pollutants. Based on Connell et al.'s (2005c) analyses of hourly data from the SCAMP central Steubenville site, the trend of higher overnight and lower midday $\mathrm{PM}_{2.5}, \mathrm{NO}_{\mathrm{x}}$, and $\mathrm{CO}$ concentrations likely results from the effect of nocturnal temperature inversions and reduced overnight mixing heights, which trap primary emissions of these emissions close to ground level, allowing them to accumulate. Greater mixing heights during midday allow pollutants to disperse through a larger volume of air, resulting in lower ambient concentrations. Based on the data plotted in Figure 24, this trend is most pronounced during the fall and winter, when the morning maxima in the diurnal profiles are more than twice as great as the afternoon minima, and least pronounced during the summer, when the maximum and minimum in the diurnal profile differ by a factor of only 1.3.

Connell et al. (2005c) also noted that the highest 1-hr $\mathrm{PM}_{2.5}$ concentrations (i.e., those greater than $65 \mu \mathrm{g} / \mathrm{m}^{3}$ ) observed during SCAMP occurred during the early morning and, to a lesser extent, the evening hours, but were never observed during the mid-afternoon between 1:00 and 5:00 p.m. EST. Moreover, the authors observed that the number and severity (measured by the peak 1-hr average concentration) of transient episodes of elevated hourly $\mathrm{PM}_{2.5}$ concentration were greater during fall than during summer. These results, coupled with the observations made above, are consistent with the hypothesis that whereas secondary sulfates and other photochemically produced $\mathrm{PM}_{2.5}$ components in general promote a chronic increase in $\mathrm{PM}_{2.5}$ concentrations across all hours of the day (see Figure 24) during summertime in Steubenville, it is primary $\mathrm{PM}_{2.5}$ emitted locally during overnight and early morning periods of reduced mixing height that results in the highest short-term (e.g., hourly) $\mathrm{PM}_{2.5}$ concentrations in that city. 


\subsubsection{Comparison with Benchmark Values}

To place the concentrations of $\mathrm{PM}_{2.5}, \mathrm{PM}_{2.5}$ component, and co-pollutant concentrations measured at Steubenville in proper perspective, these concentrations must be compared with regulatory, historic, and other benchmarks. Ambient air concentrations of several of the pollutants measured at the Steubenville site are regulated by National Ambient Air Quality Standards. Moreover, concentrations of a number of the species monitored during SCAMP were measured and reported previously at Steubenville as part of the Harvard Six Cities Study, and several of the trace element components of $\mathrm{PM}_{2.5}$ are listed in the Clean Air Act as Hazardous Air Pollutants (HAPs) and have established reference concentrations denoting concentration levels at or below which no adverse health effects (non-cancer) are anticipated as a result of chronic inhalation exposure. Finally, all of the elemental components of $\mathrm{PM}_{2.5}$ measured at Steubenville are present to some extent in the earth's crust; comparing the abundances of these elements in ambient $\mathrm{PM}_{2.5}$ with their crustal abundances can provide some indication of the extent to which their ambient concentrations are enriched by anthropogenic activities. This section compares pollutant concentrations measured at Steubenville during SCAMP with various benchmark values.

\subsection{Comparison with National Ambient Air Quality Standards}

SCAMP data were not collected for the purpose of determining attainment with National Ambient Air Quality Standards, and did not meet all of the criteria required to determine attainment (e.g., 3-year collection period for certain standards). Nevertheless, comparing concentrations measured during SCAMP with NAAQS values helps to establish a context for air quality in Steubenville for the purposes of this report. Table 26 summarizes the primary National Ambient Air Quality Standards that have been set by the U.S. EPA Office of Air Quality Planning and Standards (OAQPS) (U.S. EPA, 2006), which are designed to protect public health. Secondary standards (designed to protect public welfare) are the same as primary standards for lead, $\mathrm{NO}_{2}$, annual $\mathrm{PM}_{10}$, annual $\mathrm{PM}_{2.5}$, and $\mathrm{O}_{3}$; sulfur oxides are subject to a secondary 3-hour standard of $0.5 \mathrm{ppm}$.

Table 26. Summary of primary National Ambient Air Quality Standards (U.S. EPA, 2006).

\begin{tabular}{|c|c|c|c|}
\hline Pollutant & Primary Standard & Averaging Time & Notes \\
\hline \multirow{2}{*}{ Carbon Monoxide } & $9 \mathrm{ppm}$ & 8-hour & \multirow{2}{*}{$\begin{array}{l}\text { Not to be exceeded more than } \\
\text { once/year }\end{array}$} \\
\hline & 35 ppm & 1-hour & \\
\hline Lead & $1.5 \mu \mathrm{g} / \mathrm{m}^{3}$ & Quarterly Average & \\
\hline Nitrogen Dioxide & $0.053 \mathrm{ppm}$ & Annual & Arithmetic Mean \\
\hline \multirow{2}{*}{$\mathrm{PM}_{10}$} & $50 \mu \mathrm{g} / \mathrm{m}^{3}$ & Annual & $\begin{array}{l}\text { 3-yr average of weighted annual } \\
\text { mean }\end{array}$ \\
\hline & $150 \mu \mathrm{g} / \mathrm{m}^{3}$ & 24-hour & $\begin{array}{c}\text { Not to be exceeded more than } \\
\text { once/year }\end{array}$ \\
\hline \multirow{2}{*}{$\mathrm{PM}_{2.5}$} & $15.0 \mu \mathrm{g} / \mathrm{m}^{3}$ & Annual & $\begin{array}{l}\text { 3-yr average of weighted annual } \\
\text { mean }\end{array}$ \\
\hline & $65 \mu \mathrm{g} / \mathrm{m}^{3}$ & 24-hour & $\begin{array}{l}\text { 3-yr average of the } 98^{\text {th }} \text { percentile } \\
\text { of } 24-\mathrm{hr} \text { concentrations }\end{array}$ \\
\hline Ozone & 0.08 ppm & 8-hour & $\begin{array}{l}\text { 3-yr average of } 4^{\text {th }} \text { highest daily } \\
\text { maximum } 8-\text { hr average }\end{array}$ \\
\hline \multirow[b]{2}{*}{ Sulfur Dioxide } & $0.03 \mathrm{ppm}$ & Annual & Arithmetic Mean \\
\hline & $0.14 \mathrm{ppm}$ & 24-hour & $\begin{array}{c}\text { Not to be exceeded more than } \\
\text { once/year }\end{array}$ \\
\hline
\end{tabular}


Data collected as part of SCAMP suggest that Steubenville is at risk of violating the annual $\mathrm{PM}_{2.5}$ NAAQS and the 8-hour ozone NAAQS. Although based on only two years of monitoring data, the mean $\mathrm{PM}_{2.5}$ concentration measured at Steubenville during SCAMP $\left(18.4 \mu \mathrm{g} / \mathrm{m}^{3}\right)$ was $3.4 \mu \mathrm{g} / \mathrm{m}^{3}$ greater than the annual $\mathrm{PM}_{2.5}$ NAAQS of $15 \mu \mathrm{g} / \mathrm{m}^{3}$, and 8-hour average ozone concentrations greater than $0.08 \mathrm{ppm}$ were observed on nine days during the two-year monitoring period. Steubenville is currently designated as a nonattainment area under these two standards. No 24-hr average $\mathrm{PM}_{2.5}$ concentration measured at Steubenville during SCAMP exceeded the 24-hr $\mathrm{PM}_{2.5}$ NAAQS of $65 \mu \mathrm{g} / \mathrm{m}^{3}$; the $98^{\text {th }}$ percentile concentration observed during the program $\left(49.1 \mu \mathrm{g} / \mathrm{m}^{3}\right)$ was well below the current 24-hr NAAQS, but above the revised $24-$ hour standard of $35 \mu \mathrm{g} / \mathrm{m}^{3}$ recently proposed by the U.S. EPA (71 FR 2620).

Concentrations of $\mathrm{CO}, \mathrm{NO}_{2}, \mathrm{PM}_{10}$, and $\mathrm{SO}_{2}$ observed at Steubenville were well below the NAAQS values for these pollutants. As shown in Table 22, no 1-hr average CO concentration during SCAMP exceeded the 1-hr CO standard of $35 \mathrm{ppm}$ or the 8-hr standard of $9 \mathrm{ppm}$, and the average $\mathrm{NO}_{2}$ concentration was less than $1 / 4$ as much as the annual $\mathrm{NO}_{2}$ standard of 0.053 $\mathrm{ppm}$. Mean and maximum $\mathrm{PM}_{10}$ concentrations $\left(27.4\right.$ and $102.2 \mu \mathrm{g} / \mathrm{m}^{3}$, respectively) were substantially less than the annual and 24-hour standards for this pollutant. (The maximum 24-hr average $\mathrm{PM}_{10-2.5}$ concentration of $47.9 \mu \mathrm{g} / \mathrm{m}^{3}$ was also substantially less than the recently proposed $24-\mathrm{hr}$ standard of $70 \mu \mathrm{g} / \mathrm{m}^{3}$ for inhalable coarse particles). The overall average $\mathrm{SO}_{2}$ concentration at Steubenville was about $65 \%$ less than the annual $\mathrm{SO}_{2} \mathrm{NAAQS}$, and maximum 24-hr and 1-hr average concentrations of 0.0601 and $0.2339 \mathrm{ppm}$, respectively, were appreciably less than the 24-hr primary NAAQS and 3-hr secondary NAAQS for this pollutant. Lead was not measured in TSP at Steubenville, preventing a comparison with the Pb NAAQS.

\subsection{Comparison with Six Cities Study Concentrations}

Table 27 compares concentrations of ambient air pollutants measured at Steubenville between 2000 and 2002 as part of SCAMP with concentrations measured there in the late 1970s and 1980s as part of the Harvard Six Cities Study (Dockery et al., 1993; Laden et al., 2000).

Table 27. Comparison of mean pollutant concentrations observed at the SCAMP central Steubenville site (2000-2002) with mean pollutant concentrations observed in Steubenville during the Six Cities Study. $\mathrm{PM}_{2.5}$ total mass concentrations are in $\mu \mathrm{g} / \mathrm{m}^{3} ; \mathrm{PM}_{2.5}$ component concentrations are in $\mathrm{ng} / \mathrm{m}^{3}$, and gas concentrations are in ppb.

\begin{tabular}{|l|c|c|c|c|}
\hline Pollutant & Six Cities Mean & Six Cities Period & SCAMP Mean & \% Change \\
\hline $\mathrm{PM}_{2.5}$ Total Mass & $30.5^{\mathrm{a}}$ & $1979-1988$ & 18.4 & $-40 \%$ \\
\hline $\mathrm{PM}_{2.5} \mathrm{Al}$ & $186.8^{\mathrm{a}}$ & $1979-1988$ & 97.7 & $-48 \%$ \\
\hline $\mathrm{PM}_{2.5} \mathrm{Ca}$ & $102^{\mathrm{a}}$ & $1979-1988$ & 136 & $+33 \%$ \\
\hline $\mathrm{PM}_{2.5} \mathrm{Cu}$ & $11.9^{\mathrm{a}}$ & $1979-1988$ & 3.2 & $-73 \%$ \\
\hline $\mathrm{PM}_{2.5} \mathrm{Fe}$ & $542^{\mathrm{a}}$ & $1979-1988$ & 272 & $-50 \%$ \\
\hline $\mathrm{PM}_{2.5} \mathrm{~K}$ & $344^{\mathrm{a}}$ & $1979-1988$ & 91 & $-74 \%$ \\
\hline $\mathrm{PM}_{2.5} \mathrm{Mn}$ & $30.4^{\mathrm{a}}$ & $1979-1988$ & 14.6 & $-52 \%$ \\
\hline $\mathrm{PM}_{2.5} \mathrm{Ni}$ & $3.7^{\mathrm{a}}$ & $1979-1988$ & 1.1 & $-70 \%$ \\
\hline $\mathrm{PM}_{2.5} \mathrm{~Pb}$ & $184.5^{\mathrm{a}}$ & $1979-1988$ & 15.3 & $-92 \%$ \\
\hline $\mathrm{PM}_{2.5} \mathrm{Se}$ & $5.2^{\mathrm{a}}$ & $1979-1988$ & 3.3 & $-37 \%$ \\
\hline $\mathrm{PM}_{2.5} \mathrm{SO}{ }^{2-}$ & $12745^{\mathrm{a}, \mathrm{c}}$ & $1979-1988$ & 5800 & $-54 \%$ \\
\hline $\mathrm{PM}_{2.5} \mathrm{~V}$ & $10.5^{\mathrm{a}}$ & $1979-1988$ & 1.5 & $-86 \%$ \\
\hline $\mathrm{PM}_{2.5} \mathrm{Zn}$ & $138.4^{\mathrm{a}}$ & $1979-1988$ & 84.4 & $-39 \%$ \\
\hline $\mathrm{SO}_{2}$ & $24.0^{b}$ & $1977-1985$ & 10.5 & $-56 \%$ \\
\hline $\mathrm{NO}_{2}$ & $21.9^{b}$ & $1977-1985$ & 12.7 & $-42 \%$ \\
\hline $\mathrm{O}_{3}$ & $22.3^{b}$ & $1977-1985$ & 28.4 & $+27 \%$ \\
\hline
\end{tabular}

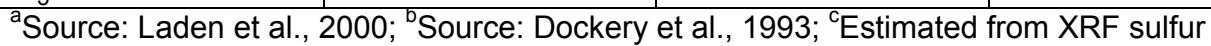


As shown in the table, concentrations of all of the pollutants examined except for $\mathrm{O}_{3}$ and fine particulate $\mathrm{Ca}$ had lower measured means in Steubenville during SCAMP than during the Harvard Six Cities Study. These differences may be due in part to analytical error, as the two monitoring campaigns used different sampling and analytical techniques. However, as discussed by Connell et al. (2005a), the widespread trend of decreasing pollutant concentrations observed at Steubenville is likely related to declines in population and industrial activity in Steubenville, leading to corresponding declines in emissions, as well as to advances in the application of air pollution control technology, spurred in part by the 1990 Clean Air Act amendments and other environmental regulations. Although $\mathrm{PM}_{2.5}$ concentrations in Steubenville remain above the annual $\mathrm{PM}_{2.5}$ NAAQS, the data presented in Table 27 suggest that the average total mass of ambient $\mathrm{PM}_{2.5}$ in that city has decreased by about $40 \%$ since the Six Cities Study was conducted. Concentrations of $\mathrm{SO}_{4}{ }^{2-}$, the largest chemical component of $\mathrm{PM}_{2.5}$ in Steubenville, and of $\mathrm{SO}_{2}$, its gaseous precursor, showed even larger decreases of 54$56 \%$. Fine particulate $\mathrm{Pb}$ exhibited the largest relative decrease in ambient concentration of all of the pollutants compared in Table 27, likely reflecting the discontinued use of leaded gasoline (Connell et al., 2006).

\subsection{Comparison with Health Reference Concentrations}

Seven of the trace elements (As, $\mathrm{Cd}, \mathrm{Co}, \mathrm{Mn}, \mathrm{Ni}, \mathrm{Pb}$, and $\mathrm{Se}$ ) determined in $\mathrm{PM}_{2.5}$ at Steubenville during SCAMP are listed as Hazardous Air Pollutants (HAPs) in the 1990 Clean Air Act amendments. To obtain some indication of the potential for adverse health effects resulting from these elements in $\mathrm{PM}_{2.5}$ in Steubenville, mean ambient air concentrations of these elements measured during SCAMP were compared with non-cancer chronic inhalation reference concentrations (RfCs), minimal risk levels (MRLs), and reference exposure levels (RELs) established by the U.S. Environmental Protection Agency (EPA), U.S. Agency for Toxic Substances and Disease Registry (ATSDR), and California EPA, respectively (U.S. EPA, $2005 b)$. These reference values represent concentration levels at or below which no adverse non-cancer health effects are anticipated as a result of chronic exposure. Although the reference values are based upon total airborne concentrations of the elements of interest, and not only the fine particulate fraction, they provide some basis for making a preliminary assessment.

Table 28 compares mean ambient air concentrations of the seven HAP elements determined in the acid-digestible $\mathrm{PM}_{2.5}$ fraction during SCAMP with the most stringent non-cancer reference concentrations established for these elements by one of the agencies listed above. For all seven elements, mean ambient air concentrations were below the non-cancer reference concentrations. Fine particulate manganese had the highest average concentration relative to the reference concentrations; the mean $\mathrm{PM}_{2.5}$ Mn concentration at Steubenville was about 37\% as great as the chronic inhalation MRL. Mean concentrations of $\mathrm{As}, \mathrm{Cd}, \mathrm{Ni}$, and Pb were 1/10 to $1 / 100$ as much as the most stringent reference concentrations, and mean concentrations of Co and Se were less than 1/1000 as much as the reference concentrations. Based upon this preliminary analysis, the risk of non-cancer adverse health effects resulting from chronic exposure to any of these single elemental constituents of $\mathrm{PM}_{2.5}$ in Steubenville appears to be low. However, it is important to note that based on the data presented in Table 16, fine particles on average contributed only about $39 \%$ of the mass of water-extractable $\mathrm{Mn}$ measured in $\mathrm{PM}_{10}$ in Steubenville. Hence, it is possible that if all particle sizes were considered, total airborne Mn in Steubenville may approach or exceed the chronic inhalation MRL. Further research should be conducted to determine whether there is any risk of adverse health effects associated with total suspended Mn in Steubenville. 
Table 28. Comparison of mean ambient air HAP concentrations in $\mathrm{PM}_{2.5}$ at Steubenville during SCAMP with non-cancer chronic inhalation RfCs, MRLs and RELs.

\begin{tabular}{|c|c|c|}
\hline Element & $\begin{array}{c}\text { Mean Ambient Air } \\
\text { Concentration in Acid- } \\
\text { Digestible } \mathbf{P M}_{\mathbf{2}} \text { Fraction } \\
\left(\mathbf{n g}_{\mathbf{3}} \mathbf{)}\right.\end{array}$ & $\begin{array}{c}\text { Most Stringent Non-Cancer } \\
\text { Reference Concentration } \\
\left(\mathbf{n g} / \mathbf{m}^{3}\right)\end{array}$ \\
\hline $\mathrm{As}$ & 1.64 & $30(\mathrm{REL})$ \\
\hline $\mathrm{Cd}$ & 0.46 & $20(\mathrm{REL})$ \\
\hline $\mathrm{Co}$ & 0.065 & $100(\mathrm{MRL})$ \\
\hline $\mathrm{Mn}$ & 14.6 & $40(\mathrm{MRL})$ \\
\hline $\mathrm{Ni}$ & 1.1 & $50(\mathrm{REL})$ \\
\hline $\mathrm{Pb}$ & 15.3 & $1,500(\mathrm{RfC})$ \\
\hline $\mathrm{Se}$ & 3.30 & $20,000(\mathrm{REL})$ \\
\hline
\end{tabular}

No chronic inhalation reference concentrations have been adopted by the agencies named above for transition metals such as Fe and Zn; however, as discussed by Connell et al. (2006), airborne concentrations of these elements, which have been implicated in $\mathrm{PM}_{2.5}$ toxicology studies, in $\mathrm{PM}_{2.5}$ at Steubenville during SCAMP were appreciably greater than concentrations reported recently for other U.S. Cities (Appendix D). Further research should be conducted to better elucidate whether these metals play any role in the health effects previously associated with $\mathrm{PM}_{2.5}$ in Steubenville.

In addition to the non-cancer reference concentrations discussed above, the U.S. EPA (2005b) identifies $\mathrm{As}$ as a carcinogen and $\mathrm{Cd}$ as a probable carcinogen. Based upon the chronic inhalation Unit Risk Estimates (UREs) that have been established for these elements and the range of mean ambient concentrations determined in the water-extractable $\mathrm{PM}_{2.5}$ fraction, aciddigestible $\mathrm{PM}_{2.5}$ fraction, and water-extractable $\mathrm{PM}_{10}$ fraction during SCAMP (both elements appeared to be largely water-extractable and largely present in the fine particle fraction), mean airborne As concentrations observed at Steubenville during SCAMP correspond to a cancer risk of about 7 in 1,000,000 to 11 in 1,000,000, and mean airborne Cd concentrations correspond to a cancer risk of about 1 in 1,000,000 or less. (The risk estimates for As should be interpreted with some caution, as the greatest mean ambient concentration and hence the greatest cancer risk was observed for the water-extractable $\mathrm{PM}_{2.5}$ fraction, which is physically expected to have the lowest ambient concentration. This incongruity may indicate the presence of sampling or analytical error, which would bias the risk estimate).

\subsection{Comparison with Crustal Abundances}

Although natural abundances of trace elements in the Earth's crust are very small, anthropogenic activities (or natural processes such as geologic weathering, volcanic eruptions, wildfires, etc.) can enrich the abundances of these elements in ambient $\mathrm{PM}_{2.5}$. In order to ascertain the extent to which such enrichment occurs in Steubenville, enrichment factors were calculated for each of the 18 elements measured in the acid-digestible $\mathrm{PM}_{2.5}$ fraction during SCAMP. For this analysis, the enrichment factor (EF) was computed as:

$$
E F(X)=\frac{(X / A l)_{P M 2.5}}{(X / A l)_{c r u s t a l}}
$$

where $X$ is the concentration of the element for which an enrichment factor is being computed, $(\mathrm{X} / \mathrm{Al})_{\mathrm{PM} 2.5}$ is the ratio of that element's mean mass concentration in $\mathrm{PM}_{2.5}$ at Steubenville to the 
mean mass concentration of $\mathrm{Al}$ in $\mathrm{PM}_{2.5}$ at Steubenville, and $(\mathrm{X} / \mathrm{Al})_{\text {crustal }}$ is the ratio of that element's average crustal concentration to the average crustal concentration of Al. Hence, it is assumed that most of the Al present in $\mathrm{PM}_{2.5}$ at Steubenville is associated with crustal material. Lacking data specific to Steubenville, the average crustal composition reported by Mason (1966) was used to compute values of $(\mathrm{X} / \mathrm{Al})_{\text {crustal. }}$.

Figure 26 shows $\mathrm{PM}_{2.5}$ enrichment factors at Steubenville for the 18 elements measured during SCAMP. The EFs for As, $\mathrm{Cd}, \mathrm{Pb}, \mathrm{Sn}, \mathrm{Zn}$, and especially Se were markedly high, ranging from 565 for Sn to almost 55,000 for Se. All of these elements are expected in emissions from industrial sources (e.g., coal-fired power plants, metal smelting and processing plants, coke plants, incinerators, etc.) that are prevalent in the Steubenville area; the large EFs likely reflect major anthropogenic contributions to their ambient concentrations. As expected, the most abundant crustal elements (i.e., $\mathrm{Fe}, \mathrm{Ca}, \mathrm{K}, \mathrm{Mg}, \mathrm{Ti}$ ) had much lower enrichment factors than the trace metal species, ranging from 1.9 for $\mathrm{Mg}$ to 4.5 for $\mathrm{Fe}$, although it is noteworthy that the Alnormalized EFs for all of these elements were greater than one. Probable emission sources of these enriched elements are discussed later in this report in the section on source apportionment.

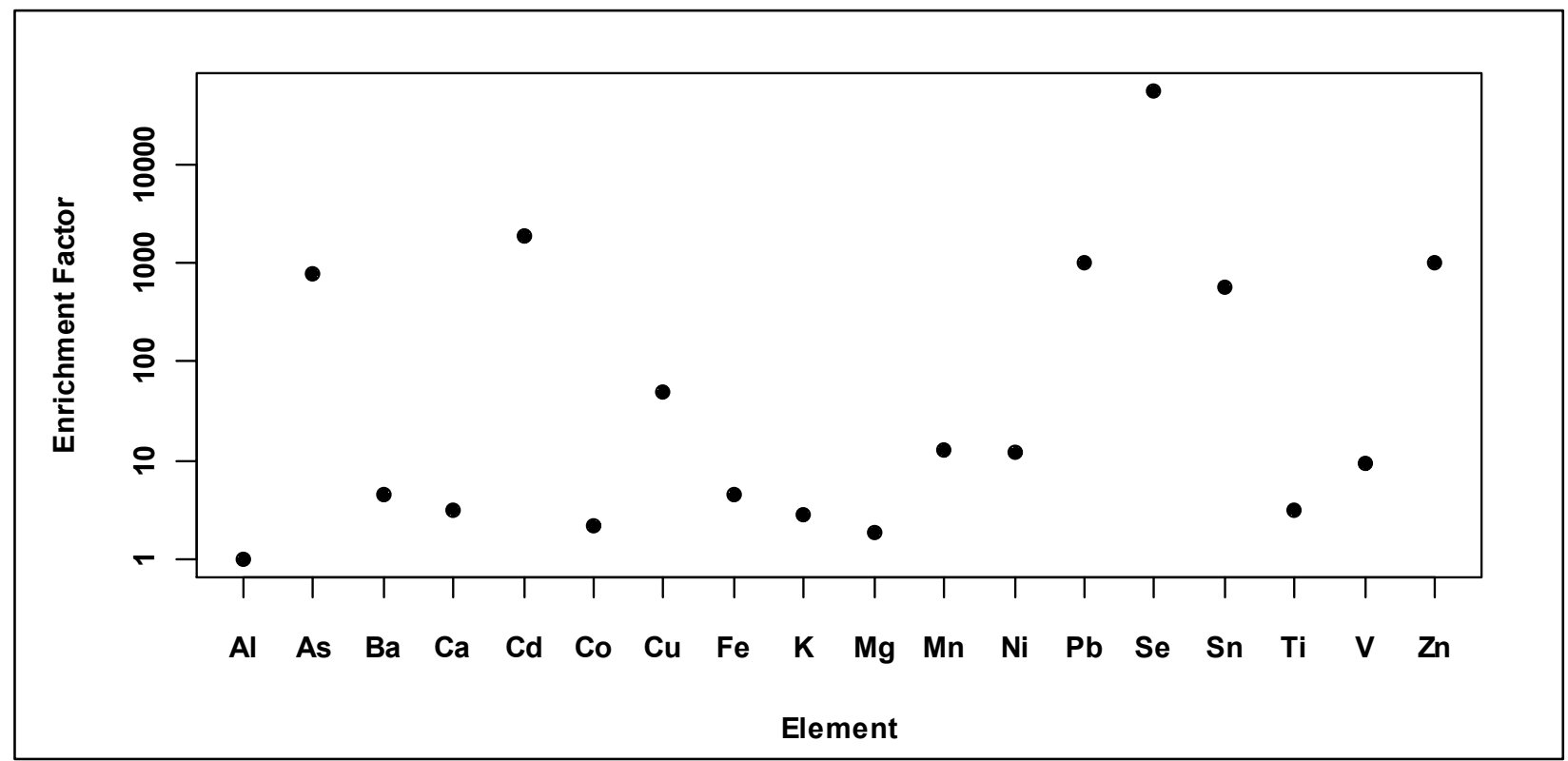

Figure 26. Al-normalized enrichment factors for elements in $\mathrm{PM}_{2.5}$ at Steubenville.

\subsubsection{Spatial Variability of $\mathrm{PM}_{2.5}$ in the Steubenville Region}

As discussed earlier, in addition to measurements made at the central site in Steubenville, the ambient air monitoring portion of SCAMP included measurements of $\mathrm{PM}_{2.5}$ and its waterextractable ionic and elemental components at four satellite sites surrounding the city, permitting a characterization of the spatial variability of these species in the Steubenville region.

Table 29 summarizes the overall mean 24-hr $\mathrm{PM}_{2.5}$ and water-extractable $\mathrm{PM}_{2.5}$ component concentrations observed at each of the SCAMP satellite sites. Mean concentrations at the Steubenville site are also provided for reference. The overall mean concentrations observed at the satellite sites were less than that observed at Steubenville, ranging from $13.9 \mu \mathrm{g} / \mathrm{m}^{3}$ at the northern and western sites to $16.0 \mu \mathrm{g} / \mathrm{m}^{3}$ at the southern site. The southern and eastern sites had mean concentrations that were greater than the annual $\mathrm{PM}_{2.5}$ NAAQS of $15 \mu \mathrm{g} / \mathrm{m}^{3}$. 
Although not shown in Table 29, maximum 24-hr concentrations at the satellite sites were all less than the current 24-hr $\mathrm{PM}_{2.5}$ NAAQS of $65 \mu \mathrm{g} / \mathrm{m}^{3}$, ranging from $51.1 \mu \mathrm{g} / \mathrm{m}^{3}$ at the southern site to $64.8 \mu \mathrm{g} / \mathrm{m}^{3}$ at the western site. Ninety-eighth percentile concentrations at the satellite sites ranged from $34.4 \mu \mathrm{g} / \mathrm{m}^{3}$ at the western site to $40.6 \mu \mathrm{g} / \mathrm{m}^{3}$ at the eastern site.

As with the Steubenville site, sulfate was the most abundant of the measured $\mathrm{PM}_{2.5}$ components at each of the satellite sites, accounting for $4.5-5.9 \mu \mathrm{g} / \mathrm{m}^{3}$, or about $32-37 \%$, of the total $\mathrm{PM}_{2.5}$ mass across the four sites. (Organic material, the second most abundant $\mathrm{PM}_{2.5}$ component at Steubenville, was not measured at the satellite sites as part of SCAMP). Ammonium, nitrate, and chloride accounted for about $12-14 \%, 4.6-6.3 \%$, and $0.35-0.46 \%$, respectively, of the total $\mathrm{PM}_{2.5}$ mass at the satellite sites based on the mean concentrations shown in Table 29.

Seasonal and weekday/weekend trends observed at the satellite sites for $\mathrm{PM}_{2.5}$ and its major components were generally similar to those observed at the central Steubenville site. Figure 27 is a plot of the ratios of the median warm season (April-September) daily average $\mathrm{PM}_{2.5}$ concentration to the median cool season (October-March) daily average $\mathrm{PM}_{2.5}$ concentration for each of the five SCAMP ambient monitoring sites. Solid points indicate statistically significant (i.e., at $\alpha=0.05$ ) differences in the locations of the distributions of 24-hr average concentrations observed during the warm and cool seasons, based on the application of Wilcoxon rank sum tests. Like the Steubenville site, each of the satellite sites exhibited a statistically significant trend of greater warm season and lesser cool season concentrations. Median warm season concentrations were $20-40 \%$ greater than median cool season concentrations at all of the SCAMP ambient air monitoring sites.

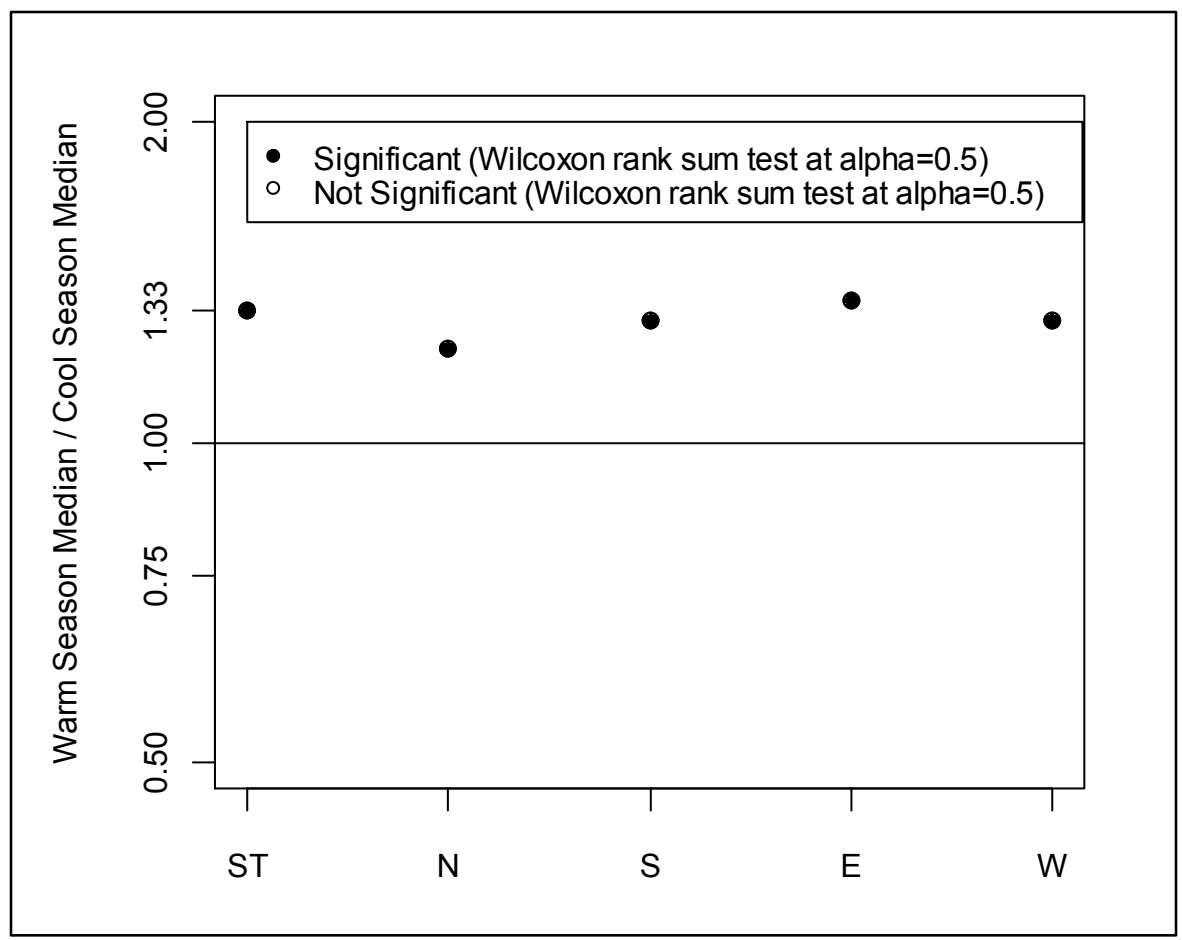

Figure 27. Ratios of warm-to-cool season median concentrations for $\mathrm{PM}_{2.5}$ at the SCAMP ambient air monitoring sites. Solid points indicate statistically significant seasonal differences. 
Table 29. Summary statistics for 24-hr average mass concentrations of $\mathrm{PM}_{2.5}$ and water-extractable $\mathrm{PM}{ }_{2.5}$ components $\left(\mu \mathrm{g} / \mathrm{m}^{3}\right)$ at the five SCAMP ambient air monitoring sites, 2000-2002.

\begin{tabular}{|c|c|c|c|c|c|c|c|c|c|c|c|c|c|c|c|}
\hline & \multicolumn{3}{|c|}{ Steubenville } & \multicolumn{3}{|c|}{ North } & \multicolumn{3}{|c|}{ South } & \multicolumn{3}{|c|}{ East } & \multicolumn{3}{|c|}{ West } \\
\hline & $\mathbf{N}$ & Mean & SD & $\mathbf{N}$ & Mean & SD & $\mathbf{N}$ & Mean & SD & $\mathbf{N}$ & Mean & SD & $\mathbf{N}$ & Mean & SD \\
\hline $\mathbf{P M}_{2.5}$ & 640 & 18.4 & 11.2 & 663 & 13.9 & 7.7 & 416 & 16.0 & 8.8 & 672 & 15.2 & 8.7 & 587 & 13.9 & 8.3 \\
\hline $\mathrm{NH}^{+}$ & 151 & 2.3 & 1.5 & 161 & 1.7 & 1.1 & 96 & 2.2 & 1.4 & 158 & 1.9 & 1.4 & 129 & 1.8 & 1.1 \\
\hline $\mathrm{SO}_{4}{ }^{2-}$ & 151 & 5.8 & 4.1 & 161 & 4.5 & 3.8 & 96 & 5.9 & 4.3 & 155 & 5.1 & 4.4 & 129 & 4.9 & 4.1 \\
\hline $\mathrm{NO}_{3}{ }^{-}$ & 151 & 1.16 & 1.16 & 161 & 0.71 & 0.97 & 96 & 0.73 & 0.95 & 155 & 0.74 & 0.93 & 129 & 0.88 & 1.14 \\
\hline $\mathrm{Cl}^{-}$ & 151 & 0.21 & 0.51 & 161 & 0.06 & 0.10 & 96 & 0.07 & 0.08 & 155 & 0.07 & 0.18 & 129 & 0.05 & 0.06 \\
\hline Al & 128 & 0.019 & 0.019 & 125 & 0.010 & 0.008 & 50 & 0.012 & 0.009 & 136 & 0.009 & 0.009 & 91 & 0.010 & 0.008 \\
\hline As & 140 & 0.00259 & 0.00284 & 138 & 0.00173 & 0.00102 & 65 & 0.00193 & 0.00107 & 144 & 0.00172 & 0.00098 & 112 & 0.00139 & 0.00069 \\
\hline $\mathrm{Ba}$ & 141 & 0.0019 & 0.0013 & 137 & 0.0011 & 0.0007 & 68 & 0.0037 & 0.0033 & 142 & 0.0018 & 0.0012 & 100 & 0.0013 & 0.0015 \\
\hline $\mathrm{Ca}$ & 111 & 0.078 & 0.051 & 117 & 0.049 & 0.033 & 52 & 0.059 & 0.035 & 123 & 0.053 & 0.039 & 74 & 0.060 & 0.031 \\
\hline $\mathrm{Cd}$ & 141 & 0.00051 & 0.00067 & 137 & 0.00037 & 0.00035 & 68 & 0.00039 & 0.00038 & 141 & 0.00033 & 0.00028 & 100 & 0.00034 & 0.00033 \\
\hline Co & 142 & 0.000037 & 0.000021 & 141 & 0.000035 & 0.000025 & 70 & 0.000049 & 0.000056 & 143 & 0.000044 & 0.000048 & 109 & 0.000054 & 0.000068 \\
\hline $\mathrm{Cu}$ & 124 & 0.0028 & 0.0027 & 118 & 0.0022 & 0.0026 & 61 & 0.0030 & 0.0025 & 122 & 0.0028 & 0.0039 & 98 & 0.0021 & 0.0018 \\
\hline $\mathrm{Fe}$ & 125 & 0.019 & 0.023 & 120 & 0.011 & 0.013 & 56 & 0.014 & 0.012 & 119 & 0.012 & 0.012 & 78 & 0.010 & 0.011 \\
\hline $\mathrm{K}$ & 126 & 0.099 & 0.062 & 118 & 0.077 & 0.047 & 50 & 0.085 & 0.058 & 129 & 0.105 & 0.088 & 96 & 0.066 & 0.033 \\
\hline $\mathrm{Mg}$ & 142 & 0.029 & 0.036 & 142 & 0.013 & 0.017 & 71 & 0.011 & 0.011 & 144 & 0.010 & 0.007 & 112 & 0.012 & 0.010 \\
\hline$M n$ & 133 & 0.0078 & 0.0080 & 131 & 0.0036 & 0.0037 & 64 & 0.0033 & 0.0042 & 137 & 0.0024 & 0.0017 & 93 & 0.0030 & 0.0035 \\
\hline $\mathrm{Na}$ & 115 & 0.090 & 0.074 & 119 & 0.054 & 0.030 & 64 & 0.060 & 0.043 & 126 & 0.058 & 0.030 & 93 & 0.062 & 0.057 \\
\hline $\mathbf{N i}$ & 139 & 0.0006 & 0.0006 & 138 & 0.0006 & 0.0007 & 71 & 0.0010 & 0.0014 & 141 & 0.0008 & 0.0013 & 105 & 0.0011 & 0.0025 \\
\hline $\mathrm{Pb}$ & 136 & 0.0090 & 0.0128 & 131 & 0.0046 & 0.0035 & 64 & 0.0047 & 0.0035 & 134 & 0.0047 & 0.0037 & 93 & 0.0042 & 0.0030 \\
\hline Se & 137 & 0.00473 & 0.00493 & 134 & 0.00516 & 0.00534 & 68 & 0.00410 & 0.00296 & 132 & 0.00557 & 0.00666 & 102 & 0.00375 & 0.00350 \\
\hline Sn & 142 & 0.00022 & 0.00031 & 139 & 0.00017 & 0.00019 & 68 & 0.00021 & 0.00023 & 142 & 0.00042 & 0.00066 & 100 & 0.00021 & 0.00023 \\
\hline V & 143 & 0.00105 & 0.00133 & 142 & 0.00075 & 0.00079 & 71 & 0.00079 & 0.00061 & 144 & 0.00056 & 0.00041 & 112 & 0.00056 & 0.00049 \\
\hline $\mathrm{Zn}$ & 143 & 0.0555 & 0.0745 & 142 & 0.0199 & 0.0142 & 71 & 0.0180 & 0.0083 & 143 & 0.0189 & 0.0158 & 112 & 0.0173 & 0.0134 \\
\hline
\end{tabular}


Figure 28 shows ratios of median warm season concentrations to median cool season concentrations for $\mathrm{PM}_{2.5}$ ions and water-soluble elemental components that were measured every fourth day at Steubenville and each of the four satellite sites during SCAMP. Sulfate concentrations were significantly greater during the warm season than during the cool season, and nitrate concentrations were significantly greater during the cool season than during the warm season at all five sites, consistent with the previously discussed effects of meteorology

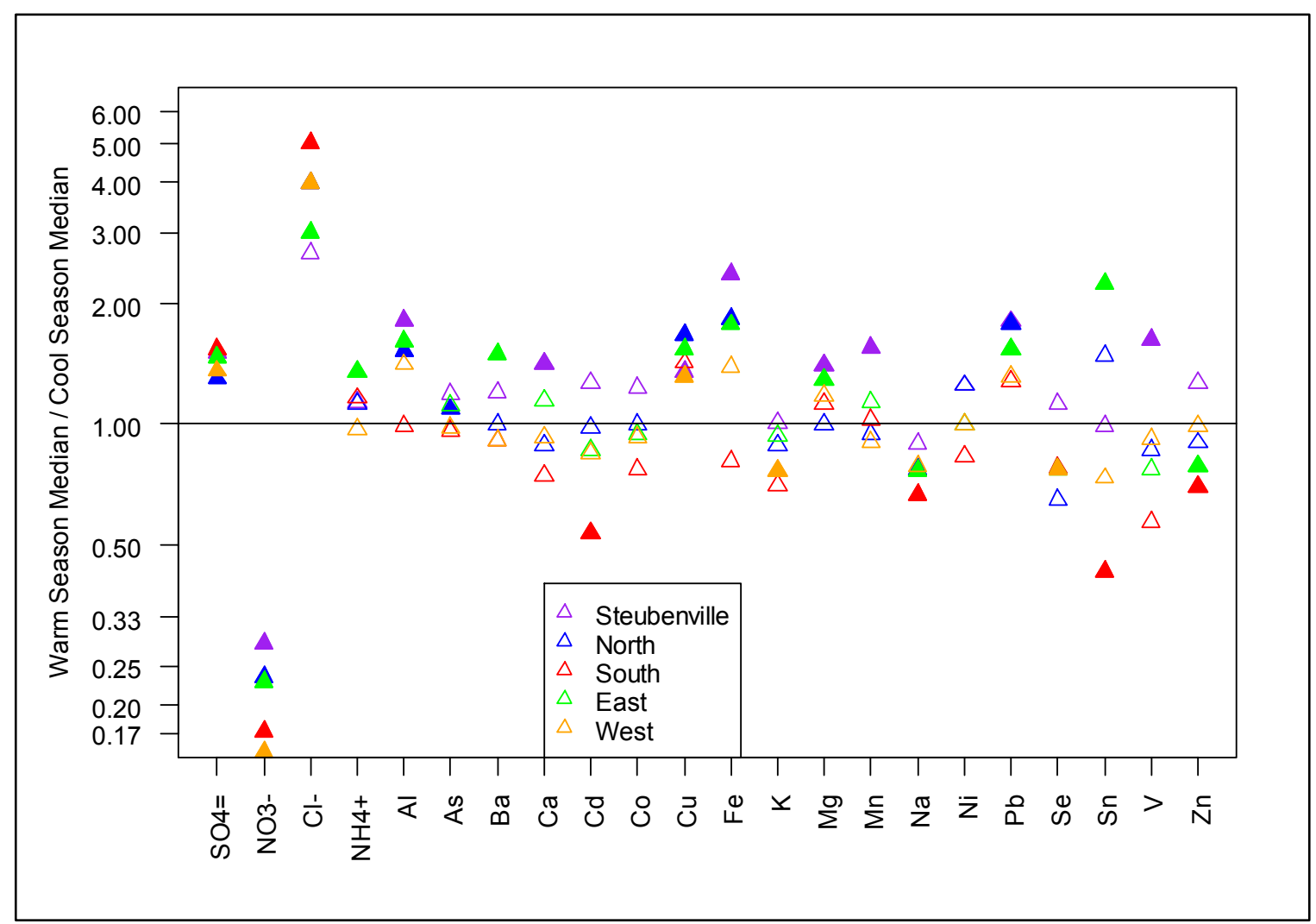

Figure 28. Ratios of warm-to-cool season median concentrations for $\mathrm{PM}_{2.5}$ water-extractable ionic and elemental components at the SCAMP ambient air monitoring sites. Solid points indicate statistically significant seasonal differences, based on the results of Wilcoxon rank sum tests at $\alpha=0.05$.

and ammonium availability on concentrations of these $\mathrm{PM}_{2.5}$ components. Among the other water-extractable $\mathrm{PM}_{2.5}$ components, $\mathrm{Cl}^{-}, \mathrm{Al}, \mathrm{Cu}, \mathrm{Fe}$, and $\mathrm{Pb}$ had significantly greater ambient concentrations during the warm season than during the cool season at a majority (i.e., at least three out of five) of the sites. These seasonal variations may be due to seasonal differences in emissions or to seasonal differences in meteorology or atmospheric chemistry that affect ambient concentrations or solubility. The list above includes the three elements ( $\mathrm{Al}, \mathrm{Fe}$, and $\mathrm{Pb})$ for which fractional solubilities were significantly greater during the warm season than during the cool season at the Steubenville site. Conversely, concentrations of water-extractable Na were significantly greater during the cool season than during the warm season at three of the five monitoring sites.

Weekday/weekend differences in $\mathrm{PM}_{2.5}$ concentrations observed at the five SCAMP ambient air monitoring sites are summarized in Figure 29. At all of the sites, median 24-hr $\mathrm{PM}_{2.5}$ concentrations observed during weekdays (Monday through Friday) were 6-11\% greater than 
those observed during the weekend (Saturday and Sunday); however, the weekday/weekend difference only reached statistical significance for the northern site. As shown in Figure 30, which summarizes weekday/weekend differences in concentrations of $\mathrm{PM}_{2.5}$ water-extractable ionic and elemental components at the five monitoring sites, the only $\mathrm{PM}_{2.5}$ component that exhibited a consistent, statistically significant weekday/weekend trend at a majority of the SCAMP ambient air monitoring sites was water-extractable Ba. Median concentrations of water-extractable Ba were $19-57 \%$ greater during weekdays than during the weekend at each of the sites, and this difference was statistically significant for four of the five sites. As shown earlier in Figures 22 and 23, ambient concentrations of $\mathrm{Ba}$ in the acid-digestible $\mathrm{PM}_{2.5}$ fraction and water-extractable $\mathrm{PM}_{10}$ fraction were also significantly greater during weekdays than during the weekend. This weekday/weekend trend may reflect the impact of weekly variations in motor vehicle emissions, which would be expected to impact all of the monitoring sites to some extent, on ambient $\mathrm{PM}_{2.5}$ in the Steubenville region. Ba is found in brake wear emissions (Garg et al., 2000) and has been suggested as an elemental tracer for heavy-duty diesel truck emissions (Chellam et al., 2005). As shown in Figure 23, concentrations of elemental carbon, which is also commonly used as a tracer for diesel emissions (Suarez and Ondov, 2002), likewise showed a significant trend of greater weekday and lower weekend concentrations at the Steubenville site.

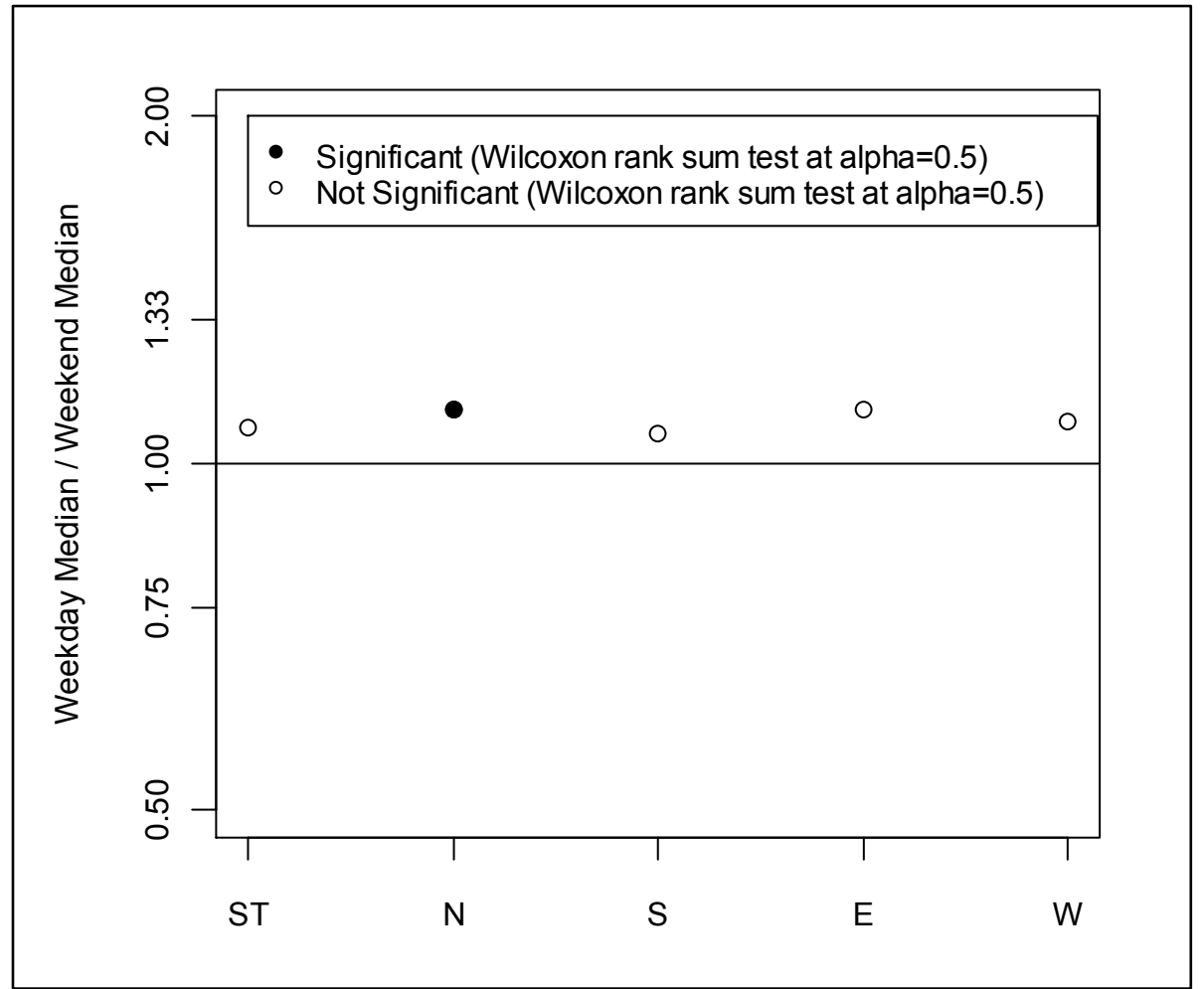

Figure 29. Ratios of weekday-to-weekend median concentrations for $\mathrm{PM}_{2.5}$ at the SCAMP ambient air monitoring sites. Solid points indicate statistically significant weekday/weekend differences. 


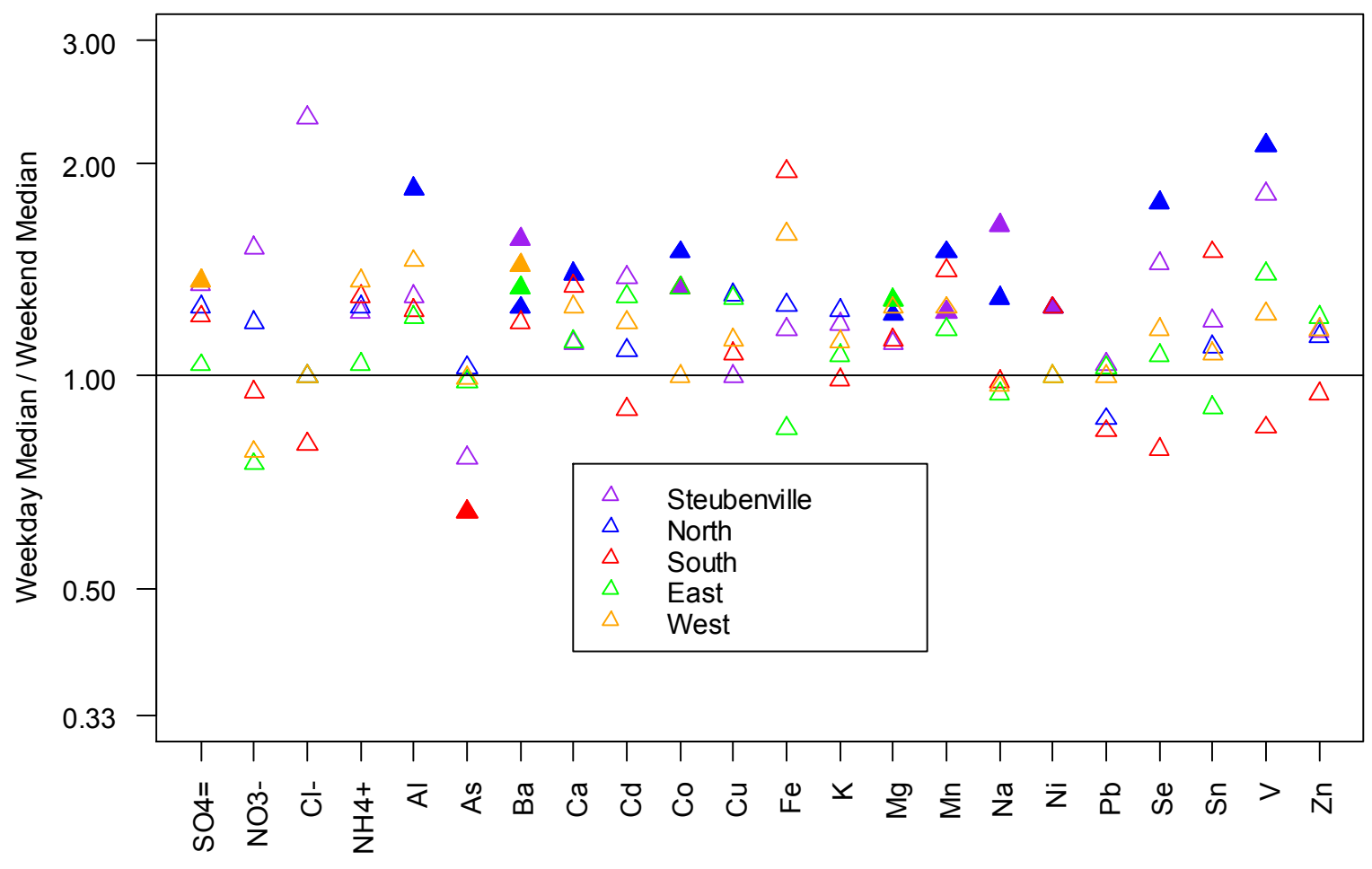

Figure 30. Ratios of weekday-to-weekend median concentrations for $\mathrm{PM}_{2.5}$ water-extractable ionic and elemental components at the SCAMP ambient air monitoring sites. Solid points indicate statistically significant weekday/weekend differences, based on the results of Wilcoxon rank sum tests at $\alpha=0.05$.

Having characterized the overall average concentrations of $\mathrm{PM}_{2.5}$ and its water-extractable components at the SCAMP satellite sites, as well as the seasonal and weekday/weekend variability in these concentrations, it is important to focus specifically on the following two questions:

1. To what extent are ambient $\mathrm{PM}_{2.5}$ and $\mathrm{PM}_{2.5}$ chemical component concentrations at Steubenville greater than or less than $\mathrm{PM}_{2.5}$ and $\mathrm{PM}_{2.5}$ chemical component concentrations in the surrounding region?

2. To what extent do concentrations of $\mathrm{PM}_{2.5}$ and its chemical components correlate in space across the Steubenville region?

Answering the first question is important for quantifying the effect of local sources in Steubenville on ambient $\mathrm{PM}_{2.5}$ concentrations there, as well as for gaining insights relevant to assessing the possible toxicological potency of the urban increment of $\mathrm{PM}_{2.5}$ mass. Answering the second question is important for assessing the extent to which concentrations measured at a given site in the Steubenville region are appropriate for representing day-to-day variations in the exposure of the region's population for the purposes of a time series epidemiology study. These questions are explored in the next two subsections. 


\subsubsection{Spatial Variability in the Magnitude of $\mathrm{PM}_{2.5}$ and $\mathrm{PM}_{2.5}$ Component Concentrations}

Table 29 provides a preliminary basis for comparing the magnitude of $\mathrm{PM}_{2.5}$ and $\mathrm{PM}_{2.5}$ component concentrations in Steubenville with the magnitude of these concentrations in the surrounding region. Based on the data provided in the table, the overall mean $\mathrm{PM}_{2.5}$ concentration at the central Steubenville site was $15-32 \%$ greater than the overall mean $\mathrm{PM}_{2.5}$ concentrations at each of the four surrounding satellite sites. Mean concentrations at the Steubenville site were greater than those at each of the four satellite sites for 14 of the $22 \mathrm{PM}_{2.5}$ components (i.e., $\mathrm{NH}_{4}{ }^{+}, \mathrm{NO}_{3}{ }^{-}, \mathrm{Cl}^{-}$, and water-extractable $\mathrm{Al}, \mathrm{As}, \mathrm{Ca}, \mathrm{Cd}, \mathrm{Fe}, \mathrm{Mg}, \mathrm{Mn}, \mathrm{Na}, \mathrm{Pb}, \mathrm{V}$, and $\mathrm{Zn}$ ) that were measured at all of the sites. The data suggest that $\mathrm{Cl}^{-}$and water-extractable $\mathrm{Mg}, \mathrm{Mn}$, and $\mathrm{Zn}$ were particularly enriched at the Steubenville site relative to the surrounding region; overall mean concentrations of these $\mathrm{PM}_{2.5}$ components measured at Steubenville were at least twice as great as mean concentrations measured at each of the satellite sites.

Given the presence of missing values in the SCAMP dataset and the appreciable temporal variability in $\mathrm{PM}_{2.5}$ and co-pollutant concentrations in the Steubenville region, intersite comparisons are more appropriately made using pairwise daily data than overall means, as comparisons based on the latter may be biased by the presence or absence of missing values during periods of high or low concentrations. Figure 31 presents parity plots comparing 24-hr average $\mathrm{PM}_{2.5}$ concentrations measured at each satellite site with corresponding 24-hr average $\mathrm{PM}_{2.5}$ concentrations measured at the Steubenville site. For all of the satellite sites, a majority of the points fall below the parity line, suggesting that $\mathrm{PM}_{2.5}$ concentrations at the satellite sites tended to be lower than $\mathrm{PM}_{2.5}$ concentrations at the Steubenville site. This trend is further quantified in Figure 32, which shows the percentage of days for which $\mathrm{PM}_{2.5}$ and waterextractable $\mathrm{PM}_{2.5}$ component concentrations observed at the Steubenville site were greater than corresponding concentrations observed at each satellite site. For total $\mathrm{PM}_{2.5}$ mass, the trend of greater Steubenville and lesser satellite site concentrations was most pronounced for the northern and western satellite sites, for which about $83 \%$ of the daily $\mathrm{PM}_{2.5}$ concentrations were less than corresponding concentrations at Steubenville, and least pronounced for the eastern site, for which $64 \%$ of daily concentrations were less than those at Steubenville. This is reasonable, as the northern and western sites were the most rural of the four satellite sites and, assuming that transport predominantly occurs from west-to-east in the Steubenville region, tended to be situated upwind or crosswind from major emission sources in Steubenville. Conversely, the eastern satellite site tended to be situated downwind of emission sources in both Steubenville and the Pittsburgh metropolitan area to the east of Steubenville, and therefore was likely more frequently impacted by $\mathrm{PM}_{2.5}$ from these sources than the northern and western sites. 


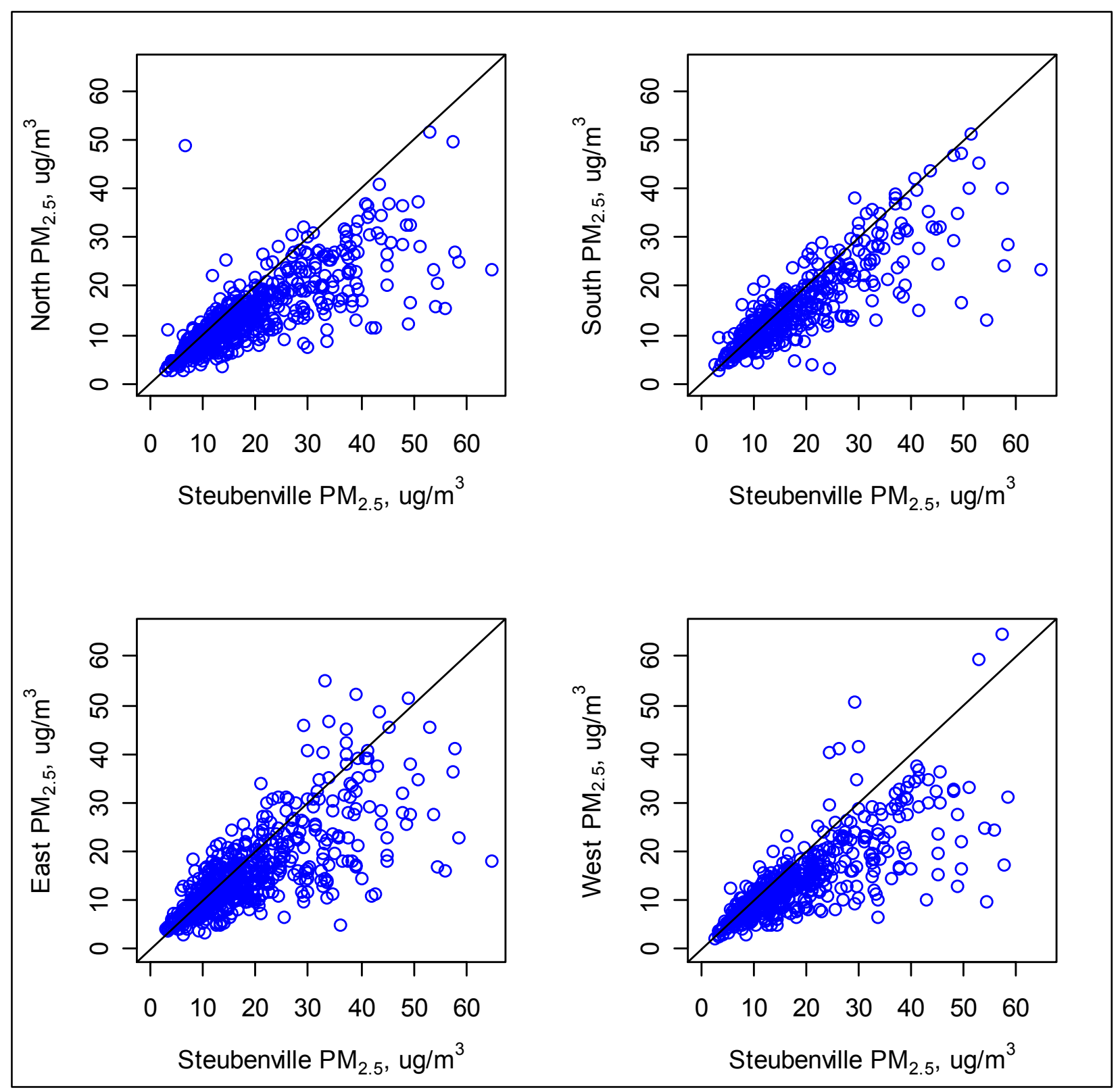

Figure 31. $\quad$ Parity plots showing 24-hr average $\mathrm{PM}_{2.5}$ concentrations measured at each of the SCAMP satellite sites versus 24-hr average $\mathrm{PM}_{2.5}$ concentrations measured simultaneously at the Steubenville site. 


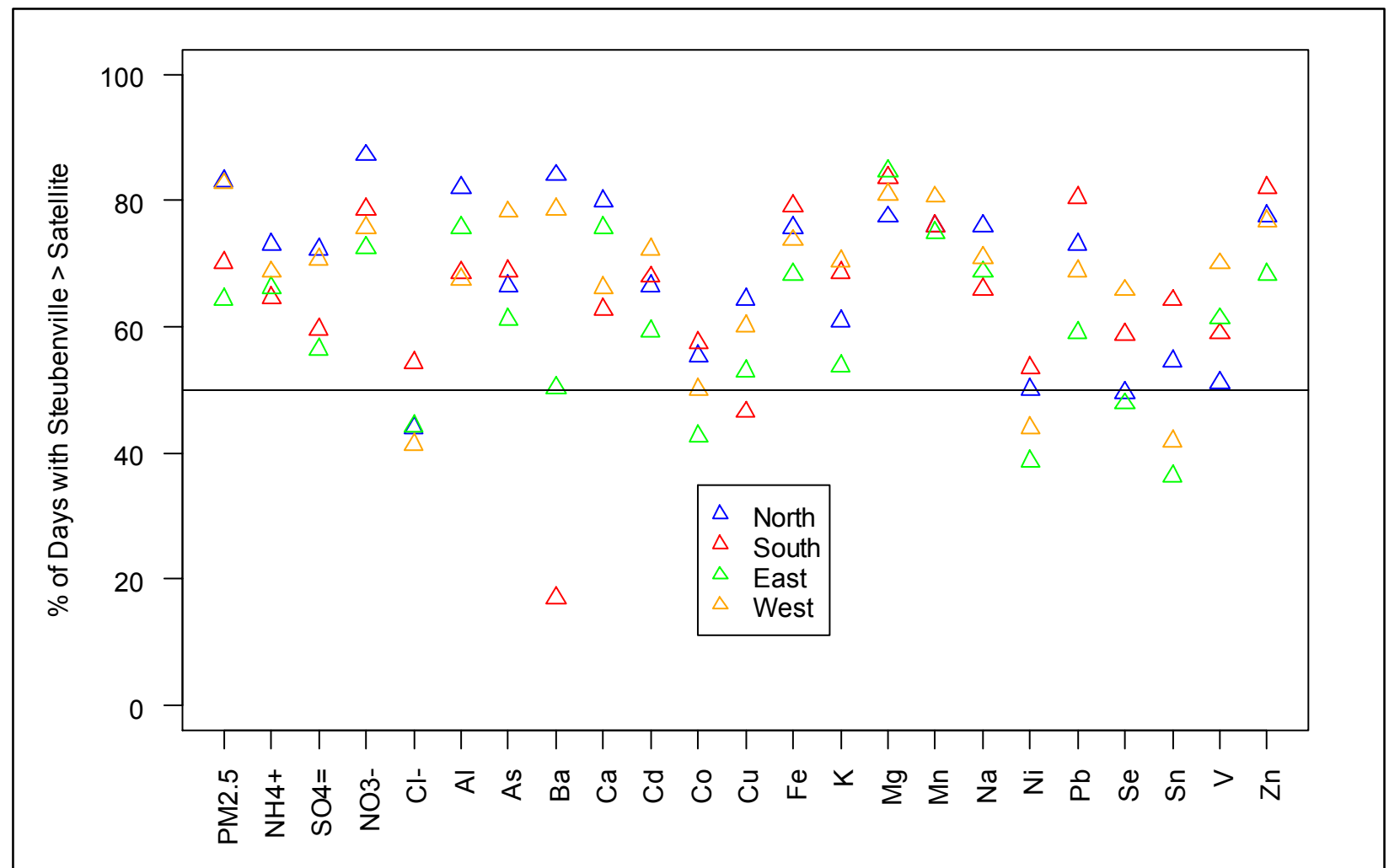

Figure 32. Percentage of days for which 24-hr average $\mathrm{PM}_{2.5}$ and water-extractable $\mathrm{PM}_{2.5}$ component concentrations measured at each SCAMP satellite site were greater than corresponding concentrations measured at the central Steubenville site.

Figure 32 and Figure 33, which plot median ratios of daily $\mathrm{PM}_{2.5}$ and $\mathrm{PM}_{2.5}$ component concentrations measured at Steubenville to corresponding daily $\mathrm{PM}_{2.5}$ and $\mathrm{PM}_{2.5}$ component concentrations measured at each satellite site, generally confirm the observations made above on the basis of overall mean concentrations. The data presented in these figures indicate that, based on pairwise comparisons, 15 of the 22 measured $\mathrm{PM}_{2.5}$ components (i.e., $\mathrm{NH}_{4}{ }^{+}, \mathrm{SO}_{4}{ }^{2-}$, $\mathrm{NO}_{3}{ }^{-}$, and water-extractable $\mathrm{Al}, \mathrm{As}, \mathrm{Ca}, \mathrm{Cd}, \mathrm{Fe}, \mathrm{K}, \mathrm{Mg}, \mathrm{Mn}, \mathrm{Na}, \mathrm{Pb}, \mathrm{V}$, and $\mathrm{Zn}$ ) had greater concentrations at Steubenville than at each of the four satellite sites on a majority of the days during SCAMP. Again, water-extractable $\mathrm{Mg}, \mathrm{Mn}$, and $\mathrm{Zn}$ exhibited appreciably higher concentrations at Steubenville than at the satellite sites; median daily Steubenville/satellite site concentration ratios were $>1.6$ for all comparisons involving these elements. Water-extractable $\mathrm{Fe}$ and $\mathrm{NO}_{3}{ }^{-}$also exhibited markedly greater typical concentrations at Steubenville than at the satellite sites; median daily Steubenville/satellite site concentration ratios were 1.62-1.77 for water-extractable $\mathrm{Fe}$ and 1.52-1.89 for $\mathrm{NO}_{3}{ }^{-}$. One noteworthy difference between the comparisons based on overall mean concentrations and the comparisons based on pairwise concentrations involved $\mathrm{Cl}^{-}$. Whereas the former comparison suggested that $\mathrm{Cl}^{-}$concentrations at Steubenville were substantially greater than those at the satellite sites, the latter suggests no appreciable difference. This discrepancy likely reflects the occurrence of several pollution episodes at Steubenville marked by abnormally elevated $\mathrm{Cl}^{-}$concentrations, which are captured when the mean is used as the measure of central tendency but not when the median is used as such. 


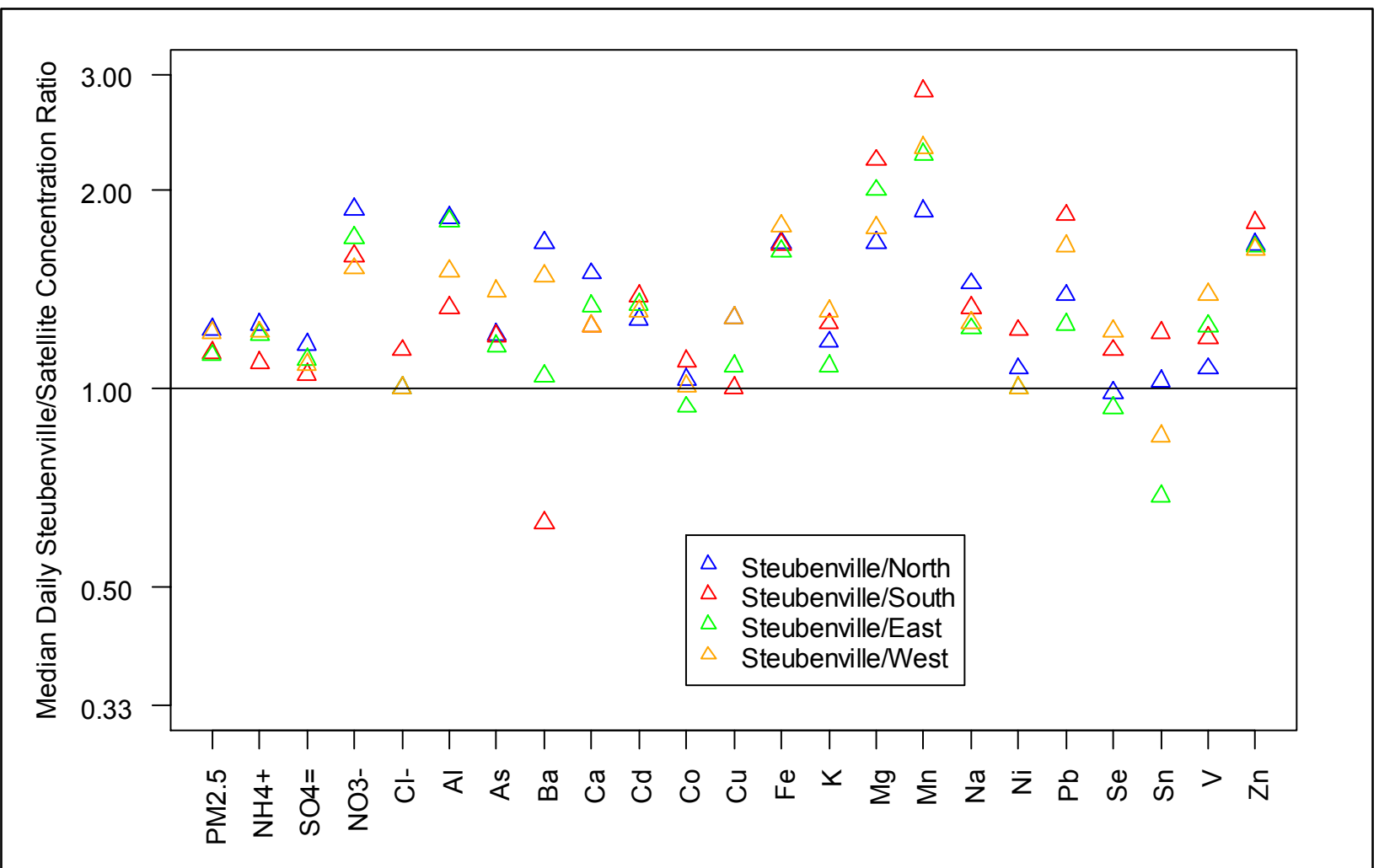

Figure 33. Median daily ratios of $\mathrm{PM}_{2.5}$ and water-extractable $\mathrm{PM}_{2.5}$ component concentrations measured at the central Steubenville site to corresponding concentrations measured at each SCAMP satellite site.

Connell and co-workers (2005a, 2006) evaluated the statistical significance of differences between $\mathrm{PM}_{2.5}$ and $\mathrm{PM}_{2.5}$ component concentrations measured at the SCAMP Steubenville site and $\mathrm{PM}_{2.5}$ and $\mathrm{PM}_{2.5}$ component concentrations measured at the satellite sites. For concentrations of total $\mathrm{PM}_{2.5}$ and its ionic components (i.e., $\mathrm{SO}_{4}{ }^{2-}, \mathrm{NH}_{4}{ }^{+}$, and $\mathrm{NO}_{3}{ }^{-}$), statistical significance was determined by applying paired t-tests to adjusted paired differences between Steubenville and satellite site concentrations. The concentrations were adjusted by applying a log-transform, which was required because paired differences in raw concentrations were not normally distributed, and by applying ARIMA modeling when necessary to remove autocorrelation from the resulting time series of log-transformed differences. Results indicated that $\mathrm{PM}_{2.5}$ concentrations and concentrations of fine particulate $\mathrm{NH}_{4}{ }^{+}$and $\mathrm{NO}_{3}{ }^{-}$at the Steubenville site were significantly greater $\left(\mathrm{p}<0.0001\right.$ for $\mathrm{PM}_{2.5}$ and $\mathrm{NO}_{3}{ }^{-} ; \mathrm{p}=0.003-0.01$ for $\mathrm{NH}_{4}{ }^{+}$) than concentrations of these species at each of the four satellite sites. Concentrations of fine particulate $\mathrm{SO}_{4}{ }^{2-}$ at Steubenville were significantly greater than concentrations at the northern $(p<0.0001)$, eastern $(p=0.015)$, and western sites $(p=0.002)$, but not the southern site $(p=0.27)$.

For ambient concentrations of water-extractable elemental $\mathrm{PM}_{2.5}$ components, statistical significance was determined by applying Wilcoxon signed rank tests to paired differences in concentrations measured at the Steubenville site and each satellite site. Of the 18 elements that were determined at all five monitoring sites, ten (Al, As, $\mathrm{Ca}, \mathrm{Cd}, \mathrm{Fe}, \mathrm{Mg}, \mathrm{Mn}, \mathrm{Na}, \mathrm{Pb}$, and $\mathrm{Zn}$ ) had significantly greater (at $\alpha=0.05$ ) concentrations at the Steubenville site than at each of the four satellite sites. Satellite site concentrations were significantly greater than Steubenville concentrations only for water-extractable $\mathrm{Sn}$ at the eastern site and water-extractable $\mathrm{Ba}$ at the southern site. 
To further evaluate the degree of homogeneity in $\mathrm{PM}_{2.5}$ component concentrations among the five SCAMP monitoring sites, coefficients of divergence (Wongphatarakul et al., 1998) were computed for each site pair using overall mean concentrations of the 22 water-extractable ionic and elemental $\mathrm{PM}_{2.5}$ components measured at each site. The coefficient of divergence (CD) is a self-normalizing measure of the degree of similarity or difference between two sites based on a comparison of the overall average concentrations of pollutants (in this case, $\mathrm{PM}_{2.5}$ components) measured at both sites. Each component is given equal weight in the computation of the CD, which is defined as:

$$
C D_{j k}=\sqrt{\frac{1}{n} \sum_{i=1}^{n}\left(\frac{x_{i j}-x_{i k}}{x_{i j}+x_{i k}}\right)^{2}}
$$

where $j$ and $k$ represent two sampling sites, $x_{i j}$ represents the mean concentration of component $i$ at site $j$, and $n$ is the number of chemical components. The CD for a site pair will equal zero if the average $\mathrm{PM}_{2.5}$ component concentrations measured at the two sites are identical for each of the components being studied. Greater CD values indicate less similarity among the sites.

Coefficients of divergence computed for each SCAMP site pair are plotted in Figure 34 . In all cases, CDs for the Steubenville site / satellite site pairs were greater than those for the satellite site / satellite site pairs. This indicates that $\mathrm{PM}_{2.5}$ component concentrations measured at Steubenville were relatively dissimilar to those measured at other sites throughout the region, and suggests the influence of local emission sources on the concentrations of many $\mathrm{PM}_{2.5}$ constituents in Steubenville. Among the Steubenville site / satellite site pairs, the Stuebenville site was most similar to the southern site, which may be expected, as this site was located in Wheeling, WV, a small city along the Ohio River that is expected to be impacted by local sources similar to those impacting Steubenville. The pair comprising the northern and western satellite sites had the lowest CD, suggesting that these were the most similar of the SCAMP sites. As discussed previously, the northern and western sites also had the lowest overall average $\mathrm{PM}_{2.5}$ concentrations $\left(13.9 \mu \mathrm{g} / \mathrm{m}^{3}\right)$ of the SCAMP sites, despite being located closer to Steubenville than any of the other sites, and were not generally situated downwind of Steubenville. Moreover, as discussed by Connell et al. (2005a), sulfate values for the northern and western sites were more highly correlated than for any other site pair, suggesting that these sites are most representative of regional concentrations of secondary $\mathrm{PM}_{2.5}$.

Hence, for the purposes of this analysis, the northern and western sites are assumed to be representative of regional "background" concentrations in the Steubenville area. The background concentration measured on a given day is taken as the average concentration measured at the northern and western sites on that day. As discussed by Connell et al. (2005a) and summarized in Figure 35, on the basis of this assumption, local sources in the immediate Steubenville vicinity contributed an estimated $4.6 \mu \mathrm{g} / \mathrm{m}^{3}$ to Steubenville's overall average $\mathrm{PM}_{2.5}$ concentration of $18.4 \mu \mathrm{g} / \mathrm{m}^{3}$ during SCAMP. (This may be an underestimate of the contribution of local sources to the extent that the northern and western sites were impacted by emissions from Steubenville or by local sources located near these satellite sites). Results suggest that about $20 \%$ of the $\mathrm{SO}_{4}{ }^{2-}$ and $\mathrm{NH}_{4}{ }^{+}$and $30 \%$ of the $\mathrm{NO}_{3}{ }^{-}$observed in Steubenville was produced locally; this is consistent with the expectation that these secondary $\mathrm{PM}_{2.5}$ components would be predominantly regional pollutants. The more than half of the estimated local source contribution labeled "other" in Figure 35 likely consists of carbonaceous species, crustal materials, trace elements, and particle-bound water. 


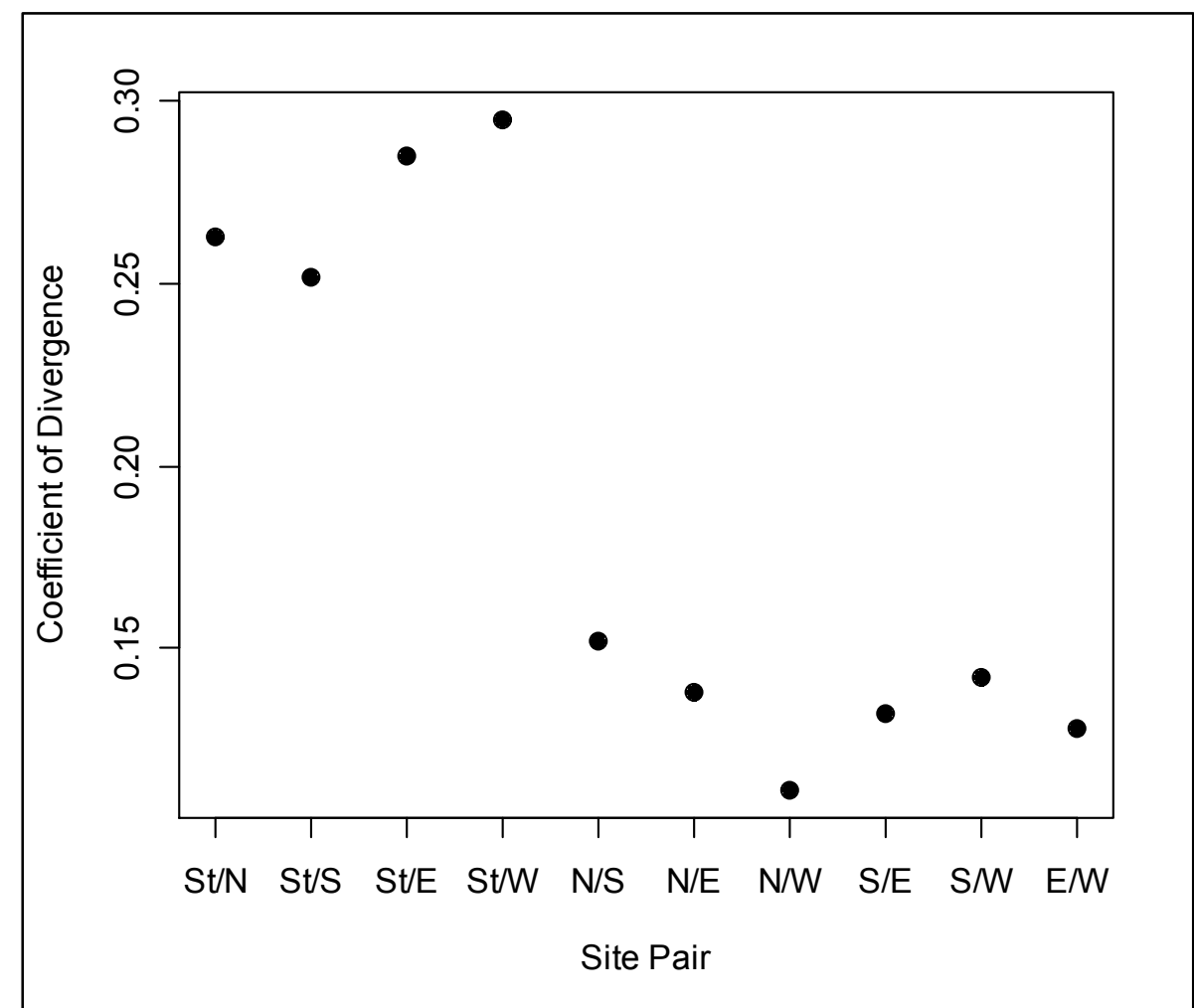

Figure 34. Intersite coefficients of divergence for all possible SCAMP site pairs based on mean concentrations of 22 water-extractable $\mathrm{PM}_{2.5}$ components.

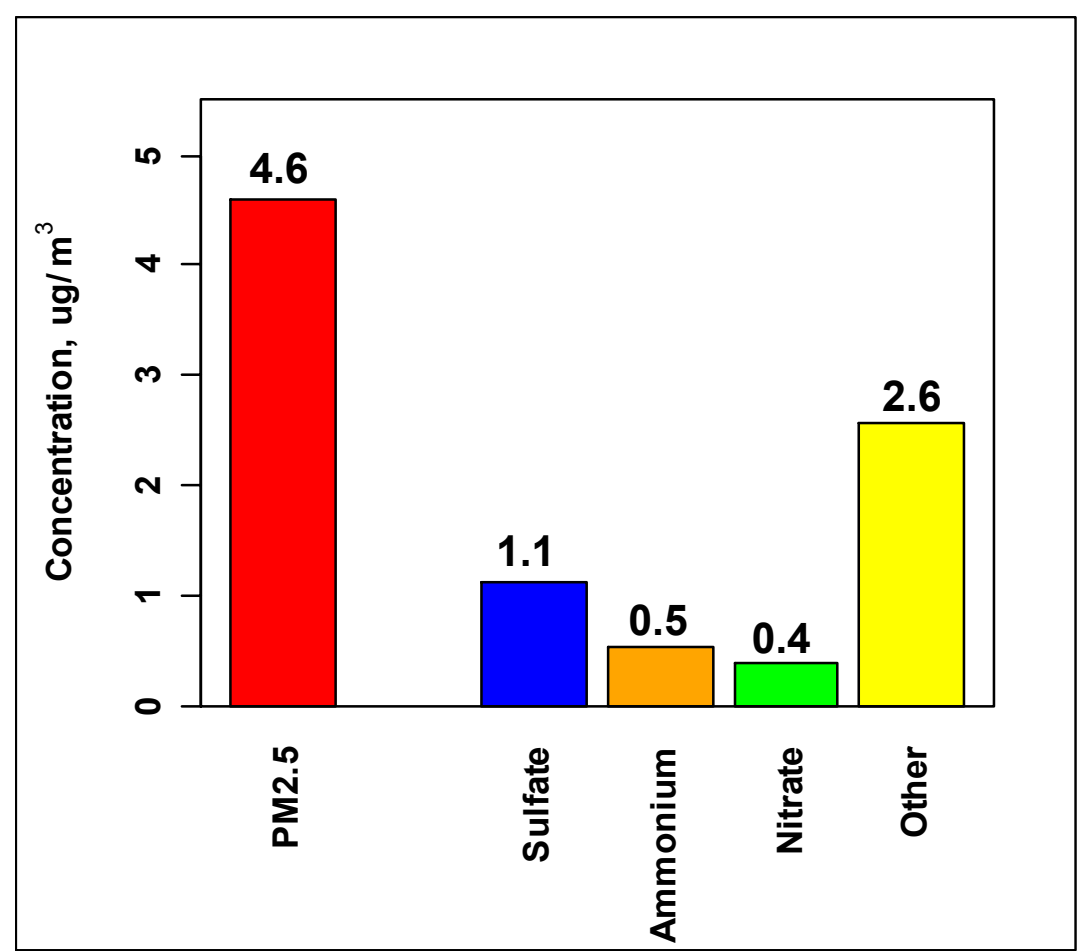

Figure 35. Estimated contribution of local sources to concentrations of $\mathrm{PM}_{2.5}$ and its major ionic components at Steubenville during SCAMP. 
Although they do not contribute a large percentage to the total mass of $\mathrm{PM}_{2.5}$ in Steubenville, trace metals such as $\mathrm{Fe}, \mathrm{Zn}$, and $\mathrm{Mn}$, which comprise a portion of the local source contribution labeled "other," may have implications for the health effects of $\mathrm{PM}_{2.5}$ in Steubenville. The results presented earlier in this section suggest that local sources in the immediate Steubenville vicinity contribute substantially to ambient concentrations of these metals in $\mathrm{PM}_{2.5}$ in Steubenville. Based on the mean paired differences between Steubenville concentrations and estimated "background" concentrations of these elements, this local source contribution accounted for more than half of the total average mass of water-extractable $\mathrm{Fe}, \mathrm{Mn}$, and $\mathrm{Zn}$ observed in Steubenville. $\mathrm{Mn}$ is a HAP, and Fe and $\mathrm{Zn}$ have been implicated in PM toxicology studies (e.g., Adamson et al., 2000; Ghio et al., 1999a); hence, this result again reinforces the need for further research to elucidate the toxicological potency of these trace metals in Steubenville and similar locations.

\subsubsection{Intersite Correlations}

Figure 36 presents a boxplot summarizing intersite Spearman correlation coefficients computed for $\mathrm{PM}_{2.5}$ total mass and each of the 22 water-extractable $\mathrm{PM}_{2.5}$ components that were measured at all five SCAMP ambient air monitoring sites. The box plotted for each variable represents the distribution of ten correlation coefficients computed using pairwise daily concentrations of that variable for each of the ten possible site pairs.

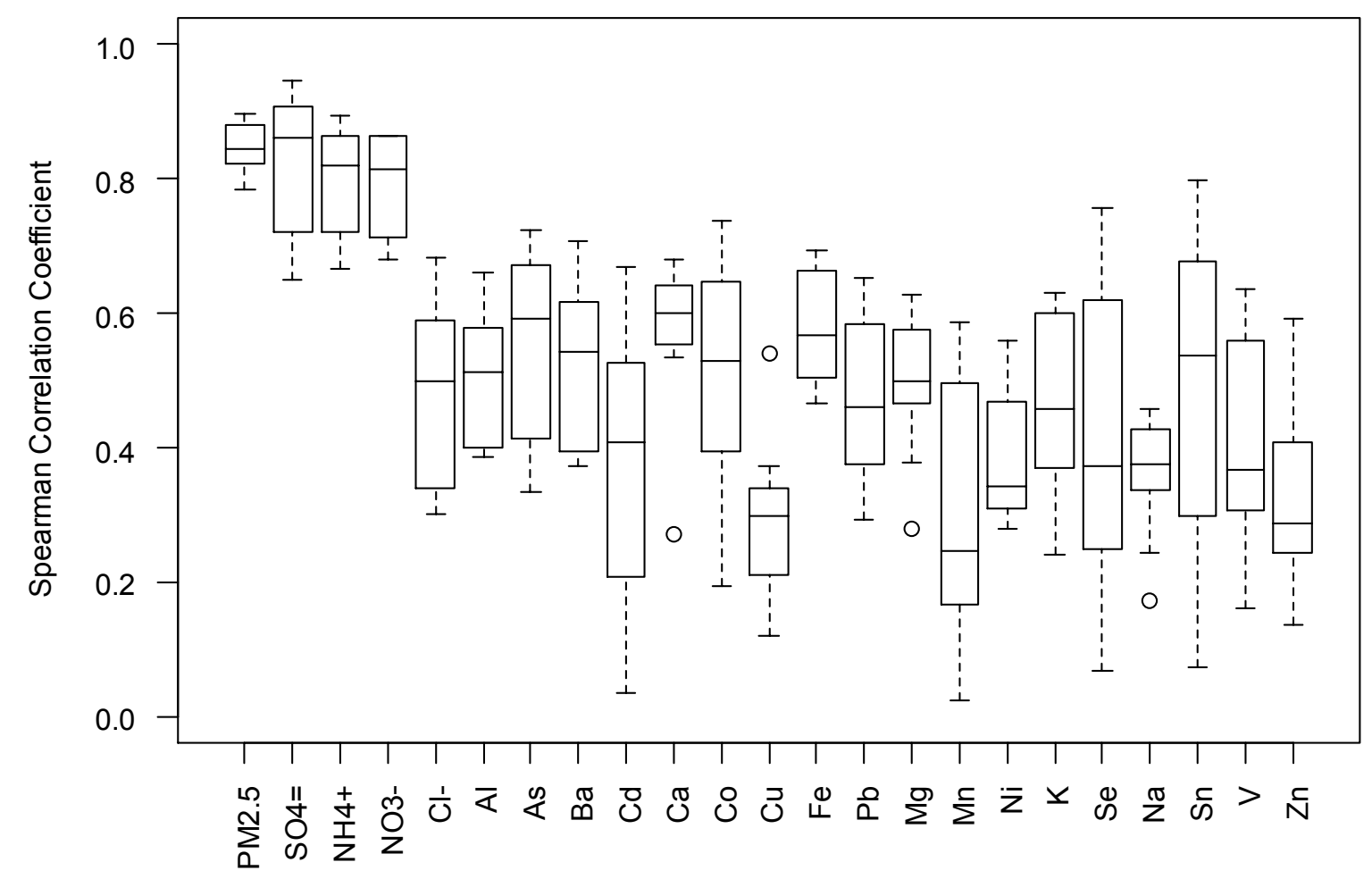

Figure 36. Intersite Spearman correlation coefficients for $\mathrm{PM}_{2.5}$ and its water-extractable components in the Steubenville region. Ten correlations are plotted for each variable, corresponding to the ten possible SCAMP site pairs. 
As shown in the figure, daily $\mathrm{PM}_{2.5}$ concentrations were well-correlated across the SCAMP monitoring sites; Spearman correlation coefficients describing these correlations ranged from 0.78 (for the Steubenville and eastern sites) to 0.90 (for the northern and western sites), with a median of 0.84 . Concentrations of $\mathrm{SO}_{4}{ }^{2-}, \mathrm{NH}_{4}{ }^{+}$, and $\mathrm{NO}_{3}{ }^{-}$were similarly well-correlated in space throughout the region, with median intersite Spearman correlation coefficients of 0.86 for $\mathrm{SO}_{4}{ }^{2-}$, 0.82 for $\mathrm{NH}_{4}{ }^{+}$, and 0.81 for $\mathrm{NO}_{3}{ }^{-}$. These strong correlations likely reflect the influence of longrange transport and meteorology on concentrations of these secondary $\mathrm{PM}_{2.5}$ components throughout the region.

Because of the autocorrelated nature of concentrations of $\mathrm{PM}_{2.5}$ and some of its major components measured during SCAMP, it is possible that the associations described above are induced to some extent by seasonal and other temporal patterns in the datasets, and therefore do not reflect the extent to which concentrations at the various sites are associated on a day-today basis. To better evaluate the day-to-day associations among concentrations of $\mathrm{PM}_{2.5}$, sulfate, ammonium, and nitrate measured at the SCAMP monitoring sites, and to assess the statistical significance of these associations, Connell et al. (2005a) adjusted the SCAMP data to remove seasonal trends and autocorrelation (by applying ARIMA modeling or subtracting a 3month moving average) and then computed intersite correlations using the resulting adjusted data. Even after accounting for autocorrelation, daily concentrations of $\mathrm{PM}_{2.5}$, fine particulate sulfate, and fine particulate ammonium were strongly and significantly associated across all of the monitoring sites. Pearson correlation coefficients describing these associations were 0.660.79 for $\mathrm{PM}_{2.5}$, and 0.57-0.94 for $\mathrm{NH}_{4}{ }^{+}$and $\mathrm{SO}_{4}{ }^{2-}$. Intersite $\mathrm{NO}_{3}{ }^{-}$associations, while statistically significant for all possible site pairs, were weaker, with Pearson correlation coefficients of 0.330.73 . This suggests that the $\mathrm{NO}_{3}{ }^{-}$correlations reported in Figure 36 are likely induced to some extent by the strong seasonal trend exhibited by this $\mathrm{PM}_{2.5}$ component (see Figure 28).

Intersite correlations for $\mathrm{Cl}^{-}$and the 18 water-extractable $\mathrm{PM}_{2.5}$ components measured as part of SCAMP were generally less than those for $\mathrm{PM}_{2.5}, \mathrm{SO}_{4}{ }^{2-}, \mathrm{NH}_{4}{ }^{+}$, and $\mathrm{NO}_{3}{ }^{-}$, as evidenced in Figure 36. Median intersite correlations for these 19 components ranged from 0.25 for $\mathrm{Mn}$ to 0.60 for $\mathrm{Ca}$. The lower correlations likely reflect the fact that local source emissions, rather than regional transport and secondary formation, are responsible for much of the variability in concentrations of these primary pollutants at the various SCAMP monitoring sites. They may also be due in part to the greater uncertainty (i.e., noise) in the measured values of these components, which are present in much smaller quantities than $\mathrm{PM}_{2.5}$ and its major ionic components.

In general, the strength of correlation between $\mathrm{PM}_{2.5}$ and $\mathrm{PM}_{2.5}$ component concentrations at the SCAMP monitoring sites decreased as the distance between the sites increased, although there was considerable variability in this trend from species to species. Figure 37 summarizes the overall average trend by showing the $25^{\text {th }}, 50^{\text {th }}$, and $75^{\text {th }}$ percentile intersite Spearman correlations (out of the 23 correlations, corresponding to the 23 measured $\mathrm{PM}_{2.5}$ variables, that were computed for each pair of sites) for each SCAMP site pair as a function of the distance separating the sites. Linear least squares trend lines are also shown. For all three percentile measures, the strongest correlation was observed for the Steubenville site / northern site pair, perhaps reflecting the impact of emission sources in the immediate Steubenville vicinity on concentrations measured at both of these sites, which were the most closely situated of the SCAMP ambient air monitoring sites. The weakest correlation for all three percentile measures was observed for the southern site / eastern site pair. This is likely a result of the distance separating the sites and the influence of different types of local emission sources and/or localized meteorological regimes on ambient $\mathrm{PM}_{2.5}$ at the sites. 


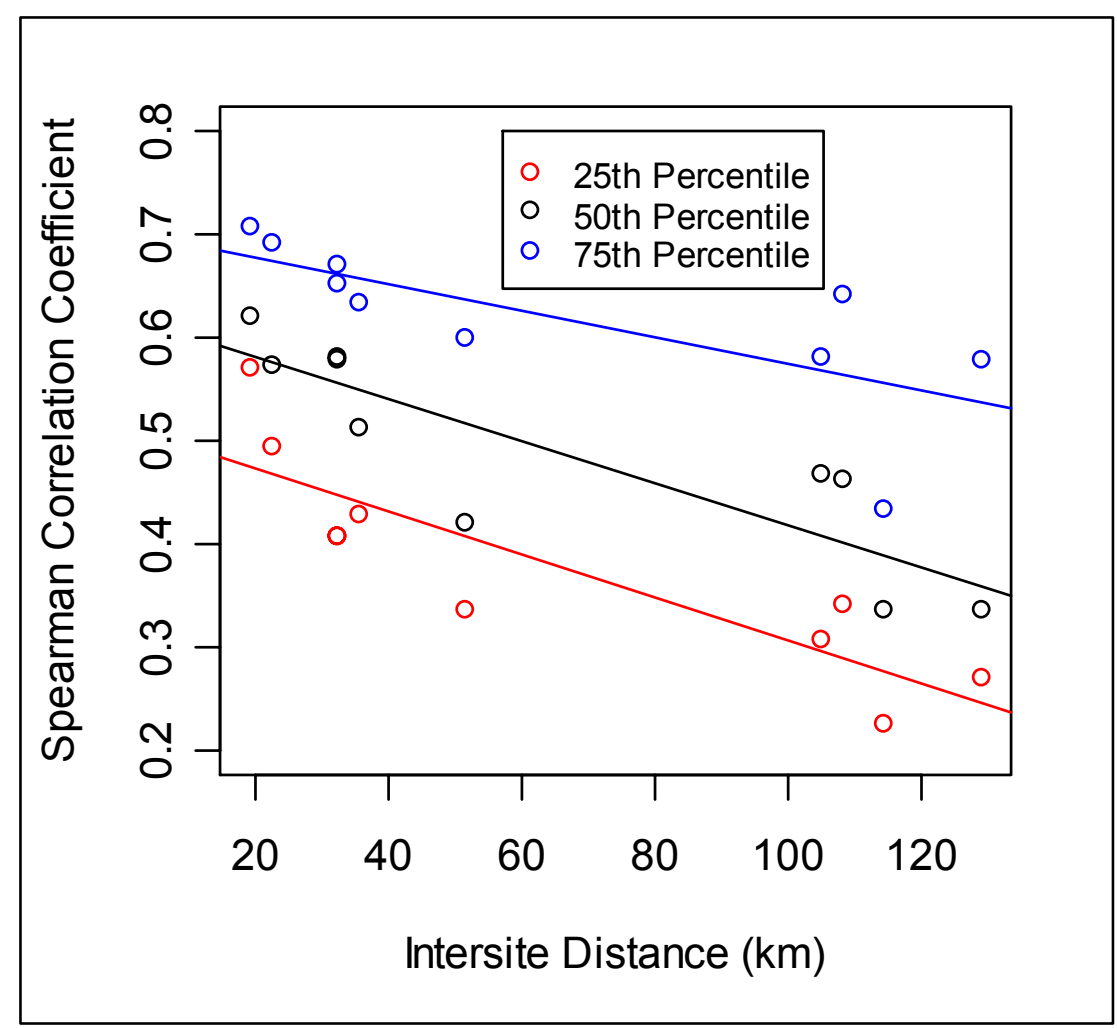

Figure 37. Scatterplot illustrating the association between intersite distance and the strength of association between $\mathrm{PM}_{2.5}$ and $\mathrm{PM}_{2.5}$ component concentrations measured at SCAMP site pairs. Plotted are the $25^{\text {th }}, 50^{\text {th }}$, and $75^{\text {th }}$ percentile Spearman correlation coefficients for each site pair, with linear least squares lines.

Whereas intersite correlations for total $\mathrm{PM}_{2.5}$ mass were consistently strong during all seasons of the year, intersite correlations for several water-extractable $\mathrm{PM}_{2.5}$ components exhibited appreciable seasonal variability across the SCAMP monitoring sites. This is illustrated in Figure 38, which shows the distributions of intersite correlations (for all 10 possible SCAMP site pairs) observed for each measured $\mathrm{PM}_{2.5}$ component during the warm season (April-September) and during the cool season (October-March). Appreciable seasonal trends were observed in particular for $\mathrm{NO}_{3}{ }^{-}$and water-extractable $\mathrm{K}, \mathrm{Na}, \mathrm{V}$, and $\mathrm{Zn}$, which had $25^{\text {th }}$ percentile intersite Spearman correlation coefficients during the cool season that were greater than their $75^{\text {th }}$ percentile intersite Spearman correlation coefficients during the warm season. The seasonal variation in the strength of association between sites for these components may reflect seasonal variability in the predominance of various emission sources that impact the sites to a greater or lesser extent (e.g., the stronger correlations observed for water-extractable $\mathrm{Na}$ during the cool season may reflect the use of rock salt containing $\mathrm{Na}$ to treat icy roads throughout the region during this season). Alternatively, this seasonal variation may be due to differences in meteorology or transport conditions that affect the extent to which the sites are impacted by local and regional sources of certain pollutants. For example, the seasonal variation in intersite correlations for $\mathrm{NO}_{3}{ }^{-}$reflects the increased regional-scale formation and transport of this $\mathrm{PM}_{2.5}$ component during the cool part of the year, when atmospheric production of secondary $\mathrm{NH}_{4} \mathrm{NO}_{3}$ is thermodynamically favored. To some extent, the greater intersite correlations during the cool season likely result from the larger signal-to-noise ratio (i.e., resulting from the larger average magnitude of ambient $\mathrm{NO}_{3}{ }^{-}$concentrations) for measured $\mathrm{NO}_{3}{ }^{-}$values during this season. 


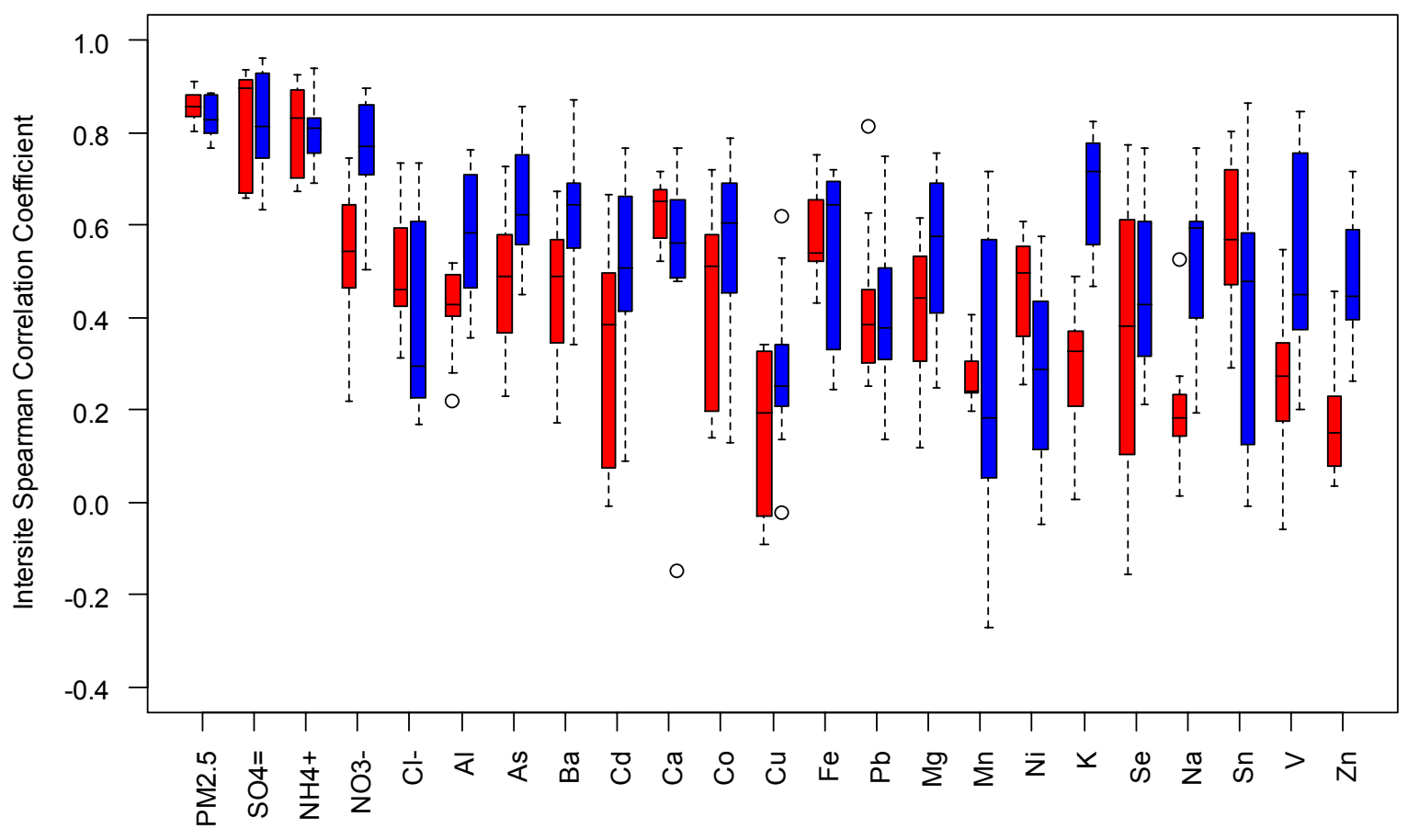

Figure 38. Intersite Spearman correlation coefficients for $\mathrm{PM}_{2.5}$ and its water-extractable components in the Steubenville region during the warm season (red; April-September) and the cool season (blue; October-March). Ten correlations are plotted for each variable, corresponding to the ten possible SCAMP site pairs.

In summary, the results presented in this subsection suggest that concentrations of $\mathrm{PM}_{2.5}$ and several of its major components (i.e., $\mathrm{SO}_{4}{ }^{2-}, \mathrm{NH}_{4}{ }^{+}$, and $\mathrm{NO}_{3}{ }^{-}$) generally tend to vary on a regional scale in the Steubenville area. Although correlations between sites did generally exhibit a downward trend with increasing intersite distance, moderate-to-strong intersite correlations were observed for these variables for all pairs of SCAMP monitoring sites. Even the eastern satellite site, which was located about 100-130 km from the other four SCAMP ambient air monitoring sites and was separated from these sites by the Pittsburgh metropolitan source region, exhibited relatively strong correlations with the other SCAMP sites for total $\mathrm{PM}_{2.5}\left(r_{\mathrm{s}}=0.78-0.85\right)$ and fine particulate $\mathrm{SO}_{4}{ }^{2-}\left(r_{\mathrm{s}}=0.65-0.73\right), \mathrm{NH}_{4}{ }^{+}\left(r_{\mathrm{s}}=0.66-0.74\right)$, and $\mathrm{NO}_{3}^{-}\left(r_{\mathrm{s}}=0.68-0.74\right)$. This reflects the largely regional nature of $\mathrm{PM}_{2.5}$ in the Upper Ohio River Valley region, driven largely by secondary $\mathrm{PM}_{2.5}$ components such as $\mathrm{NH}_{4} \mathrm{NO}_{3}$ and especially $\left(\mathrm{NH}_{4}\right)_{2} \mathrm{SO}_{4}$, and suggests that for the purposes of time series epidemiological studies, central site measurements of $\mathrm{PM}_{2.5}$, $\mathrm{SO}_{4}{ }^{2-}, \mathrm{NH}_{4}{ }^{+}$, and $\mathrm{NO}_{3}{ }^{-}$are likely sufficient for representing the daily fluctuations in concentrations of these species throughout the Steubenville region. However, intersite correlations for water-extractable elemental components of $\mathrm{PM}_{2.5}$, many of which are present in trace quantities and are expected to be emitted largely by local sources in the region, were considerably weaker and more variable. Caution should be exercised before using central site measurements of these components (or other trace or primary $\mathrm{PM}_{2.5}$ components, which may be subject to substantial measurement noise or to spatial variability resulting from localized primary source impacts) to represent daily variations in the region's exposure to them. The seasonal variability in the strength of intersite correlations for certain $\mathrm{PM}_{2.5}$ components, as shown in Figure 38, should also be accounted for when designing $\mathrm{PM}_{2.5}$ epidemiology studies, as the exposure error resulting from the use of measurements of these components from a 
single ambient monitoring site may be much greater during certain times of year than during others.

\subsubsection{Associations of $\mathrm{PM}_{2.5}$ and $\mathrm{PM}_{10}$ with Co-Pollutants and Meteorological Conditions}

Having examined the overall concentrations, composition, and temporal variability of $\mathrm{PM}_{2.5}$ and $\mathrm{PM}_{10}$ in Steubenville, as well as the spatial variability of $\mathrm{PM}_{2.5}$ in the Steubenville region, it is next important to study the extent to which $\mathrm{PM}_{2.5}$ and $\mathrm{PM}_{10}$ in Steubenville are associated with various gaseous pollutants and meteorological conditions. These associations can provide valuable insights into the atmospheric conditions and types of sources that affect PM concentrations in Steubenville. Moreover, both weather conditions (e.g., temperature) and gaseous pollutant (e.g., $\mathrm{SO}_{2}, \mathrm{NO}_{2}, \mathrm{CO}, \mathrm{O}_{3}$ ) concentrations are important for inclusion in $\mathrm{PM}_{2.5}$ epidemiological models as potential explanatory factors, as these variables can affect mortality and/or morbidity.

As discussed in the Introduction, if daily measures of weather or gases are collinear (i.e., correlated) with daily PM concentrations, they may confound the results of PM time series epidemiology studies, making it difficult to separate the effect of PM from the effects of these other variables. Moolgavkar and Luebeck's (1996) and Lipfert and Wyzga's (1997) criticisms of epidemiology studies for not adequately considering the potential confounding effects of gases such as $\mathrm{CO}$ and $\mathrm{NO}_{2}$ cited several studies that were conducted in Steubenville (Schwartz and Dockery, 1992; Schwartz et al., 1996). Direct evidence of confounding by gaseous pollutants has been observed in at least one time series particulate matter epidemiology study in Steubenville; in a reanalysis of Steubenville data originally presented by Schwartz and Dockery (1992), Moolgavkar et al. (1995) reported that, whereas TSP was significantly associated with daily mortality in a single-pollutant model, addition of $\mathrm{SO}_{2}$ to the model caused the effect of TSP to become statistically insignificant. In nearby Pittsburgh, Chock et al. (2000) reported that although $\mathrm{PM}_{10}$ was significantly associated with daily mortality among those less than 75 years of age in non-seasonal single- and multi-pollutant models, the use of seasonal models revealed collinearity problems among concentrations of $\mathrm{PM}_{10}, \mathrm{CO}, \mathrm{NO}_{2}$, and $\mathrm{O}_{3}$ (spring and summer), casting doubt upon the findings of the non-seasonal models.

This section, by presenting correlation analyses of PM and gaseous pollutant data collected at Steubenville during SCAMP, provides an indication of the potential for such collinearity problems to occur in $\mathrm{PM}_{2.5}$ time series epidemiology studies conducted there. Collinearity can also cause problems for time series studies exploring the health effects of $\mathrm{PM}_{2.5}$ components if these components are correlated with each other or with co-pollutants. Hence, these correlations are explored as well using the speciated $\mathrm{PM}_{2.5}$ data collected at the central Steubenville site during SCAMP. In addition to correlation analyses, this section presents case studies illustrating the effect of meteorology on the behavior of $\mathrm{PM}_{2.5}$ during high-concentration episodes at Steubenville, and also presents the results of a binary recursive partitioning analysis, which was applied to identify factors that are associated with elevated hourly $\mathrm{PM}_{2.5}$ concentrations at Steubenville. 


\subsubsection{Correlation Analyses}

Table 30 shows Spearman correlation coefficients between concentrations of $\mathrm{PM}_{2.5}$ (both 1-hr and 24-hr averages), $\mathrm{PM}_{10}$, and $\mathrm{PM}_{10-2.5}$ and corresponding concentrations of gaseous pollutants measured at the central Steubenville site. (One-hour average gaseous pollutant concentrations were used when computing the correlations for 1-hr average $\mathrm{PM}_{2.5}$ concentrations). Correlation coefficients were computed using all data collected during SCAMP ("overall"), as well as using data stratified by astronomical season. Correlations of the gaseous pollutants (and other variables) with $\mathrm{PM}_{10}$ are expected to be similar to those with $\mathrm{PM}_{2.5}$, because, as discussed earlier, $\mathrm{PM}_{2.5}$ typically accounted for about $58-77 \%$ (interquartile range) of the mass of $\mathrm{PM}_{10}$ at Steubenville. The Spearman correlation coefficient describing the association between $\mathrm{PM}_{2.5}$ and $\mathrm{PM}_{10}$ total mass is 0.91 . Hence, correlations with estimated mass concentrations of $\mathrm{PM}_{10-2.5}$ (computed by differencing measured $\mathrm{PM}_{10}$ and $\mathrm{PM}_{2.5}$ mass concentrations) are shown to illustrate differences between fine and coarse particles. The Spearman correlation coefficient describing the association between $\mathrm{PM}_{2.5}$ and $\mathrm{PM}_{10-2.5}$ concentrations observed during SCAMP is 0.47 , indicating that fine and coarse particle mass concentrations were only moderately collinear at Steubenville.

Table 30. Spearman correlation coefficients between ambient concentrations of various PM measures (i.e., hourly $\mathrm{PM}_{2.5}$, daily $\mathrm{PM}_{2.5}$, daily $\mathrm{PM}_{10}$, and daily $\mathrm{PM}_{10-2.5}$ ) and ambient concentrations of various gaseous pollutants at the central Steubenville site, both overall and by astronomical season.

\begin{tabular}{|c|c|c|c|c|c|c|}
\hline \multirow{2}{*}{$\begin{array}{l}\text { Gaseous } \\
\text { Pollutant }\end{array}$} & \multirow{2}{*}{ PM Measure } & \multicolumn{5}{|c|}{ Spearman Correlation Coefficient } \\
\hline & & Overall & Winter & Spring & Summer & Fall \\
\hline \multirow{4}{*}{$\mathrm{SO}_{2}$} & $\mathrm{PM}_{2.5}-1-\mathrm{h}$ & 0.50 & 0.62 & 0.61 & 0.48 & 0.60 \\
\hline & $\mathrm{PM}_{2.5}-24-\mathrm{h}$ & 0.55 & 0.64 & 0.58 & 0.49 & 0.69 \\
\hline & $\mathrm{PM}_{10}-24-\mathrm{h}$ & 0.55 & 0.63 & 0.58 & 0.57 & 0.69 \\
\hline & $\mathrm{PM}_{10-2.5}-24-\mathrm{h}$ & 0.44 & 0.54 & 0.36 & 0.42 & 0.51 \\
\hline \multirow{4}{*}{ NO } & $\mathrm{PM}_{2.5}-1-\mathrm{h}$ & 0.33 & 0.51 & 0.29 & 0.09 & 0.58 \\
\hline & $\mathrm{PM}_{2.5}-24-\mathrm{h}$ & 0.40 & 0.74 & 0.32 & -0.09 & 0.66 \\
\hline & $\mathrm{PM}_{10}-24-\mathrm{h}$ & 0.44 & 0.76 & 0.36 & 0.11 & 0.66 \\
\hline & $\mathrm{PM}_{10-2.5}-24-\mathrm{h}$ & 0.48 & 0.66 & 0.32 & 0.50 & 0.49 \\
\hline \multirow{4}{*}{$\mathrm{NO}_{2}$} & $\mathrm{PM}_{2.5}-1-\mathrm{h}$ & 0.50 & 0.69 & 0.55 & 0.30 & 0.66 \\
\hline & $\mathrm{PM}_{2.5}-24-\mathrm{h}$ & 0.51 & 0.77 & 0.43 & 0.29 & 0.72 \\
\hline & $\mathrm{PM}_{10}-24-\mathrm{h}$ & 0.59 & 0.80 & 0.53 & 0.47 & 0.74 \\
\hline & $\mathrm{PM}_{10-2.5}-24-\mathrm{h}$ & 0.58 & 0.66 & 0.43 & 0.68 & 0.58 \\
\hline \multirow{4}{*}{$\mathrm{NO}_{x}$} & $\mathrm{PM}_{2.5}-1-\mathrm{h}$ & 0.49 & 0.68 & 0.54 & 0.27 & 0.68 \\
\hline & $\mathrm{PM}_{2.5}-24-\mathrm{h}$ & 0.49 & 0.77 & 0.47 & 0.14 & 0.72 \\
\hline & $\mathrm{PM}_{10}-24-\mathrm{h}$ & 0.55 & 0.80 & 0.55 & 0.33 & 0.72 \\
\hline & $\mathrm{PM}_{10-2.5}-24-\mathrm{h}$ & 0.56 & 0.67 & 0.45 & 0.65 & 0.54 \\
\hline \multirow{4}{*}{$\mathrm{CO}$} & $\mathrm{PM}_{2.5}-1-\mathrm{h}$ & 0.46 & 0.64 & 0.45 & 0.53 & 0.72 \\
\hline & $\mathrm{PM}_{2.5}-24-\mathrm{h}$ & 0.52 & 0.74 & 0.44 & 0.52 & 0.78 \\
\hline & $\mathrm{PM}_{10}-24-\mathrm{h}$ & 0.59 & 0.77 & 0.45 & 0.69 & 0.79 \\
\hline & $\mathrm{PM}_{10-2.5}-24-\mathrm{h}$ & 0.55 & 0.65 & 0.39 & 0.60 & 0.60 \\
\hline \multirow{4}{*}{$\mathrm{O}_{3}$} & $\mathrm{PM}_{2.5}-1-\mathrm{h}$ & -0.16 & -0.61 & -0.24 & 0.06 & -0.38 \\
\hline & $\mathrm{PM}_{2.5}-24-\mathrm{h}$ & 0.05 & -0.51 & -0.04 & 0.47 & -0.21 \\
\hline & $\mathrm{PM}_{10}-24-\mathrm{h}$ & 0.12 & -0.47 & 0.08 & 0.41 & -0.20 \\
\hline & $\mathrm{PM}_{10-2.5}-24-\mathrm{h}$ & 0.04 & -0.28 & 0.12 & -0.07 & 0.03 \\
\hline
\end{tabular}


As shown in the table, $\mathrm{PM}$ concentrations were moderately correlated with primary gaseous pollutant (i.e., $\mathrm{SO}_{2}, \mathrm{NO}, \mathrm{NO}_{2}, \mathrm{NO}_{x}$, and $\mathrm{CO}$ ) concentrations at Steubenville. Overall Spearman correlations between the various PM measures and these gaseous pollutants ranged from 0.4 to 0.6 for all of the comparisons except that between 1-hr $\mathrm{PM}_{2.5}$ and 1-hr $\mathrm{NO}\left(r_{\mathrm{s}}=0.33\right)$. Conversely, the PM measures were uncorrelated with $\mathrm{O}_{3}$; Spearman correlation coefficients describing the associations between $\mathrm{PM}$ and $\mathrm{O}_{3}$ ranged from -0.16 to 0.12 .

Whereas overall correlations between $\mathrm{PM}_{2.5}$ and $\mathrm{PM}_{10}$ and gaseous pollutants at Steubenville were moderate (i.e., for predominantly primary gases) or weak (i.e., for $\mathrm{O}_{3}$ ), stronger correlations were observed when the data were stratified by season. Correlations of $\mathrm{PM}_{2.5}$ and $\mathrm{PM}_{10}$ with $\mathrm{SO}_{2}, \mathrm{CO}$, and especially $\mathrm{NO}, \mathrm{NO}_{2}$, and $\mathrm{NO}_{\mathrm{x}}$ generally were stronger during the fall and winter and weaker during the spring or summer. For 24-hr average $\mathrm{PM}_{2.5}$ concentrations, which are of most interest with respect to recent daily time series epidemiology studies, Spearman correlations with $\mathrm{NO}_{2}$ ranged from 0.77 in the winter to 0.29 in the summer; Spearman correlations with $\mathrm{CO}$ ranged from 0.78 in the fall to 0.44 in the spring, and Spearman correlations with $\mathrm{SO}_{2}$ ranged from 0.69 in the fall to 0.49 in the summer. Seasonal differences in the strength of association between 24-hr average $\mathrm{PM}_{2.5}$ and 24-hr average $\mathrm{NO}_{2}$ are graphically illustrated in Figure 39, which presents scatterplots comparing log-transformed concentrations of these variables during summer and winter, with linear least squares lines. (The log-transform was applied to improve the homoscedasticity of the data). The stronger wintertime association is evidenced by the greater slope and tighter scatter of the data around the least squares line during winter than during summer.

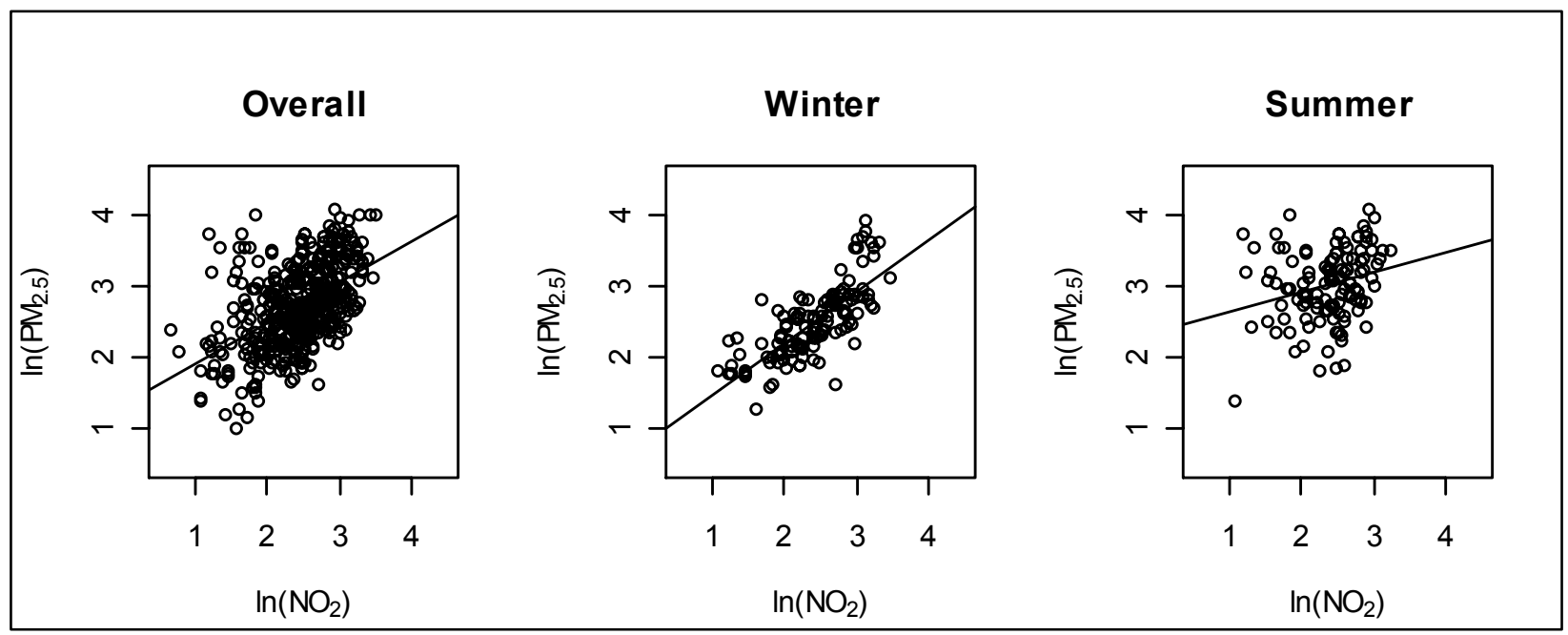

Figure 39. Scatterplots showing the association between log-transformed daily $\mathrm{PM}_{2.5}$ concentrations and log-transformed daily $\mathrm{NO}_{2}$ concentrations measured at the central Steubenville site during SCAMP, with linear least squares lines. The leftmost plot shows all data collected during SCAMP; the center and rightmost plots show only those data that were collected during the winter and summer, respectively.

In contrast to the seasonal trends evident in the correlations between primary gaseous pollutants and $\mathrm{PM}_{2.5}$ and $\mathrm{PM}_{10}$, correlations between $\mathrm{O}_{3}$, a secondary pollutant, and daily measures of these PM variables were positive and moderately strong during summer and negative and moderately strong during winter. This discrepancy likely results from seasonal differences in the factors that influence ambient mass concentrations of $\mathrm{PM}_{2.5}$ and $\mathrm{PM}_{10}$ in Steubenville. As discussed earlier, $\mathrm{PM}_{2.5}$ mass during summer in Steubenville is dominated by secondary sulfates, which tend to be formed on a regional scale during the same photochemically-active conditions that favor $\mathrm{O}_{3}$ formation. This is consistent with the moderate, 
positive correlation observed between $\mathrm{PM}_{2.5}$ and $\mathrm{O}_{3}$ during summer. It is noteworthy, however, that whereas daily $\mathrm{PM}_{2.5}$ concentrations were moderately correlated with daily $\mathrm{O}_{3}$ concentrations during summer $\left(r_{s}=0.47\right)$, hourly concentrations of these species were uncorrelated $\left(r_{s}=0.06\right)$ during that season, suggesting that peak concentrations tended to occur during different times of the day. $\mathrm{NO}_{x}, \mathrm{CO}$, and $\mathrm{SO}_{2}$, which are expected to result predominantly from primary emission sources in the Steubenville area, were more weakly correlated with $\mathrm{PM}_{2.5}$ during summer, when secondary production of $\mathrm{PM}_{2.5}$ is maximal, than during fall and winter, when a larger percentage of total $\mathrm{PM}_{2.5}$ mass is expected to result from local, primary emission sources than from regional, secondary $\mathrm{PM}_{2.5}$ formation. Correlations of $\mathrm{NO}_{\mathrm{x}}, \mathrm{CO}$, and $\mathrm{SO}_{2}$ with $\mathrm{PM}_{2.5}$ were similar regardless of whether daily or hourly data were used, suggesting some similarity in the diurnal behavior of these pollutants. This is consistent with the average diurnal profiles shown in Figures 24 and 25. Daily and hourly $\mathrm{O}_{3}$ concentrations were negatively correlated with $\mathrm{PM}_{2.5}$ during winter, suggesting that a mechanism other than photochemically-assisted secondary formation is dominant in controlling $\mathrm{PM}_{2.5}$ mass concentrations during that season.

Correlations of the gaseous pollutants measured at the central Steubenville site during SCAMP with coarse particle ( $\left.\mathrm{PM}_{10-2.5}\right)$ mass concentrations estimated for that site are consistent with the above interpretation. Daily concentrations of $\mathrm{PM}_{10-2.5}$, which is expected to result largely from primary emissions in the Steubenville area, showed less-pronounced seasonal variations in their associations with $\mathrm{NO}, \mathrm{NO}_{2}$, and $\mathrm{CO}$ concentrations than did daily $\mathrm{PM}_{2.5}$ concentrations, and did not exhibit any appreciable correlation with $\mathrm{O}_{3}$ concentrations during summer. This suggests that the effect of primary emission sources on $\mathrm{PM}_{10-2.5}$ mass concentrations is more consistent throughout the year than the effect of these sources on $\mathrm{PM}_{2.5}$ mass concentrations. Correlations between daily concentrations of $\mathrm{PM}_{2.5}$ and $\mathrm{PM}_{10-2.5}$ at Steubenville were strongest during winter $\left(r_{s}=0.62\right)$ and weakest during summer $\left(r_{s}=0.28\right)$, further supporting the hypothesis that primary sources control the day-to-day variability of $\mathrm{PM}_{2.5}$ mass concentrations in Steubenville to a greater extent during summer than during winter.

The correlations presented in Table 30 do not account for the autocorrelated nature of the time series of PM and gaseous pollutant data collected at the central Steubenville site. Connell et al. (2005b) employed ARIMA modeling to account for autocorrelation in a more thorough analysis of the associations between daily $\mathrm{PM}_{2.5}$ concentrations and daily gaseous pollutant concentrations measured at the Steubenville site during SCAMP. The application of linear regression analysis to ARIMA-adjusted daily $\mathrm{PM}_{2.5}$ and gaseous pollutant concentrations indicated statistically significant, moderate, positive overall associations between $\mathrm{PM}_{2.5}$ and $\mathrm{SO}_{2}, \mathrm{NO}, \mathrm{NO}_{2}$, and $\mathrm{CO}\left(\mathrm{R}^{2}=0.25-0.46\right)$, consistent with the overall Spearman correlations reported in Table 30. The overall association between $\mathrm{PM}_{2.5}$ and $\mathrm{O}_{3}$, while statistically significant, was weak $\left(R^{2}=0.029\right)$. Moreover, the associations between $\mathrm{PM}_{2.5}$ and $\mathrm{NO}, \mathrm{NO}_{2}$, $\mathrm{CO}$, and $\mathrm{O}_{3}$ exhibited a statistically significant interaction with season. Associations of $\mathrm{NO}$ and $\mathrm{NO}_{2}$ with $\mathrm{PM}_{2.5}$ were strongest during fall $\left(\mathrm{R}^{2}=0.53\right.$ and 0.61 , respectively; slope $=0.39$ and 0.57 , respectively) and weakest during summer $\left(R^{2}=0.0014\right.$ and 0.086 , respectively; slope $=$ -0.015 and 0.20 , respectively). The association between $\mathrm{CO}$ and $\mathrm{PM}_{2.5}$ was strongest during winter $\left(R^{2}=0.60\right.$; slope $\left.=0.66\right)$ and weakest during summer $\left(R^{2}=0.24\right.$; slope $\left.=0.27\right)$, whereas the association between $\mathrm{O}_{3}$ and $\mathrm{PM}_{2.5}$ was weakly positive during summer $\left(\mathrm{R}^{2}=0.12\right.$; slope $=$ 0.17 ) and moderately negative during winter $\left(R^{2}=0.25\right.$; slope $\left.=-0.29\right)$. Seasonal variations in the strength of association between $\mathrm{SO}_{2}$ and $\mathrm{PM}_{2.5}$ were not statistically significant.

These results generally confirm the observations made on the basis of Table 30 above, and suggest that confounding by criteria pollutants such as $\mathrm{NO}_{2}, \mathrm{CO}$, and $\mathrm{SO}_{2}$, which have wellestablished effects on human health, is a possibility in time series epidemiology studies conducted in Steubenville. Moolgavkar and Luebeck (1996) state that "seasonal influences are 
effect modifiers in epidemiologic studies of air pollution;" results from the ambient air monitoring portion of SCAMP suggest that in addition to possibly modifying the effect of pollutants on health outcomes, as suggested by Moolgavkar and Luebeck, season can significantly modify the degree of collinearity among pollutants. The correlations above suggest that, as observed by Chock et al. (2000) in nearby Pittsburgh, gaseous pollutants such as $\mathrm{CO}$ and $\mathrm{NO}_{2}$ may cause seasonally-dependent multicollinearity problems in $\mathrm{PM}_{2.5}$ time series epidemiology studies focusing on Steubenville. This interaction with season is observed even after autocorrelation (including seasonality) has been removed from the individual pollutant time series. Hence, results from SCAMP reinforce the need for future epidemiology studies to employ separate analyses by season in order to better capture and control for the collinearity between $\mathrm{PM}_{2.5}$ and co-pollutants, and suggest that caution should be exercised when interpreting the results of previous epidemiology studies in Steubenville (e.g., Schwartz and Dockery, 1992; Schwartz et al., 1996) and similar locations that did not consider the effects of pollutants such as CO and $\mathrm{NO}_{2}$ and their seasonal interactions with $\mathrm{PM}$.

Table 31 presents Spearman correlation coefficients describing the associations between 24-hr average mass concentrations of $\mathrm{PM}_{2.5}, \mathrm{PM}_{10}$, and $\mathrm{PM}_{10-2.5}$ and corresponding 24-hr number concentrations of total pollen, total spores, and several prevalent types of spores measured at the central Steubenville site. As with the correlations between PM and gaseous pollutants, correlation coefficients were computed using all data collected during SCAMP ("overall"), as well as using data stratified by astronomical season. No appreciable positive correlations were observed between the various PM measures and the various pollen and spore measures, suggesting little possibility that pollen and spores would confound the results of PM epidemiology studies in Steubenville. (The strongest positive correlation, $r_{s}=0.34$, was between total pollen and $\mathrm{PM}_{10-2.5}$ in spring, when pollen counts in Steubenville are maximal).

Table 31. Spearman correlation coefficients between daily ambient concentrations of $\mathrm{PM}_{2.5}, \mathrm{PM}_{10}$, and $\mathrm{PM}_{10-2.5}$ and daily ambient pollen and spore counts at the central Steubenville site, both overall and by astronomical season.

\begin{tabular}{|c|c|c|c|c|c|c|}
\hline $\begin{array}{c}\text { Pollen/Spore } \\
\text { Type }\end{array}$ & $\begin{array}{c}\text { PM } \\
\text { Measure }\end{array}$ & \multicolumn{5}{|c|}{ Spearman Correlation Coefficient } \\
\cline { 2 - 7 } Ascospores & $\mathrm{PM}_{2.5}$ & 0.10 & -0.07 & 0.04 & -0.15 & -0.20 \\
\cline { 2 - 6 } & $\mathrm{PM}_{10}$ & 0.03 & -0.13 & -0.06 & -0.33 & -0.30 \\
\cline { 2 - 7 } & $\mathrm{PM}_{10-2.5}$ & -0.18 & -0.27 & -0.10 & -0.52 & -0.40 \\
\hline \multirow{3}{*}{ Basidiospores } & $\mathrm{PM}_{2.5}$ & 0.28 & -0.15 & 0.18 & 0.15 & 0.04 \\
\cline { 2 - 7 } & $\mathrm{PM}_{10}$ & 0.21 & -0.20 & 0.13 & -0.01 & -0.06 \\
\cline { 2 - 7 } & $\mathrm{PM}_{10-2.5}$ & -0.03 & -0.32 & 0.11 & -0.25 & -0.21 \\
\hline \multirow{3}{*}{ Cladosporium } & $\mathrm{PM}_{2.5}$ & 0.29 & -0.04 & 0.16 & 0.24 & 0.04 \\
\cline { 2 - 7 } & $\mathrm{PM}_{10}$ & 0.27 & 0.02 & 0.21 & 0.12 & 0.05 \\
\cline { 2 - 7 } Smut/Myxo/ & $\mathrm{PM}_{10-2.5}$ & 0.12 & 0.02 & 0.32 & -0.02 & 0.05 \\
\cline { 2 - 7 } & $\mathrm{PM}_{2.5}$ & 0.17 & 0.09 & 0.06 & -0.16 & 0.06 \\
\cline { 2 - 7 } & $\mathrm{PM}_{10}$ & 0.22 & 0.23 & 0.22 & -0.11 & 0.16 \\
\hline \multirow{3}{*}{ Total Spores } & $\mathrm{PM}_{10-2.5}$ & 0.19 & 0.27 & 0.25 & -0.04 & 0.32 \\
\cline { 2 - 7 } & $\mathrm{PM}_{2.5}$ & 0.25 & -0.07 & 0.12 & 0.09 & -0.02 \\
\cline { 2 - 6 } & $\mathrm{PM}_{10}$ & 0.19 & -0.08 & 0.08 & -0.11 & -0.07 \\
\hline \multirow{3}{*}{ Total Pollen } & $\mathrm{PM}_{10-2.5}$ & -0.03 & -0.17 & 0.09 & -0.36 & -0.17 \\
\cline { 2 - 7 } & $\mathrm{PM}_{2.5}$ & 0.07 & -0.07 & 0.11 & 0.06 & -0.04 \\
\cline { 2 - 6 } & $\mathrm{PM}_{10}$ & 0.16 & 0.03 & 0.25 & 0.07 & -0.05 \\
\cline { 2 - 7 } & $\mathrm{PM}_{10-2.5}$ & 0.17 & 0.09 & 0.34 & 0.23 & 0.04 \\
\hline
\end{tabular}


Table 32 similarly presents Spearman correlation coefficients describing the overall and seasonal associations between concentrations of $\mathrm{PM}_{2.5}$ (both 1-hr and 24-hr), $\mathrm{PM}_{10}$, and $\mathrm{PM}_{10-2.5}$ and simultaneously-measured meteorological conditions at the central Steubenville site. (Onehour average meteorological condition values were used when computing the correlations for 1$\mathrm{hr}$ average $\mathrm{PM}_{2.5}$ concentrations). As shown in the table, wind speed exhibited a negative association with all of the PM measures, likely reflecting the tendency of air pollutant concentrations to build up during periods of poor ventilation characterized by low wind speeds. As indicated in the table and confirmed by Connell et al. (2005b) using more advanced time series analyses, the association between daily $\mathrm{PM}_{2.5}$ and daily average wind speed varied appreciably by season, with the strongest negative association observed during winter (when local primary sources are expected to contribute a larger relative proportion of total $\mathrm{PM}_{2.5}$ mass in Steubenville) and a much weaker negative association observed during summer (when increases of locally-emitted $\mathrm{PM}_{2.5}$ during periods of stagnation have less of an effect on secondary-sulfate-dominated total $\mathrm{PM}_{2.5}$ mass). Correlations of daily $\mathrm{PM}_{2.5}$ with daily temperature exhibited an opposite seasonal trend. The strongest association between these variables was observed during the summer, when secondary particle formation is favored on warm, photochemically-active days. The summertime correlation between $\mathrm{PM}_{2.5}$ and temperature was substantially stronger for 24-hr average data than for 1-hr average data, though, suggesting that the greatest $\mathrm{PM}_{2.5}$ concentrations did not necessarily occur during the warmest times of day.

Table 32. Spearman correlation coefficients between ambient concentrations of various PM measures (i.e., hourly $\mathrm{PM}_{2.5}$, daily $\mathrm{PM}_{2.5}$, daily $\mathrm{PM}_{10}$, and daily $\mathrm{PM}_{10-2.5}$ ) and meteorological conditions at the central Steubenville site, both overall and by astronomical season.

\begin{tabular}{|c|c|c|c|c|c|c|}
\hline \multirow{2}{*}{$\begin{array}{l}\text { Meteorological } \\
\text { Parameter }\end{array}$} & \multirow{2}{*}{ PM Measure } & \multicolumn{5}{|c|}{ Spearman Correlation Coefficient } \\
\hline & & Overall & Winter & Spring & Summer & Fall \\
\hline \multirow{4}{*}{ Wind Speed } & $\mathrm{PM}_{2.5}-1-\mathrm{h}$ & -0.38 & -0.38 & -0.31 & -0.08 & -0.39 \\
\hline & $\mathrm{PM}_{2.5}-24-\mathrm{h}$ & -0.43 & -0.48 & -0.30 & -0.03 & -0.47 \\
\hline & $\mathrm{PM}_{10}-24-\mathrm{h}$ & -0.42 & -0.48 & -0.25 & -0.12 & -0.48 \\
\hline & $\mathrm{PM}_{10-2.5}-24-\mathrm{h}$ & -0.28 & -0.37 & -0.20 & -0.25 & -0.25 \\
\hline \multirow{4}{*}{ Temperature } & $\mathrm{PM}_{2.5}-1-\mathrm{h}$ & 0.42 & 0.22 & 0.38 & 0.36 & 0.22 \\
\hline & $\mathrm{PM}_{2.5}-24-\mathrm{h}$ & 0.50 & 0.33 & 0.50 & 0.71 & 0.40 \\
\hline & $\mathrm{PM}_{10}-24-\mathrm{h}$ & 0.49 & 0.31 & 0.53 & 0.64 & 0.36 \\
\hline & $\mathrm{PM}_{10-2.5}-24-\mathrm{h}$ & 0.26 & 0.29 & 0.42 & 0.14 & 0.24 \\
\hline \multirow{4}{*}{$\begin{array}{l}\text { Relative } \\
\text { Humidity }\end{array}$} & $\mathrm{PM}_{2.5}-1-\mathrm{h}$ & 0.23 & 0.17 & 0.21 & 0.19 & 0.20 \\
\hline & $\mathrm{PM}_{2.5}-24-\mathrm{h}$ & 0.08 & -0.10 & 0.07 & 0.03 & 0.04 \\
\hline & $\mathrm{PM}_{10}-24-\mathrm{h}$ & -0.12 & -0.31 & -0.20 & -0.11 & -0.16 \\
\hline & $\mathrm{PM}_{10-2.5}-24-\mathrm{h}$ & -0.43 & -0.54 & -0.39 & -0.42 & -0.51 \\
\hline \multirow{4}{*}{ Solar Radiation } & $\mathrm{PM}_{2.5}-1-\mathrm{h}$ & 0.03 & -0.08 & -0.03 & -0.04 & -0.02 \\
\hline & $\mathrm{PM}_{2.5}-24-\mathrm{h}$ & 0.34 & 0.18 & 0.21 & 0.24 & 0.24 \\
\hline & $\mathrm{PM}_{10}-24-\mathrm{h}$ & 0.46 & 0.38 & 0.42 & 0.31 & 0.38 \\
\hline & $\mathrm{PM}_{10-2.5}-24-\mathrm{h}$ & 0.47 & 0.55 & 0.49 & 0.50 & 0.57 \\
\hline \multirow{4}{*}{$\begin{array}{l}\text { Barometric } \\
\text { Pressure }\end{array}$} & $\mathrm{PM}_{2.5}-1-\mathrm{h}$ & 0.16 & 0.05 & 0.11 & 0.03 & 0.21 \\
\hline & $\mathrm{PM}_{2.5}-24-\mathrm{h}$ & 0.29 & 0.23 & 0.24 & 0.07 & 0.31 \\
\hline & $\mathrm{PM}_{10}-24-\mathrm{h}$ & 0.36 & 0.35 & 0.41 & 0.15 & 0.35 \\
\hline & $\mathrm{PM}_{10-2.5}-24-\mathrm{h}$ & 0.37 & 0.43 & 0.43 & 0.38 & 0.31 \\
\hline
\end{tabular}


As expected, $\mathrm{PM}_{10-2.5}$, which consists predominantly of primary rather than secondary particles, did not correlate strongly with temperature during summertime. Rather, coarse particles correlated more strongly with relative humidity (negative association), solar radiation (positive association), and barometric pressure (positive association) than did fine particles. This suggests that elevated ambient concentrations of coarse PM in all seasons tended to occur on clear, dry, high-pressure days. Winds are capable of suspending coarse particles; however, as shown in Table 32, coarse particles at Steubenville exhibited a weakly negative association with wind speed, suggesting that ventilation may have a larger effect on ambient $\mathrm{PM}_{10-2.5}$ concentrations than wind-blown dust.

Figure 40 graphically illustrates the seasonal variability in the strength of the association between daily $\mathrm{PM}_{2.5}$ total mass concentrations (log-transformed values are plotted in the figure to improve homoscedasticity) and daily average temperatures at Steubenville. Temperature affects mortality and is commonly controlled for in $\mathrm{PM}_{2.5}$ epidemiology studies. However, the data presented in Table 32 and Figure 40 suggest that, like the gaseous pollutants discussed earlier, temperature exhibits a statistically significant seasonal interaction with $\mathrm{PM}_{2.5}$. This again reinforces the need for time series studies exploring the health effects of $\mathrm{PM}_{2.5}$ to use seasonal models so that these seasonal variations in collinearity with potential confounders can be appropriately accounted for.

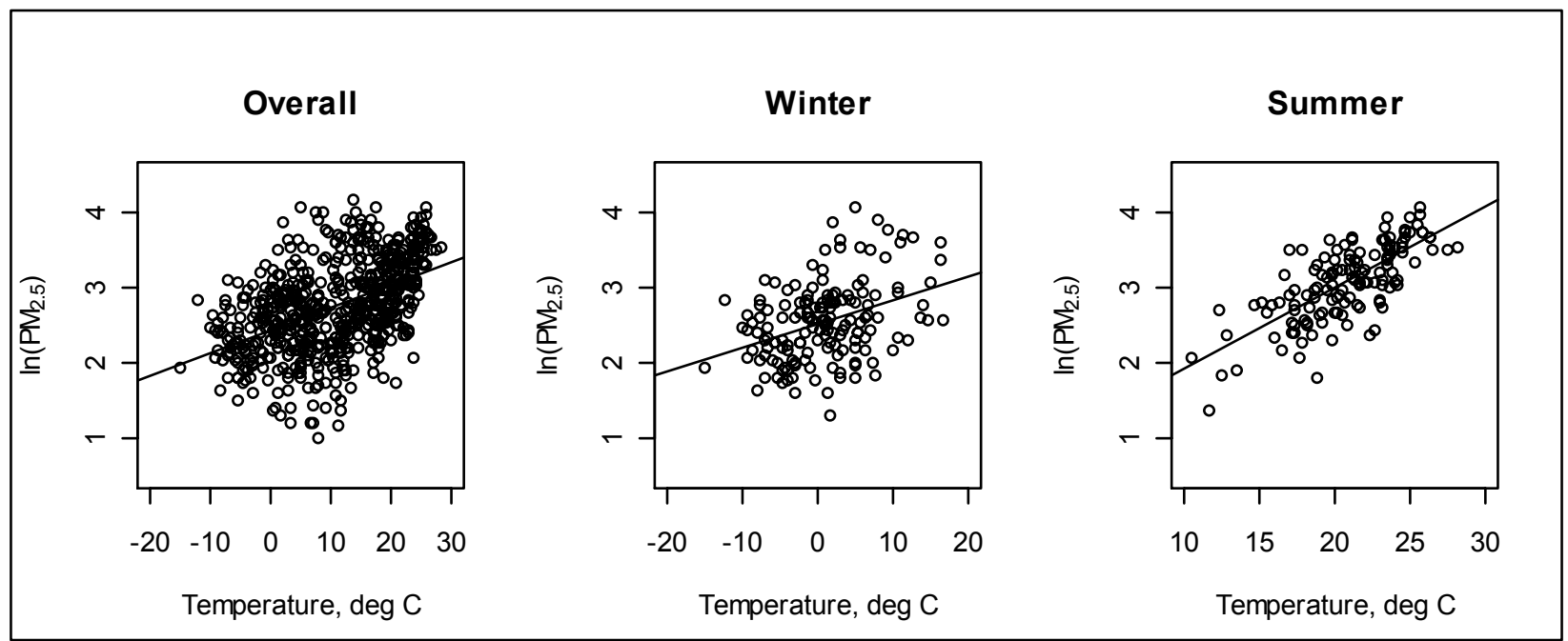

Figure 40. Scatterplots showing the association between log-transformed daily $\mathrm{PM}_{2.5}$ concentrations and daily temperatures measured at the central Steubenville site during SCAMP, with linear least squares lines. The leftmost plot shows all data collected during SCAMP; the center and rightmost plots show only those data that were collected during the winter and summer, respectively.

Spearman correlation coefficients describing the overall associations between 1-hr average $\mathrm{PM}_{2.5}$, wind speed, and barometric pressure measurements at Steubenville during SCAMP are relatively small, as shown in Table 32 . However, the scatterplots presented in Figure 41 provide additional insight into the nature of the associations among these variables. As shown in the figure, 1-hr $\mathrm{PM}_{2.5}$ concentrations greater than $50 \mu \mathrm{g} / \mathrm{m}^{3}$ occurred at Steubenville only when the wind speed was moderate-to-low (i.e., $<3.2 \mathrm{~m} / \mathrm{s}$ ) and the barometric pressure was moderate-tohigh (i.e., $>727 \mathrm{~mm} \mathrm{Hg}$ ). Hours having the greatest wind speeds and the lowest barometric pressures were characterized by relatively low $\mathrm{PM}_{2.5}$ concentrations. This again reflects the effects of ventilation and atmospheric stability on $\mathrm{PM}_{2.5}$ concentrations at Steubenville. Figure 42 indicates that the greatest $\mathrm{PM}_{2.5}$ concentrations at Steubenville also tended to occur during 
periods that were free from precipitation, likely resulting from increased instability and particle removal via wet deposition during these precipitation events.

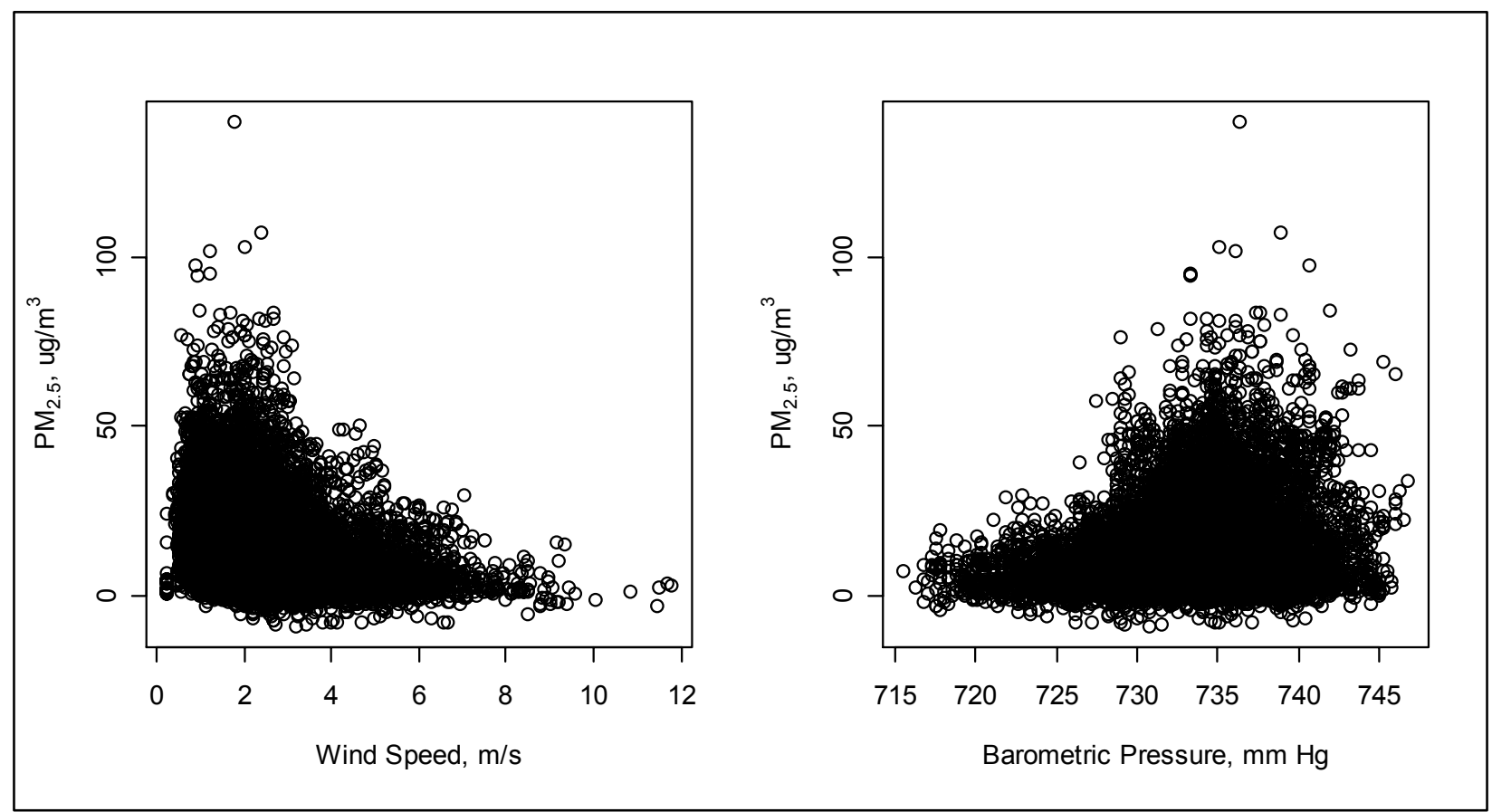

Figure 41. Scatterplots showing 1-hr average $\mathrm{PM}_{2.5}$ concentrations versus 1-hr average wind speeds and barometric pressures measured at the central Steubenville site during SCAMP.

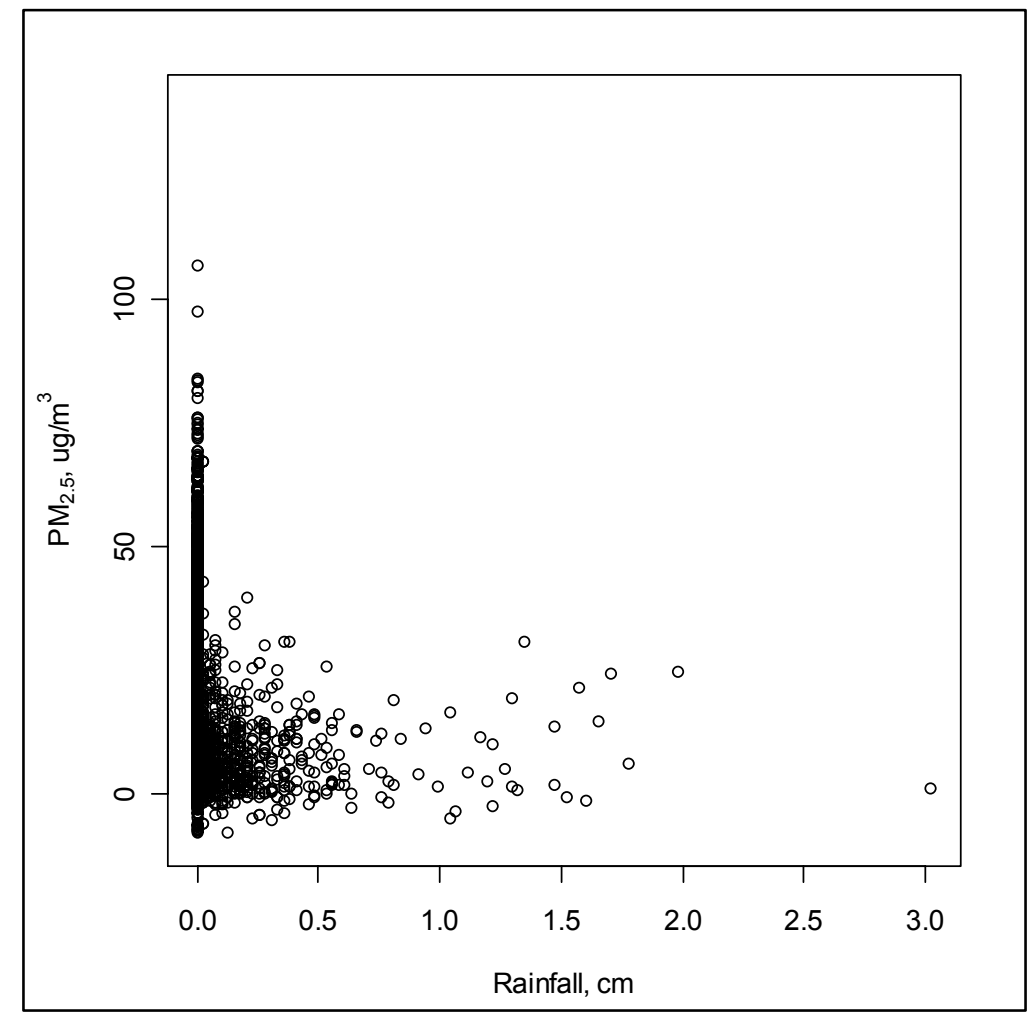

Figure 42. Scatterplot showing 1-hr average $\mathrm{PM}_{2.5}$ concentrations versus 1-hr rainfall at the central Steubenville site during SCAMP. 
To better understand the associations observed between total $\mathrm{PM}_{2.5}$ mass and co-pollutants and meteorological conditions at Steubenville, it is informative to explore correlations involving chemical components of $\mathrm{PM}_{2.5}$. Table 33 presents Spearman correlation coefficients describing associations between ionic, carbonaceous, and acid-digestible elemental components of $\mathrm{PM}_{2.5}$ and corresponding daily total mass concentrations of $\mathrm{PM}_{2.5}, \mathrm{PM}_{10}$, and $\mathrm{PM}_{10-2.5}$ at Steubenville. As expected, $\mathrm{NH}_{4}{ }^{+}$and $\mathrm{SO}_{4}{ }^{2-}$ correlated strongly with total $\mathrm{PM}_{2.5}$ mass, as $\left(\mathrm{NH}_{4}\right)_{2} \mathrm{SO}_{4}$ is the largest contributor to $\mathrm{PM}_{2.5}$ mass at Steubenville. However, a number of other $\mathrm{PM}_{2.5}$ components, including organic material, elemental carbon, and even elements such as Fe, $\mathrm{K}$, $\mathrm{Mn}, \mathrm{Se}, \mathrm{Sn}$, and $\mathrm{Zn}$, exhibited moderately strong (i.e., $\mathrm{r}_{\mathrm{s}}=0.66-0.78$ ) correlations with $\mathrm{PM}_{2.5}$ mass as well. These correlations allow for the possibility that total $\mathrm{PM}_{2.5}$ mass could act as a surrogate not only for its major components (e.g., $\mathrm{SO}_{4}{ }^{2-}, \mathrm{OM}$, and $\mathrm{NH}_{4}{ }^{2}$ ), but also for its minor but toxicologically relevant trace metal constituents. These trace constituents are subject to greater measurement noise than are total $\mathrm{PM}_{2.5}$ mass and major $\mathrm{PM}_{2.5}$ components; Lipfert and Wyzga (1997) point out that "In joint regressions of two correlated variables with differing exposure errors, the entire effect may be shifted onto the more precisely measured variable." Hence, the appreciable correlations observed between total $\mathrm{PM}_{2.5}$ mass and both major and minor chemical constituents reinforce the need for further research to elucidate the health implications of these individual chemical components.

Table 33. Spearman correlations between concentrations of $\mathrm{PM}_{2.5}$ ionic, carbonaceous, and aciddigestible elemental components and concentrations of $\mathrm{PM}_{2.5}, \mathrm{PM}_{10}$, and $\mathrm{PM}_{10-2.5}$ total mass measured at the central Steubenville site during SCAMP.

\begin{tabular}{|c|c|c|c|}
\hline & $\mathbf{P M}_{\mathbf{2 . 5}}$ & $\mathbf{P M}_{\mathbf{1 0}}$ & $\mathbf{P M}_{\mathbf{1 0}-\mathbf{2 . 5}}$ \\
\hline $\mathbf{N H}_{4}{ }^{-}$ & 0.89 & 0.75 & 0.34 \\
\hline $\mathbf{S O}_{\mathbf{4}}{ }^{-2}$ & 0.91 & 0.79 & 0.39 \\
\hline $\mathbf{N O}^{-}$ & 0.17 & 0.10 & 0.03 \\
\hline $\mathbf{C l}{ }^{-}$ & 0.44 & 0.46 & 0.65 \\
\hline $\mathbf{E C}$ & 0.68 & 0.73 & 0.73 \\
\hline $\mathbf{O M}$ & 0.78 & 0.84 & 0.60 \\
\hline $\mathbf{A l}$ & 0.58 & 0.67 & 0.64 \\
\hline $\mathbf{B a}$ & 0.70 & 0.74 & 0.70 \\
\hline $\mathbf{C a}$ & 0.61 & 0.73 & 0.66 \\
\hline $\mathbf{C d}$ & 0.55 & 0.62 & 0.47 \\
\hline $\mathbf{C o}$ & 0.55 & 0.53 & 0.60 \\
\hline $\mathbf{C u}$ & 0.64 & 0.65 & 0.54 \\
\hline $\mathbf{F e}$ & 0.53 & 0.54 & 0.71 \\
\hline $\mathbf{K}$ & 0.67 & 0.75 & 0.65 \\
\hline $\mathbf{M g}$ & 0.67 & 0.75 & 0.74 \\
\hline $\mathbf{M n}$ & 0.57 & 0.70 & 0.70 \\
\hline $\mathbf{N i}$ & 0.66 & 0.71 & 0.49 \\
\hline $\mathbf{P b}$ & 0.54 & 0.56 & 0.56 \\
\hline $\mathbf{S e}$ & 0.63 & 0.64 & 0.48 \\
\hline $\mathbf{S n}$ & 0.71 & 0.67 & 0.59 \\
\hline $\mathbf{T i}$ & 0.66 & 0.64 & 0.41 \\
\hline $\mathbf{V}$ & 0.30 & 0.37 & 0.52 \\
\hline $\mathbf{Z n}$ & 0.52 & 0.54 & 0.62 \\
\hline & 0.70 & 0.70 & \\
\hline & & & \\
\hline & & & \\
\hline
\end{tabular}


Whereas the largely secondary components of $\mathrm{PM}_{2.5}$ (i.e., $\mathrm{NH}_{4}{ }^{+}, \mathrm{SO}_{4}{ }^{2-}, \mathrm{NO}_{3}{ }^{-}$) exhibited relatively weak correlations $\left(r_{s}=0.03-0.39\right)$ with coarse $P M$ mass, a number of other $\mathrm{PM}_{2.5}$ components (e.g., EC, OM, Ba, Ca, Fe, K, Mg, Mn) showed moderately strong correlations (i.e., $r_{\mathrm{s}}=0.65-$ $0.74)$ with $\mathrm{PM}_{10-2.5}$. This suggests that common or closely-situated primary emission sources likely affect ambient concentrations of both coarse PM and these $\mathrm{PM}_{2.5}$ constituents.

Table 34 presents a matrix showing Spearman correlations among ionic, carbonaceous, and acid-digestible elemental components of $\mathrm{PM}_{2.5}$ that were measured at the central Steubenville site. As indicated in the table, a number of the $\mathrm{PM}_{2.5}$ components at Steubenville were moderately-to-strongly collinear; all of the components except for $\mathrm{NO}_{3}^{-}, \mathrm{Cl}^{-}, \mathrm{Cu}$, Se, and $\mathrm{Ti}$ exhibited a correlation $\geq 0.70$ with at least one other component. This suggests the potential for collinearity problems in time series epidemiology studies focusing on chemical components of $\mathrm{PM}_{2.5}$ in Steubenville. Several of the correlations reported in Table 34 are readily explainable on the basis of emission profiles and atmospheric chemistry. For example, $\mathrm{SO}_{4}{ }^{2-}$ and $\mathrm{NH}_{4}{ }^{+}$ correlated more strongly with each other $\left(r_{s}=0.91\right)$ than with any other $\mathrm{PM}_{2.5}$ components, and Se correlated more strongly with $\mathrm{SO}_{4}{ }^{2-}\left(r_{\mathrm{s}}=0.68\right)$ than with any other $\mathrm{PM}_{2.5}$ component. These associations are expected, as secondary $\mathrm{SO}_{4}{ }^{2-}$ particles are generally present as $\left(\mathrm{NH}_{4}\right)_{2} \mathrm{SO}_{4}$ or $\mathrm{NH}_{4} \mathrm{HSO}_{4}$ in Steubenville, and $\mathrm{Se}$ is often used as a tracer for coal-fired power plant emissions, which are a major source of secondary $\mathrm{SO}_{4}{ }^{2-}$ in the Steubenville region.

Many of the strongest intercomponent associations were observed among a group of elements comprising $\mathrm{As}, \mathrm{Fe}, \mathrm{Mn}, \mathrm{Pb}, \mathrm{Sn}$, and $\mathrm{Zn}$. Spearman correlations among these components ranged from 0.76 to 0.90 for all possible component pairs. Concentrations of each of these six elements were also more strongly associated with concentrations of elemental carbon and organic material $\left(r_{s}=0.67-78\right)$ than with concentrations of $\mathrm{SO}_{4}{ }^{2-}\left(r_{s}=0.50-0.59\right)$. (Concentrations of Fe and $\mathrm{Mn}$ were also strongly associated with concentrations of $\mathrm{Mg}$, with Spearman correlation coefficients of 0.85 and 0.80 , respectively). These strong associations may indicate a common emission source for these elements, or alternatively may reflect the influence of meteorological conditions on ambient concentrations of pollutants originating from several sources. Elevated concentrations of particulate $\mathrm{Fe}$ and $\mathrm{Mn}$ are often found near steel production facilities (Dusseldorp et al., 1995), and based on the U.S. EPA's 2001 Toxic Release Inventory (TRI) for air emissions, the primary metals industry accounts for $93 \%$ of $\mathrm{Zn}$ emissions and $83 \%$ of Mn emissions from stationary sources in Jefferson County, $\mathrm{OH}$, where Steubenville is located. Hence, the correlations observed among $\mathrm{Fe}, \mathrm{Mn}$, and $\mathrm{Zn}$ are likely at least in part attributable to Steubenville's iron and steel facilities. Further analyses of sources of $\mathrm{PM}_{2.5}$ in Steubenville are presented in section 4.2 .5 of this report.

Table 35 summarizes overall Spearman correlation coefficients between daily concentrations of $\mathrm{PM}_{2.5}$ chemical components and daily average gaseous pollutant concentrations and meteorological conditions. $\mathrm{SO}_{2}$ correlated more strongly with $\mathrm{Se}\left(r_{\mathrm{s}}=0.78\right)$ than with any of the other $\mathrm{PM}_{2.5}$ components, likely reflecting the common emission of these two species from coalfired electric power plants and other coal combustion sources. Se was also well-correlated with $\mathrm{NO}_{2}$, which results from coal combustion emissions. Again, many of the strongest correlations involved the group of six collinear elements identified above (i.e., As, $\mathrm{Fe}, \mathrm{Mn}, \mathrm{Pb}, \mathrm{Sn}$, and $\mathrm{Zn}$ ). These elements, as well as elemental carbon, exhibited appreciable associations with $\mathrm{NO}, \mathrm{NO}_{2}$, $\mathrm{NO}_{x}$, and $\mathrm{CO}$; pairwise Spearman correlation coefficients describing these associations ranged from 0.62 to 0.84 . Correlations of $\mathrm{Ba}$ with $\mathrm{NO}_{2}$ and $\mathrm{K}$ with $\mathrm{CO}$ were also $>0.70$, perhaps reflecting common combustion sources of these species. None of the $\mathrm{PM}_{2.5}$ components correlated well with $\mathrm{O}_{3}$. 
Table 34. Matrix of Spearman correlations computed for pairwise concentrations of $\mathrm{PM}_{2.5}$ ionic, carbonaceous, and acid-digestible elemental components measured at the central Steubenville site during SCAMP.

\begin{tabular}{|c|c|c|c|c|c|c|c|c|c|c|c|c|c|c|c|c|c|c|c|c|c|c|c|c|}
\hline & $\mathrm{NH}_{4}{ }^{+}$ & $\mathrm{SO}_{4}{ }^{2-}$ & $\mathrm{NO}_{3}{ }^{-}$ & $\mathrm{Cl}^{-}$ & EC & OM & Al & As & $\mathrm{Ba}$ & $\mathrm{Ca}$ & Cd & Co & $\mathrm{Cu}$ & $\mathrm{Fe}$ & $\mathrm{K}$ & $\mathbf{M g}$ & $M n$ & $\mathrm{Ni}$ & $\mathrm{Pb}$ & Se & Sn & $\mathrm{Ti}$ & V & $\mathrm{Zn}$ \\
\hline $\mathrm{NH}_{4}{ }^{+}$ & & 0.91 & 0.26 & 0.27 & 0.46 & 0.52 & 0.39 & 0.46 & 0.37 & 0.31 & 0.40 & 0.50 & 0.36 & 0.40 & 0.46 & 0.35 & 0.39 & 0.40 & 0.38 & 0.58 & 0.42 & 0.26 & 0.38 & 0.45 \\
\hline $\mathrm{SO}_{4}{ }^{2-}$ & 0.91 & & 0.01 & 0.36 & 55 & .60 & 0.49 & 0.59 & 0.48 & 0.46 & 0.50 & 0.59 & 0.43 & 0.54 & .54 & 0.48 & 0.52 & 0.56 & 0.50 & 68 & .53 & 0.32 & 0.49 & 0.56 \\
\hline $\mathrm{NO}_{3}{ }^{-}$ & 0.26 & 0.01 & & 0.13 & 0.02 & 0.05 & -0.04 & -0.09 & -0.09 & -0.02 & 0.02 & 0.08 & -0.05 & -0.09 & 0.09 & -0.03 & -0.06 & -0.13 & -0.08 & 0.05 & -0.01 & -0.05 & -0.10 & -0.03 \\
\hline $\mathrm{Cl}^{-}$ & 0.27 & 0.36 & 0.13 & & 0.60 & 0.43 & 0.41 & 0.54 & 0.49 & 0.47 & 0.39 & 0.56 & 0.48 & 0.61 & .46 & 0.58 & 0.59 & 0.49 & 0.55 & 0.42 & .56 & 0.32 & 0.43 & 0.55 \\
\hline EC & 0.46 & 0.55 & 0.02 & 0.60 & & 0.71 & 0.56 & 0.75 & 0.70 & 0.62 & 0.51 & 0.58 & 0.64 & 0.75 & 0.64 & 0.64 & 0.73 & 0.48 & 0.71 & 0.55 & 0.69 & 0.40 & 0.48 & 0.71 \\
\hline OM & 0.52 & 0.60 & 0.05 & 0.43 & 0.71 & & 0.71 & 0.78 & 0.75 & 0.62 & 0.48 & 0.52 & 0.56 & 0.73 & 0.78 & 0.66 & 0.70 & 0.49 & 0.67 & 0.59 & 69 & 0.30 & 0.56 & 0.72 \\
\hline Al & 0.39 & 0.49 & -0.04 & 0.41 & 0.56 & 0.71 & & 0.64 & 0.65 & 0.72 & 0.41 & 0.42 & 0.38 & 0.70 & 0.78 & 0.71 & 0.66 & 0.52 & 0.54 & 0.58 & .57 & 0.28 & 0.50 & 0.62 \\
\hline As & 0.46 & 0.59 & -0.09 & 0.54 & 0.75 & 0.78 & 0.64 & & 0.72 & 0.59 & 0.68 & 0.63 & 0.65 & 0.85 & 0.75 & 0.72 & 0.78 & 0.64 & 0.86 & 0.59 & 0.81 & 0.38 & 0.64 & 0.85 \\
\hline $\mathrm{Ba}$ & 0.37 & 0.48 & -0.09 & 0.49 & 0.70 & 0.75 & 0.65 & 0.72 & & 0.70 & 0.53 & 0.64 & 0.64 & 0.75 & .64 & 0.72 & 0.69 & 0.60 & 0.63 & .50 & .61 & 0.49 & 0.59 & 0.67 \\
\hline $\mathrm{Ca}$ & 0.31 & 0.46 & -0.02 & 0.47 & 0.62 & 0.62 & 0.72 & 0.59 & 0.70 & & 0.53 & 0.63 & 0.52 & 0.73 & 0.62 & 0.77 & 0.78 & 0.55 & 0.53 & 0.54 & 0.58 & 0.53 & 0.55 & 0.66 \\
\hline Cd & 0.40 & 0.50 & -0.02 & 0.39 & 0.51 & 0.48 & 0.41 & 0.68 & 0.53 & 0.53 & & 0.59 & 066 & 0.59 & 0.47 & 0.52 & 062 & 0.71 & 0.70 & 0.39 & .64 & 0.38 & 0.62 & 0.69 \\
\hline Co & 0.50 & 0.59 & 0.08 & 0.56 & 0.58 & 0.52 & 0.42 & 0.63 & 0.64 & 0.63 & 0.59 & & 0.62 & 0.67 & 0.47 & 0.58 & 0.67 & 0.70 & 0.55 & 0.61 & 0.61 & 0.49 & 0.57 & 0.63 \\
\hline $\mathrm{Cu}$ & 0.36 & 0.43 & -0.05 & 0.48 & 0.64 & 0.56 & 0.38 & 0.65 & 0.64 & 0.52 & 0.66 & 0.62 & & 0.64 & 0.53 & 0.52 & 0.64 & 0.60 & 0.65 & 0.38 & 0.69 & 0.51 & 0.57 & 0.67 \\
\hline $\mathrm{Fe}$ & 0.40 & 0.54 & -0.09 & 0.61 & 0.75 & 0.73 & 0.70 & 0.85 & 0.75 & 0.73 & 0.59 & 0.67 & 0.64 & & 0.77 & 0.85 & 0.90 & 0.62 & 0.79 & 0.59 & 0.81 & 0.41 & 0.59 & 0.87 \\
\hline$K$ & 0.46 & 0.54 & 0.09 & 0.46 & 0.64 & 0.78 & 0.78 & 0.75 & 0.64 & 0.62 & 0.47 & 0.47 & 0.53 & 0.77 & & 0.72 & 0.71 & 0.46 & 0.65 & 0.56 & 0.59 & 0.23 & 0.47 & 0.73 \\
\hline $\mathrm{Mg}$ & 0.35 & 0.48 & -0.03 & 0.58 & 0.64 & 0.66 & 0.71 & 0.72 & 0.72 & 0.77 & 0.52 & 0.58 & $05 ?$ & 0.85 & 72 & & 0.80 & 0.55 & 0.65 & 0.48 & .61 & 0.39 & 0.50 & 0.73 \\
\hline Mn & 0.39 & 0.52 & -0.06 & 0.59 & 0.73 & 0.70 & 0.66 & 0.78 & 0.69 & 0.78 & 0.62 & 0.67 & 0.64 & 0.90 & 0.71 & 0.80 & & 0.61 & 0.77 & 0.63 & 0.76 & 0.44 & 0.60 & 0.85 \\
\hline $\mathrm{Ni}$ & 0.40 & 0.56 & -0.13 & 0.49 & 0.48 & 0.49 & 0.52 & 0.64 & 0.60 & 0.55 & 0.71 & 0.70 & 0.60 & 0.62 & 0.46 & 0.55 & 0.61 & & 0.63 & 0.56 & 65 & 0.41 & 0.70 & 0.62 \\
\hline $\mathrm{Pb}$ & 0.38 & 0.50 & -0.08 & 0.55 & 0.71 & 0.67 & 0.54 & 0.86 & 0.63 & 0.53 & 0.70 & 0.55 & 0.65 & 0.79 & 0.65 & 0.65 & 0.77 & 0.63 & & 0.51 & 0.81 & 0.28 & 0.63 & 0.86 \\
\hline Se & 0.58 & 0.68 & 0.05 & 0.42 & 0.55 & 0.59 & 0.58 & 0.59 & 0.50 & 0.54 & 0.39 & 0.61 & 0.38 & 0.59 & 0.56 & 0.48 & 0.63 & 0.56 & 0.51 & & 0.56 & 0.32 & 0.49 & 0.57 \\
\hline Sn & 0.42 & 0.53 & -0.01 & 0.56 & 0.69 & 0.69 & 0.57 & 0.81 & 0.61 & 0.58 & 0.64 & 0.61 & 0.69 & 0.81 & 0.59 & 0.61 & 0.76 & 0.65 & 0.81 & 0.56 & & 0.42 & 0.69 & 0.82 \\
\hline $\mathrm{Ti}$ & 0.26 & 0.32 & -0.05 & 0.32 & 0.40 & 0.30 & 0.28 & 0.38 & 0.49 & 0.53 & 0.38 & 0.49 & 0.51 & 0.41 & 0.23 & 0.39 & 0.44 & 0.41 & 0.28 & 0.32 & 0.42 & & 0.57 & 0.36 \\
\hline V & 0.38 & 0.49 & -0.10 & 0.43 & 0.48 & 0.56 & 0.50 & 0.64 & 0.59 & 0.55 & 0.62 & 0.57 & 0.57 & 0.59 & 0.47 & 0.50 & 0.60 & 0.70 & 0.63 & 0.49 & 0.69 & 0.57 & & 0.66 \\
\hline $\mathrm{Zn}$ & 0.45 & 0.56 & -0.03 & 0.55 & 0.71 & 0.72 & 0.62 & 0.85 & 0.67 & 0.66 & 0.69 & 0.63 & 0.67 & 0.87 & 0.73 & 0.73 & 0.85 & 0.62 & 0.86 & 0.57 & 0.82 & 0.36 & 0.66 & \\
\hline
\end{tabular}


Table 35. Spearman correlations between concentrations of $\mathrm{PM}_{2.5}$ ionic, carbonaceous, and aciddigestible elemental components and gaseous co-pollutant concentrations and meteorological conditions measured at the central Steubenville site during SCAMP.

\begin{tabular}{|c|c|c|c|c|c|c|c|c|c|c|c|}
\hline & $\mathrm{SO}_{2}$ & NO & $\mathrm{NO}_{2}$ & $\mathrm{NO}_{\mathrm{x}}$ & $\mathrm{CO}$ & $\mathrm{O}_{3}$ & WS & Temp & RH & Rad & BP \\
\hline $\mathrm{NH}_{4}^{+}$ & 0.37 & 0.22 & 0.27 & 0.24 & 0.45 & 0.02 & -0.30 & 0.39 & 0.23 & 0.17 & 0.11 \\
\hline $\mathrm{SO}_{4}{ }^{2-}$ & 0.44 & 0.22 & 0.29 & 0.26 & 0.43 & 0.15 & -0.35 & 0.59 & 0.19 & 0.33 & 0.24 \\
\hline $\mathrm{NO}_{3}{ }^{-}$ & 0.04 & 0.18 & 0.04 & 0.07 & 0.23 & -0.37 & 0.12 & -0.56 & 0.03 & -0.43 & -0.27 \\
\hline $\mathrm{Cl}^{-}$ & 0.24 & 0.41 & 0.30 & 0.36 & 0.39 & -0.01 & -0.18 & 0.21 & -0.14 & 0.29 & 0.23 \\
\hline EC & 0.51 & 0.76 & 0.73 & 0.79 & 0.73 & -0.23 & -0.45 & 0.27 & -0.17 & 0.25 & 0.33 \\
\hline OM & 0.49 & 0.57 & 0.66 & 0.64 & 0.68 & -0.01 & -0.47 & 0.43 & -0.25 & 0.38 & 0.36 \\
\hline Al & 0.52 & 0.41 & 0.63 & 0.58 & 0.60 & 0.03 & -0.16 & 0.36 & -0.38 & 0.30 & 0.29 \\
\hline As & 0.52 & 0.72 & 0.80 & 0.80 & 0.76 & -0.06 & -0.55 & 0.41 & -0.23 & 0.43 & 0.41 \\
\hline $\mathrm{Ba}$ & 0.43 & 0.60 & 0.74 & 0.68 & 0.57 & -0.02 & -0.46 & 0.41 & -0.40 & 0.41 & 0.39 \\
\hline $\mathrm{Ca}$ & 0.57 & 0.59 & 0.66 & 0.63 & 0.52 & -0.18 & -0.21 & 0.23 & -0.41 & 0.27 & 0.46 \\
\hline Cd & 0.35 & 0.59 & 0.63 & 0.63 & 0.48 & -0.22 & -0.42 & 0.23 & -0.09 & 0.19 & 0.42 \\
\hline Co & 0.57 & 0.58 & 0.62 & 0.57 & 0.53 & -0.22 & -0.28 & 0.21 & -0.27 & 0.18 & 0.43 \\
\hline $\mathrm{Cu}$ & 0.28 & 0.60 & 0.62 & 0.67 & 0.44 & -0.29 & -0.48 & 0.26 & -0.14 & 0.30 & 0.38 \\
\hline $\mathrm{Fe}$ & 0.59 & 0.71 & 0.76 & 0.77 & 0.75 & -0.07 & -0.36 & 0.37 & -0.32 & 0.36 & 0.47 \\
\hline $\mathrm{K}$ & 0.52 & 0.52 & 0.68 & 0.62 & 0.74 & 0.02 & -0.19 & 0.27 & -0.38 & 0.29 & 0.30 \\
\hline Mg & 0.48 & 0.55 & 0.61 & 0.59 & 0.67 & 0.10 & -0.26 & 0.34 & -0.47 & 0.47 & 0.42 \\
\hline$M n$ & 0.62 & 0.72 & 0.73 & 0.77 & 0.68 & -0.21 & -0.32 & 0.29 & -0.30 & 0.27 & 0.45 \\
\hline $\mathbf{N i}$ & 0.45 & 0.46 & 0.58 & 0.54 & 0.35 & -0.06 & -0.34 & 0.42 & -0.15 & 0.26 & 0.39 \\
\hline $\mathbf{P b}$ & 0.44 & 0.70 & 0.74 & 0.78 & 0.67 & -0.15 & -0.49 & 0.35 & -0.17 & 0.33 & 0.37 \\
\hline $\mathrm{Se}$ & 0.78 & 0.56 & 0.74 & 0.65 & 0.57 & -0.27 & -0.25 & 0.24 & -0.08 & 0.06 & 0.16 \\
\hline Sn & 0.45 & 0.75 & 0.79 & 0.84 & 0.62 & -0.26 & -0.49 & 0.34 & -0.12 & 0.22 & 0.45 \\
\hline $\mathrm{Ti}$ & 0.23 & 0.48 & 0.40 & 0.40 & 0.22 & -0.12 & -0.32 & 0.22 & -0.05 & 0.27 & 0.33 \\
\hline $\mathbf{V}$ & 0.32 & 0.53 & 0.63 & 0.61 & 0.40 & -0.04 & -0.44 & 0.42 & -0.09 & 0.31 & 0.43 \\
\hline $\mathrm{Zn}$ & 0.52 & 0.74 & 0.75 & 0.80 & 0.74 & -0.17 & -0.43 & 0.32 & -0.21 & 0.31 & 0.41 \\
\hline
\end{tabular}

NOTE: $\mathrm{WS}=$ wind speed; Temp = temperature; $\mathrm{RH}=$ relative humidity; Rad = solar radiation; $\mathrm{BP}=$ barometric pressure.

Overall correlations of 24-hr average $\mathrm{PM}_{2.5}$ chemical component concentrations with 24-hr weather conditions were in most cases similar to those exhibited by total $\mathrm{PM}_{2.5}$ mass. A vast majority of the components exhibited weak-to-moderate negative correlations with wind speed, and weak-to-moderate positive correlations with temperature, solar radiation, and barometric pressure. The strongest correlations were a positive correlation between $\mathrm{SO}_{4}{ }^{2-}$ and temperature $\left(r_{\mathrm{s}}=0.59\right)$ and a negative correlation between $\mathrm{NO}_{3}{ }^{-}$and temperature $\left(r_{\mathrm{s}}=-0.56\right)$. These correlations reflect the similar seasonal trends exhibited by $\mathrm{SO}_{4}{ }^{2-}$ and temperature and the dissimilar trend exhibited by $\mathrm{NO}_{3}{ }^{-}$, and they may also reflect the thermodynamic and kinetic effects of temperature on the secondary formation of these species.

\subsubsection{Case Studies of $\mathrm{PM}_{2.5}$ Episodes}

In order to better understand the factors that affect $\mathrm{PM}_{2.5}$ and co-pollutant concentrations at Steubenville, it is informative to perform case studies of episodes characterized by elevated concentrations of these species. Many such case studies were conducted as part of the data analysis portion of the SCAMP ambient air monitoring program; results have been discussed in 
depth by Connell et al. (2005b, 2005c). Hence, rather than reiterate the results reported there, this section summarizes important findings via a discussion of two representative $\mathrm{PM}_{2.5}$ episodes that were not detailed by Connell et al. but illustrate their key conclusions.

The case studies presented by Connell et al. (2005b, 2005c) suggest that two distinctly different types of $\mathrm{PM}_{2.5}$ episode commonly occur at Steubenville. Figure 43 presents an example of each of these episode types. The first episode, which occurred from September 5 through September 11, 2001, is characteristic of several episodes that were observed during the warm part of the year (e.g., summer) in Steubenville. As depicted in the Figure, which shows the time series of hourly $\mathrm{PM}_{2.5}$ concentrations observed during each episode, this warm season episode consisted of a prolonged period of moderately elevated $\mathrm{PM}_{2.5}$ concentrations. Hourly $\mathrm{PM}_{2.5}$ concentrations determined by the TEOM at the central Steubenville site remained between 30.2 and $53.5 \mu \mathrm{g} / \mathrm{m}^{3}$ during the 45-hour period from 5:00 a.m. on September 7 through 1:00 a.m. on September 9. Maximum 1-hr average concentrations occurred during the early morning or overnight periods (i.e., 6:00 a.m. on September 7; 9:00 p.m. on September 7 through 12:00 a.m. on September 8), likely driven by reduced mixing heights, but $\mathrm{PM}_{2.5}$ concentrations did not exhibit a pronounced diurnal pattern, remaining well above average during mid-afternoon on September 7 and September 8.

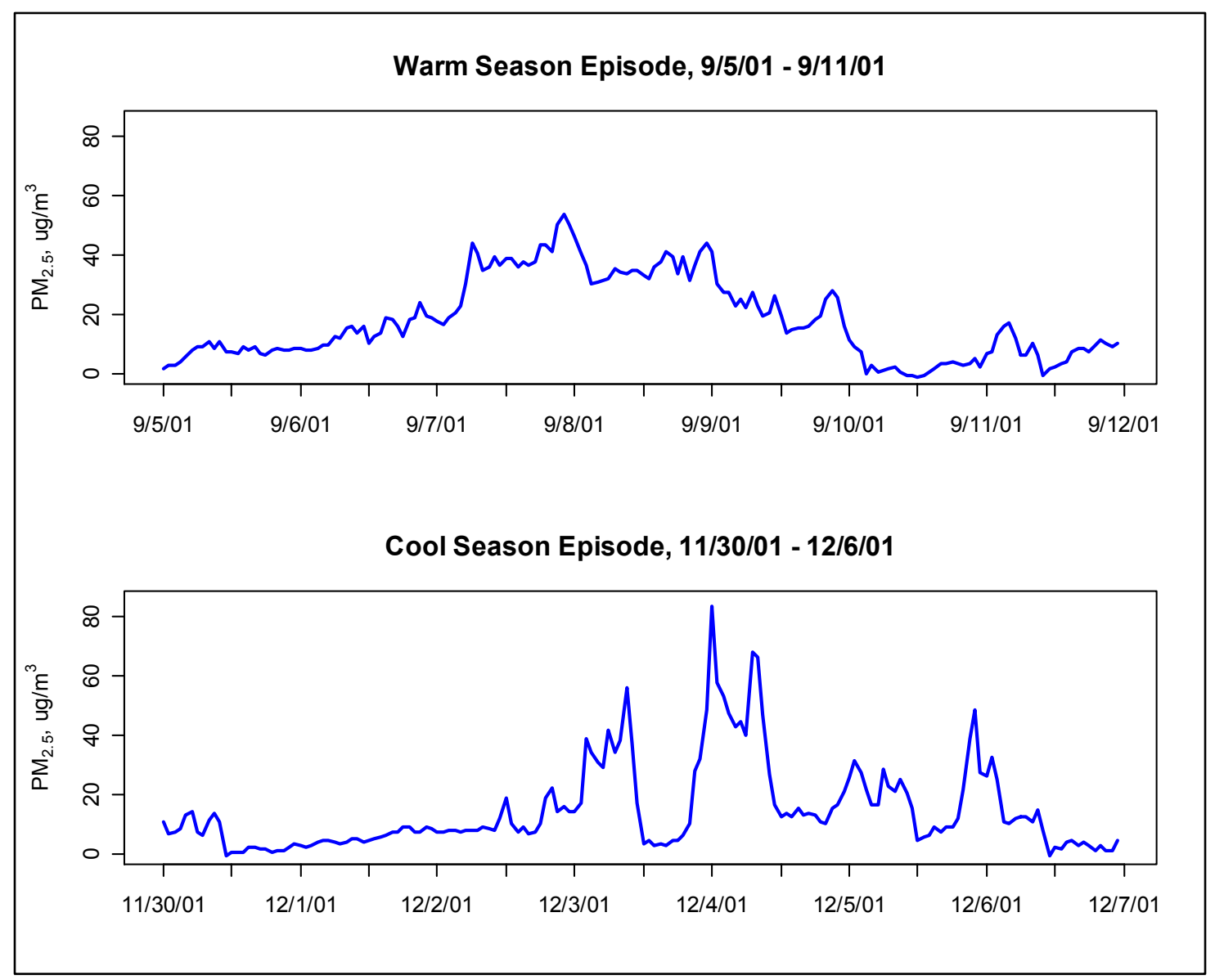

Figure 43. Time series of hourly $\mathrm{PM}_{2.5}$ concentrations measured by the TEOM monitor at the central Steubenville site during a warm season episode of elevated $\mathrm{PM}_{2.5}$ concentrations, which occurred between September 5 and September 11, 2001, and a cool season episode of elevated $\mathrm{PM}_{2.5}$ concentrations, which occurred between November 30 and December 6, 2001. 
Conversely, $\mathrm{PM}_{2.5}$ concentrations exhibited a very pronounced diurnal profile during the second episode, which occurred from November 30 through December 6, 2001, and is characteristic of a number of episodes that were observed during cooler parts of the year in Steubenville. As shown in Figure 43, $\mathrm{PM}_{2.5}$ concentrations during this cool-season episode were acutely elevated during the late evening, overnight, and early morning periods on December 3, December 4, and to a lesser extent, December 5 and December 6, but fell to or below the overall average TEOMdetermined $\mathrm{PM}_{2.5}$ concentration $\left(12.7 \mu \mathrm{g} / \mathrm{m}^{3}\right)$ by $12: 00 \mathrm{p} . \mathrm{m}$. on each of these days and remained low for the duration of each afternoon. Although the overall average $\mathrm{PM}_{2.5}$ concentration during the 3-day "heart" of the warm season episode (i.e., $31.4 \mu \mathrm{g} / \mathrm{m}^{3}$ determined by the TEOM from 12:00 a.m. on September 7 through 11:00 p.m. on September 9) was greater than that during the 3-day "heart" of the cool season episode (i.e., $24.6 \mu \mathrm{g} / \mathrm{m}^{3}$ determined by the TEOM from 12:00 a.m. on December 3 through 11:00 p.m. on December 5), the maximum 1-hr concentration during the cool season episode $\left(83.4 \mu \mathrm{g} / \mathrm{m}^{3}\right)$ was more than 1.5 times as great as that during the warm season episode $\left(53.5 \mu \mathrm{g} / \mathrm{m}^{3}\right)$. This trend of greater $1-\mathrm{hr}$ maximum $\mathrm{PM}_{2.5}$ concentrations during fall, winter, and spring $\mathrm{PM}_{2.5}$ episodes than during summer episodes was noted by Connell et al. (2005c); out of 22 episodes characterized by at least one 1-hr $\mathrm{PM}_{2.5}$ concentration $\geq 65 \mu \mathrm{g} / \mathrm{m}^{3}$, the five occurring during June-August had maximum 1-hr $\mathrm{PM}_{2.5}$ concentrations $\leq 76.6 \mu \mathrm{g} / \mathrm{m}^{3}$. Episodes occurring during the non-summer months often had much higher peak concentrations; five episodes observed during the months of October, November, and April had maximum 1-hr $\mathrm{PM}_{2.5}$ concentrations $\geq 95.0 \mu \mathrm{g} / \mathrm{m}^{3}$.

Figures 44 and 45 compare $\mathrm{PM}_{2.5}$ concentrations observed during the warm and cool season episodes, respectively, with gaseous pollutant concentrations observed during these episodes. As shown in Figure 45, during the cool season episode, concentrations of $P_{2.5}$ and concentrations of primary gaseous pollutants, including $\mathrm{SO}_{2}, \mathrm{NO}, \mathrm{NO}_{2}$, and $\mathrm{CO}$, covaried remarkably well, exhibiting very similar diurnal patterns of sharply elevated overnight and morning concentrations and dramatically reduced afternoon concentrations. $\mathrm{NO}$ and $\mathrm{CO}$ in particular reached very high 1-hr peak concentrations during the episode; maximum concentrations of these species were 17 and 27 times greater, respectively, than their overall mean 1-hr concentrations. Concentrations of $\mathrm{O}_{3}$, on the other hand, exhibited a diurnal pattern opposite to those displayed by concentrations of $\mathrm{PM}_{2.5}$ and the primary gases.

During the warm season episode shown in Figure 44, however, associations between $\mathrm{PM}_{2.5}$ concentrations and gaseous pollutant concentrations were much weaker. Concentrations of $\mathrm{NO}_{2}$, NO (during the early part of the episode), and especially $\mathrm{CO}$ continued to show a general diurnal profile of greater nighttime and morning concentrations and lesser afternoon concentrations; however, maximum 1-hr average concentrations of NO and CO were much less than those observed during the cool season episode. The timing of local maxima in the concentration profiles of these gases often corresponded closely to the timing of overnight peaks in $\mathrm{PM}_{2.5}$ concentrations during the warm season episode, but $\mathrm{PM}_{2.5}$ concentrations remained relatively elevated throughout the afternoon when primary gaseous pollutant concentrations decreased more substantially. $\mathrm{O}_{3}$ concentrations exhibited greater midafternoon maxima during the warm season episode than during the cool season episode, exceeding $70 \mathrm{ppb}$ on three consecutive days, but did not correlate strongly with $\mathrm{PM}_{2.5}$ concentrations.

Meteorological conditions are now examined to provide insight into the mechanisms responsible for the different $\mathrm{PM}_{2.5}$ and gaseous pollutant behaviors observed during the warm and cool season episodes. Based on case studies of daily data collected at Steubenville during SCAMP, Connell et al. (2005b) concluded that "Episodes of elevated $\mathrm{PM}_{2.5}$ concentrations frequently 
consisted of an increase in concentration during a period of locally high pressure or elevated temperature, followed by a rapid decrease in concentration with the passage of a frontal system." The data presented in Figures 46 and 47, which show time series of hourly $\mathrm{PM}_{2.5}$ concentrations and meteorological conditions during the warm and cool season episodes being examined, are consistent with this conclusion. As shown in Figure 46, the September 5-11, 2001, episode occurred during a period of locally elevated temperatures. During the 72-hr period of greatest concentration, afternoon maximum temperatures were $28-29{ }^{\circ} \mathrm{C}$, and overnight minima were $>20^{\circ} \mathrm{C}$ (with the exception of the very beginning of the period). (To place these temperatures in perspective, maxima were $<25^{\circ} \mathrm{C}$ and minima were $<15{ }^{\circ} \mathrm{C}$ for days just before and after the episode period). The greatest $\mathrm{PM}_{2.5}$ concentrations during the cool season episode, which is depicted in Figure 47, occurred during local minima in temperature; however, this episode happened during a period of high barometric pressure. The association between barometric pressure and $\mathrm{PM}_{2.5}$ concentrations during the warm season episode was more complex but generally consistent with the observation of Connell et al. (2005b) that, on the basis of cross-correlation analyses, barometric pressure exhibited a unique lagged relationship with $\mathrm{PM}_{2.5}$. Specifically, "an increase in barometric pressure precedes an increase in $\mathrm{PM}_{2.5}$ concentration by $\sim 1$ day, and a decrease in $\mathrm{PM}_{2.5}$ concentration with the passage of a frontal system is followed by an increase in barometric pressure $\sim 1$ day later." The arrows in the bottommost subplots in Figures 46 and 47 denote the passage of frontal systems through Steubenville. Elevated $\mathrm{PM}_{2.5}$ concentrations during both the warm and cool season episodes occurred during periods when no frontal systems passed through the area (Unisys Weather, 2006). (The greatest $\mathrm{PM}_{2.5}$ concentrations during the September 5-11, 2001, episode occurred when a front was stalled to the west of Steubenville and an area of high pressure was located off the coast of the eastern United States). The episodes ended with the passage of cold fronts through Steubenville on the mornings of September 10, 2001, and December 6, 2001. As shown in Figures 46 and 47, $\mathrm{PM}_{2.5}$ concentrations dropped to near-zero with the passage of these frontal systems. These abrupt decreases in concentration could be caused by increased atmospheric instability associated with the frontal systems, increased removal of $\mathrm{PM}_{2.5}$ from the atmosphere by precipitation that commonly accompanies the frontal systems, or the arrival of cleaner air masses with the passage of the frontal systems. Similar behavior was observed during many of the episodes of elevated $\mathrm{PM}_{2.5}$ concentrations that occurred during SCAMP.

Figure 46 reveals no other noteworthy trends between $\mathrm{PM}_{2.5}$ concentrations and meteorological conditions during the September 5-11, 2001, $\mathrm{PM}_{2.5}$ episode. However, as shown in Figure 47, during the cool season episode days having the highest $\mathrm{PM}_{2.5}$ concentrations (e.g., 12/3/01 and 12/4/01), the diurnal variability of $\mathrm{PM}_{2.5}$ concentrations was distinctly similar to that of relative humidity and opposite that of wind speed, temperature, and solar radiation. Elevated $\mathrm{PM}_{2.5}$ concentrations during this episode occurred during a period of relatively clear skies, as evidenced by the increased levels of solar radiation during the heart of the episode as compared to the surrounding days. This episode, like a number of others that occurred during cooler portions of the year in Steubenville (Connell et al., 2005c), was likely driven by nocturnal temperature inversions, which trap primary emissions of $\mathrm{PM}_{2.5}$ and co-pollutants (e.g., $\mathrm{CO}, \mathrm{NO}_{\mathrm{x}}$, and $\mathrm{SO}_{2}$ ) in a small volume of air close to ground level and thereby allow their concentrations to build up. (Conversely, concentrations of $\mathrm{O}_{3}$ are appreciably depleted during nocturnal temperature inversions, as photochemical production of $\mathrm{O}_{3}$ stops, and $\mathrm{O}_{3}$ is removed from the atmosphere by deposition and reaction with concentrated levels of primary gases such as NO). 


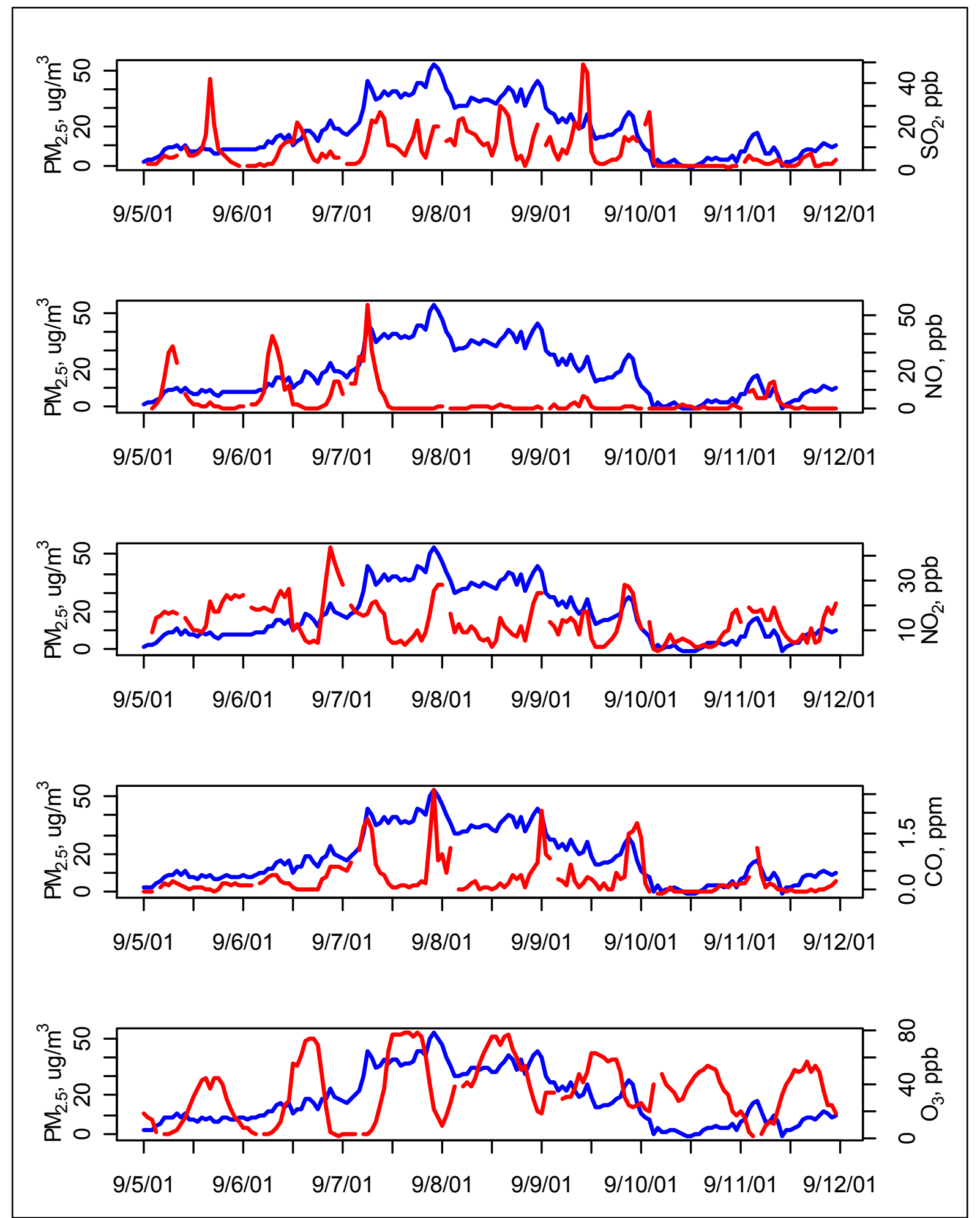

Figure 44. Time series of 1-hr $\mathrm{PM}_{2.5}$ concentrations (blue) and gaseous pollutant concentrations (red) observed at the central Steubenville site on September 5-11, 2001. 

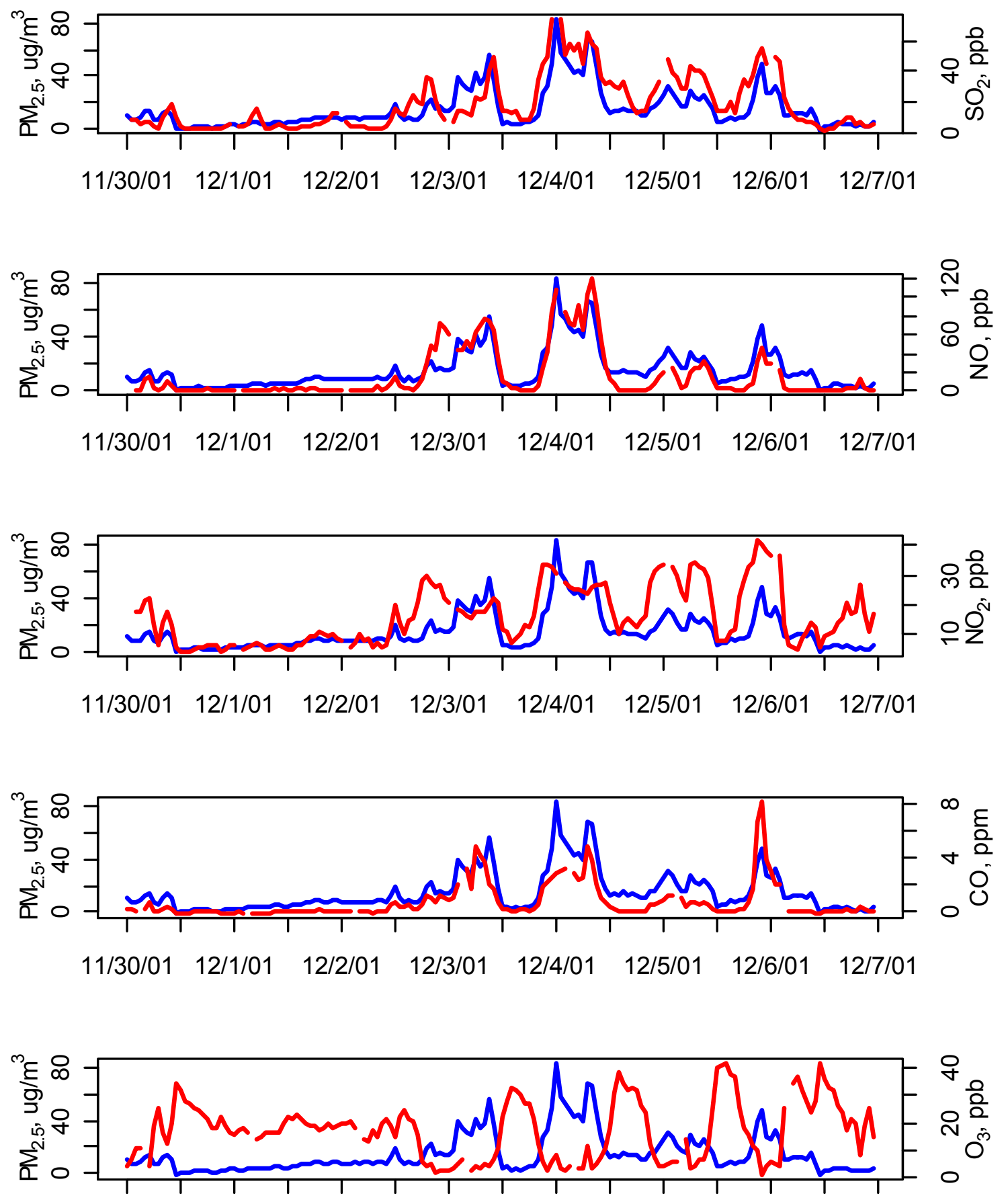

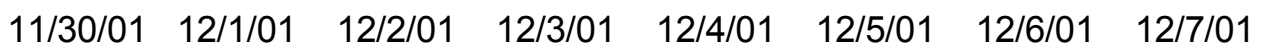

Figure 45. Time series of 1-hr $\mathrm{PM}_{2.5}$ concentrations (blue) and gaseous pollutant concentrations (red) observed at the central Steubenville site on November 30 - December 6, 2001. 


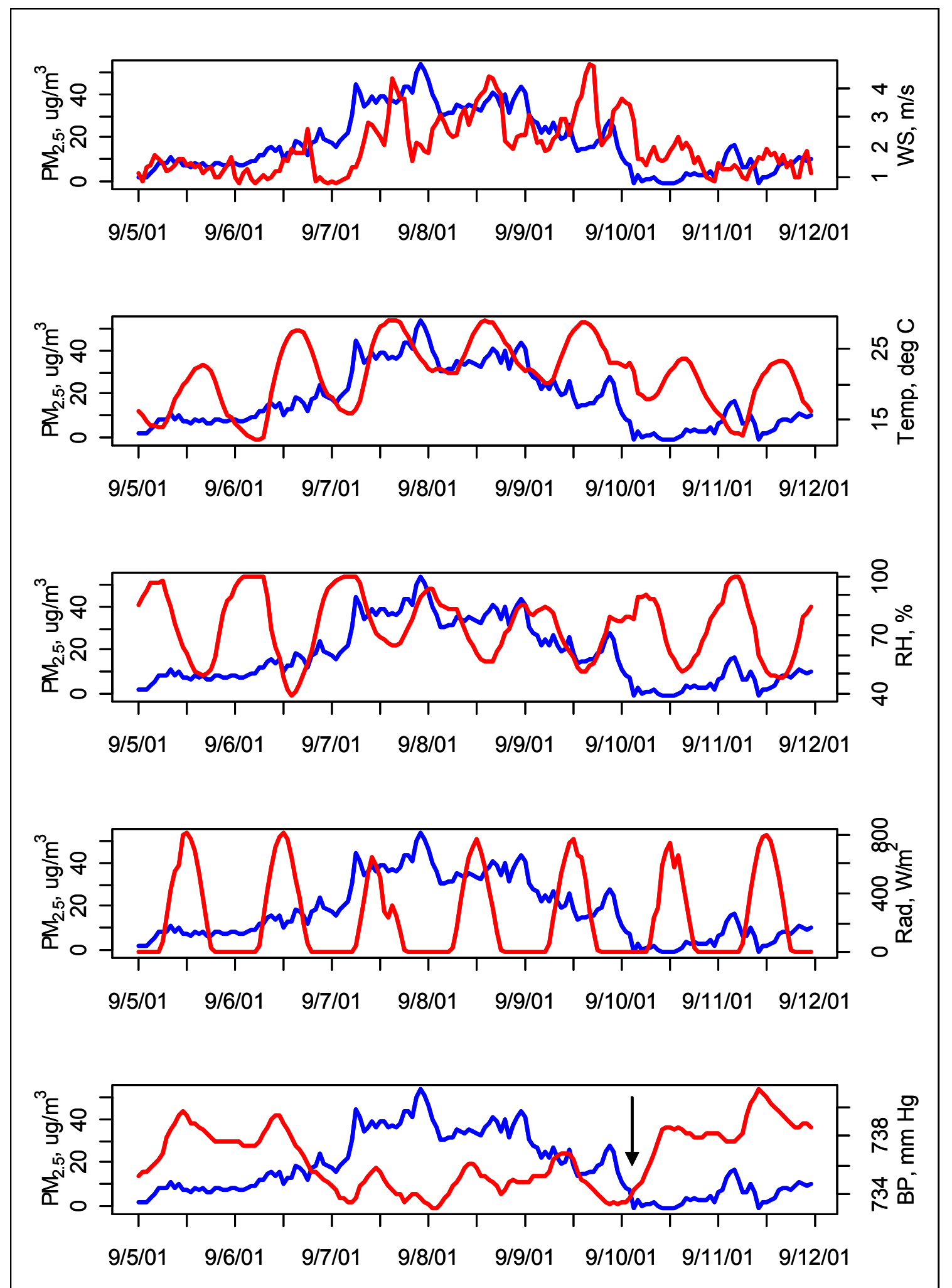

Figure 46. Time series of 1-hr $\mathrm{PM}_{2.5}$ concentrations (blue) and meteorological conditions (red) observed at the central Steubenville site on September 5-11, 2001. 


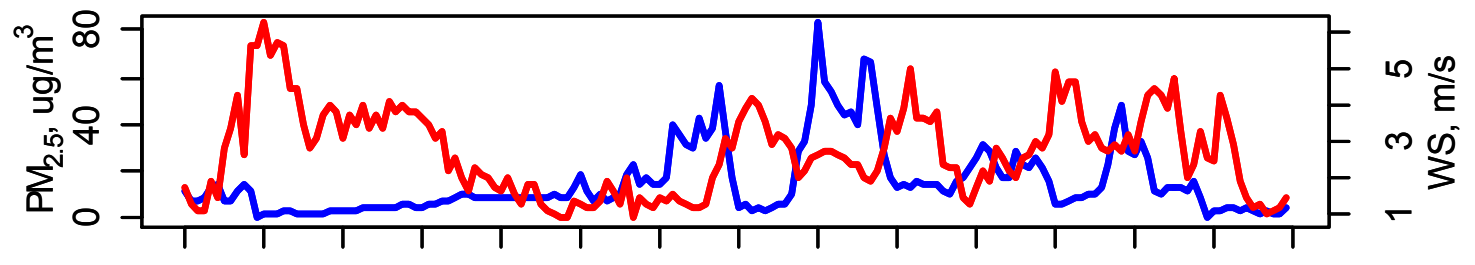

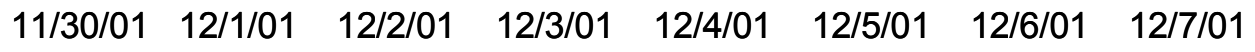

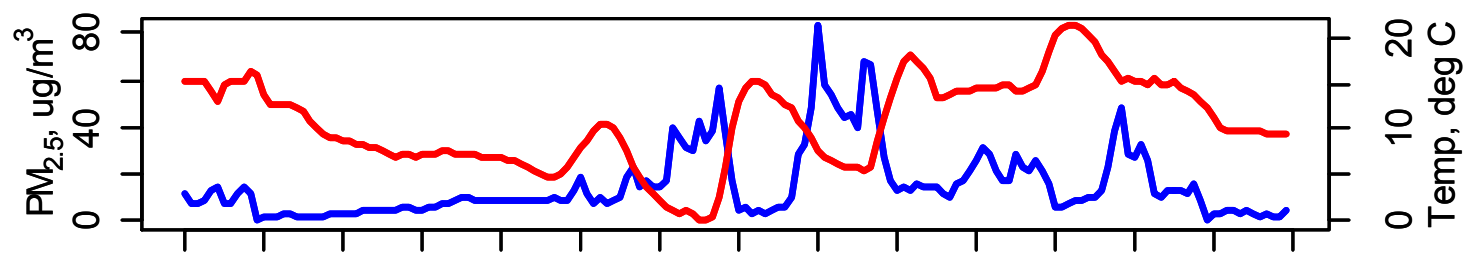

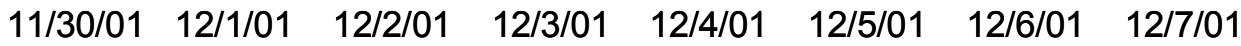

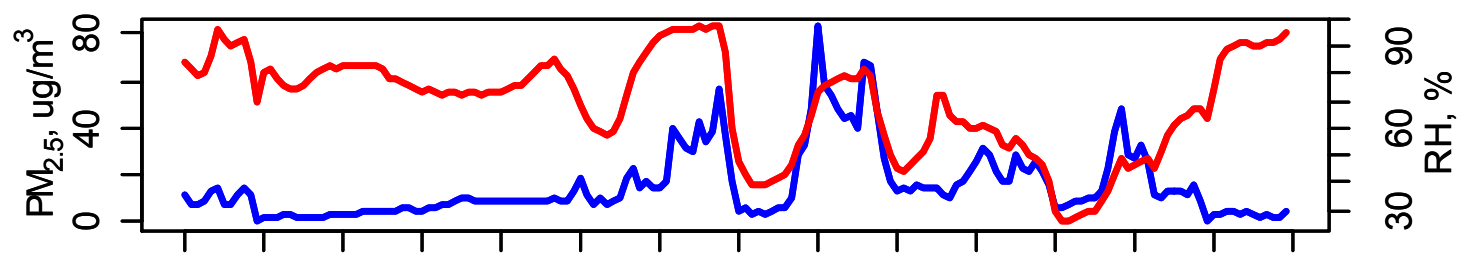

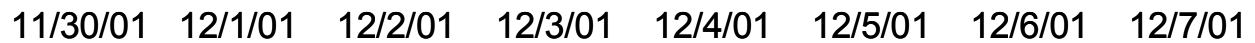

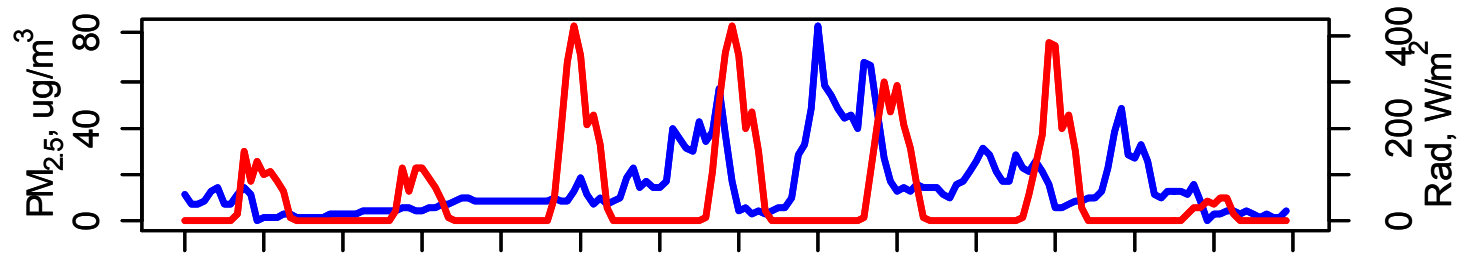

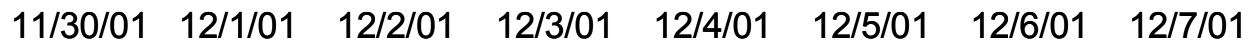

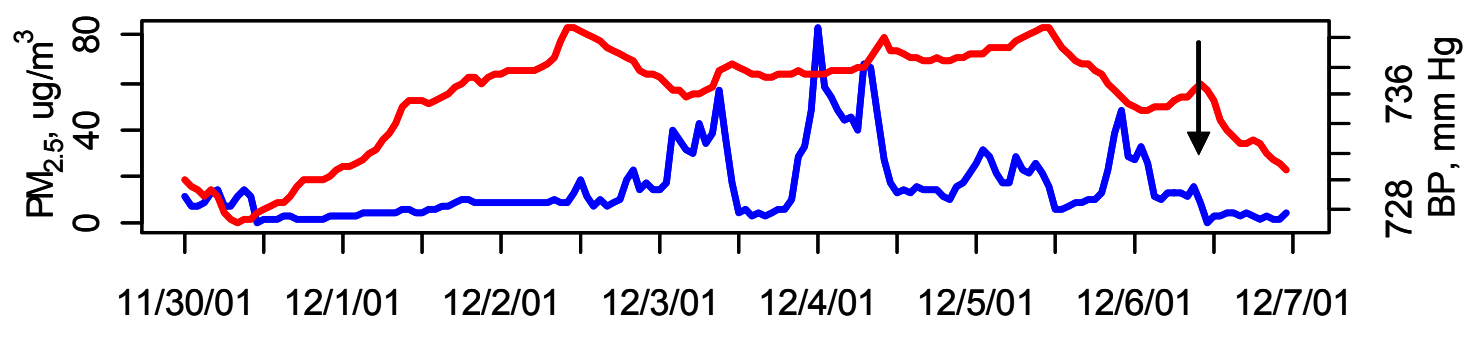

Figure 47. Time series of 1-hr $\mathrm{PM}_{2.5}$ concentrations (blue) and meteorological conditions (red) observed at the central Steubenville site on November 30 - December 6, 2001. 
Nocturnal inversions result from radiational cooling of the earth's surface, which occurs most readily during periods of clear skies; such cooling typically results in a pronounced diurnal surface temperature profile. Relative humidity near ground level increases during the inversion, whereas wind speed decreases as a result of the vertical instability resulting from the inversion. This is consistent with the behavior depicted in Figure 47. As shown in the figure, the periods of elevated $\mathrm{PM}_{2.5}$ concentrations during the December 2001 episode ended abruptly each day during the mid-to-late morning, as increases in solar radiation heated the earth's surface, causing the inversions to break.

Temperature inversions are characterized by negative lapse rates near the surface, meaning that the air temperature increases with increasing height above ground level in the inversion layer. Temperature soundings were not taken at the Steubenville site during SCAMP but were available from the National Weather Service station in Moon Township, PA, which is located about $38 \mathrm{~km}$ east-northeast of Steubenville. As shown in Figure 48, which presents vertical temperature soundings taken at Moon Township at 7:00 a.m. EST on each day during the warm and cool season episodes being studied, very strong temperature inversions were observed on the two days during the cool season episode (i.e., 12/3/01 and 12/4/01) for which $\mathrm{PM}_{2.5}$ concentrations at 7:00 a.m. were the greatest (i.e., 34.0 and $67.7 \mu \mathrm{g} / \mathrm{m}^{3}$, respectively). On $12 / 5 / 01$, the inversion at 7:00 a.m. EST was weaker, and the average $\mathrm{PM}_{2.5}$ concentration for that hour was a more modest $23 \mu \mathrm{g} / \mathrm{m}^{3}$. $\mathrm{PM}_{2.5}$ concentrations at 7:00 a.m. EST on 11/30/01, $12 / 1 / 01,12 / 2 / 01$, and $12 / 6 / 01$ were $\leq 12.4 \mu \mathrm{g} / \mathrm{m}^{3}$; these days had only weak surface inversions or no surface inversions at that time.

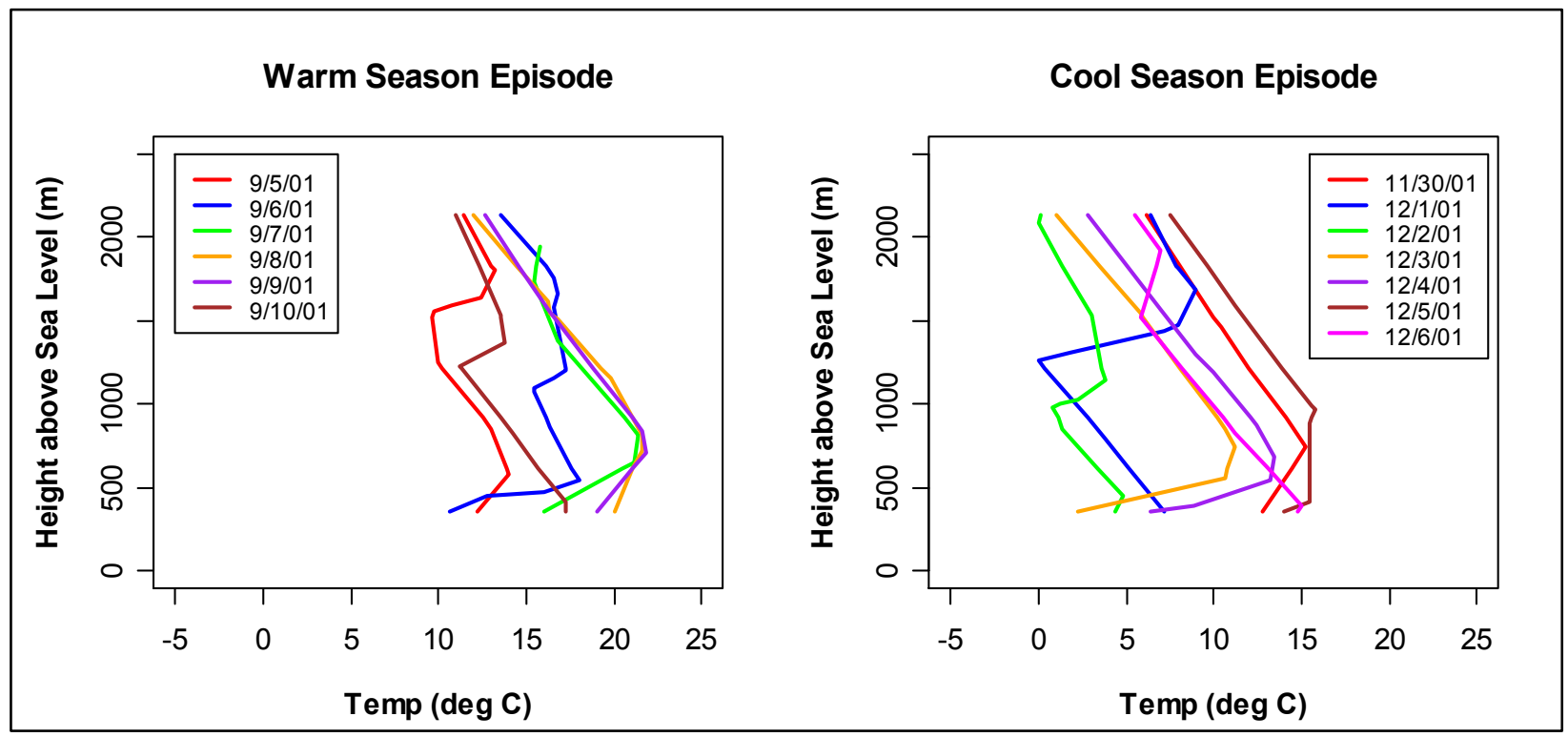

Figure 48. Vertical temperature soundings taken at 7:00 a.m. EST at the Moon Township, PA, National Weather Service station on each day of the September 5-11, 2001, "warm season" $\mathrm{PM}_{2.5}$ episode and the November 30-December 6, 2001, "cool season" $\mathrm{PM}_{2.5}$ episode.

Surface-based temperature inversions were also evident at 7:00 a.m. on several days during the warm season episode (e.g., 9/6/01, 9/7/01). As shown in Figure 34, these inversions likely helped to elevate concentrations of primary gaseous pollutants such as $\mathrm{NO}$ and $\mathrm{CO}$, which exhibited peak concentrations around 7:00 a.m. EST on these days. (On days with weaker inversions at 7:00 a.m., such as 9/8/01 and 9/9/01, CO concentrations peaked earlier during the 
overnight period, and $\mathrm{NO}$ concentrations did not exhibit appreciable peaks). However, $\mathrm{PM}_{2.5}$ concentrations during this warm season episode did not display the inversion-driven behavior characteristic of the November 30-December 6 episode, suggesting that a different mechanism was primarily responsible for the September 2001 episode.

Figure 49 summarizes the composition of $\mathrm{PM}_{2.5}$ determined from 24-hr integrated $\mathrm{PM}_{2.5}$ samples collected during the warm and cool season episodes. The warm season episode sample was collected from 9:00 a.m. EST on September 8, 2001, through 9:00 a.m. EST on September 9, 2001, and the cool season episode sample was collected from 9:00 a.m. EST on December 5, 2001, through 9:00 a.m. EST on December 6, 2001. To clearly illustrate departures from typical $\mathrm{PM}_{2.5}$ composition at Steubenville, Figure 49 shows compositional enrichment factors (CEFs) computed for each $\mathrm{PM}_{2.5}$ component during each of the two episode days. The CEF for component $x$ on day $i$ is defined as:

$$
C E F_{x, i}=\frac{w_{x, i}}{w_{x, \text { median }}},
$$

where $w_{x, i}$ is the weight fraction of component $x$ in the $\mathrm{PM}_{2.5}$ sample collected on day $i$, and $W_{x, \text { median }}$ is the overall median weight fraction of component $x$ in 24-hour $\mathrm{PM}_{2.5}$ samples collected at Steubenville during SCAMP. As shown in the figure, $\mathrm{PM}_{2.5}$ collected during the 24-hr period from the warm season episode was enriched in $\mathrm{SO}_{4}{ }^{2-}$ and $\mathrm{NH}_{4}{ }^{+}$, but contained less $\mathrm{NO}_{3}{ }^{-}, \mathrm{Cl}^{-}$, carbonaceous material, and trace elements than normal on a percentage basis (valid data were not available for $\mathrm{Ba}, \mathrm{Co}, \mathrm{Ni}, \mathrm{Se}$, and $\mathrm{Ti}$ for 9/8/01). This compositional profile suggests that the elevated $\mathrm{PM}_{2.5}$ concentrations observed at Steubenville between September 5 and September 11,2001 , were likely driven by a regional episode of secondary ammonium sulfate formation.

The $\mathrm{PM}_{2.5}$ compositional profile for the 24-hr period during the cool season episode was largely opposite that observed for the warm season episode. $\mathrm{PM}_{2.5}$ collected on 12/5/01 was enriched in organic material, $\mathrm{Cl}^{-}$, and a number of trace elements, which are expected to be emitted by primary sources in Steubenville, but depleted in more regional pollutants such as $\mathrm{SO}_{4}{ }^{2-}, \mathrm{NH}_{4}{ }^{+}$, and $\mathrm{NO}_{3}{ }^{-}$. In particular, the high CEFs for trace metals such as $\mathrm{Fe}, \mathrm{Mn}$, and $\mathrm{Zn}$, which as discussed earlier are particularly enriched at Steubenville relative to the surrounding area, support the interpretation that nocturnal temperature inversions drove this cool season episode in Steubenville by permitting short-term buildups in concentrations of locally-emitted primary pollutants. 


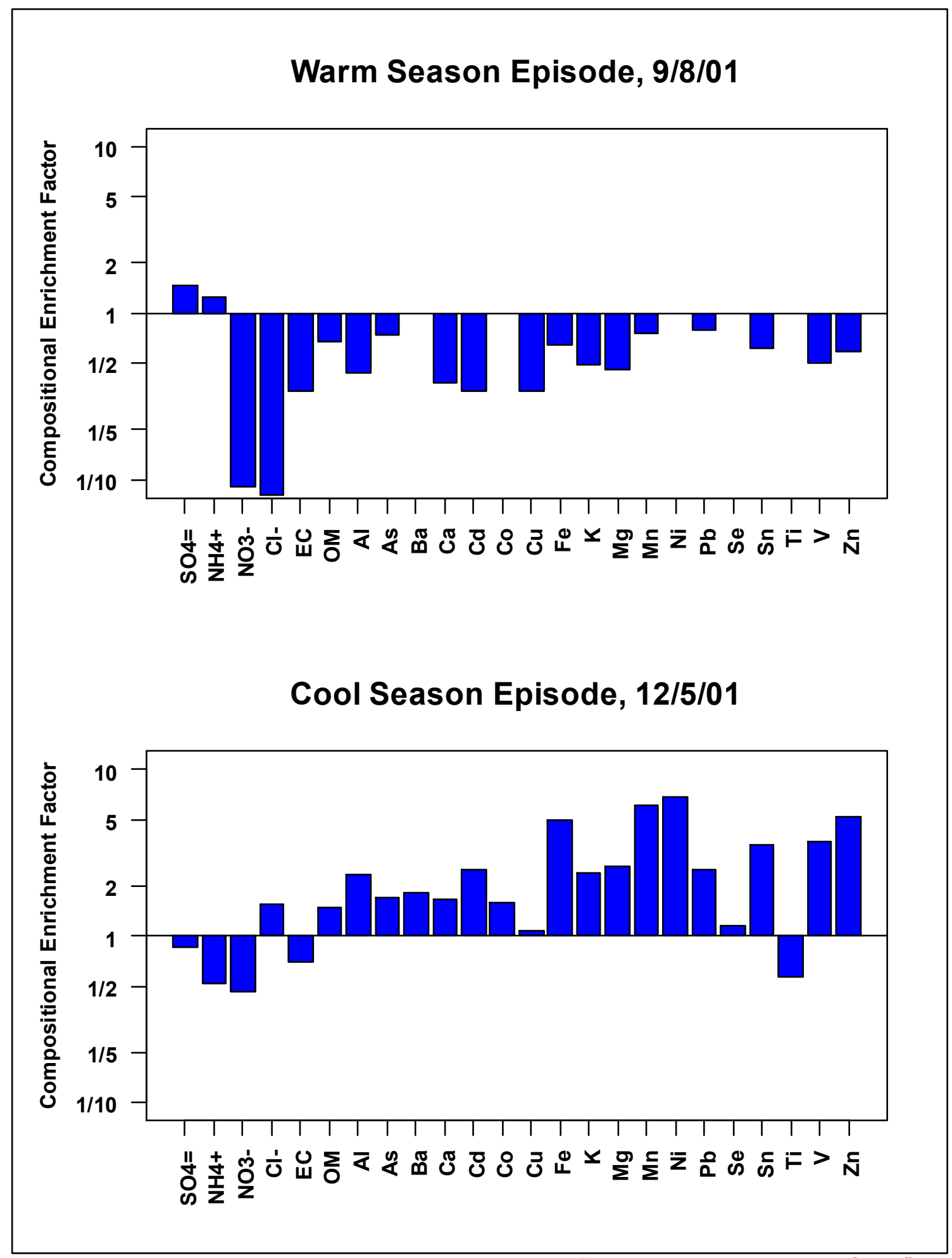

Figure 49. Normalized $\mathrm{PM}_{2.5}$ composition (expressed as a "compositional enrichment factor" per the definition given in the text) at Steubenville during the 24-hr period from 9:00 a.m. on 9/8/01 to 9:00 a.m. on 9/9/01 and the 24-hr period from 9:00 a.m. on 12/5/01 to 9:00 a.m. on 12/6/01. 
If the September 5-11, 2001, $\mathrm{PM}_{2.5}$ episode was a regional episode driven by secondary-sulfatedominated $\mathrm{PM}_{2.5}$, then it should have been observed on a regional scale across the SCAMP monitoring sites. Similarly, if the November 30-December 6, 2001, $\mathrm{PM}_{2.5}$ episode resulted from the nocturnal inversion-driven accumulation of primary $\mathrm{PM}_{2.5}$ and co-pollutant emissions, then it should have been more pronounced at the Steubenville site, which was located near a number of major primary emission sources, than at the more remote satellite sites. Figure 50 confirms both of these expectations.

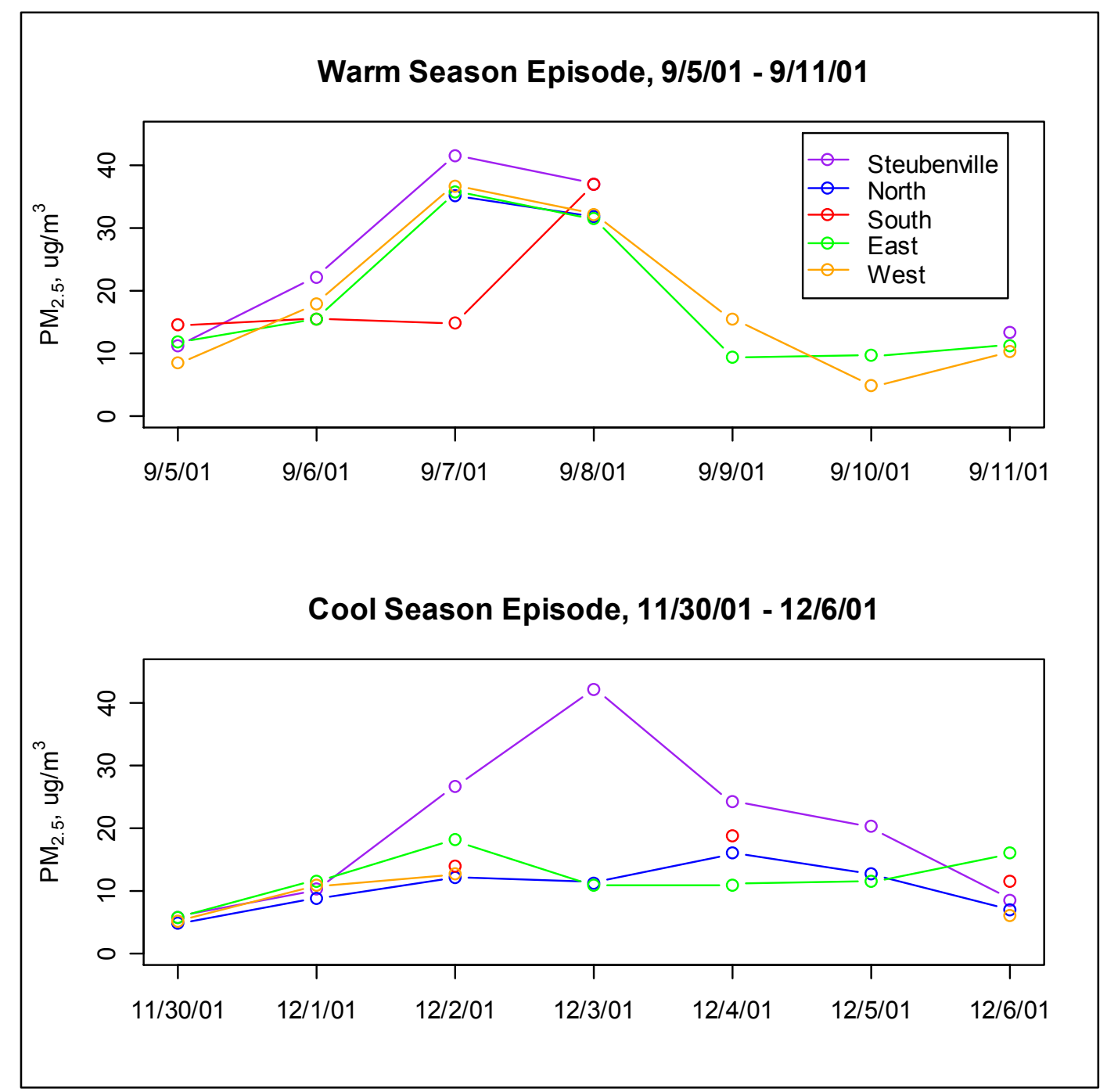

Figure 50. Time series of 24-hr average $\mathrm{PM}_{2.5}$ concentrations measured at the five SCAMP monitoring sites from September 5 through September 11, 2001, and from November 30 through December 6, 2001.

The figure, which plots time series of 24-hr $\mathrm{PM}_{2.5}$ concentrations (collected from 9:00 a.m. EST on the indicated day to 9:00 a.m. EST on the following day) observed during the warm and cool season episodes, shows that the elevated $\mathrm{PM}_{2.5}$ concentrations associated with the warm season episode were generally observed at all of the satellite sites for which data were available (concentrations at the southern site did not increase until 9/8/01), whereas the elevated $\mathrm{PM}_{2.5}$ concentrations associated with the cool season episode were unique to Steubenville (data were not available for the southern and western sites on 12/3/01, the date on which the 24-hr $\mathrm{PM}_{2.5}$ concentration at Steubenville exhibited a local maximum). 
Further support for this interpretation is provided by Figure 51, which shows 24-hr $\mathrm{PM}_{2.5}$ and $\mathrm{PM}_{10-2.5}$ concentrations observed at the central Steubenville site during each of the episodes. As shown in this figure, during the warm season $\mathrm{PM}_{2.5}$ episode that was dominated by secondary ammonium sulfates, concentrations of $\mathrm{PM}_{10-2.5}$, which is expected to originate predominantly from primary emission sources in Steubenville, did not show any appreciable increase. Conversely, during the cool season $\mathrm{PM}_{2.5}$ episode that was dominated by local emissions in the immediate Steubenville vicinity, concentrations of $\mathrm{PM}_{10-2.5}$ tracked concentrations of $\mathrm{PM}_{2.5}$ very closely.

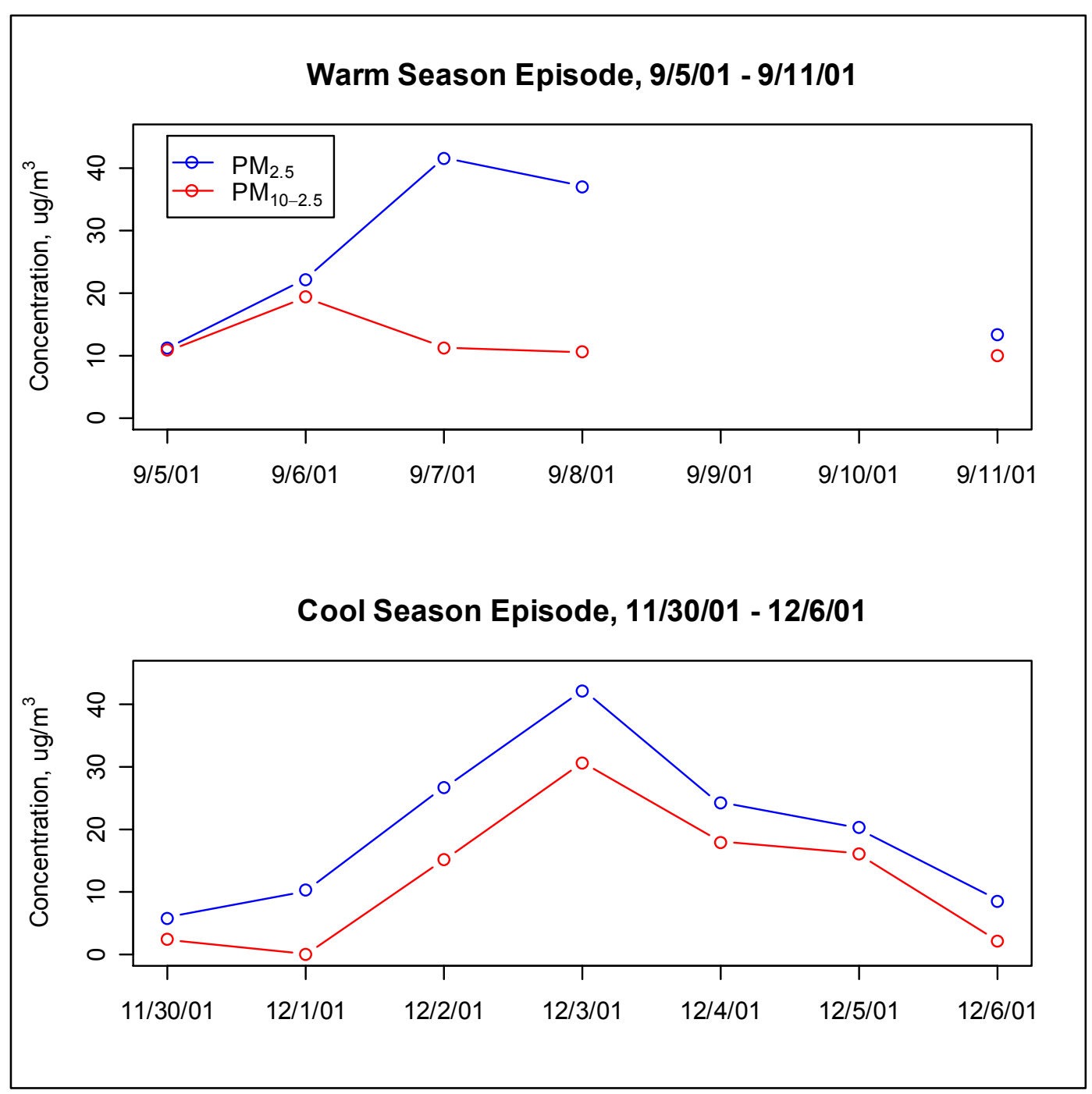

Figure 51. Time series of 24-hr average $\mathrm{PM}_{2.5}$ and $\mathrm{PM}_{10-2.5}$ concentrations observed at the central Steubenville site from September 5 through September 11, 2001, and from November 30 through December 6, 2001.

In summary, the case studies presented above clearly illustrate two distinctly different types of episode that led to elevated $\mathrm{PM}_{2.5}$ concentrations at Steubenville during SCAMP:

1. A regional episode type characterized by a multiple-day period of consistently and moderately elevated concentrations of secondary-sulfate-dominated $\mathrm{PM}_{2.5}$, which typically occurred during warmer portions of the year in Steubenville, and

2. A local episode type characterized by shorter overnight periods of more acutely elevated concentrations of $\mathrm{PM}_{2.5}$ resulting from the buildup of primary particles enriched in trace 
metals and carbonaceous species during nocturnal temperature inversions, which typically occurred during cooler portions of the year in Steubenville.

As mentioned earlier, more examples of these types of episodes can be found in Connell et al. (2005b, 2005c). Further evidence of the distinction between regional daylong episodes of elevated secondary $\mathrm{PM}_{2.5}$ concentrations and localized nighttime episodes of elevated primary $\mathrm{PM}_{2.5}$ concentrations is provided in Table 36. The first two columns of this table present Spearman correlation coefficients between 24-hr average concentrations of $\mathrm{PM}_{2.5}$ chemical components at Steubenville and estimated 24-hr "local" and "background" $\mathrm{PM}_{2.5}$ concentrations. "Background" concentrations were estimated as the average $\mathrm{PM}_{2.5}$ concentration measured at the northern and western satellite sites on a given day, and "local" concentrations were estimated as the difference between the concentration measured at Steubenville and this "background" concentration. The last two columns of the table present Spearman correlation coefficients between 24-hr concentrations of $\mathrm{PM}_{2.5}$ chemical components at Steubenville and 1hr maximum $\mathrm{PM}_{2.5}$ concentrations measured by the TEOM during the "afternoon" (12:00 p.m. EST - 7:00 p.m. EST) and "overnight" (2:00 a.m. EST - 9:00 a.m. EST) portions of the same 24-hr periods. The data in the table show that $\mathrm{SO}_{4}{ }^{2-}$ and $\mathrm{NH}_{4}{ }^{+}$correlated more strongly with "background" $\mathrm{PM}_{2.5}$ concentrations than with "local" $\mathrm{PM}_{2.5}$ concentrations and more strongly with "afternoon" maximum concentrations than with "overnight" maximum concentrations, consistent with the first type of episode described above. Conversely, elemental carbon, organic material, and a number of trace elements, including especially those highlighted earlier as being locally enriched at Steubenville (e.g., As, $\mathrm{Fe}, \mathrm{Mn}, \mathrm{Pb}, \mathrm{Zn}$ ), correlated more strongly with "local" $\mathrm{PM}_{2.5}$ concentrations than with "background" concentrations and more strongly with "overnight" maximum $\mathrm{PM}_{2.5}$ concentrations than with "afternoon" maximum concentrations, consistent with the second type of episode.

Both of the $\mathrm{PM}_{2.5}$ episode types identified during SCAMP must be considered when developing an implementation plan to reduce concentrations of $\mathrm{PM}_{2.5}$ in Steubenville, as both can lead to elevated 24-hr $\mathrm{PM}_{2.5}$ concentrations (e.g., concentrations exceeding the recently proposed 24-hr standard of $35 \mu \mathrm{g} / \mathrm{m}^{3}$ ), which contribute to Steubenville's high annual average $\mathrm{PM}_{2.5}$ concentration. As shown above, these episode types result from very different mechanisms; therefore, reducing their occurrences will require the application of unique strategies. The distinct differences between the behavior and composition of $\mathrm{PM}_{2.5}$ during the episode types also reinforces the need for further research to clarify several uncertainties related to possible effects of fine particulate matter on human health. These include:

1. Whether health effects are more likely to result from prolonged (e.g., multiple-day) exposure to chronically elevated $\mathrm{PM}_{2.5}$ concentrations, as were observed during the warm season episode, or from shorter-term (e.g., < $1 / 2$ day) exposure to more acutely elevated $\mathrm{PM}_{2.5}$ concentrations, as were observed during the cool season episode;

2. Whether the composition of $\mathrm{PM}_{2.5}$ influences its effect on human health (e.g., whether particles enriched in trace metals and carbonaceous species, which were prevalent during the cool season episode, are more toxic than the secondary-sulfate-dominated particles that were prevalent during the warm season episode, or whether the mere existence of particles, regardless of composition, triggers the observed health effects); and

3. Whether primary gases such as $\mathrm{CO}, \mathrm{NO}_{2}$, and $\mathrm{SO}_{2}$, which exhibited elevated concentrations and correlated strongly with $\mathrm{PM}_{2.5}$ during the cool season episode, account for some or all of the health effects commonly attributed to $\mathrm{PM}_{2.5}$ or, as suggested by several studies (Jakab et al., 1996; Kleinman et al., 2000; Schlesinger, 1995), exhibit synergistic toxicological interactions with $\mathrm{PM}_{2.5}$. 
Table 36. Spearman correlation coefficients between 24-hr $\mathrm{PM}_{2.5}$ chemical component (i.e., ion, carbon, and acid-digestible element) concentrations at the central Steubenville site and measures of the intraday timing of $\mathrm{PM}_{2.5}$ episodes and the impact of local versus regional sources on $\mathrm{PM}_{2.5}$ concentrations in Steubenville.

\begin{tabular}{|c|c|c|c|c|}
\hline $\mathrm{PM}_{2.5}$ Component & $\begin{array}{l}\text { Local } \\
\mathrm{PM}_{2.5}{ }^{\mathrm{a}}\end{array}$ & $\begin{array}{c}\text { Background } \\
\mathrm{PM}_{2.5}\end{array}$ & $\begin{array}{c}\text { Afternoon } \\
\text { Maximum } \mathrm{PM}_{2.5}{ }^{c}\end{array}$ & $\begin{array}{c}\text { Overnight } \\
\text { Maximum } \mathrm{PM}_{2.5}{ }^{\mathrm{d}}\end{array}$ \\
\hline $\mathrm{SO}_{4}{ }^{2-}$ & 0.68 & 0.84 & 0.77 & 0.61 \\
\hline $\mathrm{NH}_{4}^{+}$ & 0.61 & 0.87 & 0.67 & 0.49 \\
\hline $\mathrm{NO}_{3}^{-}$ & 0.04 & 0.17 & -0.08 & -0.10 \\
\hline $\mathrm{Cl}^{-}$ & 0.46 & 0.10 & 0.06 & 0.53 \\
\hline EC & 0.70 & 0.35 & 0.24 & 0.73 \\
\hline OM & 0.67 & 0.55 & 0.41 & 0.71 \\
\hline $\mathrm{Al}$ & 0.65 & 0.39 & 0.39 & 0.50 \\
\hline As & 0.71 & 0.38 & 0.26 & 0.70 \\
\hline $\mathrm{Ba}$ & 0.63 & 0.41 & 0.29 & 0.57 \\
\hline $\mathrm{Ca}$ & 0.55 & 0.21 & 0.28 & 0.51 \\
\hline $\mathrm{Cd}$ & 0.58 & 0.27 & 0.17 & 0.33 \\
\hline Co & 0.45 & 0.38 & 0.27 & 0.45 \\
\hline $\mathrm{Cu}$ & 0.53 & 0.19 & 0.08 & 0.43 \\
\hline $\mathrm{Fe}$ & 0.75 & 0.33 & 0.24 & 0.69 \\
\hline $\mathrm{K}$ & 0.62 & 0.46 & 0.33 & 0.55 \\
\hline $\mathrm{Mg}$ & 0.56 & 0.25 & 0.23 & 0.59 \\
\hline $\mathrm{Mn}$ & 0.74 & 0.28 & 0.22 & 0.63 \\
\hline $\mathrm{Ni}$ & 0.48 & 0.35 & 0.39 & 0.36 \\
\hline $\mathrm{Pb}$ & 0.71 & 0.29 & 0.21 & 0.61 \\
\hline $\mathrm{Se}$ & 0.56 & 0.63 & 0.50 & 0.45 \\
\hline Sn & 0.73 & 0.22 & 0.27 & 0.58 \\
\hline $\mathrm{Ti}$ & 0.33 & 0.14 & 0.22 & 0.43 \\
\hline $\mathrm{V}$ & 0.50 & 0.23 & 0.37 & 0.49 \\
\hline $\mathrm{Zn}$ & 0.80 & 0.35 & 0.26 & 0.66 \\
\hline
\end{tabular}

${ }^{\mathrm{a}}$ Difference between 24-hr concentration measured at the central Steubenville site and the average of the 24-hr concentrations measured at the northern and western satellite sites; ${ }^{b}$ Average of the 24-hr concentrations measured at the northern and western satellite sites; 'Maximum 1-hr concentration measured between 12:00 p.m. and 7:00 p.m. EST; ${ }^{\mathrm{d}}$ Maximum 1-hr concentration measured between 2:00 a.m. and 9:00 a.m. EST

The diurnal behavior of $\mathrm{PM}_{2.5}$ during the different episode types also suggests a need for further research using time-resolved measurements to elucidate the effect of the intraday timing of $\mathrm{PM}_{2.5}$ episodes on actual human exposure to $\mathrm{PM}_{2.5}$.

\subsubsection{Binary Recursive Partitioning of Hourly $\mathrm{PM}_{2.5}$ Data}

To help to validate the conclusions drawn from the correlation analyses and case studies presented above, binary recursive partitioning (rpart) was applied to the 14,682 valid hourly $\mathrm{PM}_{2.5}$ observations made at the central Steubenville site during SCAMP. Binary recursive partitioning (Breiman et al., 1984; Therneau and Atkinson, 1997), which has been used to study the influence of meteorological conditions on daily PM $_{2.5}$ concentrations (Kenski, 2003) but has not been discussed extensively in the $\mathrm{PM}_{2.5}$ literature, classifies a categorical dependent variable via a series of binary splits based upon "yes/no" questions about predictor (splitting) 
variables (e.g., is NO < $40 \mathrm{ppm}$ ?). As a result, a classification tree is developed, which identifies factors that tend to be associated with the various categories of the dependent variable and which may also be used as a predictive tool. The technique is nonparametric and handles both continuous and categorical splitting variables. For each node of the classification tree, the rpart algorithm considers all possible binary divisions of the data based upon all values of all splitting variables specified in the analysis and chooses the best split, which minimizes the impurity or heterogeneity (measured using the Gini diversity index) in the resulting nodes while causing the greatest improvement in the number of correct classifications of the dependent variable. Missing values in the primary splitting variable are handled via secondary splitting rules based upon surrogate variables that show strong agreement with the primary variable. Trees are validated using cross-validation; to avoid over- or under-fitting the data, the tree size is selected that minimizes the cross-validation error. Generally, the simplest tree having a cross-validation error within one standard error of the minimum is selected as the "optimal" tree.

In order to use rpart to classify hourly $\mathrm{PM}_{2.5}$ data collected during SCAMP, a categorical variable describing hourly $\mathrm{PM}_{2.5}$ concentrations was defined. Class $A$ includes all $\mathrm{PM}_{2.5}$ concentrations less than $10.0 \mu \mathrm{g} / \mathrm{m}^{3}$; class $B$ includes concentrations greater than or equal to $10.0 \mu \mathrm{g} / \mathrm{m}^{3}$ and less than $30.0 \mu \mathrm{g} / \mathrm{m}^{3}$; class $C$ includes concentrations greater than or equal to $30.0 \mu \mathrm{g} / \mathrm{m}^{3}$ and less than $50.0 \mu \mathrm{g} / \mathrm{m}^{3}$, and class $D$ includes all concentrations of $50.0 \mu \mathrm{g} / \mathrm{m}^{3}$ or greater. All gas and weather variables specified in Tables 22 and 25 (except for $\mathrm{NO}_{\mathrm{x}}$, because $\mathrm{NO}$ and $\mathrm{NO}_{2}$ are included) were specified as predictor variables. In addition, to account for the possibility of lagged relationships, 1, 3, 12, and 24-hr lags of each of these variables were included, as were 1,12 , and 24-hr changes in the value of each variable. Moreover, categorical variables indicating astronomical season, time of day (in 3-hr increments), and time of week (weekday versus weekend) were specified. Because of the large number of observations, splits were only attempted for nodes having at least 75 observations, and terminal nodes having less than 25 observations were not allowed. Up to five surrogate rules were allowed for each split, and 60 cross-validations were used. According to the criterion discussed above, the "optimal" tree had approximately 76 terminal nodes; however, for ease of presentation, the tree was pruned to 37 terminal nodes. Pruning was done in the standard way based upon the complexity parameter (Therneau and Atkinson, 1997).

This tree is shown in Figure 52. For each split, cases satisfying the primary splitting criterion (shown) or a surrogate criterion are sent to the left; all other cases are sent to the right. Table 37 shows the number of observations falling in each terminal node, as well as the percent composition of each node on the basis of the $\mathrm{PM}_{2.5}$ classes defined above. Although not perfectly homogenous, the homogeneity of each terminal node with respect to its predicted class is greater than the homogeneity of the root node. The model correctly classified 11460, or $78.05 \%$, of the 1-hr $\mathrm{PM}_{2.5}$ concentrations observed during SCAMP, compared with $55.62 \%$ correct classification in the root node (assuming its predicted class is A). A clearer depiction of the performance of the model is provided in Figure 53, which shows the distribution of actual $\mathrm{PM}_{2.5}$ concentrations $\left(\mu \mathrm{g} / \mathrm{m}^{3}\right)$ falling in each terminal node. Nodes are sorted by increasing median concentration.

As shown in Figure 53, only one terminal node (Node 31) had a median concentration and a majority of its observations in class $D\left(P_{2.5}\right.$ concentration $\left.\geq 50 \mu \mathrm{g} / \mathrm{m}^{3}\right)$. Cases falling in this node were characterized by a CO concentration greater than $2.67 \mathrm{ppm}$ and a NO concentration greater than $35.8 \mathrm{ppb}$. This is consistent with the previous observation that above-average 


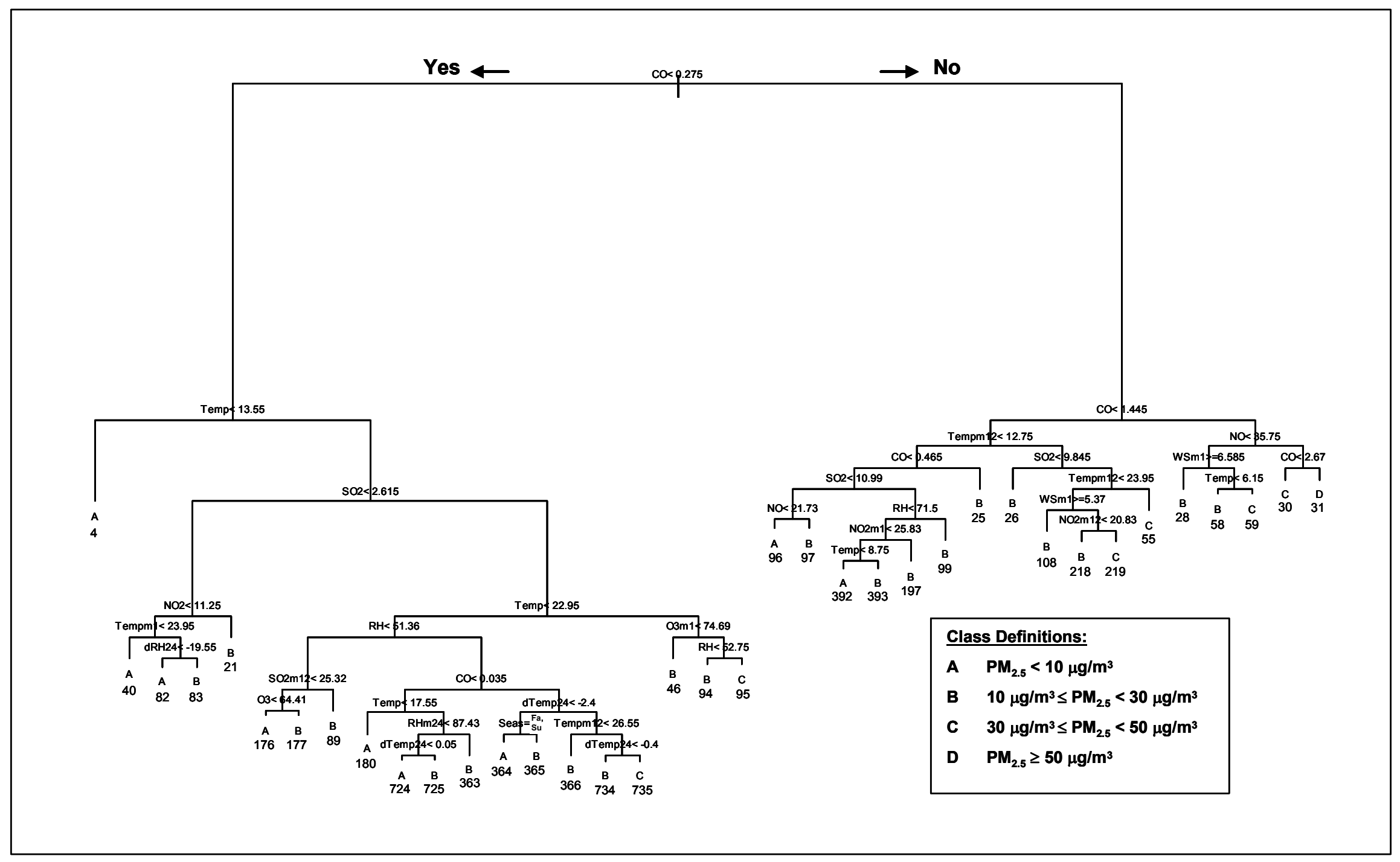

Figure 52. Binary recursive partitioning classification tree constructed using all valid 1-hr average $\mathrm{PM}_{2.5}$ concentrations measured at Steubenville during SCAMP. For each splitting node, observations satisfying the splitting criterion are sent to the left; all other observations are sent to the right. Each terminal node is labeled with its predicted class as well as an identification number. Units are $\mathrm{ppm}$ for $\mathrm{CO}, \mathrm{ppb}$ for all other gases, ${ }^{\circ} \mathrm{C}$ for temperature (Temp), \% for relative humidity (RH), $\mathrm{mph}$ for wind speed (WS), $\mathrm{kW} / \mathrm{m}^{2}$ for solar radiation (Rad), and inches of $\mathrm{Hg}$ for barometric pressure (BP). For a splitting variable $\mathrm{V}$, VmN represents the 1-hr average value of that variable observed $\mathrm{N}$ hours earlier; dVN represents the N-hr change in that variable's value. Seas is season; Fa is Fall, and Su is Summer. 
Table 37. Summary of terminal nodes of the binary recursive partitioning tree shown in Figure 52.

\begin{tabular}{|c|c|c|c|c|c|c|}
\hline \multirow[b]{2}{*}{ Node } & \multirow{2}{*}{$\begin{array}{l}\text { Predicted } \\
\text { Class }^{\mathrm{a}}\end{array}$} & \multirow[b]{2}{*}{$\mathbf{N}$} & \multicolumn{4}{|c|}{ Distribution of Observations by Class $^{a}(\%)$} \\
\hline & & & A & B & C & D \\
\hline Root & A & 14682 & 55.62 & 34.72 & 7.87 & 1.79 \\
\hline 4 & A & 6121 & 88.09 & 11.24 & 0.44 & 0.23 \\
\hline 21 & $\mathrm{~B}$ & 212 & 38.68 & 58.02 & 3.30 & 0.00 \\
\hline 25 & $B$ & 850 & 16.35 & 74.12 & 8.59 & 0.94 \\
\hline 26 & $B$ & 585 & 7.18 & 76.07 & 15.73 & 1.03 \\
\hline 28 & $\mathrm{~B}$ & 28 & 3.57 & 92.86 & 3.57 & 0.00 \\
\hline 30 & C & 180 & 0.00 & 14.44 & 66.11 & 19.44 \\
\hline 31 & $\mathrm{D}$ & 109 & 0.00 & 3.67 & 26.61 & 69.72 \\
\hline 40 & A & 774 & 82.82 & 17.18 & 0.00 & 0.00 \\
\hline 46 & $B$ & 893 & 10.97 & 64.28 & 22.51 & 2.24 \\
\hline 55 & $C$ & 134 & 0.00 & 15.67 & 66.42 & 17.91 \\
\hline 58 & $B$ & 32 & 0.00 & 78.13 & 15.63 & 6.25 \\
\hline 59 & C & 155 & 3.23 & 30.97 & 49.68 & 16.13 \\
\hline 82 & $\bar{A}$ & 36 & 94.44 & 5.56 & 0.00 & 0.00 \\
\hline 83 & $B$ & 193 & 35.23 & 61.14 & 3.63 & 0.00 \\
\hline 89 & $B$ & 100 & 36.00 & 62.00 & 1.00 & 1.00 \\
\hline 94 & $B$ & 71 & 0.00 & 66.20 & 33.80 & 0.00 \\
\hline 95 & C & 108 & 0.00 & 13.89 & 78.70 & 7.41 \\
\hline 96 & $A$ & 412 & 68.93 & 30.58 & 0.24 & 0.24 \\
\hline 97 & $B$ & 77 & 23.38 & 74.03 & 1.30 & 1.30 \\
\hline 99 & $B$ & 131 & 11.45 & 86.26 & 2.29 & 0.00 \\
\hline 108 & $B$ & 126 & 8.73 & 80.95 & 6.35 & 3.97 \\
\hline 176 & $A$ & 426 & 79.11 & 20.42 & 0.47 & 0.00 \\
\hline 177 & $B$ & 27 & 14.81 & 85.19 & 0.00 & 0.00 \\
\hline 180 & $\bar{A}$ & 230 & 80.43 & 19.57 & 0.00 & 0.00 \\
\hline 197 & $B$ & 101 & 29.70 & 69.31 & 0.99 & 0.00 \\
\hline 218 & $B$ & 231 & 2.16 & 65.80 & 26.84 & 5.19 \\
\hline 219 & C & 147 & 0.68 & 31.29 & 59.18 & 8.84 \\
\hline 363 & $B$ & 164 & 20.73 & 74.39 & 4.88 & 0.00 \\
\hline 364 & $\bar{A}$ & 155 & 65.81 & 29.68 & 4.52 & 0.00 \\
\hline 365 & $B$ & 83 & 31.33 & 67.47 & 1.20 & 0.00 \\
\hline 366 & $B$ & 1227 & 24.69 & 67.40 & 7.17 & 0.73 \\
\hline 392 & A & 104 & 74.04 & 25.96 & 0.00 & 0.00 \\
\hline 393 & $B$ & 69 & 28.99 & 69.57 & 1.45 & 0.00 \\
\hline 724 & A & 142 & 70.42 & 28.17 & 1.41 & 0.00 \\
\hline 725 & $B$ & 151 & 43.05 & 56.95 & 0.00 & 0.00 \\
\hline 734 & B & 35 & 22.86 & 71.43 & 5.71 & 0.00 \\
\hline 735 & C & 63 & 4.76 & 20.63 & 69.84 & 4.76 \\
\hline
\end{tabular}

${ }^{\mathrm{a}}$ Class definitions: $\mathrm{A}$ is $\mathrm{PM}_{2.5}<10 \mu \mathrm{g} / \mathrm{m}^{3}$; $\mathrm{B}$ is $10 \mu \mathrm{g} / \mathrm{m}^{3} \leq \mathrm{PM}_{2.5}<30 \mu \mathrm{g} / \mathrm{m}^{3}$; C is $30 \mu \mathrm{g} / \mathrm{m}^{3} \leq \mathrm{PM}_{2.5}<50$ $\mu \mathrm{g} / \mathrm{m}^{3}$; $\mathrm{D}$ is $\mathrm{PM}_{2.5} \geq 50 \mu \mathrm{g} / \mathrm{m}^{3}$. 


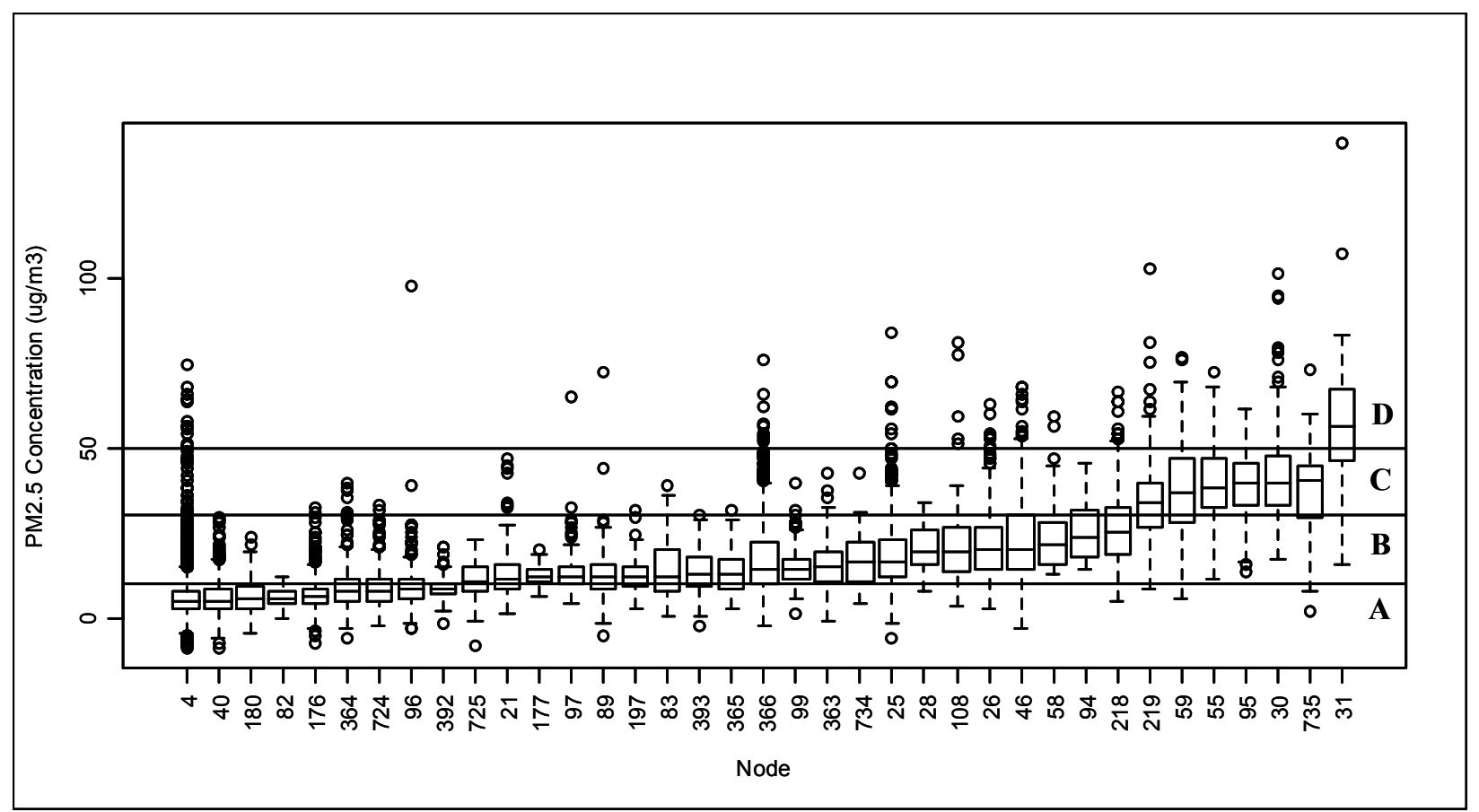

Figure 53. Boxplot showing the distribution of actual $\mathrm{PM}_{2.5}$ concentrations $\left(\mu \mathrm{g} / \mathrm{m}^{3}\right)$ falling in each terminal node of the classification tree presented in Figure 42. Nodes are sorted by increasing median concentration. Regions corresponding to classes A through $D$ are labeled.

$\mathrm{PM}_{2.5}$ concentrations at Steubenville were frequently accompanied by elevated concentrations of primary pollutant gases such as $\mathrm{CO}, \mathrm{NO}_{x}$, and $\mathrm{SO}_{2}$, especially during nocturnal temperature inversions. Moreover, the choice of $\mathrm{CO}$ and $\mathrm{NO}$, rather than $\mathrm{SO}_{2}$, as splitting variables is consistent with the observation that $\mathrm{PM}_{2.5}, \mathrm{CO}$, and $\mathrm{NO}_{\mathrm{x}}$ exhibited similar overall average diurnal profiles, while $\mathrm{SO}_{2}$ displayed a somewhat different profile.

Six nodes had median concentrations in class C. Conditions associated with these nodes also generally reflected scenarios observed in the case studies discussed previously. For instance, Nodes 59 and 219 both suggest that $\mathrm{PM}_{2.5}$ concentrations between 30 and $49.9 \mu \mathrm{g} / \mathrm{m}^{3}$ often occurred $1 \mathrm{hr}$ after a period of low wind speeds (less than 2.95 or $2.40 \mathrm{~m} / \mathrm{s}$, respectively). Nodes 55 and 219 both suggest a positive association between 1-hr $\mathrm{PM}_{2.5}$ concentrations and temperatures observed $12 \mathrm{hr}$ earlier, likely reflecting the opposing diurnal patterns that were exhibited by $\mathrm{PM}_{2.5}$ and temperature during some episodes, as well as the tendency of $\mathrm{PM}_{2.5}$ episodes to occur during periods of locally warm temperatures (Connell et al., 2005b). These nodes also indicate a positive association between $\mathrm{PM}_{2.5}$ and $\mathrm{SO}_{2}$ concentrations. Node 95 shows that moderately elevated $\mathrm{PM}_{2.5}$ concentrations (i.e., between 30 and $49.9 \mu \mathrm{g} / \mathrm{m}^{3}$ ) at Steubenville tended to occur when the concentration of $\mathrm{CO}$ was less than $0.28 \mathrm{ppm}$, but the concentration of $\mathrm{O}_{3} 1 \mathrm{hr}$ earlier was greater than $74.7 \mathrm{ppb}$, the temperature was greater than $23.0{ }^{\circ} \mathrm{C}$, and the relative humidity was greater than $52.75 \%$. These conditions are likely indicative of summertime episodes of secondary $\mathrm{PM}_{2.5}$ formation like the September 5-11, 2001, episode discussed in the preceding section. The emergence of relative humidity as an important predictor of $\mathrm{PM}_{2.5}$ concentration when it was included with other independent variables in binary recursive partitioning is noteworthy, as this variable showed relatively weak associations with hourly $\mathrm{PM}_{2.5}$ concentrations in overall and seasonal bivariate correlation analyses $\left(r_{s} \leq 0.23\right)$. Connell et al. (2005b) similarly reported that whereas daily average relative humidity was not significantly associated with daily average $\mathrm{PM}_{2.5}$ concentration in simple linear regression analyses performed using the SCAMP data, relative humidity was a 
statistically significant, positive predictor of $\mathrm{PM}_{2.5}$ when included with $\mathrm{NO}_{\mathrm{x}}, \mathrm{CO}, \mathrm{SO}_{2}, \mathrm{O}_{3}$, temperature, and wind speed in a multiple regression time series model.

Node 4 had the lowest median $\mathrm{PM}_{2.5}$ concentration and the greatest number of observations of all terminal nodes. It included 14 class-D and 27 class-C $\mathrm{PM}_{2.5}$ concentrations; however, these represented less than $1 \%$ of the total observations in the node. Observations in this node occurred during hours when the concentration of $\mathrm{CO}$ was less than $0.28 \mathrm{ppm}$ and the temperature was less than $13.6{ }^{\circ} \mathrm{C}$. Hence, the node probably largely represents low background $\mathrm{PM}_{2.5}$ concentrations experienced during cool portions of the year. The eight other class-A nodes also tended to occur when temperatures or gaseous co-pollutant concentrations were below various threshold values, again suggesting the strong association between $\mathrm{PM}_{2.5}$ and these potential epidemiologic confounders.

Thus, the results presented here demonstrate the usefulness of binary recursive partitioning for systematically analyzing large quantities of $\mathrm{PM}_{2.5}$ air monitoring data and also affirm the conclusions drawn from the correlation analyses and examination of $\mathrm{PM}_{2.5}$ episodes presented earlier.

\subsubsection{Source Apportionment of $\mathrm{PM}_{2.5}$ at Steubenville}

The case studies and correlation analyses presented above provide insights into factors that affect $\mathrm{PM}_{2.5}$ concentrations at Steubenville. However, to more systematically identify sources of $\mathrm{PM}_{2.5}$ that impacted the central Steubenville monitoring site during SCAMP, receptor modeling was applied to $\mathrm{PM}_{2.5}$ mass and speciation data collected at that site during the program. The general receptor modeling problem is given by:

$$
x_{i j}=\sum_{k=1}^{p} g_{i k} f_{k j}+e_{i j}
$$

where $x_{i j}$ is the ambient mass concentration of the jth chemical species from the ith $\mathrm{PM}_{2.5}$ sample collected at the receptor site; $g_{i k}$ is the $\mathrm{PM}_{2.5}$ mass concentration from the $k$ th source contributing to the ith sample; $f_{k j}$ is the mass fraction of the jth chemical species in $\mathrm{PM}_{2.5}$ from the $k$ th source; $e_{i j}$ is the residual associated with $x_{i j}$, and $p$ is the total number of sources contributing to $\mathrm{PM}_{2.5}$ at the receptor site. If the compositional profiles of the various sources impacting the receptor site are known (i.e., if the matrix of source compositions, $F$, can be specified), then the receptor modeling problem can be solved for the matrix of source contributions, G, via the commonly used Chemical Mass Balance (CMB) technique (Hidy and Friedlander, 1971). In many cases, though, source compositions are not known; hence, there are an infinite number of possible solutions to the receptor modeling equation corresponding to different rotations of the $F$ and $G$ matrices. Such was the case in SCAMP. Several different factor analytic techniques have been proposed for use in resolving physically reasonable combinations of the matrix of source contributions, G, and the matrix of source compositions, $F$, for any given set of speciated $\mathrm{PM}_{2.5}$ data, $\mathrm{X}$, measured at a receptor site. Two of the most commonly used techniques, Positive Matrix Factorization (PMF) and Unmix, were applied to the SCAMP central site data. Results are described in the following two subsections.

\subsubsection{Positive Matrix Factorization Results}

Positive Matrix Factorization (Paatero, 1997) solves the general receptor modeling problem given above for the $F$ and $G$ matrices by imposing non-negativity constraints on these matrices 
and employing an iterative least squares procedure in which observations are weighted by the inverse of their estimated uncertainties. PMF was applied to $\mathrm{PM}_{2.5}$ mass, ion, carbon, and aciddigestible elemental data collected at the SCAMP central Steubenville site. Only the 115 days for which data were available for total mass, all four ions $\left(\mathrm{NH}_{4}{ }^{+}, \mathrm{SO}_{4}{ }^{2-}, \mathrm{NO}_{3}{ }^{-}\right.$, and $\left.\mathrm{Cl}^{-}\right)$, both elemental and organic carbon, and at least 10 out of the 18 routinely determined acid-digestible elements were included in the model runs. Details of the application of PMF to these data are provided by Connell et al. (2006); a copy of this manuscript is included as Appendix D to this report. As discussed in the manuscript, a final 7-source PMF model for the Steubenville site was selected based on an evaluation of the model goodness-of-fit and the physical reasonableness of the source profiles obtained from several candidate PMF solutions. Potential source contribution function (PSCF) modeling was applied to the source contribution time series resolved by PMF to help identify the probable geographic locations of each of the seven PMF sources; these PSCF results are also presented in Appendix D.

Table 38 shows the source profiles resolved for the seven PMF source factors, and Figure 54 presents boxplots showing the seasonal distributions of daily source contributions estimated for each source factor. Table 39 summarizes probable identities of the seven source factors based on the interpretation provided in Appendix D. The PMF and PSCF results suggest that secondary sulfates likely originating from coal-fired power plants located to the west and southwest of Steubenville (Factor 1) are the largest contributor to $\mathrm{PM}_{2.5}$ in Steubenville, accounting for about $7.4 \mu \mathrm{g} / \mathrm{m}^{3}$, or about $42 \%$, of the total $\mathrm{PM}_{2.5}$ mass. Correlation analyses similar to those presented in Table 36 for individual $\mathrm{PM}_{2.5}$ components indicate that elevated concentrations of this ammonium sulfate-dominated source typically were observed on a regional scale and tended to occur during warm summertime afternoons, when photochemical activity would have been maximal. Local sources in the immediate Steubenville vicinity, represented by Factors 2 and 3, collectively accounted for about $5.3 \mu \mathrm{g} / \mathrm{m}^{3}$, or $30 \%$, of the total $\mathrm{PM}_{2.5}$ mass. These sources include motor vehicles and other local sources of carbonaceous aerosols (Factor 2), which contributed $\sim 20 \%$ of the total $\mathrm{PM}_{2.5}$ mass, as well as iron and steel production facilities (Factor 3 ), which contributed $\sim 10 \%$ of the total $\mathrm{PM}_{2.5}$ mass. The PMFestimated local source contribution of $5.3 \mu \mathrm{g} / \mathrm{m}^{3}$ is similar to the local source contribution of 4.6 $\mu \mathrm{g} / \mathrm{m}^{3}$ reported above on the basis of pairwise comparisons of $\mathrm{PM}_{2.5}$ concentrations measured at the Steubenville site and $\mathrm{PM}_{2.5}$ concentrations measured the northern and western satellite sites. The estimated contributions of Factors 2 and 3 to total $\mathrm{PM}_{2.5}$ mass were more strongly correlated with overnight maximum $\mathrm{PM}_{2.5}$ concentrations than with afternoon maximum concentrations and with estimated local source $\mathrm{PM}_{2.5}$ mass concentrations than with estimated background concentrations, consistent with the previously discussed effects of nocturnal temperature inversions and reduced nighttime mixing heights on locally-emitted pollutant concentrations. Both sources also exhibited moderate-to-strong correlations with concentrations of $\mathrm{CO}, \mathrm{NO}$, and $\mathrm{NO}_{2}$ consistent with the cool-season case study presented above.

Other sources of $\mathrm{PM}_{2.5}$ resolved by PMF include a nitrate source (Factor 4 ), which accounted for about $15 \%$ of the total $\mathrm{PM}_{2.5}$ mass and was associated with source regions in the vicinity of urban areas located to the west of Steubenville, a crustal source (Factor 5, 6\% of total mass), a mixed nonferrous metals and industrial source (Factor $6,3 \%$ of total mass), for which the source region estimated by PSCF was consistent with the locations of metal smelting and processing plants and industrial facilities that reported air emissions of $\mathrm{Pb}, \mathrm{Cd}$, and other nonferrous trace metals to the EPA's Toxics Release Inventory (TRI), and a primary coal combustion source (Factor $7,3 \%$ of total mass), for which PSCF identified a source region comprising portions of 
the Monongahela and Ohio River Valleys, where the region's major coal-fired power plants are located.

Table 38. Source profile $\left(\mathrm{ng} / \mathrm{m}^{3}\right)$ for the seven-source PMF model run using $\mathrm{PM}_{2.5}$ total mass, ion, carbon, and acid-digestible element data collected at the central Steubenville site during SCAMP. Estimated concentrations with magnitudes at least twice as great as their standard deviations are highlighted in bold.

\begin{tabular}{|c|c|c|c|c|c|c|c|}
\hline & Factor 1 & Factor 2 & Factor 3 & Factor 4 & Factor 5 & Factor 6 & Factor 7 \\
\hline $\mathrm{PM}_{2.5}$ & $\mathbf{7 4 0 0}$ & $\mathbf{3 5 0 0}$ & $\mathbf{1 8 0 0}$ & $\mathbf{2 7 0 0}$ & $\mathbf{1 0 0 0}$ & 600 & 600 \\
\hline $\mathrm{NH}_{4}{ }^{+}$ & $\mathbf{1 5 0 0}$ & 0 & $\mathbf{1 0 0}$ & $\mathbf{4 0 0}$ & 0 & $\mathbf{1 0 0}$ & $\mathbf{1 0 0}$ \\
\hline $\mathrm{NO}_{3}{ }^{-}$ & 0 & $\mathbf{5 0}$ & 0 & $\mathbf{1 1 0 0}$ & 0 & 0 & 0 \\
\hline $\mathrm{SO}_{4}{ }^{2-}$ & $\mathbf{3 8 0 0}$ & $\mathbf{6 0 0}$ & $\mathbf{3 0 0}$ & $\mathbf{3 0 0}$ & 0 & 100 & $\mathbf{1 0 0}$ \\
\hline $\mathrm{Cl}^{-}$ & 0 & 0 & 0 & 0 & 0 & 0 & 0 \\
\hline $\mathrm{EC}$ & 0 & $\mathbf{6 3 0}$ & 0 & 0 & 0 & $\mathbf{7 0}$ & $\mathbf{5 0}$ \\
\hline $\mathrm{OM}$ & $\mathbf{4 0 0}$ & $\mathbf{2 8 0 0}$ & $\mathbf{4 0 0}$ & $\mathbf{4 0 0}$ & $\mathbf{3 0 0}$ & 0 & 0 \\
\hline $\mathrm{Al}$ & 1.5 & 0.7 & $\mathbf{1 3 . 5}$ & $\mathbf{1 4 . 0}$ & $\mathbf{4 4 . 5}$ & 5.5 & $\mathbf{9 . 6}$ \\
\hline $\mathrm{As}$ & 0.09 & $\mathbf{0 . 3 5}$ & $\mathbf{0 . 4 3}$ & 0.06 & 0.14 & $\mathbf{0 . 3 0}$ & 0.12 \\
\hline $\mathrm{Ba}$ & 0 & $\mathbf{1 . 1}$ & 0 & $\mathbf{0 . 2}$ & 0.1 & 0.0 & $\mathbf{0 . 6}$ \\
\hline $\mathrm{Ca}$ & 2 & 14 & $\mathbf{1 8}$ & $\mathbf{2 5}$ & $\mathbf{5 3}$ & 5 & 7 \\
\hline $\mathrm{Cd}$ & 0.01 & $\mathbf{0 . 0 6}$ & 0.01 & 0 & 0 & $\mathbf{0 . 2}$ & $\mathbf{0 . 0 2}$ \\
\hline $\mathrm{Co}$ & 0.008 & $\mathbf{0 . 0 2 3}$ & 0.009 & 0.002 & 0 & 0.001 & 0.007 \\
\hline $\mathrm{Cu}$ & 0.2 & $\mathbf{0 . 7}$ & $\mathbf{0 . 3}$ & $\mathbf{0 . 4}$ & $\mathbf{0 . 3}$ & $\mathbf{0 . 7}$ & 0 \\
\hline $\mathrm{Fe}$ & $\mathbf{1 0}$ & $\mathbf{4 8}$ & $\mathbf{1 8 4}$ & $\mathbf{2}$ & $\mathbf{1 1}$ & 0 & $\mathbf{1 9}$ \\
\hline $\mathrm{K}$ & 0 & $\mathbf{5}$ & $\mathbf{2 3}$ & $\mathbf{1 5}$ & $\mathbf{4 5}$ & 0 & 2 \\
\hline $\mathrm{Mg}$ & 0 & $\mathbf{5}$ & $\mathbf{1 7}$ & $\mathbf{4}$ & $\mathbf{1 3}$ & 0 & 0 \\
\hline $\mathrm{Mn}$ & 0 & $\mathbf{3 . 3}$ & $\mathbf{8 . 6}$ & 0 & 0.2 & 0.1 & $\mathbf{1 . 4}$ \\
\hline $\mathrm{Ni}$ & 0.1 & 0.1 & 0.1 & 0 & 0 & 0 & 0 \\
\hline $\mathrm{Pb}$ & 0 & $\mathbf{1 . 4}$ & $\mathbf{4}$ & $\mathbf{0 . 8}$ & $\mathbf{1}$ & $\mathbf{7 . 3}$ & 0 \\
\hline $\mathrm{Se}$ & $\mathbf{0 . 1 1}$ & 0 & 0.04 & $\mathbf{0 . 2}$ & 0 & 0 & $\mathbf{2 . 9 6}$ \\
\hline $\mathrm{Sn}$ & 0.08 & $\mathbf{0 . 1 5}$ & $\mathbf{0 . 4 4}$ & $\mathbf{0 . 1 1}$ & 0.02 & $\mathbf{0 . 3 9}$ & $\mathbf{0 . 1 2}$ \\
\hline $\mathrm{Ti}$ & $\mathbf{1 . 6}$ & 0 & 0 & $\mathbf{1}$ & $\mathbf{4 . 2}$ & $\mathbf{2}$ & 0 \\
\hline $\mathrm{V}$ & 0.05 & $\mathbf{0 . 1 7}$ & 0 & 0 & $\mathbf{0 . 2 2}$ & $\mathbf{0 . 3 3}$ & $\mathbf{0 . 1 1}$ \\
\hline $\mathbf{Z n}$ & $\mathbf{7 . 2}$ & 0 & $\mathbf{4 7 . 3}$ & $\mathbf{7 . 5}$ & $\mathbf{2 . 2}$ & $\mathbf{1 8 . 1}$ & $\mathbf{3 . 8}$ \\
\hline & & & & & & & \\
\hline
\end{tabular}

Table 39. Summary of results of the seven-source PMF model run using $\mathrm{PM}_{2.5}$ total mass, ion, carbon, and acid-digestible element data collected at the central Steubenville site during SCAMP.

\begin{tabular}{|c|c|c|c|}
\hline Factor \# & Source & Enriched Species & $\begin{array}{c}\text { Contribution to Total } \\
\mathbf{P M}_{\mathbf{2 . 5}} \text { Mass }\end{array}$ \\
\hline 1 & Secondary Sulfates & $\mathrm{SO}_{4}{ }^{2-}, \mathrm{NH}_{4}{ }^{+}$ & $42 \%$ \\
\hline 2 & Vehicular / Local Carbon & $\mathrm{EC}, \mathrm{OM}, \mathrm{Ba}$ & $20 \%$ \\
\hline 3 & Iron and Steel & $\mathrm{Fe}, \mathrm{Mg}, \mathrm{Mn}, \mathrm{Sn}, \mathrm{Zn}$ & $10 \%$ \\
\hline 4 & Nitrates & $\mathrm{NO}_{3}{ }^{-}$ & $15 \%$ \\
\hline 5 & Crustal & $\mathrm{Al}, \mathrm{Ca}, \mathrm{K}, \mathrm{Mg}, \mathrm{Ti}, \mathrm{V}$ & $6 \%$ \\
\hline 6 & Nonferrous Metals / Industrial & $\mathrm{Cd}, \mathrm{Pb}, \mathrm{V}, \mathrm{Sn}, \mathrm{Cu}, \mathrm{Ti}, \mathrm{Zn}, \mathrm{As}$ & $3 \%$ \\
\hline 7 & Primary Coal Combustion & $\mathrm{Se}, \mathrm{Ba}, \mathrm{Co}, \mathrm{V}, \mathrm{Al}, \mathrm{Mn}$ & $3 \%$ \\
\hline
\end{tabular}




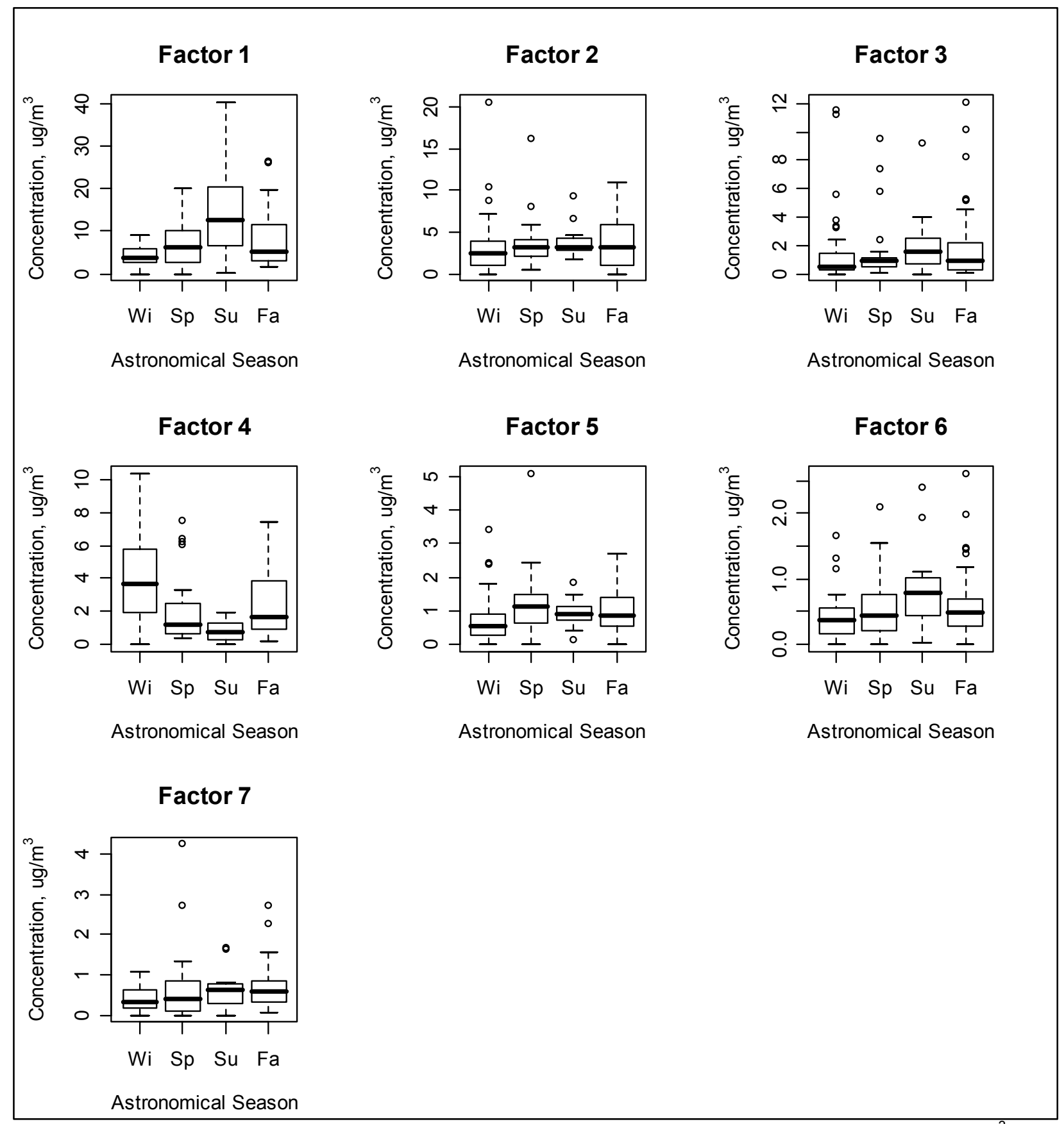

Figure 54. Boxplots showing the distributions of estimated source contributions $\left(\mu \mathrm{g} / \mathrm{m}^{3}\right)$ by astronomical season for each of the seven sources resolved by PMF for the central Steubenville site.

\subsubsection{Unmix Results}

Source apportionment was also performed on $\mathrm{PM}_{2.5}$ mass and speciation data from the central Steubenville site using the EPA Unmix 2.3 receptor model. Like PMF, the Unmix model solves the general receptor modeling problem given above for the $F$ and $G$ matrices; however, unlike $\mathrm{PMF}$, it does this by first estimating the number of sources, $k$, that can be resolved from the 
dataset being modeled, based on signal-to-noise ratios, and then employing an algorithm to detect "edges" (i.e., constant ratios among species concentrations) in ( $k$-1)-dimensional space. These edges are used to determine the source compositions and contributions. Bootstrapping is then employed to estimate the uncertainties in the results (Lewis et al., 2003). Unmix does not utilize user-specified measurement uncertainties as PMF does, and it often fails to resolve as many sources as PMF. Moreover, feasible solutions are typically obtained only when a subset of the measured species (rather than all of these species) are included in the model. Hence, the results are less detailed than those produced by PMF. Nevertheless, the application of Unmix to the SCAMP central site $\mathrm{PM}_{2.5}$ speciation data provided a means for independently validating the PMF source apportionment results presented above.

A number of Unmix runs were performed (using the software's "Unmix Overnight" utility) to systematically explore the effects of including various ionic, carbonaceous, and acid-digestible elemental components of $\mathrm{PM}_{2.5}$. Several satisfactory five-source solutions were obtained for which diagnostic indicators met or exceeded specifications provided with the software (i.e., minimum $\mathrm{R}^{2} \geq 0.8$; minimum signal-to-noise ratio $\geq 2$ ). Strength, a third indicator that measures confidence in the solution, is recommended to be greater than 3; however, as discussed by researchers from Carnegie Mellon University (2005), strengths less than 3 may be acceptable for some datasets. The Carnegie Mellon researchers reported a strength of 1.41 for a sixsource Unmix model of speciated $\mathrm{PM}_{2.5}$ data in Pittsburgh, PA. Strengths for the five-source SCAMP model runs ranged from 1.45 to 3.65 . To further aid in the selection of the best fivesource Unmix solutions, the satisfactory models obtained from the Unmix Overnight process were re-run with the inclusion of $\mathrm{PM}_{2.5}$ speciation data from EPA sampling intensives that were conducted at the Steubenville site during June-August 2001 and January 2002. (These data have otherwise been excluded from the analyses presented in this paper). Based on an assessment of the stability of the models when these additional days were included, three models were determined to be superior to the others. (No further distinction among the merits of these three could be made, as they included different combinations of $\mathrm{PM}_{2.5}$ chemical species). These three models are now discussed in greater detail (for the solutions that did not include data from the EPA sampling intensives).

Table 40 summarizes model specifications and diagnostics for each of the three best fivesource Unmix solutions. Table 41 presents Unmix-derived source profiles (in $\mathrm{ng} / \mathrm{m}^{3}$ ) for each of these solutions. As shown in Figure 55, which compares 24-hr average $\mathrm{PM}_{2.5}$ concentrations predicted by the Unmix models with actual 24-hr average $\mathrm{PM}_{2.5}$ concentrations measured at Steubenville, the models were generally successful in predicting total $\mathrm{PM}_{2.5}$ mass concentrations at Steubenville. $R^{2}$ values resulting from simple linear regression of predicted versus observed values ranged from 0.96 to 0.98 .

Table 40. Model specifications and diagnostics for the three best five-source Unmix model runs using $\mathrm{PM}_{2.5}$ total mass, ion, carbon, and acid-digestible element data collected at the central Steubenville site during SCAMP.

\begin{tabular}{|c|c|c|c|}
\hline & Solution \# 1 & Solution \# 2 & Solution \# 3 \\
\hline Number of Days & 108 & 104 & 113 \\
\hline Species & $\begin{array}{c}\mathrm{PM}_{2.5}, \mathrm{NH}_{4}{ }^{+}, \mathrm{NO}_{3}^{-}, \\
\mathrm{SO}_{4}{ }^{2-}, \mathrm{OM}, \mathrm{Al}, \mathrm{K}, \mathrm{Pb}, \mathrm{V}\end{array}$ & $\begin{array}{c}\mathrm{PM}_{2.5}, \mathrm{NH}_{4}^{+}, \mathrm{NO}_{3}{ }^{-}, \\
\mathrm{SO}_{4}^{2-}, \mathrm{OM}, \mathrm{Fe}, \mathrm{K}, \mathrm{Mn}, \\
\mathrm{Se}, \mathrm{Zn}\end{array}$ & $\begin{array}{c}\mathrm{PM}_{2.5}, \mathrm{NH}_{4}{ }^{+}, \mathrm{SO}_{4}{ }^{2-}, \mathrm{Al}, \\
\mathrm{Cd}, \mathrm{Fe}, \mathrm{Mn}, \mathrm{V}, \mathrm{Zn}\end{array}$ \\
\hline $\begin{array}{c}\text { Minimum } \mathbf{R}^{2} \\
\begin{array}{c}\text { Minum Signal } / \\
\text { Noise }\end{array}\end{array}$ & 0.86 & 0.88 & 0.94 \\
\hline Strength & 2.23 & 2.15 & 2.01 \\
\hline
\end{tabular}


Table 41. Source profiles $\left(\mathrm{ng} / \mathrm{m}^{3}\right)$ for the three best five-source Unmix model runs using $\mathrm{PM}_{2.5}$ total mass, ion, carbon, and acid-digestible element data collected at the central Steubenville site during SCAMP. Estimated concentrations with magnitudes at least twice as great as their uncertainties are highlighted in bold.

\begin{tabular}{|c|c|c|c|c|c|}
\hline \multicolumn{6}{|c|}{ UNMIX Solution \# 1} \\
\hline & Factor 1 & Factor 2 & Factor 3 & Factor 4 & Factor 5 \\
\hline $\mathrm{PM}_{2.5}$ & 1100 & 3600 & 1200 & 4000 & 7700 \\
\hline $\mathrm{NH}_{4}^{+}$ & 100 & 600 & 100 & 200 & 1200 \\
\hline $\mathrm{NO}_{3}^{-}$ & -10 & 1260 & -20 & 40 & -70 \\
\hline $\mathrm{SO}_{4}{ }^{2-}$ & 200 & 600 & 400 & 500 & 3500 \\
\hline OM & 500 & 400 & 200 & 2100 & 1200 \\
\hline Al & 9.1 & 4.9 & 3.4 & 63.5 & 17.1 \\
\hline $\mathbf{K}$ & 6 & 9 & 9 & 51 & 16 \\
\hline $\mathbf{P b}$ & 1.0 & 0.7 & 10.7 & 1.3 & 2.2 \\
\hline $\mathbf{V}$ & 1.07 & -0.01 & 0.06 & 0.20 & 0.21 \\
\hline \multicolumn{6}{|c|}{ UNMIX Solution \# 2} \\
\hline & Factor 1 & Factor 2 & Factor 3 & Factor 4 & Factor 5 \\
\hline $\mathrm{PM}_{2.5}$ & 2900 & 2200 & 3500 & 1000 & 8500 \\
\hline $\mathrm{NH}_{4}^{+}$ & 500 & 200 & 100 & 100 & 1400 \\
\hline $\mathrm{NO}_{3}^{-}$ & 1130 & 30 & 110 & -70 & 20 \\
\hline $\mathrm{SO}_{4}{ }^{2-}$ & 400 & 400 & 300 & 400 & 4000 \\
\hline OM & 300 & 600 & 2200 & 300 & 1200 \\
\hline $\mathrm{Fe}$ & -4 & 217 & 25 & 31 & 41 \\
\hline $\mathbf{K}$ & 8 & 23 & 44 & 4 & 15 \\
\hline Mn & 0.3 & 10.5 & 3.8 & 1.1 & 0.3 \\
\hline Se & 0.22 & 0.40 & -0.03 & 2.42 & 0.53 \\
\hline $\mathrm{Zn}$ & 5.2 & 59.4 & 6.2 & 3.8 & 12.6 \\
\hline \multicolumn{6}{|c|}{ UNMIX Solution \# 3} \\
\hline & Factor 1 & Factor 2 & Factor 3 & Factor 4 & Factor 5 \\
\hline $\mathrm{PM}_{2.5}$ & 1500 & 1900 & 4800 & 1300 & 7400 \\
\hline $\mathrm{NH}_{4}^{+}$ & 100 & 300 & 600 & 0 & 1200 \\
\hline $\mathrm{SO}_{4}{ }^{2-}$ & 400 & 700 & 1100 & 100 & 3100 \\
\hline Al & 10.7 & 3.9 & 58 & 10.1 & 15.8 \\
\hline Cd & 0.06 & 0.36 & -0.03 & 0.08 & 0.01 \\
\hline $\mathrm{Fe}$ & 27 & 19 & -2 & 196 & 32 \\
\hline Mn & 2.0 & 0.0 & 2.4 & 9.6 & 0.4 \\
\hline $\mathbf{V}$ & 1.07 & 0.04 & 0.20 & 0.16 & 0.03 \\
\hline $\mathrm{Zn}$ & 8.4 & 5.3 & 11.9 & 49.2 & 9.2 \\
\hline
\end{tabular}


UNMIX Solution \# 1

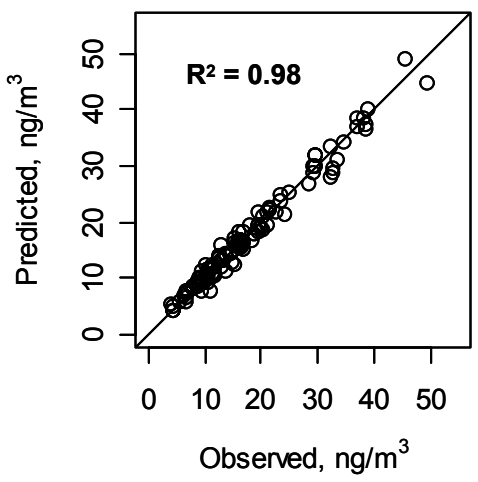

UNMIX Solution \# 2

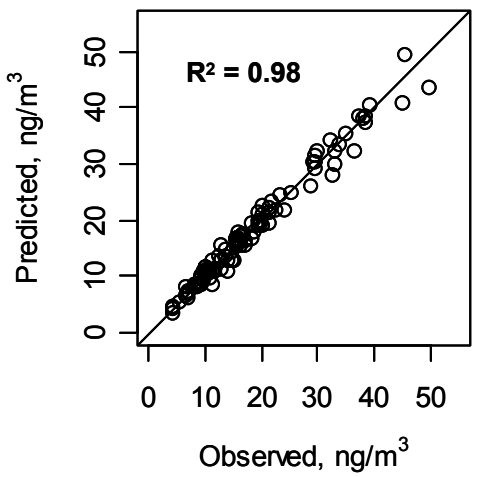

UNMIX Solution \# 3

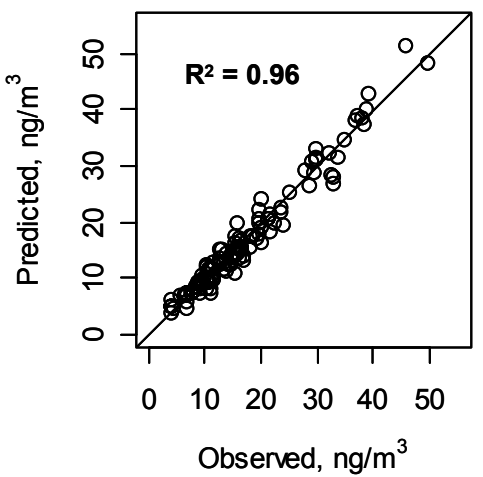

Figure 55. $\quad \mathrm{PM}_{2.5}$ concentrations at Steubenville predicted by each of the three best five-source Unmix model runs vs. corresponding $\mathrm{PM}_{2.5}$ concentrations measured at the central Steubenville site.

Table 42 presents Spearman correlation coefficients comparing the estimated contributions of the Unmix sources to total $\mathrm{PM}_{2.5}$ mass with the estimated source contributions of the seven PMF sources discussed in the previous subsection. Figure 56 presents boxplots showing the seasonal distributions of daily source contributions estimated for each Unmix source factor, and Tables 43 and 44 show Spearman correlation coefficients comparing estimated daily Unmix source contributions with daily average gaseous pollutant concentrations and meteorological conditions and daily measures of the impact of local versus regional sources on $\mathrm{PM}_{2.5}$ concentrations in Steubenville.

Table 42. Spearman correlation coefficients comparing estimated daily source contributions (to total $\mathrm{PM}_{2.5}$ mass at Steubenville) for the three best five-source Unmix solutions with estimated daily source contributions for the seven-source PMF model.

\begin{tabular}{|c|c|c|c|c|c|c|c|c|}
\hline & & $\begin{array}{c}\text { PMF } \\
\text { Source } 1\end{array}$ & $\begin{array}{c}\text { PMF } \\
\text { Source } 2\end{array}$ & $\begin{array}{c}\text { PMF } \\
\text { Source } 3\end{array}$ & $\begin{array}{c}\text { PMF } \\
\text { Source } 4\end{array}$ & $\begin{array}{c}\text { PMF } \\
\text { Source } 5\end{array}$ & $\begin{array}{c}\text { PMF } \\
\text { Source } 6\end{array}$ & $\begin{array}{c}\text { PMF } \\
\text { Source } 7\end{array}$ \\
\hline & Source 1 & 0.12 & 0.42 & 0.36 & -0.10 & 0.28 & 0.50 & 0.36 \\
\hline & Source 2 & 0.11 & 0.03 & -0.13 & 0.93 & -0.41 & -0.08 & 0.02 \\
\hline 结吾 & Source 3 & 0.01 & 0.48 & 0.67 & -0.12 & 0.24 & 0.79 & 0.29 \\
\hline & Source 4 & -0.13 & 0.52 & 0.56 & 0.02 & 0.51 & 0.04 & 0.36 \\
\hline & Source 5 & 0.95 & 0.34 & 0.15 & -0.03 & 0.26 & 0.25 & 0.40 \\
\hline & Source 1 & -0.01 & -0.09 & -0.24 & 0.93 & -0.50 & -0.11 & -0.03 \\
\hline & Source 2 & 0.14 & 0.67 & 0.95 & -0.16 & 0.38 & 0.48 & 0.45 \\
\hline 焉荎 & Source 3 & -0.08 & 0.63 & 0.53 & -0.02 & 0.58 & 0.08 & 0.28 \\
\hline & Source 4 & 0.32 & 0.45 & 0.29 & -0.01 & 0.32 & 0.31 & 0.94 \\
\hline & Source 5 & 0.96 & 0.39 & 0.19 & -0.08 & 0.31 & 0.35 & 0.44 \\
\hline & Source 1 & 0.29 & 0.37 & 0.25 & -0.19 & 0.34 & 0.50 & 0.33 \\
\hline & Source 2 & 0.22 & 0.29 & 0.24 & -0.01 & 0.22 & 0.58 & 0.34 \\
\hline 톨 & Source 3 & -0.20 & 0.20 & 0.25 & 0.06 & 0.39 & -0.11 & 0.25 \\
\hline 5 க & Source 4 & 0.17 & 0.69 & 0.87 & -0.08 & 0.39 & 0.35 & 0.50 \\
\hline & Source 5 & 0.80 & 0.24 & 0.01 & 0.26 & 0.01 & 0.16 & 0.20 \\
\hline
\end{tabular}




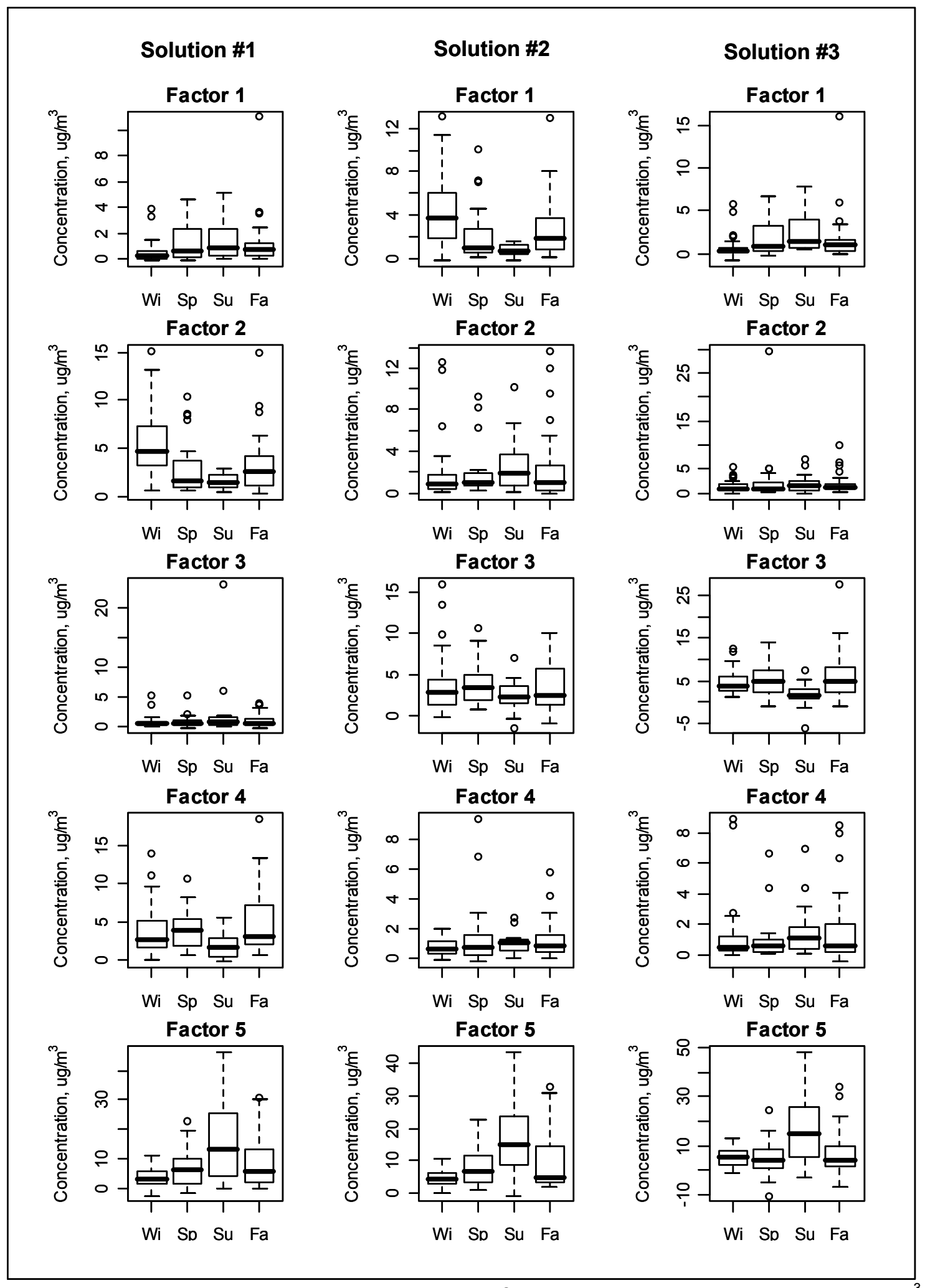

Figure 56. Boxplots showing the distributions of estimated source contributions $\left(\mu \mathrm{g} / \mathrm{m}^{3}\right)$ by astronomical season for each of the source factors resolved by the three best five-source Unmix solutions. 
Table 43. Spearman correlation coefficients comparing estimated daily source contributions (to total $\mathrm{PM}_{2.5}$ mass at Steubenville) for the three best five-source Unmix solutions with daily average gaseous pollutant concentrations and meteorological conditions.

\begin{tabular}{|c|c|c|c|c|c|c|c|c|c|c|}
\hline \multicolumn{2}{|c|}{ - the } & $\mathrm{SO}_{2}$ & NO & $\mathrm{NO}_{2}$ & $\mathrm{CO}$ & $\mathrm{O}_{3}$ & WS & Temp & RH & BP \\
\hline \multirow{5}{*}{ 希 } & Source 1 & 0.23 & 0.51 & 0.58 & 0.32 & -0.17 & -0.41 & 0.26 & -0.01 & 0.29 \\
\hline & Source 2 & 0.06 & 0.14 & 0.01 & 0.17 & -0.36 & 0.04 & -0.47 & 0.17 & -0.23 \\
\hline & Source 3 & 0.32 & 0.67 & 0.68 & 0.62 & -0.20 & -0.36 & 0.20 & -0.22 & 0.29 \\
\hline & Source 4 & 0.31 & 0.34 & 0.45 & 0.43 & -0.09 & -0.05 & 0.13 & -0.53 & 0.26 \\
\hline & Source 5 & 0.30 & 0.06 & 0.09 & 0.28 & 0.17 & -0.22 & 0.49 & 0.23 & 0.07 \\
\hline \multirow{5}{*}{ 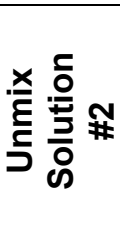 } & Source 1 & -0.02 & 0.10 & -0.02 & 0.06 & -0.41 & 0.07 & -0.58 & 0.19 & -0.26 \\
\hline & Source 2 & 0.50 & 0.71 & 0.70 & 0.75 & -0.09 & -0.28 & 0.31 & -0.42 & 0.46 \\
\hline & Source 3 & 0.28 & 0.32 & 0.46 & 0.39 & 0.09 & -0.19 & 0.24 & -0.52 & 0.36 \\
\hline & Source 4 & 0.70 & 0.41 & 0.63 & 0.40 & -0.27 & -0.22 & 0.17 & -0.10 & 0.13 \\
\hline & Source 5 & 0.27 & 0.09 & 0.18 & 0.33 & 0.24 & -0.30 & 0.55 & 0.21 & 0.15 \\
\hline \multirow{5}{*}{ 出 } & Source 1 & 0.21 & 0.37 & 0.52 & 0.27 & -0.01 & -0.45 & 0.41 & 0.10 & 0.31 \\
\hline & Source 2 & 0.24 & 0.36 & 0.44 & 0.37 & -0.15 & -0.25 & 0.17 & -0.03 & 0.21 \\
\hline & Source 3 & 0.21 & 0.14 & 0.31 & 0.22 & -0.10 & 0.18 & -0.03 & -0.36 & 0.08 \\
\hline & Source 4 & 0.57 & 0.70 & 0.68 & 0.70 & -0.15 & -0.29 & 0.31 & -0.36 & 0.40 \\
\hline & Source 5 & 0.20 & 0.09 & 0.08 & 0.27 & 0.09 & -0.24 & 0.22 & 0.31 & -0.03 \\
\hline
\end{tabular}

Table 44. Spearman correlation coefficients between estimated daily source contributions (to total $\mathrm{PM}_{2.5}$ mass at Steubenville) for the three best five-source Unmix solutions and estimates of the impact of local versus regional sources on $\mathrm{PM}_{2.5}$ concentrations in Steubenville.

\begin{tabular}{|c|c|c|c|}
\hline \multicolumn{2}{|c|}{ 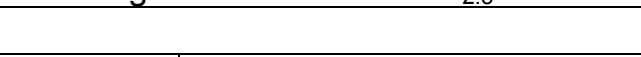 } & Local $\mathbf{P M}_{2.5}{ }^{\mathrm{a}}$ & Background $\mathrm{PM}_{2.5}^{\mathrm{b}}$ \\
\hline \multirow{5}{*}{ 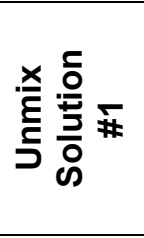 } & Source 1 & 0.28 & 0.01 \\
\hline & Source 2 & 0.17 & 0.34 \\
\hline & Source 3 & 0.44 & 0.01 \\
\hline & Source 4 & 0.28 & -0.02 \\
\hline & Source 5 & 0.47 & 0.72 \\
\hline \multirow{5}{*}{ 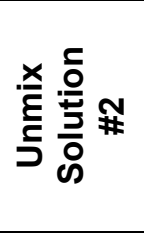 } & Source 1 & 0.05 & 0.26 \\
\hline & Source 2 & 0.70 & 0.09 \\
\hline & Source 3 & 0.32 & 0.05 \\
\hline & Source 4 & 0.34 & 0.44 \\
\hline & Source 5 & 0.52 & 0.74 \\
\hline \multirow{5}{*}{ 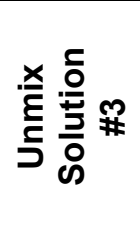 } & Source 1 & 0.38 & 0.28 \\
\hline & Source 2 & 0.33 & 0.36 \\
\hline & Source 3 & 0.12 & -0.11 \\
\hline & Source 4 & 0.65 & 0.28 \\
\hline & Source 5 & 0.43 & 0.78 \\
\hline
\end{tabular}

${ }^{a}$ Difference between 24-hr concentration measured at the central Steubenville site and the average of the 24-hr concentrations measured at the northern and western satellite sites; ${ }^{b}$ Average of the 24-hr concentrations measured at the northern and western satellite sites

The results presented in Table 42 indicate that the results of the Unmix models were generally similar to those of the PMF model. Estimated source contributions for each of the seven PMF source factors exhibited a Spearman correlation coefficient of $\geq 0.58$ with estimated source contributions for at least one of the 15 source factors resolved by the three best Unmix solutions. 
Source 5 from each of the three Unmix solutions correlated well with Source 1 from the sevensource PMF model $\left(r_{s}=0.80-0.96\right)$. As with Source 1 from the PMF model, which was comprised of $\sim 71 \%(\mathrm{w} / \mathrm{w}) \mathrm{NH}_{4}{ }^{+}$and $\mathrm{SO}_{4}{ }^{2-}$ and accounted for an estimated $7.4 \mu \mathrm{g} / \mathrm{m}^{3}$ of the total $\mathrm{PM}_{2.5}$ mass in Steubenville, these Unmix sources were dominated by $\mathrm{NH}_{4}{ }^{+}$and $\mathrm{SO}_{4}{ }^{2-}$ (these species in combination accounted for $58-64 \%$ of the total source mass) and contributed an estimated $7.4-8.5 \mu \mathrm{g} / \mathrm{m}^{3}$ to the total mass of $\mathrm{PM}_{2.5}$ at Steubenville. The slightly greater $\mathrm{PM}_{2.5}$ mass contributions and lower $\mathrm{NH}_{4}{ }^{+}$and $\mathrm{SO}_{4}{ }^{2-}$ weight percentages for the Unmix sources compared to the PMF source likely result from the fact that Unmix was able to resolve fewer sources than PMF; hence, the Unmix sources incorporate some $\mathrm{PM}_{2.5}$ mass that was able to be further resolved and apportioned to additional sources by PMF. As shown in Figure 56, source contributions estimated for Source 5 from each of the three Unmix solutions exhibited pronounced seasonal patterns of higher summertime and lower wintertime concentrations, and as indicated in Table 44, these source contributions correlated more strongly with regional background $\mathrm{PM}_{2.5}$ concentrations than did source contributions from any of the other Unmix sources. Hence, consistent with the interpretation provided earlier for Source 1 from the sevensource PMF model, these Unmix sources represent the contribution of regional, sulfatedominated secondary particles to $\mathrm{PM}_{2.5}$ in Steubenville.

Unmix Solution \#2, Source 2, and Unmix Solution \#3, Source 4, each correlated strongly with PMF Source $3\left(r_{s}=0.87-0.95\right)$. As shown in Tables 41 and 43 respectively, both of these Unmix sources are enriched in $\mathrm{Fe}, \mathrm{Mn}$, and $\mathrm{Zn}$, and correlate strongly with concentrations of $\mathrm{CO}, \mathrm{NO}$, and $\mathrm{NO}_{2}$. According to the U.S. EPA's $2001 \mathrm{TRI}$ for air emissions, the primary metals industry accounts for $93 \%$ of $\mathrm{Zn}$ emissions and $83 \%$ of $\mathrm{Mn}$ emissions from stationary sources in Jefferson County, $\mathrm{OH}$, where Steubenville is located. (Although not reported to the TRI, substantial Fe emissions would also be expected from these facilities). The approximate ratio of the mass of $\mathrm{Mn}$ to the mass of $\mathrm{Zn}$ emitted by these facilities is 0.16 based upon the TRI data. $\mathrm{Mn} / \mathrm{Zn}$ ratios computed for Unmix Solution \#2, Source 2, and Unmix Solution \#3, Source 4 of 0.18 and 0.20 , respectively, agree remarkably well with the TRI value of 0.16 . Moreover, as shown in Table 44, these two source factors correlated more strongly than any of the other Unmix source factors with estimated concentrations of $\mathrm{PM}_{2.5}$ from local sources in the immediate Steubenville vicinity. Hence, they likely represent the contribution of the local iron and steel industry to ambient $\mathrm{PM}_{2.5}$ concentrations in Steubenville. The total average $\mathrm{PM}_{2.5}$ mass contributions of $2.2 \mu \mathrm{g} / \mathrm{m}^{3}$ and $1.3 \mu \mathrm{g} / \mathrm{m}^{3}$ estimated for Unmix Solution \#2, Source 2, and Unmix Solution \#3, Source 4, respectively (average of these two solutions $=1.8 \mu \mathrm{g} / \mathrm{m}^{3}$ ), are comparable to the contribution of $1.8 \mu \mathrm{g} / \mathrm{m}^{3}$ estimated for PMF Factor 3, which is likewise believed to represent local iron and steel emissions.

Other common sources resolved by both the Unmix and PMF models are as follows:

- A source enriched in $\mathrm{Pb}$, which contributed an estimated $0.6 \mu \mathrm{g} / \mathrm{m}^{3}$ (PMF Source 6) to $1.2 \mu \mathrm{g} / \mathrm{m}^{3}$ (Unmix Solution \#1, Source 3) to the total mass of $\mathrm{PM}_{2.5}$ in Steubenville. As discussed in the previous subsection, the PMF source profile and PSCF results suggest that this source includes contributions from various nonferrous metal smelting and processing plants and other industrial facilities located in southwestern Pennsylvania, northern West Virginia, and eastern Ohio.

- A nitrate-dominated source (PMF Source 4; Unmix Solution \#1, Source 2; Unmix Solution \#2, Source 1), which contributed an estimated $2.7-3.6 \mu \mathrm{g} / \mathrm{m}^{3}$ to the total mass of $\mathrm{PM}_{2.5}$ in Steubenville and, as shown in Figures 54 and 56, exhibited the expected seasonal trend of greater wintertime contributions and lesser summertime contributions. 
- A source enriched in Se, which contributed an estimated $0.6 \mu \mathrm{g} / \mathrm{m}^{3}$ (PMF Source 7) to $1.0 \mu \mathrm{g} / \mathrm{m}^{3}$ (Unmix Solution \#2, Source 4) to the total mass of $\mathrm{PM}_{2.5}$ in Steubenville and, as shown in Table 43 and Appendix $\mathrm{D}$, correlated well with $\mathrm{SO}_{2}$ and $\mathrm{NO}_{2}$. Per the discussion in the previous section, this source likely represents the contribution of primary coal combustion emissions to $\mathrm{PM}_{2.5}$ in Steubenville.

The remaining two PMF sources, the vehicular / local carbon source (Source 2) and the crustal source (Source 5), were not clearly resolved by the three best five-source Unmix solutions. The lack of a clearly resolved vehicular source in the Unmix solutions is not surprising, because the Unmix model runs that produced these solutions included neither EC nor $\mathrm{Ba}$, two of the important tracers used by PMF to resolve this source. The lack of a clearly resolved crustal source in the Unmix solutions is also not surprising, because the Unmix model specifications each included only one or two of the five major species ( $\mathrm{Al}, \mathrm{Ca}, \mathrm{K}, \mathrm{Mg}, \mathrm{Ti}$ ) that were abundant in the PMF crustal source. These species cannot be expected to individually serve as tracers for a unique crustal source, because they are each found in significant quantities in the compositional profiles of a number of other sources. Two of the Unmix sources, however, appear to represent a blending of vehicular / local carbon particles and crustal particles. These are Unmix Solution \#2, Source 3, which correlated moderately with PMF Sources 2 and $5\left(r_{s}=0.63\right.$ and 0.58 , respectively) and was enriched in $\mathrm{OM}$ and $\mathrm{K}$, and Unmix Solution \#1, Source 4, which also correlated moderately with both of these PMF sources $\left(r_{s}=0.51-0.52\right)$ and was enriched in OM, $\mathrm{Al}$, and $\mathrm{K}$. The estimated contributions of these Unmix sources to total $\mathrm{PM}_{2.5}$ mass were within $25 \%$ of the combined estimated mass contribution of PMF Sources 2 and 5.

Hence, the Unmix results, although limited by their inability to utilize all of the available $\mathrm{PM}_{2.5}$ speciation data from the central Steubenville site, confirm the reasonableness of the seven sources resolved by PMF. Results from both source apportionment models confirm the existence of distinct regional and local source mechanisms that contribute to ambient $\mathrm{PM}_{2.5}$ concentrations in Steubenville, consistent with the case studies presented earlier in this report. These mechanisms will need to be considered independently when developing an implementation plan for Steubenville. The various model runs concur that regional, secondarysulfate dominated $\mathrm{PM}_{2.5}$ is the largest contributor to total $\mathrm{PM}_{2.5}$ mass in Steubenville. These secondary sulfates likely originate primarily from $\mathrm{SO}_{2}$ emitted by coal-fired power plants (and other more minor sources) in the eastern United States. However, source apportionment results suggest that primary particle emissions from coal-fired power plants contribute very little (i.e., $\leq 1 \mu \mathrm{g} / \mathrm{m}^{3}$ ) to total $\mathrm{PM}_{2.5}$ mass in Steubenville. Local sources, including motor vehicles and iron and steel facilities, also contribute appreciably to $\mathrm{PM}_{2.5}$ mass concentrations in the immediate Steubenville vicinity. Unlike secondary sulfate particles, the particles produced by these sources are enriched in carbon species and metals such as $\mathrm{Fe}, \mathrm{Mn}$, and $\mathrm{Zn}$, and elevated concentrations of these particles tend to be accompanied by elevated concentrations of primary pollutant gases such as $\mathrm{NO}_{2}$ and $\mathrm{CO}$. Further research is recommended to elucidate possible differences in the health implications of these chemically dissimilar types of particles.

\subsection{Indoor and Personal Exposure Program}

\subsubsection{Older Adult Cohort}

\subsubsection{Participant Summary and Characteristics}

Twenty-eight subjects ( 25 female, 3 male) were involved in the indoor and personal monitoring components of the study. The average age was 71.8 years (range: $53-90$ years). No 
participants were current smokers, although four participants reported guests or family visitors who smoked occasionally.

\subsubsection{Housing Summary and Characteristics}

Results from the one-time dwelling questionnaire are presented in Table 45. About half of the subjects lived in the Kennedy complex, and approximately one-sixth lived in each of the other apartment complexes and in other houses. Locations of the apartment complexes relative to the SCAMP central ambient air monitoring site are shown in Figure 57.

Table 45. Housing characteristics for the older adult cohort.

\begin{tabular}{|l|l|c|c|c|c|}
\hline \multirow{4}{*}{$\begin{array}{c}\text { Building } \\
\text { Characteristics }\end{array}$} & Apartment & E & G & K & O \\
\cline { 2 - 6 } & Subjects & 5 & 4 & 15 & 4 \\
\cline { 2 - 6 } & Date Built (year) & 1962 & 1975 & 1964 & $\mathrm{n} / \mathrm{a}$ \\
\cline { 2 - 6 } & Units & 88 & 100 & 155 & $\mathrm{n} / \mathrm{a}$ \\
\hline \multirow{5}{*}{ Ventilation } & Floors & 6 & 8 & 9 & 2 \\
\cline { 2 - 6 } & AC & 4 & 4 & 14 & 3 \\
\cline { 2 - 6 } & Whole House Fan & 0 & 0 & 0 & 1 \\
\cline { 2 - 6 } & Indoor Fan, Summer & 4 & 3 & 14 & 2 \\
\cline { 2 - 6 } & Indoor Fan, Fall & 3 & 2 & 7 & 4 \\
\hline \multirow{5}{*}{ Heat Source } & Radiator & 5 & 0 & 15 & 3 \\
\cline { 2 - 6 } & Forced Air & 0 & 0 & 0 & 2 \\
\cline { 2 - 6 } & Open Stove & 0 & 0 & 0 & 1 \\
\cline { 2 - 6 } & Electric Heater & 0 & 4 & 0 & 1 \\
\cline { 2 - 6 } & Gas Heater & 0 & 0 & 0 & 1 \\
\cline { 2 - 6 } & Fireplace & 0 & 0 & 0 & 1 \\
\hline \multirow{4}{*}{ Cooking Fuel } & Electric & 0 & 4 & 15 & 1 \\
\cline { 2 - 6 } & Gas & 5 & 0 & 0 & 3 \\
\hline
\end{tabular}

${ }^{*} \mathrm{E}=$ Elmer White, $\mathrm{G}=$ Gaylord, $\mathrm{K}=\mathrm{J} . \mathrm{F}$. Kennedy, O = other homes. Data obtained from housing questionnaires. Values for ventilation, heating source, and cooking fuel expressed as number of participants.

Air conditioning was present in the majority of buildings, whereas whole house fans were rare, and indoor fans were more prevalent in the summer compared to the fall. Gas stoves were prevalent in the Elmer White building and in other homes, and electric stoves were found in the Gaylord and Kennedy apartments. Heat was primarily dissipated via radiators, except in the Gaylord apartments where electric heaters were used.

\subsubsection{Time-Activity Data Summary}

Results from the time-activity questionnaires are summarized in Tables 46 through 49 . Table 46 displays statistics for the number of 30-minute segments per personal sampling day spent in various locations. During both seasons, participants spent the majority of segments in the home, although more time was spent at home during the fall season. This difference is 
accounted for by more segments being spent outdoors in the summer. Other significant locations frequented during the summer season included others' homes, the apartment's community room, church, and other public buildings. In the fall, others' homes, public buildings, and health testing rooms were frequently visited, as were outdoor locations.

Table 46. Average number of 30-minute segments per day spent in various locations for the older adult cohort.* $^{*}$

\begin{tabular}{|c|c|c|c|c|c|c|c|c|c|c|c|}
\hline \multirow{2}{*}{$\begin{array}{l}\text { General } \\
\text { Location }\end{array}$} & \multirow{2}{*}{$\begin{array}{l}\text { Specific } \\
\text { Location }\end{array}$} & \multicolumn{5}{|c|}{ Summer } & \multicolumn{5}{|c|}{ Fall } \\
\hline & & Mean & SD & Median & Min & Max & Mean & SD & Median & Min & Max \\
\hline Own Home & Indoors at Home & 31.6 & 8.1 & 34.8 & 15.0 & 40.6 & 36.5 & 5.5 & 35.8 & 28.8 & 46.7 \\
\hline \multirow{6}{*}{$\begin{array}{l}\text { Other's } \\
\text { Home }\end{array}$} & Same Building & 1.2 & 0.7 & 1.2 & 0.6 & 1.7 & 1.5 & 1.4 & 0.8 & 0.6 & 3.1 \\
\hline & Laundry Room & 0.3 & 0.4 & 0.2 & 0.0 & 0.9 & 0.7 & 0.5 & 0.8 & 0.1 & 1.4 \\
\hline & $\begin{array}{l}\text { Community } \\
\text { Room }\end{array}$ & 1.4 & 1.8 & 0.4 & 0.1 & 4.7 & 2.3 & 3.0 & 1.0 & 0.0 & 8.4 \\
\hline & Indoor Lobby & 0.5 & 0.3 & 0.5 & 0.0 & 1.0 & 0.9 & 1.2 & 0.4 & 0.0 & 3.5 \\
\hline & Hallway & 0.3 & 0.4 & 0.2 & 0.0 & 1.0 & 0.3 & 0.2 & 0.3 & 0.1 & 0.5 \\
\hline & $\begin{array}{l}\text { Health Testing } \\
\text { Room }\end{array}$ & 0.9 & 0.2 & 1.0 & 0.7 & 1.2 & 0.9 & 0.2 & 0.9 & 0.7 & 1.2 \\
\hline \multirow{4}{*}{ Transit } & Car & 0.9 & 1.2 & 0.4 & 0.0 & 3.1 & 0.9 & 0.8 & 0.6 & 0.1 & 2.6 \\
\hline & Truck & & & & & & 0.8 & 0.6 & 1.0 & 0.1 & 1.3 \\
\hline & Bus & 0.1 & 0.1 & 0.1 & 0.0 & 0.3 & 0.2 & 0.1 & 0.2 & 0.2 & 0.3 \\
\hline & Walking & 0.1 & & 0.1 & 0.1 & 0.1 & 0.5 & 0.6 & 0.4 & 0.0 & 1.3 \\
\hline \multirow{7}{*}{ Other Indoor } & $\begin{array}{l}\text { Different } \\
\text { Building }\end{array}$ & 1.4 & 2.3 & 0.6 & 0.1 & 6.0 & 1.7 & 2.1 & 0.9 & 0.0 & 5.6 \\
\hline & Public Building & 1.1 & 1.0 & 0.8 & 0.0 & 3.3 & 1.1 & 1.0 & 0.8 & 0.0 & 3.3 \\
\hline & Bar/Night Club & 0.3 & 0.2 & 0.3 & 0.2 & 0.5 & 0.4 & 0.1 & 0.4 & 0.4 & 0.5 \\
\hline & Health Care & 0.5 & 0.8 & 0.2 & 0.0 & 2.1 & 1.0 & 1.5 & 0.5 & 0.1 & 3.7 \\
\hline & Beauty Parlor & 0.0 & & 0.0 & 0.0 & 0.0 & 0.1 & 0.0 & 0.1 & 0.0 & 0.1 \\
\hline & Restroom & 0.5 & 0.6 & 0.2 & 0.1 & 1.4 & 0.3 & 0.2 & 0.3 & 0.0 & 0.5 \\
\hline & Church & 1.2 & 1.5 & 0.5 & 0.0 & 2.9 & 0.7 & 0.6 & 0.6 & 0.1 & 1.4 \\
\hline \multirow{4}{*}{$\begin{array}{l}\text { Outdoors } \\
\text { (Not Home) }\end{array}$} & Other Outside & & & & & & 0.2 & & 0.2 & 0.2 & 0.2 \\
\hline & $\begin{array}{l}\text { Sidewalk/Street, } \\
\text { Parking Lot }\end{array}$ & 0.0 & 0.0 & 0.0 & 0.0 & 0.0 & 0.1 & & 0.1 & 0.1 & 0.1 \\
\hline & $\begin{array}{l}\text { Park, Pool, } \\
\text { River, Lake }\end{array}$ & 0.9 & & 0.9 & 0.9 & 0.9 & & & & & \\
\hline & $\begin{array}{l}\text { Yard/Patio/Other } \\
\text { Outside }\end{array}$ & 0.3 & 0.0 & 0.3 & 0.3 & 0.3 & 0.4 & & 0.4 & 0.4 & 0.4 \\
\hline \multirow{4}{*}{$\begin{array}{l}\text { Outdoors } \\
\text { (Near Home) }\end{array}$} & Other Outside & & & & & & 0.7 & 0.4 & 0.7 & 0.4 & 1.0 \\
\hline & Sidewalk/Street & 2.1 & 3.3 & 0.8 & 0.1 & 8.7 & 0.6 & 0.5 & 0.5 & 0.2 & 1.4 \\
\hline & Parking Lot & 0.0 & & 0.0 & 0.0 & 0.0 & 0.1 & 0.1 & 0.1 & 0.0 & 0.2 \\
\hline & $\begin{array}{l}\text { Yard/Patio/Other } \\
\text { Outside }\end{array}$ & 1.8 & 2.1 & 0.9 & 0.3 & 5.3 & 0.5 & 0.6 & 0.1 & 0.0 & 1.4 \\
\hline
\end{tabular}

${ }^{*}$ Total number of 30-minute segments in a day is 48. Data obtained from participant-completed timeactivity diaries for the ten subjects participating in personal monitoring each season. Five subjects participated in both seasons. Blank cells indicate subjects did not visit the particular location. 


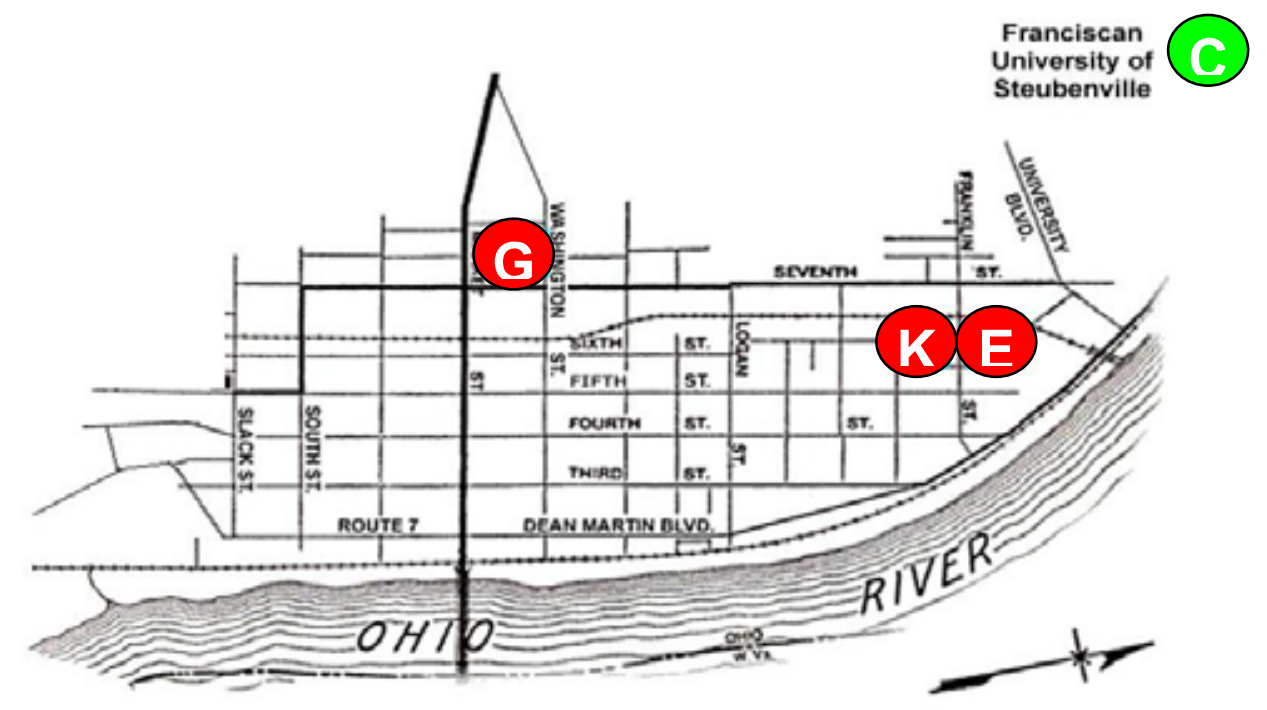

Figure 57. Locations of the apartment complexes where many of the older adult participants resided ("G", "K", "E") and the central ambient air monitoring site ("C") in Steubenville, OH. "G" represents the location of the Gaylord apartment building, "K" the Kennedy apartment building, " $E$ " the Elmer White apartment building, and " $\mathrm{C}$ " the central ambient site located at the Franciscan University of Steubenville.

Table 47 gives the average count of 30-minute segments per sampling day spent doing various activities. Personal needs and care, communications, and household work were the most frequent activities in both the summer and fall. Overall, the personal needs and care category, which included bathing, eating, sleeping, and personal hygiene activities, had the greatest average count, with 17.3 segments per day in the summer and 20.3 in the fall. All categories, with the exception of child care, in transit, and educational, had higher mean counts in the fall season than in the summer season. Median values for the communications, child care, in transit, organizational, and obtaining goods and services activity categories, however, were greater in the summer than in the fall.

Table 47. Average number of 30-minute segments per day spent doing various activities for the older adult cohort.*

\begin{tabular}{|l|c|c|c|c|c|c|c|c|c|c|}
\hline \multirow{2}{*}{ Activity } & \multicolumn{5}{|c|}{ Summer } & \multicolumn{5}{c|}{ Fall } \\
\cline { 2 - 12 } & Mean & SD & Median & Min & Max & Mean & SD & Median & Min & Max \\
\hline Household Work & 2.6 & 1.4 & 3.0 & 0.8 & 4.3 & 4.3 & 3.1 & 4.1 & 0.0 & 9.5 \\
\hline Child Care & 2.6 & 1.8 & 2.6 & 1.3 & 3.8 & 0.5 & 0.4 & 0.3 & 0.2 & 0.9 \\
\hline $\begin{array}{l}\text { Obtaining Goods, } \\
\text { Services }\end{array}$ & 1.1 & 0.8 & 0.9 & 0.3 & 2.7 & 1.3 & 1.3 & 0.8 & 0.3 & 3.8 \\
\hline $\begin{array}{l}\text { Personal Needs and } \\
\text { Care }\end{array}$ & 17.3 & 4.4 & 17.5 & 7.0 & 22.2 & 20.3 & 3.4 & 21.3 & 15.6 & 24.3 \\
\hline Educational & 0.4 & & 0.4 & 0.4 & 0.4 & 0.1 & 0.1 & 0.1 & 0.0 & 0.1 \\
\hline Organizational & 1.3 & 1.3 & 0.9 & 0.0 & 3.4 & 1.4 & 1.7 & 0.6 & 0.0 & 5.3 \\
\hline Entertainment/Social & 1.2 & 0.7 & 1.3 & 0.3 & 2.7 & 2.6 & 2.6 & 1.3 & 0.3 & 6.3 \\
\hline Recreation & 1.1 & 1.0 & 1.2 & 0.0 & 2.4 & 1.5 & 1.1 & 1.8 & 0.1 & 3.6 \\
\hline Communications & 8.6 & 4.3 & 8.2 & 2.9 & 17.0 & 8.8 & 4.5 & 7.7 & 4.3 & 19.4 \\
\hline In Transit & 2.1 & 2.3 & 1.7 & 0.0 & 8.2 & 1.6 & 0.7 & 1.6 & 0.3 & 2.5 \\
\hline
\end{tabular}

${ }^{*}$ Total number of 30-minute segments in a day is 48 . Data obtained from participant-completed timeactivity diaries for the ten subjects participating in personal monitoring each season. Five subjects participated in both seasons. 
The proximity of the monitored individuals to particle sources and the indoor ventilation conditions that they encountered during monitoring were recorded as well. Summary statistics are given in Table 48. Subjects on average spent more time near busy roads and in indoor environments with air conditioners (AC) and open windows in the summer season than they did in the fall season. Subjects on average spent slightly more time near cooking, cleaning, and smoking in the fall season than in the summer season, however. Overall, subjects were in indoor environments with air conditioning and open windows more frequently than they were near busy roads, cooking, cleaning, and smoking.

As shown in Table 49, more time was spent in transit, on average, during the summer as compared to the fall (24.91 versus $19.89 \mathrm{~min} /$ day, respectively). Similarly, subjects spent more time outdoors in the summer, with an average value more than three times as great as that in fall.

Table 48. Proximity to sources/ventilation, average count of 30-minute segments per day for the older adult cohort. ${ }^{*}$

\begin{tabular}{|c|c|c|c|c|c|c|c|c|c|c|}
\hline & \multicolumn{9}{|c|}{ Summer } & \multicolumn{6}{c|}{ Fall } \\
\cline { 2 - 14 } Proximity to: & Mean & SD & Median & Min & Max & Mean & SD & Median & Min & Max \\
\hline Busy Road & 3.3 & 4.1 & 1.7 & 0.5 & 12.9 & 1.3 & 1.0 & 1.0 & 0.2 & 3.2 \\
\hline AC & 17.0 & 11.9 & 17.9 & 2.4 & 31.9 & 5.4 & 6.8 & 3.5 & 0.0 & 19.8 \\
\hline Window & 16.3 & 10.8 & 18.2 & 1.0 & 27.3 & 11.1 & 13.8 & 7.0 & 0.0 & 43.7 \\
\hline Cooking & 1.9 & 1.3 & 1.8 & 0.7 & 5.2 & 3.3 & 2.1 & 3.2 & 0.3 & 6.9 \\
\hline Cleaning & 0.8 & 1.0 & 0.6 & 0.1 & 3.3 & 1.0 & 1.1 & 0.6 & 0.0 & 3.6 \\
\hline Smoker & 0.5 & 0.5 & 0.4 & 0.0 & 1.4 & 0.9 & 1.0 & 0.8 & 0.0 & 3.0 \\
\hline
\end{tabular}

*Total number of 30-minute segments in a day is 48 . Data obtained from participant-completed timeactivity diaries for the ten subjects participating in personal monitoring each season. Five subjects participated in both seasons

Table 49. Average duration ( $\min /$ day) in transit and outdoors $(n=10)$.

\begin{tabular}{|c|c|c|c|c|c|c|c|c|c|c|}
\hline & \multicolumn{4}{|c|}{ Summer } & \multicolumn{5}{c|}{ Fall } \\
\cline { 2 - 11 } Microenvironment & Mean & SD & Median & Min & Max & Mean & SD & Median & Min & Max \\
\hline In Transit & 24.9 & 26.4 & 13.5 & 1.6 & 72.8 & 19.9 & 16.3 & 18.1 & 2.7 & 56.7 \\
\hline Outdoors & 83.9 & 113.3 & 43.2 & 1.1 & 358.0 & 24.6 & 21.0 & 19.6 & 8.7 & 81.5 \\
\hline
\end{tabular}

Note: Data are for 10 subjects each season; 5 subjects participated in both seasons.

\subsubsection{Pollutant Summary}

\subsection{Precision, Accuracy, and Data Completeness}

Sample validity, limits of detection (LOD), completeness, imprecision, and accuracy for pollutant measurements made for the older adult cohort are presented in Table 50. There were 7-22 valid repeated measures per subject per pollutant in the summer season. In the fall, there were 13-24 valid samples per subject for indoor monitoring and 16-24 valid samples for personal monitoring.

Relatively few EC and $\mathrm{NO}_{2}$ samples were below the LODs for these species, whereas a considerable percentage of fall $\mathrm{O}_{3}$ indoor/personal, summer and fall $\mathrm{SO}_{2}$, and summer and fall elemental data were non-detects, thus making their distributions left-censored. This issue was handled by the selection of appropriate statistical analysis techniques (detailed below) and by the insertion of random numbers to represent the noise in the data. Values were randomly chosen from data below the analytical LODs that were collected during a previous field study in 
Baltimore, MD. Two hundred ninety-one, 755, and 10 observations were required for $\mathrm{O}_{3}, \mathrm{SO}_{2}$, and $\mathrm{NO}_{2}$, respectively. In addition, 45 observations were required for EC; these were obtained from a random number generator using a uniform distribution. The random number insertions were verified by conducting three trials. Different combinations of random numbers had no effect on overall pollutant concentrations and other summary statistics.

Table 50. Quality assurance parameters for pollutant data collected for the older adult cohort.

\begin{tabular}{|c|c|c|c|c|c|c|c|c|}
\hline \multirow{3}{*}{ Pollutant } & \multirow[b]{3}{*}{ Season } & \multirow[b]{3}{*}{$\mathbf{N}$} & \multirow{2}{*}{\multicolumn{3}{|c|}{ Field LOD* }} & \multirow[b]{3}{*}{ Completeness } & \multirow[b]{3}{*}{ Imprecision } & \multirow[b]{3}{*}{ Accuracy } \\
\hline & & & & & & & & \\
\hline & & & $\begin{array}{c}\text { Ambient } \\
\text { (Outdoor) }\end{array}$ & Indoor & Personal & & & \\
\hline \multirow{2}{*}{$\mathrm{PM}_{2.5}$} & Summer & 214 & 3.0 & 3.0 & 6.6 & $93 \%$ & $1-2 \%$ & \multirow{2}{*}{$93 \%$} \\
\hline & Fall & 256 & 2.9 & 2.9 & 5.7 & $94 \%$ & $0-2 \%$ & \\
\hline \multirow{2}{*}{$\mathrm{SO}_{4}{ }^{2-}$} & Summer & 106 & 0.2 & 0.3 & 0.4 & $92 \%$ & \multirow{2}{*}{$10.8 \%$} & \multirow{2}{*}{ NA } \\
\hline & Fall & 127 & 0.2 & 0.2 & 0.2 & $93 \%$ & & \\
\hline \multirow{2}{*}{ EC } & Summer & 100 & 0.55 & 0.55 & 0.55 & $90 \%$ & \multirow{2}{*}{$14.5 \%$} & \multirow{2}{*}{ NA } \\
\hline & Fall & 128 & 0.04 & 0.04 & 0.04 & $94 \%$ & & \\
\hline \multirow{2}{*}{$\mathrm{O}_{3}$} & Summer & 98 & 12.7 & 12.7 & 12.7 & $97 \%$ & \multirow{2}{*}{$10.4 \%$} & \multirow{2}{*}{$92 \%$} \\
\hline & Fall & 121 & 10.7 & 10.7 & 10.7 & $99 \%$ & & \\
\hline \multirow{2}{*}{$\mathrm{NO}_{2}$} & Summer & 95 & 10.8 & 10.8 & 10.8 & $96 \%$ & \multirow{2}{*}{$17.0 \%$} & \multirow{2}{*}{$106 \%$} \\
\hline & Fall & 120 & 6.4 & 6.4 & 6.4 & $99 \%$ & & \\
\hline \multirow{2}{*}{$\mathrm{SO}_{2}$} & Summer & 97 & 5.5 & 5.5 & 5.5 & $98 \%$ & \multirow{2}{*}{$24.9 \%$} & \multirow{2}{*}{$73 \%$} \\
\hline & Fall & 121 & 3.8 & 3.8 & 3.8 & $99 \%$ & & \\
\hline
\end{tabular}

"Limit of detection for $\mathrm{PM}_{2.5}, \mathrm{SO}_{4}{ }^{-2}$ and $\mathrm{EC}$ in $\mu \mathrm{g} / \mathrm{m}^{3}$; for gases in $\mathrm{ppb}$; "N" is the number of blanks; $\mathrm{EC}$ LOD was lower in the fall due to the use of a new measurement method for EC; NA = not available.

\subsection{Ambient Concentrations}

Table 51 presents descriptive statistics for ambient pollutant concentrations measured at the central monitoring site on the campus of Franciscan University of Steubenville using the Harvard multi-pollutant monitor. Ambient $\mathrm{PM}_{2.5}$ concentrations were comparable during both of the seasons in which monitoring was conducted, with averages of $20.1( \pm 9.3) \mu \mathrm{g} / \mathrm{m}^{3}$ during the summer and $19.3( \pm 12.2) \mu \mathrm{g} / \mathrm{m}^{3}$ during the fall. Ambient $\mathrm{SO}_{4}{ }^{2-}$ (expressed as ammonium sulfate) comprised a large fraction of the total $\mathrm{PM}_{2.5}$ mass, with contributions of $52 \%$ and $43 \%$ in the summer and fall, respectively. Ambient EC, in contrast, comprised only $6 \%$ of the $\mathrm{PM}_{2.5}$ mass in either season. The composition of $\mathrm{PM}_{2.5}$ reflects the pollutant sources in the Steubenville region, which include numerous coal-fired power plants that contribute to $\mathrm{SO}_{4}{ }^{2-}$, but relatively little motor vehicle traffic, which is a source of EC.

Among the gases, ambient $\mathrm{O}_{3}$ concentrations showed the greatest seasonal differences, with considerably higher mean concentrations during the summer $(29.3 \pm 13.4 \mathrm{ppb})$ as compared to the fall $(16.0 \pm 8.1 \mathrm{ppb})$. The higher summertime concentrations likely reflect the importance of photochemical processes for $\mathrm{O}_{3}$ production. For both $\mathrm{SO}_{2}$ and $\mathrm{NO}_{2}$, mean summer concentrations were low, falling below their respective field LODs, and fall concentrations were slightly higher. 
Table 51. Ambient and outdoor concentrations by season for the older adult cohort.*

\begin{tabular}{|c|c|c|c|c|c|c|c|c|}
\hline Location & Pollutant & Season & $\mathbf{N}$ & \#ND & Mean & Median & SD & Max \\
\hline \multirow{14}{*}{ Ambient } & \multirow{2}{*}{$\mathrm{PM}_{2.5}$} & Summer & 65 & 0 & 20.1 & 18.5 & 9.3 & 46.6 \\
\hline & & Fall & 72 & 0 & 19.3 & 16.1 & 12.2 & 50.7 \\
\hline & \multirow{2}{*}{$\mathrm{SO}_{4}^{-2}$} & Summer & 61 & 0 & 7.7 & 7.2 & 4.8 & 25.0 \\
\hline & & Fall & 72 & 0 & 6.2 & 5.2 & 4.7 & 22.4 \\
\hline & \multirow{2}{*}{ EC } & Summer & 61 & 5 & 1.0 & 1.0 & 0.6 & 2.9 \\
\hline & & Fall & 71 & 0 & 1.1 & 0.9 & 0.7 & 3.6 \\
\hline & \multirow{2}{*}{$\mathrm{O}_{3}$} & Summer & 62 & 0 & 29.3 & 26.4 & 13.4 & 74.8 \\
\hline & & Fall & 72 & 0 & 16.0 & 14.4 & 8.1 & 42.4 \\
\hline & \multirow{2}{*}{$\mathrm{SO}_{2}$} & Summer & 63 & 23 & 2.7 & 2.2 & 3.9 & 21.9 \\
\hline & & Fall & 71 & 24 & 5.4 & 2.6 & 9.6 & 63.6 \\
\hline & \multirow{2}{*}{$\begin{array}{l}\mathrm{SO}_{2}> \\
\mathrm{ND}^{* *}\end{array}$} & Summer & 40 & 0 & 4.6 & 3.7 & 3.6 & 21.9 \\
\hline & & Fall & 47 & 0 & 8.2 & 4.2 & 10.8 & 63.6 \\
\hline & \multirow{2}{*}{$\mathrm{NO}_{2}$} & Summer & 62 & 1 & 9.5 & 8.5 & 7.4 & 37.9 \\
\hline & & Fall & 71 & 0 & 11.3 & 10.1 & 6.0 & 27.9 \\
\hline \multirow{14}{*}{$\begin{array}{l}\text { Kennedy } \\
\text { Roof }\end{array}$} & \multirow{2}{*}{$\mathrm{PM}_{2.5}$} & Summer & 61 & 0 & 21.6 & 21.0 & 9.2 & 47.3 \\
\hline & & Fall & 70 & 0 & 21.1 & 18.0 & 11.8 & 64.7 \\
\hline & \multirow{2}{*}{$\mathrm{SO}_{4}^{-2}$} & Summer & 58 & 0 & 7.7 & 7.2 & 4.3 & 24.4 \\
\hline & & Fall & 69 & 0 & 6.3 & 4.7 & 4.4 & 18.1 \\
\hline & \multirow{2}{*}{ EC } & Summer & 55 & 2 & 1.2 & 1.1 & 0.5 & 2.4 \\
\hline & & Fall & 68 & 0 & 1.3 & 1.2 & 0.7 & 3.8 \\
\hline & \multirow[b]{2}{*}{$\mathrm{O}_{3}$} & Summer & 64 & 0 & 30.6 & 29.0 & 13.5 & 87.3 \\
\hline & & Fall & 71 & 1 & 15.2 & 13.9 & 8.3 & 46.2 \\
\hline & \multirow{2}{*}{$\mathrm{SO}_{2}$} & Summer & 64 & 26 & 2.6 & 1.9 & 3.9 & 22.4 \\
\hline & & Fall & 69 & 17 & 4.4 & 3.5 & 5.9 & 38.1 \\
\hline & \multirow{2}{*}{$\mathrm{SO}_{2}>\mathrm{ND}$} & Summer & 38 & 0 & 4.7 & 3.9 & 3.7 & 22.4 \\
\hline & & Fall & 52 & 0 & 6.0 & 4.0 & 6.0 & 38.1 \\
\hline & \multirow{2}{*}{$\mathrm{NO}_{2}$} & Summer & 64 & 3 & 9.6 & 9.7 & 6.6 & 34.8 \\
\hline & & Fall & 69 & 0 & 12.9 & 11.8 & 5.6 & 26.9 \\
\hline \multirow{14}{*}{$\begin{array}{l}\text { Gaylord } \\
\text { Roof }\end{array}$} & \multirow{2}{*}{$\mathrm{PM}_{2.5}$} & Summer & 30 & 0 & 19.3 & 17.1 & 10.2 & 51.5 \\
\hline & & Fall & 34 & 0 & 19.5 & 17.8 & 11.3 & 61.7 \\
\hline & \multirow{2}{*}{$\mathrm{SO}_{4}^{-2}$} & Summer & 28 & 0 & 7.7 & 6.2 & 5.7 & 26.2 \\
\hline & & Fall & 33 & 0 & 5.9 & 5.1 & 3.7 & 16.5 \\
\hline & \multirow{2}{*}{ EC } & Summer & 25 & 0 & 1.1 & 1.0 & 0.5 & 2.4 \\
\hline & & Fall & 32 & 0 & 1.3 & 1.0 & 0.8 & 3.7 \\
\hline & \multirow{2}{*}{$\mathrm{O}_{3}$} & Summer & 32 & 0 & 31.6 & 30.0 & 10.9 & 60.3 \\
\hline & & Fall & 35 & 1 & 15.4 & 14.3 & 9.2 & 42.9 \\
\hline & \multirow{2}{*}{$\mathrm{SO}_{2}$} & Summer & 32 & 14 & 3.3 & 1.7 & 5.6 & 27.9 \\
\hline & & Fall & 35 & 5 & 5.8 & 3.5 & 7.5 & 37.1 \\
\hline & \multirow{2}{*}{$\mathrm{SO}_{2}>\mathrm{ND}$} & Summer & 18 & 0 & 6.2 & 5.2 & 6.0 & 27.9 \\
\hline & & Fall & 30 & 0 & 6.8 & 4.2 & 7.7 & 37.1 \\
\hline & $\mathrm{NO}_{2}$ & Summer & 32 & 0 & 9.3 & 9.4 & 5.0 & 20.0 \\
\hline & $\mathrm{NVO}_{2}$ & Fall & 35 & 0 & 12.3 & 11.1 & 6.2 & 26.4 \\
\hline
\end{tabular}

${ }^{*} \mathrm{PM}_{2.5}, \mathrm{SO}_{4}{ }^{-2}$ and $\mathrm{EC}$ in $\mu \mathrm{g} / \mathrm{m}^{3}$; gases in $\mathrm{ppb}$

**" $N$ " represents the number of valid samples; "ND" represents the number of samples with concentrations below the analytical detection limits; "SD" is the standard deviation; "max" is the maximum measured concentration. 
Correspondingly, we found significant summertime associations among ambient $\mathrm{PM}_{2.5}, \mathrm{SO}_{4}{ }^{2-}$, and $\mathrm{O}_{3}$ concentrations, which were likely due to the common effects of photochemistry on concentrations of these pollutants. Table 52 shows associations among the ambient pollutants by season. During the fall, associations between ambient particles and $\mathrm{O}_{3}$ were negative, which may be due to meteorological conditions during this season. As discussed earlier in the section describing results from the ambient air monitoring portion of SCAMP, Steubenville experiences considerable inversions during the fall, which can trap $\mathrm{PM}_{2.5}$ and local pollutants close to the ground while preventing mixing with the air aloft containing regional pollutants, such as $\mathrm{O}_{3}$. Associations between ambient particles and $\mathrm{NO}_{2}$ and $\mathrm{SO}_{2}$ were only significant during the fall. In this season, associations between ambient $\mathrm{EC}$ and $\mathrm{NO}_{2}$ concentrations were particularly strong and positive (t-value $=11.39)$. This strong association is likely explained by the fact that both $\mathrm{EC}$ and $\mathrm{NO}_{2}$ are emitted by motor vehicles and other similar sources.

Table 52. Associations (analyzed via mixed models) among ambient pollutants measured at the central Steubenville site during the summer and fall of 2000 using Harvard multi-pollutant monitors. *

\begin{tabular}{|c|c|c|c|c|c|c|c|c|c|c|c|}
\hline \multirow{2}{*}{\multicolumn{2}{|c|}{ Comparison }} & \multicolumn{5}{|c|}{ Summer } & \multicolumn{5}{|c|}{ Fall } \\
\hline & & $\mathbf{N}$ & $\beta$ & SE & t-stat & $\mathbf{R}^{2}$ & $\mathbf{N}$ & $\beta$ & SE & t-stat & $\mathbf{R}^{2}$ \\
\hline $\mathrm{O}_{3}$ & \multirow{3}{*}{$\mathrm{PM}_{2.5}$} & 62 & 0.74 & 0.16 & 4.55 & 0.26 & 72 & -0.2 & 0.08 & -2.41 & 0.07 \\
\hline $\mathrm{NO}_{2}$ & & 62 & -0.01 & 0.11 & -0.1 & 0 & 71 & 0.38 & 0.04 & 9.75 & 0.61 \\
\hline $\mathrm{SO}_{2}$ & & 63 & 0.07 & 0.05 & 1.37 & 0.03 & 71 & 0.4 & 0.1 & 4.14 & 0.22 \\
\hline $\mathrm{O}_{3}$ & \multirow{3}{*}{$\mathrm{SO}_{4}^{2-}$} & 58 & 1.45 & 0.28 & 5.09 & 0.27 & 72 & -0.52 & 0.23 & -2.24 & 0.07 \\
\hline $\mathrm{NO}_{2}$ & & 58 & -0.17 & 0.21 & -0.79 & 0.01 & 71 & 0.96 & 0.12 & 7.9 & 0.49 \\
\hline $\mathrm{SO}_{2}$ & & 59 & 0.18 & 0.11 & 1.66 & 0.05 & 71 & 1.38 & 0.25 & 5.45 & 0.33 \\
\hline $\mathrm{O}_{3}$ & \multirow{3}{*}{$\mathrm{EC}$} & 53 & -6.98 & 3.9 & -1.79 & 0.06 & 71 & -3.18 & 1.44 & -2.2 & 0.06 \\
\hline $\mathrm{NO}_{2}$ & & 53 & 3.76 & 2.19 & 1.72 & 0.06 & 70 & 7.01 & 0.62 & 11.39 & 0.68 \\
\hline $\mathrm{SO}_{2}$ & & 54 & -0.65 & 0.81 & -0.8 & 0.01 & 70 & 9.39 & 1.56 & 6.03 & 0.34 \\
\hline
\end{tabular}

*bold numbers indicate $p$-values less than or equal to 0.05

\subsection{Outdoor Concentrations}

Mean and median outdoor pollutant concentrations were comparable at the Kennedy and Gaylord apartment buildings in both the summer and the fall. In addition, seasonal trends in outdoor pollutant concentrations were comparable at the sites (Table 51). As with the ambient concentrations, mean outdoor $\mathrm{O}_{3}$ concentrations in summer were approximately two times as great as those in fall. For example, at the Kennedy site, the mean summer outdoor $\mathrm{O}_{3}$ concentration was $30.6 \mathrm{ppb}$, while the mean fall concentration was $15.2 \mathrm{ppb}$. Mean and median outdoor $\mathrm{PM}_{2.5}$ and $\mathrm{EC}$ concentrations did not vary seasonally, whereas outdoor $\mathrm{SO}_{4}{ }^{2-}$ concentrations were slightly greater in the summer than in the fall $\left(7.7\right.$ versus $6.3 \mu \mathrm{g} / \mathrm{m}^{3}$, respectively, at the Kennedy site; 7.7 versus $5.9 \mu \mathrm{g} / \mathrm{m}^{3}$, respectively, at the Gaylord site). Mean $\mathrm{SO}_{2}$ and $\mathrm{NO}_{2}$ concentrations, on the other hand, were slightly greater in the fall than in the summer.

Outdoor pollutant concentrations were also comparable to those measured at the central ambient air monitoring site at Franciscan University of Steubenville. Table 53 shows correlations between ambient and outdoor concentrations for each of the major pollutants 
measured using the Harvard multi-pollutant monitors at these sites. Figures 58 through 63 show pollutant-specific scatterplots of ambient vs. outdoor concentrations. A parity line is also shown on each plot for reference. These correlations and scatterplots indicate little spatial variability across the study area in outdoor concentrations of $\mathrm{PM}_{2.5}, \mathrm{SO}_{4}{ }^{2-}$, and $\mathrm{O}_{3}$ in both seasons, and in outdoor concentrations of $\mathrm{EC}$ and $\mathrm{NO}_{2}$, especially during the fall. For these pollutants and seasons, strong correlations justify using the ambient data to represent outdoor concentrations in longitudinal analyses.

Table 53 Correlations between ambient pollutant concentrations at the SCAMP central site and outdoor concentrations measured at apartment complexes in Steubenville using Harvard multi-pollutant monitors in Summer and Fall of 2000.*

\begin{tabular}{|c|c|c|c|c|c|}
\hline \multirow{2}{*}{ Pollutant } & \multirow{2}{*}{ Location } & \multicolumn{2}{|c|}{ Summer } & \multicolumn{2}{|c|}{ Fall } \\
\hline & & Kennedy & Gaylord & Kennedy & Gaylord \\
\hline \multirow{2}{*}{$\mathrm{PM}_{2.5}$} & Ambient & $0.98^{+}$ & $0.94^{+}$ & $0.95^{+}$ & $0.95^{+}$ \\
\hline & Kennedy & & $0.96^{+}$ & & $0.96^{+}$ \\
\hline \multirow{2}{*}{$\mathrm{O}_{3}$} & Ambient & $0.83^{+}$ & $0.82^{+}$ & $0.74^{+}$ & $0.72^{+}$ \\
\hline & Kennedy & & $0.79^{*}$ & & $0.75^{\star}$ \\
\hline \multirow{2}{*}{ EC } & Ambient & $0.53^{+}$ & 0.64 & $0.93^{+}$ & $0.89^{+}$ \\
\hline & Kennedy & & $0.83^{*}$ & & $0.91^{*}$ \\
\hline \multirow{2}{*}{$\mathrm{NO}_{2}$} & Ambient & $0.55^{+}$ & 0.58 & $0.86^{+}$ & $0.73^{+}$ \\
\hline & Kennedy & & $0.68^{*}$ & & $0.65^{*}$ \\
\hline \multirow{2}{*}{$\mathrm{SO}_{4}{ }^{2-}$} & Ambient & $0.91^{+}$ & $0.97^{+}$ & $0.93^{+}$ & $0.95^{+}$ \\
\hline & Kennedy & & $0.98^{*}$ & & $0.88^{*}$ \\
\hline \multirow{2}{*}{$\mathrm{SO}_{2}$} & Ambient & 0.20 & 0.37 & $0.68^{+}$ & $0.81^{+}$ \\
\hline & Kennedy & & 0.41 & & $0.74^{+}$ \\
\hline
\end{tabular}

*bold numbers indicate $p$-values $\leq 0.05$

+ indicate $p$-values $\leq 0.0001$

Note: Kennedy and Gaylord are rooftop concentrations 


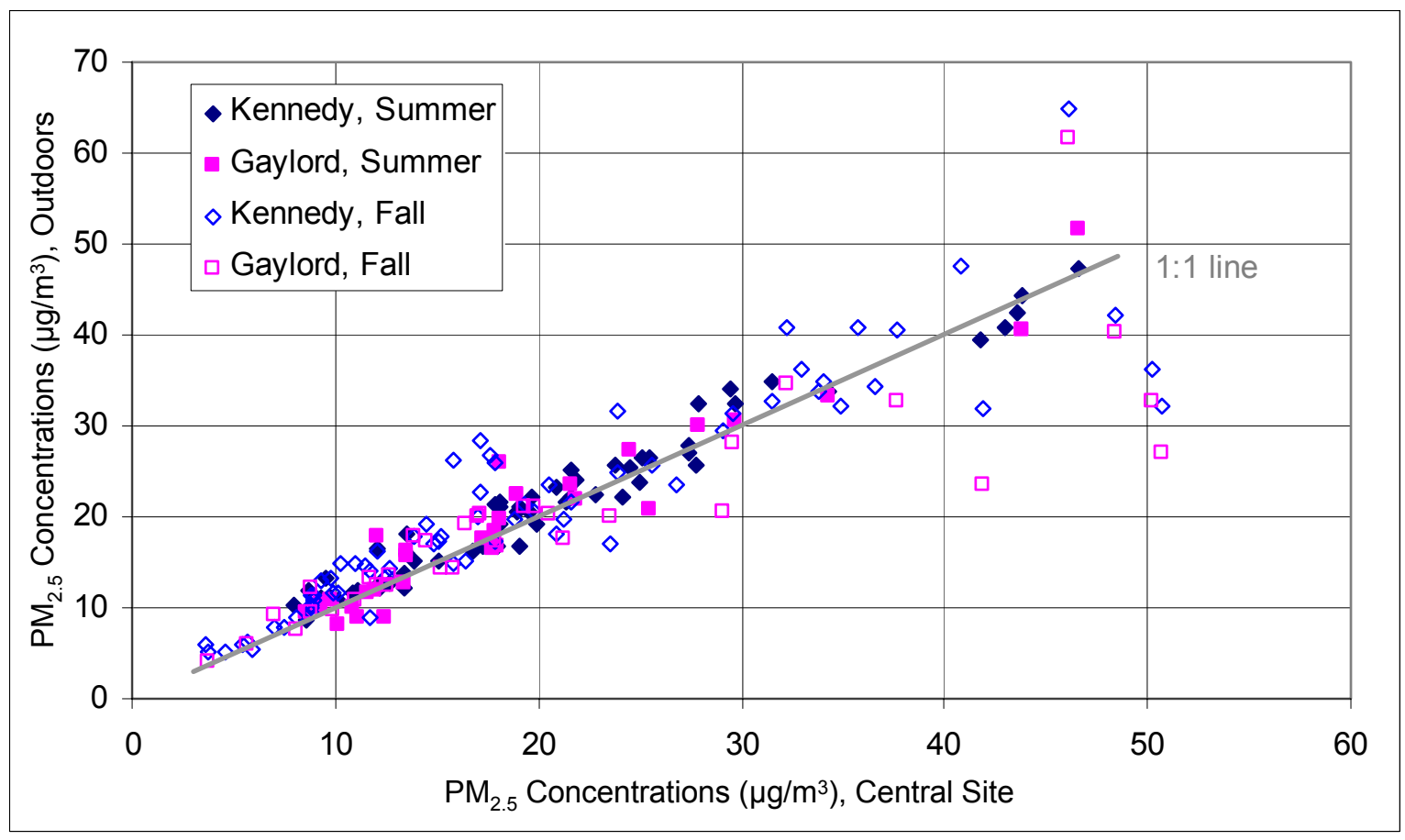

Figure 58. Ambient and outdoor $\mathrm{PM}_{2.5}$ concentrations in Steubenville measured using Harvard multipollutant monitors in the summer and fall of 2000.

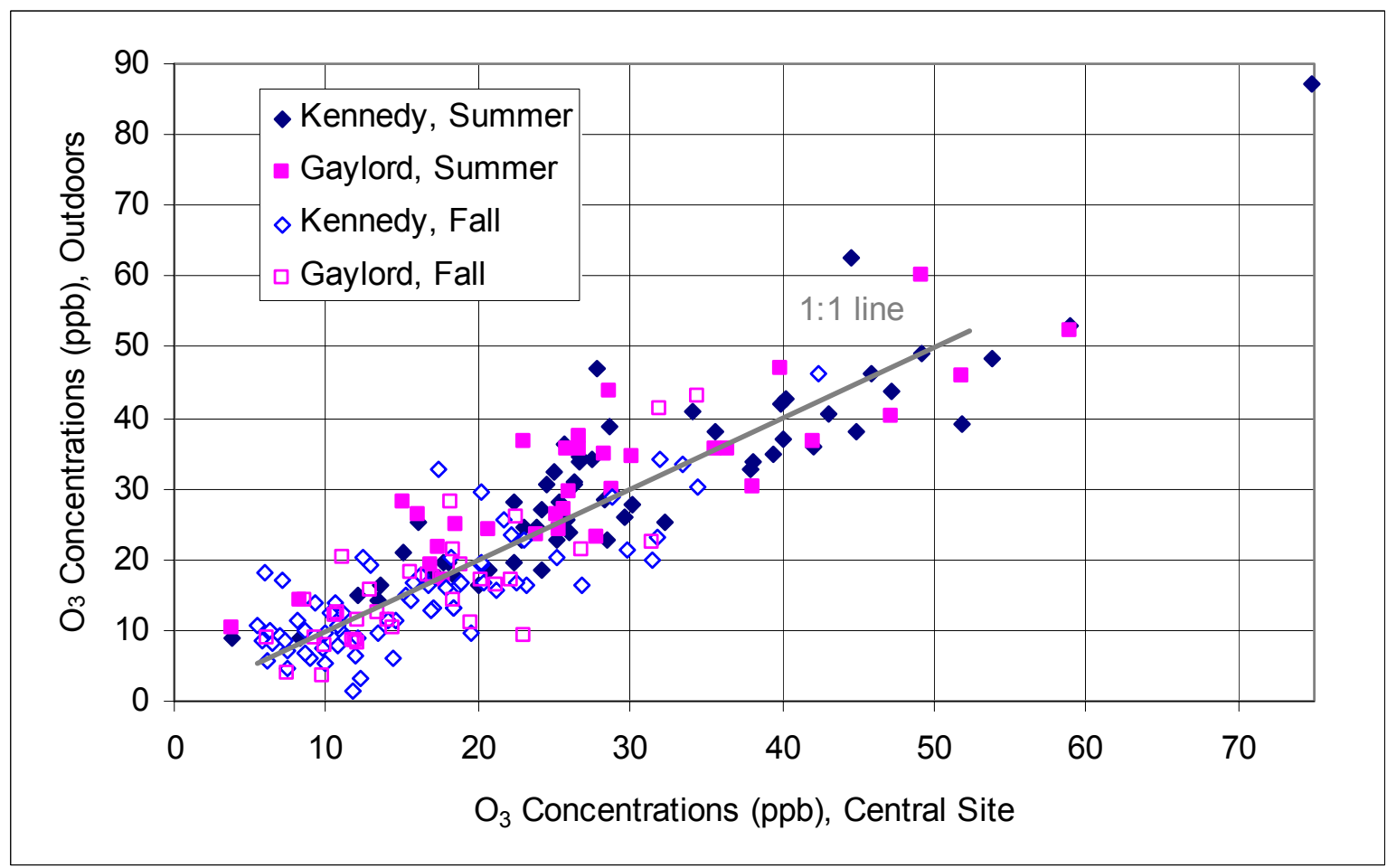

Figure 59. Ambient and outdoor $\mathrm{O}_{3}$ concentrations in Steubenville measured using Harvard multipollutant monitors in the summer and fall of 2000. 


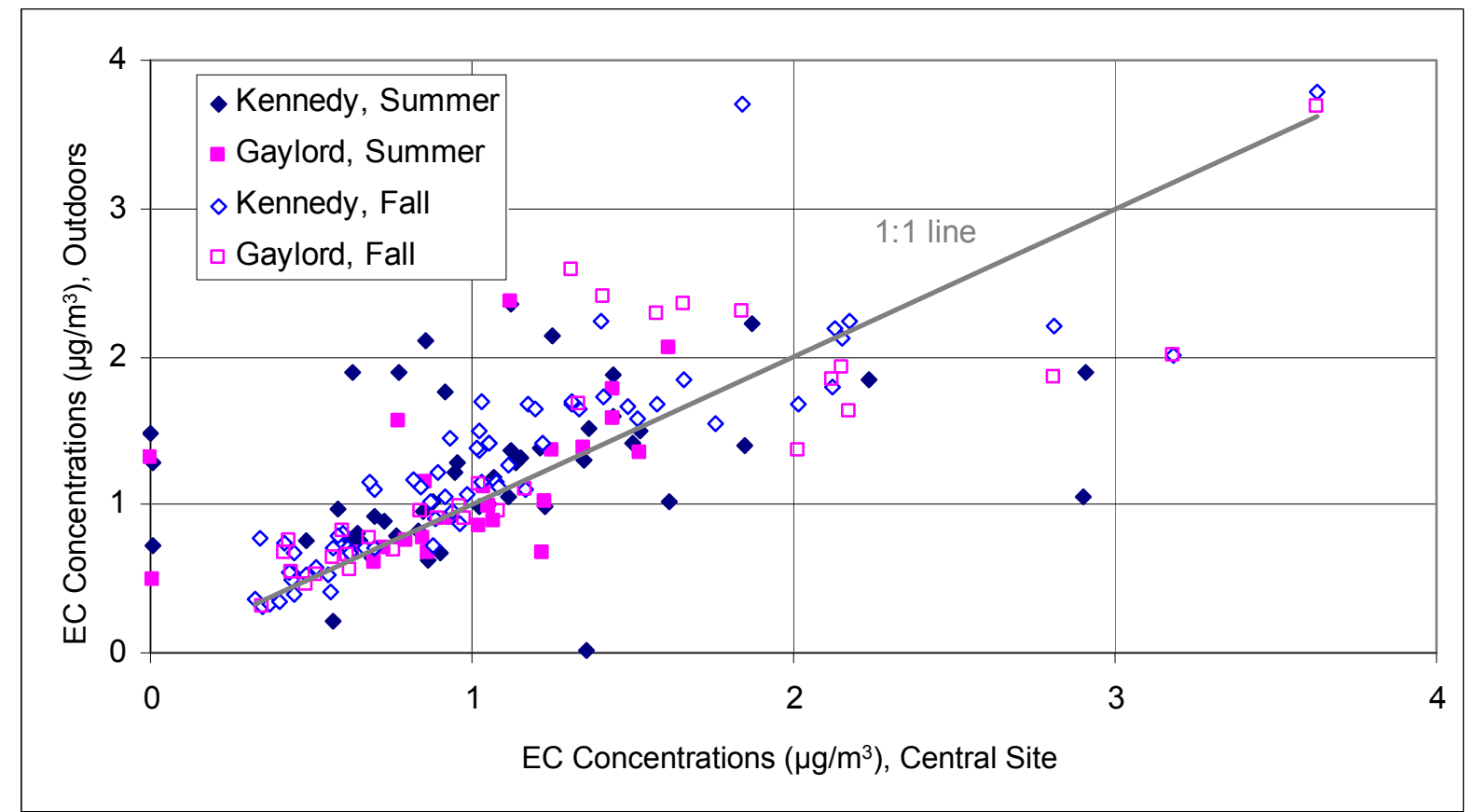

Figure 60. Ambient and outdoor EC concentrations in Steubenville measured using Harvard multipollutant monitors in the summer and fall of 2000.

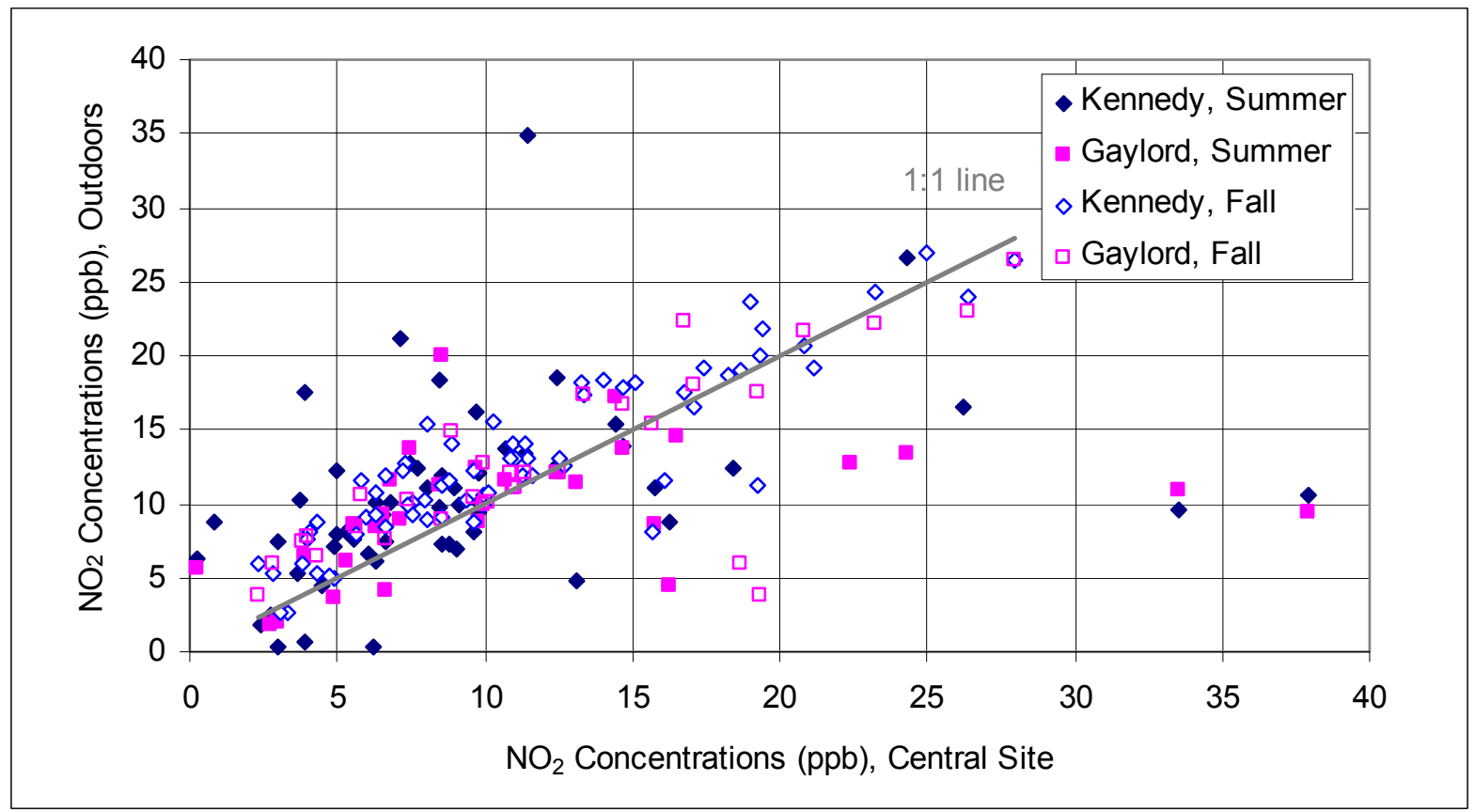

Figure 61. Ambient and outdoor $\mathrm{NO}_{2}$ concentrations in Steubenville measured using Harvard multipollutant monitors in the summer and fall of 2000. 


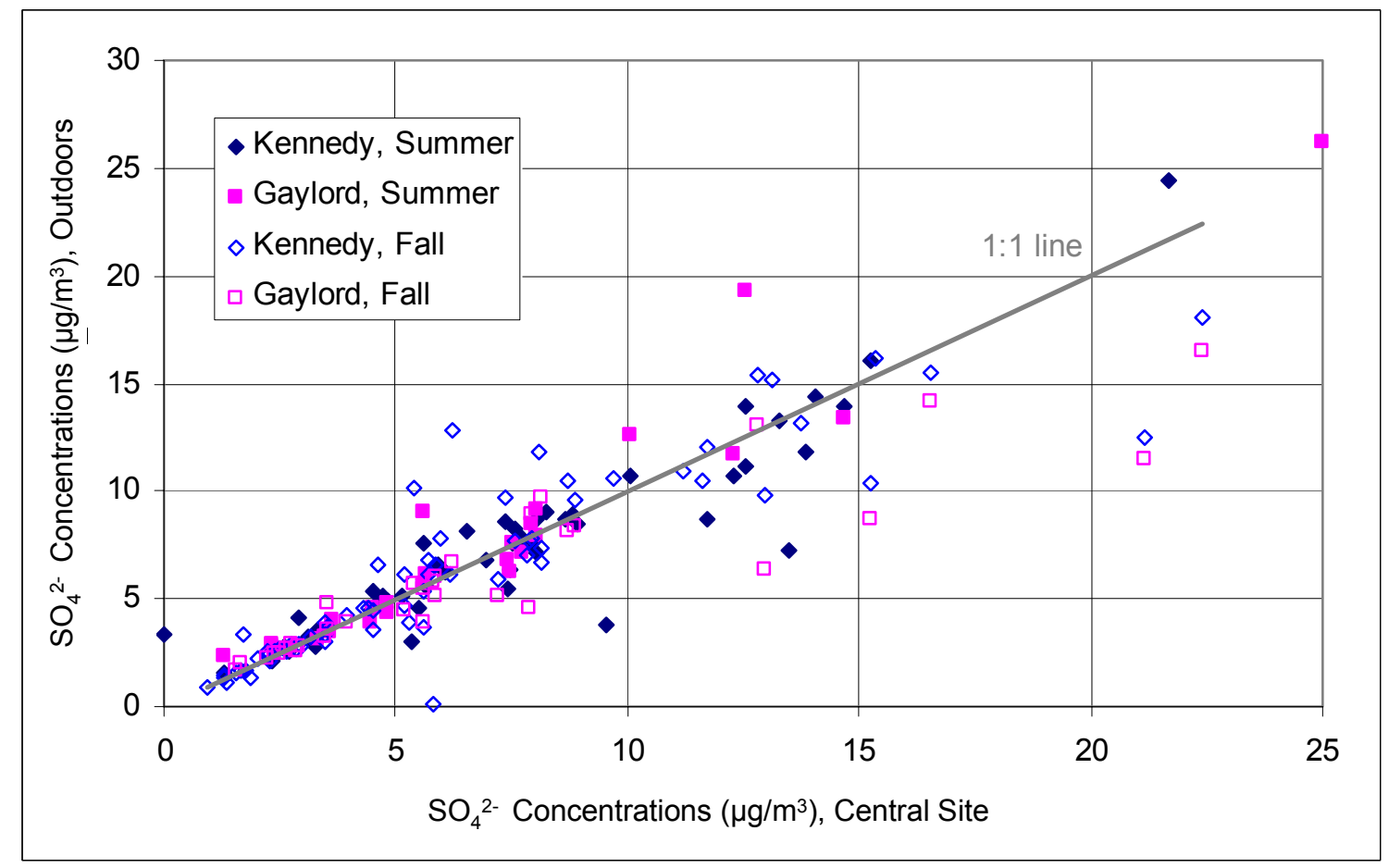

Figure 62. Ambient and outdoor $\mathrm{SO}_{4}{ }^{2-}$ concentrations in Steubenville measured using Harvard multipollutant monitors in the summer and fall of 2000.

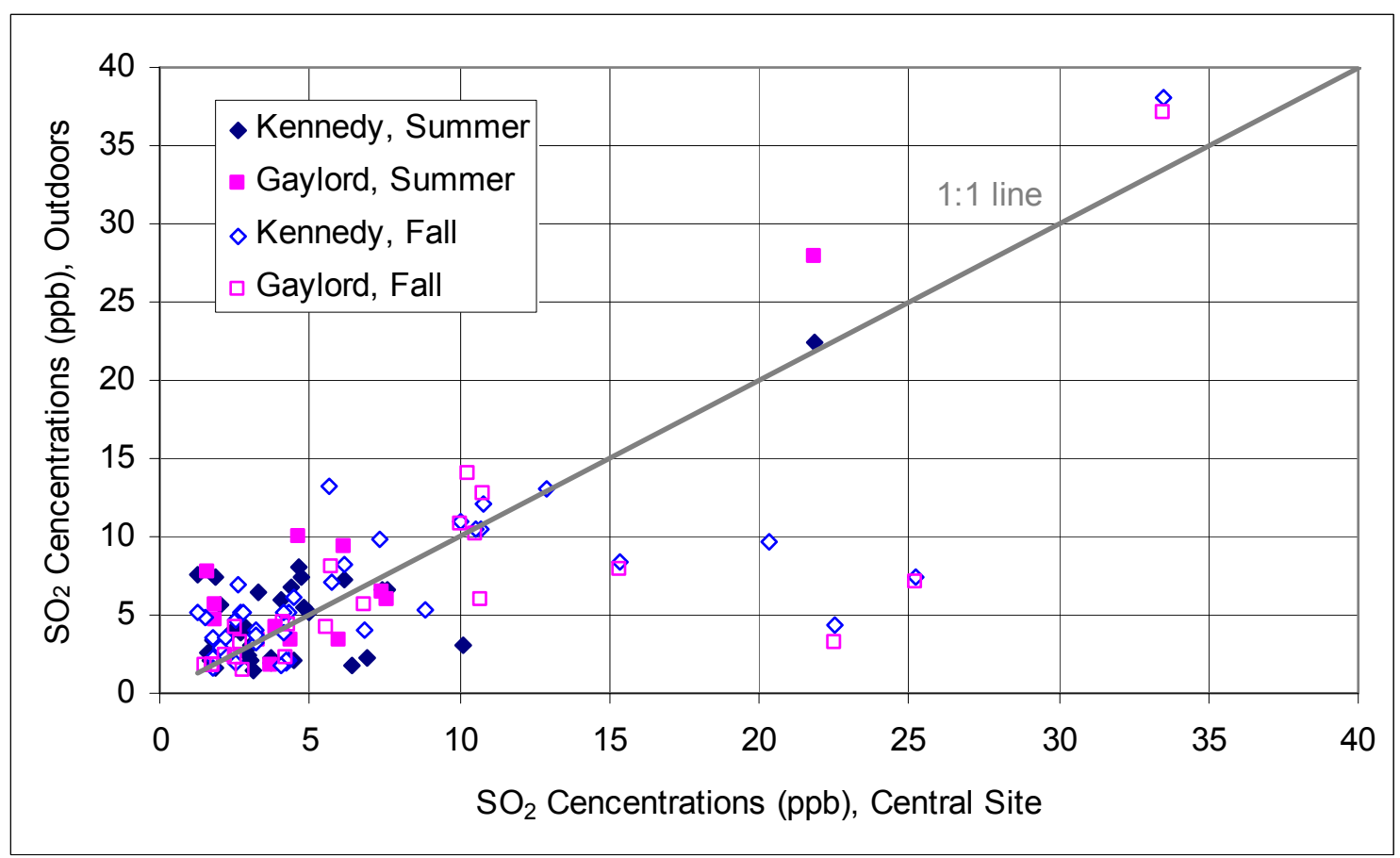

Figure 63. Ambient and outdoor $\mathrm{SO}_{2}$ concentrations in Steubenville measured using Harvard multipollutant monitors in the summer and fall of 2000. 
As would be expected given the similarities between outdoor and ambient pollutant concentrations, associations among the pollutants outside Gaylord and Kennedy buildings were similar to those reported in Table 52 among ambient pollutant concentrations.

\subsection{Personal and Indoor Concentrations}

\subsection{Summary Concentrations}

Summary statistics for personal and indoor concentrations for the older adult cohort are given in Table 54. Means and standard deviations for the indoor and personal microenvironments for all pollutants were comparable. Mean indoor and personal $\mathrm{PM}_{2.5}$, $\mathrm{EC}$, and $\mathrm{NO}_{2}$ concentrations were similar across seasons, while $\mathrm{SO}_{4}{ }^{2-}, \mathrm{O}_{3}$, and $\mathrm{SO}_{2}$ mean indoor and personal levels were higher in the summer than in the fall.

On average, personal $\mathrm{PM}_{2.5}$, EC, and $\mathrm{NO}_{2}$ exposures were slightly higher than corresponding ambient levels. Mean personal/ambient ratios for $\mathrm{PM}_{2.5}$ (ratio $\left.=1.14\right), \mathrm{EC}$ (ratio $\left.=1.15\right)$ and $\mathrm{NO}_{2}$ (ratio $=2.05$ and 1.27, for subjects with and without gas stoves in their homes, respectively) all exceeded 1.00, likely due to influences of indoor sources. For pollutants without significant indoor sources, including $\mathrm{SO}_{4}{ }^{2-}$ and in particular $\mathrm{O}_{3}$, mean personal/ambient ratios were lower than 1.00 (0.75 and 0.24, respectively).

\subsection{Associations among Pollutants}

Tables 55 and 56 display the relationships (by season) among $\mathrm{PM}_{2.5}$ and gas levels for personal exposures and indoor concentrations for the older adult cohort. Personal $\mathrm{PM}_{2.5}$ and $\mathrm{SO}_{4}{ }^{2-}$ (but not personal EC) were significantly associated with personal $\mathrm{O}_{3}$ in both seasons. The slopes describing the summer particle- $\mathrm{O}_{3}$ relationships for personal exposures $\left(0.34\right.$ for $\mathrm{PM}_{2.5}, 0.17$ for $\mathrm{SO}_{4}{ }^{2-}$ ) were similar to the slopes describing corresponding summer relationships among ambient concentrations of these pollutants $\left(0.36\right.$ for $\mathrm{PM}_{2.5}, 0.21$ for $\left.\mathrm{SO}_{4}{ }^{2-}\right)$, although model fits were weaker for personal data. The indoor particle- $\mathrm{O}_{3}$ relationships were similar to those observed for personal exposures. Neither personal nor indoor concentrations of $\mathrm{SO}_{2}$ were associated with any of the personal or indoor particle measures. In the summer, personal $\mathrm{NO}_{2}$ was associated only with personal EC. (This result did not hold for corresponding indoor concentrations, though). In the fall, however, for both indoor and personal exposure measurements, concentrations of $\mathrm{NO}_{2}$ were significantly associated with corresponding concentrations of $\mathrm{PM}_{2.5}, \mathrm{SO}_{4}{ }^{2-}$, and EC. (Note that the personal $\mathrm{SO}_{4}{ }^{2-}-\mathrm{NO}_{2}$ association was significant only when homes with gas stoves were excluded.) This result is similar to that observed among ambient concentrations of these pollutants. The associations among indoor concentrations were stronger than were those among personal exposures (as evidenced by the greater slopes and t-statistics for the indoor associations), which may be a result of indoor sources affecting both indoor particle and indoor $\mathrm{NO}_{2}$ concentrations to a greater extent than they affect personal exposures to these species. 
Table 54. Personal and indoor pollutant concentrations by season for the older adult cohort.*

\begin{tabular}{|c|c|c|c|c|c|c|c|c|}
\hline (2) & Pollutant & Season & $\mathbf{N}$ & \#ND & Mean & Median & SD & Max \\
\hline \multirow{12}{*}{ Personal } & \multirow{2}{*}{$\mathrm{PM}_{2.5}$} & Summer & 169 & 0 & 19.9 & 17.9 & 9.4 & 59 \\
\hline & & Fall & 204 & 0 & 20.1 & 16.8 & 11.6 & 66 \\
\hline & \multirow{2}{*}{$\mathrm{SO}_{4}^{-2}$} & Summer & 165 & 0 & 5.9 & 5 & 4.2 & 25.6 \\
\hline & & Fall & 188 & 0 & 4.4 & 3.4 & 3.3 & 16.3 \\
\hline & \multirow{2}{*}{ EC } & Summer & 166 & 7 & 1.1 & 1 & 0.6 & 4.6 \\
\hline & & Fall & 197 & 1 & 1.2 & 1.1 & 0.7 & 6.2 \\
\hline & \multirow[b]{2}{*}{$\mathrm{O}_{3}$} & Summer & 183 & 2 & 5.3 & 4.3 & 5.2 & 35.7 \\
\hline & & Fall & 226 & 84 & 3.9 & 3.5 & 4.4 & 21.3 \\
\hline & \multirow{2}{*}{$\mathrm{SO}_{2}$} & Summer & 185 & 99 & 1.5 & 1.3 & 3.3 & 30.4 \\
\hline & & Fall & 228 & 72 & 0.7 & 0.4 & 1.9 & 14.2 \\
\hline & \multirow{2}{*}{$\mathrm{NO}_{2}$} & Summer & 183 & 1 & 9.9 & 9 & 6 & 38.9 \\
\hline & & Fall & 228 & 1 & 12.1 & 10.8 & 6.1 & 38.8 \\
\hline \multirow{12}{*}{$\begin{array}{c}\text { Indoor } \\
\text { (subset 10)** }\end{array}$} & \multirow{2}{*}{$\mathrm{PM}_{2.5}$} & Summer & 178 & 0 & 20 & 17.8 & 10.1 & 54.5 \\
\hline & & Fall & 216 & 0 & 19.3 & 15.9 & 12.2 & 79.9 \\
\hline & \multirow{2}{*}{$\mathrm{SO}_{4}^{-2}$} & Summer & 183 & 0 & 6.4 & 5.4 & 4.6 & 26.9 \\
\hline & & Fall & 223 & 0 & 5.1 & 3.9 & 3.9 & 20.8 \\
\hline & \multirow{2}{*}{ EC } & Summer & 179 & 14 & 1 & 1 & 0.5 & 3.7 \\
\hline & & Fall & 223 & 0 & 1.2 & 1.1 & 0.8 & 8.5 \\
\hline & \multirow[b]{2}{*}{$\mathrm{O}_{3}$} & Summer & 190 & 3 & 6.2 & 5.1 & 6 & 41 \\
\hline & & Fall & 228 & 73 & 4.3 & 3.6 & 4.1 & 23.8 \\
\hline & \multirow{2}{*}{$\mathrm{SO}_{2}$} & Summer & 190 & 109 & 1.5 & 1.1 & 2.7 & 18.5 \\
\hline & & Fall & 227 & 74 & 1.1 & 0.7 & 2.3 & 19 \\
\hline & \multirow[b]{2}{*}{$\mathrm{NO}_{2}$} & Summer & 185 & 5 & 11.3 & 9.5 & 7.1 & 38.4 \\
\hline & & Fall & 219 & 1 & 13.2 & 11.9 & 6.8 & 51.9 \\
\hline \multirow{12}{*}{$\begin{array}{l}\text { Indoor } \\
\text { (subset 15) }\end{array}$} & \multirow{2}{*}{$\mathrm{PM}_{2.5}$} & Summer & 291 & 0 & 18.6 & 17.8 & 7.4 & 59.3 \\
\hline & & Fall & 297 & 0 & 19.8 & 16.6 & 14.2 & 131.4 \\
\hline & \multirow{2}{*}{$\mathrm{SO}_{4}^{-2}$} & Summer & 292 & 0 & 6.2 & 5.6 & 3.8 & 21.5 \\
\hline & & Fall & 303 & 0 & 4.8 & 3.5 & 3.8 & 18.9 \\
\hline & \multirow{2}{*}{ EC } & Summer & 285 & 19 & 1 & 1 & 0.5 & 2.9 \\
\hline & & Fall & 311 & 2 & 1.2 & 1.1 & 0.7 & 5.6 \\
\hline & \multirow{2}{*}{$\mathrm{O}_{3}$} & Summer & 296 & 8 & 5.6 & 4.8 & 5.4 & 32.3 \\
\hline & & Fall & 320 & 127 & 3.6 & 3.1 & 4.6 & 27.2 \\
\hline & \multirow{2}{*}{$\mathrm{SO}_{2}$} & Summer & 303 & 169 & 2.1 & 1.1 & 7.3 & 84.1 \\
\hline & & Fall & 320 & 98 & 0.8 & 0.7 & 1.8 & 10.9 \\
\hline & $\mathrm{NO}$ & Summer & 299 & 3 & 10.2 & 9.3 & 8.2 & 61.7 \\
\hline & $\mathrm{NU}_{2}$ & Fall & 308 & 0 & 10.6 & 8.8 & 7.6 & 60.3 \\
\hline & $P M_{2}$ & Summer & 469 & 0 & 19.1 & 17.8 & 8.5 & 59.3 \\
\hline & $\mathrm{PIV}_{2.5}$ & Fall & 513 & 0 & 19.6 & 16.4 & 13.4 & 131.4 \\
\hline & $\mathrm{sO}^{-2}$ & Summer & 475 & 0 & 6.2 & 5.5 & 4.2 & 26.9 \\
\hline & $\mathrm{SO}_{4}$ & Fall & 526 & 0 & 4.9 & 3.6 & 3.8 & 20.8 \\
\hline & $\mathrm{FC}$ & Summer & 464 & 33 & 1 & 1 & 0.5 & 3.7 \\
\hline Indoor & ᄃ乙 & Fall & 534 & 2 & 1.2 & 1.1 & 0.7 & 8.5 \\
\hline (All) & مि & Summer & 486 & 11 & 5.8 & 4.9 & 5.7 & 41 \\
\hline & $O_{3}$ & Fall & 548 & 200 & 3.9 & 3.3 & 4.4 & 27.2 \\
\hline & & Summer & 493 & 278 & 1.9 & 1.1 & 6 & 84.1 \\
\hline & $\mathrm{SO}_{2}$ & Fall & 547 & 172 & 0.9 & 0.7 & 2 & 19 \\
\hline & & Summer & 484 & 8 & 10.6 & 9.3 & 7.8 & 61.7 \\
\hline & $\mathrm{NO}_{2}$ & Fall & 527 & 1 & 11.7 & 10.2 & 7.4 & 60.3 \\
\hline
\end{tabular}

${ }^{*} \mathrm{PM}_{2.5}, \mathrm{SO}_{4}{ }^{2-}$ and $\mathrm{EC}$ in $\mu \mathrm{g} / \mathrm{m}^{3}$; gases in $\mathrm{ppb}$

** "subset 10" includes indoor concentrations for individuals with personal monitoring data; "subset 15" includes indoor concentrations for individuals without personal monitoring data; "All" includes indoor concentrations for every study participant. "N" represents the number of valid samples; "ND" represents the number of samples with concentrations below the analytical detection limits; "SD" is the standard deviation; "max" is the maximum measured concentration. 
Table 55. Associations between personal particle concentrations and personal gas concentrations, by season, for the older adult cohort.*

\begin{tabular}{|c|c|c|c|c|c|c|c|c|c|c|c|}
\hline \multirow{2}{*}{\multicolumn{2}{|c|}{ Comparison }} & \multicolumn{5}{|c|}{ Summer } & \multicolumn{5}{|c|}{ Fall } \\
\hline & & $\mathbf{N}$ & $\beta$ & SE & t-stat & Int. & $\mathbf{N}$ & $\beta$ & SE & t-stat & Int. \\
\hline \multirow{6}{*}{$\mathrm{PM}_{2.5}$} & $\mathrm{O}_{3}$ & 163 & 0.36 & 0.16 & 2.28 & 17.97 & 202 & 0.52 & 0.18 & 2.91 & 18.09 \\
\hline & $\mathrm{O}_{3}>\mathrm{ND}$ & NA & NA & NA & NA & NA & 129 & 0.36 & 0.28 & 1.27 & 20.29 \\
\hline & $\mathrm{SO}_{2}$ & 166 & -0.05 & 0.21 & -0.22 & 19.87 & 204 & -0.47 & 0.41 & -1.13 & 20.42 \\
\hline & $\mathrm{SO}_{2}>\mathrm{ND}$ & 77 & -0.11 & 0.31 & -0.35 & 21.36 & 139 & -0.44 & 0.46 & -0.96 & 19.09 \\
\hline & $\mathrm{NO}_{2}$ & 164 & -0.07 & 0.13 & -0.52 & 20.43 & 204 & 0.37 & 0.13 & 2.73 & 15.54 \\
\hline & $\begin{array}{c}\mathrm{NO}_{2} \\
\text { (no gas stove) }\end{array}$ & 118 & -0.06 & 0.16 & -0.35 & 21.02 & 122 & 0.67 & 0.19 & 3.59 & 12.28 \\
\hline \multirow{6}{*}{$\mathrm{SO}_{4}{ }^{2-}$} & $\mathrm{O}_{3}$ & 159 & 0.17 & 0.04 & 4.9 & 5.03 & 186 & 0.19 & 0.05 & 3.7 & 3.62 \\
\hline & $\mathrm{O}_{3}>\mathrm{ND}$ & NA & NA & NA & NA & NA & 119 & 0.2 & 0.09 & 2.35 & 3.67 \\
\hline & $\mathrm{SO}_{2}$ & 162 & -0.24 & 0.1 & -2.53 & 6.24 & 188 & -0.05 & 0.12 & -0.43 & 4.44 \\
\hline & $\mathrm{SO}_{2}>\mathrm{ND}$ & 74 & -0.15 & 0.11 & -1.4 & 5.96 & 133 & 0.16 & 0.11 & 1.38 & 3.65 \\
\hline & $\mathrm{NO}_{2}$ & 160 & -0.09 & 0.06 & -1.57 & 6.78 & 188 & 0.04 & 0.04 & 1.05 & 3.9 \\
\hline & $\begin{array}{c}\mathrm{NO}_{2} \\
\text { (no gas stove) }\end{array}$ & 113 & -0.1 & 0.07 & -1.42 & 6.81 & 111 & 0.15 & 0.07 & 2.29 & 3.08 \\
\hline \multirow{6}{*}{ EC } & $\mathrm{O}_{3}$ & 160 & -0.02 & 0.01 & -1.7 & 1.15 & 195 & 0.02 & 0.01 & 1.54 & 1.14 \\
\hline & $\mathrm{O}_{3}>\mathrm{ND}$ & NA & NA & NA & NA & NA & 122 & 0.01 & 0.02 & 0.42 & 1.25 \\
\hline & $\mathrm{SO}_{2}$ & 162 & -0.24 & 0.1 & -2.53 & 6.24 & 188 & -0.05 & 0.12 & -0.43 & 4.44 \\
\hline & $\mathrm{SO}_{2}>\mathrm{ND}$ & 74 & -0.15 & 0.11 & -1.4 & 5.96 & 133 & 0.16 & 0.11 & 1.38 & 3.65 \\
\hline & $\mathrm{NO}_{2}$ & 161 & 0.03 & 0.01 & 3.67 & 0.77 & 197 & 0.04 & 0.01 & 4.87 & 0.75 \\
\hline & $\begin{array}{c}\mathrm{NO}_{2} \\
\text { (no gas stove) }\end{array}$ & 114 & 0.04 & 0.01 & 4.02 & 0.73 & 119 & 0.06 & 0.01 & 6.76 & 0.55 \\
\hline
\end{tabular}

* Bold represents $p$-values $\leq 0.05$. "ND" indicates data below detection limit. $\mathrm{NA}=$ not applicable. 
Table 56. Associations between indoor particle concentrations and indoor gas concentrations, by season, for the older adult cohort.*

\begin{tabular}{|c|c|c|c|c|c|c|c|c|c|c|c|c|}
\hline \multirow{2}{*}{\multicolumn{2}{|c|}{ Comparison }} & \multirow[b]{2}{*}{ Cohort } & \multicolumn{5}{|c|}{ Summer } & \multicolumn{5}{|c|}{ Fall } \\
\hline & & & \multirow{2}{*}{$\frac{\mathbf{N}}{175}$} & \multirow{2}{*}{$\frac{\beta}{0.58}$} & \multirow{2}{*}{\begin{tabular}{|c|} 
SE \\
0.15 \\
\end{tabular}} & \multirow{2}{*}{$\frac{\text { t-stat }}{3.97}$} & \multirow{2}{*}{$\begin{array}{c}\text { Int. } \\
16.29\end{array}$} & \multirow{2}{*}{$\frac{\mathbf{N}}{216}$} & \multirow{2}{*}{$\frac{\beta}{0.61}$} & \multirow{2}{*}{$\frac{\text { SE }}{0.19}$} & \multirow{2}{*}{$\frac{t \text {-stat }}{3.14}$} & \multirow{2}{*}{$\begin{array}{c}\text { Int. } \\
16.69\end{array}$} \\
\hline \multirow{18}{*}{$\mathrm{PM}_{2.5}$} & $\mathrm{O}_{3}$ & \multirow{2}{*}{ subset 10} & & & & & & & & & & \\
\hline & $\mathrm{O}_{3}>\mathrm{ND}$ & & $\mathrm{n} / \mathrm{a}$ & $\mathrm{n} / \mathrm{a}$ & $\mathrm{n} / \mathrm{a}$ & $\mathrm{n} / \mathrm{a}$ & $\mathrm{n} / \mathrm{a}$ & 149 & 0.36 & 0.3 & 1.18 & 18.97 \\
\hline & $\mathrm{O}_{3}$ & \multirow{2}{*}{ subset 15} & 283 & 0.35 & 0.09 & 3.96 & 16.71 & 296 & 0.23 & 0.17 & 1.36 & 19.39 \\
\hline & $\mathrm{O}_{3}>\mathrm{ND}$ & & $\mathrm{n} / \mathrm{a}$ & $\mathrm{n} / \mathrm{a}$ & $\mathrm{n} / \mathrm{a}$ & $\mathrm{n} / \mathrm{a}$ & $\mathrm{n} / \mathrm{a}$ & 181 & 0.1 & 0.22 & 0.45 & 20.33 \\
\hline & $\mathrm{O}_{3}$ & \multirow{2}{*}{ All } & 458 & 0.44 & 0.08 & 5.59 & 16.6 & 512 & 0.37 & 0.13 & 2.95 & 18.4 \\
\hline & $\mathrm{O}_{3}>\mathrm{ND}$ & & $\mathrm{n} / \mathrm{a}$ & $\mathrm{n} / \mathrm{a}$ & $\mathrm{n} / \mathrm{a}$ & $\mathrm{n} / \mathrm{a}$ & $\mathrm{n} / \mathrm{a}$ & 330 & 0.2 & 0.18 & 1.09 & 19.8 \\
\hline & $\mathrm{SO}_{2}$ & \multirow{2}{*}{ subset 10} & 175 & 0.21 & 0.27 & 0.78 & 19.65 & 215 & -0.4 & 0.35 & -1.14 & 19.81 \\
\hline & $\mathrm{SO}_{2}>\mathrm{ND}$ & & 80 & 0.45 & 0.46 & 0.98 & 18.76 & 146 & -0.08 & 0.42 & -0.18 & 19.08 \\
\hline & $\mathrm{SO}_{2}$ & \multirow{2}{*}{ subset 15} & 290 & -0.02 & 0.06 & -0.31 & 18.69 & 295 & -0.17 & 0.44 & -0.39 & 20.37 \\
\hline & $\mathrm{SO}_{2}>\mathrm{ND}$ & & 127 & -0.03 & 0.05 & -0.47 & 18.69 & 208 & 0.28 & 0.56 & 0.5 & 18.69 \\
\hline & $\mathrm{SO}_{2}$ & \multirow{2}{*}{ All } & 465 & 0 & 0.06 & -0.05 & 19.17 & 510 & -0.3 & 0.28 & -1.05 & 20.16 \\
\hline & $\mathrm{SO}_{2}>\mathrm{ND}$ & & 207 & -0.01 & 0.07 & -0.15 & 19.32 & 354 & 0.09 & 0.34 & 0.26 & 18.91 \\
\hline & \multirow{3}{*}{$\mathrm{NO}_{2}$} & subset 10 & 175 & 0.23 & 0.11 & 2.05 & 17.38 & 215 & 0.85 & 0.13 & 6.7 & 8.13 \\
\hline & & subset 15 & 288 & -0.08 & 0.05 & -1.52 & 19.48 & 295 & 0.95 & 0.11 & 8.36 & 9.84 \\
\hline & & All & 463 & 0.01 & 0.05 & 0.13 & 19.11 & 510 & 0.9 & 0.08 & 10.64 & 9.15 \\
\hline & \multirow{3}{*}{$\begin{array}{c}\mathrm{NO}_{2} \\
\text { (no gas stove) }\end{array}$} & subset 10 & 119 & 0.1 & 0.15 & 0.69 & 19.34 & 133 & 1.28 & 0.18 & 7.33 & 5.44 \\
\hline & & subset 15 & 228 & -0.05 & 0.06 & -0.9 & 19.25 & 220 & 1.38 & 0.17 & 7.98 & 7.36 \\
\hline & & All & 347 & -0.02 & 0.06 & -0.35 & 19.52 & 353 & 1.32 & 0.12 & 10.68 & 6.87 \\
\hline \multirow{18}{*}{$\mathrm{SO}_{4}^{2-}$} & $\mathrm{O}_{3}$ & subset 10 & 180 & 0.23 & 0.04 & 6.49 & 4.98 & 223 & 0.24 & 0.06 & 4.01 & 4.05 \\
\hline & $\mathrm{O}_{3}>\mathrm{ND}$ & Sel iv & $\mathrm{n} / \mathrm{a}$ & $\mathrm{n} / \mathrm{a}$ & $\mathrm{n} / \mathrm{a}$ & $\mathrm{n} / \mathrm{a}$ & $\mathrm{n} / \mathrm{a}$ & 152 & 0.19 & 0.1 & 1.95 & 4.48 \\
\hline & $\mathrm{O}_{3}$ & & 284 & 0.27 & 0.04 & 6.62 & 4.71 & 302 & 0.18 & 0.05 & 3.98 & 4.16 \\
\hline & $\mathrm{O}_{3}>\mathrm{ND}$ & & $\mathrm{n} / \mathrm{a}$ & $\mathrm{n} / \mathrm{a}$ & $\mathrm{n} / \mathrm{a}$ & $\mathrm{n} / \mathrm{a}$ & $\mathrm{n} / \mathrm{a}$ & 185 & 0.14 & 0.08 & 1.81 & 4.59 \\
\hline & $\mathrm{O}_{3}$ & All & 464 & 0.27 & 0.03 & 8.77 & 4.69 & 525 & 0.2 & 0.04 & 5.49 & 4.15 \\
\hline & $\mathrm{O}_{3}>\mathrm{ND}$ & & $\mathrm{n} / \mathrm{a}$ & $\mathrm{n} / \mathrm{a}$ & $\mathrm{n} / \mathrm{a}$ & $\mathrm{n} / \mathrm{a}$ & $\mathrm{n} / \mathrm{a}$ & 337 & 0.16 & 0.06 & 2.64 & 4.55 \\
\hline & $\mathrm{SO}_{2}$ & & 180 & 0.07 & 0.13 & 0.54 & 6.26 & 222 & -0.16 & 0.11 & -1.48 & 5.3 \\
\hline & $\mathrm{SO}_{2}>\mathrm{ND}$ & & 81 & 0.18 & 0.19 & 0.91 & 5.73 & 151 & 0.02 & 0.11 & 0.19 & 4.63 \\
\hline & $\mathrm{SO}_{2}$ & subset 15 & 291 & -0.03 & 0.03 & -0.87 & 6.25 & 301 & -0.11 & 0.01 & -0.92 & 4.93 \\
\hline & $\mathrm{SO}_{2}>\mathrm{ND}$ & Sunsel Is & 129 & -0.03 & 0.03 & -0.96 & 6.25 & 211 & 0.14 & 0.13 & 1.03 & 4.07 \\
\hline & $\mathrm{SO}_{2}$ & All $>>$ & 471 & -0.02 & 0.03 & -0.54 & 6.28 & 523 & -0.14 & 0.08 & -1.76 & 5.09 \\
\hline & $\mathrm{SO}_{2}>\mathrm{ND}$ & All & 210 & -0.02 & 0.03 & -0.59 & 6.27 & 362 & 0.07 & 0.08 & 0.8 & 4.32 \\
\hline & & subset 10 & 175 & 0.08 & 0.05 & 1.51 & 5.51 & 214 & 0.12 & 0.04 & 2.81 & 3.49 \\
\hline & $\mathrm{NO}_{2}$ & subset 15 & 287 & -0.05 & 0.03 & -1.77 & 6.65 & 291 & 0.22 & 0.03 & 6.32 & 2.51 \\
\hline & & All & 462 & -0.01 & 0.02 & -0.22 & 6.3 & 505 & 0.17 & 0.03 & 6.63 & 2.89 \\
\hline & & subset 10 & 119 & 0 & 0.07 & 0.06 & 6.25 & 132 & 0.41 & 0.07 & 6.01 & 1.11 \\
\hline & $\begin{array}{c}\mathrm{NO}_{2} \\
\text { (no gas stove) }\end{array}$ & subset 15 & 227 & -0.03 & 0.03 & -1.05 & 6.44 & 217 & 0.5 & 0.04 & 11.21 & 0.6 \\
\hline & & All & 346 & -0.02 & 0.03 & -0.79 & 6.4 & 349 & 0.44 & 0.03 & 12.91 & 1 \\
\hline
\end{tabular}


Table 56. (continued)

\begin{tabular}{|c|c|c|c|c|c|c|c|c|c|c|c|c|}
\hline \multirow{2}{*}{\multicolumn{2}{|c|}{ Comparison }} & \multirow[b]{2}{*}{ Cohort } & \multicolumn{5}{|c|}{ Summer } & \multicolumn{5}{|c|}{ Fall } \\
\hline & & & $\mathbf{N}$ & $\beta$ & SE & t-stat & Int. & $\mathbf{N}$ & $\beta$ & SE & t-stat & Int. \\
\hline \multirow{18}{*}{ EC } & $\mathrm{O}_{3}$ & \multirow{2}{*}{ subset 10} & 176 & 0 & 0.01 & -0.64 & 1.04 & 223 & 0.02 & 0.01 & 1.43 & 1.15 \\
\hline & $\mathrm{O}_{3}>\mathrm{ND}$ & & $\mathrm{n} / \mathrm{a}$ & $\mathrm{n} / \mathrm{a}$ & $\mathrm{n} / \mathrm{a}$ & $\mathrm{n} / \mathrm{a}$ & $\mathrm{n} / \mathrm{a}$ & 152 & 0 & 0.02 & 0.16 & 1.28 \\
\hline & $\mathrm{O}_{3}$ & \multirow{2}{*}{ subset 15} & 277 & 0.01 & 0.01 & 1.44 & 0.98 & 310 & 0.01 & 0.01 & 1.39 & 1.13 \\
\hline & $\mathrm{O}_{3}>\mathrm{ND}$ & & $\mathrm{n} / \mathrm{a}$ & $\mathrm{n} / \mathrm{a}$ & $\mathrm{n} / \mathrm{a}$ & $\mathrm{n} / \mathrm{a}$ & $\mathrm{n} / \mathrm{a}$ & 189 & -0.03 & 0.01 & -2.14 & 1.46 \\
\hline & $\mathrm{O}_{3}$ & \multirow{2}{*}{ All } & 453 & 0 & 0 & 0.58 & 1 & 533 & 0.01 & 0.01 & 2.06 & 1.14 \\
\hline & $\mathrm{O}_{3}>\mathrm{ND}$ & & $\mathrm{n} / \mathrm{a}$ & $\mathrm{n} / \mathrm{a}$ & $\mathrm{n} / \mathrm{a}$ & $\mathrm{n} / \mathrm{a}$ & $\mathrm{n} / \mathrm{a}$ & 341 & -0.01 & 0.01 & -1.31 & 1.39 \\
\hline & $\mathrm{SO}_{2}$ & \multirow{2}{*}{ subset 10} & 176 & 0 & 0.02 & 0.25 & 1 & 222 & -0.03 & 0.02 & -1.42 & 1.27 \\
\hline & $\mathrm{SO}_{2}>\mathrm{ND}$ & & 78 & -0.05 & 0.04 & -1.3 & 1.24 & 151 & 0 & 0.03 & -0.09 & 1.14 \\
\hline & $\mathrm{SO}_{2}$ & \multirow{2}{*}{ subset 15} & 284 & 0 & 0 & -0.32 & 1.03 & 309 & -0.04 & 0.02 & -1.7 & 1.21 \\
\hline & $\mathrm{SO}_{2}>\mathrm{ND}$ & & 123 & 0 & 0 & -0.28 & 1.02 & 215 & -0.02 & 0.03 & -0.85 & 1.14 \\
\hline & $\mathrm{SO}_{2}$ & \multirow{2}{*}{ All } & 460 & 0 & 0 & -0.18 & 1.02 & 531 & -0.03 & 0.02 & -2.12 & 1.23 \\
\hline & $\mathrm{SO}_{2}>\mathrm{ND}$ & & 201 & 0 & 0 & -0.55 & 1.04 & 366 & -0.01 & 0.02 & -0.5 & 1.14 \\
\hline & \multirow{3}{*}{$\mathrm{NO}_{2}$} & subset 10 & 171 & 0 & 0.01 & -0.76 & 1.06 & 214 & 0.08 & 0.01 & 10.07 & 0.11 \\
\hline & & subset 15 & 280 & 0 & 0 & 0.85 & 0.99 & 298 & 0.04 & 0.01 & 7.95 & 0.74 \\
\hline & & All & 451 & 0 & 0 & 0.38 & 1 & 512 & 0.06 & 0 & 12.38 & 0.51 \\
\hline & \multirow{3}{*}{$\begin{array}{c}\mathrm{NO}_{2} \\
\text { (no gas stove) }\end{array}$} & subset 10 & 116 & -0.01 & 0.01 & -0.67 & 1.1 & 132 & 0.11 & 0.01 & 12.17 & 0.1 \\
\hline & & subset 15 & 222 & 0 & 0 & 1.01 & 0.98 & 223 & 0.09 & 0.01 & 10.58 & 0.41 \\
\hline & & All & 338 & 0 & 0 & 0.57 & 1 & 355 & 0.09 & 0.01 & 15.96 & 0.29 \\
\hline
\end{tabular}

*bold = p $\leq$ 0.05; "subset 10" includes data for subjects with personal monitoring data; "subset 15" includes data for subjects without personal monitoring data. "N" is the valid sample number; "ND" the number of samples with values below the LOD; "SD" the standard deviation; "t-stat" the t-statistic of the slope.

\subsubsection{Associations among Personal, Indoor, and Ambient Pollutant Concentrations}

\subsection{Personal Exposures vs. Ambient Concentrations}

Table 57 presents the slopes from regressions of ambient concentrations on corresponding personal exposures for $\mathrm{PM}_{2.5}, \mathrm{SO}_{4}{ }^{2-}$, and $\mathrm{EC}$. Associations between ambient $\mathrm{PM}_{2.5}$ concentrations and corresponding personal exposures were strong, with high slopes and tstatistics (t-value > 13.32). The association varied slightly by season, with slopes of $0.73( \pm$ $0.05)$ in the summer and $0.63( \pm 0.05)$ in the fall. Personal-ambient $\mathrm{SO}_{4}{ }^{2-}$ slopes were similar to those for $\mathrm{PM}_{2.5}$ during both seasons (summer slope $=0.74 \pm 0.02$; fall slope $=0.64 \pm 0.02$ ), with stronger associations than those found for $\mathrm{PM}_{2.5}$ (t-value $>26.36$ ). The strong $\mathrm{SO}_{4}{ }^{2-}$ associations are consistent with previous findings (Sarnat et al., 2000; Ebelt et al., 2000) and are likely due to the fact that $\mathrm{SO}_{4}{ }^{2-}$ is a stable particle with few indoor sources. The slope describing the personal-ambient EC association for the fall $(0.69 \pm 0.06)$ was also similar to that for total $\mathrm{PM}_{2.5}$ in the fall, but the slope for $\mathrm{EC}$ in the summer $(0.33 \pm 0.10)$ was substantially lower than that for $\mathrm{PM}_{2.5}$. The lower summertime slope suggests a lower effective penetration efficiency for EC as compared to other particle measures in the summer. Reasons for this lower association are unclear; however, it should be noted that greater noise in the personal and ambient EC measurements during the summer likely decreased the strength of the summertime 
EC association. Summertime EC measurements showed a very high field LOD, which was approximately $50 \%$ as great as mean EC exposures, which likely contributed to the low tstatistic of the personal-ambient EC association during the summer ( $\mathrm{t}$-value $=3.24$ ) as compared to the fall ( $\mathrm{t}$-value $=12.47)$.

For each of the measured gases, slopes of personal-ambient regressions were statistically significant in both seasons, with the exception of summertime $\mathrm{SO}_{2}$. For $\mathrm{O}_{3}$ and $\mathrm{NO}_{2}$, fall slopes were almost two times as great as summer slopes. The personal-ambient $\mathrm{O}_{3}$ slope was 0.15 $( \pm 0.02)$ in the summer and $0.27( \pm 0.03)$ in the fall. For $\mathrm{NO}_{2}$, the summer and fall slopes were $0.25( \pm 0.06)$ and $0.49( \pm 0.05)$, respectively. For all gases in both seasons, however, slopes were generally lower than those found for particles, particularly for $\mathrm{SO}_{2}$.

\subsection{Indoor Concentrations vs. Ambient Concentrations}

For all participants, indoor-ambient slopes were greater in the summer than in the fall for $\mathrm{PM}_{2.5}$, $\mathrm{SO}_{4}{ }^{2-}$, and $\mathrm{SO}_{2}$. Slopes for $\mathrm{EC}, \mathrm{O}_{3}$, and $\mathrm{NO}_{2}$ were greater in the fall than in the summer, with the largest seasonal differences observed for $\mathrm{EC}$ and $\mathrm{NO}_{2}$ (slopes approximately three times greater in fall than in summer). Similar seasonal variability in the relationships between indoor and ambient concentrations was found for all measured pollutants when the data set was limited to individuals participating in personal monitoring, although seasonal differences in the indoorambient associations were even greater for $\mathrm{EC}$ and $\mathrm{NO}_{2}$ when this subset of participants was used. The association between indoor and ambient $\mathrm{NO}_{2}$ concentrations followed a similar seasonal trend for individuals living in homes with and without gas stoves; however, as shown by the lower and less-significant slopes, the indoor-ambient $\mathrm{NO}_{2}$ association was weaker for individuals living in homes with gas stoves than for those living in homes without gas stoves.

When compared to the corresponding associations between personal exposures and ambient concentrations, the associations between indoor and ambient concentrations (for individuals with simultaneous personal monitoring - subset 10 ) were slightly greater for $\mathrm{PM}_{2.5}, \mathrm{SO}_{4}{ }^{2-}, \mathrm{EC}$ (fall), $\mathrm{O}_{3}$ (summer), and $\mathrm{NO}_{2}$ (all homes in fall and homes without gas stoves) (Table 57). Slopes were similar, however, when they were normalized to mean personal or indoor levels. Similar normalized slopes suggest that ambient pollutants predicted personal and indoor levels equally well and suggest a high influence of housing factors on personal exposures. The greater slopes for indoor-ambient as compared to personal-ambient associations for $\mathrm{PM}_{2.5}$ and $\mathrm{SO}_{4}{ }^{2-}$ suggest that individuals spent time in other environments for which the indoor-ambient slopes were lower.

\subsection{Personal Exposures vs. Indoor Concentrations}

All slopes describing personal-indoor associations were significant except for those for $\mathrm{SO}_{2}$ and $\mathrm{NO}_{2}$ (in homes with gas stoves) in the summer season. In both seasons, slopes describing personal-indoor associations tended to be greater than those describing personal-ambient associations. For example, slopes and t-statistics (t-value $>19.44$ ) describing the relationship between personal and indoor $\mathrm{PM}_{2.5}$ were higher when compared to personal-ambient values (Table 57). Similarly, personal-indoor $\mathrm{SO}_{4}{ }^{2-}$ and $\mathrm{EC}$ slopes were greater than corresponding personal-ambient $\mathrm{SO}_{4}{ }^{2-}$; the strengths of the personal-indoor associations for $\mathrm{SO}_{4}{ }^{2-}$ (t-value > 30.6) were even greater than those for $\mathrm{PM}_{2.5}$. These high and significant slopes for the particulate measures indicate that indoor concentrations are strong proxies of corresponding personal particulate exposure. 
Table 57. Comparison of personal-ambient, personal-indoor, and indoor-ambient relationships (by season) for the older adult cohort via mixed models. *

\begin{tabular}{|c|c|c|c|c|c|c|c|c|c|c|c|c|}
\hline \multirow{2}{*}{ Pollutant } & \multirow{2}{*}{ Cohort** } & \multirow{2}{*}{ Comparison } & \multicolumn{5}{|c|}{ Summer } & \multicolumn{5}{|c|}{ Fall } \\
\hline & & & $\mathbf{N}$ & $\beta$ & SE & t-stat & Int. & $\mathbf{N}$ & $\beta$ & SE & t-stat & Int. \\
\hline \multirow{5}{*}{$\mathrm{PM}_{2.5}$} & \multirow{3}{*}{ subset 10} & personal vs. indoor & 155 & 0.83 & 0.03 & 29.28 & 2.80 & 193 & 0.73 & 0.04 & 19.44 & 5.56 \\
\hline & & personal vs. ambient & 167 & 0.73 & 0.05 & 16.08 & 4.83 & 204 & 0.63 & 0.05 & 13.32 & 7.42 \\
\hline & & \multirow{3}{*}{ indoor vs. ambient } & 176 & 0.83 & 0.04 & 21.97 & 2.97 & 216 & 0.70 & 0.05 & 14.70 & 5.68 \\
\hline & subset 15 & & 288 & 0.69 & 0.02 & 30.08 & 4.82 & 297 & 0.60 & 0.05 & 11.44 & 8.08 \\
\hline & all & & 464 & 0.75 & 0.02 & 36.35 & 4.05 & 513 & 0.64 & 0.04 & 17.65 & 7.05 \\
\hline \multirow{5}{*}{$\mathrm{SO}_{4}{ }^{2-}$} & \multirow{3}{*}{ subset 10} & personal vs. indoor & 156 & 0.84 & 0.03 & 30.60 & 0.52 & 183 & 0.88 & 0.02 & 58.36 & 0.03 \\
\hline & & personal vs. ambient & 150 & 0.74 & 0.02 & 32.35 & -0.10 & 188 & 0.64 & 0.02 & 26.36 & 0.45 \\
\hline & & \multirow{3}{*}{ indoor vs. ambient } & 168 & 0.86 & 0.03 & 31.58 & -0.59 & 223 & 0.76 & 0.02 & 31.77 & 0.39 \\
\hline & subset 15 & & 268 & 0.68 & 0.02 & 38.30 & 0.68 & 303 & 0.69 & 0.03 & 27.38 & 0.48 \\
\hline & all & & 436 & 0.75 & 0.02 & 47.79 & 0.18 & 526 & 0.72 & 0.02 & 40.64 & 0.43 \\
\hline \multirow{5}{*}{ EC } & \multirow{3}{*}{ subset 10} & personal vs. indoor & 137 & 0.64 & 0.08 & 7.90 & 0.41 & 191 & 0.75 & 0.02 & 34.89 & 0.27 \\
\hline & & personal vs. ambient $\left(>N D^{\S}\right)$ & 146 & 0.33 & 0.10 & 3.24 & 0.74 & 197 & 0.69 & 0.06 & 12.47 & 0.44 \\
\hline & & \multirow{3}{*}{ indoor vs. ambient (> ND) } & 156 & 0.23 & 0.07 & 3.11 & 0.74 & 223 & 0.83 & 0.06 & 12.93 & 0.32 \\
\hline & subset 15 & & 247 & 0.26 & 0.05 & 4.83 & 0.73 & 311 & 0.67 & 0.04 & 16.58 & 0.42 \\
\hline & all & & 403 & 0.24 & 0.04 & 5.65 & 0.73 & 534 & 0.74 & 0.04 & 20.40 & 0.38 \\
\hline \multirow{5}{*}{$\mathrm{O}_{3}$} & \multirow{3}{*}{ subset 10} & personal vs. indoor & 180 & 0.64 & 0.05 & 12.65 & 1.49 & 117 & 0.58 & 0.08 & 7.28 & 2.68 \\
\hline & & personal vs. ambient & 174 & 0.15 & 0.02 & 7.21 & 0.88 & 226 & 0.27 & 0.03 & 8.64 & -0.30 \\
\hline & & \multirow{3}{*}{ indoor vs. ambient } & 180 & 0.17 & 0.02 & 7.59 & 1.31 & 228 & 0.23 & 0.03 & 7.46 & 0.79 \\
\hline & subset 15 & & 282 & 0.17 & 0.02 & 8.87 & 0.91 & 320 & 0.29 & 0.03 & 10.16 & -0.92 \\
\hline & all & & 462 & 0.17 & 0.01 & 11.66 & 1.07 & 548 & 0.26 & 0.02 & 12.64 & -0.25 \\
\hline \multirow{9}{*}{$\mathrm{SO}_{2}$} & \multirow{5}{*}{ subset 10} & personal vs. indoor & 56 & 0.34 & 0.22 & 1.54 & 2.74 & 131 & 0.49 & 0.05 & 9.52 & 0.55 \\
\hline & & personal vs. ambient & 179 & 0.14 & 0.06 & 2.16 & 1.17 & 227 & 0.10 & 0.01 & 6.92 & 0.25 \\
\hline & & personal vs. ambient (> ND) & 106 & 0.03 & 0.10 & 0.29 & 2.05 & 153 & 0.08 & 0.02 & 4.98 & 0.49 \\
\hline & & indoor vs. ambient & 184 & 0.15 & 0.05 & 3.03 & 1.13 & 226 & 0.09 & 0.02 & 5.26 & 0.66 \\
\hline & & indoor vs. ambient (> ND) & 111 & 0.07 & 0.07 & 1.00 & 1.71 & 152 & 0.08 & 0.02 & 3.35 & 0.92 \\
\hline & \multirow{2}{*}{ subset 15} & indoor vs. ambient & 291 & 0.16 & 0.11 & 1.43 & 1.81 & 318 & 0.02 & 0.01 & 1.73 & 0.74 \\
\hline & & indoor vs. ambient (> ND) & 173 & 0.03 & 0.16 & 0.20 & 2.62 & 216 & -0.01 & 0.01 & -0.88 & 1.31 \\
\hline & \multirow{2}{*}{ all } & indoor vs. ambient & 475 & 0.15 & 0.07 & 2.18 & 1.55 & 544 & 0.05 & 0.01 & 4.84 & 0.71 \\
\hline & & indoor vs. ambient (> ND) & 284 & 0.05 & 0.11 & 0.46 & 2.27 & 368 & 0.02 & 0.01 & 1.87 & 1.16 \\
\hline
\end{tabular}


Table $57 . \quad$ (continued)

\begin{tabular}{|c|c|c|c|c|c|c|c|c|c|c|c|c|}
\hline \multirow{2}{*}{ Pollutant } & \multirow{2}{*}{ Cohort** } & \multirow{2}{*}{ Comparison } & \multicolumn{5}{|c|}{ Summer } & \multicolumn{5}{|c|}{ Fall } \\
\hline & & & $\mathbf{N}$ & $\beta$ & SE & t-stat & Int. & $\mathbf{N}$ & $\beta$ & SE & t-stat & Int. \\
\hline \multirow{15}{*}{$\mathrm{NO}_{2}$} & \multirow{3}{*}{ subset 10} & personal (all) vs. indoor & 174 & 0.23 & 0.06 & 3.78 & 7.45 & 218 & 0.66 & 0.04 & 17.48 & 3.33 \\
\hline & & personal (all) vs. ambient & 173 & 0.23 & 0.05 & 4.67 & 7.62 & 227 & 0.39 & 0.05 & 7.56 & 7.72 \\
\hline & & \multirow{3}{*}{ indoor (all) vs. ambient } & 175 & 0.22 & 0.06 & 3.74 & 9.42 & 218 & 0.43 & 0.05 & 8.11 & 8.43 \\
\hline & subset 15 & & 282 & 0.09 & 0.06 & 1.51 & 9.10 & 306 & 0.38 & 0.04 & 8.52 & 6.55 \\
\hline & all & & 457 & 0.14 & 0.04 & 3.28 & 9.19 & 524 & 0.40 & 0.03 & 11.76 & 7.30 \\
\hline & \multirow{3}{*}{ subset 10} & personal (no gas stove) vs. indoor & 125 & 0.22 & 0.07 & 2.96 & 7.01 & 135 & 0.72 & 0.06 & 11.94 & 2.49 \\
\hline & & personal (no gas stove) vs. ambient & 122 & 0.25 & 0.06 & 4.30 & 6.45 & 138 & 0.49 & 0.05 & 10.09 & 4.27 \\
\hline & & \multirow{3}{*}{ indoor (no gas stove) vs. ambient } & 121 & 0.32 & 0.07 & 4.76 & 6.65 & 135 & 0.59 & 0.04 & 15.28 & 3.57 \\
\hline & subset 15 & & 226 & 0.09 & 0.07 & 1.21 & 8.39 & 230 & 0.35 & 0.03 & 11.37 & 4.33 \\
\hline & all & & 347 & 0.17 & 0.05 & 3.13 & 7.77 & 365 & 0.44 & 0.02 & 17.64 & 4.02 \\
\hline & \multirow{3}{*}{ subset 10} & personal (gas stove) vs. indoor & 49 & 0.17 & 0.11 & 1.50 & 10.00 & 83 & 0.60 & 0.06 & 10.11 & 4.72 \\
\hline & & personal (gas stove) vs. ambient & 51 & 0.19 & 0.09 & 2.03 & 10.25 & 89 & 0.25 & 0.10 & 2.39 & 12.84 \\
\hline & & \multirow{3}{*}{ indoor (gas stove) vs. ambient } & 54 & 0.02 & 0.11 & 0.21 & 15.01 & 83 & 0.18 & 0.12 & 1.56 & 15.88 \\
\hline & subset 15 & & 56 & 0.07 & 0.10 & 0.78 & 12.12 & 76 & 0.44 & 0.15 & 3.02 & 12.62 \\
\hline & all & & 110 & 0.05 & 0.07 & 0.63 & 13.56 & 159 & 0.31 & 0.09 & 3.33 & 14.31 \\
\hline
\end{tabular}

* Tobit model results were similar to mixed model results; bold numbers indicate $p$-values less than or equal to 0.05

** "subset 10" - indoor concentrations for individuals with personal monitoring data; "subset 15" - indoor concentrations for individuals without personal monitoring data; "all” - full cohort; " "ND" - non-detectable concentrations. 
In contrast, the slopes describing personal-indoor gas associations were lower than those describing personal-indoor particle associations, especially for $\mathrm{NO}_{2}$ and $\mathrm{SO}_{2}$ during summertime. These results suggest that indoor concentrations are poorer proxies of corresponding personal exposures for gases than for particles.

\subsection{Cross-Pollutant Associations between Personal Exposures and Ambient Concentrations}

Table 58 shows results from cross-pollutant analyses examining associations between ambient particle concentrations and personal gas exposures. Associations between ambient $\mathrm{PM}_{2.5}$ concentrations and personal gas exposures were significant for $\mathrm{O}_{3}$ in both seasons and for $\mathrm{NO}_{2}$ in the fall. While significant, however, the slopes for the associations were quite low (slopes < 0.17 ) and indicate that 24-hr personal $\mathrm{O}_{3}$ and $\mathrm{NO}_{2}$ exposures increased on average by only 1.1 and $1.7 \mathrm{ppb}$ with every $10 \mu \mathrm{g} / \mathrm{m}^{3}$ increase in ambient $\mathrm{PM}_{2.5}$. Associations were also significant between the specific ambient particle components and personal $\mathrm{O}_{3}$ and $\mathrm{NO}_{2}$ exposures. Ambient particles were not significant predictors of personal $\mathrm{SO}_{2}$ levels.

Table 59 shows results from cross-pollutant analyses examining associations between ambient gas concentrations and personal particle exposures. Associations between ambient $\mathrm{O}_{3}$ concentrations and personal particle exposures were significant in the summer, although the slopes and $R^{2}$ values were low $\left(R^{2}<0.16\right)$. Associations between ambient $\mathrm{NO}_{2}$ concentrations and personal particle exposures were significant in the fall, in particular for EC (t-value $=13.6$, $\mathrm{R}^{2}=0.49$ ). The slopes for the associations with ambient $\mathrm{NO}_{2}$ were moderate, suggesting that 24-hour personal exposures to $\mathrm{PM}_{2.5}$ increased by $9.3 \mu \mathrm{g} / \mathrm{m}^{3}$ for each $10 \mathrm{ppb}$ increase in ambient $\mathrm{NO}_{2}$.

Table 58. Associations between personal gas exposures and ambient particle concentrations for the older adult cohort, by season. *

\begin{tabular}{|c|c|c|c|c|c|c|c|c|c|c|c|}
\hline \multirow{2}{*}{\multicolumn{2}{|c|}{ Comparison }} & \multicolumn{5}{|c|}{ Summer } & \multicolumn{5}{|c|}{ Fall } \\
\hline & & $\mathbf{N}$ & $\beta$ & SE & t-stat & $\mathbf{R}^{2}$ & $\mathbf{N}$ & $\beta$ & SE & t-stat & $\mathbf{R}^{2}$ \\
\hline $\mathrm{O}_{3}$ & \multirow{3}{*}{$\mathrm{PM}_{2.5}$} & 181 & 0.11 & 0.03 & 3.46 & 0.06 & 226 & 0.1 & 0.02 & 4.24 & 0.07 \\
\hline $\mathrm{NO}_{2}^{* *}$ & & 128 & -0.01 & 0.05 & -0.24 & 0.00 & 139 & 0.17 & 0.03 & 5.82 & 0.21 \\
\hline $\mathrm{SO}_{2}$ & & 183 & -0.0004 & 0.03 & -0.02 & 0.00 & 228 & 0.0005 & 0.01 & 0.05 & 0.00 \\
\hline $\mathrm{O}_{3}$ & \multirow{3}{*}{$\mathrm{SO}_{4}{ }^{2-}$} & 168 & 0.16 & 0.06 & 2.58 & 0.04 & 226 & 0.27 & 0.06 & 4.42 & 0.08 \\
\hline $\mathrm{NO}_{2}^{* *}$ & & 118 & -0.09 & 0.10 & -0.86 & 0.01 & 139 & 0.34 & 0.08 & 4.14 & 0.12 \\
\hline $\mathrm{SO}_{2}$ & & 169 & -0.06 & 0.05 & -1.22 & 0.01 & 228 & 0.007 & 0.03 & 0.27 & 0.00 \\
\hline $\mathrm{O}_{3}$ & \multirow{3}{*}{ EC } & 154 & -0.81 & 0.64 & -1.28 & 0.01 & 222 & 1.27 & 0.44 & 2.92 & 0.04 \\
\hline $\mathrm{NO}_{2}^{* *}$ & & 107 & 1.81 & 0.91 & 1.99 & 0.03 & 136 & 3.71 & 0.51 & 7.32 & 0.32 \\
\hline $\mathrm{SO}_{2}$ & & 157 & 0.59 & 0.52 & 1.14 & 0.01 & 224 & -0.11 & 0.20 & -0.57 & 0.00 \\
\hline
\end{tabular}

*bold numbers indicate $\mathrm{p}$-values $\leq 0.05$

${ }^{* *}$ models predicting $\mathrm{NO}_{2}$ exposures restricted to subjects residing in homes without gas stoves 
Table 59. Associations between personal particle exposures and ambient gas concentrations for the older adult cohort, by season.*

\begin{tabular}{|c|c|c|c|c|c|c|c|c|c|c|c|}
\hline \multirow{2}{*}{\multicolumn{2}{|c|}{ Comparison }} & \multicolumn{5}{|c|}{ Summer } & \multicolumn{5}{|c|}{ Fall } \\
\hline & & $\mathbf{N}$ & $\beta$ & SE & t-stat & $\mathbf{R}^{2}$ & $\mathbf{N}$ & $\beta$ & SE & t-stat & $\mathbf{R}^{2}$ \\
\hline \multirow{3}{*}{$\mathrm{PM}_{2.5}$} & $\mathrm{O}_{3}$ & 159 & 0.28 & 0.05 & 5.46 & 0.16 & 204 & 0.08 & 0.10 & 0.78 & 0.00 \\
\hline & $\mathrm{NO}_{2}$ & 159 & -0.07 & 0.09 & -0.80 & 0.00 & 203 & 0.93 & 0.11 & 8.25 & 0.25 \\
\hline & $\mathrm{SO}_{2}{ }^{* *}$ & 95 & 0.73 & 0.27 & 2.70 & 0.07 & 136 & 0.18 & 0.11 & 1.60 & 0.02 \\
\hline \multirow{3}{*}{$\mathrm{SO}_{4}{ }^{2-}$} & $\mathrm{O}_{3}$ & 155 & 0.14 & 0.02 & 5.56 & 0.16 & 188 & 0.01 & 0.03 & 0.49 & 0.00 \\
\hline & $\mathrm{NO}_{2}$ & 155 & -0.06 & 0.04 & -1.55 & 0.01 & 187 & 0.28 & 0.04 & 7.78 & 0.27 \\
\hline & $\mathrm{SO}_{2}^{* *}$ & 93 & 0.21 & 0.12 & 1.70 & 0.03 & 125 & 0.07 & 0.03 & 2.48 & 0.06 \\
\hline \multirow{3}{*}{ EC } & $\mathrm{O}_{3}$ & 157 & -0.01 & 0.004 & -2.60 & 0.04 & 197 & -0.02 & 0.006 & -3.00 & 0.04 \\
\hline & $\mathrm{NO}_{2}$ & 157 & 0.02 & 0.006 & 3.45 & 0.07 & 196 & 0.08 & 0.006 & 13.60 & 0.49 \\
\hline & $\mathrm{SO}_{2}{ }^{* *}$ & 92 & 0.02 & 0.02 & 0.88 & 0.01 & 135 & 0.02 & 0.008 & 2.47 & 0.05 \\
\hline
\end{tabular}

*bold numbers indicate $\mathrm{p}$-values $\leq 0.05$

${ }^{* *}$ models using ambient $\mathrm{SO}_{2}$ restricted to data greater than the analytical LOD

\subsubsection{Factors Affecting Relationships}

Mixed model results showing the effects of activity patterns (i.e., time spent outdoors, time spent in transit) and ventilation conditions (i.e., presence of open windows, AC use) on associations between ambient pollutant concentrations and personal exposures are presented in Tables $60-$ 67. Time spent outdoors generally increased the personal-ambient slopes, except for $\mathrm{SO}_{4}{ }^{2-}$ in summer and $\mathrm{PM}_{2.5}$ and $\mathrm{EC}$ in fall. The overall effect of this variable, however, was slight. For example, the only significant increase in slope was observed for $\mathrm{NO}_{2}$ in the fall, which was attributed primarily to individuals living in homes with gas stoves. Further, with the exception of the personal-ambient association for EC in summertime, all significant associations between personal exposures and corresponding ambient concentrations remained significant even when individuals spent no time outdoors. Time spent in transit tended to decrease personal-ambient associations for $\mathrm{O}_{3}$ in the summer and for $\mathrm{SO}_{4}{ }^{2-}$ and $\mathrm{SO}_{2}$ in fall. Weaker associations for $\mathrm{O}_{3}$ could arise because its concentrations are lower near traffic; however, this theory is not supported by the similarly weaker associations that were observed for the traffic-related pollutants $\mathrm{EC}$ and $\mathrm{NO}_{2}$. The weaker associations for $\mathrm{SO}_{4}{ }^{2-}$ and $\mathrm{SO}_{2}$ are unexpected and may be spurious due to the relatively low fraction of time individuals spent in transit.

Home ventilation was an important modifying factor for many of the personal-ambient relationships, with the greatest slopes and strongest associations observed for subjects spending time indoors with open windows. The influence of home ventilation was particularly evident in the summer for $\mathrm{SO}_{4}{ }^{2-}$ and for $\mathrm{O}_{3}$. The slope of the regression line of ambient $\mathrm{O}_{3}$ concentrations on corresponding personal $\mathrm{O}_{3}$ exposures for individuals spending time in indoor environments with open windows (slope $=0.18 \pm 0.03$, t-value $=7.34$ ), for example, was twice that of individuals spending no time indoors with open windows (slope $=0.08 \pm 0.04$, $\mathrm{t}$-value $=$ 1.89). The stronger associations and higher slopes during conditions in which homes were well ventilated was probably due to the fact that $\mathrm{O}_{3}$, a reactive pollutant, could penetrate indoors more efficiently during these conditions.

The effects of ventilation on the associations between indoor and corresponding ambient pollutant concentrations (Tables 68 - 75) were similar to its effects on associations between 
personal exposures and ambient concentrations, as the high ventilation category (either any windows use or no AC use) resulted in increased indoor-ambient slopes and increased statistical significance relative to the corresponding low ventilation category. The differences between levels of each ventilation factor, however, were more striking for the indoor-ambient associations than for the personal-ambient associations; statistically significant differences between the levels of each factor were observed more frequently for the indoor-ambient associations. For $\mathrm{NO}_{2}$ in the fall, ventilation effects were more apparent for indoor-ambient associations than for corresponding personal-ambient associations (especially when excluding gas stove homes). Stronger effects of ventilation on indoor-ambient associations as compared to personal-ambient associations may be explained by the fact that individuals do not spend all of their time indoors at home. 
Table 60. Personal vs. ambient $\mathrm{PM}_{2.5}$ concentrations by activity and proximity to ventilation for the older adult cohort.*

\begin{tabular}{|c|c|c|c|c|c|c|c|c|c|}
\hline \multirow[b]{2}{*}{ Modifier } & \multirow[b]{2}{*}{ Status } & \multicolumn{4}{|c|}{ Summer } & \multicolumn{4}{|c|}{ Fall } \\
\hline & & $\beta$ & SE & t-stat & Int. & $\beta$ & SE & t-stat & Int. \\
\hline \multicolumn{10}{|c|}{ Activity Pattern } \\
\hline \multirow{2}{*}{ Time Spent Outdoors } & none & 0.69 & 0.07 & 10.22 & 5.81 & 0.63 & 0.05 & 11.70 & 9.06 \\
\hline & any & 0.77 & 0.06 & 12.35 & 2.92 & 0.62 & 0.10 & 5.97 & 8.97 \\
\hline \multirow{2}{*}{ Time Spent in Transit } & none & 0.72 & 0.07 & 10.04 & 4.78 & 0.69 & 0.07 & 9.92 & 7.65 \\
\hline & any & 0.73 & 0.06 & 12.27 & 4.03 & 0.57 & 0.06 & 8.83 & 10.35 \\
\hline \multicolumn{10}{|c|}{ Ventilation } \\
\hline \multirow{2}{*}{ Open Windows } & none $^{\dagger}$ & 0.59 & 0.12 & 5.14 & 3.82 & 0.53 & 0.07 & 7.22 & 9.29 \\
\hline & any & 0.76 & 0.05 & 15.39 & 4.34 & 0.65 & 0.06 & 10.14 & 9.96 \\
\hline \multirow{2}{*}{ Air Conditioner } & none & 0.84 & 0.06 & 13.57 & 3.34 & 0.69 & 0.06 & 10.87 & 7.86 \\
\hline & any & 0.60 & 0.07 & 9.08 & 6.22 & 0.54 & 0.07 & 7.35 & 11.07 \\
\hline
\end{tabular}

*shaded cells represent significant interaction effect; bold numbers indicate $p$-values $\leq 0.05$

${ }^{\dagger}$ for summer season only: none $=$ subjects spend $<33 \%$ of time; any $=$ subjects spend $>33 \%$ of time

Table 61. Personal vs. ambient $\mathrm{SO}_{4}{ }^{2-}$ concentrations by activity and proximity to ventilation for the older adult cohort. ${ }^{*}$

\begin{tabular}{|c|c|c|c|c|c|c|c|c|c|}
\hline \multirow{2}{*}{ Modifier } & \multirow{2}{*}{ Status } & \multicolumn{4}{|c|}{ Summer } & \multicolumn{4}{|c|}{ Fall } \\
\hline & & $\beta$ & SE & t-stat & Int. & $\beta$ & SE & t-stat & Int. \\
\hline \multicolumn{10}{|c|}{ Activity Pattern } \\
\hline \multirow{2}{*}{ Time Spent Outdoors } & none & 0.80 & 0.03 & 24.78 & -0.47 & 0.63 & 0.03 & 22.57 & 0.02 \\
\hline & any & 0.68 & 0.03 & 20.99 & 0.21 & 0.68 & 0.05 & 13.97 & 0.02 \\
\hline \multirow{2}{*}{ Time Spent in Transit } & none & 0.71 & 0.04 & 18.91 & 0.10 & 0.75 & 0.04 & 19.69 & -0.45 \\
\hline & any & 0.75 & 0.03 & 25.76 & -0.33 & 0.58 & 0.03 & 19.26 & 0.37 \\
\hline \multicolumn{10}{|c|}{ Ventilation } \\
\hline \multirow{2}{*}{ Open Windows } & none $^{\dagger}$ & 0.51 & 0.06 & 8.32 & 1.40 & 0.57 & 0.04 & 14.86 & 0.11 \\
\hline & any & 0.77 & 0.02 & 32.81 & -0.36 & 0.67 & 0.03 & 21.31 & 0.12 \\
\hline \multirow{2}{*}{ Air Conditioner } & none & 0.80 & 0.03 & 28.82 & -0.56 & 0.68 & 0.03 & 20.83 & -0.12 \\
\hline & any & 0.62 & 0.04 & 16.75 & 0.62 & 0.60 & 0.04 & 16.62 & 0.13 \\
\hline
\end{tabular}

*shaded cells represent significant interaction effect; bold numbers indicate $p$-values $\leq 0.05$

${ }^{\dagger}$ for summer season only: none $=$ subjects spend $<33 \%$ of time; any $=$ subjects spend $>33 \%$ of time 
Table 62. Personal vs. ambient EC ( $>N^{* *}$ ) concentrations by activity and proximity to ventilation for the older adult cohort.*

\begin{tabular}{|c|c|c|c|c|c|c|c|c|c|}
\hline \multirow{2}{*}{ Modifier } & \multirow{2}{*}{ Status } & \multicolumn{4}{|c|}{ Summer } & \multicolumn{4}{|c|}{ Fall } \\
\hline & & $\beta$ & SE & t-stat & Int. & $\beta$ & SE & t-stat & Int. \\
\hline \multicolumn{10}{|c|}{ Activity Pattern } \\
\hline \multirow{2}{*}{ Time Spent Outdoors } & none & 0.26 & 0.16 & 1.60 & 0.73 & 0.72 & 0.06 & 11.31 & 0.40 \\
\hline & any & 0.33 & 0.13 & 2.55 & 0.75 & 0.62 & 0.12 & 5.04 & 0.47 \\
\hline \multirow{2}{*}{ Time Spent in Transit } & none & 0.41 & 0.14 & 3.04 & 0.60 & 0.83 & 0.09 & 9.61 & 0.37 \\
\hline & any & 0.18 & 0.15 & 1.14 & 0.86 & 0.62 & 0.07 & 8.31 & 0.46 \\
\hline \multicolumn{10}{|c|}{ Ventilation } \\
\hline \multirow{2}{*}{ Open Windows } & none $^{\dagger}$ & 0.14 & 0.19 & 0.72 & 0.65 & 0.66 & 0.08 & 8.74 & 0.41 \\
\hline & any & 0.40 & 0.12 & 3.39 & 0.67 & 0.73 & 0.08 & 8.87 & 0.42 \\
\hline \multirow{2}{*}{ Air Conditioner } & none & 0.36 & 0.14 & 2.50 & 0.74 & 0.69 & 0.07 & 9.62 & 0.35 \\
\hline & any & 0.28 & 0.14 & 1.97 & 0.69 & 0.66 & 0.09 & 7.34 & 0.58 \\
\hline
\end{tabular}

*shaded cells represent significant interaction effect; bold numbers indicate p-values $\leq 0.05$

${ }^{* *} \mathrm{ND}-$ non detectable concentrations

${ }^{\dagger}$ for summer season only: none $=$ subjects spend $<33 \%$ of time; any $=$ subjects spend $>33 \%$ of time

Table 63. Personal vs. ambient $\mathrm{O}_{3}$ concentrations by activity and proximity to ventilation for the older adult cohort. ${ }^{*}$

\begin{tabular}{|c|c|c|c|c|c|c|c|c|c|}
\hline \multirow{2}{*}{ Modifier } & \multirow{2}{*}{ Status } & \multicolumn{4}{|c|}{ Summer } & \multicolumn{4}{|c|}{ Fall } \\
\hline & & $\beta$ & SE & t-stat & Int. & $\beta$ & SE & t-stat & Int. \\
\hline \multicolumn{10}{|c|}{ Activity Pattern } \\
\hline \multirow{2}{*}{ Time Spent Outdoors } & none & 0.12 & 0.03 & 3.70 & 0.72 & 0.23 & 0.04 & 6.24 & -0.38 \\
\hline & any & 0.18 & 0.03 & 6.24 & -0.18 & 0.35 & 0.06 & 6.09 & -1.84 \\
\hline \multirow{2}{*}{ Time Spent in Transit } & none & 0.19 & 0.03 & 6.55 & -1.39 & 0.29 & 0.04 & 7.60 & -1.70 \\
\hline & any & 0.11 & 0.03 & 3.42 & 1.90 & 0.22 & 0.05 & 4.14 & 0.27 \\
\hline \multicolumn{10}{|c|}{ Ventilation } \\
\hline \multirow{2}{*}{ Open Windows } & none $^{\dagger}$ & 0.08 & 0.04 & 1.89 & 1.73 & 0.20 & 0.05 & 3.90 & -1.17 \\
\hline & any & 0.18 & 0.03 & 7.34 & -0.54 & 0.27 & 0.04 & 7.38 & 0.52 \\
\hline \multirow{2}{*}{ Air Conditioner } & none & 0.25 & 0.03 & 8.79 & -1.82 & 0.24 & 0.04 & 6.14 & -1.35 \\
\hline & any & 0.06 & 0.03 & 2.06 & 2.60 & 0.30 & 0.05 & 6.25 & 0.02 \\
\hline
\end{tabular}

*shaded cells represent significant interaction effect; bold numbers indicate $p$-values $\leq 0.05$

${ }^{\dagger}$ for summer season only: none $=$ subjects spend $<33 \%$ of time; any $=$ subjects spend $>33 \%$ of time 
Table 64. Personal vs. ambient $\mathrm{SO}_{2}$ concentrations by activity and proximity to ventilation for the older adult cohort.*

\begin{tabular}{|c|c|c|c|c|c|c|c|c|c|}
\hline \multirow{2}{*}{ Modifier } & \multirow{2}{*}{ Status } & \multicolumn{4}{|c|}{ Summer } & \multicolumn{4}{|c|}{ Fall } \\
\hline & & $\beta$ & SE & t-stat & Int. & $\beta$ & SE & t-stat & Int. \\
\hline \multicolumn{10}{|c|}{ Activity Pattern } \\
\hline \multirow{2}{*}{ Time Spent Outdoors } & none & 0.09 & 0.09 & 1.07 & 0.74 & 0.09 & 0.02 & 5.75 & 0.14 \\
\hline & any & 0.19 & 0.10 & 1.92 & 1.32 & 0.14 & 0.04 & 3.88 & 0.05 \\
\hline \multirow{2}{*}{ Time Spent in Transit } & none & 0.09 & 0.08 & 1.04 & 1.21 & 0.20 & 0.03 & 7.43 & -0.13 \\
\hline & any & 0.20 & 0.11 & 1.83 & 0.83 & 0.06 & 0.02 & 3.87 & 0.25 \\
\hline \multicolumn{10}{|c|}{ Ventilation } \\
\hline \multirow{2}{*}{ Open Windows } & none $^{\dagger}$ & 0.16 & 0.10 & 1.55 & 0.91 & 0.08 & 0.02 & 5.00 & 0.37 \\
\hline & any & 0.11 & 0.09 & 1.26 & 1.09 & 0.15 & 0.03 & 4.68 & -0.14 \\
\hline \multirow{2}{*}{ Air Conditioner } & none & 0.18 & 0.10 & 1.69 & 0.92 & 0.10 & 0.02 & 6.62 & 0.20 \\
\hline & any & 0.10 & 0.09 & 1.13 & 1.10 & 0.06 & 0.03 & 1.87 & 0.13 \\
\hline
\end{tabular}

*shaded cells represent significant interaction effect; bold numbers indicate p-values $\leq 0.05$

${ }^{\dagger}$ for summer season only: none $=$ subjects spend $<33 \%$ of time; any $=$ subjects spend $>33 \%$ of time

Table 65. Personal vs. ambient $\mathrm{SO}_{2}\left(>\mathrm{ND}^{* *}\right)$ concentrations by activity and proximity to ventilation for the older adult cohort. ${ }^{*}$

\begin{tabular}{|c|c|c|c|c|c|c|c|c|c|}
\hline \multirow{2}{*}{ Modifier } & \multirow{2}{*}{ Status } & \multicolumn{4}{|c|}{ Summer } & \multicolumn{4}{|c|}{ Fall } \\
\hline & & $\beta$ & SE & t-stat & Int. & $\beta$ & SE & t-stat & Int. \\
\hline \multicolumn{10}{|c|}{ Activity Pattern } \\
\hline \multirow{2}{*}{ Time Spent Outdoors } & none & -0.03 & 0.14 & -0.22 & 1.77 & 0.08 & 0.02 & 4.18 & 0.31 \\
\hline & any & 0.10 & 0.17 & 0.59 & 1.89 & 0.15 & 0.04 & 3.35 & -0.26 \\
\hline \multirow{2}{*}{ Time Spent in Transit } & none & 0.01 & 0.13 & 0.05 & 2.01 & 0.22 & 0.03 & 6.64 & -0.52 \\
\hline & any & 0.03 & 0.18 & 0.15 & 1.75 & 0.05 & 0.02 & 2.58 & 0.59 \\
\hline \multicolumn{10}{|c|}{ Ventilation } \\
\hline \multirow{2}{*}{ Open Windows } & none $^{\dagger}$ & 0.07 & 0.15 & 0.46 & 2.01 & 0.07 & 0.02 & 3.90 & 0.48 \\
\hline & any & -0.06 & 0.15 & -0.39 & 2.13 & 0.13 & 0.04 & 3.15 & -0.14 \\
\hline \multirow{2}{*}{ Air Conditioner } & none & -0.03 & 0.16 & -0.18 & 2.08 & 0.10 & 0.02 & 5.37 & 0.22 \\
\hline & any & 0.05 & 0.15 & 0.32 & 1.76 & 0.01 & 0.05 & 0.26 & 0.67 \\
\hline
\end{tabular}

*shaded cells represent significant interaction effect; bold numbers indicate $p$-values $\leq 0.05$

${ }^{* *} \mathrm{ND}$ - non detectable concentrations

${ }^{\dagger}$ for summer season only: none $=$ subjects spend $<33 \%$ of time; any $=$ subjects spend $>33 \%$ of time 
Table 66. Personal vs. ambient $\mathrm{NO}_{2}$ concentrations by activity and proximity to ventilation for the older adult cohort.*

\begin{tabular}{|c|c|c|c|c|c|c|c|c|c|}
\hline \multirow{2}{*}{ Modifier } & \multirow{2}{*}{ Status } & \multicolumn{4}{|c|}{ Summer } & \multicolumn{4}{|c|}{ Fall } \\
\hline & & $\beta$ & SE & t-stat & Int. & $\beta$ & $\mathrm{SE}$ & t-stat & Int. \\
\hline \multicolumn{10}{|l|}{ Activity Pattern } \\
\hline \multirow{2}{*}{ Time Spent Outdoors } & none & 0.16 & 0.07 & 2.52 & 8.69 & 0.33 & 0.06 & 5.63 & 9.77 \\
\hline & any & 0.32 & 0.07 & 4.29 & 8.41 & 0.57 & 0.11 & 5.28 & 8.49 \\
\hline \multirow{2}{*}{ Time Spent in Transit } & none & 0.24 & 0.07 & 3.43 & 9.10 & 0.38 & 0.07 & 5.36 & 9.41 \\
\hline & any & 0.20 & 0.07 & 2.85 & 8.33 & 0.39 & 0.08 & 5.24 & 9.29 \\
\hline \multicolumn{10}{|l|}{ Ventilation } \\
\hline \multirow{2}{*}{ Open Windows } & none $^{\dagger}$ & 0.25 & 0.11 & 2.32 & 7.33 & 0.52 & 0.08 & 6.60 & 7.55 \\
\hline & any & 0.23 & 0.06 & 4.05 & 8.88 & 0.24 & 0.07 & 3.43 & 11.75 \\
\hline \multirow{2}{*}{ Air Conditioner } & none & 0.18 & 0.07 & 2.42 & 10.18 & 0.41 & 0.07 & 6.02 & 9.23 \\
\hline & any & 0.26 & 0.07 & 3.94 & 7.70 & 0.36 & 0.08 & 4.30 & 9.50 \\
\hline
\end{tabular}

*shaded cells represent significant interaction effect; bold numbers $p$-values $\leq 0.05$;

${ }^{\dagger}$ for summer: none $=$ subjects spend $<33 \%$ of time; any $=$ subjects spend $>33 \%$ of time

Table 67. Personal vs. ambient $\mathrm{NO}_{2}$ concentrations by activity and proximity to ventilation for individuals without gas stoves for the older adult cohort.*

\begin{tabular}{|c|c|c|c|c|c|c|c|c|c|}
\hline \multirow{2}{*}{ Modifier } & \multirow{2}{*}{ Status } & \multicolumn{4}{|c|}{ Summer } & \multicolumn{4}{|c|}{ Fall } \\
\hline & & $\beta$ & SE & t-stat & Int. & $\beta$ & SE & t-stat & Int. \\
\hline \multicolumn{10}{|l|}{ Activity Pattern } \\
\hline \multirow{2}{*}{ Time Spent Outdoors } & none & 0.18 & 0.07 & 2.45 & 5.53 & 0.45 & 0.06 & 7.79 & 4.08 \\
\hline & any & 0.34 & 0.09 & 3.87 & 5.66 & 0.51 & 0.09 & 6.00 & 5.12 \\
\hline \multirow{2}{*}{ Time Spent in Transit } & none & 0.24 & 0.07 & 3.50 & 5.78 & 0.48 & 0.06 & 8.32 & 3.76 \\
\hline & any & 0.27 & 0.11 & 2.31 & 5.23 & 0.54 & 0.08 & 6.43 & 4.85 \\
\hline \multicolumn{10}{|l|}{ Ventilation } \\
\hline \multirow{2}{*}{ Open Windows } & none $^{\dagger}$ & 0.24 & 0.11 & 2.26 & 3.94 & 0.44 & 0.07 & 6.83 & 3.84 \\
\hline & any & 0.27 & 0.07 & 3.88 & 5.77 & 0.46 & 0.07 & 6.15 & 5.86 \\
\hline \multirow{2}{*}{ Air Conditioner } & none & 0.34 & 0.11 & 3.04 & 5.55 & 0.45 & 0.06 & 8.04 & 4.50 \\
\hline & any & 0.23 & 0.07 & 3.39 & 4.92 & 0.57 & 0.10 & 5.65 & 3.71 \\
\hline
\end{tabular}

${ }^{*}$ Bold numbers indicate $p$-values $\leq 0.05$;

${ }^{\dagger}$ for summer: none $=$ subjects spend $<33 \%$ of time; any $=$ subjects spend $>33 \%$ of time 
Table 68. Indoor vs. ambient $\mathrm{PM}_{2.5}$ concentrations by ventilation conditions for the older adult cohort.*

\begin{tabular}{|c|c|c|c|c|c|c|c|c|c|}
\hline \multirow{2}{*}{ Modifier } & \multirow{2}{*}{ Status } & \multicolumn{4}{|c|}{ Summer } & \multicolumn{4}{|c|}{ Fall } \\
\hline & & $\beta$ & SE & t-stat & Int. & $\beta$ & SE & t-stat & Int. \\
\hline \multirow{3}{*}{ Open Windows } & $\mathrm{LO}^{* *}$ & 0.54 & 0.05 & 10.95 & 7.89 & 0.66 & 0.06 & 11.22 & 6.71 \\
\hline & Med & 0.64 & 0.04 & 16.93 & 5.71 & 0.56 & 0.06 & 8.63 & 8.52 \\
\hline & $\mathrm{Hi}$ & 0.86 & 0.03 & 32.04 & 2.53 & 0.7 & 0.07 & 9.74 & 6.85 \\
\hline \multirow{2}{*}{$A C$} & None & 0.84 & 0.05 & 18.48 & 3.12 & 0.65 & 0.04 & 17.03 & 6.73 \\
\hline & Any & 0.71 & 0.03 & 21.98 & 5.35 & 0.46 & 0.11 & 4.31 & 12.77 \\
\hline
\end{tabular}

${ }^{*}$ shaded cells represent significant interaction effect; bold numbers indicate $p$-values $\leq 0.05$

${ }^{* *} \mathrm{Lo}=$ no windows open, Med $=$ the sum of open windows up to 24-hours, $\mathrm{Hi}=$ the sum of open windows $>24$-hours

Table 69. Indoor vs. ambient $\mathrm{SO}_{4}{ }^{2-}$ concentrations by ventilation conditions for the older adult cohort. ${ }^{*}$

\begin{tabular}{|c|c|c|c|c|c|c|c|c|c|}
\hline \multirow{2}{*}{ Modifier } & \multirow{2}{*}{ Status } & \multicolumn{4}{|c|}{ Summer } & \multicolumn{4}{|c|}{ Fall } \\
\hline & & $\beta$ & SE & t-stat & Int. & $\beta$ & SE & t-stat & Int. \\
\hline \multirow{3}{*}{ Open Windows } & $\mathrm{LO}^{* *}$ & 0.52 & 0.04 & 14.41 & 1.12 & 0.66 & 0.03 & 23.75 & 0.03 \\
\hline & Med & 0.66 & 0.03 & 23.17 & 0.7 & 0.61 & 0.03 & 22.26 & 0.69 \\
\hline & $\mathrm{Hi}$ & 0.86 & 0.02 & 45.16 & -0.28 & 0.9 & 0.03 & 26.01 & -0.49 \\
\hline \multirow{2}{*}{$A C$} & None & 0.9 & 0.03 & 28.34 & -0.57 & 0.71 & 0.02 & 37.06 & 0.08 \\
\hline & Any & 0.74 & 0.02 & 30.9 & 0.38 & 0.72 & 0.05 & 14.8 & -0.24 \\
\hline
\end{tabular}

*shaded cells represent significant interaction effect; bold numbers indicate p-values $\leq 0.05$

${ }^{* *} \mathrm{Lo}=$ no windows open, Med $=$ the sum of open windows up to 24 -hours, $\mathrm{Hi}=$ the sum of open windows $>24$-hours

Table 70. Indoor vs. ambient EC $\left(>N^{* *}\right)$ concentrations by ventilation conditions for the older adult cohort. ${ }^{*}$

\begin{tabular}{|c|c|c|c|c|c|c|c|c|c|}
\hline \multirow{2}{*}{ Modifier } & \multirow{2}{*}{ Status } & \multicolumn{4}{|c|}{ Summer } & \multicolumn{4}{|c|}{ Fall } \\
\hline & & $\beta$ & SE & t-stat & Int. & $\beta$ & SE & t-stat & Int. \\
\hline \multirow{3}{*}{ Open Windows } & Lo $^{* * *}$ & 0.19 & 0.09 & 2.04 & 0.61 & 0.71 & 0.05 & 13.4 & 0.32 \\
\hline & Med & 0.14 & 0.09 & 1.6 & 0.75 & 0.67 & 0.07 & 10.07 & 0.54 \\
\hline & $\mathrm{Hi}$ & 0.3 & 0.06 & 5.12 & 0.72 & 0.96 & 0.08 & 11.53 & 0.12 \\
\hline \multirow{2}{*}{$A C$} & None & 0.4 & 0.07 & 5.81 & 0.59 & 0.76 & 0.04 & 19.52 & 0.32 \\
\hline & Any & 0.32 & 0.04 & 7.32 & 0.58 & 0.71 & 0.14 & 5.11 & 0.48 \\
\hline
\end{tabular}

*shaded cells represent significant interaction effect; bold numbers indicate p-values $\leq 0.05$

**ND - non detectable concentrations

${ }^{* * *}$ Lo $=$ no windows open, Med $=$ the sum of open windows up to 24 -hours, $\mathrm{Hi}=$ the sum of open windows $>24$-hours 
Table 71. Indoor vs. ambient $\mathrm{O}_{3}$ concentrations by ventilation conditions for the older adult cohort.*

\begin{tabular}{|c|c|c|c|c|c|c|c|c|c|}
\hline \multirow{2}{*}{ Modifier } & \multirow{2}{*}{ Status } & \multicolumn{4}{|c|}{ Summer } & \multicolumn{4}{|c|}{ Fall } \\
\hline & & $\beta$ & SE & t-stat & Int. & $\beta$ & SE & t-stat & Int. \\
\hline \multirow{3}{*}{ Open Windows } & $\mathrm{LO}^{* *}$ & 0.07 & 0.03 & 2.3 & 2.32 & 0.18 & 0.03 & 5.54 & -0.32 \\
\hline & Med & 0.14 & 0.03 & 4.41 & 0.47 & 0.3 & 0.04 & 7.18 & -0.82 \\
\hline & $\mathrm{Hi}$ & 0.22 & 0.02 & 12.01 & 0.42 & 0.31 & 0.03 & 9.49 & 0.24 \\
\hline \multirow{2}{*}{$A C$} & None & 0.27 & 0.03 & 7.88 & -0.38 & 0.26 & 0.02 & 11.22 & -0.67 \\
\hline & Any & 0.17 & 0.02 & 8.03 & 0.8 & 0.27 & 0.05 & 5.37 & 0.56 \\
\hline
\end{tabular}

${ }^{*}$ shaded cells represent significant interaction effect; bold numbers indicate $p$-values $\leq 0.05$

${ }^{* *}$ Lo $=$ no windows open, Med = the sum of open windows up to 24-hours, Hi $=$ the sum of open windows $>24-$ hours

Table 72. Indoor vs. ambient $\mathrm{SO}_{2}$ concentrations by ventilation conditions for the older adult cohort.*

\begin{tabular}{|c|c|c|c|c|c|c|c|c|c|}
\hline \multirow{2}{*}{ Modifier } & \multirow{2}{*}{ Status } & \multicolumn{4}{|c|}{ Summer } & \multicolumn{4}{|c|}{ Fall } \\
\hline & & $\beta$ & SE & t-stat & Int. & $\beta$ & SE & t-stat & Int. \\
\hline \multirow{3}{*}{ Open Windows } & $\mathrm{LO}^{* *}$ & 0.12 & 0.13 & 0.9 & 0.44 & 0.07 & 0.02 & 4.95 & 0.63 \\
\hline & Med & 0.18 & 0.16 & 1.17 & 0.81 & 0.02 & 0.02 & 1.4 & 0.47 \\
\hline & $\mathrm{Hi}$ & 0.18 & 0.11 & 1.65 & 2 & 0.12 & 0.04 & 3.09 & 0.17 \\
\hline \multirow{2}{*}{$A C$} & None & 0.1 & 0.18 & 0.56 & 0.79 & 0.06 & 0.01 & 5.23 & 0.58 \\
\hline & Any & 0.05 & 0.13 & 0.37 & 1.74 & 0.01 & 0.06 & 0.09 & 0.18 \\
\hline
\end{tabular}

*shaded cells represent significant interaction effect; bold numbers indicate $p$-values $\leq 0.05$

${ }^{* *}$ Lo $=$ no windows open, Med $=$ the sum of open windows up to 24-hours, Hi $=$ the sum of open windows $>24-$ hours

Table 73. Indoor vs. ambient $\mathrm{SO}_{2}\left(>\mathrm{ND}^{* *}\right)$ concentrations by ventilation conditions for the older adult cohort.*

\begin{tabular}{|c|c|c|c|c|c|c|c|c|c|}
\hline \multirow{2}{*}{ Modifier } & \multirow{2}{*}{ Status } & \multicolumn{4}{|c|}{ Summer } & \multicolumn{4}{|c|}{ Fall } \\
\hline & & $\beta$ & SE & t-stat & Int. & $\beta$ & SE & t-stat & Int. \\
\hline \multirow{3}{*}{ Open Windows } & Lo*** $^{* *}$ & 0.14 & 0.19 & 0.74 & 0.49 & 0.05 & 0.02 & 2.82 & 0.94 \\
\hline & Med & 0.03 & 0.23 & 0.12 & 2 & 0 & 0.02 & 0.18 & 0.89 \\
\hline & $\mathrm{Hi}$ & 0.01 & 0.18 & 0.07 & 3.11 & 0.08 & 0.05 & 1.53 & 0.43 \\
\hline \multirow{2}{*}{$A C$} & None & -0.09 & 0.27 & -0.32 & 1.81 & 0.04 & 0.01 & 2.59 & 0.89 \\
\hline & Any & -0.3 & 0.21 & -1.43 & 3.3 & -0.08 & 0.09 & -0.9 & 0.99 \\
\hline
\end{tabular}

${ }^{*}$ shaded cells represent significant interaction effect; bold numbers indicate $p$-values $\leq 0.05$

${ }^{* *} \mathrm{ND}$ - non detectable concentrations

${ }^{* * *}$ Lo $=$ no windows open, Med $=$ the sum of open windows up to 24-hours, $\mathrm{Hi}=$ the sum of open windows $>24-$ hours 
Table 74. Indoor vs. ambient $\mathrm{NO}_{2}$ concentrations by ventilation conditions for the older adult cohort.*

\begin{tabular}{|c|c|c|c|c|c|c|c|c|c|}
\hline \multirow{2}{*}{ Modifier } & \multirow{2}{*}{ Status } & \multicolumn{4}{|c|}{ Summer } & \multicolumn{4}{|c|}{ Fall } \\
\hline & & $\beta$ & SE & t-stat & Int. & $\beta$ & SE & t-stat & Int. \\
\hline \multirow{3}{*}{ Open Windows } & Lo** & 0.26 & 0.1 & 2.64 & 8.74 & 0.38 & 0.06 & 6.79 & 6.48 \\
\hline & Med & 0.16 & 0.09 & 1.81 & 8.58 & 0.34 & 0.06 & 5.22 & 8.85 \\
\hline & $\mathrm{Hi}$ & 0.13 & 0.06 & 1.98 & 9.97 & 0.32 & 0.07 & 4.86 & 10.32 \\
\hline \multirow{2}{*}{$A C$} & None & 0.16 & 0.07 & 2.29 & 8.9 & 0.45 & 0.04 & 12.24 & 7.03 \\
\hline & Any & 0.14 & 0.05 & 3.09 & 9.16 & -0.03 & 0.11 & -0.29 & 13.19 \\
\hline
\end{tabular}

${ }^{*}$ shaded cells represent significant interaction effect; bold numbers indicate $p$-values $\leq 0.05$

${ }^{* *} \mathrm{Lo}=$ no windows open, Med $=$ the sum of open windows up to 24-hours, $\mathrm{Hi}=$ the sum of open windows $>24$-hours

Table 75. Indoor vs. ambient $\mathrm{NO}_{2}$ concentrations by ventilation conditions for homes without gas stoves for the older adult cohort.*

\begin{tabular}{|c|c|c|c|c|c|c|c|c|c|}
\hline \multirow{2}{*}{ Modifier } & \multirow{2}{*}{ Status } & \multicolumn{6}{|c|}{ Summer } & \multicolumn{4}{c|}{ Fall } \\
\cline { 3 - 10 } & & $\beta$ & SE & $\mathbf{t}$-stat & Int. & $\beta$ & SE & t-stat & Int. \\
\hline \multirow{3}{*}{ Open Windows } & Lo** & $\mathbf{0 . 3 4}$ & 0.12 & 2.91 & $\mathbf{5 . 5 7}$ & $\mathbf{0 . 3 3}$ & 0.04 & 9.34 & $\mathbf{3 . 0 2}$ \\
\cline { 2 - 11 } & $\mathrm{Med}$ & 0.15 & 0.09 & 1.62 & $\mathbf{7 . 0 7}$ & $\mathbf{0 . 4}$ & 0.04 & 9.49 & $\mathbf{3 . 4 3}$ \\
\cline { 2 - 11 } & $\mathrm{Hi}$ & 0.15 & 0.08 & 1.82 & $\mathbf{7 . 3 3}$ & $\mathbf{0 . 5 3}$ & 0.05 & 9.68 & $\mathbf{3 . 7 7}$ \\
\hline \multirow{2}{*}{$\mathrm{AC}$} & None & $\mathbf{0 . 2 1}$ & 0.09 & 2.43 & $\mathbf{6 . 3 8}$ & $\mathbf{0 . 4 4}$ & 0.03 & 17.21 & $\mathbf{2 . 6 8}$ \\
\cline { 2 - 10 } & Any & $\mathbf{0 . 1 9}$ & 0.05 & 3.98 & $\mathbf{5 . 1 6}$ & 0.24 & 0.12 & 1.93 & $\mathbf{6 . 1 7}$ \\
\hline
\end{tabular}

*shaded cells represent significant interaction effect; bold numbers indicate $p$-values $\leq 0.05$

${ }^{* *} \mathrm{Lo}=$ no windows open, Med $=$ the sum of open windows up to 24-hours, $\mathrm{Hi}=$ the sum of open windows $>24$-hours 
In addition to home ventilation, we also examined whether stove type modified the association between ambient pollutant concentrations and both indoor concentrations and personal exposures. Results for indoor-ambient concentration comparisons are presented in Table 76. The intercepts for models of indoor $\mathrm{NO}_{2}$ as a function of ambient $\mathrm{NO}_{2}$ were significantly higher in both seasons for participants living in homes with gas as compared to electric stoves; this was expected, because gas stoves are known sources of $\mathrm{NO}_{2}$ indoors. Stove type did not modify the indoor-ambient intercepts for the other measured pollutants, as significant differences in the intercepts for gas as compared to electric stoves were not found. Stove type was found to modify the indoor-ambient slopes for $\mathrm{PM}_{2.5}$ and $\mathrm{SO}_{4}{ }^{2-}$ in the summer and $\mathrm{EC}$ and $\mathrm{O}_{3}$ in the fall, with this effect generally resulting in greater slopes for homes with gas stoves as compared to homes with electric stoves (except for $\mathrm{O}_{3}$ in the fall, which exhibited the opposite trend). Greater slopes suggest greater effective penetration efficiencies of ambient pollutants; however, it is not clear how stove type would impact the effective penetration efficiency of any pollutant. It is possible that the results reflect the effect of different buildings rather than the effect of stove type, as stove type and place of residence were directly correlated. Electric stoves were present only in residences in the Gaylord and Kennedy buildings, whereas gas stoves were present only in the Elmer White residences and in private homes. As a result, it is not possible to separate the effects of cooking fuel use from those of building of residence.

Table 76. Indoor vs. ambient pollutant concentrations by stove type for the older adult cohort.*

\begin{tabular}{|c|c|c|c|c|c|c|c|c|c|c|c|}
\hline \multicolumn{2}{|c|}{} & \multicolumn{9}{|c|}{ Summer } & \multicolumn{4}{|c|}{ Fall } \\
\hline Pollutant & Fuel & $\mathbf{N}$ & $\boldsymbol{\beta}$ & $\mathbf{S E}$ & $\mathbf{t}-\mathbf{s t a t}$ & $\mathbf{I n t}$ & $\mathbf{N}$ & $\boldsymbol{\beta}$ & $\mathbf{S E}$ & t-stat & Int. \\
\hline \multirow{2}{*}{$\mathrm{PM}_{2.5}$} & gas & 118 & $\mathbf{0 . 8 2}$ & 0.04 & 20.38 & 2.84 & 158 & $\mathbf{0 . 6 9}$ & 0.06 & 10.71 & $\mathbf{8 . 0 4}$ \\
\cline { 2 - 12 } & electric & 351 & $\mathbf{0 . 7 2}$ & 0.02 & 30.32 & $\mathbf{4 . 5 1}$ & 355 & $\mathbf{0 . 6 2}$ & 0.04 & 14.04 & $\mathbf{6 . 5 9}$ \\
\hline \multirow{2}{*}{$\mathrm{SO}_{4}{ }^{2-}$} & gas & 112 & $\mathbf{0 . 8 6}$ & 0.03 & 28.22 & -0.22 & 171 & $\mathbf{0 . 7 1}$ & 0.03 & 23.40 & 0.33 \\
\cline { 2 - 12 } & electric & 345 & $\mathbf{0 . 7 2}$ & 0.02 & 39.89 & 0.34 & 355 & $\mathbf{0 . 7 3}$ & 0.02 & 33.19 & 0.47 \\
\hline \multirow{2}{*}{$\mathrm{EC}$} & gas & 116 & 0.15 & 0.08 & 1.96 & $\mathbf{0 . 8 7}$ & 173 & $\mathbf{0 . 8 7}$ & 0.06 & 14.53 & $\mathbf{0 . 3 3}$ \\
\cline { 2 - 12 } & electric & 348 & $\mathbf{0 . 1 5}$ & 0.04 & 3.65 & $\mathbf{0 . 8 6}$ & 361 & $\mathbf{0 . 6 6}$ & 0.05 & 14.67 & $\mathbf{0 . 4 1}$ \\
\hline \multirow{2}{*}{$\mathrm{O}_{3}$} & gas & 113 & $\mathbf{0 . 1 5}$ & 0.03 & 4.62 & 2.80 & 174 & $\mathbf{0 . 1 9}$ & 0.04 & 4.68 & 0.71 \\
\cline { 2 - 12 } & electric & 357 & $\mathbf{0 . 1 7}$ & 0.17 & 10.73 & 0.55 & 374 & $\mathbf{0 . 2 9}$ & 0.02 & 11.96 & -0.60 \\
\hline \multirow{2}{*}{$\mathrm{SO}_{2}$} & gas & 116 & 0.30 & 0.17 & 1.77 & 1.24 & 174 & 0.02 & 0.02 & 1.12 & $\mathbf{0 . 8 1}$ \\
\cline { 2 - 11 } & electric & 363 & 0.12 & 0.08 & 1.57 & $\mathbf{1 . 6 4}$ & 373 & $\mathbf{0 . 0 6}$ & 0.01 & 4.95 & $\mathbf{0 . 6 7}$ \\
\hline \multirow{2}{*}{$\mathrm{NO}_{2}$} & gas & 113 & 0.04 & 0.09 & 0.49 & $\mathbf{1 3 . 6 4}$ & 159 & $\mathbf{0 . 3 1}$ & 0.06 & 5.21 & $\mathbf{1 4 . 3 2}$ \\
\cline { 2 - 11 } & electric & 357 & $\mathbf{0 . 1 7}$ & 0.05 & 3.37 & $\mathbf{7 . 7 6}$ & 368 & $\mathbf{0 . 4 4}$ & 0.04 & 10.70 & $\mathbf{4 . 0 2}$ \\
\hline
\end{tabular}

* shaded cells represent significant interaction effect; bold numbers indicate $p$-value $\leq 0.05$

As shown in Table 77, stove type also modified associations between personal pollutant exposures and corresponding ambient concentrations. As with indoor-ambient associations, intercepts for models of personal $\mathrm{NO}_{2}$ as a function of ambient $\mathrm{NO}_{2}$ were significantly higher in the fall for participants living in homes with gas stoves as compared to those living in homes with electric stoves. Similar trends were observed in the summer, although the intercepts did not differ significantly by stove type. Again, higher $\mathrm{NO}_{2}$ intercepts for individuals with gas stoves likely resulted from the fact that gas stoves are major sources of $\mathrm{NO}_{2}$ indoors. Slopes of personal-ambient associations were also significantly modified by stove type; however, this modification was inconsistent and did not generally agree with that observed for indoor-ambient concentration comparisons. Inconsistent personal-ambient and indoor-ambient results suggest that results are highly dependent on the participants, as individuals with personal monitoring data include only a subset of individuals for whom indoor concentrations were measured. 
Table 77. Personal vs. ambient pollutant concentrations by stove type for the older adult cohort.*

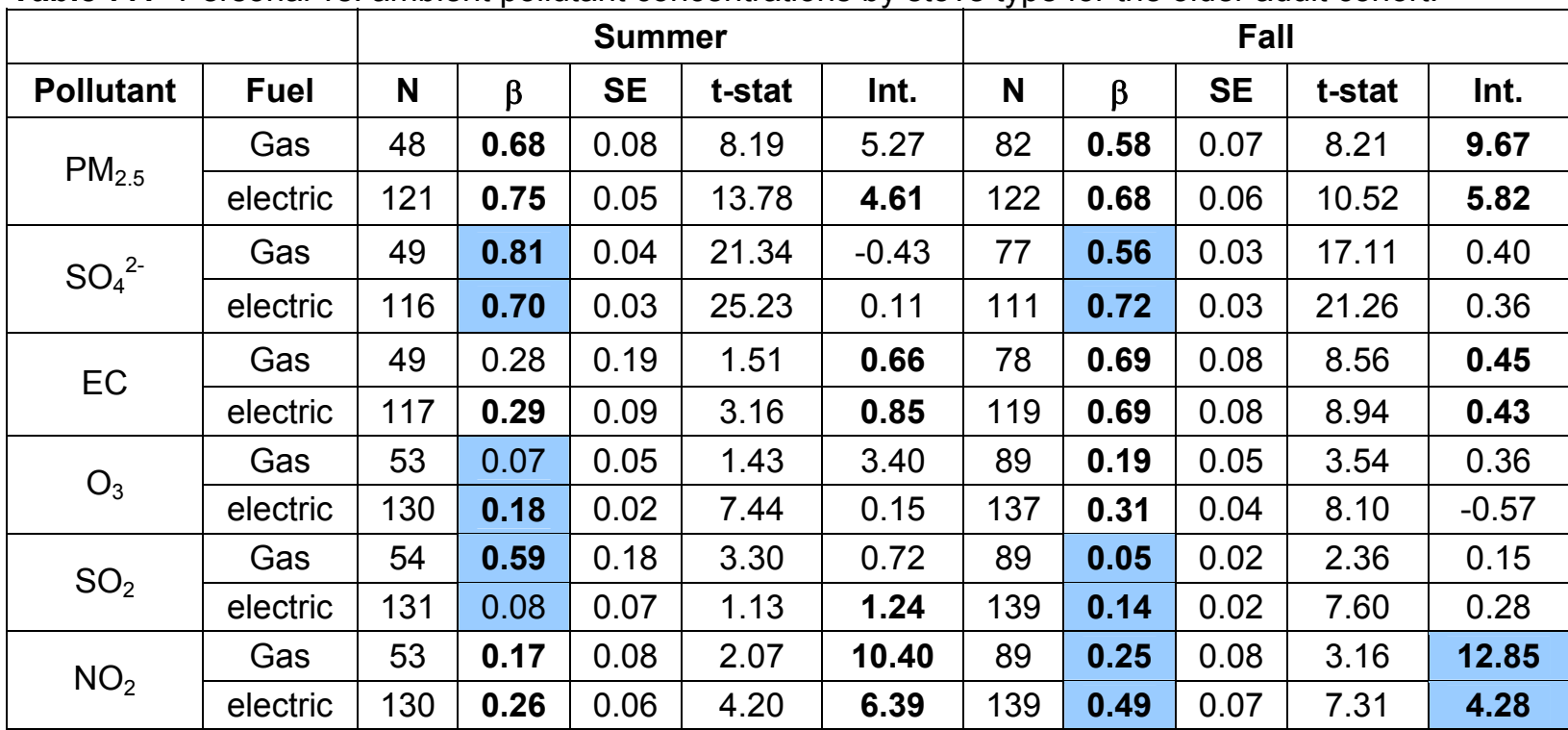

*shaded cells represent significant interaction effect; bold numbers indicate p-value $\leq 0.05$

Cooking and cleaning were additionally tested in the personal-ambient and indoor-ambient models. Interaction terms with these factors were not significant; these activities were not expected to vary the slopes of the associations but only possibly to increase the intercepts of the associations. Indeed, when included as main effects only, the overall trends were for cooking and cleaning to cause very small increases in intercepts; significant differences in indoor concentrations between any cooking and no cooking were found in the fall for indoor $\mathrm{PM}_{2.5}$ and $\mathrm{NO}_{2}$. However, the presence of these factors, whether significant or not, did not affect the t-statistics of the indoor-ambient or personal-ambient slopes.

\subsubsection{Summary of Elemental Data}

Table 78 summarizes water-extractable element concentrations measured as part of the adult cohort exposure assessment. As shown in the table, water-extractable concentrations of many elements were below their field limits of detection in personal, indoor, outdoor, and ambient environments. For eight elements, including $\mathrm{As}, \mathrm{Ba}, \mathrm{Cd}, \mathrm{Pb}, \mathrm{Mg}, \mathrm{K}, \mathrm{Se}$, and $\mathrm{V}$, waterextractable concentrations were above the respective LODs for more than $50 \%$ of the samples. Median water-extractable concentrations of these elements were generally highest outdoors, with the exceptions of water-extractable $\mathrm{K}$ and $\mathrm{Cd}$ for which indoor and outdoor concentrations were comparable. Median personal exposures to water-extractable $\mathrm{Ba}, \mathrm{Cd}, \mathrm{Pb}, \mathrm{Se}$, and $\mathrm{V}$ were below the LOD. For water-extractable $\mathrm{Pb}, \mathrm{As}$, and $\mathrm{Cd}$, median indoor and outdoor concentrations were greater in the fall than in the summer, and for water-extractable As, median personal exposures were also greater in the fall than in the summer. 
Table 78. Water-extractable elements concentrations $\left(\mathrm{ng} / \mathrm{m}^{3}\right)$ measured in personal, indoor, outdoor, and ambient environments for the older adult cohort.

\begin{tabular}{|c|c|c|c|c|c|c|c|c|c|c|c|}
\hline \multirow[b]{2}{*}{ Element } & \multirow[b]{2}{*}{ Location } & \multicolumn{5}{|c|}{ Summer } & \multicolumn{5}{|c|}{ Fall } \\
\hline & & $\mathbf{N}$ & $\begin{array}{l}\text { Field } \\
\text { LOD } \\
\end{array}$ & 10th & 50th & 90th & $\mathbf{N}$ & $\begin{array}{l}\text { Field } \\
\text { LOD }\end{array}$ & 10th & $50^{\text {th }}$ & 90th \\
\hline \multirow{5}{*}{ Aluminum } & Personal & 183 & 287.93 & $<$ LOD & $<$ LOD & $<L O D$ & 210 & 287.93 & $<\mathrm{LOD}$ & $<$ LOD & $<L O D$ \\
\hline & Indoor & 483 & 129.14 & $<\mathrm{LOD}$ & $<$ LOD & $<\mathrm{LOD}$ & 495 & 129.14 & $<L O D$ & $<\mathrm{LOD}$ & $<$ LOD \\
\hline & Gaylord* & 32 & 129.14 & $<L O D$ & $<$ LOD & $<$ LOD & 32 & 129.14 & $<\mathrm{LOD}$ & $<$ LOD & $<L O D$ \\
\hline & Kennedy & 62 & 129.14 & $<$ LOD & $<$ LOD & $<$ LOD & 65 & 129.14 & $<L O D$ & $<L O D$ & $<$ LOD \\
\hline & Ambient & 101 & 129.14 & $<$ LOD & $<L O D$ & $<\mathrm{LOD}$ & 116 & 129.14 & $<\mathrm{LOD}$ & $<\mathrm{LOD}$ & $<$ LOD \\
\hline \multirow{5}{*}{ Arsenic } & Personal & 188 & 0.05 & $<L O D$ & 0.5 & 2.1 & 214 & 0.05 & $<L O D$ & 1.2 & 3.8 \\
\hline & Indoor & 494 & 0.02 & 0.2 & 1.0 & 2.4 & 519 & 0.02 & 0.2 & 1.5 & 4.4 \\
\hline & Gaylord & 33 & 0.02 & 0.3 & 1.5 & 3.6 & 33 & 0.02 & 0.6 & 1.6 & 5.3 \\
\hline & Kennedy & 65 & 0.02 & 0.4 & 1.4 & 2.9 & 68 & 0.02 & 0.5 & 2.1 & 5.3 \\
\hline & Ambient & 103 & 0.02 & 0.2 & 1.3 & 2.9 & 115 & 0.02 & 0.5 & 2.3 & 7.3 \\
\hline \multirow{5}{*}{ Barium } & Personal & 180 & 0.38 & $<\mathrm{LOD}$ & $<L O D$ & 30.6 & 167 & 0.38 & $<L O D$ & $<\mathrm{LOD}$ & 5.0 \\
\hline & Indoor & 448 & 0.17 & $<\mathrm{LOD}$ & 0.9 & 15.5 & 387 & 0.17 & $<\mathrm{LOD}$ & 1.5 & 10.5 \\
\hline & Gaylord & 29 & 0.17 & 0.4 & 1.4 & 11.3 & 27 & 0.17 & $<L O D$ & 3.1 & 18.9 \\
\hline & Kennedy & 57 & 0.17 & 0.4 & 3.5 & 33.0 & 52 & 0.17 & $<L O D$ & 2.7 & 11.1 \\
\hline & Ambient & 93 & 0.17 & $<\mathrm{LOD}$ & 1.6 & 14.8 & 89 & 0.17 & $<L O D$ & 1.2 & 6.7 \\
\hline \multirow{5}{*}{ Cadmium } & Personal & 170 & 0.10 & $<$ LOD & $<L O D$ & 2.3 & 162 & 0.10 & $<L O D$ & $<\mathrm{LOD}$ & 1.4 \\
\hline & Indoor & 428 & 0.04 & $<$ LOD & 0.2 & 1.6 & 401 & 0.04 & $<L O D$ & 0.4 & 1.9 \\
\hline & Gaylord & 29 & 0.04 & $<L O D$ & 0.1 & 1.2 & 25 & 0.04 & $<L O D$ & 0.5 & 1.9 \\
\hline & Kennedy & 56 & 0.04 & $<$ LOD & 0.2 & 3.0 & 54 & 0.04 & $<L O D$ & 0.4 & 2.0 \\
\hline & Ambient & 91 & 0.04 & $<\mathrm{LOD}$ & 0.2 & 2.0 & 89 & 0.04 & $<L O D$ & 0.5 & 2.6 \\
\hline \multirow{5}{*}{ Calcium } & Personal & 181 & 141.59 & $<L O D$ & $<$ LOD & $<L O D$ & 176 & 141.59 & $<L O D$ & $<L O D$ & 288.3 \\
\hline & Indoor & 459 & 63.50 & $<$ LOD & $<$ LOD & $<$ LOD & 404 & 63.50 & $<L O D$ & $<L O D$ & 652.8 \\
\hline & Gaylord & 30 & 63.50 & $<\mathrm{LOD}$ & $<$ LOD & $<$ LOD & 28 & 63.50 & $<L O D$ & $<L O D$ & 630.3 \\
\hline & Kennedy & 62 & 63.50 & $<$ LOD & $<L O D$ & $<L O D$ & 53 & 63.50 & $<L O D$ & $<\mathrm{LOD}$ & 916.2 \\
\hline & Ambient & 95 & 63.50 & $<$ LOD & $<$ LOD & $<L O D$ & 95 & 63.50 & $<L O D$ & $<L O D$ & 542.0 \\
\hline \multirow{5}{*}{ Cobalt } & Personal & 188 & 0.19 & $<\mathrm{LOD}$ & $<\mathrm{LOD}$ & $<$ LOD & 214 & 0.19 & $<\mathrm{LOD}$ & $<\mathrm{LOD}$ & $<$ LOD \\
\hline & Indoor & 490 & 0.09 & $<$ LOD & $<L O D$ & $<L O D$ & 518 & 0.09 & $<L O D$ & $<\mathrm{LOD}$ & 0.1 \\
\hline & Gaylord & 33 & 0.09 & $<\mathrm{LOD}$ & $<L O D$ & $<L O D$ & 33 & 0.09 & $<L O D$ & $<L O D$ & 0.1 \\
\hline & Kennedy & 65 & 0.09 & $<$ LOD & $<L O D$ & $<L O D$ & 68 & 0.09 & $<L O D$ & $<L O D$ & $<$ LOD \\
\hline & Ambient & 102 & 0.09 & $<L O D$ & $<$ LOD & $<$ LOD & 115 & 0.09 & $<L O D$ & $<L O D$ & 0.1 \\
\hline \multirow{5}{*}{ Copper } & Personal & 179 & 447.02 & $<L O D$ & $<L O D$ & $<L O D$ & 212 & 447.02 & $<L O D$ & $<L O D$ & $<$ LOD \\
\hline & Indoor & 470 & 200.49 & $<$ LOD & $<L O D$ & $<L O D$ & 511 & 200.49 & $<\mathrm{LOD}$ & $<L O D$ & $<$ LOD \\
\hline & Gaylord & 33 & 200.49 & $<L O D$ & $<$ LOD & $<$ LOD & 33 & 200.49 & $<L O D$ & $<L O D$ & $<$ LOD \\
\hline & Kennedy & 62 & 200.49 & $<$ LOD & $<L O D$ & $<L O D$ & 68 & 200.49 & $<\mathrm{LOD}$ & $<\mathrm{LOD}$ & $<$ LOD \\
\hline & Ambient & 96 & 200.49 & $<\mathrm{LOD}$ & $<$ LOD & $<\mathrm{LOD}$ & 115 & 200.49 & $<L O D$ & $<L O D$ & $<$ LOD \\
\hline \multirow{5}{*}{ Iron } & Personal & 178 & 201.37 & $<\mathrm{LOD}$ & $<L O D$ & $<L O D$ & 136 & 201.37 & $<\mathrm{LOD}$ & $<L O D$ & $<$ LOD \\
\hline & Indoor & 430 & 90.31 & $<L O D$ & $<$ LOD & $<L O D$ & 314 & 90.31 & $<L O D$ & $<L O D$ & 123.0 \\
\hline & Gaylord & 27 & 90.31 & $<$ LOD & $<$ LOD & $<$ LOD & 21 & 90.31 & $<\mathrm{LOD}$ & $<$ LOD & 185.9 \\
\hline & Kennedy & 58 & 90.31 & $<$ LOD & $<L O D$ & $<L O D$ & 39 & 90.31 & $<L O D$ & $<L O D$ & 145.6 \\
\hline & Ambient & 88 & 90.31 & $<$ LOD & $<\mathrm{LOD}$ & $<L O D$ & 76 & 90.31 & $<\mathrm{LOD}$ & $<\mathrm{LOD}$ & 130.6 \\
\hline
\end{tabular}


Table $78 . \quad$ (continued)

\begin{tabular}{|c|c|c|c|c|c|c|c|c|c|c|c|}
\hline \multirow[b]{2}{*}{ Element } & \multirow[b]{2}{*}{ Location } & \multicolumn{5}{|c|}{ Summer } & \multicolumn{5}{|c|}{ Fall } \\
\hline & & $\mathbf{N}$ & $\begin{array}{l}\text { Field } \\
\text { LOD }\end{array}$ & 10th & 50th & 90th & $\mathbf{N}$ & $\begin{array}{l}\text { Field } \\
\text { LOD }\end{array}$ & 10th & $50^{\text {th }}$ & 90th \\
\hline \multirow{5}{*}{ Lead } & Personal & 125 & 6.85 & $<L O D$ & $<L O D$ & 44.1 & 167 & 6.85 & $<$ LOD & $<L O D$ & 28.7 \\
\hline & Indoor & 338 & 3.07 & $<L O D$ & 4.8 & 20.7 & 411 & 3.07 & $<$ LOD & 8.6 & 39.8 \\
\hline & Gaylord & 24 & 3.07 & $<$ LOD & 5.7 & 34.5 & 27 & 3.07 & $<$ LOD & 16.4 & 33.0 \\
\hline & Kennedy & 49 & 3.07 & $<$ LOD & 7.0 & 42.0 & 55 & 3.07 & $<$ LOD & 11.1 & 46.9 \\
\hline & Ambient & 68 & 3.07 & $<$ LOD & 7.8 & 24.6 & 93 & 3.07 & $<$ LOD & 12.3 & 51.2 \\
\hline \multirow{5}{*}{ Magnesium } & Personal & 188 & 12.41 & $<L O D$ & 22.4 & 43.7 & 209 & 12.41 & $<$ LOD & 13.0 & 61.6 \\
\hline & Indoor & 494 & 5.56 & $<\mathrm{LOD}$ & 15.6 & 38.2 & 497 & 5.56 & $<$ LOD & 17.5 & 65.1 \\
\hline & Gaylord & 33 & 5.56 & 8.2 & 18.9 & 40.8 & 32 & 5.56 & $<$ LOD & 20.7 & 88.7 \\
\hline & Kennedy & 65 & 5.56 & 10.8 & 23.1 & 54.4 & 66 & 5.56 & $<L O D$ & 22.7 & 91.1 \\
\hline & Ambient & 103 & 5.56 & 8.8 & 19.0 & 40.1 & 112 & 5.56 & $<$ LOD & 20.2 & 83.8 \\
\hline \multirow{5}{*}{ Manganese } & Personal & 181 & 17.40 & $<L O D$ & $<L O D$ & $<$ LOD & 131 & 17.40 & $<L O D$ & $<L O D$ & $<$ LOD \\
\hline & Indoor & 442 & 7.80 & $<L O D$ & $<L O D$ & 8.4 & 296 & 7.80 & $<$ LOD & $<$ LOD & 17.8 \\
\hline & Gaylord & 28 & 7.80 & $<$ LOD & $<L O D$ & 13.0 & 21 & 7.80 & $<L O D$ & $<$ LOD & 18.3 \\
\hline & Kennedy & 60 & 7.80 & $<L O D$ & $<L O D$ & 12.7 & 38 & 7.80 & $<$ LOD & $<\mathrm{LOD}$ & 21.8 \\
\hline & Ambient & 91 & 7.80 & $<$ LOD & $<$ LOD & 11.6 & 74 & 7.80 & $<$ LOD & $<$ LOD & 17.5 \\
\hline \multirow{5}{*}{ Nickel } & Personal & 188 & 2.80 & $<$ LOD & $<$ LOD & $<$ LOD & 213 & 2.80 & $<L O D$ & $<\mathrm{LOD}$ & $<$ LOD \\
\hline & Indoor & 494 & 1.25 & $<\mathrm{LOD}$ & $<L O D$ & $<$ LOD & 513 & 1.25 & $<$ LOD & $<$ LOD & $<$ LOD \\
\hline & Gaylord & 33 & 1.25 & $<L O D$ & $<L O D$ & $<L O D$ & 32 & 1.25 & $<$ LOD & $<$ LOD & 1.9 \\
\hline & Kennedy & 65 & 1.25 & $<$ LOD & $<\mathrm{LOD}$ & $<$ LOD & 68 & 1.25 & $<L O D$ & $<\mathrm{LOD}$ & 1.4 \\
\hline & Ambient & 103 & 1.25 & $<$ LOD & $<L O D$ & $<$ LOD & 114 & 1.25 & $<$ LOD & $<$ LOD & 1.3 \\
\hline \multirow{5}{*}{ Potassium } & Personal & 147 & 44.57 & $<L O D$ & 60.7 & 219.0 & 192 & 44.57 & $<$ LOD & 67.5 & 225.8 \\
\hline & Indoor & 388 & 19.99 & 28.1 & 61.3 & 214.1 & 458 & 19.99 & $<\mathrm{LOD}$ & 79.6 & 196.1 \\
\hline & Gaylord & 25 & 19.99 & 30.4 & 60.1 & 148.2 & 28 & 19.99 & 24.8 & 56.8 & 157.2 \\
\hline & Kennedy & 48 & 19.99 & 41.1 & 68.2 & 222.7 & 60 & 19.99 & 29.5 & 74.5 & 177.7 \\
\hline & Ambient & 83 & 19.99 & 25.0 & 46.8 & 133.0 & 102 & 19.99 & $<$ LOD & 61.1 & 145.9 \\
\hline \multirow{5}{*}{ Selenium } & Personal & 188 & 1.52 & $<\mathrm{LOD}$ & $<L O D$ & 3.3 & 183 & 1.52 & $<$ LOD & $<L O D$ & 7.8 \\
\hline & Indoor & 494 & 0.68 & $<$ LOD & 1.0 & 3.7 & 460 & 0.68 & $<L O D$ & 1.4 & 7.2 \\
\hline & Gaylord & 33 & 0.68 & 0.8 & 2.7 & 7.0 & 30 & 0.68 & $<$ LOD & 3.6 & 15.2 \\
\hline & Kennedy & 65 & 0.68 & $<$ LOD & 2.0 & 6.8 & 61 & 0.68 & $<L O D$ & 3.6 & 16.1 \\
\hline & Ambient & 103 & 0.68 & $<L O D$ & 2.3 & 6.3 & 104 & 0.68 & $<$ LOD & 4.0 & 16.5 \\
\hline \multirow{5}{*}{ Sodium } & Personal & 183 & 97.31 & $<\mathrm{LOD}$ & $<$ LOD & 460.7 & 214 & 97.31 & $<$ LOD & $<L O D$ & 152.1 \\
\hline & Indoor & 457 & 43.65 & $<$ LOD & $<\mathrm{LOD}$ & 175.6 & 507 & 43.65 & $<L O D$ & $<$ LOD & 140.0 \\
\hline & Gaylord & 31 & 43.65 & $<$ LOD & $<L O D$ & 72.2 & 32 & 43.65 & $<$ LOD & $<L O D$ & 116.4 \\
\hline & Kennedy & 62 & 43.65 & $<\mathrm{LOD}$ & $<L O D$ & 105.0 & 64 & 43.65 & $<\mathrm{LOD}$ & $<\mathrm{LOD}$ & 186.0 \\
\hline & Ambient & 95 & 43.65 & $<$ LOD & $<L O D$ & 114.4 & 111 & 43.65 & $<$ LOD & $<L O D$ & 128.3 \\
\hline \multirow{5}{*}{ Tin } & Personal & 157 & 0.29 & $<$ LOD & $<L O D$ & $<$ LOD & 163 & 0.29 & $<L O D$ & $<L O D$ & $<$ LOD \\
\hline & Indoor & 415 & 0.13 & $<$ LOD & $<L O D$ & $<$ LOD & 386 & 0.13 & $<L O D$ & $<L O D$ & $<$ LOD \\
\hline & Gaylord & 29 & 0.13 & $<L O D$ & $<L O D$ & $<L O D$ & 26 & 0.13 & $<$ LOD & $<L O D$ & $<L O D$ \\
\hline & Kennedy & 56 & 0.13 & $<\mathrm{LOD}$ & $<\mathrm{LOD}$ & $<$ LOD & 52 & 0.13 & $<L O D$ & $<$ LOD & $<\mathrm{LOD}$ \\
\hline & Ambient & 89 & 0.13 & $<\mathrm{LOD}$ & $<$ LOD & $<$ LOD & 91 & 0.13 & $<$ LOD & $<$ LOD & $<$ LOD \\
\hline \multirow{5}{*}{ Titanium } & Personal & 188 & 0.00 & $<$ LOD & $<L O D$ & $<$ LOD & 214 & 0.00 & $<L O D$ & $<L O D$ & $<$ LOD \\
\hline & Indoor & 493 & 0.00 & $<$ LOD & $<\mathrm{LOD}$ & 0.2 & 517 & 0.00 & $<L O D$ & $<$ LOD & 1.4 \\
\hline & Gaylord & 33 & 0.00 & $<$ LOD & $<$ LOD & 0.6 & 33 & 0.00 & $<$ LOD & $<L O D$ & $<$ LOD \\
\hline & Kennedy & 65 & 0.00 & $<L O D$ & $<L O D$ & 0.5 & 68 & 0.00 & $<\mathrm{LOD}$ & $<\mathrm{LOD}$ & 2.4 \\
\hline & Ambient & 103 & 0.00 & $<$ LOD & $<\mathrm{LOD}$ & 1.6 & 115 & 0.00 & $<$ LOD & $<\mathrm{LOD}$ & 4.0 \\
\hline
\end{tabular}


Table $78 . \quad$ (continued)

\begin{tabular}{|c|c|c|c|c|c|c|c|c|c|c|c|}
\hline \multirow[b]{2}{*}{ Element } & \multirow[b]{2}{*}{ Location } & \multicolumn{5}{|c|}{ Summer } & \multicolumn{5}{|c|}{ Fall } \\
\hline & & $\mathbf{N}$ & $\begin{array}{l}\text { Field } \\
\text { LOD }\end{array}$ & 10th & 50th & 90th & $\mathbf{N}$ & $\begin{array}{l}\text { Field } \\
\text { LOD }\end{array}$ & 10th & $50^{\text {th }}$ & 90th \\
\hline \multirow{5}{*}{ Vanadium } & Personal & 188 & 0.00 & $<\mathrm{LOD}$ & $<L O D$ & 0.8 & 214 & 0.00 & $<L O D$ & $<L O D$ & 3.2 \\
\hline & Indoor & 494 & 0.00 & $<$ LOD & 0.3 & 1.2 & 518 & 0.00 & $<L O D$ & 0.4 & 3.7 \\
\hline & Gaylord & 33 & 0.00 & $<\mathrm{LOD}$ & 0.4 & 1.5 & 33 & 0.00 & $<L O D$ & 0.6 & 3.0 \\
\hline & Kennedy & 65 & 0.00 & $<$ LOD & 0.5 & 1.5 & 68 & 0.00 & $<$ LOD & 0.9 & 5.0 \\
\hline & Ambient & 103 & 0.00 & $<$ LOD & 0.5 & 2.3 & 115 & 0.00 & $<L O D$ & 1.0 & 8.2 \\
\hline \multirow{5}{*}{ Zinc } & Personal & 188 & 417.00 & $<$ LOD & $<$ LOD & $<L O D$ & 211 & 417.00 & $<L O D$ & $<L O D$ & $<$ LOD \\
\hline & Indoor & 489 & 187.03 & $<$ LOD & $<$ LOD & $<$ LOD & 506 & 187.03 & $<L O D$ & $<L O D$ & $<$ LOD \\
\hline & Gaylord & 33 & 187.03 & $<$ LOD & $<L O D$ & $<L O D$ & 33 & 187.03 & $<L O D$ & $<L O D$ & 207.1 \\
\hline & Kennedy & 65 & 187.03 & $<L O D$ & $<L O D$ & $<L O D$ & 67 & 187.03 & $<L O D$ & $<L O D$ & $<L O D$ \\
\hline & Ambient & 101 & 187.03 & $<$ LOD & $<$ LOD & $<$ LOD & 113 & 187.03 & $<\mathrm{LOD}$ & $<L O D$ & $<$ LOD \\
\hline
\end{tabular}

*Gaylord and Kennedy are rooftop monitors. " $<$ LOD" indicates concentrations that were below the corresponding field LOD.

Similarly, median acid-digestible concentrations were above their field LOD for several of the measured elements, including $\mathrm{Al}, \mathrm{Cu}$ (fall only), $\mathrm{Fe}, \mathrm{K}, \mathrm{Mg}, \mathrm{Mn}, \mathrm{Pb}, \mathrm{Se}, \mathrm{V}$, and $\mathrm{Zn}$ (Table 79). Median acid-digestible $\mathrm{Al}, \mathrm{Fe}, \mathrm{Pb}$, Se, and $\mathrm{Zn}$ concentrations tended to be higher outdoors than in indoor and personal environments. Median acid-digestible aluminum and zinc concentrations were higher in summer as compared to fall, while the opposite was true for copper and iron. Seasonal variation in the median acid-digestible concentrations for the other elements was not apparent.

Table 79. Water-extractable elements concentrations $\left(\mathrm{ng} / \mathrm{m}^{3}\right)$ measured in personal, indoor, outdoor, and ambient environments for the older adult cohort.

\begin{tabular}{|c|c|c|c|c|c|c|c|c|c|c|c|}
\hline \multirow[b]{2}{*}{ Element } & \multirow[b]{2}{*}{ Location } & \multicolumn{5}{|c|}{ Summer } & \multicolumn{5}{|c|}{ Fall } \\
\hline & & $\mathbf{N}$ & $\begin{array}{l}\text { Field } \\
\text { LOD }\end{array}$ & 10th & 50th & 90th & $\mathbf{N}$ & $\begin{array}{l}\text { Field } \\
\text { LOD }\end{array}$ & 10th & 50th & 90th \\
\hline \multirow{5}{*}{ Aluminum } & Personal & 84 & 0.02 & $<\mathrm{LOD}$ & 87.9 & 323.8 & 154 & 0.02 & $<L O D$ & 5.4 & 486.1 \\
\hline & Indoor & 198 & 0.05 & $<\mathrm{LOD}$ & 55.5 & 241.5 & 352 & 0.05 & $<L O D$ & 19.2 & 186.4 \\
\hline & Gaylord* & 12 & 0.05 & $<$ LOD & 60.9 & 197.8 & 23 & 0.05 & $<$ LOD & 30.2 & 202.4 \\
\hline & Kennedy & 29 & 0.05 & 11.0 & 103.7 & 258.0 & 39 & 0.05 & $<$ LOD & 33.5 & 166.5 \\
\hline & Ambient & 41 & 0.05 & $<$ LOD & 88.8 & 233.3 & 78 & 0.05 & $<$ LOD & 29.7 & 171.8 \\
\hline \multirow{5}{*}{ Arsenic } & Personal & 157 & 0.12 & $<$ LOD & $<\mathrm{LOD}$ & $<\mathrm{LOD}$ & 198 & 0.12 & $<L O D$ & $<\mathrm{LOD}$ & 0.4 \\
\hline & Indoor & 410 & 0.30 & $<\mathrm{LOD}$ & $<\mathrm{LOD}$ & 1.0 & 470 & 0.30 & $<\mathrm{LOD}$ & $<\mathrm{LOD}$ & 1.8 \\
\hline & Gaylord & 24 & 0.30 & $<$ LOD & $<$ LOD & 1.8 & 30 & 0.30 & $<$ LOD & $<$ LOD & 2.5 \\
\hline & Kennedy & 56 & 0.30 & $<$ LOD & $<\mathrm{LOD}$ & 1.2 & 59 & 0.30 & $<$ LOD & 1.0 & 2.9 \\
\hline & Ambient & 82 & 0.30 & $<\mathrm{LOD}$ & $<\mathrm{LOD}$ & 1.0 & 107 & 0.30 & $<L O D$ & 0.5 & 2.9 \\
\hline \multirow{5}{*}{ Barium } & Personal & 144 & 0.17 & $<\mathrm{LOD}$ & $<\mathrm{LOD}$ & 5.5 & 167 & 0.17 & $<\mathrm{LOD}$ & $<\mathrm{LOD}$ & 2.0 \\
\hline & Indoor & 382 & 0.27 & $<\mathrm{LOD}$ & $<\mathrm{LOD}$ & 4.4 & 401 & 0.27 & $<$ LOD & $<$ LOD & 5.0 \\
\hline & Gaylord & 23 & 0.27 & $<$ LOD & 0.5 & 2.9 & 27 & 0.27 & $<$ LOD & 0.7 & 10.1 \\
\hline & Kennedy & 52 & 0.27 & $<\mathrm{LOD}$ & 0.3 & 6.0 & 50 & 0.27 & $<L O D$ & 0.7 & 6.6 \\
\hline & Ambient & 72 & 0.27 & $<\mathrm{LOD}$ & $<\mathrm{LOD}$ & 5.5 & 91 & 0.27 & $<L O D$ & $<\mathrm{LOD}$ & 2.6 \\
\hline \multirow{5}{*}{ Cadmium } & Personal & 133 & 0.17 & $<\mathrm{LOD}$ & $<\mathrm{LOD}$ & 0.9 & 174 & 0.17 & $<\mathrm{LOD}$ & 0.3 & 2.0 \\
\hline & Indoor & 355 & 0.37 & $<\mathrm{LOD}$ & $<\mathrm{LOD}$ & 0.7 & 409 & 0.37 & $<L O D$ & $<L O D$ & 1.3 \\
\hline & Gaylord & 23 & 0.37 & $<\mathrm{LOD}$ & $<\mathrm{LOD}$ & $<\mathrm{LOD}$ & 29 & 0.37 & $<$ LOD & $<$ LOD & 1.2 \\
\hline & Kennedy & 48 & 0.37 & $<\mathrm{LOD}$ & $<\mathrm{LOD}$ & 0.6 & 52 & 0.37 & $<L O D$ & $<\mathrm{LOD}$ & 1.3 \\
\hline & Ambient & 67 & 0.37 & $<$ LOD & $<$ LOD & 1.0 & 94 & 0.37 & $<\mathrm{LOD}$ & $<$ LOD & 1.4 \\
\hline
\end{tabular}


Table $79 . \quad$ (continued)

\begin{tabular}{|c|c|c|c|c|c|c|c|c|c|c|c|}
\hline \multirow[b]{2}{*}{ Element } & \multirow[b]{2}{*}{ Location } & \multicolumn{5}{|c|}{ Summer } & \multicolumn{5}{|c|}{ Fall } \\
\hline & & $\mathbf{N}$ & $\begin{array}{l}\text { Field } \\
\text { LOD }\end{array}$ & 10th & 50th & 90th & $\mathbf{N}$ & $\begin{array}{l}\text { Field } \\
\text { LOD }\end{array}$ & 10th & 50th & 90th \\
\hline \multirow{5}{*}{ Calcium } & Personal & 3 & 0.07 & $<L O D$ & $<L O D$ & $<L O D$ & 96 & 0.07 & $<L O D$ & $<L O D$ & 82.3 \\
\hline & Indoor & 41 & 0.05 & $<$ LOD & $<L O D$ & $<$ LOD & 232 & 0.05 & $<$ LOD & $<\mathrm{LOD}$ & 610.3 \\
\hline & Gaylord & 1 & 0.05 & $<$ LOD & $<L O D$ & $<$ LOD & 18 & 0.05 & $<$ LOD & $<$ LOD & $<L O D$ \\
\hline & Kennedy & 7 & 0.05 & $<\mathrm{LOD}$ & $<L O D$ & $<\mathrm{LOD}$ & 27 & 0.05 & $<\mathrm{LOD}$ & $<L O D$ & 235.3 \\
\hline & Ambient & 6 & 0.05 & $<$ LOD & $<$ LOD & 72.4 & 57 & 0.05 & $<$ LOD & $<$ LOD & 537.2 \\
\hline \multirow{5}{*}{ Cobalt } & Personal & 89 & 0.02 & $<$ LOD & $<L O D$ & $<$ LOD & 135 & 0.02 & $<$ LOD & $<$ LOD & 1.9 \\
\hline & Indoor & 230 & 0.05 & $<$ LOD & $<L O D$ & $<$ LOD & 318 & 0.05 & $<$ LOD & $<\mathrm{LOD}$ & 1.1 \\
\hline & Gaylord & 12 & 0.05 & $<L O D$ & $<L O D$ & $<L O D$ & 24 & 0.05 & $<L O D$ & $<$ LOD & $<L O D$ \\
\hline & Kennedy & 31 & 0.05 & $<$ LOD & $<L O D$ & $<$ LOD & 41 & 0.05 & $<\mathrm{LOD}$ & $<\mathrm{LOD}$ & 0.3 \\
\hline & Ambient & 47 & 0.05 & $<$ LOD & $<L O D$ & $<$ LOD & 79 & 0.05 & $<$ LOD & $<\mathrm{LOD}$ & $<\mathrm{LOD}$ \\
\hline \multirow{5}{*}{ Copper } & Personal & 145 & 0.02 & $<$ LOD & $<L O D$ & 9.5 & 186 & 0.02 & $<$ LOD & 3.6 & 33.0 \\
\hline & Indoor & 391 & 0.02 & $<\mathrm{LOD}$ & $<L O D$ & 6.1 & 442 & 0.02 & $<$ LOD & 2.7 & 13.6 \\
\hline & Gaylord & 21 & 0.02 & $<$ LOD & $<$ LOD & 2.8 & 29 & 0.02 & $<$ LOD & 2.7 & 22.9 \\
\hline & Kennedy & 53 & 0.02 & $<L O D$ & $<L O D$ & 2.7 & 55 & 0.02 & $<L O D$ & 3.9 & 23.6 \\
\hline & Ambient & 77 & 0.02 & $<$ LOD & $<L O D$ & 4.3 & 101 & 0.02 & $<$ LOD & 2.6 & 13.5 \\
\hline \multirow{5}{*}{ Iron } & Personal & 149 & 0.33 & $<$ LOD & 114.8 & 449.6 & 204 & 0.33 & $<$ LOD & 132.4 & 573.5 \\
\hline & Indoor & 375 & 0.54 & 21.7 & 114.1 & 383.3 & 454 & 0.54 & $<$ LOD & 167.6 & 590.9 \\
\hline & Gaylord & 23 & 0.54 & 43.4 & 167.0 & 503.8 & 30 & 0.54 & 4.3 & 193.9 & 876.1 \\
\hline & Kennedy & 51 & 0.54 & 41.1 & 146.8 & 483.0 & 58 & 0.54 & $<$ LOD & 208.1 & 771.4 \\
\hline & Ambient & 76 & 0.54 & 20.5 & 119.2 & 325.5 & 104 & 0.54 & $<$ LOD & 169.9 & 861.2 \\
\hline \multirow{5}{*}{ Lead } & Personal & 141 & 0.09 & 0.4 & 5.2 & 14.0 & 169 & 0.09 & $<$ LOD & 6.5 & 19.4 \\
\hline & Indoor & 382 & 0.16 & 2.1 & 5.8 & 14.2 & 385 & 0.16 & 1.5 & 7.0 & 20.3 \\
\hline & Gaylord & 23 & 0.16 & 2.7 & 8.1 & 17.6 & 25 & 0.16 & 1.6 & 10.4 & 27.3 \\
\hline & Kennedy & 52 & 0.16 & 2.6 & 8.5 & 17.6 & 49 & 0.16 & 2.7 & 9.7 & 20.6 \\
\hline & Ambient & 73 & 0.16 & 2.9 & 7.4 & 15.7 & 91 & 0.16 & 2.0 & 8.2 & 27.6 \\
\hline \multirow{5}{*}{ Magnesium } & Personal & 151 & 0.16 & $<$ LOD & 24.3 & 66.4 & 194 & 0.16 & $<$ LOD & 24.9 & 82.6 \\
\hline & Indoor & 389 & 0.33 & 3.0 & 20.8 & 52.6 & 461 & 0.33 & 4.4 & 24.6 & 76.9 \\
\hline & Gaylord & 23 & 0.33 & $<$ LOD & 30.4 & 53.7 & 30 & 0.33 & 2.6 & 24.1 & 85.4 \\
\hline & Kennedy & 53 & 0.33 & 6.7 & 27.9 & 55.4 & 58 & 0.33 & 7.5 & 29.7 & 98.1 \\
\hline & Ambient & 77 & 0.33 & 3.0 & 26.3 & 63.3 & 105 & 0.33 & 4.3 & 21.0 & 104.0 \\
\hline \multirow{5}{*}{ Manganese } & Personal & 140 & 0.10 & $<$ LOD & 5.7 & 20.7 & 155 & 0.10 & $<$ LOD & 3.5 & 24.8 \\
\hline & Indoor & 352 & 0.30 & 1.5 & 6.5 & 18.2 & 378 & 0.30 & $<$ LOD & 8.2 & 27.3 \\
\hline & Gaylord & 23 & 0.30 & 2.6 & 12.4 & 21.1 & 23 & 0.30 & $<\mathrm{LOD}$ & 9.8 & 40.2 \\
\hline & Kennedy & 48 & 0.30 & 2.8 & 9.1 & 21.9 & 44 & 0.30 & $<\mathrm{LOD}$ & 12.9 & 38.0 \\
\hline & Ambient & 69 & 0.30 & 1.8 & 8.0 & 22.6 & 83 & 0.30 & $<$ LOD & 11.8 & 33.6 \\
\hline \multirow{5}{*}{ Nickel } & Personal & 70 & 0.00 & $<$ LOD & $<$ LOD & 7.9 & 151 & 0.00 & $<$ LOD & $<$ LOD & $<L O D$ \\
\hline & Indoor & 198 & 0.01 & $<L O D$ & 0.3 & 3.8 & 344 & 0.01 & $<L O D$ & $<L O D$ & $<\mathrm{LOD}$ \\
\hline & Gaylord & 11 & 0.01 & $<L O D$ & $<L O D$ & 3.4 & 23 & 0.01 & $<L O D$ & $<L O D$ & $\angle L O D$ \\
\hline & Kennedy & 26 & 0.01 & $<\mathrm{LOD}$ & 0.1 & 3.5 & 46 & 0.01 & $<\mathrm{LOD}$ & $<\mathrm{LOD}$ & 4.9 \\
\hline & Ambient & 44 & 0.01 & $<\mathrm{LOD}$ & 0.8 & 8.1 & 83 & 0.01 & $<\mathrm{LOD}$ & $<$ LOD & $<\mathrm{LOD}$ \\
\hline \multirow{5}{*}{ Potassium } & Personal & 117 & 0.16 & $<$ LOD & 144.0 & 296.1 & 169 & 0.16 & $<$ LOD & 54.7 & 165.2 \\
\hline & Indoor & 286 & 0.33 & 27.4 & 67.4 & 234.6 & 394 & 0.33 & $<$ LOD & 65.5 & 199.3 \\
\hline & Gaylord & 17 & 0.33 & 35.4 & 65.1 & 128.6 & 24 & 0.33 & $<$ LOD & 62.6 & 172.7 \\
\hline & Kennedy & 39 & 0.33 & 8.6 & 67.8 & 138.3 & 45 & 0.33 & $<$ LOD & 57.4 & 185.0 \\
\hline & Ambient & 55 & 0.33 & 12.2 & 67.0 & 199.2 & 88 & 0.33 & $<$ LOD & 62.8 & 161.4 \\
\hline
\end{tabular}


Table $79 . \quad$ (continued)

\begin{tabular}{|c|c|c|c|c|c|c|c|c|c|c|c|}
\hline \multirow[b]{2}{*}{ Element } & \multirow[b]{2}{*}{ Location } & \multicolumn{5}{|c|}{ Summer } & \multicolumn{5}{|c|}{ Fall } \\
\hline & & $\mathbf{N}$ & $\begin{array}{l}\text { Field } \\
\text { LOD }\end{array}$ & 10th & 50th & 90th & $\mathbf{N}$ & $\begin{array}{l}\text { Field } \\
\text { LOD }\end{array}$ & 10th & 50th & 90th \\
\hline \multirow{5}{*}{ Selenium } & Personal & 88 & 0.03 & $<L O D$ & $<L O D$ & 3.8 & 80 & 0.03 & $<L O D$ & $<$ LOD & 8.3 \\
\hline & Indoor & 221 & 0.05 & $<$ LOD & 1.0 & 3.4 & 214 & 0.05 & $<$ LOD & 0.7 & 5.0 \\
\hline & Gaylord & 10 & 0.05 & 0.9 & 1.9 & 7.3 & 15 & 0.05 & $<$ LOD & 2.1 & 9.1 \\
\hline & Kennedy & 28 & 0.05 & 0.2 & 1.6 & 4.8 & 29 & 0.05 & $<L O D$ & 2.3 & 13.4 \\
\hline & Ambient & 46 & 0.05 & $<$ LOD & 1.8 & 6.3 & 56 & 0.05 & 0.2 & 3.5 & 13.8 \\
\hline \multirow{5}{*}{ Sodium } & Personal & 108 & 0.07 & $<$ LOD & $<$ LOD & 967.7 & 0 & 0.07 & NA & NA & NA \\
\hline & Indoor & 287 & 0.05 & $<$ LOD & $<L O D$ & 345.7 & 0 & 0.05 & NA & NA & NA \\
\hline & Gaylord & 18 & 0.05 & $<$ LOD & $<$ LOD & 103.0 & 0 & 0.05 & NA & NA & NA \\
\hline & Kennedy & 38 & 0.05 & $<$ LOD & $<$ LOD & 212.2 & 0 & 0.05 & NA & NA & NA \\
\hline & Ambient & 48 & 0.05 & $<$ LOD & $<$ LOD & 287.7 & 0 & 0.05 & NA & NA & NA \\
\hline \multirow{5}{*}{ Tin } & Personal & 118 & 0.04 & $<\mathrm{LOD}$ & $<L O D$ & 4.0 & 167 & 0.04 & $<L O D$ & $<$ LOD & 1.4 \\
\hline & Indoor & 311 & 0.05 & $<$ LOD & 0.2 & 3.0 & 395 & 0.05 & $<$ LOD & 0.1 & 2.5 \\
\hline & Gaylord & 18 & 0.05 & $<L O D$ & 0.1 & 1.4 & 28 & 0.05 & $<L O D$ & 0.1 & 4.6 \\
\hline & Kennedy & 41 & 0.05 & $<$ LOD & 0.1 & 1.2 & 49 & 0.05 & $<L O D$ & $<$ LOD & 3.0 \\
\hline & Ambient & 59 & 0.05 & $<L O D$ & 0.1 & 2.2 & 88 & 0.05 & $<L O D$ & $<L O D$ & 2.6 \\
\hline \multirow{5}{*}{ Titanium } & Personal & 130 & 0.02 & $<$ LOD & $<$ LOD & 79.1 & 138 & 0.02 & $<$ LOD & $<L O D$ & 46.3 \\
\hline & Indoor & 326 & 0.06 & $<$ LOD & $<L O D$ & 32.2 & 331 & 0.06 & $<L O D$ & $<$ LOD & 45.2 \\
\hline & Gaylord & 19 & 0.06 & $<L O D$ & $<L O D$ & 15.0 & 22 & 0.06 & $<L O D$ & $<L O D$ & 28.5 \\
\hline & Kennedy & 48 & 0.06 & $<$ LOD & $<$ LOD & 25.0 & 43 & 0.06 & $<$ LOD & $<L O D$ & 45.6 \\
\hline & Ambient & 64 & 0.06 & $<$ LOD & $<$ LOD & 74.7 & 81 & 0.06 & $<$ LOD & $<L O D$ & 60.9 \\
\hline \multirow{5}{*}{ Vanadium } & Personal & 130 & 0.02 & $<\mathrm{LOD}$ & 2.3 & 9.7 & 148 & 0.02 & $<$ LOD & 0.3 & 4.7 \\
\hline & Indoor & 336 & 0.05 & $<L O D$ & 1.3 & 3.9 & 369 & 0.05 & $<$ LOD & 1.0 & 5.4 \\
\hline & Gaylord & 18 & 0.05 & $<$ LOD & 1.0 & 2.1 & 28 & 0.05 & $<$ LOD & 1.2 & 2.7 \\
\hline & Kennedy & 48 & 0.05 & $<$ LOD & 1.3 & 3.5 & 45 & 0.05 & $<$ LOD & 1.8 & 6.3 \\
\hline & Ambient & 63 & 0.05 & $<$ LOD & 1.8 & 4.2 & 85 & 0.05 & $<$ LOD & 1.5 & 10.1 \\
\hline \multirow{5}{*}{ Zinc } & Personal & 140 & 0.05 & 2.5 & 64.4 & 211.8 & 169 & 0.05 & $<L O D$ & 12.0 & 171.2 \\
\hline & Indoor & 370 & 0.08 & 9.8 & 47.3 & 125.2 & 398 & 0.08 & $<L O D$ & 26.9 & 129.2 \\
\hline & Gaylord & 22 & 0.08 & 19.4 & 72.5 & 171.0 & 27 & 0.08 & $<$ LOD & 61.0 & 344.8 \\
\hline & Kennedy & 52 & 0.08 & 12.9 & 66.9 & 141.7 & 50 & 0.08 & $<$ LOD & 46.6 & 205.3 \\
\hline & Ambient & 74 & 0.08 & 9.0 & 43.3 & 122.5 & 92 & 0.08 & $<$ LOD & 27.0 & 185.1 \\
\hline
\end{tabular}

"Gaylord and Kennedy are rooftop monitors. "LLOD" indicates concentrations that were below the corresponding field LOD.

\subsubsection{Associations Among Personal, Indoor, and Ambient Elemental Concentrations}

Associations among personal, indoor, and ambient concentrations were examined for a subset of six elements, including $\mathrm{Cu}, \mathrm{Fe}, \mathrm{K}, \mathrm{Pb}$, Se, and $\mathrm{V}$. These elements were selected based on their water-extractable and acid-digestible concentrations, their relevance to health studies, and their precision (as determined from QA/QC results). Despite being selected on the basis of these considerations, it is important to note that measurements of these elements were nevertheless relatively imprecise, and their concentrations were still low relative to the sensitivity of the method. Hence, the results presented below should be interpreted with caution. 


\subsection{Association between Personal Exposures and Indoor Concentrations}

Associations between personal exposures and indoor concentrations differed by element, extraction method, and season (Table 80). For acid-digestible concentrations, intercepts of the regression lines for personal concentrations as a function of indoor concentrations were generally significant in both seasons (with the exception of $\mathrm{Pb}$ in the fall), with very large intercepts for $\mathrm{Fe}$ and $\mathrm{K}$. These large intercepts suggest that personal exposures to $\mathrm{Fe}$ and $\mathrm{K}$ are affected by a source that is independent of the indoor microenvironment. Slopes describing the personal-indoor associations tended to be significant in the summer, with the exception of $\mathrm{Cu}$. Slopes were close to 1.00 for $\mathrm{V}$, and to a lesser extent for Fe, which is consistent with the fact that individuals spend most of their time indoors. In the fall, slopes describing the personal-indoor associations were significant only for $\mathrm{V}$ and $\mathrm{Fe}$, with slopes for both elements lower than those in the summer.

Table 80. Personal vs. indoor concentrations of select elements (acid-digestible) for the older adult cohort.*

\begin{tabular}{|c|c|c|c|c|c|c|c|c|c|c|}
\hline \multirow{2}{*}{ Pollutant } & \multicolumn{9}{|c|}{ Summer } & \multicolumn{5}{|c|}{ Fall } \\
\cline { 2 - 11 } & $\mathbf{N}$ & $\boldsymbol{\beta}$ & $\mathbf{S E}$ & $\mathbf{t}-\mathbf{s t a t}$ & $\mathbf{I n t}$ & $\mathbf{N}$ & $\boldsymbol{\beta}$ & $\mathbf{S E}$ & $\mathbf{t}-\mathbf{s t a t}$ & Int. \\
\hline $\mathrm{Cu}$ & 57 & 0.20 & 0.15 & 1.35 & $\mathbf{1 0 . 8 9}$ & 186 & 0.13 & 0.10 & 1.28 & $\mathbf{1 3 . 9 1}$ \\
\hline $\mathrm{Fe}$ & 149 & $\mathbf{0 . 7 5}$ & 0.12 & 6.33 & $\mathbf{1 5 5 . 1 9}$ & 204 & $\mathbf{0 . 5 7}$ & 0.04 & 15.11 & $\mathbf{1 1 2 . 8 7}$ \\
\hline $\mathrm{K}$ & 117 & $\mathbf{0 . 2 5}$ & 0.04 & 5.64 & $\mathbf{1 5 1 . 9 4}$ & 169 & 0.04 & 0.03 & 1.10 & $\mathbf{1 3 2 . 5 6}$ \\
\hline $\mathrm{Pb}$ & 141 & $\mathbf{0 . 5 8}$ & 0.08 & 7.49 & $\mathbf{3 . 5 7}$ & 169 & 0.38 & 0.24 & 1.58 & 7.52 \\
\hline $\mathrm{Se}$ & 78 & $\mathbf{0 . 4 2}$ & 0.09 & 4.59 & $\mathbf{1 . 9 0}$ & 60 & 0.31 & 0.19 & 1.67 & $\mathbf{4 . 2 3}$ \\
\hline $\mathrm{V}$ & 130 & $\mathbf{0 . 9 6}$ & 0.49 & 1.96 & $\mathbf{2 . 9 2}$ & 148 & $\mathbf{0 . 3 9}$ & 0.08 & 4.86 & $\mathbf{1 . 6 9}$ \\
\hline
\end{tabular}

*bold numbers indicate $p$-value $\leq 0.05$

The personal-indoor associations for the six water-extractable elements showed a different pattern, although they too varied by element and season (Table 81). Intercepts of the personalon-indoor regression lines for the water-extractable elements were largely significant, especially in the fall. Intercepts, however, were lower for water-soluble $\mathrm{K}$ and especially $\mathrm{Fe}$ in both seasons as compared to those for their acid-digestible counterparts. Slopes describing the personal-indoor associations were generally well below 1.00 , even when significant. In contrast to the acid-digestible elements, slopes for the six elements tended to be significant in the fall as compared to summer, as all but $\mathrm{Cu}$ had significant fall slopes. However, for $\mathrm{V}$, Se, and $\mathrm{K}$, for which the slopes were significant in both seasons, the slopes were greater in the summer than in the fall.

Table 81. Personal vs. indoor concentrations of select elements (water-extractable) for the older adult cohort.* $^{*}$

\begin{tabular}{|c|c|c|c|c|c|c|c|c|c|c|}
\hline \multirow{2}{*}{ Pollutant } & \multicolumn{9}{|c|}{ Summer } & \multicolumn{4}{c|}{ Fall } \\
\cline { 2 - 12 } & $\mathbf{N}$ & $\boldsymbol{\beta}$ & $\mathbf{S E}$ & $\mathbf{t}-\mathbf{s t a t}$ & Int. & $\mathbf{N}$ & $\boldsymbol{\beta}$ & $\mathbf{S E}$ & t-stat & Int. \\
\hline $\mathrm{Cu}$ & 11 & $\mathrm{n} / \mathrm{a}$ & $\mathrm{n} / \mathrm{a}$ & $\mathrm{n} / \mathrm{a}$ & $\mathrm{n} / \mathrm{a}$ & 84 & -0.02 & 0.46 & 0.96 & $\mathbf{5 0 . 3 6}$ \\
\hline $\mathrm{Fe}$ & 88 & 0.04 & 0.02 & 1.67 & $\mathbf{2 9 . 6 7}$ & 76 & $\mathbf{0 . 3 8}$ & 0.04 & 9.11 & $\mathbf{3 4 . 7 3}$ \\
\hline $\mathrm{K}$ & 83 & $\mathbf{0 . 4 0}$ & 0.07 & 5.76 & $\mathbf{5 4 . 4 7}$ & 102 & $\mathbf{0 . 0 7}$ & 0.04 & 2.00 & $\mathbf{8 9 . 6 5}$ \\
\hline $\mathrm{Pb}$ & 68 & 0.10 & 0.09 & 1.10 & $\mathbf{1 6 . 3 4}$ & 93 & $\mathbf{0 . 1 3}$ & 0.02 & 5.86 & $\mathbf{1 2 . 9 9}$ \\
\hline $\mathrm{Se}$ & 103 & $\mathbf{0 . 7 5}$ & 0.04 & 19.77 & 0.25 & 104 & $\mathbf{0 . 4 7}$ & 0.06 & 8.41 & $\mathbf{1 . 5 8}$ \\
\hline $\mathrm{V}$ & 103 & $\mathbf{0 . 6 0}$ & 0.04 & 14.46 & $\mathbf{0 . 2 7}$ & 115 & $\mathbf{0 . 4 0}$ & 0.04 & 10.47 & $\mathbf{1 . 0 8}$ \\
\hline
\end{tabular}

${ }^{*}$ bold numbers indicate $p$-value $\leq 0.05$ 


\subsection{Association between Indoor Concentrations and Ambient Concentrations}

Indoor concentrations of all of the selected acid-digestible elements (except for $\mathrm{Cu}$ in the summer) were significantly associated with corresponding ambient concentrations in both seasons, as evidenced by the significant slopes shown in Table 82. As was the case with personal-indoor associations, intercepts for the indoor-ambient associations were largest for $\mathrm{Fe}$ and $\mathrm{K}$ in both seasons. Although significant, indoor-ambient slopes for the acid-digestible elements varied around 0.50 , with $\mathrm{K}$ having the greatest slope in both seasons. Slopes did not show a consistent seasonal pattern.

Water-extractable elements also tended to exhibit significant associations between indoor and ambient concentrations (Table 83). Indoor-ambient slopes for the water-extractable elements tended to be more strongly significant than those for the acid-digestible elements, as evidenced by the higher t-statistics. Furthermore, indoor-ambient slopes for the water-extractable elements, particularly for $\mathrm{Cu}$ in the fall and for $\mathrm{Fe}$ and $\mathrm{K}$ in both seasons, tended to be closer to 1.00 than slopes for corresponding acid-digestible elements. Associations between indoor and ambient concentrations for both the acid-extractable and water-soluble elements differed substantially from those observed between personal and indoor levels. Factors contributing to these differences are not known.

Table 82. Indoor vs. ambient concentrations of select elements (acid-digestible) for the older adult cohort.* $^{*}$

\begin{tabular}{|c|c|c|c|c|c|c|c|c|c|c|}
\hline \multirow{2}{*}{ Pollutant } & \multicolumn{9}{|c|}{ Summer } & \multicolumn{5}{c|}{ Fall } \\
\cline { 2 - 11 } & $\mathbf{N}$ & $\boldsymbol{\beta}$ & $\mathbf{S E}$ & $\mathbf{t}-\mathbf{s t a t}$ & Int. & $\mathbf{N}$ & $\boldsymbol{\beta}$ & $\mathbf{S E}$ & t-stat & Int. \\
\hline $\mathrm{Cu}$ & 57 & 0.02 & 0.07 & 0.31 & $\mathbf{6 . 0 8}$ & 101 & $\mathbf{0 . 0 4}$ & 0.02 & 2.13 & $\mathbf{8 . 6 2}$ \\
\hline $\mathrm{Fe}$ & 76 & $\mathbf{0 . 2 8}$ & 0.04 & 6.90 & $\mathbf{1 1 0 . 5 4}$ & 104 & $\mathbf{0 . 4 1}$ & 0.03 & 13.88 & $\mathbf{1 3 4 . 1 7}$ \\
\hline $\mathrm{K}$ & 55 & $\mathbf{0 . 7 0}$ & 0.06 & 10.98 & $\mathbf{4 0 . 8 6}$ & 88 & $\mathbf{0 . 6 5}$ & 0.19 & 3.38 & $\mathbf{6 6 . 0 8}$ \\
\hline $\mathrm{Pb}$ & 73 & $\mathbf{0 . 3 4}$ & 0.06 & 5.75 & $\mathbf{4 . 0 4}$ & 91 & $\mathbf{0 . 4 3}$ & 0.03 & 14.86 & $\mathbf{3 . 9 9}$ \\
\hline $\mathrm{Se}$ & 46 & $\mathbf{0 . 3 9}$ & 0.03 & 11.62 & $\mathbf{0 . 7 6}$ & 56 & $\mathbf{0 . 2 6}$ & 0.03 & 10.21 & $\mathbf{0 . 8 9}$ \\
\hline $\mathrm{V}$ & 63 & $\mathbf{0 . 5 0}$ & 0.04 & 14.11 & $\mathbf{0 . 8 5}$ & 85 & $\mathbf{0 . 4 7}$ & 0.04 & 11.29 & $\mathbf{0 . 8 2}$ \\
\hline
\end{tabular}

*bold numbers indicate $p$-value $\leq 0.05$

Table 83. Indoor vs. ambient concentrations of select elements (water-extractable) for the older adult cohort.* $^{*}$

\begin{tabular}{|c|c|c|c|c|c|c|c|c|c|c|}
\hline \multirow{2}{*}{ Pollutant } & \multicolumn{9}{|c|}{ Summer } & \multicolumn{5}{|c|}{ Fall } \\
\cline { 2 - 11 } & $\mathbf{N}$ & $\boldsymbol{\beta}$ & $\mathbf{S E}$ & $\mathbf{t}-\mathbf{s t a t}$ & Int. & $\mathbf{N}$ & $\boldsymbol{\beta}$ & $\mathbf{S E}$ & t-stat & Int. \\
\hline $\mathrm{Cu}$ & 21 & 0.04 & 0.07 & 0.59 & 22.24 & 101 & $\mathbf{1 . 0 7}$ & 0.44 & 2.42 & $\mathbf{9 . 3 3}$ \\
\hline $\mathrm{Fe}$ & 76 & $\mathbf{0 . 2 5}$ & 0.11 & 2.24 & $\mathbf{1 8 . 3 5}$ & 104 & $\mathbf{0 . 8 4}$ & 0.05 & 16.60 & 4.16 \\
\hline $\mathrm{K}$ & 55 & $\mathbf{0 . 8 1}$ & 0.03 & 28.77 & $\mathbf{2 9 . 1 6}$ & 88 & $\mathbf{0 . 8 5}$ & 0.14 & 6.12 & $\mathbf{4 9 . 7 2}$ \\
\hline $\mathrm{Pb}$ & 73 & $\mathbf{0 . 3 7}$ & 0.06 & 5.73 & $\mathbf{5 . 4 8}$ & 91 & $\mathbf{0 . 1 8}$ & 0.06 & 2.90 & $\mathbf{1 3 . 9 0}$ \\
\hline $\mathrm{Se}$ & 46 & $\mathbf{0 . 4 4}$ & 0.02 & 22.39 & 0.30 & 56 & $\mathbf{0 . 4 2}$ & 0.03 & 13.28 & 0.42 \\
\hline $\mathrm{V}$ & 63 & $\mathbf{0 . 3 6}$ & 0.02 & 22.69 & $\mathbf{0 . 1 8}$ & 85 & $\mathbf{0 . 4 8}$ & 0.03 & 17.43 & $\mathbf{0 . 5 8}$ \\
\hline
\end{tabular}

${ }^{*}$ bold numbers indicate $p$-value $\leq 0.05$

\subsection{Association between Personal Exposures and Ambient Concentrations}

Summertime personal exposures were significantly associated with corresponding ambient concentrations of all the selected acid-digestible elements, except for $\mathrm{Cu}$, as evidenced by the significant slopes shown in Table 84. In the fall, personal-ambient slopes were significant for $\mathrm{Fe}, \mathrm{Pb}$, and $\mathrm{V}$, with significant intercepts for all selected elements except for Se. As was the case with personal-indoor and indoor-ambient associations, intercepts for the personal-ambient 
associations were largest for $\mathrm{Fe}$ and $\mathrm{K}$ in both seasons. Slopes for the acid-digestible elements did not show a pattern consistent with season or with personal-indoor or indoor-ambient associations.

Water-extractable elements also tended to exhibit significant associations between personal exposures and ambient concentrations (Table 85); however, associations were unrelated to those for acid-digestible elements. Associations between personal and ambient concentrations for both the acid-digestible and water-extractable elements differed substantially from those observed between personal and indoor levels and between indoor and ambient levels. Factors contributing to these differences are not known.

Table 84. Personal vs. ambient concentrations of select elements (acid-digestible) for the older adult cohort. * $^{*}$

\begin{tabular}{|c|c|c|c|c|c|c|c|c|c|c|}
\hline \multirow{2}{*}{ Pollutant } & \multicolumn{9}{|c|}{ Summer } & \multicolumn{4}{|c|}{ Fall } \\
\cline { 2 - 12 } & $\mathbf{N}$ & $\boldsymbol{\beta}$ & $\mathbf{S E}$ & $\mathbf{t}-\mathbf{s t a t}$ & Int. & $\mathbf{N}$ & $\boldsymbol{\beta}$ & $\mathbf{S E}$ & $\mathbf{t}-\mathbf{s t a t}$ & Int. \\
\hline $\mathrm{Cu}$ & 47 & $\mathrm{NA}$ & $\mathrm{NA}$ & $\mathrm{NA}$ & NA & 101 & 0.11 & 0.06 & 1.84 & $\mathbf{1 4 . 4 1}$ \\
\hline $\mathrm{Fe}$ & 76 & $\mathbf{0 . 2 7}$ & 0.10 & 2.59 & $\mathbf{2 1 3 . 8 5}$ & 104 & $\mathbf{0 . 4 2}$ & 0.02 & 16.94 & $\mathbf{1 2 5 . 2 3}$ \\
\hline $\mathrm{K}$ & 55 & $\mathbf{0 . 3 9}$ & 0.05 & 7.39 & $\mathbf{1 4 2 . 1 2}$ & 88 & -0.36 & 0.18 & -2.02 & $\mathbf{1 8 1 . 5 9}$ \\
\hline $\mathrm{Pb}$ & 73 & $\mathbf{0 . 2 0}$ & 0.06 & 3.36 & $\mathbf{5 . 0 4}$ & 91 & $\mathbf{0 . 4 3}$ & 0.02 & 19.19 & $\mathbf{2 . 6 9}$ \\
\hline $\mathrm{Se}$ & 46 & $\mathbf{0 . 1 5}$ & 0.05 & 3.19 & $\mathbf{1 . 8 7}$ & 56 & NA & NA & NA & NA \\
\hline $\mathrm{V}$ & 63 & $\mathbf{0 . 7 3}$ & 0.10 & 7.26 & $\mathbf{2 . 0 6}$ & 85 & $\mathbf{0 . 3 3}$ & 0.08 & 4.06 & $\mathbf{1 . 7 9}$ \\
\hline
\end{tabular}

*bold numbers indicate $p$-value $\leq 0.05$

Table 85. Personal vs. ambient concentrations of select elements (water-extractable) for the older adult cohort.*

\begin{tabular}{|c|c|c|c|c|c|c|c|c|c|c|}
\hline \multirow{2}{*}{ Pollutant } & \multicolumn{9}{|c|}{ Summer } & \multicolumn{5}{c|}{ Fall } \\
\cline { 2 - 12 } & $\mathbf{N}$ & $\boldsymbol{\beta}$ & $\mathbf{S E}$ & $\mathbf{t}-\mathbf{s t a t}$ & Int. & $\mathbf{N}$ & $\boldsymbol{\beta}$ & $\mathbf{S E}$ & t-stat & Int. \\
\hline $\mathrm{Cu}$ & 15 & $\mathrm{NA}$ & $\mathrm{NA}$ & NA & NA & 95 & -1.20 & 1.24 & -0.96 & $\mathbf{5 3 . 3 4}$ \\
\hline $\mathrm{Fe}$ & 76 & $\mathbf{0 . 2 1}$ & 0.04 & 5.92 & $\mathbf{1 8 . 0 9}$ & 104 & $\mathbf{0 . 4 5}$ & 0.05 & 9.02 & $\mathbf{2 6 . 7 5}$ \\
\hline $\mathrm{K}$ & 55 & 0.27 & 0.23 & 1.17 & $\mathbf{9 2 . 7 4}$ & 88 & $\mathbf{0 . 4 5}$ & 0.11 & 3.97 & $\mathbf{7 4 . 4 4}$ \\
\hline $\mathrm{Pb}$ & 73 & $\mathbf{0 . 4 0}$ & 0.14 & 2.95 & $\mathbf{1 4 . 1 4}$ & 91 & $\mathbf{0 . 1 4}$ & 0.03 & 5.44 & $\mathbf{1 2 . 1 2}$ \\
\hline $\mathrm{Se}$ & 46 & $\mathbf{0 . 5 1}$ & 0.02 & 30.04 & -0.21 & 56 & $\mathbf{0 . 3 1}$ & 0.04 & 7.10 & $\mathbf{1 . 0 3}$ \\
\hline $\mathrm{V}$ & 63 & $\mathbf{0 . 3 0}$ & 0.02 & 15.64 & $\mathbf{0 . 2 7}$ & 85 & $\mathbf{0 . 3 2}$ & 0.02 & 13.27 & $\mathbf{0 . 9 5}$ \\
\hline
\end{tabular}

*bold numbers indicate $p$-value $\leq 0.05$

\subsubsection{Children's Cohort}

\subsubsection{Participant Summary and Characteristics}

A total of 19 children participated in the study. Their homes are identified in Figure 64. Sixteen subjects between the ages of 10 and 12 years participated in the winter 2001 season; 62.5\% were female. Fifteen participants between the ages of 9 and 13 years, including 12 who had participated in the winter season, were sampled in the summer; $66.7 \%$ of the participants in the summer season were female.

\subsubsection{Housing Summary and Characteristics}

Housing characteristics for the cohort of children are summarized in Table 86. A large fraction of the children's homes had electric stoves and central heating systems. Central heating systems were also supplemented with gas and space heaters in a few homes. All but one 
home had a source of ventilation in the kitchen area (i.e., fan over the cooking stove, range, oven, or elsewhere). Fourteen of the 19 homes had central air conditioning. Window air conditioning units were found in nine homes, with four of these homes having at least two units. Identifiable sources of dust (i.e., busy road, dirt road, other source of dust) were found at six homes. Two homes were located next to both a busy road and a dirt road.

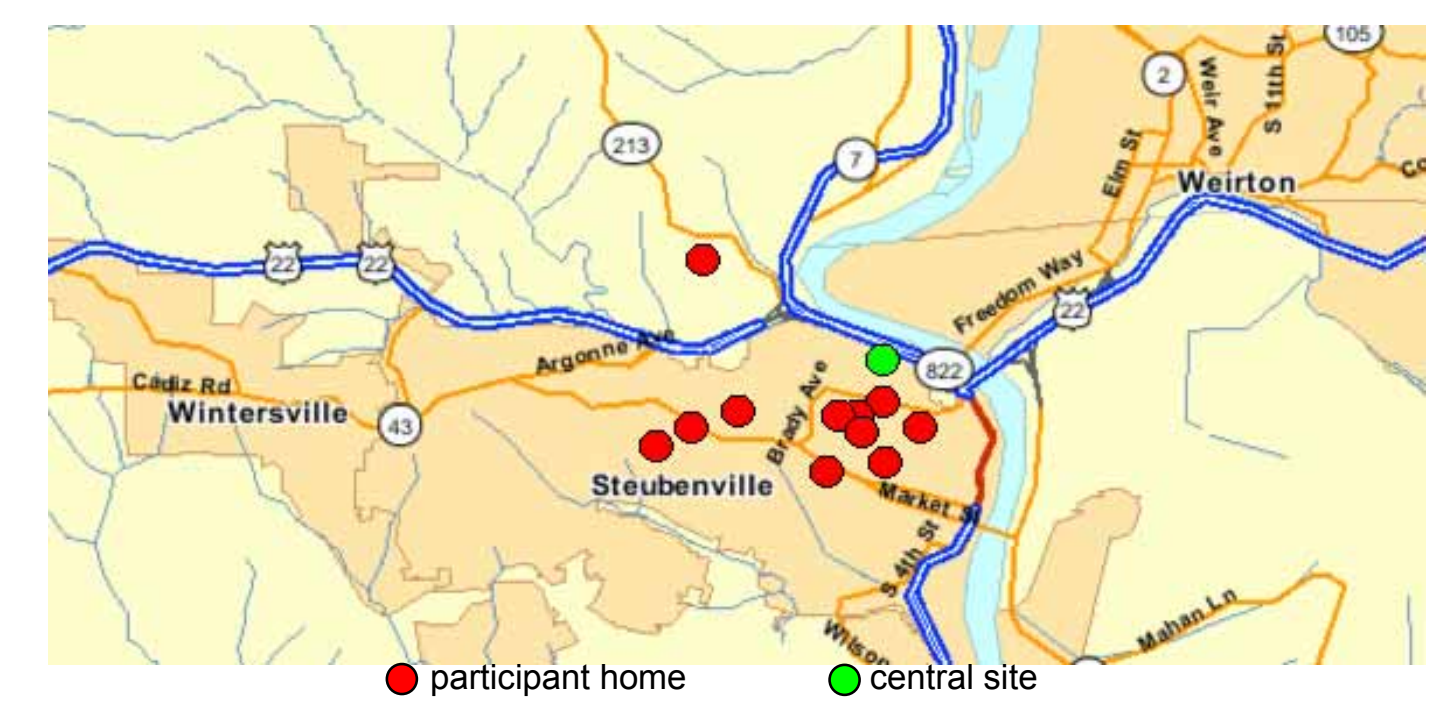

Figure 64. Locations of the residences of participants in the children's cohort. The central ambient air monitoring site was located at the Franciscan University of Steubenville.

Table 86. Housing characteristics of the children's cohort.

\begin{tabular}{|c|l|c|}
\hline \multicolumn{2}{|c|}{ Housing Characteristic } & Count \\
\hline \multirow{4}{*}{ Cooking Fuel } & Gas & 5 \\
\cline { 2 - 3 } & Electric & 14 \\
\hline \multirow{4}{*}{ Heating Source } & Central & 16 \\
\cline { 2 - 3 } & Radiator & 3 \\
\cline { 2 - 3 } & Space & 2 \\
\cline { 2 - 3 } & Fireplace & 1 \\
\cline { 2 - 3 } & Gas & 1 \\
\cline { 2 - 3 } & Electric Coil & 1 \\
\hline \multirow{4}{*}{ Ventilation } & Kitchen Fan & 18 \\
\cline { 2 - 3 } & Central AC Units & 14 \\
\cline { 2 - 3 } & Window Units & 9 \\
\hline \multirow{2}{*}{ Outdoor Sources } & Busy Road & 4 \\
\cline { 2 - 3 } & Dirt Road & 4 \\
\hline
\end{tabular}

\subsubsection{Time-Activity Data Summary}

Results from the children's time-activity questionnaires are summarized in Table 87. This table displays the mean fraction of time spent in various microenvironments, in transit, or near pollutant sources or ventilation over the 24-hr periods when personal measurements were collected. When averaged over all sampling days, subjects spent the vast majority of their time 
indoors at home. In the winter, $71 \%$ of the time was spent indoors at home, while in the summer, the mean percent of time spent indoors at home equaled $81 \%$. Subjects spent the next largest fraction of time indoors but away from home. On average, subjects spent $15 \%$ of the day indoors but away from home ( $24 \%$ in winter; $8 \%$ in the summer). The children's cohort spent, on average, $2 \%$ and $9 \%$ of their time outdoors for the winter and summer seasons, respectively. Only two participants, on average, spent greater than $10 \%$ of their time outdoors. Relatively little time was spent in transit, with the highest average travel time being spent in a car when compared to other modes of transportation (i.e., bus, walking, bicycle).

Table 87. Fraction of time spent in various locations, in transit, and near sources for the children's cohort.

\begin{tabular}{|l|c|c|c|c|c|c|c|c|c|c|}
\hline \multirow{2}{*}{\multicolumn{1}{c|}{ Location }} & \multicolumn{4}{|c|}{ Winter } & \multicolumn{4}{c|}{ Summer } \\
\cline { 2 - 12 } & Mean & SD & Median & Min & Max & Mean & SD & Median & Min & Max \\
\hline Indoors, Home and Away & 0.95 & 0.02 & 0.96 & 0.88 & 0.99 & 0.88 & 0.06 & 0.88 & 0.78 & 0.99 \\
\hline Indoors, Home & 0.71 & 0.07 & 0.71 & 0.59 & 0.79 & 0.81 & 0.09 & 0.81 & 0.68 & 0.98 \\
\hline Indoors, Away from Home & 0.24 & 0.06 & 0.23 & 0.16 & 0.36 & 0.08 & 0.05 & 0.08 & 0.01 & 0.19 \\
\hline Outdoors & 0.02 & 0.01 & 0.02 & 0.00 & 0.04 & 0.09 & 0.06 & 0.09 & 0.00 & 0.21 \\
\hline Travel by Car & 0.02 & 0.01 & 0.02 & 0.01 & 0.07 & 0.02 & 0.01 & 0.02 & 0.01 & 0.05 \\
\hline Travel by Bus & 0.00 & 0.01 & 0.00 & 0.00 & 0.04 & 0.00 & 0.00 & 0.00 & 0.00 & 0.00 \\
\hline Travel by Walking & 0.00 & 0.00 & 0.00 & 0.00 & 0.01 & 0.00 & 0.00 & 0.00 & 0.00 & 0.00 \\
\hline Travel by Bicycle & 0.00 & 0.00 & 0.00 & 0.00 & 0.00 & 0.00 & 0.00 & 0.00 & 0.00 & 0.00 \\
\hline Near Smoker & 0.00 & 0.00 & 0.00 & 0.00 & 0.02 & 0.00 & 0.01 & 0.00 & 0.00 & 0.02 \\
\hline Near Open Window & 0.01 & 0.02 & 0.00 & 0.00 & 0.08 & 0.32 & 0.29 & 0.28 & 0.00 & 0.82 \\
\hline
\end{tabular}

Note: Data obtained from time-activity diaries. Values represent mean fraction of time over 24-hr period for all person-days.

\subsubsection{Pollutant Summary}

\subsection{Precision, Accuracy, and Data Completeness}

Sample validity, limits of detection, completeness, and imprecision for the major pollutant data collected for the children's cohort are presented in Table 88.

Pollutant concentrations were measured successfully during the study, as indicated by the high rates of completeness found in this study. The field LODs were calculated as the $95^{\text {th }}$ percentile of the net mass of the blank samples. $\mathrm{SO}_{4}{ }^{2-}$ and indoor and outdoor $\mathrm{PM}_{2.5}$ concentrations were typically greater than the limit of detection. Note that $\mathrm{SO}_{2}$ values were not reported, because they were largely below the LOD.

Table 88. Quality assurance parameters - children's cohort. ${ }^{*}$

\begin{tabular}{|l|c|c|c|c|c|}
\hline Pollutant & $\mathbf{N}$ & Field LOD & \% > Field LOD & Completeness & Precision \\
\hline $\mathrm{PM}_{2.5}$ (personal) & 509 & 18.71 & $83 \%$ & $100 \%$ & $8 \%$ \\
\hline $\mathrm{PM}_{2.5}$ (indoor/outdoor) & 1024 & 8.36 & $99 \%$ & $100 \%$ & $9 \%$ \\
\hline $\mathrm{SO}_{4}{ }^{2-}$ & 769 & 0.18 & $100 \%$ & $99 \%$ & $7 \%$ \\
\hline $\mathrm{EC}$ & 762 & 0.33 & $75 \%$ & $100 \%$ & $17 \%$ \\
\hline $\mathrm{O}_{3}$ & 803 & 7.03 & $58 \%$ & $98 \%$ & $24 \%$ \\
\hline $\mathrm{NO}_{2}$ & 801 & 10.36 & $53 \%$ & $99 \%$ & $29 \%$ \\
\hline
\end{tabular}

*Limit of detection for $\mathrm{PM}_{2.5}, \mathrm{SO}_{4}{ }^{2-}$, and $\mathrm{EC}$ in $\mu \mathrm{g}$, for gases in $\mathrm{ng}$ 


\subsection{Ambient Concentrations}

Table 89 shows summary statistics for ambient pollutant concentrations (by season) measured by the Harvard multi-pollutant monitor at the SCAMP central ambient air monitoring site. Mean ambient concentrations were higher in the summer than in the winter, particularly for the regional pollutants $\mathrm{PM}_{2.5}, \mathrm{SO}_{4}{ }^{2-}$, and $\mathrm{O}_{3}$. For example, the ratio of summer/winter means for $\mathrm{SO}_{4}{ }^{2-}$ was about 2.5. In contrast, ambient $\mathrm{EC}$ and $\mathrm{NO}_{2}$ concentrations were only slightly higher in the summer as compared to winter (summer/winter ratio $=1.1$ for both pollutants). $\mathrm{O}_{3}$ and $\mathrm{PM}_{2.5}$ concentrations were the most variable, with standard deviations of 10.04 (winter) and 27.26 (summer), and 7.22 (winter) and 13.96 (summer), respectively.

\subsection{Outdoor Concentrations}

Mean concentrations of each of the pollutants (except for $\mathrm{NO}_{2}$ ) measured outside of the participants' homes were greater in the summer than in the winter (Table 89). As was the case with ambient pollution, the greatest seasonal difference was found for $\mathrm{SO}_{4}{ }^{2-}$, with the average summer concentration almost three times higher than that in the winter. The mean value for $\mathrm{PM}_{2.5}$ was almost two times higher in the summer as compared to the winter. Values in the summer were also more variable (with the exception of EC values), as shown by the greater standard deviations during that season.

\subsection{Personal and Indoor Concentrations}

As was the case outdoors, mean concentrations of all of the major pollutants except for $\mathrm{NO}_{2}$ inside the participants' homes were higher in the summer than in the winter (Table 89), with a mean $\mathrm{SO}_{4}{ }^{2-}$ concentration three times higher in the summer as compared to the winter (ratios of summer-to-winter means were 2.0 for $\mathrm{PM}_{2.5} ; 1.2$ for $\mathrm{EC} ; 2.2$ for $\mathrm{O}_{3}$; and 0.7 for $\mathrm{NO}_{2}$ ). Mean indoor concentrations, however, were less than outdoor concentrations with the exception of $\mathrm{NO}_{2}$ in the winter and EC in the summer (indoor/outdoor ratio is 1.1 for both exceptions). Indoor $\mathrm{O}_{3}$ concentrations were substantially less than corresponding outdoor values. In the winter and summer, the mean outdoor $\mathrm{O}_{3}$ concentration was eight and four times greater than that indoors, respectively. Similarly, mean personal exposures for all pollutants except $\mathrm{NO}_{2}$ were higher in the summer season as compared to the winter (ratios of summer-to-winter means: $\mathrm{PM}_{2.5}=1.7$; $\left.\mathrm{SO}_{4}{ }^{2-}=3.3 ; \mathrm{EC}=1.9 ; \mathrm{O}_{3}=1.8 ; \mathrm{NO}_{2}=0.7\right)$.

Personal exposures were similar to, although typically greater than, indoor concentrations. For example, personal-indoor ratios were $1.6 \pm 1.0,1.1 \pm 0.4,1.3 \pm 0.5,1.8 \pm 3.6$, and $1.2 \pm 0.9$ for $\mathrm{PM}_{2.5}, \mathrm{SO}_{4}{ }^{2-}, \mathrm{EC}, \mathrm{O}_{3}$, and $\mathrm{NO}_{2}$, respectively, in the winter, and $1.1 \pm 0.4,1.2 \pm 0.6,1.2 \pm 0.5,1.2$ \pm 1.7 , and $1.3 \pm 2.1$, respectively, for these pollutants in the summer.

Mean personal exposures were typically less than outdoor concentrations. Exceptions include $\mathrm{EC}$ (personal/outdoor ratio $=1.2 \pm 0.8$ in the winter, $2.2 \pm 12$ in the summer) and $\mathrm{NO}_{2}$ in the winter (personal/outdoor ratio $=1.6 \pm 2.3$ ), for which mean personal exposures were slightly greater than mean outdoor concentrations. 
Table 89. Personal, indoor, outdoor, and ambient pollutant concentrations by season for the children's cohort.* $^{*}$

\begin{tabular}{|c|c|c|c|c|c|c|c|c|}
\hline Location & Pollutant & Season & $\mathbf{N}$ & \#ND & Mean & Median & SD & Max \\
\hline \multirow{10}{*}{ Ambient } & \multirow{2}{*}{$\mathrm{PM}_{2.5}$} & Winter & 56 & 0 & 15.41 & 14.97 & 7.22 & 37.47 \\
\hline & & Summer & 58 & 0 & 25.14 & 21.23 & 13.96 & 58.10 \\
\hline & \multirow{2}{*}{$\mathrm{SO}_{4}{ }^{2-}$} & Winter & 28 & 0 & 3.84 & 3.71 & 2.11 & 10.84 \\
\hline & & Summer & 29 & 0 & 9.39 & 7.80 & 6.58 & 25.34 \\
\hline & \multirow{2}{*}{ EC } & Winter & 28 & 1 & 0.74 & 0.53 & 0.43 & 1.55 \\
\hline & & Summer & 29 & 0 & 0.81 & 0.79 & 0.31 & 1.42 \\
\hline & \multirow{2}{*}{$\mathrm{O}_{3}$} & Winter & 28 & 0 & 24.80 & 21.13 & 10.04 & 62.82 \\
\hline & & Summer & 29 & 1 & 35.17 & 33.63 & 27.26 & 148.09 \\
\hline & \multirow{2}{*}{$\mathrm{NO}_{2}$} & Winter & 28 & 0 & 8.12 & 7.25 & 4.27 & 17.43 \\
\hline & & Summer & 29 & 2 & 9.04 & 6.21 & 10.38 & 46.47 \\
\hline \multirow{10}{*}{ Outdoor } & \multirow{2}{*}{$\mathrm{PM}_{2.5}$} & Winter & 220 & 0 & 13.44 & 12.62 & 6.10 & 36.38 \\
\hline & & Summer & 210 & 0 & 24.23 & 20.93 & 13.57 & 57.44 \\
\hline & \multirow{2}{*}{$\mathrm{SO}_{4}{ }^{2-}$} & Winter & 110 & 0 & 3.39 & 2.96 & 1.68 & 10.68 \\
\hline & & Summer & 105 & 0 & 9.03 & 8.13 & 5.88 & 24.79 \\
\hline & \multirow{2}{*}{ EC } & Winter & 110 & 2 & 0.58 & 0.47 & 0.32 & 1.45 \\
\hline & & Summer & 105 & 1 & 0.67 & 0.61 & 0.30 & 1.58 \\
\hline & \multirow{2}{*}{$\mathrm{O}_{3}$} & Winter & 110 & 0 & 20.17 & 19.53 & 7.07 & 45.13 \\
\hline & & Summer & 105 & 0 & 26.13 & 26.44 & 10.05 & 45.10 \\
\hline & \multirow{2}{*}{$\mathrm{NO}_{2}$} & Winter & 110 & 0 & 7.48 & 6.97 & 4.36 & 21.46 \\
\hline & & Summer & 105 & 11 & 6.43 & 5.93 & 5.91 & 23.79 \\
\hline \multirow{10}{*}{ Indoor } & \multirow{2}{*}{$\mathrm{PM}_{2.5}$} & Winter & 220 & 0 & 9.12 & 7.15 & 5.90 & 31.20 \\
\hline & & Summer & 210 & 0 & 18.50 & 15.09 & 12.42 & 60.85 \\
\hline & \multirow{2}{*}{$\mathrm{SO}_{4}{ }^{2-}$} & Winter & 110 & 0 & 1.93 & 1.46 & 1.23 & 7.09 \\
\hline & & Summer & 105 & 0 & 5.84 & 4.38 & 4.71 & 23.19 \\
\hline & \multirow{2}{*}{ EC } & Winter & 110 & 2 & 0.59 & 0.41 & 0.68 & 4.86 \\
\hline & & Summer & 105 & 0 & 0.71 & 0.50 & 1.57 & 16.14 \\
\hline & \multirow{2}{*}{$\mathrm{O}_{3}$} & Winter & 110 & 4 & 2.67 & 2.69 & 1.65 & 6.11 \\
\hline & & Summer & 105 & 48 & 5.95 & 1.70 & 8.61 & 48.68 \\
\hline & \multirow{2}{*}{$\mathrm{NO}_{2}$} & Winter & 110 & 0 & 8.08 & 6.31 & 5.56 & 27.20 \\
\hline & & Summer & 105 & 18 & 5.44 & 3.28 & 5.43 & 21.66 \\
\hline \multirow{10}{*}{ Personal } & \multirow{2}{*}{$\mathrm{PM}_{2.5}$} & Winter & 220 & 0 & 11.58 & 10.64 & 7.00 & 43.80 \\
\hline & & Summer & 210 & 0 & 19.63 & 16.25 & 12.86 & 63.89 \\
\hline & \multirow{2}{*}{$\mathrm{SO}_{4}{ }^{2-}$} & Winter & 110 & 0 & 1.91 & 1.44 & 1.25 & 6.50 \\
\hline & & Summer & 105 & 1 & 6.19 & 4.96 & 4.65 & 22.88 \\
\hline & \multirow{2}{*}{ EC } & Winter & 110 & 1 & 0.61 & 0.51 & 0.33 & 1.82 \\
\hline & & Summer & 105 & 2 & 1.14 & 0.54 & 4.02 & 35.46 \\
\hline & \multirow{2}{*}{$\mathrm{O}_{3}$} & Winter & 110 & 4 & 3.11 & 2.79 & 2.33 & 17.79 \\
\hline & & Summer & 105 & 25 & 5.56 & 3.46 & 7.12 & 43.34 \\
\hline & \multirow{2}{*}{$\mathrm{NO}_{2}$} & Winter & 110 & 0 & 7.65 & 6.93 & 4.33 & 31.73 \\
\hline & & Summer & 105 & 6 & 5.63 & 4.01 & 5.76 & 33.00 \\
\hline
\end{tabular}

Note: Values represent summary statistics over all person-days. $\mathrm{N}$ represents the total number of collected valid samples. Concentrations expressed in $\mu \mathrm{g} / \mathrm{m}^{3}$ for $\mathrm{PM}_{2.5}, \mathrm{EC}$, and $\mathrm{SO}_{4}{ }^{2-}$, and in $\mathrm{ppb}$ for $\mathrm{O}_{3}$ and $\mathrm{NO}_{2}$. 


\subsubsection{Associations among Pollutants}

Spearman correlation coefficients were very similar for between-pollutant comparisons using ambient (i.e., central site) and outdoor (i.e., outside of the participants' homes) concentrations (Table 90). At both the ambient and outdoor monitoring locations, concentrations of $\mathrm{PM}_{2.5}$ were strongly associated with concentrations of its components, $\mathrm{SO}_{4}{ }^{2-}$ and $\mathrm{EC}$. Correlations between concentrations of $\mathrm{PM}_{2.5}$ and gases were weaker, with Spearman correlation coefficients of 0.26 and 0.41 for pairwise comparisons between ambient $\mathrm{PM}_{2.5}$ and ambient $\mathrm{O}_{3}$ and $\mathrm{NO}_{2}$, respectively. Correlations of $\mathrm{SO}_{4}{ }^{2-}$ with the gases were similar to those for $\mathrm{PM}_{2.5}$, whereas $\mathrm{EC}$ correlated more strongly with $\mathrm{NO}_{2}$ than did $\mathrm{PM}_{2.5}$, but did not show any significant correlation with $\mathrm{O}_{3}$.

Table 90. Correlations among outdoor and ambient $\mathrm{PM}_{2.5}, \mathrm{SO}_{4}{ }^{2-}, \mathrm{EC}, \mathrm{O}_{3}$, and $\mathrm{NO}_{2}$ concentrations for the children's cohort.*

\begin{tabular}{|c|c|c|c|c|c|}
\hline & $\mathrm{PM}_{2.5}$ & $\mathrm{SO}_{4}{ }^{2-}$ & $\mathrm{EC}$ & $\mathrm{O}_{3}$ & $\mathrm{NO}_{2}$ \\
\hline $\mathrm{PM}_{2.5}$ & -- & 0.89 & 0.68 & 0.26 & 0.41 \\
\hline $\mathrm{SO}_{4}{ }^{2-}$ & 0.88 & -- & 0.51 & 0.16 & 0.32 \\
\hline $\mathrm{EC}$ & 0.65 & 0.55 & -- & 0.03 & 0.59 \\
\hline $\mathrm{O}_{3}$ & 0.26 & 0.26 & 0.01 & -- & 0.03 \\
\hline $\mathrm{NO}_{2}$ & 0.42 & 0.32 & 0.60 & -0.12 & -- \\
\hline
\end{tabular}

${ }^{*}$ Values are Spearman correlation coefficients for pairwise comparisons among the pollutants. A total of $202 \mathrm{PM}_{2.5}, 203 \mathrm{SO}_{4}{ }^{2-}, 200 \mathrm{EC}, 214 \mathrm{O}_{3}$, and $210 \mathrm{NO}_{2}$ outdoor samples and $52 \mathrm{PM}_{2.5}, 51 \mathrm{SO}_{4}{ }^{2-}, 52 \mathrm{EC}, 53$ $\mathrm{O}_{3}$, and $54 \mathrm{NO}_{2}$ ambient samples were included in the analysis. Outdoor correlations shown in shaded boxes (lower left); ambient correlations shown in clear boxes (upper right).

In both indoor and personal microenvironments, correlations among the measured pollutants generally followed similar trends, although associations between $\mathrm{NO}_{2}$ and $\mathrm{PM}_{2.5}, \mathrm{SO}_{4}{ }^{2-}$, and $\mathrm{EC}$ were much lower than those observed outdoors (Tables 91 and 92). In contrast, $\mathrm{O}_{3}$ and $\mathrm{NO}_{2}$ were more strongly associated indoors as compared to outdoors, with Spearman correlation coefficients of 0.26 indoors and -0.12 outdoors. The correlation between $\mathrm{PM}_{2.5}$ and $\mathrm{NO}_{2}$ personal exposures was slightly greater than that between indoor concentrations of these pollutants; otherwise, between-pollutant correlations for personal exposures mirrored those observed indoors.

Table 91. Correlations among indoor $\mathrm{PM}_{2.5}, \mathrm{SO}_{4}{ }^{2-}, \mathrm{EC}, \mathrm{O}_{3}$, and $\mathrm{NO}_{2}$ concentrations for the children's cohort. $^{*}$

\begin{tabular}{|c|c|c|c|c|c|}
\hline & $\mathrm{PM}_{2.5}$ & $\mathrm{SO}_{4}{ }^{2-}$ & $\mathrm{EC}$ & $\mathrm{O}_{3}$ & $\mathrm{NO}_{2}$ \\
\hline $\mathrm{PM}_{2.5}$ & -- & & & & \\
\hline $\mathrm{SO}_{4}{ }^{2-}$ & 0.79 & -- & & & \\
\hline $\mathrm{EC}$ & 0.57 & 0.48 & -- & & \\
\hline $\mathrm{O}_{3}$ & 0.30 & 0.22 & 0.30 & -- & -- \\
\hline $\mathrm{NO}_{2}$ & 0.04 & -0.02 & 0.29 & 0.26 & \\
\hline
\end{tabular}

*Values are Spearman correlation coefficients for pairwise comparisons among the pollutants. A total of $209 \mathrm{PM}_{2.5}, 205 \mathrm{SO}_{4}{ }^{2-}, 207 \mathrm{EC}, 211 \mathrm{O}_{3}$, and $211 \mathrm{NO}_{2}$ samples were included in the analysis. 
Table 92. Correlations among personal $\mathrm{PM}_{2.5}, \mathrm{SO}_{4}{ }^{2-}, \mathrm{EC}, \mathrm{O}_{3}$, and $\mathrm{NO}_{2}$ exposures for the children's cohort.* $^{*}$

\begin{tabular}{|c|c|c|c|c|c|}
\hline & $\mathrm{PM}_{2.5}$ & $\mathrm{SO}_{4}{ }^{2-}$ & $\mathrm{EC}$ & $\mathrm{O}_{3}$ & $\mathrm{NO}_{2}$ \\
\hline $\mathrm{PM}_{2.5}$ & -- & & & & \\
\hline $\mathrm{SO}_{4}{ }^{2-}$ & 0.70 & -- & & & \\
\hline $\mathrm{EC}$ & 0.51 & 0.38 & -- & & \\
\hline $\mathrm{O}_{3}$ & 0.29 & 0.30 & 0.16 & -- & \\
\hline $\mathrm{NO}_{2}$ & 0.26 & -0.01 & 0.25 & 0.19 & -- \\
\hline
\end{tabular}

*Values are Spearman correlation coefficients for pairwise comparisons among the pollutants. A total of $206 \mathrm{PM}_{2.5}, 208 \mathrm{SO}_{4}{ }^{2-}, 205 \mathrm{EC}, 210 \mathrm{O}_{3}$, and $215 \mathrm{NO}_{2}$ samples were included in the analysis.

Table 93 displays the associations among pollutants within each microenvironment that were estimated using mixed models. Outdoors in the winter, particle and gas concentrations were significantly associated. In the summer, outdoor $\mathrm{PM}_{2.5}$ and $\mathrm{SO}_{4}{ }^{2-}$ were significantly associated with outdoor $\mathrm{O}_{3}$ and $\mathrm{NO}_{2}$. The association between outdoor $\mathrm{EC}$ and $\mathrm{NO}_{2}$ in the summer was also significant. Similarly, indoors, $\mathrm{PM}_{2.5}$ and $\mathrm{SO}_{4}{ }^{2-}$ were significantly associated with both $\mathrm{O}_{3}$ and $\mathrm{NO}_{2}$ in the summer season. The only significant association observed within the indoor environment in the winter season was that between $\mathrm{EC}$ and $\mathrm{NO}_{2}$, however. Personal $\mathrm{PM}_{2.5}$ exposures were also significantly related to personal $\mathrm{O}_{3}$ and $\mathrm{NO}_{2}$ exposures in the summer, while personal $\mathrm{SO}_{4}{ }^{2-}$ was only significantly associated with personal $\mathrm{O}_{3}$ (and not $\mathrm{NO}_{2}$ ) during that season. In the winter, personal exposures to the particle measures were significantly associated with personal exposures to $\mathrm{NO}_{2}$.

\subsubsection{Associations among Personal, Outdoor, Indoor, and Ambient Pollutant Concentrations}

Associations between personal exposures and ambient concentrations for the children's cohort differed by particulate measure and by season (Table 94). Personal-ambient associations were strong for $\mathrm{SO}_{4}{ }^{2-}$, a regional pollutant with few indoor sources, with greater slopes observed during the summer than during the winter. Significant personal-ambient associations were also found for $\mathrm{PM}_{2.5}$ when data from both seasons were analyzed together, with slopes again greater in summer as compared to winter. For EC, however, associations between personal exposures and corresponding ambient concentrations were only significant in the winter season. Greater slopes for $\mathrm{SO}_{4}{ }^{2-}$ and $\mathrm{PM}_{2.5}$ in the summer as compared to the winter are consistent with the fact that the effective penetration efficiency of ambient particles is generally greater during the summer due to increased indoor ventilation. Stronger summertime associations for $\mathrm{SO}_{4}{ }^{2-}$ and $\mathrm{PM}_{2.5}$ as compared to $\mathrm{EC}$ may be attributed the fact that $\mathrm{SO}_{4}{ }^{2-}$ comprises a large fraction of $\mathrm{PM}_{2.5}$, especially in the summer, and to the fact that EC tends to be smaller and thus may have a lower effective penetration efficiency. Both summer and winter slopes in Steubenville are lower than those found in our exposure studies of children in Baltimore and in Boston.

Personal-ambient associations for $\mathrm{O}_{3}$ and $\mathrm{NO}_{2}$ also varied seasonally, with similar patterns as observed for $\mathrm{PM}_{2.5}$ and $\mathrm{SO}_{4}{ }^{2-}$. In the summer, personal $\mathrm{O}_{3}$ and $\mathrm{NO}_{2}$ exposures were significantly associated with their respective ambient concentrations, although the slope was low for $\mathrm{O}_{3}$. In contrast, in the winter, the slopes describing the personal-ambient associations were insignificant for both $\mathrm{O}_{3}$ and $\mathrm{NO}_{2}$. Since ventilation was greater during the summer months, significant slopes in the summer but not in the winter suggest that ambient gas concentrations are strong proxies of their corresponding gaseous exposures only when individuals spend time in well-ventilated environments. 
Table 93. Mixed model results describing associations among particle and gas concentrations measured in the indoor, personal, and outdoor microenvironments for the children's cohort.*

\begin{tabular}{|c|c|c|c|c|c|c|c|c|c|c|c|c|}
\hline \multirow{2}{*}{\multicolumn{3}{|c|}{ Comparison }} & \multicolumn{5}{|c|}{ Winter } & \multicolumn{5}{|c|}{ Summer } \\
\hline & & & \multirow{2}{*}{$\begin{array}{c}\text { Slope } \\
0.51 \\
\end{array}$} & \multirow{2}{*}{$\begin{array}{c}\text { SE } \\
0.31 \\
\end{array}$} & \multirow{2}{*}{$\begin{array}{c}\text { t-stat } \\
1.66 \\
\end{array}$} & \multirow{2}{*}{$\begin{array}{c}\text { Int. } \\
7.90 \\
\end{array}$} & \multirow{2}{*}{$\begin{array}{c}\text { SE } \\
1.02 \\
\end{array}$} & \multirow{2}{*}{$\begin{array}{c}\text { Slope } \\
0.36 \\
\end{array}$} & \multirow{2}{*}{$\begin{array}{c}\text { SE } \\
0.13 \\
\end{array}$} & \multirow{2}{*}{$\begin{array}{c}\text { t-stat } \\
2.71 \\
\end{array}$} & \multirow{2}{*}{$\begin{array}{c}\text { Int. } \\
17.27 \\
\end{array}$} & \multirow{2}{*}{$\begin{array}{c}\text { SE } \\
1.59 \\
\end{array}$} \\
\hline \multirow{9}{*}{ Indoor } & \multirow{3}{*}{$\mathrm{PM}_{2.5}$} & $\mathrm{O}_{3}$ & & & & & & & & & & \\
\hline & & $\mathrm{NO}_{2}$ & 0.09 & 0.11 & 0.82 & 8.64 & 1.10 & 0.48 & 0.19 & 2.51 & 16.51 & 1.76 \\
\hline & & $\mathrm{SO}_{2}$ & 0.44 & 0.66 & 0.67 & 9.57 & 0.70 & 0.09 & 0.34 & 0.27 & 18.66 & 1.70 \\
\hline & \multirow{3}{*}{$\mathrm{SO}_{4}{ }^{2-}$} & $\mathrm{O}_{3}$ & 0.03 & 0.06 & 0.44 & 1.93 & 0.24 & 0.16 & 0.05 & 3.13 & 5.20 & 0.59 \\
\hline & & $\mathrm{NO}_{2}$ & 0.00 & 0.03 & -0.10 & 2.04 & 0.28 & 0.32 & 0.07 & 4.66 & 4.25 & 0.66 \\
\hline & & $\mathrm{SO}_{2}$ & 0.23 & 0.15 & 1.56 & 2.13 & 0.18 & -0.13 & 0.13 & -0.95 & 6.00 & 0.62 \\
\hline & \multirow{3}{*}{ EC } & $\mathrm{O}_{3}$ & 0.02 & 0.04 & 0.66 & 0.54 & 0.12 & -0.01 & 0.02 & -0.37 & 0.75 & 0.18 \\
\hline & & $\mathrm{NO}_{2}$ & 0.03 & 0.01 & 1.99 & 0.39 & 0.13 & -0.01 & 0.03 & -0.51 & 0.77 & 0.20 \\
\hline & & $\mathrm{SO}_{2}$ & -0.03 & 0.08 & -0.43 & 0.59 & 0.09 & 0.08 & 0.05 & 1.70 & 0.61 & 0.17 \\
\hline \multirow{9}{*}{ Personal } & \multirow{3}{*}{$\mathrm{PM}_{2.5}$} & $\mathrm{O}_{3}$ & -0.09 & 0.29 & -0.30 & 12.79 & 1.22 & 0.56 & 0.16 & 3.47 & 17.58 & 1.64 \\
\hline & & $\mathrm{NO}_{2}$ & 0.43 & 0.17 & 2.58 & 9.18 & 1.52 & 0.50 & 0.19 & 2.61 & 17.07 & 1.83 \\
\hline & & $\mathrm{SO}_{2}$ & 0.07 & 0.83 & 0.09 & 12.56 & 0.94 & -0.42 & 0.29 & -1.47 & 20.65 & 1.69 \\
\hline & \multirow{3}{*}{$\mathrm{SO}_{4}{ }^{2-}$} & $\mathrm{O}_{3}$ & 0.04 & 0.04 & 0.98 & 1.82 & 0.21 & 0.35 & 0.05 & 6.70 & 4.71 & 0.49 \\
\hline & & $\mathrm{NO}_{2}$ & 0.06 & 0.03 & 2.06 & 1.52 & 0.26 & 0.11 & 0.07 & 1.62 & 5.55 & 0.72 \\
\hline & & $\mathrm{SO}_{2}$ & 0.11 & 0.13 & 0.84 & 2.00 & 0.16 & -0.17 & 0.10 & -1.70 & 6.50 & 0.64 \\
\hline & \multirow{3}{*}{ EC } & $\mathrm{O}_{3}$ & 0.00 & 0.01 & 0.18 & 0.62 & 0.06 & -0.06 & 0.06 & -0.99 & 1.43 & 0.49 \\
\hline & & $\mathrm{NO}_{2}$ & 0.01 & 0.01 & 1.99 & 0.52 & 0.07 & -0.07 & 0.06 & -1.11 & 1.53 & 0.52 \\
\hline & & $\mathrm{SO}_{2}$ & 0.00 & 0.03 & 0.05 & 0.63 & 0.05 & 0.13 & 0.09 & 1.40 & 0.90 & 0.42 \\
\hline \multirow{9}{*}{ Outdoor } & \multirow{3}{*}{$\mathrm{PM}_{2.5}$} & $\mathrm{O}_{3}$ & -0.25 & 0.07 & -3.41 & 18.62 & 1.63 & 0.57 & 0.13 & 4.34 & 9.61 & 3.72 \\
\hline & & $\mathrm{NO}_{2}$ & 0.79 & 0.10 & 7.59 & 7.67 & 0.93 & 0.66 & 0.18 & 3.64 & 20.31 & 2.03 \\
\hline & & $\mathrm{SO}_{2}$ & 0.50 & 0.17 & 2.98 & 12.93 & 0.67 & -0.63 & 0.37 & -1.70 & 25.33 & 1.87 \\
\hline & \multirow{3}{*}{$\mathrm{SO}_{4}{ }^{2-}$} & $\mathrm{O}_{3}$ & -0.06 & 0.02 & -3.06 & 4.72 & 0.45 & 0.18 & 0.06 & 3.06 & 4.20 & 1.68 \\
\hline & & $\mathrm{NO}_{2}$ & 0.19 & 0.03 & 6.46 & 2.13 & 0.29 & 0.20 & 0.08 & 2.39 & 7.56 & 0.93 \\
\hline & & $\mathrm{SO}_{2}$ & 0.13 & 0.05 & 2.94 & 3.41 & 0.24 & -0.14 & 0.16 & -0.89 & 9.00 & 0.84 \\
\hline & \multirow{3}{*}{ EC } & $\mathrm{O}_{3}$ & -0.02 & 0.00 & -4.30 & 0.94 & 0.09 & 0.00 & 0.00 & 0.26 & 0.65 & 0.09 \\
\hline & & $\mathrm{NO}_{2}$ & 0.05 & 0.01 & 10.52 & 0.19 & 0.04 & 0.03 & 0.00 & 10.55 & 0.47 & 0.03 \\
\hline & & $\mathrm{SO}_{2}$ & 0.04 & 0.01 & 4.81 & 0.53 & 0.03 & -0.01 & 0.01 & -0.74 & 0.69 & 0.04 \\
\hline
\end{tabular}

*bold numbers indicate $p$-values $\leq 0.05$. Slopes and intercepts were calculated using season-specific mixed models.

When analyzed by participant, considerable inter-personal variability in the associations between personal exposures and ambient concentrations was found for each of the particulate measures, even for $\mathrm{SO}_{4}{ }^{2-}$ and even during the summer when overall associations were strong. Median individual-specific $\mathrm{R}^{2}$ values differed by participant (Figures 65-67). Results indicate that the ability of ambient concentrations to reflect personal exposures varies by child and by particulate component. 
Table 94. Associations between personal exposures and ambient concentrations of particle and gaseous pollutants monitored for the children's cohort.

\begin{tabular}{|c|l|c|c|c|c|c|c|c|c|c|}
\hline \multicolumn{2}{|c}{ Pollutant } & \multicolumn{3}{|c|}{ Both seasons } & \multicolumn{3}{c|}{ Winter } & \multicolumn{3}{c|}{ Summer } \\
\cline { 2 - 11 } & Estimate & StdErr & p-value & Estimate & StdErr & p-value & Estimate & StdErr & $\mathrm{p}$-value \\
\hline \multirow{2}{*}{$\mathrm{PM}_{2.5}\left(\mathrm{ug} / \mathrm{m}^{3}\right)$} & Intercept & 6.01 & 1.65 & 0.00 & 10.16 & 2.47 & 0.00 & 5.32 & 2.45 & 0.05 \\
& Slope & 0.54 & 0.06 & $<.0001$ & 0.25 & 0.14 & 0.08 & 0.58 & 0.08 & $<.0001$ \\
\hline \multirow{2}{*}{$\mathrm{SO}_{4}{ }^{2-}\left(\mathrm{ug} / \mathrm{m}^{3}\right)$} & Intercept & 0.08 & 0.34 & 0.81 & 0.43 & 0.27 & 0.14 & 0.58 & 0.58 & 0.34 \\
& Slope & 0.60 & 0.03 & $<.0001$ & 0.37 & 0.05 & $<.0001$ & 0.59 & 0.04 & $<.0001$ \\
\hline \multirow{2}{*}{$\mathrm{EC}\left(\mathrm{ug} / \mathrm{m}^{3}\right)$} & Intercept & 1.07 & 0.63 & 0.10 & 0.37 & 0.07 & 0.00 & 2.10 & 1.32 & 0.13 \\
& Slope & -0.05 & 0.67 & 0.94 & 0.41 & 0.07 & $<.0001$ & -0.94 & 1.42 & 0.51 \\
\hline \multirow{2}{*}{$\mathrm{O}_{3}(\mathrm{ppb})$} & Intercept & 1.54 & 0.75 & 0.05 & 2.94 & 0.67 & 0.00 & 2.13 & 1.24 & 0.11 \\
& Slope & 0.08 & 0.02 & $<.0001$ & -0.01 & 0.03 & 0.71 & 0.09 & 0.03 & 0.0009 \\
\hline \multirow{2}{*}{$\mathrm{NO}_{2}(\mathrm{ppb})$} & Intercept & 4.59 & 0.57 & $<.0001$ & 7.27 & 0.81 & $<.0001$ & 3.39 & 0.78 & 0.00 \\
& Slope & 0.31 & 0.05 & $<.0001$ & 0.10 & 0.07 & 0.12 & 0.36 & 0.06 & $<.0001$ \\
\hline
\end{tabular}

Note: Slopes and intercepts calculated using mixed effect models.

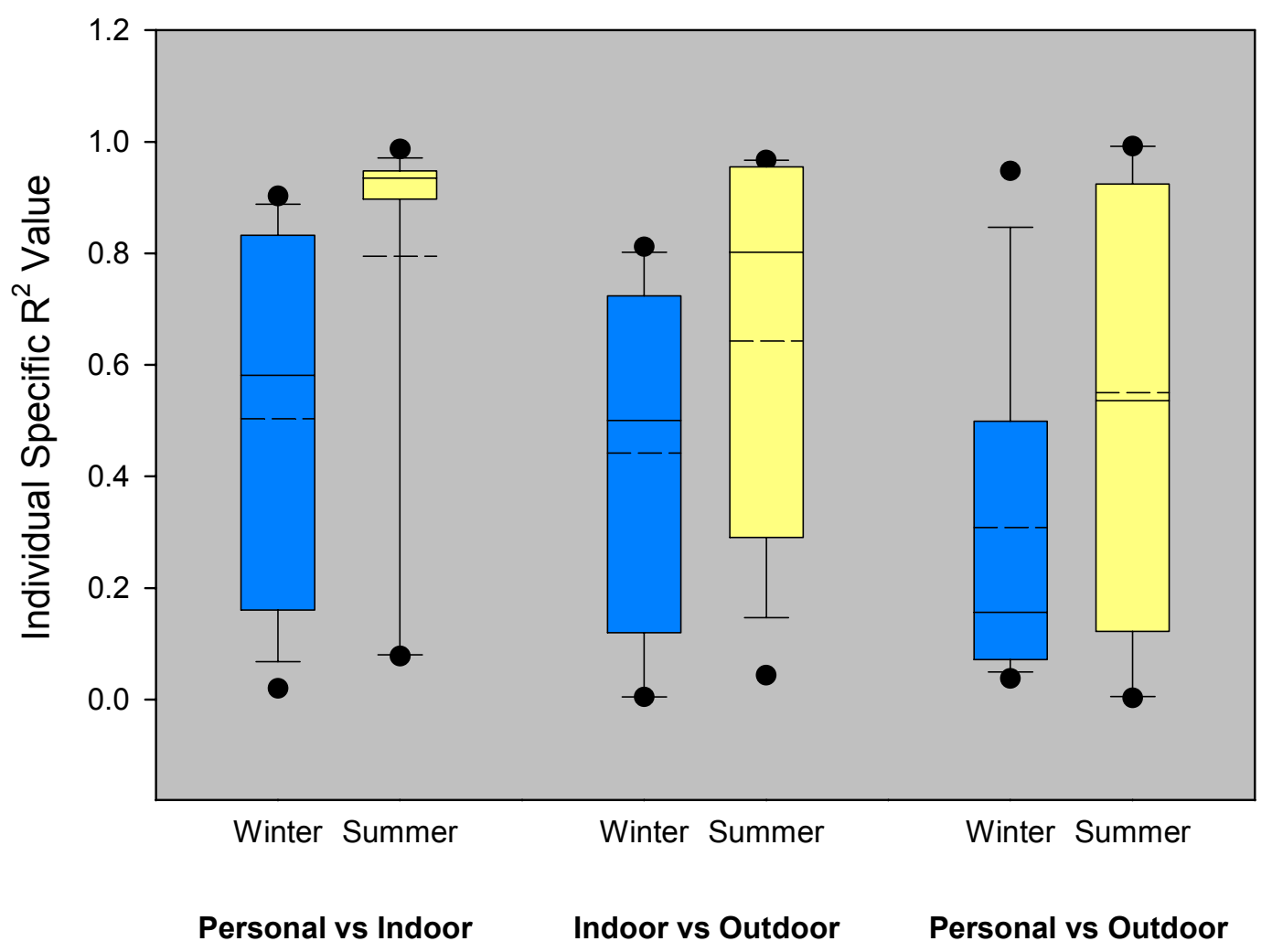

Figure 65. Individual-specific $\mathrm{R}^{2}$ values for associations among personal, indoor, and outdoor $\mathrm{PM}_{2.5}$ concentrations measured for the children's cohort. 


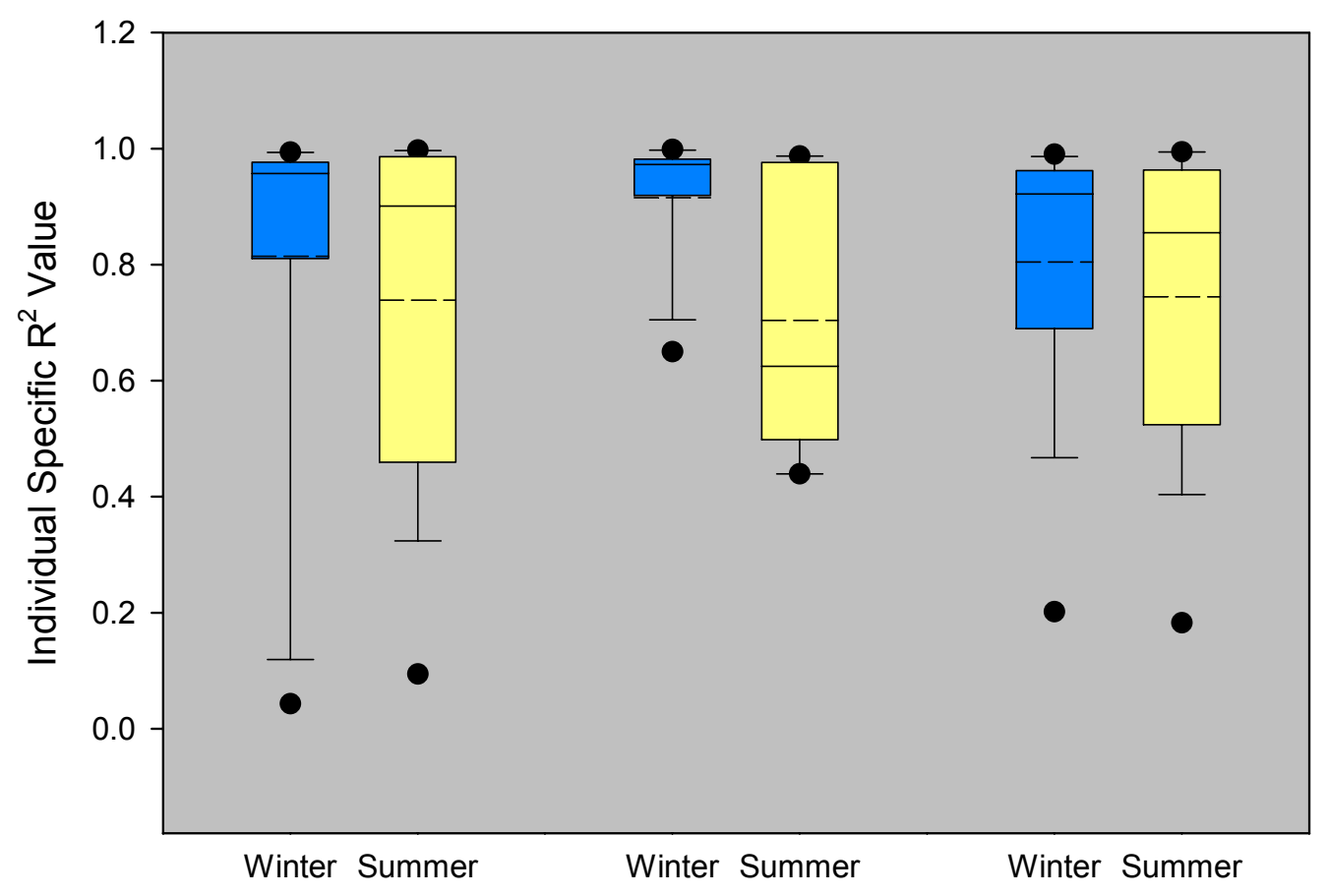

\section{Personal vs Indoor Indoor vs Outdoor Personal vs Outdoor}

Figure 66. Individual-specific $\mathrm{R}^{2}$ values for associations among personal, indoor, and outdoor $\mathrm{SO}_{4}{ }^{2-}$ concentrations measured for the children's cohort.

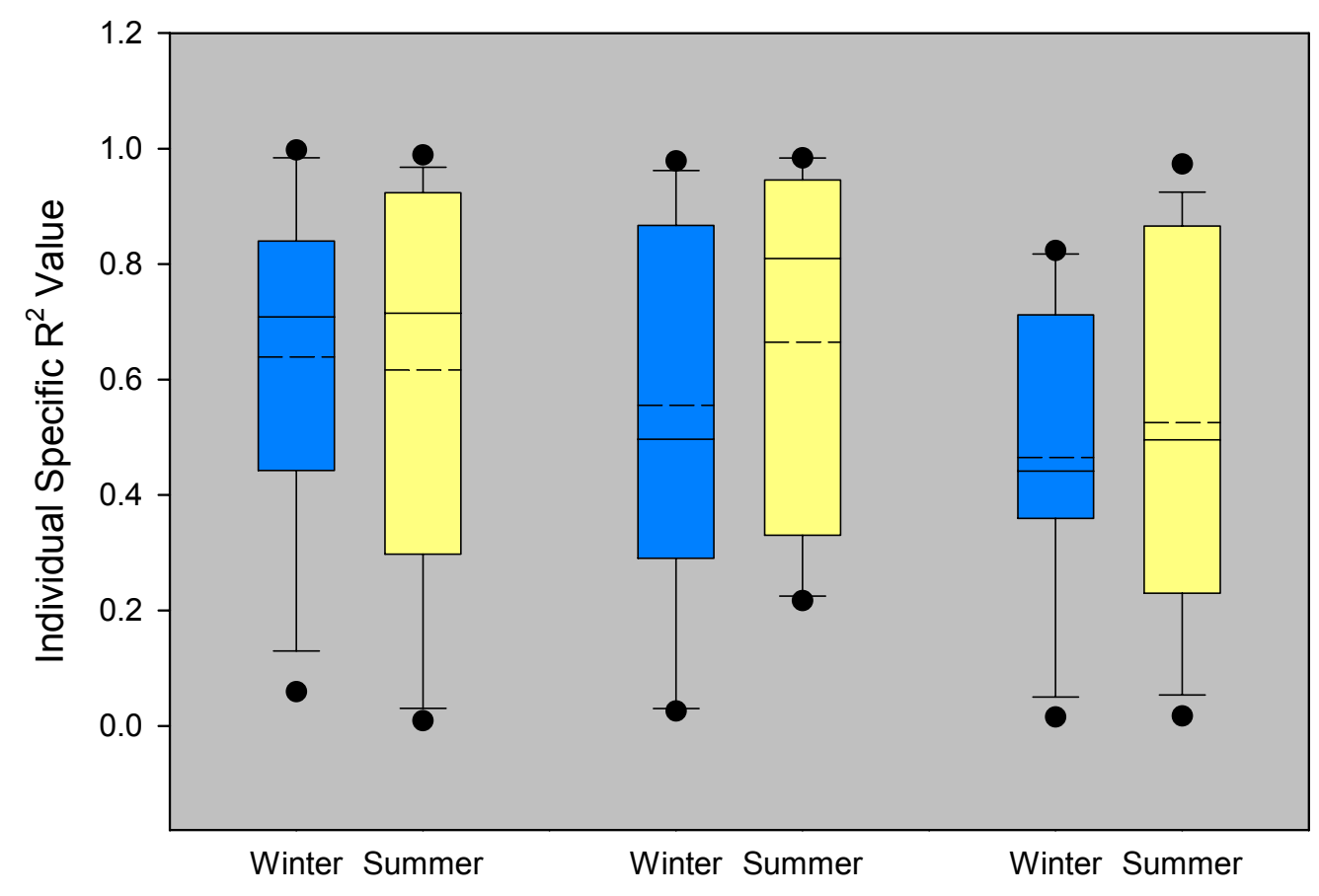

\footnotetext{
Personal vs Indoor Indoor vs Outdoor Personal vs Outdoor

Figure 67. Individual-specific $\mathrm{R}^{2}$ values for associations among personal, indoor, and outdoor EC concentrations measured for the children's cohort.
} 


\subsubsection{Cross-Pollutant Associations}

Associations between ambient particle concentrations and personal gas exposures for the children are given in Table 95. Significant associations were found between personal $\mathrm{O}_{3}$ and ambient $\mathrm{PM}_{2.5}$, personal $\mathrm{O}_{3}$ and ambient $\mathrm{SO}_{4}{ }^{2-}$, and personal $\mathrm{NO}_{2}$ and ambient $\mathrm{EC}$, but all occurred only in the summer season. All winter cross-pollutant associations of ambient particle concentrations with personal gas exposures were not statistically significant. As shown with the adult data, slopes were relatively low, with the possible exception of associations between the gases and EC.

In contrast to the summertime associations observed between ambient particle measures and personal gas exposures, ambient gas concentrations were not significantly associated with corresponding personal exposures to any of the particle measures in the summer. In the winter, however, associations between ambient $\mathrm{NO}_{2}$ concentrations and personal particle exposures were significant. Ambient $\mathrm{O}_{3}$ concentrations were not significantly associated with personal exposures to any of the particle measures in either season (Table 95).

Results indicate that during the summer, which was characterized by more frequent open window usage by the participants, ambient particle concentrations were strong proxies of children's personal exposures to gases from similar sources, such as was observed with the traffic-related pollutants $\mathrm{NO}_{2}$ and $\mathrm{EC}$ and with the regional pollutants $\mathrm{O}_{3}, \mathrm{SO}_{4}{ }^{2-}$, and $\mathrm{PM}_{2.5}$ (likely because of its large mass fraction of $\mathrm{SO}_{4}{ }^{2-}$ ). Despite this, the low slopes further suggest that ambient particle concentrations are much better proxies of children's exposures to the particles themselves. Ambient gas concentrations, with the exception of ambient $\mathrm{NO}_{2}$ in the winter, were poor proxies of personal particle exposures.

Table 95. Cross-pollutant associations between ambient particle and gas concentrations and personal gas and particle exposures for the children's cohort.

\begin{tabular}{|c|c|c|c|c|c|c|c|c|c|c|c|}
\hline \multicolumn{2}{|c|}{ Comparison } & \multicolumn{5}{|c|}{ Winter } & \multicolumn{5}{|c|}{ Summer } \\
\hline Personal & Ambient & $\mathbf{N}$ & $\beta$ & SE & t-stat & Int. & $\mathbf{N}$ & $\beta$ & SE & t-stat & Int. \\
\hline $\mathrm{O}_{3}$ & \multirow{2}{*}{$\mathrm{PM}_{2.5}$} & 69 & 0.02 & 0.04 & 0.44 & 2.94 & 66 & 0.25 & 0.06 & 4.11 & 0.81 \\
\hline $\mathrm{NO}_{2}$ & & 75 & 0.06 & 0.04 & 1.24 & 6.65 & 81 & 0.04 & 0.04 & 0.99 & 5.34 \\
\hline $\mathrm{O}_{3}$ & \multirow{2}{*}{$\mathrm{SO}_{4}{ }^{2-}$} & 69 & 0.18 & 0.14 & 1.28 & 2.55 & 63 & 0.46 & 0.13 & 3.53 & 2.65 \\
\hline $\mathrm{NO}_{2}$ & & 75 & 0.05 & 0.15 & 0.30 & 7.34 & 78 & 0.02 & 0.08 & 0.22 & 6.34 \\
\hline $\mathrm{O}_{3}$ & \multirow{2}{*}{ EC } & 67 & 0.37 & 0.78 & 0.48 & 3.01 & 66 & 1.02 & 3.07 & 0.33 & 6.61 \\
\hline $\mathrm{NO}_{2}$ & & 73 & 1.53 & 0.78 & 1.96 & 6.29 & 81 & 4.03 & 1.80 & 2.25 & 3.12 \\
\hline \multirow{2}{*}{$\mathrm{PM}_{2.5}$} & $\mathrm{O}_{3}$ & 76 & 0.12 & 0.08 & 1.47 & 11.11 & 87 & -0.01 & 0.05 & -0.23 & 21.81 \\
\hline & $\mathrm{NO}_{2}$ & 79 & 0.46 & 0.19 & 2.35 & 9.89 & 76 & 0.06 & 0.14 & 0.43 & 20.84 \\
\hline \multirow{2}{*}{$\mathrm{SO}_{4}{ }^{2-}$} & $\mathrm{O}_{3}$ & 78 & -0.01 & 0.01 & -0.94 & 2.08 & 87 & 0.01 & 0.02 & 0.55 & 6.47 \\
\hline & $\mathrm{NO}_{2}$ & 81 & 0.12 & 0.02 & 4.98 & 0.80 & 77 & -0.06 & 0.06 & -1.12 & 7.56 \\
\hline \multirow{2}{*}{ EC } & $\mathrm{O}_{3}$ & 78 & 0.00 & 0.00 & 0.13 & 0.60 & 85 & -0.02 & 0.02 & -1.29 & 2.10 \\
\hline & $\mathrm{NO}_{2}$ & 81 & 0.03 & 0.01 & 5.50 & 0.35 & 74 & -0.01 & 0.03 & -0.45 & 1.06 \\
\hline
\end{tabular}




\subsubsection{Factors Affecting Associations}

\subsection{Ventilation}

Table 96 presents mixed model results showing the effects of ventilation (window and air conditioning use) on the associations between indoor and ambient pollutant concentrations in the summer season. A three-level variable for window use was created by using information obtained from questionnaires. The number of hours of open windows and doors over the sampling period were summed and categorized by approximate tertiles. The levels included "Lo," representing that no windows or doors were open during the sampling period, "Med," representing that the sum of time for which windows and doors were open during the sampling period was 24 hours or less, and "Hi," representing that the sum of time for which windows and doors were open during the sampling period was greater than 24 hours. The use of air conditioning was dichotomized into "any use" and "no use."

Results for the children's cohort are similar to those discussed earlier for the older adult cohort in that indoor-ambient slopes increased with a change from "Lo" to "Hi" ventilation. The slopes for all pollutants were significant and statistically greater for indoor environments characterized by open windows. These results indicate that the effective penetration efficiency for all pollutants was higher for well-ventilated as compared to poorly ventilated indoor environments.

Results were less consistent when $A C$ use was used as the measure of ventilation. For $\mathrm{PM}_{2.5}$, $\mathrm{SO}_{4}{ }^{2-}$, and to a lesser extent $\mathrm{O}_{3}$, the use of air conditioning increased the slopes of the indoorambient associations. This is contrary to previous findings and expected findings. The results may indicate that the air conditioner use categories did not accurately reflect home ventilation conditions. For $\mathrm{EC}$ and $\mathrm{NO}_{2}$, the presence of $\mathrm{AC}$ decreased the slope of the indoor-ambient associations.

\subsection{Stove Type}

The types of stoves (gas or electric) found in the participants' homes were examined to determine whether stove type affected the associations between indoor and ambient pollutant concentrations and between personal exposures and ambient concentrations. Results for the mixed models, stratified by season, are presented in Tables 97 and 98, respectively.

As was the case for the older adults, intercepts of the indoor-on-ambient associations for $\mathrm{NO}_{2}$ were greater in the winter for participants living in homes with gas stoves as compared to those living in homes with electric stoves; however, these differences were not significant. Indoorambient $\mathrm{NO}_{2}$ intercepts differed by stove type in the summer as well, although differences were extremely small. Differences between the intercepts of indoor-on-ambient regression lines for homes with gas stoves and homes with electric stoves were significant for $\mathrm{PM}_{2.5}, \mathrm{SO}_{4}{ }^{2-}$, and $\mathrm{EC}$ in both seasons, with greater intercepts generally found for homes with gas stoves than for those with electric stoves, especially in the winter. Intercepts were often insignificant, however, making these results questionable. 
Table 96. Effect of ventilation on indoor-ambient associations in the summer season for the children's cohort.*

\begin{tabular}{|c|c|c|c|c|c|c|}
\hline Pollutant & Factor & Level & Slope & SE & t-stat & Int. \\
\hline \multirow{3}{*}{$\mathrm{PM}_{2.5}$} & \multirow{15}{*}{ Window Use } & Lo & 0.28 & 0.13 & 2.17 & 5.29 \\
\hline & & Med & 0.27 & 0.27 & 0.88 & 7.09 \\
\hline & & $\mathrm{Hi}$ & 0.73 & 0.08 & 9.42 & 3.24 \\
\hline \multirow{3}{*}{$\mathrm{SO}_{4}{ }^{2-}$} & & Lo & 0.26 & 0.08 & 3.12 & 1.17 \\
\hline & & Med & 0.28 & 0.21 & 1.33 & 2.22 \\
\hline & & $\mathrm{Hi}$ & 0.87 & 0.05 & 16.61 & -1.14 \\
\hline \multirow{3}{*}{ EC } & & Lo & 0.71 & 0.51 & 1.40 & -0.10 \\
\hline & & Med & -0.68 & 0.16 & -4.14 & 0.97 \\
\hline & & $\mathrm{Hi}$ & 0.75 & 0.09 & 8.69 & 0.11 \\
\hline \multirow{3}{*}{$\mathrm{O}_{3}$} & & Lo & 0.00 & 0.33 & 0.00 & -2.84 \\
\hline & & Med & 0.00 & 0.13 & -0.01 & -2.77 \\
\hline & & $\mathrm{Hi}$ & 0.63 & 2.51 & 6.62 & -6.87 \\
\hline \multirow{3}{*}{$\mathrm{NO}_{2}$} & & Lo & 0.19 & 0.59 & 0.32 & 1.06 \\
\hline & & Med & 0.02 & 0.14 & 0.16 & 4.26 \\
\hline & & $\mathrm{Hi}$ & 0.80 & 0.07 & 11.42 & 0.88 \\
\hline \multirow{2}{*}{$\mathrm{PM}_{2.5}$} & \multirow{10}{*}{ AC Use } & None & 0.40 & 0.10 & 4.14 & 6.26 \\
\hline & & Any & 0.76 & 0.09 & 8.45 & 3.57 \\
\hline \multirow{2}{*}{$\mathrm{SO}_{4}{ }^{2-}$} & & None & 0.43 & 0.07 & 5.93 & 1.47 \\
\hline & & Any & 0.88 & 0.06 & 14.15 & -0.92 \\
\hline \multirow{2}{*}{ EC } & & None & 0.62 & 0.14 & 4.51 & 0.08 \\
\hline & & Any & 0.33 & 0.12 & 2.69 & 0.46 \\
\hline \multirow{2}{*}{$\mathrm{O}_{3}$} & & None & 0.22 & 0.11 & 1.98 & -3.40 \\
\hline & & Any & 0.23 & 0.16 & 1.45 & 2.47 \\
\hline \multirow{2}{*}{$\mathrm{NO}_{2}$} & & None & 0.72 & 0.11 & 6.69 & -0.20 \\
\hline & & Any & 0.52 & 0.09 & 5.65 & 3.02 \\
\hline
\end{tabular}

${ }^{*}$ Bold numbers indicate $p$-values $\leq 0.05$. Slopes and intercepts calculated using season-specific mixed models that included an interaction term for ventilation. Air conditioner use was classified as "none" if air conditioners were not used during the 24-hr monitoring period and "any" if air conditioners were used at all during the 24-hr monitoring period.

Table 97. Indoor vs. ambient concentrations by stove type for the children's cohort.*

\begin{tabular}{|c|c|c|c|c|c|c|c|c|c|c|c|}
\hline \multirow{2}{*}{ Pollutant } & Fuel & $\mathbf{N}$ & $\beta$ & $\mathbf{S E}$ & $\mathbf{t}$-stat & Int. & $\mathbf{N}$ & $\beta$ & SE & t-stat & Int. \\
\hline \multirow{2}{*}{$\mathrm{PM}_{2.5}$} & gas & 19 & $\mathbf{0 . 5 9}$ & 0.23 & 2.63 & $\mathbf{7 . 5 7}$ & 24 & $\mathbf{0 . 7 7}$ & 0.24 & 3.21 & 8.99 \\
\cline { 2 - 13 } & electric & 56 & $\mathbf{0 . 3 5}$ & 0.10 & 3.44 & 2.45 & 74 & $\mathbf{0 . 5 0}$ & 0.07 & 6.75 & 3.40 \\
\hline \multirow{2}{*}{$\mathrm{SO}_{4}{ }^{2-}$} & gas & 19 & $\mathbf{0 . 5 9}$ & 0.07 & 8.50 & 0.63 & 24 & 0.90 & 0.18 & 5.05 & 0.21 \\
\cline { 2 - 12 } & electric & 56 & $\mathbf{0 . 4 5}$ & 0.03 & 13.70 & -0.10 & 74 & 0.50 & 0.05 & 10.81 & 0.58 \\
\hline \multirow{2}{*}{$\mathrm{EC}$} & gas & 19 & $\mathbf{0 . 4 6}$ & 0.14 & 3.16 & $\mathbf{0 . 3 8}$ & 24 & $\mathbf{3 . 0 4}$ & 1.18 & 2.57 & -0.95 \\
\cline { 2 - 12 } & electric & 56 & $\mathbf{0 . 3 6}$ & 0.05 & 6.72 & $\mathbf{0 . 2 2}$ & 76 & 0.45 & 0.62 & 0.72 & 0.21 \\
\hline \multirow{2}{*}{$\mathrm{O}_{3}$} & gas & 21 & 0.00 & 0.03 & -0.08 & $\mathbf{2 . 3 3}$ & 28 & $\mathbf{0 . 2 7}$ & 0.07 & 3.89 & 0.26 \\
\cline { 2 - 12 } & electric & 60 & $\mathbf{- 0 . 0 4}$ & 0.02 & -2.04 & $\mathbf{3 . 1 5}$ & 71 & $\mathbf{0 . 1 4}$ & 0.02 & 6.52 & 0.82 \\
\hline \multirow{2}{*}{$\mathrm{NO}_{2}$} & gas & 21 & 0.03 & 0.13 & 0.23 & $\mathbf{9 . 6 6}$ & 26 & $\mathbf{0 . 7 3}$ & 0.17 & 4.21 & 2.78 \\
\cline { 2 - 11 } & electric & 63 & $\mathbf{0 . 2 0}$ & 0.07 & 2.70 & $\mathbf{6 . 4 2}$ & 71 & $\mathbf{0 . 3 3}$ & 0.06 & 5.93 & $\mathbf{2 . 6 8}$ \\
\hline
\end{tabular}

*shaded cells represent significant interaction effect; bold numbers indicate $p$-value $\leq 0.05$ 
Stove type modified the slopes of the indoor-on-ambient associations for $\mathrm{SO}_{4}{ }^{2-}$ and $\mathrm{NO}_{2}$ in the summer, with higher slopes observed for homes with gas stoves. Reasons for these higher slopes are not known, but may suggest that the results are spurious or that homes with gas stoves had different characteristics that were associated with increased penetration efficiency.

Table 98. Personal vs. ambient concentrations by stove type for the children's cohort.*

\begin{tabular}{|c|c|c|c|c|c|c|c|c|c|c|c|}
\hline \multirow{2}{*}{ Pollutant } & Fuel & $\mathbf{N}$ & $\boldsymbol{\beta}$ & $\mathbf{S E}$ & $\mathbf{t}-\mathbf{s t a t}$ & $\mathbf{I n t .}$ & $\mathbf{N}$ & $\boldsymbol{\beta}$ & $\mathbf{S E}$ & t-stat & Int. \\
\hline \multirow{2}{*}{$\mathrm{PM}_{2.5}$} & gas & 19 & $\mathbf{0 . 6 2}$ & 0.27 & 2.35 & $\mathbf{9 . 4 4}$ & 24 & 0.43 & 0.24 & 1.76 & $\mathbf{1 4 . 5 3}$ \\
\cline { 2 - 13 } & electric & 56 & 0.17 & 0.15 & 1.13 & $\mathbf{9 . 8 8}$ & 75 & $\mathbf{0 . 5 7}$ & 0.07 & 7.84 & 3.39 \\
\hline \multirow{2}{*}{$\mathrm{SO}_{4}{ }^{2-}$} & gas & 19 & $\mathbf{0 . 6 2}$ & 0.08 & 7.33 & 0.57 & 24 & $\mathbf{0 . 8 6}$ & 0.14 & 6.08 & -0.02 \\
\cline { 2 - 13 } & electric & 56 & $\mathbf{0 . 3 3}$ & 0.04 & 7.48 & 0.27 & 74 & $\mathbf{0 . 5 5}$ & 0.04 & 15.32 & 0.57 \\
\hline \multirow{2}{*}{$\mathrm{EC}$} & gas & 19 & $\mathbf{0 . 7 0}$ & 0.14 & 5.10 & $\mathbf{0 . 3 0}$ & 24 & -3.89 & 3.18 & -1.23 & $\mathbf{6 . 7 9}$ \\
\cline { 2 - 12 } & electric & 56 & $\mathbf{0 . 3 7}$ & 0.07 & 5.37 & $\mathbf{0 . 3 4}$ & 74 & 0.59 & 1.32 & 0.45 & 0.12 \\
\hline \multirow{2}{*}{$\mathrm{O}_{3}$} & gas & 21 & 0.03 & 0.04 & 0.81 & 1.89 & 28 & 0.15 & 0.08 & 1.91 & -1.49 \\
\cline { 2 - 12 } & electric & 60 & -0.05 & 0.03 & -1.42 & $\mathbf{3 . 8 3}$ & 71 & $\mathbf{0 . 0 6}$ & 0.03 & 2.38 & $\mathbf{4 . 5 8}$ \\
\hline \multirow{2}{*}{$\mathrm{NO}_{2}$} & gas & 21 & 0.11 & 0.14 & 0.80 & $\mathbf{9 . 6 6}$ & 26 & $\mathbf{0 . 7 8}$ & 0.20 & 3.96 & 1.66 \\
\cline { 2 - 11 } & electric & 63 & 0.10 & 0.08 & 1.31 & $\mathbf{6 . 4 5}$ & 71 & $\mathbf{0 . 3 2}$ & 0.06 & 5.09 & $\mathbf{3 . 5 4}$ \\
\hline
\end{tabular}

*shaded cells represent significant interaction effect; bold numbers indicate p-value $\leq 0.05$

Stove type had similar confusing effects on the associations between personal exposures and ambient concentrations, with individuals living in homes with gas stoves having higher intercepts for $\mathrm{NO}_{2}$ in the winter but not summer and higher slopes for $\mathrm{SO}_{4}{ }^{2-}$ in both seasons, $\mathrm{EC}$ in the winter, and $\mathrm{NO}_{2}$ in the summer. The interpretation of these results is unclear.

\subsection{Activity Patterns}

The impact of time spent in different microenvironments on the relationship between personal exposures and ambient concentrations was examined for the children's cohort. Because participants spent the vast majority of their time indoors, time spent in other micro-environments was generally extremely low. For example, the median fraction of time spent outdoors equaled only 0.03 (or 43 minutes over 24 hours); even less time was spent in other microenvironments. As a result, findings of modification by time spent in microenvironments should be interpreted with caution.

As shown in Table 99, time spent outdoors modified the personal-ambient associations for the particle measures, as evidenced by the significantly greater slopes in both seasons for $\mathrm{SO}_{4}{ }^{2-}$ for individuals spending a larger fraction of their time outdoors (as compared to the median). Although differences were not statistically significant, similar trends were found for $\mathrm{PM}_{2.5}$ in the summer and EC in the winter. Personal-ambient intercepts for $\mathrm{PM}_{2.5}$ and $\mathrm{EC}$ in both seasons were also higher, although not statistically significant, for individuals who spent more time outdoors. Time spent outdoors did not have consistent effects on the associations between personal exposures and ambient concentrations for the gases $\mathrm{O}_{3}$ and $\mathrm{NO}_{2}$, although intercepts for $\mathrm{NO}_{2}$ in both seasons and for $\mathrm{O}_{3}$ in the summer were significantly higher for individuals spending more time outdoors.

In the summer, time spent indoors near an open window was found to modify the association between personal exposures and ambient concentrations for most of the measured pollutants, with significantly higher personal-ambient $\mathrm{PM}_{2.5}, \mathrm{SO}_{4}{ }^{2-}$, and $\mathrm{O}_{3}$ slopes for individuals who spent greater-than-average (median) amounts of time indoors near open windows (Table 100). 
Table 99. Personal vs. ambient concentrations by fraction of time spent outdoors for the children's cohort.*

\begin{tabular}{|c|c|c|c|c|c|c|c|c|c|c|c|}
\hline \multirow[b]{2}{*}{ Pollutant } & \multirow[b]{2}{*}{ Status } & \multicolumn{5}{|c|}{ Winter } & \multicolumn{5}{|c|}{ Summer } \\
\hline & & $\mathbf{N}$ & $\beta$ & SE & t-stat & Int. & $\mathbf{N}$ & $\beta$ & SE & t-stat & Int. \\
\hline \multirow{2}{*}{$\mathrm{PM}_{2.5}$} & LO $^{* *}$ & 87 & 0.17 & 0.13 & 1.30 & 8.67 & 20 & 0.24 & 0.28 & 0.86 & 6.23 \\
\hline & $\mathrm{Hi}$ & 14 & 0.06 & 0.29 & 0.19 & 18.64 & 80 & 0.57 & 0.07 & 8.11 & 7.19 \\
\hline \multirow{2}{*}{$\mathrm{SO}_{4}{ }^{2-}$} & Lo & 88 & 0.51 & 0.05 & 10.23 & 0.10 & 19 & 0.25 & 0.16 & 1.56 & 1.43 \\
\hline & $\mathrm{Hi}$ & 14 & 0.80 & 0.13 & 6.30 & -0.23 & 81 & 0.64 & 0.04 & 16.89 & 0.83 \\
\hline \multirow{2}{*}{ EC } & Lo & 85 & 0.34 & 0.09 & 3.57 & 0.42 & 19 & 0.05 & 3.73 & 0.01 & 0.52 \\
\hline & $\mathrm{Hi}$ & 14 & 0.56 & 0.16 & 3.37 & 0.51 & 79 & -1.22 & 1.27 & -0.95 & 2.13 \\
\hline \multirow{2}{*}{$\mathrm{O}_{3}$} & Lo & 96 & -0.05 & 0.03 & -1.37 & 3.57 & 21 & 0.06 & 0.17 & 0.36 & -0.05 \\
\hline & $\mathrm{Hi}$ & 14 & 0.07 & 0.08 & 0.83 & 1.52 & 79 & 0.01 & 0.08 & 0.11 & 6.33 \\
\hline \multirow{2}{*}{$\mathrm{NO}_{2}$} & Lo & 91 & 0.10 & 0.09 & 1.09 & 6.91 & 21 & 0.53 & 0.20 & 2.62 & 0.39 \\
\hline & $\mathrm{Hi}$ & 14 & -0.01 & 0.22 & -0.04 & 11.05 & 84 & 0.58 & 0.08 & 7.63 & 2.62 \\
\hline
\end{tabular}

*shaded cells represent significant interaction effect; bold numbers indicate p-value $\leq 0.05$

** "Lo" $\leq$ median fraction of time outside (0.03); "Hi" > median fraction of time outside

Table 100. Personal vs. ambient concentrations by fraction of time spent indoors near open windows for the children's cohort.*

\begin{tabular}{|c|c|c|c|c|c|c|c|c|c|c|c|}
\hline \multirow[b]{2}{*}{ Pollutant } & \multirow[b]{2}{*}{ Status } & \multicolumn{5}{|c|}{ Winter } & \multicolumn{5}{|c|}{ Summer } \\
\hline & & $\mathbf{N}$ & $\beta$ & SE & t-stat & Int. & $\mathbf{N}$ & $\beta$ & SE & t-stat & Int. \\
\hline \multirow{2}{*}{$\mathrm{PM}_{2.5}$} & Lo & 66 & 0.22 & 0.16 & 1.37 & 9.00 & 26 & 0.29 & 0.12 & 2.37 & 7.07 \\
\hline & $\mathrm{Hi}$ & 34 & 0.08 & 0.18 & 0.45 & 10.93 & 74 & 0.68 & 0.08 & 9.02 & 5.22 \\
\hline \multirow{2}{*}{$\mathrm{SO}_{4}{ }^{2-}$} & Lo & 67 & 0.55 & 0.06 & 8.72 & -0.05 & 27 & 0.30 & 0.05 & 5.91 & 1.65 \\
\hline & $\mathrm{Hi}$ & 34 & 0.53 & 0.07 & 7.14 & 0.35 & 73 & 0.79 & 0.04 & 22.07 & -0.19 \\
\hline \multirow{2}{*}{ EC } & Lo & 65 & 0.49 & 0.11 & 4.56 & 0.35 & 26 & 0.24 & 2.96 & 0.08 & 0.35 \\
\hline & $\mathrm{Hi}$ & 33 & 0.28 & 0.13 & 2.19 & 0.49 & 73 & -1.20 & 1.30 & -0.93 & 2.17 \\
\hline \multirow{2}{*}{$\mathrm{O}_{3}$} & Lo & 75 & -0.06 & 0.04 & -1.61 & 3.83 & 28 & -0.12 & 0.13 & -0.99 & 6.72 \\
\hline & $\mathrm{Hi}$ & 35 & 0.03 & 0.05 & 0.51 & 2.31 & 72 & 0.23 & 0.09 & 2.52 & 0.93 \\
\hline \multirow{2}{*}{$\mathrm{NO}_{2}$} & Lo & 70 & 0.09 & 0.11 & 0.80 & 6.84 & 28 & 0.19 & 0.23 & 0.81 & 3.16 \\
\hline & $\mathrm{Hi}$ & 35 & 0.08 & 0.13 & 0.64 & 8.66 & 77 & 0.64 & 0.07 & 8.80 & 2.41 \\
\hline
\end{tabular}

*shaded cells represent significant interaction effect; bold numbers indicate p-value $\leq 0.05$

** "Lo" $\leq$ than median fraction of time near an open window (0.01); "Hi" > median fraction of time

Although not significant, spending time near an open window was found to have a similar effect on the personal-ambient $\mathrm{NO}_{2}$ association. Spending time near open windows in the winter had no significant effects on the associations between personal exposures and ambient concentrations for any of the measured pollutants, which may result from the fact that individuals tended to spend little time near open windows in this season. The summertime results followed a pattern similar to that observed in Table 96 for window usage, where the indoor-outdoor slope was greatest for indoor environments with open windows.

As shown in Table 101, children spending a greater fraction of time traveling by car (as compared to the median amount of time) had significantly lower personal-ambient slopes for $\mathrm{PM}_{2.5}, \mathrm{SO}_{4}{ }^{2-}$, and $\mathrm{NO}_{2}$ in the summer and for $\mathrm{EC}$ in the winter than did those spending lesser amounts of time in cars. Lower personal-ambient slopes for individuals spending more time in transit suggest that, for a given increase in ambient concentrations, the increase in personal exposures is smaller for these individuals. However, since children spent a very small fraction of time traveling by car, it is likely that time in transit is acting as a proxy for general activity or another modifying variable. 
Table 101. Personal vs. ambient concentrations by fraction of time spent traveling by car for the children's cohort. *

\begin{tabular}{|c|c|c|c|c|c|c|c|c|c|c|c|}
\hline \multirow[b]{2}{*}{ Pollutant } & \multirow[b]{2}{*}{ Status } & \multicolumn{5}{|c|}{ Winter } & \multicolumn{5}{|c|}{ Summer } \\
\hline & & $\mathbf{N}$ & $\beta$ & SE & t-stat & Int. & $\mathbf{N}$ & $\beta$ & SE & t-stat & Int. \\
\hline \multirow{2}{*}{$\mathrm{PM}_{2.5}$} & Lo & 53 & 0.19 & 0.17 & 1.11 & 12.54 & 48 & 0.78 & 0.09 & 8.32 & 1.81 \\
\hline & $\mathrm{Hi}$ & 48 & 0.11 & 0.17 & 0.66 & 7.43 & 53 & 0.36 & 0.09 & 4.05 & 9.17 \\
\hline \multirow{2}{*}{$\mathrm{SO}_{4}{ }^{2-}$} & Lo & 52 & 0.59 & 0.07 & 8.00 & -0.12 & 48 & 0.85 & 0.05 & 17.97 & -0.72 \\
\hline & $\mathrm{Hi}$ & 49 & 0.52 & 0.06 & 8.27 & 0.18 & 53 & 0.44 & 0.04 & 10.40 & 1.40 \\
\hline \multirow{2}{*}{ EC } & Lo & 50 & 0.52 & 0.10 & 5.30 & 0.35 & 47 & 0.89 & 1.80 & 0.50 & 0.01 \\
\hline & $\mathrm{Hi}$ & 49 & 0.13 & 0.14 & 0.93 & 0.55 & 53 & -2.17 & 1.59 & -1.36 & 2.91 \\
\hline \multirow{2}{*}{$\mathrm{O}_{3}$} & Lo & 54 & -0.05 & 0.04 & -1.15 & 3.80 & 47 & -0.06 & 0.10 & -0.61 & 7.77 \\
\hline & $\mathrm{Hi}$ & 56 & 0.01 & 0.05 & 0.15 & 2.28 & 53 & 0.15 & 0.11 & 1.37 & 1.05 \\
\hline \multirow{2}{*}{$\mathrm{NO}_{2}$} & Lo & 54 & 0.22 & 0.11 & 1.92 & 7.19 & 49 & 0.77 & 0.11 & 6.80 & 1.28 \\
\hline & $\mathrm{Hi}$ & 51 & -0.08 & 0.13 & -0.63 & 7.95 & 56 & 0.48 & 0.09 & 5.46 & 2.37 \\
\hline
\end{tabular}

*shaded cells represent significant interaction effect; bold numbers indicate p-value $\leq 0.05$

** "Lo" $\leq$ median fraction of time in car (0.02); "Hi" > median fraction of time in car

\subsubsection{Summary of Elemental Data}

Table 102 summarizes water-extractable element concentrations measured as part of the children's exposure assessment. Water-extractable concentrations of several elements were below their respective limits of detection. Those elements that had median water-extractable concentrations below the LOD included: Al (winter only), $\mathrm{Cu}, \mathrm{Mn}, \mathrm{Ti}$, and $\mathrm{Zn}$ (winter only). For many elements, especially those associated with smaller particle sizes, median outdoor and ambient concentrations tended to be greater than indoor and personal levels. Personal exposures to elements that are commonly associated with larger particle sizes, such as $\mathrm{Ca}$ and $\mathrm{K}$, were generally greater than indoor concentrations of these elements and comparable to or greater than outdoor concentrations.

Table 102. Water-extractable element concentrations $\left(\mathrm{ng} / \mathrm{m}^{3}\right)$ measured in personal, indoor, outdoor, and ambient environments for the children's cohort.

\begin{tabular}{|c|c|c|c|c|c|c|c|c|c|}
\hline \multirow[b]{2}{*}{ Element } & \multirow[b]{2}{*}{ Location } & \multicolumn{4}{|c|}{ Winter } & \multicolumn{4}{|c|}{ Summer } \\
\hline & & $\mathbf{N}$ & 10th & 50th & 90th & $\mathbf{N}$ & 10th & 50th & $90^{\text {th }}$ \\
\hline \multirow{4}{*}{$\mathrm{Al}$} & Personal & 103 & $<\mathrm{LOD}$ & $<\mathrm{LOD}$ & 32.14 & 101 & $<$ LOD & 9.75 & 101.92 \\
\hline & Indoor & 107 & $<\mathrm{LOD}$ & $<\mathrm{LOD}$ & 23.62 & 98 & $<$ LOD & 15.91 & 57.35 \\
\hline & Outdoor & 103 & $<\mathrm{LOD}$ & $<\mathrm{LOD}$ & 21.48 & 99 & $<$ LOD & 17.81 & 47.70 \\
\hline & Central & 25 & $<$ LOD & 1.71 & 33.89 & 26 & $<$ LOD & 20.14 & 67.20 \\
\hline \multirow{4}{*}{ As } & Personal & 103 & $<\mathrm{LOD}$ & 0.57 & 1.26 & 102 & $<$ LOD & 0.87 & 2.77 \\
\hline & Indoor & 107 & $<$ LOD & 0.59 & 1.29 & 103 & 0.43 & 1.43 & 3.15 \\
\hline & Outdoor & 103 & $<\mathrm{LOD}$ & 0.94 & 2.49 & 103 & 0.76 & 1.91 & 3.96 \\
\hline & Central & 25 & $<\mathrm{LOD}$ & 1.14 & 4.20 & 27 & 0.51 & 2.09 & 4.33 \\
\hline \multirow{4}{*}{$\mathrm{Ba}$} & Personal & 103 & 0.35 & 1.14 & 4.05 & 84 & 0.72 & 1.72 & 4.10 \\
\hline & Indoor & 107 & 0.16 & 0.80 & 1.76 & 79 & 0.33 & 1.08 & 3.80 \\
\hline & Outdoor & 103 & 0.52 & 1.22 & 2.41 & 75 & 0.83 & 1.89 & 4.54 \\
\hline & Central & 25 & 0.49 & 1.61 & 2.62 & 23 & 1.00 & 2.36 & 4.77 \\
\hline \multirow{4}{*}{$\mathrm{Cd}$} & Personal & 103 & 0.11 & 0.24 & 0.54 & 84 & $<$ LOD & 0.18 & 0.60 \\
\hline & Indoor & 101 & 0.06 & 0.15 & 0.36 & 79 & $<$ LOD & 0.19 & 0.75 \\
\hline & Outdoor & 95 & 0.11 & 0.22 & 0.62 & 75 & $<$ LOD & 0.32 & 0.78 \\
\hline & Central & 25 & 0.12 & 0.28 & 0.95 & 23 & 0.05 & 0.34 & 0.88 \\
\hline
\end{tabular}


Table $102 . \quad$ (continued)

\begin{tabular}{|c|c|c|c|c|c|c|c|c|c|}
\hline \multirow[b]{2}{*}{ Element } & \multirow[b]{2}{*}{ Location } & \multicolumn{4}{|c|}{ Winter } & \multicolumn{4}{|c|}{ Summer } \\
\hline & & $\mathbf{N}$ & 10th & 50th & 90th & $\mathbf{N}$ & 10th & 50th & $90^{\text {th }}$ \\
\hline \multirow{4}{*}{$\mathrm{Ca}$} & Personal & 85 & 31.72 & 149.09 & 541.47 & 95 & $<$ LOD & 92.36 & 208.02 \\
\hline & Indoor & 89 & 31.93 & 60.29 & 115.95 & 93 & $<\mathrm{LOD}$ & 57.88 & 127.38 \\
\hline & Outdoor & 85 & $<$ LOD & 42.11 & 88.50 & 91 & $<$ LOD & 71.64 & 145.72 \\
\hline & Central & 20 & 20.98 & 50.35 & 122.52 & 23 & $<\mathrm{LOD}$ & 82.96 & 222.78 \\
\hline \multirow{4}{*}{ Co } & Personal & 102 & $<\mathrm{LOD}$ & $<\mathrm{LOD}$ & 0.07 & 102 & $<$ LOD & 0.02 & 0.07 \\
\hline & Indoor & 106 & $<\mathrm{LOD}$ & 0.01 & 0.06 & 103 & $<$ LOD & 0.02 & 0.05 \\
\hline & Outdoor & 102 & $<\mathrm{LOD}$ & 0.02 & 0.09 & 103 & 0.01 & 0.04 & 0.07 \\
\hline & Central & 25 & $<\mathrm{LOD}$ & 0.02 & 0.09 & 27 & 0.02 & 0.04 & 0.07 \\
\hline \multirow{4}{*}{$\mathrm{Cu}$} & Personal & 103 & $<\mathrm{LOD}$ & $<\mathrm{LOD}$ & $<$ LOD & 102 & $<$ LOD & $<\mathrm{LOD}$ & 6.41 \\
\hline & Indoor & 107 & $<\mathrm{LOD}$ & $<\mathrm{LOD}$ & $<$ LOD & 103 & $<$ LOD & $<\mathrm{LOD}$ & 2.87 \\
\hline & Outdoor & 103 & $<$ LOD & $<$ LOD & 0.04 & 103 & $<$ LOD & $<$ LOD & 2.89 \\
\hline & Central & 25 & $<\mathrm{LOD}$ & $<\mathrm{LOD}$ & $<$ LOD & 27 & $<$ LOD & $<\mathrm{LOD}$ & 9.57 \\
\hline \multirow{4}{*}{$\mathrm{Fe}$} & Personal & 103 & $<\mathrm{LOD}$ & $<\mathrm{LOD}$ & 56.70 & 81 & $<$ LOD & 18.72 & 58.31 \\
\hline & Indoor & 107 & $<\mathrm{LOD}$ & 1.99 & 35.44 & 73 & $<$ LOD & 20.57 & 70.63 \\
\hline & Outdoor & 103 & $<\mathrm{LOD}$ & 11.94 & 41.98 & 75 & 7.44 & 31.84 & 156.00 \\
\hline & Central & 25 & $<$ LOD & 23.52 & 70.34 & 21 & 17.47 & 54.20 & 186.26 \\
\hline \multirow{4}{*}{$\mathrm{Pb}$} & Personal & 103 & 1.51 & 2.78 & 9.01 & 70 & 1.54 & 4.91 & 14.01 \\
\hline & Indoor & 107 & 1.06 & 2.71 & 8.00 & 64 & 1.60 & 4.47 & 14.12 \\
\hline & Outdoor & 103 & 2.23 & 4.60 & 14.23 & 68 & 2.39 & 6.98 & 25.24 \\
\hline & Central & 25 & 2.32 & 5.43 & 17.44 & 17 & 3.10 & 7.05 & 14.65 \\
\hline \multirow{4}{*}{$\mathrm{Mg}$} & Personal & 103 & 4.08 & 12.35 & 45.93 & 102 & 7.52 & 15.27 & 39.54 \\
\hline & Indoor & 107 & 3.49 & 8.87 & 27.63 & 103 & 5.02 & 11.42 & 38.55 \\
\hline & Outdoor & 103 & 5.11 & 11.98 & 34.99 & 103 & 6.80 & 21.84 & 48.34 \\
\hline & Central & 25 & 5.23 & 14.25 & 62.22 & 27 & 8.62 & 27.24 & 71.95 \\
\hline \multirow{4}{*}{$\mathrm{Mn}$} & Personal & 103 & $<\mathrm{LOD}$ & $<\mathrm{LOD}$ & 9.49 & 102 & $<\mathrm{LOD}$ & $<\mathrm{LOD}$ & 11.03 \\
\hline & Indoor & 107 & $<\mathrm{LOD}$ & $<\mathrm{LOD}$ & 7.68 & 103 & $<$ LOD & $<\mathrm{LOD}$ & 10.15 \\
\hline & Outdoor & 103 & $<\mathrm{LOD}$ & 3.75 & 17.56 & 103 & $<\mathrm{LOD}$ & 4.19 & 15.52 \\
\hline & Central & 25 & $<\mathrm{LOD}$ & 6.20 & 24.32 & 27 & $<\mathrm{LOD}$ & 5.30 & 13.15 \\
\hline \multirow{4}{*}{$\mathrm{Ni}$} & Personal & 103 & $<$ LOD & 0.78 & 5.69 & 98 & $<$ LOD & 0.40 & 2.94 \\
\hline & Indoor & 107 & $<\mathrm{LOD}$ & 0.48 & 4.08 & 95 & $<$ LOD & 0.35 & 0.91 \\
\hline & Outdoor & 103 & $<\mathrm{LOD}$ & 0.50 & 1.86 & 95 & $<$ LOD & 0.37 & 1.42 \\
\hline & Central & 25 & $<\mathrm{LOD}$ & 0.35 & 1.18 & 25 & $<$ LOD & 0.36 & 1.59 \\
\hline \multirow{4}{*}{ K } & Personal & 103 & 12.50 & 78.43 & 191.78 & 93 & $<\mathrm{LOD}$ & 61.20 & 160.92 \\
\hline & Indoor & 107 & 20.99 & 53.59 & 116.43 & 92 & $<$ LOD & 43.57 & 121.75 \\
\hline & Outdoor & 103 & 27.27 & 61.86 & 126.11 & 93 & $<\mathrm{LOD}$ & 72.85 & 147.53 \\
\hline & Central & 25 & 24.83 & 77.01 & 172.99 & 24 & $<$ LOD & 59.77 & 153.11 \\
\hline \multirow{4}{*}{$\mathrm{Se}$} & Personal & 103 & $<\mathrm{LOD}$ & 1.19 & 2.89 & 102 & $<\mathrm{LOD}$ & 1.50 & 4.51 \\
\hline & Indoor & 107 & $<\mathrm{LOD}$ & 1.04 & 2.48 & 103 & 0.40 & 1.37 & 4.37 \\
\hline & Outdoor & 103 & 0.99 & 2.74 & 9.06 & 103 & 1.24 & 2.80 & 6.14 \\
\hline & Central & 25 & 1.43 & 3.11 & 9.29 & 27 & 1.69 & 3.21 & 5.94 \\
\hline \multirow{4}{*}{$\mathrm{Na}$} & Personal & 103 & $<\mathrm{LOD}$ & 53.89 & 193.53 & 102 & $<$ LOD & 47.41 & 193.77 \\
\hline & Indoor & 107 & $<$ LOD & 36.16 & 71.45 & 103 & 8.62 & 43.13 & 171.42 \\
\hline & Outdoor & 103 & $<\mathrm{LOD}$ & 25.12 & 81.48 & 103 & 9.20 & 34.55 & 185.47 \\
\hline & Central & 25 & $<$ LOD & 37.35 & 133.43 & 27 & 8.89 & 60.15 & 314.98 \\
\hline
\end{tabular}


Table $102 . \quad$ (continued)

\begin{tabular}{|c|c|c|c|c|c|c|c|c|c|}
\hline \multirow[b]{2}{*}{ Element } & \multirow[b]{2}{*}{ Location } & \multicolumn{4}{|c|}{ Winter } & \multicolumn{4}{|c|}{ Summer } \\
\hline & & $\mathbf{N}$ & 10th & 50th & 90th & $\mathbf{N}$ & 10th & 50th & $90^{\text {th }}$ \\
\hline \multirow{4}{*}{ Sn } & Personal & 95 & $<$ LOD & 0.25 & 0.83 & 84 & $<$ LOD & 0.24 & 0.90 \\
\hline & Indoor & 91 & $<$ LOD & 0.12 & 0.83 & 79 & $<$ LOD & 0.18 & 0.70 \\
\hline & Outdoor & 87 & $<$ LOD & $<$ LOD & 0.24 & 75 & $<$ LOD & 0.14 & 0.72 \\
\hline & Central & 23 & $<$ LOD & $<$ LOD & 0.21 & 23 & $<$ LOD & 0.15 & 0.62 \\
\hline \multirow{4}{*}{$\mathrm{Ti}$} & Personal & 103 & $<$ LOD & $<$ LOD & $<$ LOD & 102 & $<$ LOD & $<\mathrm{LOD}$ & $<\mathrm{LOD}$ \\
\hline & Indoor & 107 & $<$ LOD & $<$ LOD & $<$ LOD & 103 & $<$ LOD & $<$ LOD & $<\mathrm{LOD}$ \\
\hline & Outdoor & 103 & $<$ LOD & $<$ LOD & $<$ LOD & 103 & $<$ LOD & $<$ LOD & 0.50 \\
\hline & Central & 25 & $<$ LOD & $<$ LOD & $<$ LOD & 27 & $<$ LOD & $<\mathrm{LOD}$ & 3.25 \\
\hline \multirow{4}{*}{ V } & Personal & 103 & $<$ LOD & $<$ LOD & 1.20 & 102 & $<$ LOD & $<\mathrm{LOD}$ & 1.54 \\
\hline & Indoor & 107 & $<$ LOD & $<$ LOD & 1.46 & 103 & $<$ LOD & 0.63 & 1.67 \\
\hline & Outdoor & 103 & $<$ LOD & 0.64 & 3.00 & 103 & 0.45 & 1.25 & 4.07 \\
\hline & Central & 25 & $<$ LOD & 0.61 & 3.26 & 27 & 0.47 & 1.61 & 4.17 \\
\hline \multirow{4}{*}{$\mathrm{Zn}$} & Personal & 103 & $<$ LOD & $<$ LOD & 39.49 & 102 & $<$ LOD & 2.93 & 70.13 \\
\hline & Indoor & 107 & $<$ LOD & $<$ LOD & 42.48 & 103 & $<$ LOD & 13.50 & 85.73 \\
\hline & Outdoor & 103 & $<$ LOD & 5.51 & 57.95 & 103 & $<$ LOD & 26.39 & 123.35 \\
\hline & Central & 25 & $<$ LOD & 11.00 & 58.82 & 27 & 2.03 & 36.79 & 112.71 \\
\hline
\end{tabular}

Trends exhibited by acid-digestible element concentrations were similar to those exhibited by water-extractable element concentrations, with some elements again having median concentrations below their respective limits of detection (Table 103). The number of aciddigestible elements with median values below the LOD was larger than the number of waterextractable elements, and included $\mathrm{As}, \mathrm{Ba}, \mathrm{Cd}$, and $\mathrm{Pb}$ in the winter, $\mathrm{Ca}, \mathrm{Co}$, and $\mathrm{Ni}$ in the summer, and $\mathrm{Cu}$ in both seasons. Median personal exposures to the measured elements tended to be greater than or comparable to concentrations measured indoors and outdoors.

Table 103. Acid-digestible element concentrations $\left(\mathrm{ng} / \mathrm{m}^{3}\right)$ measured in personal, indoor, outdoor, and ambient environments for the children's cohort.

\begin{tabular}{|c|c|c|c|c|c|c|c|c|c|}
\hline \multirow[b]{2}{*}{ Element } & \multirow[b]{2}{*}{ Location } & \multicolumn{4}{|c|}{ Winter } & \multicolumn{4}{|c|}{ Summer } \\
\hline & & $\mathbf{N}$ & 10th & 50th & 90th & $\mathbf{N}$ & 10th & $50^{\text {th }}$ & 90th \\
\hline \multirow{4}{*}{$\mathrm{Al}$} & Personal & 68 & $<$ LOD & 196.47 & 518.63 & 67 & $<$ LOD & 145.52 & 418.54 \\
\hline & Indoor & 76 & $<$ LOD & 99.13 & 223.05 & 62 & $<$ LOD & 126.52 & 301.15 \\
\hline & Outdoor & 74 & $<$ LOD & 92.97 & 203.77 & 59 & $<$ LOD & 80.03 & 336.96 \\
\hline & Central & 22 & $<$ LOD & 42.89 & 135.26 & 16 & $<\mathrm{LOD}$ & 120.44 & 431.20 \\
\hline \multirow{4}{*}{ As } & Personal & 105 & $<$ LOD & $<$ LOD & $<$ LOD & 101 & $<\mathrm{LOD}$ & $<$ LOD & 3.91 \\
\hline & Indoor & 107 & $<$ LOD & $<\mathrm{LOD}$ & $<\mathrm{LOD}$ & 100 & $<\mathrm{LOD}$ & 1.44 & 2.90 \\
\hline & Outdoor & 100 & $<$ LOD & $<\mathrm{LOD}$ & 1.12 & 101 & $<\mathrm{LOD}$ & 1.81 & 3.61 \\
\hline & Central & 25 & $<$ LOD & $<\mathrm{LOD}$ & 3.13 & 27 & $<\mathrm{LOD}$ & 2.16 & 3.32 \\
\hline \multirow{4}{*}{$\mathrm{Ba}$} & Personal & 105 & $<$ LOD & $<\mathrm{LOD}$ & 8.09 & 101 & $<\mathrm{LOD}$ & $<$ LOD & 7.85 \\
\hline & Indoor & 107 & $<$ LOD & $<\mathrm{LOD}$ & 5.74 & 100 & $<\mathrm{LOD}$ & 0.34 & 4.95 \\
\hline & Outdoor & 100 & $<$ LOD & $<\mathrm{LOD}$ & 3.63 & 101 & $<\mathrm{LOD}$ & 2.23 & 5.48 \\
\hline & Central & 25 & $<$ LOD & $<$ LOD & 3.99 & 27 & $<\mathrm{LOD}$ & 2.99 & 7.45 \\
\hline \multirow{4}{*}{$\mathrm{Cd}$} & Personal & 105 & $<$ LOD & $<$ LOD & 1.00 & 101 & $<\mathrm{LOD}$ & 0.34 & 1.63 \\
\hline & Indoor & 107 & $<$ LOD & $<\mathrm{LOD}$ & 0.50 & 100 & $<$ LOD & 0.41 & 1.06 \\
\hline & Outdoor & 100 & $<$ LOD & 0.39 & 0.80 & 101 & $<\mathrm{LOD}$ & 0.53 & 1.19 \\
\hline & Central & 25 & $<$ LOD & 0.30 & 0.99 & 27 & $<\mathrm{LOD}$ & 0.62 & 1.80 \\
\hline
\end{tabular}


Table $103 . \quad$ (continued)

\begin{tabular}{|c|c|c|c|c|c|c|c|c|c|}
\hline \multirow[b]{2}{*}{ Element } & \multirow[b]{2}{*}{ Location } & \multicolumn{4}{|c|}{ Winter } & \multicolumn{4}{|c|}{ Summer } \\
\hline & & $\mathbf{N}$ & 10th & 50th & 90th & $\mathbf{N}$ & 10th & $50^{\text {th }}$ & 90th \\
\hline \multirow{4}{*}{$\mathrm{Ca}$} & Personal & 53 & $<\mathrm{LOD}$ & 156.26 & 738.69 & 24 & $<$ LOD & $<$ LOD & 35.87 \\
\hline & Indoor & 44 & $<$ LOD & 52.74 & 418.70 & 25 & $<\mathrm{LOD}$ & $<$ LOD & 101.59 \\
\hline & Outdoor & 40 & $<$ LOD & 56.91 & 617.96 & 22 & $<\mathrm{LOD}$ & $<$ LOD & 30.05 \\
\hline & Central & 10 & $<\mathrm{LOD}$ & 80.16 & 340.79 & 7 & $<\mathrm{LOD}$ & $<\mathrm{LOD}$ & 52.27 \\
\hline \multirow{4}{*}{ Co } & Personal & 18 & $<\mathrm{LOD}$ & $<\mathrm{LOD}$ & 1.82 & 38 & $<$ LOD & $<$ LOD & 0.33 \\
\hline & Indoor & 25 & 0.13 & 0.44 & 0.79 & 34 & $<$ LOD & $<$ LOD & 0.14 \\
\hline & Outdoor & 23 & $<$ LOD & 0.43 & 0.52 & 32 & $<$ LOD & $<$ LOD & $<\mathrm{LOD}$ \\
\hline & Central & 5 & 0.19 & 0.44 & 0.90 & 9 & $<\mathrm{LOD}$ & $<$ LOD & 0.25 \\
\hline \multirow{4}{*}{$\mathrm{Cu}$} & Personal & 105 & $<$ LOD & $<\mathrm{LOD}$ & 0.81 & 100 & $<$ LOD & $<$ LOD & 29.37 \\
\hline & Indoor & 107 & $<$ LOD & $<$ LOD & 1.26 & 98 & $<$ LOD & $<$ LOD & 18.14 \\
\hline & Outdoor & 100 & $<\mathrm{LOD}$ & $<$ LOD & 4.62 & 97 & $<\mathrm{LOD}$ & $<\mathrm{LOD}$ & 21.12 \\
\hline & Central & 25 & $<$ LOD & $<$ LOD & 1.67 & 26 & $<\mathrm{LOD}$ & $<$ LOD & 10.09 \\
\hline \multirow{4}{*}{$\mathrm{Fe}$} & Personal & 104 & 51.01 & 187.47 & 485.14 & 87 & $<$ LOD & 243.28 & 654.12 \\
\hline & Indoor & 105 & 44.67 & 92.07 & 257.11 & 89 & 48.88 & 163.57 & 665.93 \\
\hline & Outdoor & 98 & 50.27 & 119.21 & 471.04 & 87 & 73.02 & 215.22 & 771.94 \\
\hline & Central & 24 & 52.45 & 149.39 & 551.35 & 22 & 101.84 & 256.18 & 748.65 \\
\hline \multirow{4}{*}{$\mathrm{Pb}$} & Personal & 105 & $<\mathrm{LOD}$ & $<\mathrm{LOD}$ & 26.12 & 101 & $<$ LOD & 8.52 & 39.97 \\
\hline & Indoor & 107 & $<$ LOD & $<$ LOD & 16.08 & 100 & $<$ LOD & 7.97 & 24.21 \\
\hline & Outdoor & 100 & $<\mathrm{LOD}$ & 0.58 & 18.20 & 101 & $<$ LOD & 10.58 & 26.82 \\
\hline & Central & 25 & $<$ LOD & $<$ LOD & 15.44 & 27 & $<$ LOD & 9.88 & 29.21 \\
\hline \multirow{4}{*}{$\mathrm{Mg}$} & Personal & 93 & 3.94 & 35.25 & 74.43 & 79 & $<\mathrm{LOD}$ & 22.08 & 59.02 \\
\hline & Indoor & 101 & 1.70 & 17.88 & 40.03 & 81 & $<$ LOD & 12.15 & 46.17 \\
\hline & Outdoor & 91 & 3.45 & 17.41 & 34.77 & 83 & 1.79 & 25.93 & 58.17 \\
\hline & Central & 24 & $<\mathrm{LOD}$ & 21.64 & 67.18 & 22 & 10.19 & 37.73 & 69.06 \\
\hline \multirow{4}{*}{$\mathrm{Mn}$} & Personal & 74 & $<$ LOD & 11.69 & 32.52 & 83 & $<\mathrm{LOD}$ & 7.49 & 20.04 \\
\hline & Indoor & 78 & 2.39 & 7.47 & 16.24 & 82 & $<$ LOD & 5.50 & 19.76 \\
\hline & Outdoor & 75 & 2.60 & 10.55 & 26.69 & 80 & $<\mathrm{LOD}$ & 8.23 & 25.28 \\
\hline & Central & 21 & 3.15 & 14.03 & 45.69 & 20 & 5.57 & 13.97 & 33.54 \\
\hline \multirow{4}{*}{$\mathrm{Ni}$} & Personal & 16 & $<\mathrm{LOD}$ & 3.85 & 32.10 & 69 & $<\mathrm{LOD}$ & $<$ LOD & 12.59 \\
\hline & Indoor & 15 & $<\mathrm{LOD}$ & $<\mathrm{LOD}$ & 1.91 & 65 & $<\mathrm{LOD}$ & $<$ LOD & 3.56 \\
\hline & Outdoor & 13 & $<$ LOD & 1.43 & 3.27 & 66 & $<\mathrm{LOD}$ & $<$ LOD & 13.88 \\
\hline & Central & 2 & $<\mathrm{LOD}$ & 3.75 & 7.50 & 18 & $<$ LOD & $<$ LOD & 2.71 \\
\hline \multirow{4}{*}{ K } & Personal & 68 & $<$ LOD & 118.82 & 317.29 & 61 & 31.07 & 119.70 & 256.52 \\
\hline & Indoor & 72 & 5.09 & 82.24 & 198.04 & 54 & 21.27 & 90.25 & 204.13 \\
\hline & Outdoor & 70 & $<$ LOD & 87.09 & 189.89 & 55 & 33.35 & 98.63 & 249.74 \\
\hline & Central & 20 & $<$ LOD & 97.06 & 175.72 & 14 & 44.84 & 125.30 & 227.46 \\
\hline \multirow{4}{*}{$\mathrm{Se}$} & Personal & 0 & $\mathrm{n} / \mathrm{a}$ & $\mathrm{n} / \mathrm{a}$ & $\mathrm{n} / \mathrm{a}$ & 21 & $<$ LOD & $<$ LOD & 4.47 \\
\hline & Indoor & 0 & $\mathrm{n} / \mathrm{a}$ & $\mathrm{n} / \mathrm{a}$ & $\mathrm{n} / \mathrm{a}$ & 24 & $<$ LOD & 0.62 & 3.21 \\
\hline & Outdoor & 0 & $\mathrm{n} / \mathrm{a}$ & $\mathrm{n} / \mathrm{a}$ & $\mathrm{n} / \mathrm{a}$ & 24 & $<\mathrm{LOD}$ & 2.05 & 3.32 \\
\hline & Central & 0 & $\mathrm{n} / \mathrm{a}$ & $\mathrm{n} / \mathrm{a}$ & $\mathrm{n} / \mathrm{a}$ & 6 & $<$ LOD & 2.46 & 6.17 \\
\hline \multirow{4}{*}{$\mathrm{Na}$} & Personal & 40 & 75.09 & 307.46 & 1083.92 & 59 & $<$ LOD & 113.95 & 998.73 \\
\hline & Indoor & 44 & 8.55 & 174.48 & 579.76 & 61 & $<$ LOD & 89.98 & 303.28 \\
\hline & Outdoor & 45 & 23.18 & 120.88 & 266.87 & 63 & $<$ LOD & 62.49 & 243.36 \\
\hline & Central & 14 & 24.95 & 103.09 & 271.22 & 17 & $<\mathrm{LOD}$ & 68.22 & 462.68 \\
\hline
\end{tabular}


Table $103 . \quad$ (continued)

\begin{tabular}{|c|c|c|c|c|c|c|c|c|c|}
\hline \multirow{3}{*}{ Element } & & \multicolumn{4}{|c|}{ Winter } & \multicolumn{4}{c|}{ Summer } \\
\cline { 3 - 10 } & Location & $\mathbf{N}$ & 10th & $\mathbf{5 0 t h}$ & $\mathbf{9 0 t h}$ & $\mathbf{N}$ & 10th & $\mathbf{5 0}^{\text {th }}$ & 90th \\
\hline \multirow{4}{*}{ Sn } & Personal & 105 & $<$ LOD & 1.81 & 5.03 & 101 & $<$ LOD & 2.52 & 6.43 \\
\cline { 2 - 10 } & Indoor & 107 & $<$ LOD & 1.07 & 4.02 & 100 & 0.50 & 1.46 & 6.67 \\
\cline { 2 - 10 } & Outdoor & 100 & $<$ LOD & 0.76 & 1.71 & 101 & 0.63 & 1.28 & 3.69 \\
\cline { 2 - 10 } & Central & 25 & $<$ LOD & 1.04 & 3.16 & 27 & 0.69 & 1.45 & 3.72 \\
\hline \multirow{4}{*}{ Ti } & Personal & 101 & $<$ LOD & 10.42 & 48.78 & 101 & $<$ LOD & $<$ LOD & 94.98 \\
\cline { 2 - 10 } & Indoor & 106 & $<$ LOD & 6.42 & 25.05 & 100 & $<$ LOD & $<$ LOD & 63.81 \\
\cline { 2 - 10 } & Outdoor & 97 & $<$ LOD & 5.89 & 24.42 & 101 & $<$ LOD & 5.30 & 65.45 \\
\cline { 2 - 10 } & Central & 25 & $<$ LOD & 4.70 & 25.66 & 27 & $<$ LOD & 6.76 & 58.86 \\
\hline \multirow{4}{*}{ V } & Personal & 88 & $<$ LOD & 0.33 & 4.73 & 49 & $<$ LOD & 1.27 & 5.18 \\
\cline { 2 - 10 } & Indoor & 80 & $<$ LOD & 0.06 & 1.63 & 43 & $<$ LOD & 0.64 & 2.62 \\
\cline { 2 - 10 } & Outdoor & 80 & $<$ LOD & 0.25 & 3.37 & 42 & $<$ LOD & 0.78 & 2.78 \\
\cline { 2 - 10 } & Central & 20 & $<$ LOD & 1.16 & 3.11 & 12 & $<$ LOD & 1.21 & 3.68 \\
\hline \multirow{4}{*}{ Zn } & Personal & 102 & $<$ LOD & 6.64 & 242.20 & 101 & $<$ LOD & 34.49 & 247.39 \\
\cline { 2 - 10 } & Indoor & 103 & $<$ LOD & 9.95 & 81.62 & 100 & $<$ LOD & 38.92 & 160.34 \\
\cline { 2 - 9 } & Outdoor & 97 & $<$ LOD & 17.99 & 79.31 & 101 & $<$ LOD & 33.27 & 242.09 \\
\cline { 2 - 9 } & Central & 24 & $<$ LOD & 24.11 & 113.15 & 27 & $<$ LOD & 68.01 & 164.79 \\
\hline
\end{tabular}

\subsubsection{Associations between Personal Exposures, Indoor Concentrations, and Ambient Concentrations for Selected Elements}

\subsection{Personal Exposures and Ambient Elemental Concentrations}

The associations between personal exposures and corresponding ambient concentrations for $\mathrm{PM}_{2.5}$ elements for the children's cohort differed by element, extraction method, and season (Tables 104-105). These differences, however, did not follow a distinct pattern, as slopes and intercepts were higher in summer than in winter for some elements but were lower in summer than in winter for other elements. Furthermore, seasonal patterns in the personal-ambient association for the same element depended on whether the elemental concentration was determined in the water-extractable or acid-digestible $\mathrm{PM}_{2.5}$ fraction. It is likely that the observed inconsistencies in our findings largely reflect errors in the measurement and/or analysis techniques, as evidenced by the poor precisions and low concentrations observed for many of the elements.

\subsection{Indoor and Ambient Elemental Concentrations}

The associations between indoor concentrations and corresponding ambient concentrations for $\mathrm{PM}_{2.5}$ elements for the children's cohort also differed by element, extraction method, and season (Tables 106-107). These differences, however, did not follow a distinct pattern, as slopes and intercepts were higher in summer than in winter for some elements but were lower in summer than in winter for other elements. Furthermore, indoor-ambient associations observed for the elements often differed from corresponding personal-ambient associations. These differences may reflect differences in measurement and method performance for the determination of indoor and personal elemental concentrations. 
Table 104. Associations between personal exposures and ambient concentrations for select waterextractable elements for the children's cohort.*

\begin{tabular}{|c|c|c|c|c|c|c|c|c|c|c|}
\hline \multirow{2}{*}{\multicolumn{2}{|c|}{$\begin{array}{c}\text { Water- } \\
\text { Extractable } \\
\text { Element }\end{array}$}} & \multicolumn{3}{|c|}{ Both seasons } & \multicolumn{3}{|c|}{ Winter } & \multicolumn{3}{|c|}{ Summer } \\
\hline & & \multirow{2}{*}{$\begin{array}{c}\text { estimate } \\
0.13 \\
\end{array}$} & \multirow{2}{*}{$\begin{array}{l}\text { s.e. } \\
0.12\end{array}$} & \multirow{2}{*}{$\frac{p \text {-value }}{0.31}$} & \multirow{2}{*}{$\begin{array}{c}\text { estimate } \\
0.26 \\
\end{array}$} & \multirow{2}{*}{$\begin{array}{l}\text { s.e. } \\
0.12\end{array}$} & \multirow{2}{*}{$\frac{\text { p-value }}{0.06}$} & \multirow{2}{*}{$\begin{array}{c}\text { estimate } \\
-0.01 \\
\end{array}$} & \multirow{2}{*}{$\begin{array}{l}\text { s.e. } \\
0.19\end{array}$} & \multirow{2}{*}{$\frac{p \text {-value }}{0.95}$} \\
\hline As & Intercept & & & & & & & & & \\
\hline AS & Slope & 0.39 & 0.04 & $<.0001$ & 0.19 & 0.03 & $<.0001$ & 0.52 & 0.05 & $<.0001$ \\
\hline \multirow{2}{*}{$\mathrm{Ba}$} & Intercept & 3.70 & 1.67 & 0.04 & 1.06 & 0.98 & 0.30 & 6.81 & 3.14 & 0.05 \\
\hline & Slope & -0.24 & 0.65 & 0.71 & 0.50 & 0.48 & 0.30 & -0.95 & 1.04 & 0.36 \\
\hline \multirow{2}{*}{$\mathrm{Cd}$} & Intercept & 0.14 & 0.04 & 0.00 & 0.07 & 0.03 & 0.06 & 0.18 & 0.07 & 0.02 \\
\hline & Slope & 0.32 & 0.06 & $<.0001$ & 0.50 & 0.07 & $<.0001$ & 0.23 & 0.10 & 0.02 \\
\hline \multirow{2}{*}{$\mathrm{Fe}$} & Intercept & 18.39 & 5.87 & 0.00 & 29.69 & 10.82 & 0.02 & 6.56 & 4.24 & 0.14 \\
\hline & Slope & 0.22 & 0.08 & 0.01 & 0.03 & 0.19 & 0.89 & 0.33 & 0.04 & $<.0001$ \\
\hline \multirow{2}{*}{$\mathrm{Pb}$} & Intercept & 1.33 & 0.51 & 0.01 & 1.45 & 0.49 & 0.01 & 1.72 & 0.84 & 0.06 \\
\hline & Slope & 0.35 & 0.03 & $<.0001$ & 0.24 & 0.04 & $<.0001$ & 0.42 & 0.04 & $<.0001$ \\
\hline \multirow{2}{*}{$\mathrm{Mg}$} & Intercept & 15.24 & 9.19 & 0.11 & 29.39 & 10.51 & 0.02 & -6.79 & 15.00 & 0.66 \\
\hline & Slope & 0.57 & 0.20 & 0.00 & 0.03 & 0.20 & 0.86 & 1.23 & 0.32 & 0.00 \\
\hline \multirow{2}{*}{$\mathrm{Ni}$} & Intercept & 0.89 & 0.28 & 0.00 & 1.14 & 0.48 & 0.04 & 0.79 & 0.23 & 0.00 \\
\hline & Slope & 0.75 & 0.32 & 0.02 & 1.46 & 0.57 & 0.01 & 0.19 & 0.26 & 0.48 \\
\hline \multirow{2}{*}{$\mathrm{K}$} & Intercept & 32.38 & 9.66 & 0.00 & 41.59 & 19.18 & 0.05 & 29.50 & 10.95 & 0.02 \\
\hline & Slope & 0.64 & 0.09 & $<.0001$ & 0.57 & 0.17 & 0.00 & 0.66 & 0.11 & $<.0001$ \\
\hline \multirow{2}{*}{$\mathrm{Se}$} & Intercept & 0.57 & 0.57 & 0.33 & 0.38 & 0.36 & 0.31 & -0.86 & 1.07 & 0.43 \\
\hline & Slope & 0.39 & 0.12 & 0.00 & 0.24 & 0.06 & 0.00 & 0.98 & 0.28 & 0.00 \\
\hline \multirow{2}{*}{$\mathrm{Na}$} & Intercept & 80.88 & 18.60 & 0.00 & 103.20 & 42.84 & 0.03 & 54.70 & 12.16 & 0.00 \\
\hline & Slope & 0.32 & 0.10 & 0.00 & 0.43 & 0.41 & 0.30 & 0.36 & 0.06 & $<.0001$ \\
\hline \multirow{2}{*}{$\mathrm{V}$} & Intercept & 0.33 & 0.07 & $<.0001$ & 0.27 & 0.07 & 0.00 & 0.38 & 0.12 & 0.01 \\
\hline & Slope & 0.15 & 0.10 & 0.15 & 0.07 & 0.13 & 0.60 & 0.21 & 0.14 & 0.16 \\
\hline \multirow{2}{*}{$\mathrm{Zn}$} & Intercept & -0.19 & 0.07 & 0.01 & -0.25 & 0.06 & 0.00 & -0.14 & 0.12 & 0.27 \\
\hline & Slope & 0.46 & 0.03 & $<.0001$ & 0.50 & 0.03 & $<.0001$ & 0.44 & 0.04 & $<.0001$ \\
\hline
\end{tabular}

${ }^{*}$ All concentrations in $\mathrm{ng} / \mathrm{m}^{3}$. Bold values indicate significance at 0.05 level. 
Table 105. Associations between personal exposures and ambient concentrations for select aciddigestible elements for the children's cohort.*

\begin{tabular}{|c|c|c|c|c|c|c|c|c|c|c|}
\hline \multirow{2}{*}{\multicolumn{2}{|c|}{$\begin{array}{l}\text { Acid-Digestible } \\
\text { Element }\end{array}$}} & \multicolumn{3}{|c|}{ Both seasons } & \multicolumn{3}{|c|}{ Winter } & \multicolumn{3}{|c|}{ Summer } \\
\hline & & \multirow{2}{*}{$\begin{array}{c}\text { estimate } \\
134.64\end{array}$} & \multirow{2}{*}{$\begin{array}{c}\text { s.e. } \\
24.68\end{array}$} & \multirow{2}{*}{$\begin{array}{c}\text { p-value } \\
<.0001\end{array}$} & \multirow{2}{*}{\begin{tabular}{|c|} 
estimate \\
51.88 \\
\end{tabular}} & \multirow{2}{*}{$\begin{array}{c}\text { s.e. } \\
32.92\end{array}$} & \multirow{2}{*}{$\frac{p \text {-value }}{0.15}$} & \multirow{2}{*}{$\begin{array}{c}\text { estimate } \\
91.47\end{array}$} & \multirow{2}{*}{$\begin{array}{c}\text { s.e. } \\
26.10 \\
\end{array}$} & \multirow{2}{*}{$\frac{p \text {-value }}{0.00}$} \\
\hline Al & Intercept & & & & & & & & & \\
\hline Al & Slope & 0.43 & 0.10 & $<.0001$ & 2.22 & 0.32 & $<.0001$ & 0.38 & 0.09 & 0.00 \\
\hline \multirow{2}{*}{ As } & Intercept & 0.38 & 0.19 & 0.06 & 0.32 & 0.19 & 0.13 & 0.34 & 0.31 & 0.29 \\
\hline & Slope & 0.26 & 0.06 & $<.0001$ & -0.02 & 0.05 & 0.70 & 0.39 & 0.10 & 0.00 \\
\hline \multirow{2}{*}{$\mathrm{Ba}$} & Intercept & 4.55 & 2.54 & 0.08 & 3.11 & 4.63 & 0.52 & 5.28 & 2.47 & 0.05 \\
\hline & Slope & 0.50 & 0.80 & 0.53 & 2.51 & 1.91 & 0.19 & -0.21 & 0.68 & 0.76 \\
\hline \multirow{2}{*}{$\mathrm{Cd}$} & Intercept & 0.17 & 0.07 & 0.02 & 0.09 & 0.10 & 0.39 & 0.26 & 0.10 & 0.02 \\
\hline & Slope & 0.53 & 0.06 & $<.0001$ & 0.45 & 0.12 & 0.00 & 0.53 & 0.08 & $<.0001$ \\
\hline \multirow{2}{*}{$\mathrm{Fe}$} & Intercept & 132.45 & 31.99 & 0.00 & 190.17 & 48.53 & 0.00 & 94.76 & 43.34 & 0.05 \\
\hline & Slope & 0.53 & 0.07 & $<.0001$ & 0.37 & 0.13 & 0.00 & 0.61 & 0.08 & $<.0001$ \\
\hline \multirow{2}{*}{$\mathrm{Pb}$} & Intercept & 5.94 & 9.22 & 0.53 & -0.12 & 0.83 & 0.89 & 14.79 & 18.34 & 0.43 \\
\hline & Slope & 1.08 & 0.50 & 0.03 & 0.61 & 0.07 & $<.0001$ & 0.97 & 0.84 & 0.25 \\
\hline \multirow{2}{*}{$\mathrm{Mg}$} & Intercept & 18.66 & 9.95 & 0.07 & 43.49 & 10.96 & 0.00 & -19.99 & 17.93 & 0.28 \\
\hline & Slope & 0.74 & 0.21 & 0.00 & 0.00 & 0.23 & 0.99 & 1.75 & 0.33 & $<.0001$ \\
\hline \multirow{2}{*}{$\mathrm{Mn}$} & Intercept & 5.43 & 2.66 & 0.05 & 12.54 & 5.31 & 0.04 & -0.40 & 1.64 & 0.81 \\
\hline & Slope & 0.44 & 0.12 & 0.00 & 0.29 & 0.21 & 0.17 & 0.60 & 0.08 & $<.0001$ \\
\hline \multirow{2}{*}{ K } & Intercept & 53.50 & 22.10 & 0.02 & 62.98 & 32.87 & 0.08 & 50.29 & 28.87 & 0.10 \\
\hline & Slope & 0.77 & 0.16 & $<.0001$ & 0.81 & 0.26 & 0.00 & 0.72 & 0.18 & 0.00 \\
\hline \multirow{2}{*}{$\mathrm{Na}$} & Intercept & 450.43 & 79.87 & $<.0001$ & 571.21 & 129.34 & 0.00 & 406.87 & 110.36 & 0.00 \\
\hline & Slope & -0.48 & 0.44 & 0.28 & -1.05 & 0.94 & 0.28 & -0.42 & 0.53 & 0.43 \\
\hline \multirow{2}{*}{ Sn } & Intercept & 6.18 & 4.83 & 0.21 & 1.98 & 1.16 & 0.12 & 11.21 & 9.52 & 0.26 \\
\hline & Slope & 0.00 & 2.47 & 1.00 & 0.83 & 0.64 & 0.20 & -1.56 & 4.68 & 0.74 \\
\hline \multirow{2}{*}{ V } & Intercept & 1.18 & 0.37 & 0.01 & 0.59 & 0.54 & 0.30 & 1.50 & 0.46 & 0.01 \\
\hline & Slope & 0.50 & 0.14 & 0.00 & 0.79 & 0.22 & 0.00 & 0.39 & 0.17 & 0.03 \\
\hline \multirow{2}{*}{$\mathrm{Zn}$} & Intercept & 69.72 & 13.64 & $<.0001$ & 105.64 & 29.36 & 0.00 & 53.96 & 15.04 & 0.00 \\
\hline & Slope & 0.39 & 0.11 & 0.00 & -0.20 & 0.40 & 0.62 & 0.51 & 0.10 & $<.0001$ \\
\hline
\end{tabular}

${ }^{*}$ All concentrations in $\mathrm{ng} / \mathrm{m}^{3}$. Bold values indicate significance at 0.05 level. 
Table 106. Associations between indoor and ambient concentrations for select water-extractable elements for the children's cohort.*

\begin{tabular}{|c|c|c|c|c|c|c|c|c|c|c|}
\hline \multirow{2}{*}{\multicolumn{2}{|c|}{$\begin{array}{l}\text { Water-Extractable } \\
\text { Element }\end{array}$}} & \multicolumn{3}{|c|}{ Both seasons } & \multicolumn{3}{|c|}{ Winter } & \multicolumn{3}{|c|}{ Summer } \\
\hline & & \multirow{2}{*}{$\begin{array}{c}\text { estimate } \\
0.61 \\
\end{array}$} & \multirow{2}{*}{$\begin{array}{l}\text { s.e. } \\
0.14\end{array}$} & \multirow{2}{*}{$\frac{p \text {-value }}{0.00}$} & \multirow{2}{*}{$\begin{array}{c}\text { estimate } \\
0.41\end{array}$} & \multirow{2}{*}{ s.e. } & \multirow{2}{*}{$\frac{p \text {-value }}{0.00}$} & \multirow{2}{*}{$\begin{array}{c}\text { estimate } \\
0.74\end{array}$} & \multirow{2}{*}{$\begin{array}{l}\text { s.e. } \\
0.21 \\
\end{array}$} & \multirow{2}{*}{$\frac{p \text {-value }}{0.00}$} \\
\hline As & Intercept & & & & & & & & & \\
\hline AS & Slope & 0.33 & 0.04 & $<.0001$ & 0.15 & 0.03 & $<.0001$ & 0.43 & 0.07 & $<.0001$ \\
\hline \multirow{2}{*}{$\mathrm{Ba}$} & Intercept & 2.86 & 1.64 & 0.09 & 0.38 & 0.12 & 0.01 & 6.63 & 3.25 & 0.06 \\
\hline & Slope & -0.22 & 0.69 & 0.75 & 0.25 & 0.04 & $<.0001$ & -1.05 & 1.13 & 0.36 \\
\hline \multirow{2}{*}{$\mathrm{Cd}$} & Intercept & 0.05 & 0.02 & 0.05 & 0.03 & 0.02 & 0.25 & 0.07 & 0.04 & 0.11 \\
\hline & Slope & 0.48 & 0.04 & $<.0001$ & 0.47 & 0.05 & $<.0001$ & 0.47 & 0.06 & $<.0001$ \\
\hline \multirow{2}{*}{$\mathrm{Fe}$} & Intercept & 4.95 & 2.84 & 0.09 & 5.98 & 4.20 & 0.18 & 5.27 & 3.33 & 0.14 \\
\hline & Slope & 0.35 & 0.04 & $<.0001$ & 0.24 & 0.06 & $<.0001$ & 0.38 & 0.04 & $<.0001$ \\
\hline \multirow{2}{*}{$\mathrm{Pb}$} & Intercept & 1.29 & 0.45 & 0.01 & 1.59 & 0.37 & 0.00 & 1.52 & 0.83 & 0.09 \\
\hline & Slope & 0.35 & 0.03 & $<.0001$ & 0.22 & 0.03 & $<.0001$ & 0.44 & 0.04 & $<.0001$ \\
\hline \multirow{2}{*}{$\mathrm{Mg}$} & Intercept & 11.11 & 4.19 & 0.01 & 17.69 & 7.50 & 0.04 & 0.43 & 4.19 & 0.92 \\
\hline & Slope & 0.32 & 0.09 & 0.00 & 0.10 & 0.16 & 0.54 & 0.62 & 0.08 & $<.0001$ \\
\hline \multirow{2}{*}{$\mathrm{Ni}$} & Intercept & 1.13 & 0.62 & 0.08 & 1.91 & 1.20 & 0.14 & 0.54 & 0.15 & 0.00 \\
\hline & Slope & 0.53 & 0.72 & 0.46 & 0.89 & 1.31 & 0.50 & 0.07 & 0.19 & 0.73 \\
\hline \multirow{2}{*}{$\mathrm{K}$} & Intercept & 17.25 & 8.17 & 0.04 & 28.71 & 17.93 & 0.14 & 13.53 & 6.34 & 0.05 \\
\hline & Slope & 0.63 & 0.07 & $<.0001$ & 0.50 & 0.09 & $<.0001$ & 0.68 & 0.08 & $<.0001$ \\
\hline \multirow{2}{*}{ Se } & Intercept & 0.49 & 0.19 & 0.02 & 0.40 & 0.16 & 0.03 & -0.12 & 0.30 & 0.70 \\
\hline & Slope & 0.29 & 0.03 & $<.0001$ & 0.21 & 0.03 & $<.0001$ & 0.57 & 0.07 & $<.0001$ \\
\hline \multirow{2}{*}{$\mathrm{Na}$} & Intercept & 45.80 & 14.23 & 0.00 & 48.62 & 32.61 & 0.16 & 36.64 & 10.02 & 0.00 \\
\hline & Slope & 0.34 & 0.09 & 0.00 & 0.38 & 0.32 & 0.23 & 0.38 & 0.06 & $<.0001$ \\
\hline \multirow{2}{*}{ V } & Intercept & -0.10 & 0.06 & 0.09 & -0.12 & 0.05 & 0.05 & -0.11 & 0.11 & 0.30 \\
\hline & Slope & 0.52 & 0.03 & $<.0001$ & 0.55 & 0.03 & $<.0001$ & 0.52 & 0.04 & $<.0001$ \\
\hline \multirow{2}{*}{$\mathrm{Zn}$} & Intercept & 6.64 & 3.80 & 0.09 & 4.83 & 2.53 & 0.08 & 13.04 & 6.30 & 0.06 \\
\hline & Slope & 0.54 & 0.04 & $<.0001$ & 0.37 & 0.05 & $<.0001$ & 0.53 & 0.06 & $<.0001$ \\
\hline
\end{tabular}

${ }^{*}$ All concentrations in $\mathrm{ng} / \mathrm{m}^{3}$. Bold values indicate significance at 0.05 level. 
Table 107. Associations between indoor and ambient concentrations for select acid-digestible elements for the children's cohort.*

\begin{tabular}{|c|c|c|c|c|c|c|c|c|c|c|}
\hline \multirow{2}{*}{\multicolumn{2}{|c|}{$\begin{array}{l}\text { Acid-Digestible } \\
\text { Element }\end{array}$}} & \multicolumn{3}{|c|}{ Both seasons } & \multicolumn{3}{|c|}{ Winter } & \multicolumn{3}{|c|}{ Summer } \\
\hline & & \multirow{2}{*}{$\begin{array}{c}\text { estimate } \\
85.60\end{array}$} & \multirow{2}{*}{$\begin{array}{c}\text { s.e. } \\
15.78\end{array}$} & \multirow{2}{*}{$\begin{array}{l}\text { p-value } \\
<.0001\end{array}$} & \multirow{2}{*}{$\begin{array}{c}\text { estimate } \\
41.25\end{array}$} & \multirow{2}{*}{$\begin{array}{c}\text { s.e. } \\
16.90\end{array}$} & \multirow{2}{*}{$\frac{p \text {-value }}{0.03}$} & \multirow{2}{*}{$\begin{array}{c}\text { estimate } \\
105.55\end{array}$} & \multirow{2}{*}{$\begin{array}{l}\text { s.e. } \\
29.04\end{array}$} & \multirow{2}{*}{$\frac{p \text {-value }}{0.00}$} \\
\hline Al & Intercept & & & & & & & & & \\
\hline Al & Slope & 0.44 & 0.07 & $<.0001$ & 0.90 & 0.17 & $<.0001$ & 0.39 & 0.09 & 0.00 \\
\hline \multirow{2}{*}{ As } & Intercept & 0.27 & 0.12 & 0.04 & 0.03 & 0.05 & 0.52 & 0.33 & 0.19 & 0.11 \\
\hline & Slope & 0.49 & 0.05 & $<.0001$ & 0.10 & 0.03 & 0.00 & 0.66 & 0.07 & $<.0001$ \\
\hline \multirow{2}{*}{$\mathrm{Ba}$} & Intercept & 2.47 & 1.13 & 0.04 & 0.68 & 0.57 & 0.26 & 4.93 & 2.11 & 0.04 \\
\hline & Slope & -0.01 & 0.35 & 0.98 & 0.19 & 0.17 & 0.26 & -0.42 & 0.58 & 0.48 \\
\hline \multirow{2}{*}{$\mathrm{Cd}$} & Intercept & 0.09 & 0.03 & 0.01 & 0.05 & 0.03 & 0.13 & 0.14 & 0.06 & 0.03 \\
\hline & Slope & 0.44 & 0.04 & $<.0001$ & 0.42 & 0.05 & $<.0001$ & 0.41 & 0.06 & $<.0001$ \\
\hline \multirow{2}{*}{$\mathrm{Fe}$} & Intercept & 32.75 & 21.59 & 0.14 & 51.90 & 15.42 & 0.01 & 13.07 & 41.01 & 0.75 \\
\hline & Slope & 0.54 & 0.05 & $<.0001$ & 0.38 & 0.04 & $<.0001$ & 0.66 & 0.07 & $<.0001$ \\
\hline \multirow{2}{*}{$\mathrm{Pb}$} & Intercept & 0.45 & 3.54 & 0.90 & -1.96 & 6.81 & 0.78 & 1.64 & 1.01 & 0.13 \\
\hline & Slope & 0.89 & 0.20 & $<.0001$ & 1.91 & 0.58 & 0.00 & 0.62 & 0.04 & $<.0001$ \\
\hline \multirow{2}{*}{$\mathrm{Mg}$} & Intercept & 9.55 & 5.08 & 0.07 & 19.53 & 7.84 & 0.03 & -8.13 & 6.57 & 0.24 \\
\hline & Slope & 0.49 & 0.11 & $<.0001$ & 0.25 & 0.18 & 0.18 & 0.92 & 0.10 & $<.0001$ \\
\hline \multirow{2}{*}{$\mathrm{Mn}$} & Intercept & -0.47 & 1.35 & 0.73 & -0.68 & 2.46 & 0.79 & -0.20 & 1.47 & 0.89 \\
\hline & Slope & 0.61 & 0.06 & $<.0001$ & 0.63 & 0.10 & $<.0001$ & 0.58 & 0.07 & $<.0001$ \\
\hline \multirow{2}{*}{$\mathrm{K}$} & Intercept & 53.04 & 15.89 & 0.00 & 54.59 & 23.39 & 0.04 & 58.25 & 24.36 & 0.03 \\
\hline & Slope & 0.48 & 0.08 & $<.0001$ & 0.50 & 0.10 & $<.0001$ & 0.43 & 0.14 & 0.00 \\
\hline \multirow{2}{*}{$\mathrm{Na}$} & Intercept & 159.29 & 25.39 & $<.0001$ & 162.15 & 55.32 & 0.02 & 127.27 & 24.68 & 0.00 \\
\hline & Slope & -0.01 & 0.14 & 0.96 & 0.34 & 0.40 & 0.40 & -0.03 & 0.10 & 0.74 \\
\hline \multirow{2}{*}{ Sn } & Intercept & 0.89 & 0.56 & 0.12 & 0.38 & 0.84 & 0.66 & 1.21 & 0.91 & 0.20 \\
\hline & Slope & 1.05 & 0.27 & 0.00 & 1.33 & 0.52 & 0.01 & 1.06 & 0.16 & $<.0001$ \\
\hline \multirow{2}{*}{ V } & Intercept & 0.35 & 0.12 & 0.01 & 0.87 & 0.30 & 0.02 & 0.32 & 0.17 & 0.11 \\
\hline & Slope & 0.36 & 0.05 & $<.0001$ & -0.05 & 0.08 & 0.54 & 0.41 & 0.07 & $<.0001$ \\
\hline \multirow{2}{*}{$\mathrm{Zn}$} & Intercept & 13.02 & 8.41 & 0.13 & 7.49 & 4.40 & 0.12 & 23.02 & 14.59 & 0.14 \\
\hline & Slope & 0.58 & 0.06 & $<.0001$ & 0.44 & 0.06 & $<.0001$ & 0.58 & 0.09 & $<.0001$ \\
\hline
\end{tabular}

${ }^{*}$ All concentrations in $\mathrm{ng} / \mathrm{m}^{3}$. Bold values indicate significance at 0.05 level.

\subsubsection{Associations between $\mathrm{PM}_{2.5}$ Source Factors at the Central Site and Outdoor, Indoor, and Personal $\mathbf{P M}_{2.5}$ Concentrations}

Sources of $\mathrm{PM}_{2.5}$ were determined by applying factor analysis to $\mathrm{PM}_{2.5}$ samples collected with the Harvard multi-pollutant monitor at the central ambient air monitoring site in Steubenville. Average $\mathrm{PM}_{2.5}, \mathrm{PM}_{2.5}$ component, and gaseous pollutant concentrations observed at the site are reported in Table 108. The mean $\mathrm{PM}_{2.5}$ concentration at the central site was $20.8 \mu \mathrm{g} / \mathrm{m}^{3}$.

Factor analysis was performed using several different models. For the initial model, all species (including elements) that met the completeness and reproducibility requirements described in section 3.2.2.7 were used. Further models were then tested by removing elements individually or by exchanging between the water-extractable and the acid-digestible concentrations until an optimized solution was found. The performance of the model was evaluated using results of the regression of daily scores vs. daily $\mathrm{PM}_{2.5}$, including (1) the $\mathrm{R}^{2}$ value (which should be high), (2) the intercept (which should be low), (3) positive regression estimates for the sources, and (4) positive source contributions and source profiles. 
Using this approach, it was found that the best model was obtained using concentrations of $\mathrm{SO}_{4}{ }^{2-}, \mathrm{EC}, \mathrm{NO}_{2}, \mathrm{CO}$, water-extractable $\mathrm{As}, \mathrm{Ba}, \mathrm{Cd}, \mathrm{Fe}, \mathrm{K}, \mathrm{Mg}, \mathrm{Na}$, and $\mathrm{V}$, and acid-digestible $\mathrm{Pb}$. Using these data, four factors or source types were identified. The regression plot showing observed $\mathrm{PM}_{2.5}$ concentrations vs. concentrations predicted by the model is presented in Figure 68.

Table 108. Summary statistics for central site data considered for use in factor analysis.

\begin{tabular}{|c|c|c|c|}
\hline Pollutant & $\mathbf{N}$ & Mean & SD \\
\hline $\mathrm{PM}_{2.5}\left(\mathrm{ug} / \mathrm{m}^{3}\right)$ & 52 & 20.72 & 12.09 \\
\hline $\mathrm{SO}_{4}{ }^{2-}\left(\mathrm{ug} / \mathrm{m}^{3}\right)$ & 51 & 6.67 & 5.62 \\
\hline $\mathrm{EC}\left(\mathrm{ug} / \mathrm{m}^{3}\right)$ & 52 & 0.78 & 0.37 \\
\hline $\mathrm{O}_{3}(\mathrm{ppb})$ & 54 & 8.38 & 8.01 \\
\hline $\mathrm{NO}_{2}(\mathrm{ppb})$ & 53 & 29.84 & 20.94 \\
\hline $\mathrm{CO}(\mathrm{ppm})$ & 49 & 0.28 & 0.24 \\
\hline \multicolumn{4}{|c|}{ Water-Extractable Elements $\left(\mathrm{ng} / \mathrm{m}^{3}\right)$} \\
\hline As & 52 & 1.9 & 1.4 \\
\hline $\mathrm{Ba}$ & 48 & 2.1 & 1.4 \\
\hline $\mathrm{Cd}$ & 48 & 0.4 & 0.4 \\
\hline $\mathrm{Ca}$ & 43 & 78.4 & 73.5 \\
\hline $\mathrm{Fe}$ & 46 & 35.5 & 54.1 \\
\hline $\mathrm{Mg}$ & 52 & 30.5 & 26.9 \\
\hline $\mathrm{Mn}$ & 52 & 6.9 & 8.2 \\
\hline $\mathrm{Ni}$ & 50 & 0.4 & 0.8 \\
\hline $\mathrm{K}$ & 49 & 69.0 & 58.5 \\
\hline $\mathrm{Na}$ & 52 & 86.2 & 120.8 \\
\hline Sn & 46 & 0.2 & 0.3 \\
\hline $\mathrm{V}$ & 52 & 1.6 & 1.5 \\
\hline \multicolumn{4}{|c|}{ Acid-Digestible Elements $\left(\mathrm{ng} / \mathrm{m}^{3}\right)$} \\
\hline $\mathrm{Fe}$ & 46 & 280.4 & 287.4 \\
\hline $\mathrm{Pb}$ & 52 & 7.3 & 14.0 \\
\hline $\mathrm{Ti}$ & 52 & 4.4 & 29.9 \\
\hline
\end{tabular}

Factor analysis can only be performed with samples that have no missing values for any species. From a total of 52 samples collected, only 32 samples had no missing values for all analyzed species. The regression parameters for the model using these 32 samples are shown in Table 109.

Table 109. Parameters from the regression of $P M_{2.5}$ vs. daily source scores.

\begin{tabular}{|c|c|c|c|}
\hline Parameter & Estimate & t-value & p-value \\
\hline Intercept & 3394 & 3.03 & 0.0054 \\
\hline Factor 1 & 2318 & 4.30 & 0.0002 \\
\hline Factor 2 & 3343 & 6.20 & $<.0001$ \\
\hline Factor 3 & 8271 & 15.33 & $<.0001$ \\
\hline Factor 4 & 1582 & 2.93 & 0.006 \\
\hline
\end{tabular}




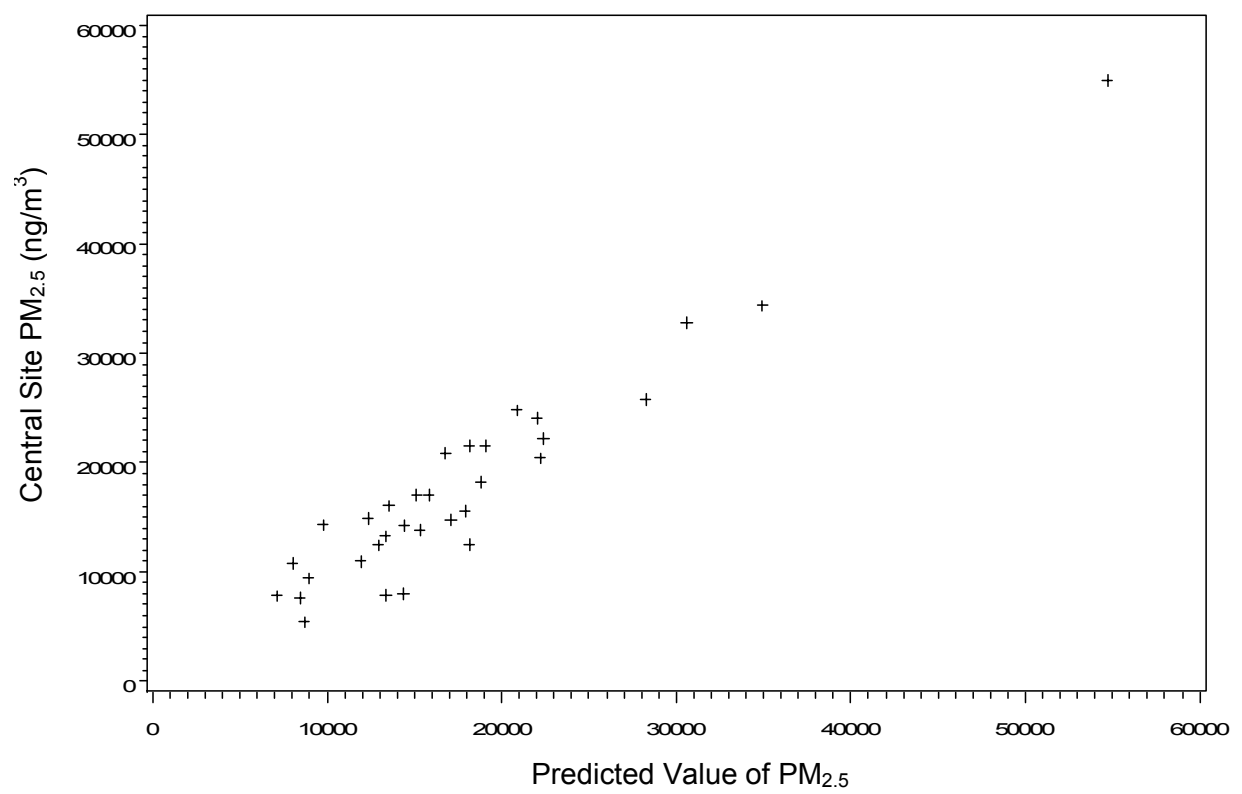

Figure 68. $\quad \mathrm{PM}_{2.5}$ concentrations observed at the central Steubenville site vs. $\mathrm{PM}_{2.5}$ concentrations predicted by the factor analysis model.

As shown in Table 109, all of the source factors were significant at the 0.05 level. The intercept was significant indicating that approximately $3.4 \mathrm{ug} / \mathrm{m}^{3}$ of $\mathrm{PM}_{2.5}$ mass was left unexplained. Considering only the samples that have no missing values, the average $P_{2.5}$ mass concentration is $17.7 \mu \mathrm{g} / \mathrm{m}^{3}$. Table 110 shows the estimated source contribution for each species for each factor. Table 111 shows the source profile for each factor.

Table 110. Average source contributions (in $\mathrm{ng} / \mathrm{m}^{3}$ ) for the four-source factor analysis model.

\begin{tabular}{|l|c|c|c|c|}
\hline \multicolumn{1}{|c|}{ Species } & Factor 1 & Factor 2 & Factor 3 & Factor 4 \\
\hline $\mathrm{PM}_{2.5}$ & 2718.64 & 945.164 & $\mathbf{9 3 9 1 . 2 9}$ & 1225.91 \\
\hline $\mathrm{SO}_{4}{ }^{2-}$ & 55.8 & 330.257 & $\mathbf{4 6 0 7 . 4 2}$ & 434.81 \\
\hline $\mathrm{EC}$ & $\mathbf{3 5 8 . 7}$ & 47.259 & 122.98 & 84.64 \\
\hline $\mathrm{NO}_{2}$ & 1.76 & $\mathbf{2 . 0 1 9}$ & 1.99 & 0.81 \\
\hline $\mathrm{CO}$ & $\mathbf{0 . 2 6}$ & 0.029 & 0.01 & 0 \\
\hline Water-Extractable Elements & & & & \\
\hline $\mathrm{As}$ & $\mathbf{1}$ & 0.213 & 0.19 & 0.45 \\
\hline $\mathrm{Ba}$ & 0.49 & 0.084 & $\mathbf{0 . 7 7}$ & 0.23 \\
\hline $\mathrm{Cd}$ & $\mathbf{0 . 2 7}$ & 0.035 & -0.02 & 0.11 \\
\hline $\mathrm{Fe}$ & $\mathbf{1 8 . 4 5}$ & 9.615 & 7.96 & 3.28 \\
\hline $\mathrm{Mg}$ & $\mathbf{2 1 . 3 6}$ & 4.843 & 4.18 & -1.25 \\
\hline $\mathrm{Mn}$ & $\mathbf{7 . 9 6}$ & 1.622 & 1.2 & -0.19 \\
\hline $\mathrm{K}$ & $\mathbf{5 7 . 5 1}$ & -2.459 & 9.49 & 3.01 \\
\hline $\mathrm{Na}$ & 2.27 & $\mathbf{3 2 . 6 5 2}$ & 25.2 & 5.83 \\
\hline $\mathrm{V}$ & 0.17 & 0.019 & 0.41 & $\mathbf{1 . 0 9}$ \\
\hline $\mathrm{Acid}-$ Digestible Elements & & & & \\
\hline $\mathrm{Pb}$ & $\mathbf{4 . 6 2}$ & 2.111 & 2.9 & 0.67 \\
\hline $\mathrm{NOTE}$ & 15 & & \\
\hline
\end{tabular}

NOTE: The maximum value for each species is shown in bold. 
Table 111. Source profiles (species mass per total mass associated with the source factor, expressed as a percentage) for the four-source factor analysis model.

\begin{tabular}{|l|c|c|c|c|}
\hline Species & Factor 1 & Factor 2 & Factor 3 & Factor 4 \\
\hline $\mathrm{SO}_{4}{ }^{2-}$ & 2.052 & 34.942 & 49.061 & 35.468 \\
\hline $\mathrm{EC}$ & 13.194 & 5.000 & 1.310 & 6.904 \\
\hline $\mathrm{NO}_{2}$ & 0.065 & 0.214 & 0.021 & 0.066 \\
\hline $\mathrm{CO}$ & 0.010 & 0.003 & 0.000 & 0.000 \\
\hline Water-Extractable Elements & & & & \\
\hline $\mathrm{As}$ & 0.037 & 0.023 & 0.002 & 0.037 \\
\hline $\mathrm{Ba}$ & 0.018 & 0.009 & 0.008 & 0.019 \\
\hline $\mathrm{Cd}$ & 0.010 & 0.004 & 0.000 & 0.009 \\
\hline $\mathrm{Fe}$ & 0.679 & 1.017 & 0.085 & 0.268 \\
\hline $\mathrm{Mg}$ & 0.786 & 0.512 & 0.044 & -0.102 \\
\hline $\mathrm{Mn}$ & 0.293 & 0.172 & 0.013 & -0.016 \\
\hline $\mathrm{K}$ & 2.115 & -0.260 & 0.101 & 0.245 \\
\hline $\mathrm{Na}$ & 0.083 & 3.455 & 0.268 & 0.475 \\
\hline $\mathrm{V}$ & 0.006 & 0.002 & 0.004 & 0.089 \\
\hline $\mathrm{Acid}-$ Digestible Elements & & & \\
\hline $\mathrm{Pb}$ & 0.170 & 0.223 & 0.031 & 0.055 \\
\hline
\end{tabular}

Results of source apportionment using factor analysis have been described in the past for Steubenville (Koutrakis and Spengler, 1987). In that paper, six sources of $\mathrm{PM}_{2.5}$ were resolved, including sources that appeared to represent secondary sulfates, coal and oil combustion, iron and steel production, titanium production, soil, and motor vehicles. Two of these six sources cannot be accounted for in our analysis. Typical tracers of soil, such as Al and $\mathrm{Si}$, did not meet our analysis requirements and therefore were not used in the analysis. Average titanium concentrations in the 1987 report were $190 \mathrm{ng} / \mathrm{m}^{3}$. However, the average concentration during the period covered by our factor analysis was $30 \mathrm{ng} / \mathrm{m}^{3}$. This large concentration drop suggests either that local sources of Ti no longer exist or that industry has installed new particle control technology. As a result, our solution with four sources instead of six is not inconsistent with the results presented by Koutrakis and Spengler.

Factor 1 is associated with $\mathrm{EC}, \mathrm{CO}, \mathrm{As}, \mathrm{Cd}, \mathrm{Fe}, \mathrm{Mg}, \mathrm{Mn}, \mathrm{K}$ and $\mathrm{Pb} . \mathrm{EC}, \mathrm{Pb}$, and $\mathrm{CO}$ are tracers that are often associated with vehicular emissions. Factor 1 contributed an average of 2.7 $\mu \mathrm{g} / \mathrm{m}^{3}(15 \%)$ of the total $\mathrm{PM}_{2.5}$ mass. A similar concentration $\left(2.6 \mu \mathrm{g} / \mathrm{m}^{3}\right)$ was associated with mobile sources in the previous report. This factor is likely associated with vehicular emissions, resuspended road dust, and other local sources.

Factor 2 is associated with $\mathrm{NO}_{2}$ and $\mathrm{Na}$ but also with $\mathrm{Fe}, \mathrm{Pb}$, and some sulfate. It is possible that this is the iron and steel production source determined previously. Factor 2 contributed 0.95 $\mu \mathrm{g} / \mathrm{m}^{3}(5.3 \%)$ of the total $\mathrm{PM}_{2.5}$ mass. In the previous report, the similar factor contributed 2.3 $\mu \mathrm{g} / \mathrm{m}^{3}$.

Factor 3 is associated with sulfate and $\mathrm{Ba}$, but also with some $\mathrm{As}, \mathrm{Fe}$ and $\mathrm{K}$, all of which are species associated with secondary sulfates. This source contributed $9.4 \mu \mathrm{g} / \mathrm{m}^{3}(54 \%)$ of the total $\mathrm{PM}_{2.5}$ mass, which is consistent with the contribution of the secondary sulfate source $\left(9.7 \mu \mathrm{g} / \mathrm{m}^{3}\right)$ reported previously.

The last source is associated mainly with $\mathrm{V}$ but also with some As and sulfate. This source likely represents coal or oil combustion. The source contributed $1.2 \mu \mathrm{g} / \mathrm{m}^{3}(6.9 \%)$ of the total 
$\mathrm{PM}_{2.5}$ mass. This contribution is much less than the $8.6 \mu \mathrm{g} / \mathrm{m}^{3}$ previously reported for coal and oil combustion. It is possible that new particle control technologies have decreased the contribution of this source. Alternatively, it is possible that this factor is not entirely separated from the secondary sulfate factor, as a major tracer for this source, $\mathrm{Ni}$, did not meet the requirements for analysis.

The masses contributed by each factor at the central site were examined as predictors of $\mathrm{PM}_{2.5}$ exposures for children. Because repeated measurements were made for each child, two different regression models were used to determine the predictive ability of the central site factors: (1) a simple regression model that does not consider repeated measures, and (2) a model that considers repeated measures and a covariance structure. Specifically, the models were applied to examine the associations between the $\mathrm{PM}_{2.5}$ factors from the central site and the $\mathrm{PM}_{2.5}$ concentrations observed inside the children's homes. For the repeated measurement models, $R^{2}$ values were calculated by regressing the predicted values against the measured $\mathrm{PM}_{2.5}$ data. Table 112 shows the results from each model in terms of $\mathrm{R}^{2}$ values, intercepts, and regression estimates.

Table 112. Comparison of results from two different models of indoor $\mathrm{PM}_{2.5}$ concentrations vs. $\mathrm{PM}_{2.5}$ factors from the central ambient air monitoring site.

\begin{tabular}{|c|c|c|c|c|c|}
\hline Model & Parameter & Value & SE & t-stat & p-value \\
\hline \multirow{4}{*}{1} & $\mathrm{R}^{2}$ & 0.27 & & & \\
\cline { 2 - 6 } & Intercept & 7235 & 1868 & 3.87 & 0.0002 \\
\cline { 2 - 6 } & Factor 1 & -0.53 & 0.39 & -1.34 & 0.1831 \\
\cline { 2 - 6 } & Factor 2 & 0.30 & 0.31 & 0.96 & 0.34 \\
\cline { 2 - 6 } & Factor 3 & 0.5182 & 0.098 & 5.29 & $<0.0001$ \\
\cline { 2 - 6 } & Factor 4 & 1.50 & 0.53 & 2.81 & 0.006 \\
\hline \multirow{4}{*}{2} & $\mathrm{R}^{2}$ & 0.24 & & 3.26 & 0.0034 \\
\cline { 2 - 6 } & Intercept & 7501 & 2299 & 0.14 & 0.88 \\
\cline { 2 - 6 } & Factor 1 & 0.06 & 0.43 & -0.23 & 0.82 \\
\cline { 2 - 6 } & Factor 2 & -0.07 & 0.31 & 4.39 & $<0.0001$ \\
\cline { 2 - 6 } & Factor 3 & 0.47 & 0.11 & 1.77 & 0.081 \\
\cline { 2 - 6 } & Factor 4 & 0.93 & 0.52 & & \\
\hline
\end{tabular}

As shown in Table 112, Model 1 (the simple regression) explained more of the variability $\left(\mathrm{R}^{2}=0.27\right)$ in indoor $\mathrm{PM}_{2.5}$ concentrations. Intercept values are similar for both approaches. The estimates, however, were more significant (lower p-values) for Model 1. Despite these differences, both approaches were relatively consistent, showing significant associations for Factors 3 and 4 only. Because Model 1 explained more of the mass, this approach was used for future analyses.

To determine the contributions of the different factors to the $\mathrm{PM}_{2.5}$ concentrations observed in various microenvironments for the children's cohort, daily outdoor, indoor, or personal $\mathrm{PM}_{2.5}$ levels were regressed against each of the four factors using random effects models. Table 113 shows the results of these regressions.

For outdoor concentrations, the model performed well, with an overall $R^{2}$ value of 0.90 . The intercept is slightly higher than in the model used for the central site (which had an intercept of $3.6 \mu \mathrm{g} / \mathrm{m}^{3}$ ), indicating that a larger portion of the mass is left unexplained in this model. All factors in the model were significant except for Factor 1. This insignificant value may result from spatial variability of the sources associated with this factor. The estimates shown in Table 113 represent the amount of outdoor $\mathrm{PM}_{2.5}$ that can be explained by each $1 \mu \mathrm{g} / \mathrm{m}^{3}$ increase in each factor at the central site. For instance, for Factors 3 and 4 , a $1 \mathrm{ug} / \mathrm{m}^{3}$ increase in $\mathrm{PM}_{2.5}$ 
concentrations at the central site corresponds to an identical $1 \mathrm{ug} / \mathrm{m}^{3}$ increase in $\mathrm{PM}_{2.5}$ outdoors at the homes. However, for Factor 2 , the estimate of approximately 0.5 suggests that only about half of the mass at the central site is captured by samples collected outside of the participants' homes. These results may suggest that Factor 2 represents a local source that has the greatest effect on the central ambient air monitoring site or that spatial and temporal variability in this Factor reduces our ability to estimate it outdoors at the homes.

Table 113. Regression results describing the ability of central site factors to predict 24-hr outdoor, indoor, or personal $\mathrm{PM}_{2.5}$ concentrations for the children's cohort.

\begin{tabular}{|c|c|c|c|c|c|}
\hline Model & Parameter & Value & SE & T & P \\
\hline \multirow{4}{*}{ Outdoor } & $\mathrm{R}^{2}$ & 0.90 & & & \\
\cline { 2 - 6 } & Intercept & 3635 & 686 & 5.29 & $<0.0001$ \\
\cline { 2 - 6 } & Factor 1 & 0.24 & 0.15 & 1.61 & 0.11 \\
\cline { 2 - 6 } & Factor 2 & 0.66 & 0.12 & 5.69 & $<0.0001$ \\
\cline { 2 - 6 } & Factor 3 & 1.02 & 0.035 & 28.7 & $<0.0001$ \\
\cline { 2 - 6 } & Factor 4 & 1.14 & 0.19 & 5.99 & $<0.0001$ \\
\hline \multirow{4}{*}{ Indoor } & $\mathrm{R}^{2}$ & 0.28 & & & \\
\cline { 2 - 6 } & Intercept & 7235 & 1868 & 3.87 & 0.0002 \\
\cline { 2 - 6 } & Factor 1 & -0.53 & 0.39 & -1.34 & 0.18 \\
\cline { 2 - 6 } & Factor 2 & 0.30 & 0.32 & 0.96 & 0.34 \\
\cline { 2 - 6 } & Factor 3 & 0.52 & 0.098 & 5.29 & $<0.0001$ \\
\cline { 2 - 6 } & Factor 4 & 1.50 & 0.53 & 2.81 & 0.006 \\
\hline & Rersonal & 0.22 & 1438 & 7.72 & $<0.0001$ \\
\cline { 2 - 6 } & Intercept & 11102 & 0.46 & -1.42 & 0.16 \\
\cline { 2 - 6 } & Factor 1 & -0.65 & 0.10 & 5.17 & $<0.0001$ \\
\cline { 2 - 6 } & Factor 2 & 0.51 & 0.39 & 2.35 & 0.02 \\
\cline { 2 - 6 } & Factor 3 & 0.92 & 0.61 & -0.91 & 0.36 \\
\cline { 2 - 6 } & Factor 4 & -0.55 & & & \\
\hline
\end{tabular}

Using the same approach, the factors at the central site were found to explain $28 \%$ of the variability in indoor $\mathrm{PM}_{2.5}$ concentrations. The intercept of the model was higher for indoor as compared to outdoor concentrations, indicating that the model explained a smaller amount of the total indoor $\mathrm{PM}_{2.5}$ mass. The model shows that Factors 1 and 2 were not significantly associated with indoor $\mathrm{PM}_{2.5}$ mass. It was expected that Factor 1 would be a poor predictor, because it was not able to predict outdoor concentrations. The poor predictive ability of Factor 2 may be due to poorer infiltration or greater indoor deposition of the types of particles associated with this factor. Additionally, these particles may contain more volatile material that can be lost indoors (like semi-volatile organic components). Factors 3 and 4 remained significantly associated with indoor $\mathrm{PM}_{2.5}$ concentrations. However, the slope estimated for Factor 3 for the indoor samples was half as great as that estimated for the outdoor samples, whereas the slope estimated for Factor 4 for the indoor samples was greater than that estimated for the outdoor samples. Lower slope estimates may be due to variable penetration of particles from outdoor to indoor environments. Higher estimates may be due to closer proximity of subjects' homes to the sources associated with Factor 4.

The model incorporating source factors resolved for the central site predicted $22 \%$ of the variability in personal $\mathrm{PM}_{2.5}$ exposures. The intercept for the model of personal exposures (11.1 $\mathrm{ug} / \mathrm{m}^{3}$ ) was much higher than the intercepts observed for the other microenvironments, indicating that a large portion of the personal $\mathrm{PM}_{2.5}$ exposures was left unexplained by the model. Factors 1 and 4 were not significant. However, the contributions of Factors 2 and 3 were significantly associated with personal $\mathrm{PM}_{2.5}$ exposures. The slopes estimated for Factors 2 and 3 for personal exposures ( 0.51 and 0.92 , respectively) were greater than those estimated 
for these factors for indoor concentrations ( 0.30 and 0.52 , respectively), but less than those estimated for these factors for outdoor concentrations ( 0.66 and 1.02 , respectively). These factors can represent the contribution of both indoor and outdoor concentrations to personal exposures.

\subsubsection{Discussion of Results from the Older Adult and Children's Cohorts}

For the older adult cohort, we found 24-hour ambient particle concentrations to be consistently strong proxies of corresponding personal exposures, regardless of the particle species (i.e., $\mathrm{PM}_{2.5}, \mathrm{SO}_{4}{ }^{2-}$, or $\mathrm{EC}$ ), season (i.e., summer or fall), and ventilation status. Associations between ambient concentrations and corresponding personal exposures were strongest for $\mathrm{SO}_{4}{ }^{2-}$, a regional pollutant with no major indoor sources. Ambient concentrations of EC were also significant proxies of corresponding exposures, although associations were weaker, likely due to the influence of local sources such as traffic and cooking. Our findings are consistent with those of previous studies (Janssen et al., 2000; Sarnat et al., 2000; Rojas-Bracho et al., 2000; Ebelt, et al., 2000; Rojas-Bracho et al., 2004) and provide additional justification for the use of ambient $\mathrm{PM}_{2.5}, \mathrm{SO}_{4}{ }^{2-}$, and to a lesser extent $\mathrm{EC}$, to represent corresponding mean personal exposures in epidemiologic analyses.

Contrary to previous findings (Liu et al., 1997; Linaker et al., 2000; Brauer et al., 1989; Patterson et al., 2000; Sarnat et al., 2001), however, associations between ambient concentrations and personal exposures for $\mathrm{O}_{3}$ and $\mathrm{NO}_{2}$ were also strong, suggesting that ambient $\mathrm{O}_{3}$ and $\mathrm{NO}_{2}$ concentrations are suitable proxies of their respective personal exposures. Significant associations in Steubenville may be due in part to the differences in study design, where the number of collected samples was larger - and, for the gases, collected with greater sensitivity - in Steubenville than in previous studies, thus improving the power to detect associations between ambient and personal gas concentrations. Our current results support this theory, as personal-ambient gas associations were stronger in the fall, when field LODs were lower, as compared to the summer.

As was the case for PM, home ventilation levels were shown to be an important modifier of the association between ambient concentrations and personal exposures for the gases. In Steubenville, personal-ambient gas associations, in particular for $\mathrm{O}_{3}$, were highest for subjects spending time indoors with windows open as compared to for those spending time indoors with windows closed. Consistent with our findings, a recent follow-up study of 43 children and healthy senior citizens in Boston, MA (Sarnat et al., 2005), found significant personal-ambient associations for $\mathrm{O}_{3}$ and $\mathrm{NO}_{2}$ in the summer but not the winter, which may be due to greater home ventilation in the summer in Boston. Results of previous indoor-outdoor monitoring studies are also consistent with our findings (Gold et al., 1996). However, no other personal monitoring studies show the impact of home ventilation as a modifier of personal-ambient gas associations, and further investigation is needed to determine its importance.

We also found significant associations between ambient particle concentrations and personal $\mathrm{O}_{3}$ and $\mathrm{NO}_{2}$ exposures, with associations varying with particle species, season, and ventilation status. Specifically, we found 24-hr ambient particle concentrations to be significantly and positively correlated with personal $\mathrm{O}_{3}$ exposures in the summer and with both personal $\mathrm{O}_{3}$ and $\mathrm{NO}_{2}$ exposures in the fall. These associations reflected similarly significant associations a) between ambient PM and ambient gas concentrations and b) between ambient gas concentrations and their corresponding personal exposures. Our results indicate that ambient particle and gas concentrations are strong proxies of personal gaseous exposures during seasons in which homes tend to be well-ventilated or in locations characterized by well- 
ventilated homes. The findings have important implications for air pollution health effect studies based on ambient concentrations, as results suggest that the health effects of particles and gases will be difficult to separate, particularly for individuals living in well-ventilated homes. This separation will be particularly difficult for pollutants originating from similar sources, as shown by the fact that associations between ambient PM and personal gases were strongest for pollutants originating from similar sources; associations between ambient $\mathrm{SO}_{4}{ }^{2-}$ and personal $\mathrm{O}_{3}$, both regional pollutants, and between ambient $\mathrm{EC}$ and personal $\mathrm{NO}_{2}$, both emitted primarily from motor vehicles, were significant in both seasons. Our results correspond to results from the Boston study (Sarnat et al., 2005) which showed significant associations between ambient $\mathrm{PM}_{2.5}$ and personal $\mathrm{O}_{3}$ in the summer only, when photochemical formation of $\mathrm{PM}_{2.5}$ and $\mathrm{O}_{3}$ is greatest. Similarly, the Boston study found significant associations between ambient $\mathrm{PM}_{2.5}$ and personal $\mathrm{NO}_{2}$ in only the fall, a season characterized more by local sources such as motor vehicle traffic that contribute to $\mathrm{PM}_{2.5}$ and $\mathrm{NO}_{2}$.

It is important to note that personal $\mathrm{O}_{3}$ and $\mathrm{NO}_{2}$ exposures were found to increase by only 1.1 and $1.7 \mathrm{ppb}$, respectively, with every $10 \mu \mathrm{g} / \mathrm{m}^{3}$ increase in ambient $\mathrm{PM}_{2.5}$. These observed increases in personal $\mathrm{O}_{3}$ and $\mathrm{NO}_{2}$ are extremely small and have not been shown to elicit adverse health effects in controlled laboratory studies (Gong et al., 1998; Devlin et al., 1997; Frampton et al., 1991). Despite this, numerous epidemiological studies have linked 24-hr ambient $\mathrm{O}_{3}$ and $\mathrm{NO}_{2}$ concentrations to adverse health impacts, suggesting that these gases may elicit health impacts along with or in combination with other pollutants, or that 24-hr concentrations of these gases are acting as proxies for shorter-term exposures.

Children were monitored when mean ambient concentrations of regional pollution were higher, while mean ambient concentrations of locally-generated pollution were lower. In the summer in which the children were monitored, for example, the mean and maximum ambient $\mathrm{PM}_{2.5}, \mathrm{SO}_{4}{ }^{2-}$, and $\mathrm{O}_{3}$ concentrations were higher than in the previous summer when the older adults were monitored. Mean ambient concentrations of $\mathrm{EC}$ and $\mathrm{NO}_{2}$, generally markers of locally generated traffic pollution, were lower in the summer when the children were monitored. Although not directly comparable, mean ambient concentrations of $\mathrm{PM}_{2.5}$ and especially $\mathrm{SO}_{4}{ }^{2-}$ were lower in the winter when the children were monitored as compared to when the older adults were monitored, while wintertime mean ambient concentrations of all other measured pollutants, even $\mathrm{O}_{3}$, observed when the children were monitored tended to be comparable to mean concentrations when the older adults were monitored.

For the children, ambient concentrations were poorer proxies of personal exposures for the gases and to a lesser extent for the particle species (i.e., $\mathrm{PM}_{2.5}, \mathrm{SO}_{4}{ }^{2-}$, and $\mathrm{EC}$ ), with personalambient slopes generally lower and less significant for children as compared to older adults. In the summer, personal-ambient slopes for $\mathrm{PM}_{2.5}$ and $\mathrm{SO}_{4}{ }^{2-}$ were approximately $20 \%$ lower for the children as compared to the adults. For every $10 \mu \mathrm{g} / \mathrm{m}^{3}$ increase in corresponding ambient concentrations, summertime personal $\mathrm{PM}_{2.5}$ and $\mathrm{SO}_{4}{ }^{2-}$ exposures increased an average of 5.8 $\mu \mathrm{g} / \mathrm{m}^{3}$ for children and $7.5 \mu \mathrm{g} / \mathrm{m}^{3}$ for older adults. Personal-ambient $\mathrm{PM}_{2.5}$ and $\mathrm{SO}_{4}{ }^{2-}$ slopes were even lower in the winter, consistent with the poorer ventilation during the winter months and the observed effect modification by open window use. The opposite seasonal pattern was found for personal-ambient associations for EC, which for the children were not significant in the summer, but were significant in the winter with a slope of $0.41 \pm 0.07$. A similar seasonal pattern in the association between personal and ambient EC was found for the older adults, with a greater slope observed in the fall than in the summer. For $\mathrm{O}_{3}$, the personal-ambient slope for the children was highest in the summer, but it was still lower than that found for older adults in the summer, with values of $0.09 \pm 0.03$ and $0.15 \pm 0.02$ for the children and older adults, respectively. In contrast to the other measured pollutants, the summertime personal-ambient 
$\mathrm{NO}_{2}$ slope of $0.36 \pm 0.06$ for children was approximately $33 \%$ higher than that for older adults $(0.23 \pm 0.05)$. Results suggest that the ability of ambient concentrations to reflect exposures for children was the greatest for $\mathrm{PM}_{2.5}$ and $\mathrm{SO}_{4}{ }^{2-}$ and generally during the summer months; however, ambient particle and gas concentrations were generally poorer proxies of corresponding exposures for children as compared to older adults.

As was the case with the older adults, home ventilation was the primary factor affecting the ability of ambient pollutant concentrations to reflect the personal exposures of children to these pollutants. Personal-ambient and indoor-ambient slopes were higher when windows were open or when participants spent more time near open windows, both conditions consistent with increased ventilation. Other factors, such as stove type or time spent outdoors, were significant but relatively minor modifiers of the relationship between ambient concentrations and either indoor or personal exposures.

Our findings also suggest that ventilation was an important determinant of the ability of ambient particles to act as proxies of personal gaseous exposures for children. During the summer, which was characterized by a greater percentage of open window usage, ambient particle concentrations were strong proxies of children's personal exposures to gases from similar sources, such as was observed with the traffic-related pollutants $\mathrm{NO}_{2}$ and $\mathrm{EC}$ and with the regional pollutants $\mathrm{O}_{3}, \mathrm{SO}_{4}{ }^{2-}$, and $\mathrm{PM}_{2.5}$ (likely because of its large mass fraction of $\mathrm{SO}_{4}{ }^{2-}$ ). Since these associations were not significant in the winter, results suggest that ambient particles can represent personal gaseous exposures only when homes are well-ventilated. However, even under these well-ventilated conditions, ambient particle concentrations were better proxies of children's exposures to the particles themselves rather than the gases, as evidenced by the observed low slopes for ambient particle-personal gas associations. Ambient $\mathrm{O}_{3}$ concentrations in both seasons and ambient $\mathrm{NO}_{2}$ in the summer were poor proxies of personal particulate exposures, which is contrary to findings for older adults in Steubenville and Baltimore.

This study provided a powerful database for characterizing the particulate and gaseous exposures of older adults and children and examining their associations with corresponding indoor and ambient concentrations. Results confirmed the results of previous studies showing that ambient $\mathrm{PM}_{2.5}$ and $\mathrm{SO}_{4}{ }^{2-}$ concentrations were strong proxies of corresponding personal exposures, especially for older adults, whereas ambient EC and gas concentrations were generally weaker proxies of corresponding personal exposures to these pollutants. Results also verified that ambient gas concentrations could act as proxies of their own exposures and also as proxies of personal particulate exposures. However, when interpreting these findings, it should be noted that results were based on a relatively small number of individuals. Hence, these results are not generalizable to other cohorts, including other cohorts of older adults or of children. Furthermore, the sensitivity and precision of the measurement and analytical methods used in the indoor and personal exposure program, particularly for the elements and $\mathrm{SO}_{2}$, were insufficient to measure pollutant concentrations in Steubenville. As a result, findings should be interpreted with caution. Similarly, the effects of stove type and activity patterns on personalambient and indoor-ambient relationships should also be interpreted cautiously. For the older adult cohort, separation of the effect of stove type from building was not possible, and relatively few children lived in homes with gas stoves. Both the older adult and child cohorts were fairly inactive, limiting the ability to explore possible effect modifications by activity patterns.

Results from our study indicate that ambient fine particles are strong proxies of corresponding exposures for older adults and to a lesser extent for children. The ability of ambient fine particle concentrations to reflect exposures differed by particle component and was greatest for 
the regional fine particle $\mathrm{SO}_{4}{ }^{2-}$ and poorest for the traffic-related particle EC. Furthermore, results indicate that ambient concentrations may represent personal exposures to both $\mathrm{PM}_{2.5}$ and gases, especially for pollutants from common sources and for individuals living in wellventilated environments. This suggests that time-series health studies based on 24-hour ambient concentrations may not be able to separate the independent effects of particles and gases. Future exposure studies should examine factors contributing to differences in pollutant exposures for older adults and children.

\subsection{Associations between Air Pollution and Cardiac Health Effects}

As discussed earlier, the SCAMP exposure study of older adults was conducted in conjunction with a companion study of cardiac health. Participants in the companion health study included the same cohort of older adults participating in the exposure study. As mentioned in Section 3.2.1.2, prior to their inclusion in the study, participants were screened to collect information on cardiovascular and respiratory health and medications and to obtain baseline electrocardiogram (12-lead MAC6, Marquette Medical Systems Inc.) recordings. Exclusion criteria included smoking, having a pacemaker, a recent acute coronary syndrome, atrial flutter, or atrial fibrillation.

For each participant, health measurements were performed weekly on the same day of the week and at the same time during summer (June 4 - August 18) and fall (September 25 December 15) of 2000. A short questionnaire on recent symptoms, hospital or doctor visits, and medication use was administered, followed by Holter electrocardiogram monitoring (SEER MC, GE Medical Systems) with electrodes in a modified V5 and AVF position. The Holter monitoring protocol included: (1) five minutes of rest in a supine position; (2) three supine blood pressure measurements (NIBP Vital Signs Monitor, Welch Allyn); (3) five minutes of standing with three standing blood pressure measurements taken after two minutes; (4) five minutes of exercise (walking) outdoors (weather and health permitting); (5) five minutes of rest in a supine position; and (6) two minutes and 20 seconds of paced breathing.

The Holter tapes were analyzed using a Marquette MARS Workstation (GE Medical Systems), with a 125 samples/second sampling rate following heart rate variability (HRV) guidelines (Task Force of the European Society of Cardiology and the North American Society of Pacing and Electrophysiology 1996). The Holter tapes were analyzed for heart rate, arrhythmias, and time and frequency domain HRV measures. HRV, average heart rate, and arrhythmia counts were obtained for the whole protocol and for each separate interval. A detailed description of health measurements and pollution-association cardiac health effects are provided in the manuscripts included in Appendices $\mathrm{E}$ and $\mathrm{F}$ to this report. Results generally suggest that in Steubenville, increased levels of ambient particulate pollution from non-traffic sources (e.g., sulfate particles) may adversely affect autonomic function and increase the risk of supraventricular arrhythmia in the elderly. 


\section{CONCLUSIONS}

The Steubenville Comprehensive Air Monitoring Program generated a powerful database of information concerning ambient, outdoor, indoor, and personal-breathing-space concentrations of $\mathrm{PM}_{2.5}$, its components, and co-pollutants in Steubenville, Ohio. Results provide valuable information in response to a number of $\mathrm{PM}_{2.5}$ research needs, including the need for better estimates of the relationship between ambient concentrations of $\mathrm{PM}_{2.5}$ and its components and actual human exposures to these species, the need for better characterization of the potential for confounding by gaseous pollutants in $\mathrm{PM}_{2.5}$ epidemiology studies, the need for better characterization of individual chemical components of $\mathrm{PM}_{2.5}$, and the need for data for development of State Implementation Plans (SIPs) in response to the $\mathrm{PM}_{2.5}$ NAAQS. Moreover, SCAMP provides a much-needed current assessment of $\mathrm{PM}_{2.5}$ in Steubenville, Ohio, which historically has been a key location for air pollution research, and remains a nonattainment area under the $\mathrm{PM}_{2.5}$ NAAQS despite major changes in industry and population during the past two decades. Major conclusions of the program are as follows:

- Average concentrations of $\mathrm{PM}_{2.5}$, as well as those of many $\mathrm{PM}_{2.5}$ components and gaseous pollutants, in Steubenville have decreased appreciably since the Harvard Six Cities Study was conducted in the late 1970 s and 1980 s, but remain elevated relative to the annual PM $\mathbf{P}_{2.5}$ NAAQS.

A comparison of mean ambient concentrations of $\mathrm{PM}_{2.5}$ total mass, twelve $\mathrm{PM}_{2.5}$ components ( $\mathrm{Al}, \mathrm{Ca}, \mathrm{Cu}, \mathrm{Fe}, \mathrm{K}, \mathrm{Mn}, \mathrm{Ni}, \mathrm{Pb}, \mathrm{Se}, \mathrm{SO}_{4}{ }^{2-}, \mathrm{V}$, and $\mathrm{Zn}$ ), and three gaseous pollutants $\left(\mathrm{SO}_{2}, \mathrm{NO}_{2}\right.$, and $\left.\mathrm{O}_{3}\right)$ measured during the SCAMP ambient air monitoring program with mean concentrations measured during the Six Cities Study indicated that ambient concentrations of all but two (fine particulate $\mathrm{Ca}$ and $\mathrm{O}_{3}$ ) of these species in Steubenville have decreased by more than $30 \%$ since the Six Cities Study was conducted. The largest decrease in concentration $(-92 \%)$ was observed for fine particulate $\mathrm{Pb}$, likely resulting from the discontinued use of leaded gasoline. The mean $\mathrm{PM}_{2.5}$ mass concentration measured during SCAMP $\left(18.4 \mu \mathrm{g} / \mathrm{m}^{3}\right)$ was about $40 \%$ less than that measured during the Six Cities Study. Mean concentrations of fine particulate $\mathrm{SO}_{4}{ }^{2-}$, a major component of $\mathrm{PM}_{2.5}$ in Steubenville, and of $\mathrm{SO}_{2}$, its gaseous precursor, were $54 \%$ and $56 \%$ lower, respectively, during SCAMP than during the Six Cities Study. Although these differences may in part be due to differences in the sampling and analytical techniques employed by the two programs, the consistent downward trend strongly suggests that appreciable improvements in Steubenville's air quality have been made over the past 25 years. Nevertheless, Steubenville remains a nonattainment area under the $\mathrm{PM}_{2.5}$ NAAQS; the overall mean $\mathrm{PM}_{2.5}$ concentration measured there during SCAMP was $3.4 \mu \mathrm{g} / \mathrm{m}^{3}$ greater than the annual standard of $15 \mu \mathrm{g} / \mathrm{m}^{3}$. Hence, further reductions in $\mathrm{PM}_{2.5}$ concentrations in Steubenville will be required; data collected as part of SCAMP are particularly relevant for informing the development of an appropriate $\mathrm{PM}_{2.5}$ implementation plan for Steubenville.

- Secondary sulfates, likely resulting to a great extent from coal-fired power plants to the west and southwest of Steubenville, are the largest contributor to ambient $\mathbf{P M}_{2.5}$ mass in Steubenville. Primary $\mathrm{PM}_{2.5}$ emissions from coal-fired power plants appear to contribute relatively little to the total mass of ambient $\mathbf{P M}_{2.5}$, however.

The overall mean $\mathrm{SO}_{4}{ }^{2-}$ concentration measured at the central Steubenville site during the SCAMP ambient air monitoring program was $5.8 \mu \mathrm{g} / \mathrm{m}^{3}$. $\mathrm{PM}_{2.5}$ mass balance calculations performed using 109 days with complete or nearly complete $\mathrm{PM}_{2.5}$ speciation data indicated 
that, on average, $\mathrm{SO}_{4}{ }^{2-}$ accounted for $30.4 \%$ of the total mass of ambient $\mathrm{PM}_{2.5}$ at Steubenville. (The second largest contributor to total $\mathrm{PM}_{2.5}$ mass was organic material, which accounted for an estimated $25.7 \%$ by weight). As expected for this predominantly secondary pollutant, $\mathrm{SO}_{4}{ }^{2-}$ concentrations at Steubenville exhibited a statistically significant seasonal pattern of greater concentrations during the summer, when meteorological conditions favor secondary sulfate formation, and lesser concentrations during the winter. This variability drove a similar statistically significant seasonal pattern in total $\mathrm{PM}_{2.5}$ mass concentrations. Sulfate accounted for $38.4 \%$ of the total mass of ambient $\mathrm{PM}_{2.5}$ during the summer at Steubenville, but only for $24.8 \%$ of the total mass during the winter. Source apportionment analysis performed by applying Positive Matrix Factorization to 115 days of speciated $\mathrm{PM}_{2.5}$ data from the central site suggested that a factor dominated by secondary sulfates (including $\mathrm{NH}_{4}{ }^{+}$and $\mathrm{SO}_{4}{ }^{2-}$ at a molar ratio of $2: 1$, consistent with the presence of secondary ammonium sulfate aerosol) was the largest contributor to $\mathrm{PM}_{2.5}$ mass at Steubenville, accounting for about $42 \%$ by weight. Potential Source Contribution Function modeling indicated a likely source region to the west and southwest of Steubenville, consistent with the general location of numerous coal-fired power plants. Conversely, the primary coal combustion source factor resolved by PMF (which was strongly enriched in Se, well-correlated with $\mathrm{SO}_{2}$ and $\mathrm{NO}_{2}$, and had a probable source region including portions of the Ohio and Monongahela River valleys in the Steubenville region), contributed $<1 \mu \mathrm{g} / \mathrm{m}^{3}$ to the total mass of ambient $\mathrm{PM}_{2.5}$. Thus, results from the SCAMP ambient air monitoring program suggest that whereas reductions in secondary sulfates originating from coal-fired power plants (as required under the Clean Air Interstate Rule) will almost certainly be needed if Steubenville is to attain compliance with the $\mathrm{PM}_{2.5}$ NAAQS, further reductions in primary particulate emissions from coal-fired power plants would be of relatively little aid in attaining a mass-based standard.

- Local sources in the immediate Steubenville vicinity, including motor vehicles, iron and steel facilities, and other point and area sources, contribute an estimated $5 \mu \mathrm{g} / \mathrm{m}^{3}$ $(\sim 30 \%)$ to the total mass of ambient $\mathbf{P M}_{2.5}$ in Steubenville.

Similar estimates of the contribution of local sources in the immediate Steubenville vicinity to the city's mean ambient $\mathrm{PM}_{2.5}$ concentration were obtained via two independent analyses, improving our confidence in this estimate. The first analysis considered pairwise differences between daily $\mathrm{PM}_{2.5}$ concentrations measured by the FRM monitor at the central ambient air monitoring site in Steubenville and daily $\mathrm{PM}_{2.5}$ concentrations measured at the northern and western satellite sites, which were considered to be most representative of regional background $\mathrm{PM}_{2.5}$ concentrations in the Steubenville area. Based on this pairwise comparison, the estimated contribution of local sources in the immediate Steubenville vicinity to the total mass of ambient $\mathrm{PM}_{2.5}$ observed there during SCAMP was $4.6 \mu \mathrm{g} / \mathrm{m}^{3}$. The second analysis - source apportionment using PMF and PSCF - identified two factors representing local sources in Steubenville, which together accounted for $5.3 \mu \mathrm{g} / \mathrm{m}^{3}$ of the total mass of $\mathrm{PM}_{2.5}$. The compositional profiles of these two local source factors suggest that they likely include motor vehicles and other local sources of carbonaceous aerosols, which contributed $\sim 20 \%$ of the total $\mathrm{PM}_{2.5}$ mass and more than half of the mass of fine particulate $\mathrm{EC}, \mathrm{OM}$, and $\mathrm{Ba}$ observed at the Steubenville site, as well as iron and steel production facilities, which contributed $\sim 10 \%$ of the total $\mathrm{PM}_{2.5}$ mass and more than half of the mass of fine particulate $\mathrm{Fe}, \mathrm{Mn}$, and $\mathrm{Zn}$ observed there. The identity of the local iron and steel production source and its estimated contribution to total $\mathrm{PM}_{2.5}$ mass were further validated by Unmix source apportionment modeling, which estimated a $\mathrm{PM}_{2.5}$ mass contribution of $1.3-2.2 \mu \mathrm{g} / \mathrm{m}^{3}$ (average $=1.8 \mu \mathrm{g} / \mathrm{m}^{3}$ ) from this source, and by comparing source apportionment results with data from the U.S. EPA's Toxic Release Inventory. 
According to the 2001 TRI for air emissions, the primary metals industry accounts for $93 \%$ of $\mathrm{Zn}$ emissions and $83 \%$ of $\mathrm{Mn}$ emissions from stationary sources in Jefferson County, $\mathrm{OH}$, where Steubenville is located. The $\mathrm{Mn} / \mathrm{Zn}$ mass ratios of $0.18-0.20$ computed for the iron and steel source factors resolved by the PMF and Unmix models agree reasonably well with the ratio of 0.16 computed using the TRI data.

- Distinct mechanisms cause local- and regional-scale episodes of elevated $\mathrm{PM}_{2.5}$ concentrations in Steubenville.

Case studies of episodes of elevated $\mathrm{PM}_{2.5}$ concentration observed during the SCAMP ambient air monitoring program revealed two distinctly different types of episodes that led to elevated $\mathrm{PM}_{2.5}$ concentrations at the central monitoring site in Steubenville:

1. A regional episode type characterized by a multiple-day period of consistently and moderately elevated concentrations of secondary-sulfate-dominated $\mathrm{PM}_{2.5}$, which typically occurred during warmer portions of the year, and

2. A local episode type characterized by shorter overnight periods of more acutely elevated concentrations of $\mathrm{PM}_{2.5}$ resulting from the buildup of primary particles enriched in trace metals and carbonaceous species during nocturnal temperature inversions, which typically occurred during cooler portions of the year.

During local, inversion-driven episodes, hourly $\mathrm{PM}_{2.5}$ concentrations were typically very strongly correlated with hourly concentrations of primary gaseous pollutants (e.g., $\mathrm{CO}, \mathrm{NO}_{\mathrm{x}}$, and $\mathrm{SO}_{2}$ ), whereas $\mathrm{PM}_{2.5}$ concentrations generally did not correlate well with gaseous pollutant concentrations during regional, secondary-sulfate-dominated episodes. Moreover, the greatest hourly $\mathrm{PM}_{2.5}$ concentrations observed during SCAMP occurred in the nighttime or early morning during cool-season episodes; none of the 76 1-hr average concentrations greater than $65 \mu \mathrm{g} / \mathrm{m}^{3}$ were observed during the mid-afternoon (between 1:00 p.m. and 5:00 p.m. EST), and none of the 20 greatest 1-hr average concentrations were observed during the summer. Both of the $\mathrm{PM}_{2.5}$ episode types identified during SCAMP must be considered when developing an implementation plan to reduce concentrations of $\mathrm{PM}_{2.5}$ in Steubenville, as both can lead to elevated 24-hr $\mathrm{PM}_{2.5}$ concentrations (e.g., concentrations exceeding the recently proposed 24-hr standard of $35 \mu \mathrm{g} / \mathrm{m}^{3}$ ), which in turn contribute to Steubenville's high annual average $\mathrm{PM}_{2.5}$ concentration. As the data collected as part of SCAMP illustrate, these episode types result from very different mechanisms; therefore, reducing their occurrences will require the application of unique strategies.

- Concentrations of certain transition metals, including Fe, Mn, and Zn, observed at Steubenville are appreciably elevated relative to concentrations observed in the surrounding region and in other larger U.S. cities.

Median daily ratios of concentrations of water-extractable $\mathrm{Fe}, \mathrm{Mn}$, and $\mathrm{Zn}$ measured at the central Steubenville site to concentrations of these elements measured at each of the four SCAMP satellite sites were $>1.5$, suggesting that local sources in the immediate Steubenville vicinity contribute substantially to their ambient concentrations there. In fact, an analysis of mean paired differences between Steubenville concentrations and estimated "regional background" concentrations of these elements indicates that their mean concentrations at Steubenville are at least twice as great as their mean concentrations in the surrounding area. Mean acid-digestible concentrations of $\mathrm{Fe}, \mathrm{Mn}$, and $\mathrm{Zn}$ observed at Steubenville during SCAMP were also substantially greater than concentrations measured in other, much larger U.S. cities during comparable time periods. (With the exception of Fe 
in St. Louis, mean concentrations of $\mathrm{Fe}, \mathrm{Mn}$, and $\mathrm{Zn}$ in Steubenville were 1.9-7.6 times as great as those reported for Atlanta, GA, Baltimore, MD, Boston, MA, Chicago, IL, New York, NY, St. Louis, MO, and Washington, DC, where data were available). Mn is defined as a Hazardous Air Pollutant in the 1990 Clean Air Act amendments (the mean concentration of fine particulate $\mathrm{Mn}$, which accounts for only a portion of total airborne $\mathrm{Mn}$, at Steubenville during SCAMP was about $37 \%$ as great as the U.S. ATSDR's MRL for Mn), and Fe and $\mathrm{Zn}$ have both been associated with pulmonary health endpoints in PM toxicology studies. Hence, further research should be conducted to better elucidate whether these metals play any role in the health effects previously associated with $\mathrm{PM}_{2.5}$ in Steubenville.

- Ambient fine particles are strong proxies of corresponding personal exposures for older adults and, to a lesser extent, for children in Steubenville.

For the older adult cohort, personal exposures to $\mathrm{PM}_{2.5}$ were significantly associated with corresponding ambient $\mathrm{PM}_{2.5}$ concentrations measured at the central ambient air monitoring site in Steubenville during both the summer and fall. Mixed model results indicated that, for every $10 \mathrm{\mu g} / \mathrm{m}^{3}$ increase in corresponding ambient $\mathrm{PM}_{2.5}$ concentrations, personal exposures of the older adults increased an average of $7.3 \pm 0.5 \mu \mathrm{g} / \mathrm{m}^{3}$ during the summer and $6.3 \pm 0.5 \mu \mathrm{g} / \mathrm{m}^{3}$ during the fall. Personal-ambient slopes (i.e., average increase in personal exposure per unit increase in corresponding ambient concentration) for $\mathrm{PM}_{2.5}$ for the children's cohort were lower and less significant than those for the older adult cohort. For every $10 \mu \mathrm{g} / \mathrm{m}^{3}$ increase in corresponding ambient concentrations, summertime personal $\mathrm{PM}_{2.5}$ exposures increased an average of $5.8 \pm 0.8$ for the children, which is about $20 \%$ less than the summertime increase in exposures observed for the older adults. In winter, personal $\mathrm{PM}_{2.5}$ exposures for the children increased an average of only $2.5 \pm 1.4 \mu \mathrm{g} / \mathrm{m}^{3}$ for every $10 \mu \mathrm{g} / \mathrm{m}^{3}$ increase in ambient concentration. Overall, results of SCAMP confirm the results of previous studies showing that ambient $\mathrm{PM}_{2.5}$ concentrations are strong proxies of corresponding personal exposures, especially for older adults.

- The ability of ambient fine particle concentrations to reflect personal exposures differs by particle component, and is greater for $\mathrm{SO}_{4}{ }^{2-}$, a predominantly regional fine particle, than for EC, a predominantly locally-emitted fine particle.

For both the older adult cohort and the children's cohort, associations between ambient concentrations and corresponding personal exposures were stronger for fine particulate $\mathrm{SO}_{4}{ }^{2-}$, a regional pollutant with no major indoor sources, than they were for total $\mathrm{PM}_{2.5}$ mass. As with total $\mathrm{PM}_{2.5}$, the associations were stronger in summer than in fall or winter and were stronger for the older adults than for the children. Personal-ambient slopes describing these associations were $0.74 \pm 0.02$ and $0.59 \pm 0.04$ for the older adults and children, respectively, in the summer, $0.64 \pm 0.02$ for the older adults in the fall, and $0.37 \pm 0.05$ for the children in the winter.

Ambient concentrations of EC were also significant proxies of corresponding exposures for the older adults in both seasons (slope $=0.33 \pm 0.10$ in summer, $0.69 \pm 0.06$ in fall) and for the children in winter (slope $=0.41 \pm 0.07$ ), although personal-ambient associations were weaker for $\mathrm{EC}$ than for $\mathrm{SO}_{4}{ }^{2-}$, likely due to the influence of local sources such as traffic and cooking. As the slopes presented above indicate, personal-ambient associations for EC were weaker during summer and stronger during fall and winter, contrary to the trend exhibited by $\mathrm{PM}_{2.5}$ and $\mathrm{SO}_{4}{ }^{2-}$. Findings are consistent with those of previous studies and provide additional justification for the use of ambient $\mathrm{SO}_{4}{ }^{2-}$, and to a lesser extent $\mathrm{EC}$, to represent corresponding mean personal exposures in epidemiologic analyses. 
Personal-ambient associations for water-extractable and acid-digestible elemental components of $\mathrm{PM}_{2.5}$, although positive and statistically significant in many instances, exhibited inconsistencies by element, extraction method, cohort, and season. Hence, no definitive conclusions could be drawn regarding these results.

- Home ventilation was the primary factor affecting the ability of ambient pollutant concentrations to reflect the personal exposures of older adults and children to these pollutants.

For both cohorts, indoor-ambient and personal-ambient slopes were generally higher when windows were open or when participants spent more time near open windows, both conditions consistent with increased ventilation. Other factors, such as stove type or time spent outdoors, were significant but relatively minor modifiers of the relationship between ambient concentrations and either indoor or personal exposures. Results from SCAMP are the first to show the impact of home ventilation as a modifier of personal-ambient gas associations, and they suggest that ventilation may be an important modifier of the magnitude of effect in time-series health studies.

- Time-series health studies based on 24-hour ambient concentrations may not be able to separate the independent effects of particles and gases in Steubenville.

An analysis of data collected at the central ambient air monitoring site in Steubenville as part of the SCAMP ambient air monitoring program revealed that, after accounting for autocorrelation, concentrations of $\mathrm{PM}_{2.5}$ exhibited statistically significant $(\alpha=0.05)$, positive associations with concentrations of $\mathrm{CO}, \mathrm{NO}, \mathrm{NO}_{2}$, and $\mathrm{SO}_{2}\left(\mathrm{R}^{2}=0.35-0.46\right)$. Associations of $\mathrm{NO}$ and $\mathrm{NO}_{2}$ with $\mathrm{PM}_{2.5}$ were strongest during fall $\left(\mathrm{R}^{2}=0.53\right.$ and 0.61 , respectively; slope $=0.39$ and 0.57 , respectively) and weakest during summer $\left(R^{2}=0.0014\right.$ and 0.086 , respectively; slope $=-0.015$ and 0.20 , respectively). The association between $\mathrm{CO}$ and $\mathrm{PM}_{2.5}$ was strongest during winter $\left(R^{2}=0.60\right.$; slope $\left.=0.66\right)$ and weakest during summer $\left(R^{2}=\right.$ 0.24 ; slope $=0.27$ ), whereas the association between $\mathrm{O}_{3}$ and $\mathrm{PM}_{2.5}$ was weakly positive during summer $\left(R^{2}=0.12\right.$; slope $\left.=0.17\right)$ and moderately negative during winter $\left(R^{2}=0.25\right.$; slope $=-0.29$ ). These associations suggest that gaseous pollutants such as $\mathrm{CO}, \mathrm{NO}_{2}$, and to a lesser extent $\mathrm{O}_{3}$, may cause seasonally-dependent collinearity problems in $\mathrm{PM}_{2.5}$ time series epidemiology studies focusing on Steubenville. For associations between $\mathrm{PM}_{2.5}$ and these gases, an interaction with season is observed even after autocorrelation (including seasonality) has been removed from the individual pollutant time series. Hence, results from the SCAMP ambient air monitoring program reinforce the need for future epidemiology studies to employ separate analyses by season or to include appropriate interaction terms in order to better capture and control for the collinearity between $\mathrm{PM}_{2.5}$ and co-pollutants, and suggest that caution should be exercised when interpreting the results of previous epidemiology studies that did not consider the effects of pollutants such as $\mathrm{CO}$ and $\mathrm{NO}_{2}$ and their seasonal interactions with PM.

Cross-pollutant analyses conducted using data from both the older adult and children's cohorts indicated statistically significant associations between ambient particle concentrations and personal $\mathrm{O}_{3}$ and $\mathrm{NO}_{2}$ exposures, with associations varying by particle species, season, and ventilation status. For the older adult cohort, 24-hr ambient particle concentrations were significantly and positively correlated with personal $\mathrm{O}_{3}$ exposures in the summer and with both personal $\mathrm{O}_{3}$ and $\mathrm{NO}_{2}$ exposures in the fall. For the children's cohort during the summer, which was characterized by a greater percentage of open window 
usage, ambient particle concentrations were strong proxies of children's personal exposures to gases from similar sources, such as was observed with the traffic-related pollutants $\mathrm{NO}_{2}$ and $\mathrm{EC}$ and with the regional pollutants $\mathrm{O}_{3}, \mathrm{SO}_{4}{ }^{2-}$, and $\mathrm{PM}_{2.5}$ (likely because of its large mass fraction of $\mathrm{SO}_{4}{ }^{2-}$ ). Since these associations were not significant in the winter, results suggest that ambient particles can represent personal gaseous exposures only when homes are well-ventilated. Hence, results from the SCAMP indoor and personal exposure program suggest that ambient pollution may represent exposures to both $\mathrm{PM}_{2.5}$ and gases in Steubenville, especially for pollutants from common sources and for individuals living in wellventilated environments, making the health effects of particles and gases difficult to separate. It is important to note, however, that ambient particle concentrations were generally better proxies of exposures to the particles themselves rather than the gases. For instance, for the older adult cohort, personal $\mathrm{O}_{3}$ and $\mathrm{NO}_{2}$ exposures were found to increase by only 1.1 and $1.7 \mathrm{ppb}$ with every $10 \mu \mathrm{g} / \mathrm{m}^{3}$ increase in ambient $\mathrm{PM}_{2.5}$, respectively. These observed increases in personal $\mathrm{O}_{3}$ and $\mathrm{NO}_{2}$ are extremely small and have not been shown to elicit adverse health effects in controlled laboratory studies. Nevertheless, numerous epidemiologic studies have linked both 24-hour ambient $\mathrm{O}_{3}$ and $\mathrm{NO}_{2}$ concentrations to adverse health impacts, suggesting that these gases may elicit health impacts along with or in combination with other pollutants, or that 24-hour ambient concentrations of these gases are acting as proxies for shorter-term pollutant exposures.

- Health effect studies conducted using $\mathrm{PM}_{2.5}$ and gaseous pollutant data collected at the SCAMP central monitoring site in Steubenville found that fine particulate sulfate, but not elemental carbon, was significantly associated with decreased heart rate variability and increased odds of supraventricular arrhythmia among members of the older adult cohort.

Although these studies were based on a fairly small cohort and did not consider all major chemical components of $\mathrm{PM}_{2.5}$ in Steubenville (e.g., organic carbon, the second largest contributor to $\mathrm{PM}_{2.5}$ mass in Steubenville, was not included in the analyses), they provide evidence that increased levels of ambient fine particulate pollution from non-traffic sources (e.g., sulfate particles) may adversely affect cardiac health in the elderly.

In addition to producing the comprehensive database and key findings described above, SCAMP made several other important contributions to advancing $\mathrm{PM}_{2.5}$ research. The program identified sensitivity issues that limited the ability to determine certain $\mathrm{PM}_{2.5}$ trace elements by conventionally-used XRF techniques, and it pioneered the development of methods for applying dynamic reaction cell ICP-MS to enable these elements to be determined with improved sensitivity. The program is one of the few that has explored both water-extractable and aciddigestible (total) $\mathrm{PM}_{2.5}$ trace element concentrations, and it is the first to do so in Steubenville. Papers published as part of SCAMP also identified statistical concerns that are common to air monitoring data but are commonly overlooked in the $\mathrm{PM}_{2.5}$ literature and provided recommendations, such as the application of ARIMA modeling, for properly accounting for these concerns. Moreover, SCAMP helped to seed several additional studies that collectively add to the understanding of air quality in the Upper Ohio River Valley region, factors that affect it, and its effects on human health. Two studies led by Ohio University, including "The Evaluation of the Emission, Transport and Deposition of Mercury, $\mathrm{PM}_{2.5}$, and Arsenic in the Ohio Valley from Coal-Fired Power Plants," which is being funded by the U.S. DOE-NETL (agreement No. DEFC26-03NT41723), and "Proposed Research and Support Activities for Air Quality Initiatives in Ohio and Surrounding States," which is being funded by U.S. EPA Region V, are using the DRC ICP-MS methodology developed during SCAMP, as well as monitoring equipment from the program. Data and statistical concepts from SCAMP are being applied in a third study, titled 
"Design and Feasibility Assessment of a Retrospective Epidemiologic Study of Coal-Fired Power Plant Emissions in the Pittsburgh, Pennsylvania, Region," which is being led by the University of Pittsburgh Graduate School of Public Health and funded by DOE-NETL (agreement No. DE-FC26-05NT42302). Data from SCAMP are also being incorporated into the database being developed as part of a DOE-NETL-funded project (agreement No. DE-FC2602NT41476) titled "Database and Analytical Tool for Air Quality in the Upper Ohio River Valley," which is being led by ATS-Chester Engineers.

Finally, results from SCAMP have important implications for guiding future $\mathrm{PM}_{2.5}$ research. Specific recommendations are as follows:

1. Future epidemiology studies focusing on $\mathrm{PM}_{2.5}$ should carefully consider the possibility for confounding by gaseous co-pollutants such as $\mathrm{CO}, \mathrm{NO}_{2}$, and $\mathrm{O}_{3}$, as well as the possibility that the associations among and effects of these pollutants may be significantly modified by season or by home ventilation status. Previous studies that did not adequately consider these possibilities should be interpreted cautiously.

2. Further research is required to determine whether the composition of $\mathbf{P M}_{2.5}$ impacts its effect on human health (e.g., whether particles enriched in trace metals and carbonaceous species, which were prevalent during the cool season episodes typically observed during SCAMP, are more toxic than the secondary-sulfate-dominated particles that were typically prevalent during summertime episodes, or whether the mere existence of particles, regardless of composition, triggers the observed health effects). In particular, given the elevated concentrations of fine particulate $\mathrm{Fe}, \mathrm{Mn}$, and $\mathrm{Zn}$ observed at Steubenville, the PM health effects that have previously been observed there, and recent toxicological findings implicating these transition metals, further research should be conducted to elucidate what role, if any, $\mathrm{Fe}, \mathrm{Mn}$, and $\mathrm{Zn}$ play in the health effects that have been attributed to $\mathrm{PM}_{2.5}$.

3. Data from SCAMP are consistent with the hypothesis that ambient secondary sulfates, under suitable photochemical conditions, may play a role in increasing the solubility of fine particulate Fe. Further research should be conducted to confirm or refute this hypothesis.

4. Findings from SCAMP illustrating that $\mathrm{PM}_{2.5}$ and co-pollutants exhibit markedly different diurnal variability during local, inversion-driven episodes as compared to regional, secondary-sulfate-driven episodes suggest a need for further research using timeresolved measurements to elucidate the effect of the intraday timing and short-term intensity of pollution episodes on human exposures and possible health effects.

5. Additional improvements are needed in methods for measuring human exposures to gaseous pollutants, especially $\mathrm{SO}_{2}$, and to fine particulate trace elements and carbonaceous species. The sensitivity and precision of sampling and analytical methods used during SCAMP were insufficient to measure personal exposures to $\mathrm{SO}_{2}$ and fine particulate trace elements. Moreover, organic carbon, the second largest contributor to the mass of ambient $\mathrm{PM}_{2.5}$ in Steubenville during SCAMP, could not be measured in personal exposure samples because of methodological limitations. Given current interest in the health implications of specific $\mathrm{PM}_{2.5}$ components, including trace metal and carbonaceous species, further method development is warranted to allow human exposures to these species to be better quantified.

6. Associations between ambient pollutant concentrations and corresponding personal exposures observed during SCAMP differed by cohort. Future exposure studies should examine factors contributing to differences in pollutant exposures for older adults and children. 


\section{REFERENCES}

Abt, E.; Suh, H.; Catalana, P.; Koutrakis, P. (2000) Relative contribution of outdoor and indoor particle sources to indoor concentrations. Environ. Sci. Technol. 34: 3579-3587.

Adamson, I.Y.; Prieditis, H.; Hedgecock, C.; Vincent, R. (2000) Zinc is the toxic factor in the lung response to an atmospheric particulate sample. Toxicol. Appl. Pharmacol. 166: 111-119.

Allen, G.; Sioutas, C.; Koutrakis, P.; Reiss, R.; Lurmann, F.W.; Roberts, P.T. (1997) Evaluation of the TEOM method for measurement of ambient particulate mass in urban areas. J. Air \& Waste Manage. Assoc. 47: 682-689.

Box, G.E.P.; Jenkins, G.M. (1976) Times series analysis: forecasting and control. San Francisco: Holden-Day.

Brauer, M.; Koutrakis, P.; Spengler, J.D. (1989) Personal exposure to acidic aerosols and gases. Environ. Sci. Technol. 23: 1408-1412.

Breiman, L.; Friedman, J.H.; Olshen, R.A.; Stone, C.J. (1984) Classification and Regression Trees. New York: Chapman \& Hall.

Brown, K. (2006) Characterization of particulate and gaseous exposures of sensitive populations living in Baltimore and Boston. Department of Environmental Health. Boston, MA, Harvard School of Public Health: 146.

Burnett, R.T.; Brook, J.; Dann, T.; Delocla, C.; Philips, O.; Cakmak, S.; Vincent, R.; Goldberg, M.S.; Krewski, D. (2000) Association between particulate- and gas phase components of urban air pollution and daily mortality in eight Canadian cities. Inhalation Toxicol. 12(suppl. 4): 15-39.

Burton, R.M.; Suh, H.H.; Koutrakis, P. (1996) Spatial variation in particulate concentrations within metropolitan Philadelphia. Environ. Sci. Technol. 30: 400-407.

Carnegie Mellon University. (2005) Atmospheric aerosol source-receptor relationships: the role of coal-fired plants. Semi-Annual Technical Progress Report to the U.S. Department of Energy for the Period September 2004-February 2005. Available: http://www.netl.doe.gov/technologies/coalpower/ewr/air_quality_research/am_monitor/pu bs/41017R08.rev.pdf [24 May 2006].

Chang, L.T.; Sarnat, J.A.; Wolfson, J.M.; Rojas-Bracho L.; Suh, H.H.; Koutrakis, P. (1999) Development of a personal multi-pollutant exposure sampler for particulate matter and criteria gases.

Chang, L.T.; Koutrakis, P.; Catalano, P.; Suh, H.H. (2000) Hourly personal exposures to fine particles and gaseous pollutants-results from Baltimore, MD. J. Air \& Waste Manage. Assoc. 50: 1223-1235.

Chellam, S.; Kulkarni, P.; Fraser, M.P. (2005) Emissions of organic compounds and trace metals in fine particulate matter from motor vehicles: a tunnel study in Houston, Texas. J. Air \& Waste Manage. Assoc. 55: 60-72.

Chock, D.P.; Winkler, S.L.; Chen, C. (2000) A study of the association between daily mortality and ambient air pollutant concentrations in Pittsburgh, Pennsylvania. J. Air \& Waste Manage. Assoc. 50: 1481-1500.

Chow, J.C.; Watson, J.G. (1998) Guideline on speciated particulate monitoring. Reno, NV: Desert Research Institute. Available: http://www.epa.gov/ttnamti1/files/ ambient/pm25/spec/drispec.pdf [22 May 2006].

Chuersuwan, N.; Turpin, B.J.; Pietarinen, C. (2000) Evaluation of time-resolved $\mathrm{PM}_{2.5}$ data in urban/suburban areas of New Jersey. J. Air \& Waste Manage. Assoc. 50: 1780-1789.

Connell, D.P.; Withum, J.A.; Winter, S.E.; Statnick, R.M.; Bilonick, R.A. (2005a) The Steubenville comprehensive air monitoring program (SCAMP): overview and statistical considerations. J. Air \& Waste Manage. Assoc. 55: 467-480.

Connell, D.P.; Withum, J.A.; Winter, S.E.; Statnick, R.M.; Bilonick, R.A. (2005b) The 
Steubenville comprehensive air monitoring program (SCAMP): associations among fine particulate matter, co-pollutants, and meteorological conditions. J. Air \& Waste Manage. Assoc. 55: 481-496.

Connell, D.P.; Withum, J.A.; Winter, S.E.; Statnick, R.M.; Bilonick, R.A. (2005c) The Steubenville comprehensive air monitoring program (SCAMP): analysis of short-term and episodic variations in $\mathrm{PM}_{2.5}$ concentrations using hourly air monitoring data. J. Air \& Waste Manage. Assoc. 55: 559-573.

Connell, D.P.; Winter, S.E.; Conrad, V.B.; Kim, M.; Crist, K.C. (2006) The Steubenville comprehensive air monitoring program (SCAMP): concentrations and solubilities of $\mathrm{PM}_{2.5}$ trace elements and their implications for source apportionment and health research. J. Air \& Waste Manage. Assoc. 56: 1750-1766.

Conrad, V.B.; Winter, S.E.; Krofcheck, D.S. (2000) ICP-MS and x-ray fluorescence: a comparative study for the elemental analysis of fine particulate matter. Presented at the International Symposium on Measurement of Toxic and Related Air Pollutants, Research Triangle Park, NC, September 2000.

Delfino, R.J.; Murphy-Moulton, A.M.; Burnett, R.T.; Brook, J.R.; Becklake, M.R. (1997) Effects of air pollution on emergency room visits for respiratory illnesses in Montreal, Quebec. Am. J. Respir. Crit. Care Med. 155: 568-576.

Delfino, R.J.; Zeiger, R.S.; Seltzer, J.M.; Street, D.H. (1998) Symptoms in pediatric asthmatics and air pollution: differences in effects by symptom severity, anti-inflammatory medication use and particulate averaging time. Environ. Health Perspect. 106: 751-761.

Demokritou, P.; Kavouras, I.G.; Ferguson, S.T.; Koutrakis, P. (2001) Development and laboratory performance evaluation of a personal multipollutant sampler for simultaneous measurements of particulate and gaseous pollutants. Aerosol Sci. Technol. 35: 741-752.

Devlin, R.B.; Folinsbee, L.J.; Biscardi, F.; Hatch, G.; Becker, S.; Madden, M.C.; et al. (1997) Inflammation and cell damage induced by repeated exposure of humans to ozone. Inhal. Toxicol. 9: 211-235.

Dockery, D.W.; Pope, C.A.; Xu, X.; Spengler, J.D.; Ware, J.H.; Fay, M.E.; Ferris, B.G.; Speizer, F.E. (1993) An association between air pollution and mortality in six U.S. cities. N. Engl. J. Med. 329: 1753-1759.

Dockery, D.W.; Cunningham, J.; Damokosh, A.I.; Neas, L.M.; Spengler, J.D.; Koutrakis, P.; Ware, J.H.; Raizenne, M.; Speizer, F.E. (1996) Health effects of acid aerosols on North American children: respiratory symptoms. Environ. Health Perspect. 104: 500-505.

Dusseldorp, A.; Kruize, H.; Brunekreef, B.; Hofschreuder, P.; de Meer, G.; van Oudvorst, A.B. (1995) Associations of $\mathrm{PM}_{10}$ and airborne iron with respiratory health of adults living near a steel factory. Am. J. Respir. Crit. Care Med. 152: 1932-1939.

Ebelt, S.T.; Petkau, A.J.; Vedal, S.; Fisher, T.V.; Brauer, M. (2000) Exposure of chronic obstructive pulmonary disease patients to particulate matter: relationships between personal and ambient air concentrations. J. Air Waste Manage. Assoc. 50: 1081-1094.

Faust, B.C. (1994) Photochemistry of clouds, fogs, and aerosols. Environ. Sci. Technol. 28: 217A-222A.

Fernandez, A.; Wendt, J.O.L.; Witten, M.L. (2005) Health effects engineering of coal and biomass combustion particulates: influence of zinc, sulfur and process changes on potential lung injury from inhaled ash. Fuel 85: 1320-1327.

Frampton, M.W.; Morrow, P.E.; Cox, C.; Gibb, F.R.; Speers, D.M.; Utell, M.J. (1991) Effects of nitrogen dioxide exposure on pulmonary function and airway reactivity in normal humans. Am. Rev. Respir. Dis. 143: 522-527.

Frampton, M.W.; Ghio, A.J.; Samet, J.M.; Carson, J.L.; Carter, J.D.; Devlin, R.B. (1999) Effects of aqueous extracts of $\mathrm{PM}_{10}$ filters from the Utah Valley on human airway epithelial cells. Am. J. Physiol. 277: L960-L967.

Frank, N.H. (2006) Retained nitrate, hydrated sulfates, and carbonaceous mass in federal 
reference method fine particulate matter for six eastern U.S. cities. J. Air \& Waste Manage. Assoc. 56: 500-511.

Garg, B.D.; Cadle, S.H.; Mulawa, P.A.; Groblicki, P.J.; Laroo, C.; Parr, G.A. (2000) Brake wear particulate matter emissions. Environ. Sci. Technol. 34: 4463-4469.

Gavett, S.H.; Haykal-Coates, N.; Copeland, L.B.; Heinrich, J.; Gilmour, M.I. (2003) Metal composition of ambient $\mathrm{PM}_{2.5}$ influences severity of allergic airways disease in mice. Environ. Health Perspect. 111: 1471-1477.

Ghio, A.J.; Carter, J.D.; Dailey, L.A.; Devlin, R.B.; Samet, J.M. (1999a) Respiratory epithelial cells demonstrate lactoferrin receptors that increase after metal exposure. Am. J. Physiol. 276: L933-L940.

Ghio, A.J.; Stoneheurner, J.; McGee, J.K.; Kinsey, J.S. (1999b) Sulfate content correlates with iron concentrations in ambient air pollution particles. Inhal. Toxicol. 11: 293-307.

Gilbert, R.O. (1987) Statistical Methods for Environmental Pollution Monitoring. New York: Van Nostrand Reinhold. pp. 177-178.

Gold, D.R.; Allen, G.; Damokosh, A.; Serrano, P.; Hayes, C.; Castillejos, M. (1996) Comparison of outdoor and classroom ozone exposures for school children in Mexico City. J. Air. Waste Manage. Assoc. 46: 335-342.

Gong, H.; Wong, R.; Sarma, R.J.; Linn, W.S.; Sullivan, E.D.; Shamoo, D.A.; et al. (1998) Cardiovascular effects of ozone exposure in human volunteers. Am. J. Respir. Crit. Care Med. 158: 538-546.

Grahame, T.J.; Schlesinger, R.B. (2005) Evaluating the health risk from secondary sulfates in eastern North American regional ambient air particulate matter. Inhal. Toxicol. 17: 15-27.

Gurgueira, S.A.; Lawrence, J.; Coull, B.; Krishna Murthy, G.G.; Gonzalez-Flecha, B. (2002) Rapid increases in the steady-state concentration of reactive oxygen species in the lungs and heart after particulate air pollution inhalation. Environ. Health Perspect. 110: 749-755.

Hidy, G.M.; Friedlander, S.K. (1971) The Nature of the Los Angeles Aerosol. Englund, H.M.; Beery, W.T., Eds. New York: Academic Press. pp. 391-404.

Huang, Y.C.; Ghio, A.J.; Stoneheurner, J.; McGee, J.; Carter, J.D.; Grambow, S.C.; Devlin, R.B. (2003) The role of soluble components in ambient fine particles - induced changes in human lungs and blood. Inhal. Toxicol. 15: 327-342.

Jakab, G.J.; Clarke, R.W.; Hemenway, D.R.; Longphre, M.V.; Kleeberger, S.R.; Frank, R. (1996) Inhalation of acid coated carbon black particles impairs alveolar macrophage phagocytosis. Toxicol. Lett. 88: 243-248.

Jansen, J.J.; Edgerton, E.S.; Hansen, D.A.; Hartsell, B.E. (2002) Sampling artifacts in the federal reference method for $\mathrm{PM}_{2.5}$. In Proceedings of the International Conference on Air Quality III, Arlington, VA, September 9-12.

Janssen, N.; Van Mansom, D.; Van Der Jagt, K.; Harssema, H.; Hoek, G. (1997) Mass concentration and elemental composition of airborne particulate matter at street and background locations. Atmos. Envir. 8: 1185-93.

Janssen, N.A.; de Hartog, J.J.; Hoek, G.; Brunekreef, B.; Lanki, T.; Timonen, K.L.; et al. (2000) Personal exposure to fine particulate matter in elderly subjects: relation between personal, indoor, and outdoor concentrations. J. Air. Waste Manage. Assoc. 50: 11331143.

Kenski, D.M. (2003) Meteorological conditions and haze: a CART analysis. Available: http://www.ladco.org/tech/monitoring/docs_gifs/cart3.pdf [5 March 2004].

Kinney, P.L.; Thurston, G.D. (1993) Field evaluation of instrument performance: statistical considerations. Appl. Occup. Environ. Hyg. 8: 267-271.

Kleinman, M.T.; Bufalino, C.; Rasmussen, R.; Hyde, D.; Bhalla, D.K.; Mautz, W.J. (2000) Toxicity of chemical components of ambient fine particulate matter $\left(\mathrm{PM}_{2.5}\right)$ inhaled by aged rats. J. Appl. Toxicol. 20: 357-364. 
Klemm, R.J.; Lipfert, F.W.; Wyzga, R.E.; Gust, C. (2004) Daily mortality and air pollution in Atlanta: two years of data from ARIES. Inhal. Toxicol. 16(suppl. 1): 131-141.

Koutrakis, P.; Spengler, J.D. (1987) Source apportionment of ambient particles in Steubenville, $\mathrm{OH}$ using specific rotation factor analysis. Atmos. Environ. 21: 1511-1519.

Koutrakis, P.; Briggs, S.L.K.; Leaderer, B.P. (1992) Source apportionment of indoor aerosols in Suffolk and Onondaga Counties, New York. Environ. Sci. Technol. 26: 521-527.

Koutrakis, P.; Wolfson, J.M.; Bunyaviroch, A.; Froehlich, S.E.; Hirano, K.; Mulik, J.D. (1993) Measurement of ambient ozone using a nitrite-coated filter. Anal. Chem. 65: 209214.

Laden, F.; Neas, L.M.; Dockery, D.W.; Schwartz, J. (2000) Association of fine particulate matter from different sources with daily mortality in six U.S. cities. Environ. Health Perspect. 108: 941-947.

Levy, J.I.; Houseman, E.A.; Ryan, L.; Richardson, D.; Spengler, J. (2000) Particle concentrations in urban microenvironments. Environ. Health Perspect. 108: 1051-1057.

Lewis, C.W.; Norris, G.A.; Conner, T.L.; Henry, R.C. (2003) Source apportionment of Phoenix $\mathrm{PM}_{2.5}$ aerosol with the Unmix Receptor Model. J. Air \& Waste Manage. Assoc. 53: 325338.

Linaker, C.H.; Chauhan, A.J.; Inskip, H.M.; Holgate, S.T.; Coggon, D. (2000) Personal exposures of children to nitrogen dioxide relative to concentrations in outdoor air. Occup. Environ. Med. 57: 472-476.

Lipfert, F.W.; Wyzga, R.E. (1997) Air pollution and mortality: the implications of uncertainties in regression modeling and exposure measurement. J. Air \& Waste Manage. Assoc. 47: 517-523.

Liu, L.J.; Koutrakis, P.; Suh, H.H.; Mulik, J.D.; Burton, R.M. (1993) Use of personal measurements for ozone exposure assessment: a pilot study. Environ. Health Perspect. 101(4): 318-324.

Liu, L.J.; Koutrakis, P.; Olson, M.P.; Allen, G.A.; McDonnell, W.F.; Gerrity, T.R. (1994) Evaluation of the Harvard ozone passive sampler on human subjects indoors. Environ. Sci. \& Technol. 28: 915-923.

Liu, L.J.; Delfino, R.; Koutrakis, P. (1997) Ozone exposure assessment in a southern California community. Environ. Health Perspect. 105: 58-65.

Mar, T.F.; Norris, G.A.; Koenig, J.Q.; Larson, T.V. (2000) Associations between air pollution and mortality in Phoenix, 1995-1997. Environ. Health Perspect. 108: 347-353.

Mason, B. (1966) Principles of Geochemistry. New York: John Wiley \& Sons. pp 4546.

Medeiros, N.; Rivero, D.H.; Kasahara, D.I.; Saiki, M.; Godleski, J.J.; Koutrakis, P.; Capelozzi, V.L.; Saldiva, P.H.; Antonangelo, L. (2004) Acute pulmonary and hematological effects of two types of particle surrogates are influenced by their elemental composition. Environ. Res. 95: 62-70.

Meng, Q.Y.; Turpin, B.J.; Polidori, A.; Lee, J.H.; Weisel, C.; Morandi, M.; Colome, S.; Stock, T.; Winer, A.; Zhang, J. (2005) $\mathrm{PM}_{2.5}$ of ambient origin: estimates and exposure errors relevant to PM epidemiology. Environ. Sci. Technol. 39: 5105-5112.

Moolgavkar, S.H. (2003) Air pollution and daily mortality in two U.S. counties: seasonspecific analyses and exposure-response relationships. Inhal. Toxicol. 15: 877-907.

Moolgavkar, S.H.; Luebeck, E.G. (1996) A critical review of the evidence on particulate air pollution and mortality. Epidemiology 7: 420-428.

Moolgavkar, S.H.; Luebeck, E.G.; Hall, T.A.; Anderson, E.L. (1995) Particulate air pollution, sulfur dioxide, and daily mortality: a reanalysis of the Steubenville data. Inhal. Toxicol. 7: $35-44$. 
Neas, L.M.; Dockery, D.W.; Burge, H.; Koutrakis, P.; Speizer, F.E. (1996) Fungus spores, air pollutants, and other determinants of peak expiratory flow rate in children. Am. J.

Epidemiol. 143: 797-807.

Ogawa, C. (1998) $\mathrm{NO}, \mathrm{NO}_{2}, \mathrm{NO}_{\mathrm{x}}$ and $\mathrm{SO}_{2}$ sampling protocol using the Ogawa sampler, Version 3.

Ohio Department of Transportation. (2004) Traffic Monitoring Reports. http://www.dot.state.oh.us/techservsite/offceorg/traffmonit/TMReports/ [17 March 2006].

Ostro, B.D.; Broadwin, R.; Lipsett, M.J. (2000) Coarse and fine particles and daily mortality in the Coachella Valley, California: a follow-up study. J. Exop. Anal. Environ. Epidemiol. 10: $412-419$.

Paatero, P. (1997) Least square formulation of robust nonnegative factor analysis. Chemomet. Intell. Lab. Systems 37: 23-35.

Patterson, E.; Eatough, D.J. (2000) Indoor/outdoor relationships for ambient $\mathrm{PM}_{2.5}$ and associated pollutants: epidemiological implications in Lindon, Utah. J. Air Waste Manage. Assoc. 50: 103-110.

Peters, A.; Wichmann, H.E.; Tuch, T.; Heinrich, J.; Heyder, J. (1997) Respiratory effects are associated with the number of ultrafine particles. Am. J. Respir. Crit. Care Med. 155: 1376-1383.

Peters, A.; Dockery, D.W.; Muller, J.E.; Mittleman, M.A. (2001) Increased particulate air pollution and the triggering of myocardial infarction. Circulation 103: 2810-2815.

Pittsburgh Air Quality Study. (2003) PM $_{2.5}$ concentrations and composition in Pittsburgh: summary of ambient measurements from Pittsburgh Air Quality Study (PAQS). http://www.netl.doe.gov/coalpower/environment/air_q/docs/Ambient_summary.pdf [20 October 2003].

Pope, C.A.; Thun, M.J.; Namboodiri, M.M.; Dockery, D.W.; Evans, J.S.; Speizer, F.E.; Heath, C.W. (1995) Particulate air pollution as a predictor of mortality in a prospective study of U.S. adults. Am. J. Respir. Crit. Care Med. 151: 669-674.

Research Triangle Institute. (2003) Standard operating procedure for the determination of organic, elemental, and total carbon in particulate matter using a thermal/optical-transmittance carbon analyzer. Research Triangle Park, NC: Environmental \& Industrial Sciences Division.

Rojas-Bracho, L.; Suh, H.; Koutrakis, P. (2000) Relationship among personal, indoor, and outdoor fine and coarse particulate concentrations for individuals with COPD. J Exposure Anal. Environ. Epidemiol. 10: 294-306.

Rojas-Bracho, L.; Suh, H.H.; Catalano, P.J.; Koutrakis, P. (2004) Personal exposures to particles and their relationships with personal activities for chronic obstructive pulmonary disease patients living in Boston. J. Air Waste Manage. Assoc. 54: 207-217.

Rosas, I.; McCartney, H.A.; Payne, R.W.; Calderon, C.; Lacey, J.; Chapela, R.; Ruiz-Velazco, S. (1998) Analysis of the relationships between environmental factors (aeroallergens, air pollution, and weather) and asthma emergency admissions to a hospital in Mexico City. Allergy 53: 394-401.

Sarnat, J.A.; Koutrakis, P.; Suh, H.H. (2000) Assessing the relationship between personal particulate and gaseous exposures of senior citizens living in Baltimore, MD. J. Air \& Waste Manage. Assoc. 50: 1184-98.

Sarnat, J.A.; Schwartz, J.; Catalano, P.J.; Suh, H.H. (2001) Gaseous pollutants in particulate matter epidemiology: confounders or surrogates? Environ. Health Perspect. 109: 10531061.

Sarnat, J.A.; Koutrakis, P.; Long, C.M.; Coull, B.; Schwartz, J.; Suh, H.H. (2002) Using sulfur as a tracer for outdoor fine particulate matter. Environ. Sci. Technol. 36: 5305-5314.

Sarnat, J.A.; Brown, K.W.; Schwartz, J.; Coull, B.A.; Koutrakis, P. (2005) Ambient gas 
concentrations and personal particulate matter exposures: implications for studying the health effects of particles. Epidemiology 16: 385-395.

Schlesinger, R.B. (1995) Interaction of gaseous and particulate pollutants in the respiratory tract: mechanisms and modulators. Toxicology 105: 315-325.

Schwartz, J.; Dockery, D. (1992) Particulate air pollution and daily mortality in Steubenville, Ohio. Am. J. Epidemiol. 135: 12-19.

Schwartz, J.; Dockery, D.W.; Neas, L.M. (1996) Is daily mortality associated specifically with fine particles? J. Air \& Waste Manage. Assoc. 46: 927-939.

Sickles, J.E. (1999) A summary of airborne concentrations of sulfur- and nitrogen-containing pollutants in the northeastern United States. J. Air \& Waste Manage. Assoc. 49: 882893.

Stieb, D.M.; Beveridge, R.C.; Brook, J.R.; Smith-Doiron, M.; Burnett, R.T.; Dales, R.E.; Beaulieu, S.; Judek, S.; Mamedov A. (2000) Air pollution, aeroallergens and cardiorespiratory emergency department visits in Saint John, Canada. J. Expo. Anal. Environ. Epidemiol. 10: 461-477.

Stieb, D.M.; Judek, S.; Burnett, R.T. (2002) Meta-analysis of time-series studies of air pollution and mortality: effects of gases and particles and the influence of cause of death, age, and season. J. Air \& Waste Manage. Assoc. 52: 470-484.

Suarez, A.E.; Ondov, J.M. (2002) Ambient aerosol concentrations of elements resolved by size and source: contributions of some cytokine-active metals from coal- and oil-fired power plants. Energy \& Fuels 16: 562-568.

Tanner, S.D.; Baranov, V.I. (1999) Theory, design, and operation of a dynamic reaction cell for ICP-MS. Atomic Spectroscopy 20(2): 45-52.

Task Force of the European Society of Cardiology and the North American Society of Pacing and Electrophysiology. (1996) Heart rate variability: standards of measurement, physiological interpretation, and clinical use. Circulation 93: 1043-1065.

Therneau, T.M.; Atkinson, E.J. (1997) An introduction to recursive partitioning using the RPART routines. Technical Report \#61. Rochester, MN: Mayo Foundation, September.

Thurston, G.D.; Spengler, J.D. (1985) A quantitative assessment of source contributions to inhalable particulate matter pollution in metropolitan Boston. Atmos. Environ. 19: 926.

Tobin, J. (1958) Estimation of relationships for limited dependent variables. Econometrica 26: 24-36.

Tolocka, M.P.; Solomon, P.A.; Mitchell, W.; Norris, G.A.; Gemmill, D.B.; Wiener, R.W.;Vanderpool, R.W.; Homolya, J.B.; Rice, J. (2001) East vs. west in the US: chemical characteristics of $\mathrm{PM}_{2.5}$ during the winter of 1999. J. Aerosol Sci. Technol. 34, 88-96.

Tropp, R.J.; Engelbrecht, J.; Lowenthal, D.H.; Kohl, S.D.; Chow, J.C.; Watson, J.G.; Dubois, D.W.; Countess, R.; Countess, S.J.; Michel, E.L. (2003) Preliminary assessment of PM $_{2.5}$ chemical speciation results for Texas. In Proceedings of the International Conference on Air Quality IV, Arlington, VA, September 22-24.

Turpin, B.J.; Lim, H.-J. (2001) Species contributions to $\mathrm{PM}_{2.5}$ mass concentrations: revisiting common assumptions for estimating organic mass. Aerosol Sci. Technol. 35: 602-610.

Unisys Weather. (2006) Image and Map Archive. http://weather.unisys.com/archive/index.html [24 May 2006].

U.S. Census Bureau. (2000) Census 2000 Gateway. http://www.census.gov/main/www/ cen2000.html [26 February 2004].

U.S. Environmental Protection Agency. (1994) Quality assurance handbook for air pollution measurement systems, volume II: ambient air specific methods. EPA 600/R-94-038b.

U.S. Environmental Protection Agency. (1998) Quality assurance guidance document 
2.12: monitoring $\mathrm{PM}_{2.5}$ in ambient air using designated reference or class I equivalent methods. Research Triangle Park, NC: Human Exposure and Atmospheric Sciences Division.

U.S. Environmental Protection Agency. (2001) AirData: Access to air pollution data. http://www.epa.gov/air/data/index.html [29 December 2005].

U.S. Environmental Protection Agency. (2005a) Technical support document for the final Clean Air Interstate Rule - air quality modeling. Research Triangle Park, NC: Office of Air Quality Planning and Standards. Available: http://www.epa.gov/ interstateairquality/pdfs/finaltech02.pdf [18 November 2005].

U.S. Environmental Protection Agency. (2005b) Technology Transfer Network, Air Toxics Website, Sources of Chronic Dose-Response Information. http://www.epa.gov/ ttn/atw/toxsource/chronicsources.html [1 December 2005].

U.S. Environmental Protection Agency. (2006) National Ambient Air Quality Standards. http://www.epa.gov/air/criteria.html [21 March 2006].

U.S. Geological Survey. (2003) Fossil Groups - Spores and Pollen. http://geology.er.usgs.gov/ paleo/sporepollen.shtml

Villeneuve, P.J.; Burnett, R.T.; Shi, Y.; Krewski, D.; Goldberg, M.S.; Hertzman, C.; Chen, Y.; Brook, J. (2003) A time-series study of air pollution, socioeconomic status, and mortality in Vancouver, Canada. J. Expo. Anal. Environ. Epidemiol. 13: 427-435.

Weber, R., et al. (2003) Short-term temporal variation in $\mathrm{PM}_{2.5}$ mass and chemical composition during the Atlanta supersite experiment, 1999. J. Air \& Waste Manage. Assoc. 53: 84-91.

West Virginia University Bureau of Business and Economic Research. (2001) SteubenvilleWeirton MSA outlook. Morgantown, WV. Available: http://www.bber.wvu.edu/ pdf_files/BBER-2001-11.pdf [3 May 2004].

Winter, S.E.; Conrad, V.B.; Ross, J. (2002) Direct reaction cell ICP-MS vs. XRF: which is the superior technique for the analysis of water soluble and total elements in fine particulate matter? Presented at the NETL PM 2.5 and Electricity Power Generation: Recent Findings and Implications conference, Pittsburgh, PA, April 9-10, 2002.

Winter, S.E.; Bilonick, R.A.; Conrad, V.B; Withum, J.A.; Statnick, R.M; Ebelt, S.T.; Koutrakis, P; Suh, H.H. (2004) A field evaluation to compare the performance of personal exposure multi-pollutant samplers vs. federal method monitors at a central ambient air monitoring station in Steubenville, Ohio. In Proceedings of Air Quality IV, Arlington VA, September 22-24, 2004.

Wongphatarakul, V.; Friedlander, S.K.; Pinto, J.P. (1998) A comparative study of $\mathrm{PM}_{2.5}$ ambient aerosol chemical databases. Environ. Sci. Technol. 32: 3926-3934.

Zeger, S.L.; Thomas, D.; Dominici, F.; Samet, J.M.; Schwartz, J.; Dockery, D.; Cohen, A. (2000) Exposure measurement error in time-series studies of air pollution: concepts and consequences. Environ. Health Perspect. 108: 419-426.

Zelikoff, J.T.; Schermerhorn, K.R.; Fang, K.; Cohen, M.D.; Schlesinger, R.B. (2002) A role for associated transition metals in the immunotoxicity of inhaled ambient particulate matter. Environ. Health Perspect. 110(suppl. 5): 871-875. 


\section{BIBLIOGRAPHY \\ Papers and Presentations Produced as Part of SCAMP}

\section{Peer-Reviewed Journal Articles}

Adamkiewicz, G.; Ebelt, S.; Syring, M.; Slater, J.; Speizer, F.E.; Schwartz, J.; Suh, H.H.; Gold, D.R. Association Between Air pollution Exposure and Exhaled Nitric Oxide in an Elderly Population; Thorax. 2004, 59, 204-209.

Connell, D.P.; Withum, J.A.; Winter, S.E.; Statnick, R.M.; Bilonick, R.A. The Steubenville Comprehensive Air Monitoring Program (SCAMP): Overview and Statistical Considerations; J. Air \& Waste Manage. Assoc. 2005, 55, 467-480.

Connell, D.P.; Withum, J.A.; Winter, S.E.; Statnick, R.M.; Bilonick, R.A. The Steubenville Comprehensive Air Monitoring Program (SCAMP): Associations among Fine Particulate Matter, Co-Pollutants, and Meteorological Conditions; J. Air \& Waste Manage. Assoc. 2005, 55, 481496.

Connell, D.P.; Withum, J.A.; Winter, S.E.; Statnick, R.M.; Bilonick, R.A. The Steubenville Comprehensive Air Monitoring Program (SCAMP): Analysis of Short-Term and Episodic Variations in $\mathrm{PM}_{2.5}$ Concentrations Using Hourly Air Monitoring Data; J. Air \& Waste Manage. Assoc. 2005, 55, 559-573.

Sarnat, S.E.; Coull, B.A.; Schwartz, J.; Gold, D.R.; Suh, H.H. Factors Affecting the Association Between Ambient Concentrations and Personal Exposures to Particles and Gases; Environ Health Perspect. 2006, 114, 649-654.

Luttmann-Gibson, H.; Suh, H.H.; Coull, B.A.; Dockery, D.W.; Sarnat, S.E.; Schwartz, J.; Stone, P.H.; Gold, D.R. Short-term Effects of Air Pollution on Heart Rate Variability in Senior Adults in Steubenville, OH; J. Occup. Environ. Med. 2006, 48, 780-788.

Sarnat, S.E.; Suh, H.H.; Coull, B.A.; Schwartz, J.; Stone, P.H.; Gold, D.R. Ambient Particulate Air Pollution and Cardiac Arrhythmia in a Panel of Older Adults in Steubenville, $\mathrm{OH}$; Occup. Environ. Med. 2006, 63, 700-706.

Connell, D.P.; Winter, S.E.; Conrad, V.B.; Kim, M.; Crist, K.C. The Steubenville Comprehensive Air Monitoring Program (SCAMP): Concentrations and Solubilities of $\mathrm{PM}_{2.5}$ Trace Elements and their Implications for Source Apportionment and Health Research; J. Air \& Waste Manage Assoc. 2006, 56, 1750-1766.

\section{Conference Proceedings}

Conrad, V.B.; Winter, S.E.; Krofcheck, D.S. ICP-MS and X-Ray Fluorescence: A Comparative Study for the Elemental Analysis of Fine Particulate Matter; Presented at the International Symposium on Measurement of Toxic and Related Air Pollutants, Research Triangle Park, NC, September 2000. 
Ebelt, S.; Koutrakis, P.; Winter, S.; Conrad, V.; Statnick, R.; Suh, H. Assessment of Exposures of an Elderly Cohort to Fine PM Concentrations in Steubenville, Ohio; Presented at the Annual Conference of the International Society of Exposure Analysis, Charleston, South Carolina, November 4-8, 2001.

Withum, J.A.; Winter, S.E.; Conrad, V.B.; Statnick, R.M. The Steubenville Comprehensive Air Monitoring Program (SCAMP): Initial Ambient Air Results; Presented at the NETL PM 2.5 and Electricity Power Generation: Recent Findings and Implications, Pittsburgh, PA, April 9-10, 2002.

Winter, S.E.; Conrad, V.B.; Ross, J. Direct Reaction Cell ICP-MS vs. XRF: Which is the Superior Technique for the Analysis of Water Soluble and Total Elements in Fine Particulate Matter?; Presented at the NETL $P M_{2.5}$ and Electricity Power Generation: Recent Findings and Implications, Pittsburgh, PA, April 9-10, 2002.

Ebelt, S.T.; Koutrakis, P.; Winter, S.; Conrad, V.; Statnick, R.; Suh, H.H. Ambient Fine Particulate Matter Exposure Estimation: A Comparison of Approaches; Presented at the Annual Conference of the International Society of Exposure Analysis, Vancouver, Canada, August 1115, 2002.

Ebelt, S.T.; Schwartz, J.; Coull, B.; Koutrakis, P.; Suh, H.H. Examining Factors that Influence the Potential for Confounding in PM Epidemiology; Presented at the Annual Conference of the International Society of Exposure Analysis, Vancouver, Canada, August 11-15, 2002.

Adamkiewicz, G.; Ebelt, S.T.; Syring, M.; Slater, J.; Speizer, F.; Schwartz, J.; Suh, H.H.; Gold, D.R. Association between Air Pollution Exposure and Exhaled Nitric Oxide in an Elderly Panel; Presented at the 14th Annual Conference of the International Society for Environmental Epidemiology, Vancouver, Canada August 11-15, 2002.

Withum, J.A.; Winter, S.E.; Conrad, V.B.; Statnick, R.M. The Steubenville Comprehensive Air Monitoring Program (SCAMP): Initial Ambient Air Results; In Proceedings of Air Quality III, Arlington, VA, September 10-12, 2002.

Ebelt, S.T.; Schwartz, J.; Coull, B.; Koutrakis, P.; Suh, H.H. Examining Factors that Influence the Potential for Confounding in PM Epidemiology; Presented at the American Association for Aerosol Research Conference Particulate Matter: Atmospheric Sciences, Exposure and the Fourth Colloquium on PM and Health, Pittsburgh, PA, March 31-April 4, 2003.

Winter, S.E.; Bilonick, R.A.; Conrad, V.B; Withum, J.A.; Statnick, R.M; Ebelt, S.T.; Koutrakis, P; Suh, H.H. A Field Evaluation to Compare the Performance of Personal Exposure MultiPollutant Samplers vs. Federal Method Monitors at a Central Ambient Air Monitoring Station in Steubenville, Ohio; Presented at the American Association for Aerosol Research Conference Particulate Matter: Atmospheric Sciences, Exposure and the Fourth Colloquium on PM and Health, Pittsburgh, PA, March 31-April 4, 2003.

Bilonick, R.A. Assessing the Precision and Accuracy of the Federal Method $\mathrm{PM}_{2.5}$ and Personal Exposure Multi-Pollutant Samplers Used in the Steubenville Comprehensive Air Monitoring Program; Presented at the Joint Statistical Meetings, San Francisco, California, August 3-7, 2003. 
Connell, D.P.; Withum, J.A.; Winter, S.E.; Bilonick, R.A. The Steubenville Comprehensive Air Monitoring Program (SCAMP): An Overview of Outdoor Ambient Results; In Proceedings of A\&WMA's 97th Annual Conference \& Exhibition, Indianapolis, IN, June 22-25, 2004; A\&WMA: Pittsburgh, PA, 2004; Paper 619.

Winter, S.E.; Bilonick, R.A.; Conrad, V.B; Withum, J.A.; Statnick, R.M; Ebelt, S.T.; Koutrakis, P; Suh, H.H. A Field Evaluation to Compare the Performance of Personal Exposure Multi-Pollutant Samplers vs. Federal Method Monitors at a Central Ambient Air Monitoring Station in Steubenville, Ohio; In Proceedings of Air Quality IV, Arlington VA, September 22-24, 2004.

Connell, D.P.; Winter, S.E.; Withum, J.A. A Current Assessment of the Nature of $\mathrm{PM}_{2.5}$ in Steubenville, Ohio, Using SCAMP Monitoring Data; Presented at the 2004 Ohio Air Quality and Coal Research Symposium; Athens, Ohio, December 2-3, 2004.

Ebelt, S.T.; Suh, H.H.; Coull, B.A.; Schwartz, J.; Stone, P.H.; Gold, D.R. Associations Between Cardiac Arrhythmia And Ambient Air Pollutants In An Elderly Population; Presented at the 16th Annual Conference of the International Society for Environmental Epidemiology, New York, NY, August 1-4, 2004.

Sullivan, J.R.; Ebelt, S.T.; Suh, H.H. Preliminary Findings from the Steubenville Multi-pollutant Exposure Study of Children; Presented at the Annual Conference of the International Society of Exposure Analysis, Philadelphia, Pennsylvania, October 17-21, 2004.

Sullivan J.R.; Slater, J.; Koutrakis, P.; Suh, H.H Multi-Pollutant Exposure Assessment Study of Children, Steubenville, $\mathrm{OH}$; Presented at the Annual Conference of the International Society of Exposure Analysis, Philadelphia, Pennsylvania, October 17-21, 2004.

Ebelt, S.T.; Suh, H.H.; Coull, B.A.; Schwartz, J.; Stone, P.H.; Gold, D.R. Associations between Cardiac Arrhythmia and Ambient Particulate Air Pollution in a Panel of Senior Adults in Steubenville, $\mathrm{OH}$; Presented at the 2005 International Conference of the American Thoracic Society (ATS) Annual Conference, San Diego, CA, May 20-25, 2005.

Connell, D.P.; Winter, S.E.; Conrad, V.B. The Elemental Composition of $\mathrm{PM}_{2.5}$ Collected During the Steubenville Comprehensive Air Monitoring Program (SCAMP); In Proceedings of A\&WMA's 98th Annual Conference \& Exhibition, Minneapolis, MN, June 21-24, 2005; A\&WMA: Pittsburgh, PA, 2005; Paper 582.

Luttmann-Gibson, H.; Suh, H.H.; Dockery, D.W.; Coull, B.A.; Ebelt, S.T.; Stone, P.H.; Gold, D.R. Short-term Effects of Air Pollution on Heart Rate Variability in Senior Adults in Steubenville, $\mathrm{OH}$; Presented at the 18th Annual Conference of the International Society for Environmental Epidemiology, Johannesburg, South Africa, September 13-16, 2005.

Connell, D.P.; Winter, S.E.; Conrad, V.B. Characterization of $\mathrm{PM}_{2.5}$ Trace Elements in Steubenville, Ohio, Using Dynamic Reaction Cell ICP-MS; In Proceedings of Air Quality V, Arlington, VA, September 19-21, 2005.

Connell, D.P.; Winter, S.E.; Sarnat, S.E.; Sullivan, J.; Koutrakis, P.; Suh, H.H. Key Findings from the Steubenville Comprehensive Air Monitoring Program; In Proceedings of A\&WMA's 99th Annual Conference \& Exhibition, New Orleans, LA, June 20-23, 2006. 


\section{FINAL BUDGET}

\section{Steubenville Comprehensive Air Monitoring Program Overall Program Budget \\ (Includes OCDO Grant Agreement CDO/D-98-2 and DOE Cooperative Agreement DE-FC26-00NT40771)}

Contributions (through June 2006)

\begin{tabular}{|l|c|c||}
\hline \multicolumn{1}{|c|}{ Organization } & Amount Obligated, \$ & $\begin{array}{c}\text { Amount Contributed, \$ } \\
\text { (through 6/06) }\end{array}$ \\
\hline OCDO & 600,000 & 594,949 \\
\hline CONSOL & 100,000 & $1,094,252$ \\
\hline $\begin{array}{l}\text { NIEHS, API, EPRI, and EPA - } \\
\text { Direct to HSPH }\end{array}$ & $1,105,818$ & $1,108,794$ \\
\hline NMA & 100,000 & 99,183 \\
\hline AISI & 100,000 & 99,183 \\
\hline EEI & 82,000 & 81,316 \\
\hline DOE & $3,265,500$ & $3,233,825$ \\
\hline Total & $5,353,318$ & $6,311,502$ \\
\hline
\end{tabular}

Expenditures (through June 2006)

\begin{tabular}{|l|c|}
\hline \multicolumn{1}{|c|}{ Item } & $\begin{array}{c}\text { Cost, \$ } \\
\text { (through 6/06) }\end{array}$ \\
\hline Materials & 161,447 \\
\hline Subcontracts & $2,867,408$ \\
\hline Direct Labor & 967,520 \\
\hline Labor Overhead & 517,569 \\
\hline Travel & 21,980 \\
\hline Other Directs (Including Equipment) & 385,383 \\
\hline Other & 34,486 \\
\hline G\&A & $1,355,709$ \\
\hline Total & $6,311,502$ \\
\hline
\end{tabular}




\section{Steubenville Comprehensive Air Monitoring Program Budget for OCDO Grant Agreement CDO/D-98-2}

Contributions (through June 2006)

\begin{tabular}{|l|c|c||}
\hline \multicolumn{1}{|c|}{ Organization } & Amount Contributed, \$ & \% of Total \\
\hline OCDO & 594,949 & 21.9 \\
\hline CONSOL & 732,640 & 27.0 \\
\hline $\begin{array}{l}\text { NIEHS, API, EPRI, and EPA - } \\
\text { Direct to HSPH }\end{array}$ & $1,108,794$ & 40.8 \\
\hline NMA & 99,183 & 3.65 \\
\hline AISI & 99,183 & 3.65 \\
\hline EEI & 81,316 & 3.0 \\
\hline Total & $2,716,065$ & 100.0 \\
\hline
\end{tabular}

Expenditures (through June 2006)

\begin{tabular}{|l|c|c|c||c|c|c||}
\hline OCDO, CDO/D-98-2 & \multicolumn{2}{|c|}{ As per CDO/D-98-2, \$ } & \multicolumn{3}{c||}{ Actual, \$ } \\
\hline \multicolumn{1}{|c|}{ Item } & OCDO & Non-OCDO & Total & OCDO & Non- OCDO & Total \\
\hline Materials & 37,735 & 17,210 & 54,945 & 12,343 & 45,427 & 57,770 \\
\hline Subcontract (Harvard) & 161,483 & $1,488,562$ & $1,650,045$ & 377,570 & $1,428,864$ & $1,806,434$ \\
\hline Labor (includes fringe benefits) & 204,938 & 93,466 & 298,404 & 106,319 & 332,851 & 439,170 \\
\hline Travel & 5,443 & 2,480 & 7,923 & 1,369 & 2,910 & 4,279 \\
\hline Other Directs (includes equip.) & 0 & 0 & 0 & 0 & 0 & 0 \\
\hline Other & 0 & 0 & 0 & 521 & 1,959 & 2,480 \\
\hline G\&A & 190,401 & 86,844 & 277,245 & 96,827 & 309,105 & 405,932 \\
\hline Total & 600,000 & $1,628,562$ & $2,288,562$ & 594,949 & $2,121,116$ & $2,716,065$ \\
\hline
\end{tabular}




\section{ACRONYMS AND ABBREVIATIONS}

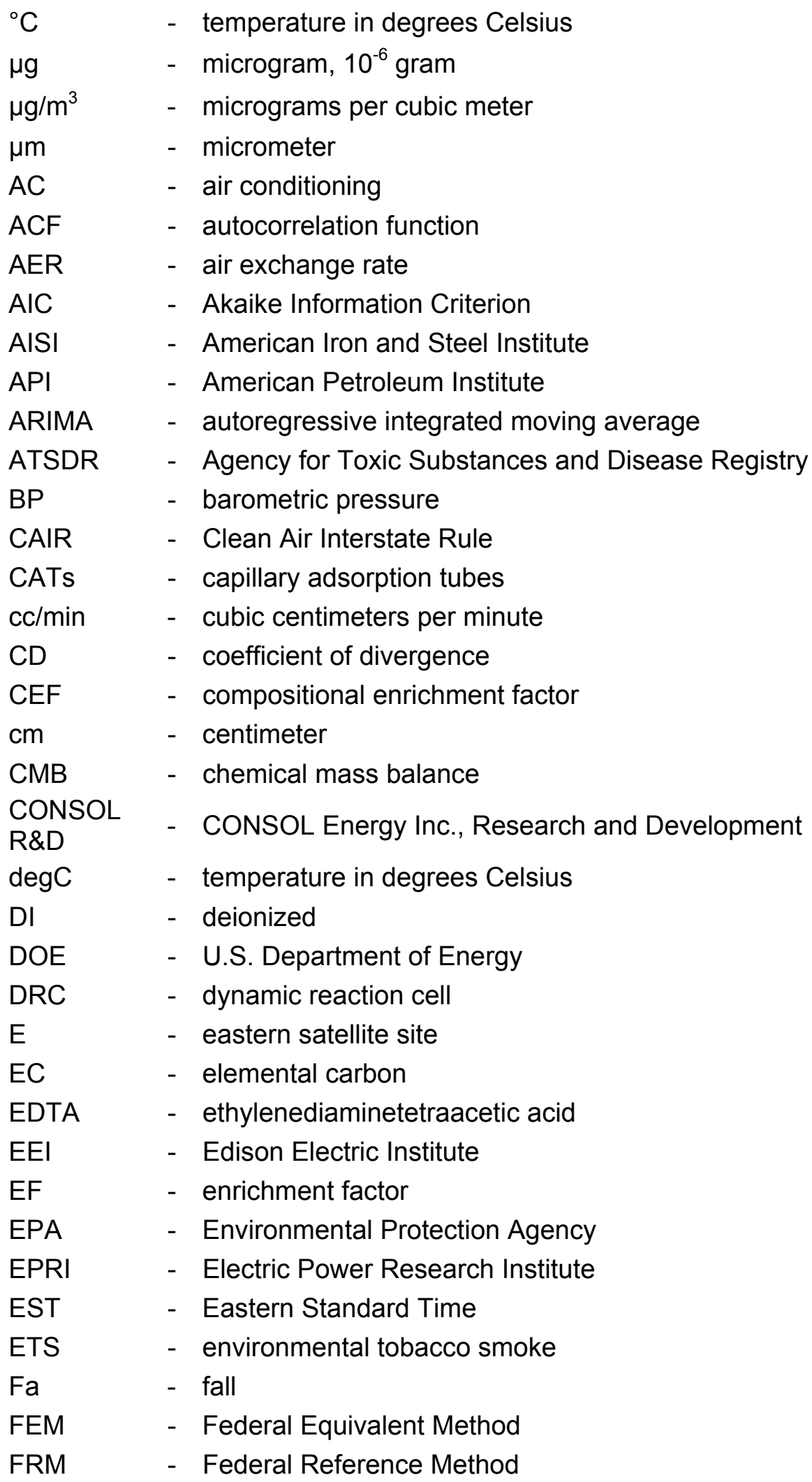




\section{ACRONYMS AND ABBREVIATIONS}

\begin{tabular}{|c|c|}
\hline GC/ECD & - gas chromatograph with electron capture detector \\
\hline HAP & - Hazardous Air Pollutant \\
\hline $\mathrm{hr}$ & - hour \\
\hline HRV & - heart rate variability \\
\hline $\mathrm{HSPH}$ & - Harvard School of Public Health \\
\hline IC & - ion chromatography \\
\hline ICP-MS & - inductively coupled plasma-mass spectrometry \\
\hline $\mathrm{km}$ & - kilometers \\
\hline $\mathrm{kW} / \mathrm{m}^{2}$ & - kilowatts per square meter \\
\hline $\mathrm{L} / \mathrm{min}$ & - liters per minute \\
\hline LOD & - limit of detection \\
\hline $\mathrm{M} \Omega$ & - mega-ohm \\
\hline Max & - Maximum \\
\hline MCAR & - missing completely at random \\
\hline $\mathrm{mg}$ & - milligram \\
\hline Min & - Minimum \\
\hline $\min$ & - minute \\
\hline $\mathrm{mL}$ & - milliliter \\
\hline $\mathrm{mmHg}$ & - millimeters of mercury \\
\hline MRL & - minimal risk level \\
\hline $\mathrm{m} / \mathrm{s}$ & - meters per second \\
\hline MSA & - Metropolitan Statistical Area \\
\hline $\mathrm{m} / \mathrm{z}$ & - mass-to-charge ratio \\
\hline $\mathrm{N}$ & - northern satellite site \\
\hline NA & - not applicable or not available \\
\hline NAAQS & - National Ambient Air Quality Standards \\
\hline ND & - non-detect \\
\hline NETL & - National Energy Technology Laboratory \\
\hline $\mathrm{ng} / \mathrm{m}^{3}$ & - nanograms per cubic meter \\
\hline NIEHS & - National Institute of Environmental Health Sciences \\
\hline NIST & - National Institute of Standards and Technology \\
\hline NMA & - National Mining Association \\
\hline NRC & - National Research Council \\
\hline OAQDA & - Ohio Air Quality Development Authority \\
\hline OAQPS & - Office of Air Quality Planning and Standards \\
\hline $\mathrm{OC}$ & - organic carbon \\
\hline OCDO & - Ohio Coal Development Office \\
\hline OM & - organic material \\
\hline
\end{tabular}




\section{ACRONYMS AND ABBREVIATIONS}

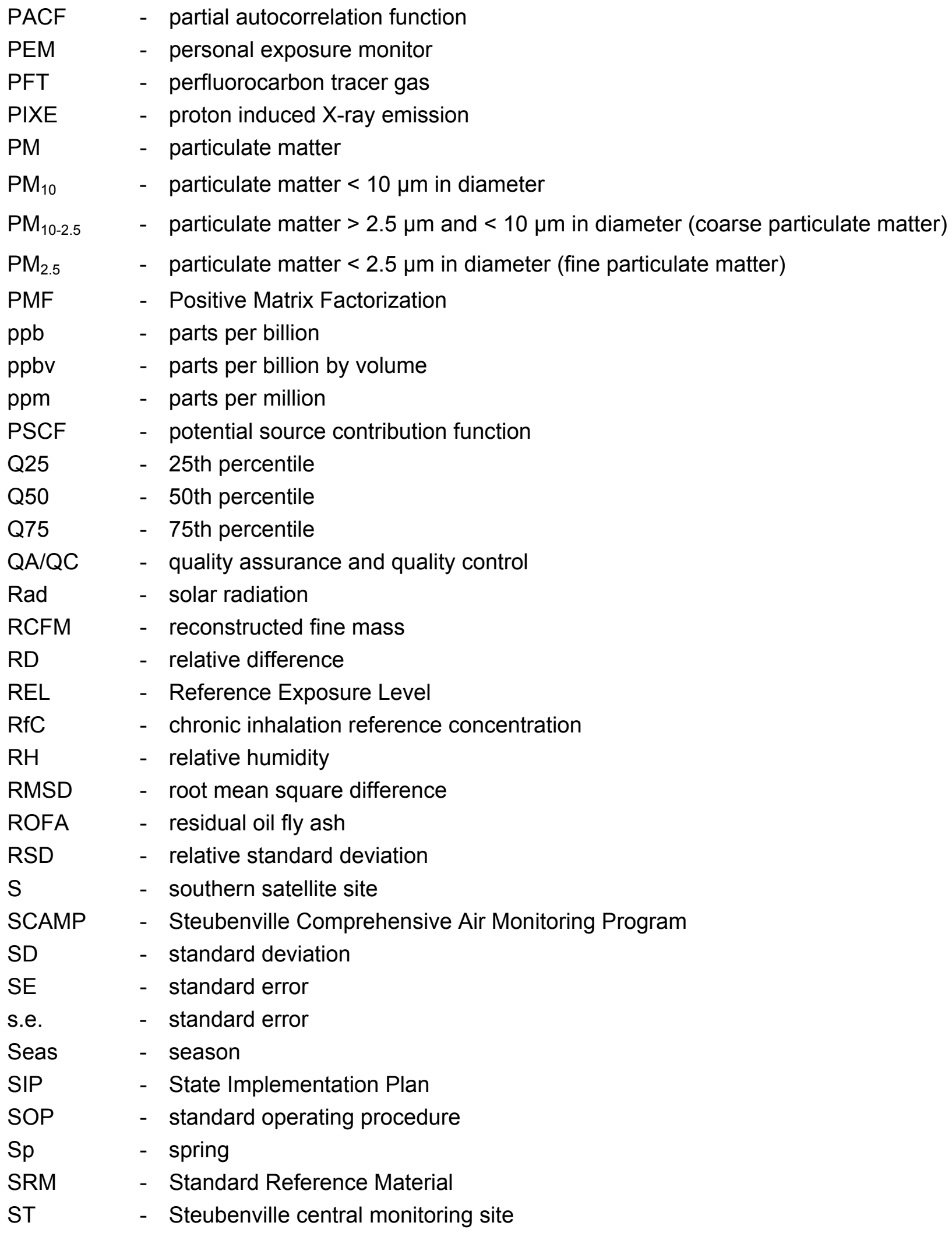




\section{ACRONYMS AND ABBREVIATIONS}

$\begin{array}{ll}\text { StdErr } & - \text { standard error } \\ \text { Su } & - \text { summer } \\ \text { TAD } & \text { - time-activity diary } \\ \text { Temp } & \text { - } \text { temperature } \\ \text { TEOM } & \text { - tapered element oscillating microbalance } \\ \text { TOT } & \text { - thermal optical transmittance } \\ \text { tot } & - \text { acid-digestible fraction } \\ \text { TRI } & - \text { Toxics Release Inventory } \\ \text { TSP } & - \text { total suspended particulate } \\ \text { URE } & - \text { Unit Risk Estimate } \\ \text { UV } & - \text { ultraviolet } \\ \text { VENT } & - \text { home ventilation variables } \\ \text { VS. } & - \text { versus } \\ \text { W } & - \text { western satellite site } \\ \text { Wi } & - \text { winter } \\ \text { W/m }{ }^{2} & - \text { watts per square meter } \\ \text { WS } & - \text { wind speed } \\ \text { WS } & - \text { water-extractable fraction } \\ \text { XRF } & - \text { X-ray fluorescence spectrometry }\end{array}$




\section{APPENDIX A}

\section{AMBIENT AIR MONITORING PROGRAM SUPPLEMENTAL QA/QC INFORMATION}


Table A.1. Schedule of QA/QC and maintenance activities for SCAMP ambient air pollutant samplers.

\begin{tabular}{|c|c|c|c|c|c|c|c|c|}
\hline Unit & Daily & Per Visit & $\begin{array}{l}\text { Weekly / As } \\
\text { Needed }\end{array}$ & Monthly & Bi-monthly & Quarterly & Semi-annually & Annually \\
\hline $\begin{array}{l}\text { RAAS } P_{10} \\
\text { and } \mathrm{PM}_{2.5} \\
\text { FRM } \\
\text { Samplers }\end{array}$ & & $\begin{array}{l}\text { Wipe } \\
\text { carousel, } \\
\text { cover plate } \\
\text { Exchange } \\
\text { impactor } \\
\text { Leak test } \\
\end{array}$ & & $\begin{array}{l}\text { Verify } \\
\text { temperature, } \\
\text { pressure, flow }\end{array}$ & $\begin{array}{l}\text { Change intake } \\
\text { filter }\end{array}$ & $\begin{array}{l}\text { Clean } \mathrm{PM}_{10} \text { inlet, } \\
\text { downtube } \\
\text { Change exhaust filter }\end{array}$ & & Calibrate \\
\hline $\begin{array}{l}\mathrm{PM}_{2.5} \\
\text { Speciation } \\
\text { Sampler }\end{array}$ & & $\begin{array}{l}\text { Wipe interior } \\
\text { of cabinet }\end{array}$ & & & & $\begin{array}{l}\text { Change denuder } \\
\text { Verify temperature, } \\
\text { pressure, flow } \\
\text { Change intake filter }\end{array}$ & & \\
\hline $\begin{array}{l}\text { Burkard } \\
\text { Pollen/Mold } \\
\text { Spore } \\
\text { Sampler }\end{array}$ & & & $\begin{array}{l}\text { Check flows } \\
\text { Check timing }\end{array}$ & & & & & \\
\hline TEOM & & $\begin{array}{l}\text { Check filter } \\
\text { load }\end{array}$ & $\begin{array}{l}\text { Change filter } \\
\text { Clean cyclone, } \\
\text { PM }_{10} \text { head }\end{array}$ & & & & $\begin{array}{l}\text { Change bypass filters } \\
\text { Test batteries, pump } \\
\text { Flow control calibration }\end{array}$ & $\begin{array}{l}\text { Clean MFC, and orifices } \\
\text { Clean air inlet system } \\
\text { Calibrations in Section } 3 \\
\text { Change flow controller filters }\end{array}$ \\
\hline $\mathrm{O}_{3}$ Monitor & $\begin{array}{l}\text { Zero / Span } \\
\text { check }\end{array}$ & & $\begin{array}{l}\text { Change } \\
\text { particulate filter }\end{array}$ & & & Multi-point cal & TEST functions & $\begin{array}{l}\text { Leak check } \\
\text { Zero/Span cal } \\
\text { Clean lines } \\
\text { Sample flow } \\
\text { Rebuild pump } \\
\text { Clean sample cell } \\
\text { Factory calibration }\end{array}$ \\
\hline CO Monitor & $\begin{array}{l}\text { Zero / Span } \\
\text { check }\end{array}$ & & $\begin{array}{l}\text { Change } \\
\text { particulate filter }\end{array}$ & & & Multi-point cal & TEST functions & $\begin{array}{l}\text { Leak check } \\
\text { Zero/Span cal } \\
\text { Clean lines } \\
\text { Sample flow } \\
\text { Rebuild pump } \\
\text { Perma Pure drier } \\
\text { Reaction cell }\end{array}$ \\
\hline
\end{tabular}


Table A.1 (continued)

\begin{tabular}{|c|c|c|c|c|c|c|c|c|}
\hline Unit & Daily & Per Visit & $\begin{array}{l}\text { Weekly / As } \\
\text { Needed }\end{array}$ & Monthly & Bi-monthly & Quarterly & Semi-annually & Annually \\
\hline $\begin{array}{l}\mathrm{NO}_{x}, \mathrm{NO} \\
\text { and } \mathrm{NO}_{2} \\
\text { Monitor }\end{array}$ & $\begin{array}{l}\text { Zero / Span } \\
\text { check }\end{array}$ & & $\begin{array}{l}\text { Change } \\
\text { particulate filter }\end{array}$ & & & $\begin{array}{l}\text { Multi-point cal } \\
\text { Charcoal on pump }\end{array}$ & $\begin{array}{l}\text { TEST functions } \\
\text { Moly converter efficiency }\end{array}$ & $\begin{array}{l}\text { Leak check } \\
\text { Zero/Span cal } \\
\text { Clean lines } \\
\text { Sample flow } \\
\text { Rebuild pump }\end{array}$ \\
\hline $\mathrm{SO}_{2}$ Monitor & $\begin{array}{l}\text { Zero / Span } \\
\text { check }\end{array}$ & & $\begin{array}{l}\text { Change } \\
\text { particulate filter }\end{array}$ & & & Multi-point cal & $\begin{array}{l}\text { TEST functions } \\
\text { Sample flow }\end{array}$ & $\begin{array}{l}\text { Leak check } \\
\text { Zero/Span cal } \\
\text { Clean lines } \\
\text { Sample flow } \\
\text { Rebuild pump } \\
\text { Clean reaction cell }\end{array}$ \\
\hline $\begin{array}{l}\text { Zero Air } \\
\text { System }\end{array}$ & & & & & & & $\begin{array}{l}\text { NO scrubber } \\
\text { Charcoal scrubber }\end{array}$ & CO Scrubber \\
\hline $\begin{array}{l}\text { Mass Flow } \\
\text { Calibrator }\end{array}$ & & & & & & $\begin{array}{l}\text { Leak Check } \\
\text { Calibrate } \mathrm{O}_{3}\end{array}$ & $\begin{array}{l}\text { Inspect Lines } \\
\text { Check MFC flows }\end{array}$ & $\begin{array}{l}\text { Check } \mathrm{O}_{3} \text { perm and bench } \\
\text { flows. Clean orifices, replace } \\
\text { filters and o-rings }\end{array}$ \\
\hline
\end{tabular}


Table A.2. QA/QC for gravimetric analysis of filter-based $\mathrm{PM}_{2.5}$ and $\mathrm{PM}_{10}$ samples

\begin{tabular}{|c|c|c|c|}
\hline Activity & $\begin{array}{l}\text { Method and } \\
\text { Frequency }\end{array}$ & Requirements & $\begin{array}{l}\text { Out of Specification } \\
\text { Action }\end{array}$ \\
\hline $\begin{array}{l}\text { Microbalance } \\
\text { Calibration }\end{array}$ & $\begin{array}{l}1 \text { per year by } \\
\text { microbalance } \\
\text { maintenance } \\
\text { company }\end{array}$ & $\begin{array}{l}\text { Manufacturer's } \\
\text { specification. }\end{array}$ & Repair. \\
\hline $\begin{array}{l}\text { Calibration Mass } \\
\text { Standards }\end{array}$ & $\begin{array}{l}1 \text { per year by } \\
\text { microbalance } \\
\text { maintenance } \\
\text { company }\end{array}$ & $\begin{array}{l}\text { NIST traceability and } \\
\text { within } 0.025 \mathrm{mg} \text {. }\end{array}$ & $\begin{array}{l}\text { Replace standard } \\
\text { weights. }\end{array}$ \\
\hline $\begin{array}{l}\text { Temperature and } \\
\text { Humidity } \\
\text { Instruments }\end{array}$ & Every 6 months. & $\begin{array}{l}\text { Within } 2^{\circ} \mathrm{C} \text {, Within } 2 \% \\
\mathrm{RH} \text {. }\end{array}$ & $\begin{array}{l}\text { Re-calibrate } \\
\text { temp/humidity logger. }\end{array}$ \\
\hline $\begin{array}{l}\text { Filter Conditioning } \\
\text { for Pre-Weighing }\end{array}$ & $\begin{array}{l}\text { Minimum } 24 \text { hours } \\
\text { (In addition, filters are } \\
\text { to be exposed } \\
\text { partially open for } 1-2 \\
\text { months.) }\end{array}$ & $\begin{array}{l}\text { Conditioning to the } \\
\text { weighing room } \\
\text { environment }\end{array}$ & Repeat conditioning. \\
\hline $\begin{array}{l}\text { Filter Conditioning } \\
\text { for Post -Weighing }\end{array}$ & Minimum 24 hours. & $\begin{array}{l}\text { Conditioning to the } \\
\text { weighing room } \\
\text { environment }\end{array}$ & Repeat conditioning. \\
\hline $\begin{array}{l}\text { Filter Integrity } \\
\text { (Pre-Weighing) }\end{array}$ & Every filter. & $\begin{array}{l}\text { Check for visual } \\
\text { defects. }\end{array}$ & Discard filter. \\
\hline $\begin{array}{l}\text { Filter Integrity } \\
\text { (Post-Weighing) }\end{array}$ & Every filter. & $\begin{array}{l}\text { Check for visual } \\
\text { defects. }\end{array}$ & Flag data point. \\
\hline $\begin{array}{l}\text { Balance Calibration } \\
\text { Verification }\end{array}$ & $\begin{array}{l}200 \text { mg calibration } \\
\text { mass standard } \\
\text { weighed every } 10 \\
\text { filters. }\end{array}$ & $\begin{array}{l}\text { Within +- } 3 \text { ug } \\
\text { accepted weight. }\end{array}$ & $\begin{array}{l}\text { Re-zero, re-calibrate } \\
\text { with mass standards } \\
\text { and re-weigh filters up } \\
\text { to the last acceptable } \\
\text { balance calibration } \\
\text { verification. }\end{array}$ \\
\hline Field Blank & $\begin{array}{l}\text { Weigh one with every } \\
\text { batch of four filters. }\end{array}$ & $\begin{array}{l}\text { Pre and Post weights } \\
\text { agree within +-30 ug. }\end{array}$ & $\begin{array}{l}\text { Flag all four filters } \\
\text { associated with this } \\
\text { blank. }\end{array}$ \\
\hline Dedicated Lab Blank & $\begin{array}{l}\text { Weigh at the } \\
\text { beginning and end of } \\
\text { each weighing } \\
\text { session. }\end{array}$ & $\begin{array}{l}\text { Within }+-15 \text { ug of } \\
\text { accepted weight. }\end{array}$ & $\begin{array}{l}\text { Check for } \\
\text { contamination source } \\
\text { and re-weigh filters if } \\
\text { warranted. }\end{array}$ \\
\hline Lot Blank & $\begin{array}{l}\text { Choose } 1 \text { filter from } \\
\text { each lot of filters. } \\
\text { Weigh once each } \\
\text { session until criteria is } \\
\text { met. }\end{array}$ & $\begin{array}{l}\text { Less than } 15 \text { ug } \\
\text { difference for } 3 \\
\text { consecutive } 24 \text { hour } \\
\text { weighing sessions. }\end{array}$ & $\begin{array}{l}\text { Revise conditioning of } \\
\text { lot of filters until } \\
\text { difference is less than } \\
15 \text { ug for } 3 \\
\text { consecutive ( } 24 \text { hour } \\
\text { conditioning) weighing } \\
\text { sessions. }\end{array}$ \\
\hline $\begin{array}{l}\text { Duplicate Filter } \\
\text { Weighing }\end{array}$ & $\begin{array}{l}\text { Re-weigh } 1 \text { filter in } \\
\text { duplicate every } 10 \\
\text { filters. }\end{array}$ & $\begin{array}{l}\text { Duplicate weighings } \\
\text { agree within }+-15 \mathrm{ug} \text {. }\end{array}$ & $\begin{array}{l}\text { Re-weigh. } \\
\text { Troubleshoot and re- } \\
\text { calibrate if necessary. }\end{array}$ \\
\hline
\end{tabular}


Table A.3. SCAMP ambient air monitoring program data validation schedule

\begin{tabular}{|c|c|c|}
\hline Parameter & Rule & Action \\
\hline \multirow{9}{*}{$\mathrm{PM}_{2.5}$ and $\mathrm{PM}_{10}$ FRM Samples } & 1. Flow rate coefficient of variation $\geq 2 \%$ & Invalid \\
\hline & 2. Elapsed sampling time $<23$ or $>25$ hours & Invalid \\
\hline & 3. Filter temperature errors & Invalid \\
\hline & 4. Average flow not within $5 \%$ of 16.67 & Invalid \\
\hline & 5. Filters removed $>96$ hours from end of run & Invalid \\
\hline & $\begin{array}{l}\text { 6. Power failures, pressure anomalies, visible } \\
\text { filter/sample defects (e.g., rips, drops, particle } \\
\text { anomalies, bugs, water droplets) }\end{array}$ & $\begin{array}{l}\text { Flagged and } \\
\text { Noted. }\end{array}$ \\
\hline & 7. Filter shipping temperature $>4^{\circ} \mathrm{C}$ & $\begin{array}{l}\text { Flagged and } \\
\text { Noted. }\end{array}$ \\
\hline & $\begin{array}{l}\text { 8. Weighing room: Temperature } \neq 68-74^{\circ} \mathrm{F} \text { or } \mathrm{RH} \\
\neq 20-50 \%(30-40 \% \text { target })\end{array}$ & $\begin{array}{l}\text { Flagged and } \\
\text { Noted. }\end{array}$ \\
\hline & $\begin{array}{l}\text { 9. Field blank pre- and post-weights differ by }>30 \\
\mu \mathrm{g} \text {. }\end{array}$ & $\begin{array}{l}\text { Flagged and } \\
\text { Noted. }\end{array}$ \\
\hline \multirow{6}{*}{$\mathrm{PM}_{2.5}$ Speciation Sampler Samples } & 1. Elapsed sampling time $<23$ or $>25$ hours & Invalid \\
\hline & 2. Filter temperature errors & Invalid \\
\hline & $\begin{array}{l}\text { 3. Power failures, pressure anomalies, visible } \\
\text { filter/sample defects (e.g., rips, drops, particle } \\
\text { anomalies, bugs, water droplets) }\end{array}$ & $\begin{array}{l}\text { Flagged and } \\
\text { Noted. }\end{array}$ \\
\hline & 4. Filter shipping temperature $>4{ }^{\circ} \mathrm{C}$ & $\begin{array}{l}\text { Flagged and } \\
\text { Noted. }\end{array}$ \\
\hline & $\begin{array}{l}\text { 5. Weighing room: Temperature } \neq 68-74^{\circ} \mathrm{F} \text { or } \mathrm{RH} \\
\neq 20-50 \%(30-40 \% \text { target })\end{array}$ & $\begin{array}{l}\text { Flagged and } \\
\text { Noted. }\end{array}$ \\
\hline & $\begin{array}{l}\text { 6. Field blank pre- and post-weights differ by }>30 \\
\mu \mathrm{g} \text {. }\end{array}$ & $\begin{array}{l}\text { Flagged and } \\
\text { Noted. }\end{array}$ \\
\hline \multirow[t]{2}{*}{$\mathrm{SO}_{2}$} & 1. $\left\{2 \mathrm{ppb}<\left|\mathrm{D}_{\mathrm{z}}\right| \leq 3 \mathrm{ppb}\right\}$ OR $\left\{5 \%<\left|\mathrm{D}_{\mathrm{s}}\right| \leq 7.5 \%\right\}$ & Flagged \\
\hline & 2. $\left\{\left|D_{Z}\right|>3 p p b\right\}$ OR $\left\{\left|D_{S}\right|>7.5 \%\right\}$ & Invalid \\
\hline \multirow[t]{2}{*}{ NO } & $\begin{array}{l}\text { 1. }\left\{0.5 \mathrm{ppb}<\left|\mathrm{D}_{z}\right| \leq 0.75 \mathrm{ppb}\right\} \text { OR }\left\{2.5 \%<\left|\mathrm{D}_{\mathrm{s}}\right| \leq\right. \\
3.75 \%\}\end{array}$ & Flagged \\
\hline & 2. $\{|\mathrm{Dz}|>0.75 \mathrm{ppb}\}$ OR $\{|\mathrm{Ds}|>3.75 \%\}$ & Invalid \\
\hline \multirow[t]{2}{*}{$\mathrm{NO}_{\mathrm{x}}$} & $\begin{array}{l}\text { 1. }\left\{1.5 \mathrm{ppb}<\left|\mathrm{D}_{z}\right| \leq 2.25 \mathrm{ppb}\right\} \text { OR }\left\{2.5 \%<\left|\mathrm{D}_{\mathrm{s}}\right| \leq\right. \\
3.75 \%\}\end{array}$ & Flagged \\
\hline & 2. $\left\{\left|D_{z}\right|>2.25 \mathrm{ppb}\right\}$ OR $\left\{\left|D_{S}\right|>3.75 \%\right\}$ & Invalid \\
\hline \multirow{2}{*}{$\mathrm{NO}_{2}$} & 1. Corresponding $\mathrm{NO}$ or $\mathrm{NO}_{x}$ data are flagged & Flagged \\
\hline & 2. Corresponding $\mathrm{NO}$ or $\mathrm{NO}_{x}$ data are invalid & Invalid \\
\hline \multirow[t]{2}{*}{$\mathrm{CO}$} & $\begin{array}{l}\text { 1. }\left\{1 \mathrm{ppm}<\left|\mathrm{D}_{\mathrm{Z}}\right| \leq 1.5 \mathrm{ppm}\right\} \text { OR }\left\{2.5 \%<\left|\mathrm{D}_{\mathrm{S}}\right| \leq\right. \\
3.75 \%\}\end{array}$ & Flagged \\
\hline & 2. $\left\{\left|D_{z}\right|>1.5 p p m\right\}$ OR $\left\{\left|D_{s}\right|>3.75 \%\right\}$ & Invalid \\
\hline \multirow{2}{*}{$\mathrm{O}_{3}$} & 1. $\left\{2.5 \mathrm{ppb}<\left|\mathrm{D}_{\mathrm{z}}\right| \leq 3.75 \mathrm{ppb}\right\}$ OR $\left\{2 \%<\left|\mathrm{D}_{\mathrm{S}}\right| \leq 3 \%\right\}$ & Flagged \\
\hline & 2. $\left\{\left|D_{z}\right|>3.75 \mathrm{ppb}\right\}$ OR $\left\{\left|D_{S}\right|>3 \%\right\}$ & Invalid \\
\hline TEOM & TEOMSTAT $\neq 4.0$ ("normal") OR TEOMFILT > 95 & Invalid \\
\hline Meteorological Data & $\begin{array}{l}\text { Examined and validated by staff meteorologist at } \\
\text { Optimal Technologies }\end{array}$ & \\
\hline Pollen and Mold Spore Samples & $\begin{array}{l}\text { Examined and validated by Air Quality Sciences } \\
\text { Laboratory }\end{array}$ & \\
\hline
\end{tabular}

NOTE: $D_{z}=$ zero drift of analyzer (checked daily) $=Z^{\prime} ; D_{s}=$ span drift of analyzer (checked daily) $=\left(m_{c}-\right.$ $1)^{\star} 100$, where $Z^{\prime}=$ unadjusted zero reading $(\mathrm{ppm}$ or $\mathrm{ppb}), \mathrm{S}^{\prime}=$ unadjusted span reading (ppm or $\left.\mathrm{ppb}\right), \mathrm{C}$ $=$ span gas concentration (ppm or ppb), and $m_{c}=$ current analyzer calibration slope $=\left(S^{\prime}-Z^{\prime}\right) / C$. 


\section{APPENDIX B}

\section{INDOOR AND PERSONAL EXPOSURE PROGRAM}

\section{QUESTIONNAIRE AND TIME-ACTIVITY DIARY FORMS}




\section{One-time Dwelling Questionnaire}

Harvard School of Public Health, Steubenville, OH - Fall 2000

Date:

Participant ID:

Operator Initials:

\section{Location of apartment}

a) Where is your home located? (circle one)
Kennedy
Gaylord
Other:
(address)

If living in Kennedy or Gaylord:

b) On which floor is the apartment located?

c) On which side of the building? (circle one)

North South East West

d) Is this a corner unit? $\quad$ Yes No

\section{General apartment characteristics}

a) How many rooms does your home have?

b) Percent of carpeting and/or floor rugs in each room: (check the applicable box for each)

\begin{tabular}{|l|l|l|l|}
\hline \multicolumn{1}{|c|}{ Room } & Carpeting? & Rugs? & None? \\
\hline Kitchen & & & \\
\hline Living room & & & \\
\hline Dining room & & & \\
\hline Bedroom & & & \\
\hline Bathroom & & & \\
\hline Hallways & & & \\
\hline Other: & & & \\
\hline Other: & & & \\
\hline Other: & & \\
\hline
\end{tabular}




\section{Ventilation Characteristics}

a) How many window/wall AC units are in the home?

\# of window/wall units:

b) What are the heating sources in the home? (circle or specify)

radiators (steam or hot water)
forced air (vents)
open stove
electric space heater
gas space heater
kerosene space heater
wood burning stove
fireplace
other:

c) Do you tend to use any heating sources during the fall? Yes No

d) What is the thermostat setting(s)?

e) Is there a whole-house fan? $\quad$ Yes $\quad$ No

f) Do you use any individual fans? $\quad$ Yes $\quad$ No

g) Are there storm windows? $\quad$ Yes $\quad$ No

h) Does the apartment have a balcony? $\quad$ Yes No

i) How would you best describe the VENTILATION FACTOR in this unit? (Specify a number between 0 and 3 (0.5 is fresh, 2.5 is very stuffy)) 


\section{Cooking/Fuel Characteristics}

a) What type of cooking fuel is used? (circle or specify)
Gas
Electric
Other:

b) Is there a fan over the cooking stove or elsewhere in the kitchen area? Yes

No

c) If so, how does this fan work? (circle or specify)

Kitchen exhaust vented outside

Recirculation of indoor air

Charcoal filter

Other:

Do not know

d) Is there a clothes dryer?

Yes No

e) If yes, is the clothes dryer unvented?

Yes No

f) Are there any pilot lights on the: (circle all applicable)
Gas range
Oven
Clothes dryer

g) What type of filter bag is used in the vacuum cleaner? (cirlce or specify)

Standard filter

High efficiency filter (HEPA)

Other:

\section{Placement of indoor sampling set up in apartment}

(specify room, location within room, approximate height, proximity to potential sources ie TV, kitchen, windows and doors, candles etc...) 


\section{DAYTIME}

Date:

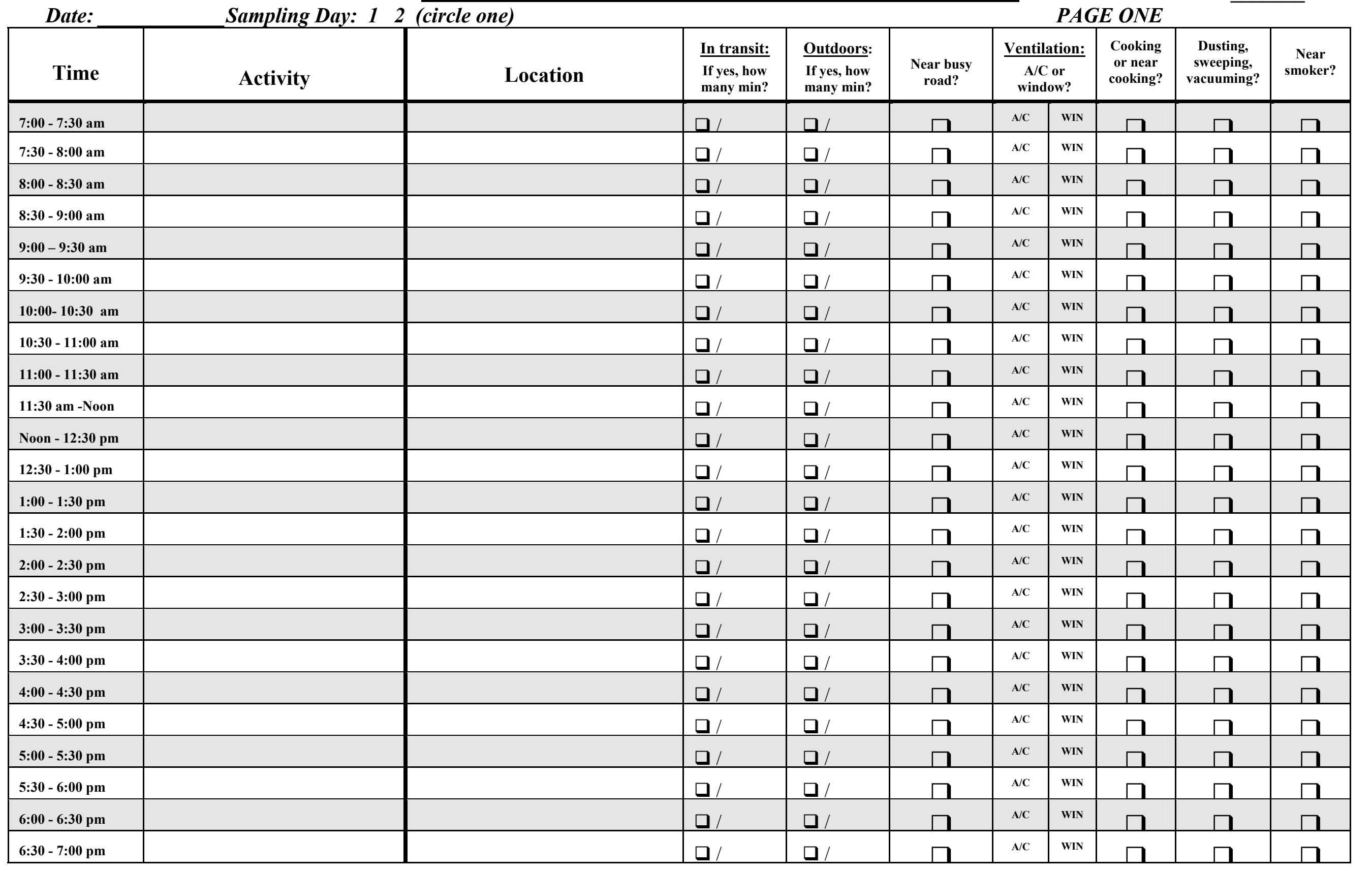

\section{SUMMER 2000 TIME-ACTIVITY DIARY-STEUBENVILLE, OH PARTICIPANT ID:}


NIGHTIME

Date:
SUMMER 2000 TIME-ACTIVITY DIARY-STEUBENVILLE, OH

Activity

\section{Location}

Please specify where you are during this activity

\begin{tabular}{|l|l|l|}
\hline $7: 00-7: 30 \mathrm{pm}$ & & \\
\hline $7: 30-8: 00 \mathrm{pm}$ & & \\
\hline $8: 00-8: 30 \mathrm{pm}$ & & \\
\hline $8: 30-9: 00 \mathrm{pm}$ & & \\
\hline
\end{tabular}

8:30 - 9:00 pm

9:00 - 9:30 pm

9:30 - 10:00 pm

10:00- 10:30 pm

10:30 - 11:00 pm

11:00 - 11:30 pm

11:30 - Midnight

Midnight - 12:30

12:30 - 1:00 am

1:00 - 1:30 am

1:30 - 2:00 am

2:00 - 2:30 am

2:30 - 3:00 am

3:00 - 3:30 am

3:30 - 4:00 am

4:00 - 4:30 am

4:30 - 5:00 am

5:00 - 5:30 am

5:30 - 6:00 am

6:00 - 6:30 am

6:30 - 7:00 am

\begin{tabular}{|c|c|c|c|c|c|c|c|}
\hline \multirow{2}{*}{$\begin{array}{l}\frac{\text { In transit: }}{\text { If yes, how }} \\
\text { many min? } \\
\square /\end{array}$} & \multirow{2}{*}{$\begin{array}{l}\frac{\text { Outdoors: }}{\text { If yes, how }} \\
\text { many min? }\end{array}$} & \multirow{2}{*}{$\begin{array}{c}\text { Near busy } \\
\text { road? }\end{array}$} & \multicolumn{2}{|c|}{$\begin{array}{c}\text { Ventilation: } \\
\begin{array}{c}\text { A/C or } \\
\text { window? }\end{array}\end{array}$} & \multirow{2}{*}{$\begin{array}{c}\begin{array}{c}\text { Cooking } \\
\text { or near } \\
\text { cooking? }\end{array} \\
\square \\
\square\end{array}$} & \multirow{2}{*}{$\begin{array}{c}\text { Dusting, } \\
\text { sweeping, } \\
\text { vacuuming? }\end{array}$} & \multirow{2}{*}{$\begin{array}{c}\begin{array}{c}\text { Near } \\
\text { smoker? }\end{array} \\
\square \\
\end{array}$} \\
\hline & & & $\mathbf{A} / \mathbf{C}$ & WIN & & & \\
\hline$\square /$ & $\square /$ & & $\mathbf{A} / \mathbf{C}$ & WIN & & & \\
\hline$\square /$ & $\square /$ & & $\mathbf{A} / \mathbf{C}$ & WIN & & & \\
\hline$\square /$ & $\square /$ & & $\mathbf{A} / \mathbf{C}$ & WIN & & & \\
\hline$\square /$ & $\square /$ & & $\mathbf{A} / \mathbf{C}$ & WIN & & & \\
\hline$\square /$ & $\square /$ & & $\mathbf{A} / \mathbf{C}$ & WIN & & & \\
\hline$\square /$ & $\square /$ & & $\mathbf{A} / \mathbf{C}$ & WIN & & & \\
\hline$\square /$ & $\square /$ & & $\mathbf{A} / \mathbf{C}$ & WIN & & & \\
\hline$\square /$ & $\square /$ & & $\mathbf{A} / \mathbf{C}$ & WIN & & & \\
\hline 口/ & $\square /$ & & $\mathbf{A} / \mathbf{C}$ & WIN & & & \\
\hline$\square /$ & $\square /$ & & $\mathbf{A} / \mathbf{C}$ & WIN & & & \\
\hline$\square /$ & $\square /$ & & $\mathbf{A} / \mathbf{C}$ & WIN & & & \\
\hline$\square /$ & $\square /$ & & $\mathbf{A} / \mathbf{C}$ & WIN & & & \\
\hline$\square /$ & $\square /$ & & $\mathbf{A} / \mathbf{C}$ & WIN & & & \\
\hline$\square /$ & $\square /$ & & $\mathbf{A} / \mathbf{C}$ & WIN & & & \\
\hline$\square /$ & $\square /$ & & $\mathbf{A} / \mathbf{C}$ & WIN & & & \\
\hline$\square /$ & $\square /$ & & $\mathbf{A} / \mathbf{C}$ & WIN & & & \\
\hline$\square /$ & $\square /$ & & $\mathbf{A} / \mathbf{C}$ & WIN & & & \\
\hline$\square /$ & $\square /$ & & $\mathbf{A} / \mathbf{C}$ & WIN & & & \\
\hline$\square /$ & $\square /$ & & $\mathbf{A} / \mathbf{C}$ & WIN & & & \\
\hline$\square /$ & $\square /$ & $\square$ & $\mathbf{A} / \mathbf{C}$ & WIN & & & \\
\hline$\square /$ & $\square /$ & 7 & $\mathbf{A} / \mathbf{C}$ & WIN & & & \\
\hline$\square /$ & $\square /$ & $\square$ & $\mathbf{A} / \mathbf{C}$ & WIN & & & \\
\hline$\square /$ & $\square /$ & $\square$ & $\mathbf{A} / \mathbf{C}$ & WIN & & & \\
\hline
\end{tabular}




\begin{tabular}{|c|c|c|c|c|c|c|c|c|c|c|}
\hline Time & Activity & $\begin{array}{l}\text { Location } \\
\text { Please specify where you are during this } \\
\text { activity }\end{array}$ & $\begin{array}{l}\text { In transit: } \\
\text { If yes, how } \\
\text { many min? }\end{array}$ & $\begin{array}{l}\text { Outdoors: } \\
\text { If yes, how } \\
\text { many min? }\end{array}$ & $\begin{array}{l}\text { Near busy } \\
\text { road? }\end{array}$ & \multicolumn{2}{|c|}{$\begin{array}{c}\text { Ventilation: } \\
\begin{array}{c}\text { A/C or } \\
\text { window? }\end{array}\end{array}$} & $\begin{array}{l}\text { Cooking } \\
\text { or near } \\
\text { cooking? }\end{array}$ & $\begin{array}{l}\text { Dusting, } \\
\text { sweeping, } \\
\text { vacuuming? }\end{array}$ & $\begin{array}{c}\text { Near } \\
\text { smoker? }\end{array}$ \\
\hline 7:00 - 7:30 am & & & $\square /$ & 口/ & $\square$ & $\mathbf{A} / \mathbf{C}$ & WIN & $\square$ & $\square$ & $\square$ \\
\hline 7:30 - 8:00 am & & & 口/ & 口/ & $\square$ & $\mathrm{A} / \mathrm{C}$ & WIN & $\square$ & $\square$ & $\square$ \\
\hline 8:00 - 8:30 am & & & $\square /$ & 口/ & $\square$ & $\mathrm{A} / \mathrm{C}$ & WIN & $\square$ & $\square$ & $\square$ \\
\hline $8: 30$ - 9:00 am & & & 口/ & 口/ & $\square$ & $\mathrm{A} / \mathrm{C}$ & WIN & $\square$ & $\square$ & $\square$ \\
\hline $9: 30$ - 10:00 am & & & 口/ & 口/ & $\square$ & $\mathrm{A} / \mathrm{C}$ & WIN & $\square$ & $\square$ & $\square$ \\
\hline 10:00- 10:30 am & & & 口/ & 口/ & $\square$ & $\mathrm{A} / \mathrm{C}$ & WIN & $\square$ & $\square$ & $\square$ \\
\hline 10:30 - 11:00 am & & & 口/ & 口/ & $\square$ & $\mathrm{A} / \mathrm{C}$ & WIN & $\square$ & $\square$ & $\square$ \\
\hline 11:00 - 11:30 am & & & 口/ & 口/ & $\square$ & $\mathrm{A} / \mathrm{C}$ & WIN & $\square$ & $\square$ & $\square$ \\
\hline 11:30 am -Noon & & & 口/ & 口/ & $\square$ & $\mathrm{A} / \mathrm{C}$ & WIN & $\square$ & $\square$ & 7 \\
\hline
\end{tabular}

\begin{tabular}{|llll|}
\hline Indoors at Home & Indoors Away from Home & In Transit & Outdoors \\
\hline Kitchen & Grocery store/Pharmacy & Car & Gas station \\
Bedroom & Hospital/Doctor's office & Bus & Park \\
Bathroom & Senior Center & Train & Bus stop \\
Dining room & Hair dresser & & Beach \\
Living room & Shopping mall/Bank & Someone else's yard \\
\hline
\end{tabular}

For use by study team only:
Initials of collector:
Start time:
End time:
Comments:




\section{HARVARD SCHOOL OF PUBLIC HEALTH}

Steubenville, $\mathrm{OH}$ - Winter, 2001

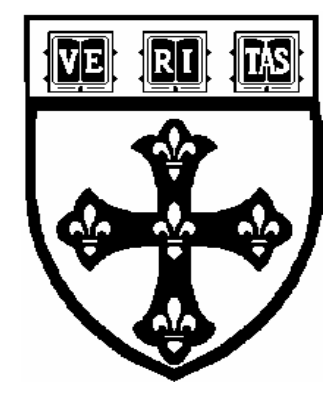

QUESTIONNAIRE ON HOUSEHOLD AND PARTICIPANT'S CHARACTERISTICS

\section{HOUSEHOLD IDENTIFICATION:}

1. Address

\begin{tabular}{ll}
\hline Number & Street \\
& \\
\hline
\end{tabular}

City

Apartment

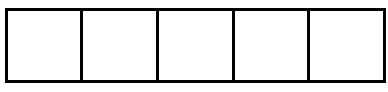

Zip Code

2. Telephone:

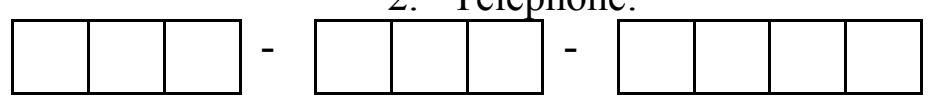

3. Social Security Number:
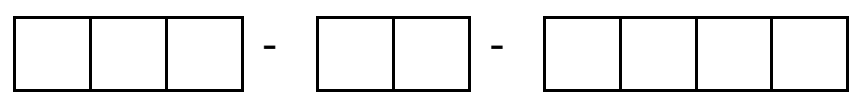
The purpose of this questionnaire is to obtain information about you and your residence. All the information will be kept confidential.

\section{HOUSEHOLD CHARACTERISTICS:}

TYPE OF RESIDENCE:

\begin{tabular}{|c|c|}
\hline 1. What type of cooking fuel do you use? & 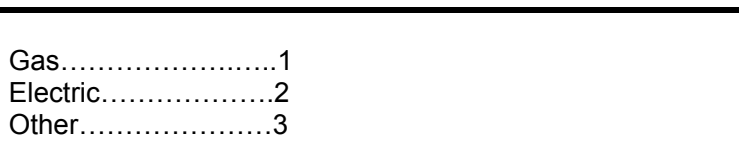 \\
\hline $\begin{array}{l}\text { 2. Does your house have storm } \\
\text { windows? }\end{array}$ & 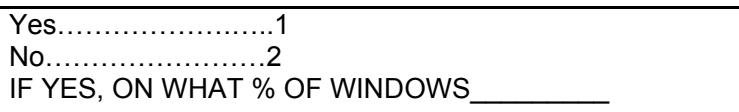 \\
\hline $\begin{array}{l}2.1 \text { What type of heating do you use during the } \\
\text { winter? }\end{array}$ & 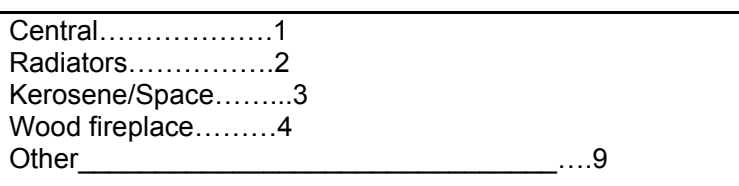 \\
\hline 2.2 Do you use a wood-burning fireplace? & $\begin{array}{l}\text { Yes..................... } \\
\text { No........................ } \\
\text { IF YES, HOW FREQUEMTLY_ }\end{array}$ \\
\hline $\begin{array}{l}\text { 3. Is there a fan over the cooking } \\
\text { stove, range, oven, or elsewhere } \\
\text { in the kitchen area? }\end{array}$ & 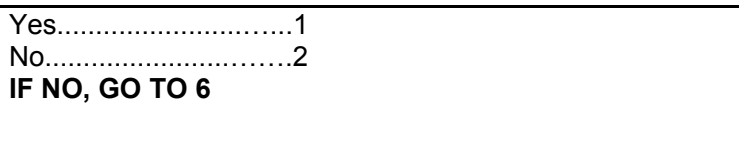 \\
\hline 4.How does this fan work? & 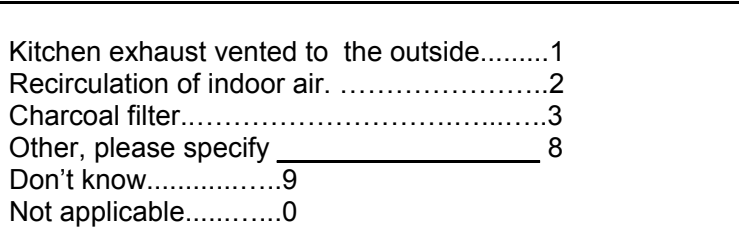 \\
\hline 5.How often is this fan used? & 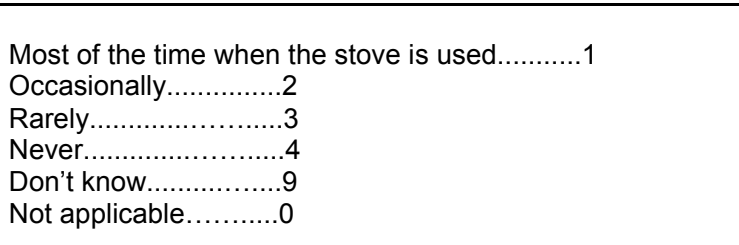 \\
\hline $\begin{array}{l}\text { 6. Do you have: } \\
\qquad \text { Circle all that apply }\end{array}$ & $\begin{array}{l}\text { An unvented clothes dryer located in the house or an } \\
\text { attached structure, such as a garage?................... } \\
\text { An unvented kerosene heater in the house or an attached } \\
\text { structure?......2 } \\
\text { A fireplace or wood stove in the house or } \\
\text { an attached structure?........ } \\
\text { A whole-house or attic fan?.................... }\end{array}$ \\
\hline
\end{tabular}




\begin{tabular}{|c|c|}
\hline $\begin{array}{l}\text { 7. Do you have any air cleaning } \\
\text { devices in your home? }\end{array}$ & 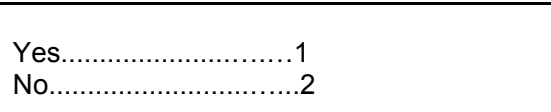 \\
\hline $\begin{array}{l}\text { 8. What type of air cleaning } \\
\text { device(s) do you have at home? } \\
\text { Circle all that apply }\end{array}$ & 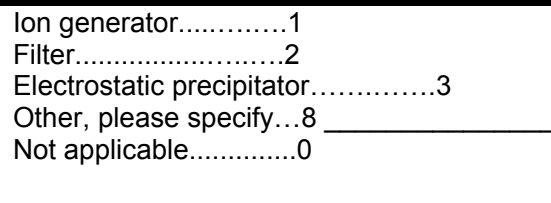 \\
\hline 9. What type of garage, if any do you have? & $\begin{array}{l}\text { None, detached or separate carport........1 } \\
\text { Attached..............2 } \\
\text { Underneath........... } \\
\text { Don't Know............ } \\
\text { IF NONE, GO TO 12 }\end{array}$ \\
\hline 10. Is this garage used for: & $\begin{array}{l}\text { Parking one car.........1 } \\
\text { Parking two cars.......2 } \\
\text { Storage only ........... }\end{array}$ \\
\hline 11. Does this garage: & 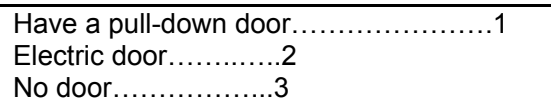 \\
\hline $\begin{array}{l}\text { 12. Where do you store your paints and } \\
\text { solvents? }\end{array}$ & 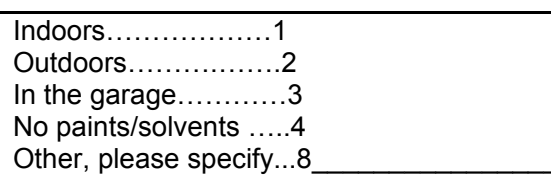 \\
\hline $\begin{array}{l}\text { 13. How many separate central } A C \text { or } \\
\text { window/wall units do you have in your home? }\end{array}$ & $\begin{array}{c}\text { number of central } \mathrm{AC} \text { units } \\
\text { number of window/wall units }\end{array}$ \\
\hline $\begin{array}{l}\text { 14. Do you have a humidifier in your } \\
\text { home? }\end{array}$ & 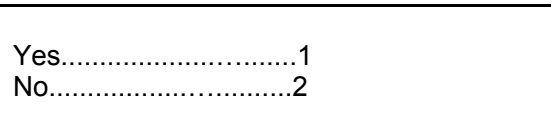 \\
\hline $\begin{array}{l}\text { 15. How frequently is your home } \\
\text { dusted? }\end{array}$ & 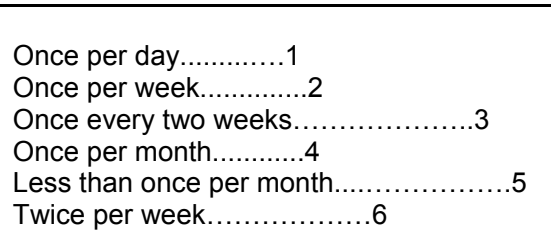 \\
\hline $\begin{array}{l}\text { 16. How frequently is your home } \\
\text { vacuumed? }\end{array}$ & 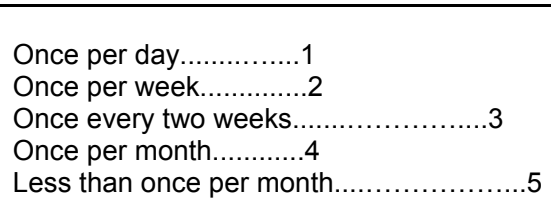 \\
\hline $\begin{array}{l}\text { 17. Is your vacuum in good working } \\
\text { order? }\end{array}$ & 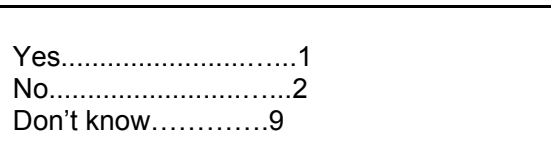 \\
\hline 18. Do you have a gas-powered lawn mower? & $\begin{array}{l}\text { Yes. } \\
\text { No NO, GO TO } 20 \\
\text { IF }\end{array}$ \\
\hline $\begin{array}{l}\text { 19a. If yes, how many times a month do you use } \\
\text { this mower? }\end{array}$ & Number of times/month \\
\hline
\end{tabular}




\begin{tabular}{|c|c|}
\hline $\begin{array}{l}\text { 19b. How many months a year do you use this } \\
\text { mower? }\end{array}$ & Number of months/year \\
\hline $\begin{array}{l}\text { 20. Do you have any pets, such as } \\
\text { dogs or cats or other furry } \\
\text { animals, which usually spend } \\
\text { some time each day in your home? }\end{array}$ & $\begin{array}{l}\text { Yes } \\
\text { No } \\
\text { IF NO, GO TO } 23\end{array}$ \\
\hline 21. If so, how many are there? & 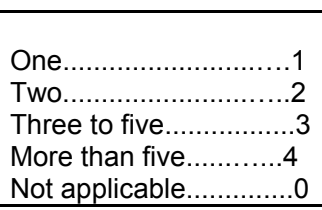 \\
\hline $\begin{array}{l}\text { 22. Could you tell me which pets you have? } \\
\text { Circle all that apply }\end{array}$ & 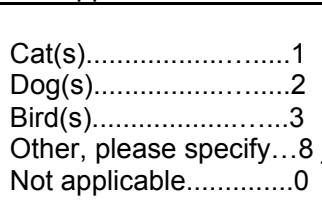 \\
\hline $\begin{array}{l}\text { 23. How many people regularly } \\
\text { smoke inside your home? }\end{array}$ & 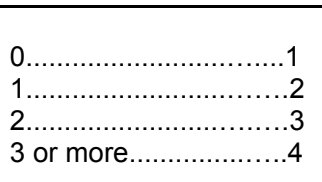 \\
\hline $\begin{array}{l}\text { 24. Did anyone smoke any tobacco products in } \\
\text { your home during the last seven days? }\end{array}$ & 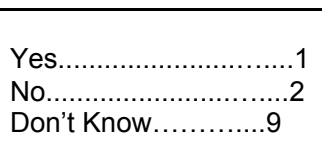 \\
\hline
\end{tabular}




\section{HOUSEHOLD RESIDENTS:}

25. How many people currently live in this home?

Number of People ( )

For each person living in this house, including yourself, please list the following information in the table below.

a) Age, in years at last birthday

b) Type of work of each person currently employed outside of the home for 30 hours a week or more.

c) Current smoking status (yes/no).

(The person is considered a smoker if he/she smoke at least 1 cigarette, cigar, or pipeful per day.)

\begin{tabular}{|l|l|c|c|}
\hline $\begin{array}{c}(26) \\
\text { Household Member's Name }\end{array}$ & $\begin{array}{c}\text { (27) } \\
\text { Age }\end{array}$ & $\begin{array}{c}\text { Type of Work Outside the Home } \\
\text { (30 hrs. a Week or More) }\end{array}$ & $\begin{array}{c}\text { (29) } \\
\text { Smoker } \\
(\text { Y/N })\end{array}$ \\
\hline 1 & & & \\
\hline 2 & & & \\
\hline 3 & & & \\
\hline 4 & & & \\
\hline 5 & & & \\
\hline 6 & & & \\
\hline 7 & & & \\
\hline
\end{tabular}




\begin{tabular}{|c|c|}
\hline $\begin{array}{l}\text { 31. Is the house located within } \\
100 \text { yards of a busy roadway }\end{array}$ & $\begin{array}{l}\text { YES } \\
\text { NO } \ldots \ldots \ldots \ldots \ldots \ldots .1 \\
1 \\
1\end{array}$ \\
\hline $\begin{array}{l}\text { 32. Is there a dirt drive located within } 100 \text { yards of } \\
\text { this house? }\end{array}$ & 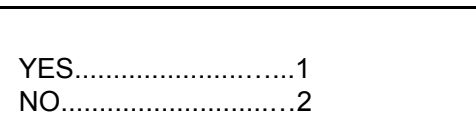 \\
\hline $\begin{array}{l}\text { 33. Are there any other sources } \\
\text { of dirt located within } 100 \\
\text { yards of the house? }\end{array}$ & 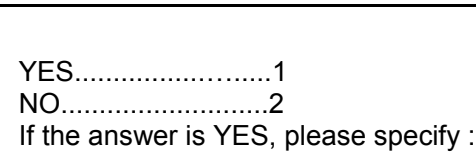 \\
\hline
\end{tabular}

List each room in the house and estimate the percentage of usable floor space covered by rugs or carpets.

\begin{tabular}{|l|c|c|}
\hline & $\begin{array}{c}(34) \\
\text { Room }\end{array}$ & $\begin{array}{c}\text { \% of floor covered by rug or } \\
\text { carpet }\end{array}$ \\
\hline 1 & & \\
\hline 2 & & \\
\hline 3 & & \\
\hline 4 & & \\
\hline 5 & & \\
\hline 6 & & \\
\hline 7 & & \\
\hline 8 & & \\
\hline 9 & & \\
\hline 10 & & \\
\hline 11 & & \\
\hline
\end{tabular}

THANK YOU VERY MUCH FOR YOUR TIME AND COOPERATION! 


\section{THIS PAGE TO BE COMPLETED BY INTERVIEWER ONLY}

Interviewer Initials:

\begin{tabular}{|l|l|}
\hline $\begin{array}{l}\text { 36. How would you best describe the } \\
\text { VENTILATION FACTOR in this unit? }\end{array}$ & $\begin{array}{r}\text { Codes from } 0 \text { to } 3: 0.5 \text { is fresh } \\
2.5 \text { is stuffy }\end{array}$ \\
\hline $\begin{array}{l}\text { 37. How would you best describe the } \\
\text { DUST FACTOR in this unit? }\end{array}$ & $\begin{array}{r}\text { Codes from } 0 \text { to } 3: 0.5 \text { is immaculate } \\
2.5 \text { is clutter }\end{array}$ \\
&
\end{tabular}

END OF QUESTIONNAIRE 
INDOOR SAMPLING: Daily Follow-up Questionnaire

\section{Harvard School of Public Health - Steubenville, OH Winter 2001}

(Daily_Follow_Up_Questionnaire.doc 1/26/01)
Date:
Participant ID:
Day: 23345678 (circle) Operator Initials:

\begin{tabular}{|c|c|c|c|}
\hline & How many people spent $>4$ hours in your house in the last 24 hours? & & \\
\hline 2. & How many cigarettes or cigars were smoked inside your home in the last 24 hours? & & \\
\hline 3. & Was any cleaning done in your home in the last 24 hours? $(\mathrm{No}=0, \mathrm{Yes}=1)$ & & \\
\hline \multirow[t]{2}{*}{4.} & Were any meals cooked in your home in the last 24 hours? $($ No $=0$, Yes $=1)$ & & \\
\hline & What kind of cooking was done? Who cooked? How may times? & Self & Other \\
\hline $4 \mathrm{a}$. & Frying, grilling, sautéing, broiling? (circle which apply) & & \\
\hline 4b. & Baking? & & \\
\hline 4c. & Toasting? & & \\
\hline $4 \mathrm{~d}$. & Boiling? (circle: water, soup, reheating liquid) & & \\
\hline 4e. & Microwave? & & \\
\hline 4f. & Was any food burned in your home in the last 24 hours? $($ No $=0$, Yes $=1)$ & & \\
\hline $4 \mathrm{~g}$. & Was the exhaust fan used for any cooking activity? $($ No $=0$, Yes $=1)$ & & \\
\hline 5. & For how long were candles burned in your house in the last 24 hours? (\# of hours) & & \\
\hline 5a. & For how long was incense used in you home in the last 24 hours? (\# of hours) & & \\
\hline \multirow[t]{8}{*}{6.} & Were any outdoor windows or doors open in the last 24 hours? $(\mathrm{No}=0, \mathrm{Yes}=1)$ & & \\
\hline & $\begin{array}{l}\text { How many inches wide were they open and how many hours were } \\
\text { they open? }\end{array}$ & Inches & Hours \\
\hline & Door 1 & & \\
\hline & Door 2 & & \\
\hline & Window 1 & & \\
\hline & Window 2 & & \\
\hline & Window 3 & & \\
\hline & Window 4 & & \\
\hline 7. & For how long was an air conditioner used in your home in the last 24 hours? (\# hrs) & & \\
\hline 8. & For how long was the heating turned on in your home in the last 24 hours? (\# hrs) & & \\
\hline $8 \mathrm{a}$. & $\begin{array}{l}\text { For how long was a space heater used in your home in the last } 24 \text { hours? (\# hrs) } \\
\text { (circle: electric, kerosene, gas) }\end{array}$ & & \\
\hline 9. & For how long was a humidifier used in your home in the last 24 hours? (\# of hours) & & \\
\hline
\end{tabular}




\section{APPENDIX C}

\section{DATA - (SEPARATE COMPACT DISC CONTAINING AIR MONITORING AND EXPOSURE DATA)}




\section{APPENDIX D}

THE STEUBENVILLE COMPREHENSIVE AIR MONITORING PROGRAM (SCAMP):

CONCENTRATIONS AND SOLUBILITIES OF PM 2.5 TRACE ELEMENTS AND THEIR IMPLICATIONS FOR SOURCE APPORTIONMENT AND HEALTH RESEARCH

MANUSCRIPT SUBMITTED TO THE JOURNAL OF THE AIR \& WASTE MANAGEMENT ASSOCIATION 
THE STEUBENVILLE COMPREHENSIVE AIR MONITORING PROGRAM (SCAMP):

2 CONCENTRATIONS AND SOLUBILITIES OF PM P.5 $_{2.5}$ TRACE ELEMENTS AND

3 THEIR IMPLICATIONS FOR SOURCE APPORTIONMENT AND HEALTH

4 RESEARCH

5

Daniel P. Connell, Stephen E. Winter, Vincent B. Conrad

CONSOL Energy Inc. Research \& Development, South Park, Pennsylvania

Myoungwoo Kim, Kevin C. Crist

Center for Air Quality, Ohio University, Athens, Ohio

12 ABSTRACT

13 The elemental compositions of the water-soluble and acid-digestible fractions of 24-hr integrated

$14 \mathrm{PM}_{2.5}$ samples collected in Steubenville, $\mathrm{OH}$, from 2000-2002 were determined using dynamic

15 reaction cell ICP-MS. The water-soluble elemental compositions of $\mathrm{PM}_{2.5}$ samples collected at

16 four satellite monitoring sites in the surrounding region were also determined. Fe was the most

17 abundant but least water-soluble of the elements determined at the Steubenville site, having a

18 mean ambient concentration of $272 \mathrm{ng} / \mathrm{m}^{3}$ and a median fractional solubility of $6 \%$. Fe solubility

19 and its correlations with $\mathrm{SO}_{4}{ }^{2-}$ and temperature varied significantly by season, consistent with the

20 hypothesis that secondary sulfates may help to mobilize soluble Fe under suitable summertime

21 photochemical conditions. Significantly higher ambient concentrations were observed at

22 Steubenville than at each of the four satellite sites for 10 of the 18 elements ( $\mathrm{Al}, \mathrm{As}, \mathrm{Ca}, \mathrm{Cd}, \mathrm{Fe}$,

$23 \mathrm{Mg}, \mathrm{Mn}, \mathrm{Na}, \mathrm{Pb}$, and $\mathrm{Zn}$ ) determined in the water-soluble $\mathrm{PM}_{2.5}$ fraction. Concentrations of $\mathrm{Fe}$,

$24 \mathrm{Mn}$, and $\mathrm{Zn}$ at Steubenville were substantially higher than concentrations recently reported for

25 larger U.S. cities. Receptor modeling identified seven sources affecting the Steubenville site.

$26 \mathrm{An}\left(\mathrm{NH}_{4}\right)_{2} \mathrm{SO}_{4}$-dominated source, likely representing secondary $\mathrm{PM}_{2.5}$ from coal-fired plants to

27 the west and southwest of Steubenville, accounted for $42 \%$ of the $\mathrm{PM}_{2.5}$ mass, and two sources

28 likely dominated by emissions from motor vehicles and from iron and steel facilities in the

29 immediate Steubenville vicinity accounted for $20 \%$ and $10 \%$, respectively. Other sources

30 included a $\mathrm{NH}_{4} \mathrm{NO}_{3}$ source (15\%), a crustal source (6\%), a mixed nonferrous metals and

31 industrial source (3\%), and a primary coal combustion source (3\%). Results suggest the 
32 importance of very different regional and local source mechanisms in contributing to $\mathrm{PM}_{2.5}$ mass

33 at Steubenville, and reinforce the need for further research to elucidate whether metals such as

$34 \mathrm{Fe}, \mathrm{Mn}$, and $\mathrm{Zn}$ play a role in the $\mathrm{PM}_{2.5}$ health effects previously observed there.

\section{IMPLICATIONS}

37 Steubenville, $\mathrm{OH}$, is located in one of the 18 counties projected by the U.S. EPA to remain in 38 nonattainment under the annual $\mathrm{PM}_{2.5}$ NAAQS in 2015 after the implementation of CAIR. This

39 paper presents source apportionment results that will be useful when developing an

40 implementation plan to address Steubenville's nonattainment status. Moreover, elevated

41 concentrations of $\mathrm{PM}_{2.5}$ in Steubenville have been epidemiologically associated with increased

42 mortality. Given recent toxicological evidence linking certain soluble particulate transition

43 metals with health endpoints, the characterization of transition metal concentrations and

44 solubilities presented here provides important insights that can be utilized by future studies to

45 help determine whether these metals play any role in the health effects previously attributed to

$46 \quad \mathrm{PM}_{2.5}$ in Steubenville.

\section{INTRODUCTION}

49 Although trace elements generally account for only a few percent of the total mass of ambient

50 fine particulate matter $\left(\mathrm{PM}_{2.5}\right)$ in the United States, their characterization is an essential part of

$51 \quad \mathrm{PM}_{2.5}$ source apportionment and health effects research. Numerous recent receptor modeling

52 studies $^{1-4}$ have utilized fine particulate trace element concentration data to help identify sources

53 that emit $\mathrm{PM}_{2.5}$ or its precursors. These studies increasingly are employing techniques such as

54 backward trajectory analysis and potential source contribution function (PSCF) modeling ${ }^{5-6}$ to

55 geographically corroborate the compositional source profiles derived from multivariate models

56 like Positive Matrix Factorization (PMF) or Unmix. The results are particularly relevant given

57 the need to develop State Implementation Plans (SIPs) to reduce ambient $\mathrm{PM}_{2.5}$ concentrations in

58 nonattainment areas under the National Ambient Air Quality Standard (NAAQS) for PM $2.5{ }^{7}$

59 Moreover, toxicology and epidemiology studies have reported associations between

60 adverse health effects and the trace metal content of particulate matter (PM). ${ }^{8-11}$ Growing

61 evidence suggests that transition metals such as Fe, V, and Zn, and especially soluble forms of

62 these metals, play a role in inducing pulmonary responses to PM. For instance, Zelikoff et al. ${ }^{12}$ 
63 found that exposure to soluble divalent Fe resulted in significant increases in bacterial burdens in

64 rats with preexisting Streptococcus pneumoniae infections; the result was similar to that

65 observed when the rats were exposed to concentrated ambient $\mathrm{PM}_{2.5}$ from New York City.

66 Residual oil combustion emissions, characterized by elevated concentrations of $\mathrm{V}$ and $\mathrm{Ni}$, have

67 been associated with cellular stress responses in human bronchial epithelial (HBE) cells; ${ }^{13}$ Carter

68 et al. ${ }^{14}$ reported that residual oil fly ash (ROFA) and vanadium-containing compounds, but not

69 nickel sulfates, triggered the production of inflammatory cytokines by normal HBE cells. In a

70 different study, ${ }^{15}$ both iron (III) sulfate and vanadyl sulfate, but not nickel sulfate, were

71 demonstrated to increase the expression of lactoferrin receptors on respiratory epithelial cells,

72 possibly indicating a response to oxidative stress induced by these catalytically active metals.

73 Huang et al. ${ }^{16}$ observed that a $\mathrm{SO}_{4}{ }^{2-} / \mathrm{Fe} / \mathrm{Se}$ factor was associated with pulmonary neutrophilic

74 inflammation and $\mathrm{Cu} / \mathrm{Zn} / \mathrm{Fe}$ factor was associated with increased blood fibrinogen in healthy

75 humans exposed to concentrated ambient particles. Zinc particles also have been implicated in

76 pulmonary health effect studies. ${ }^{17}$ For example, Adamson et al. ${ }^{18}$ discovered that soluble $\mathrm{Zn}$

77 salts stimulated increases in inflammatory cells and protein in lung lavage fluid from exposed

78 mice, whereas solutions containing $\mathrm{Cu}, \mathrm{Fe}, \mathrm{Al}, \mathrm{Pb}, \mathrm{Mg}$, and $\mathrm{Ni}$ induced minimal lung effects.

79 Current interest in the source apportionment and health effects of ambient $\mathrm{PM}_{2.5}$ and its

80 chemical constituents stems in part from research conducted in Steubenville, OH. The landmark

81 Harvard Six Cities Study, ${ }^{19}$ which discovered an association between Steubenville's elevated

$82 \mathrm{PM}_{2.5}$ concentrations and mortality using data from 1979-1985, partially drove the promulgation

83 of the $\mathrm{PM}_{2.5}$ NAAQS. In addition to having the highest atmospheric concentrations of $\mathrm{PM}_{2.5}$ and

$84 \mathrm{SO}_{4}{ }^{2-}$ of the six cities studied, Spengler and Thurston ${ }^{20}$ reported that concentrations of Fe, $\mathrm{Mn}$,

85 and Se measured in Steubenville between 1979 and 1981 were greater than those measured in the

86 other five cities during comparable time periods, and concentrations of $\mathrm{V}$ and $\mathrm{Ni}$ in Steubenville

87 were second highest among the cities. Koutrakis and Spengler ${ }^{21}$ applied specific rotation factor

88 analysis to $\mathrm{PM}_{2.5}$ elemental data collected in Steubenville in 1984 and identified six sources of

$89 \mathrm{PM}_{2.5}$. Fe and $\mathrm{Mn}$ (as well as $\mathrm{Zn}$ and $\mathrm{K}$ ) were primarily apportioned to iron and steel production;

90 Se and Ni were primarily apportioned to coal/oil combustion, and V was primarily apportioned

91 to titanium production and coal/oil combustion. More recently, Laden et al. ${ }^{22}$ used elemental

92 data collected in the six cities between 1979 and 1988 in an epidemiology study examining

93 associations between daily mortality and three generic $\mathrm{PM}_{2.5}$ source factors: a Si factor (crustal 
94 material), a $\mathrm{Pb}$ factor (automobiles), and a Se factor (coal combustion). None of the factors were 95 significantly associated with mortality in Steubenville, although associations between mortality 96 and the $\mathrm{Pb}$ and $\mathrm{Se}$ factors were statistically significant in a combined analysis across all six 97 cities. Grahame and Hidy ${ }^{23}$ challenged these findings, arguing that the Se factor in Boston likely 98 included substantial residual oil emissions that were mislabeled as coal combustion emissions, 99 perhaps causing an overstatement of the risk associated with the latter. Grahame and Hidy also 100 suggest that much of the V and Se attributed by Koutrakis and Spengler to coal and oil 101 combustion in Steubenville instead likely originated from coke and steel production facilities. 102 Hence, there is still considerable uncertainty regarding which particular components or sources 103 of $\mathrm{PM}_{2.5}$ in Steubenville, if any, are responsible for the association between $\mathrm{PM}_{2.5}$ and mortality 104 observed in the Six Cities Study.

105 As discussed by Connell et al., ${ }^{24}$ Steubenville's population, industrial activity, and air 106 pollution have declined appreciably since the Six Cities Study was conducted. Average $\mathrm{PM}_{2.5}$ 107 concentrations in Steubenville today are more than $35 \%$ lower than the $29.6 \mu \mathrm{g} / \mathrm{m}^{3}$ reported by 108 Dockery et al. ${ }^{19}$ for the 1979-1985 time period. Nevertheless, Jefferson County, OH, where 109 Steubenville is located, is a nonattainment area under the annual NAAQS for $\mathrm{PM}_{2.5}$ and is one of 110 the 18 counties projected by the U.S. Environmental Protection Agency (EPA) to remain in 111 nonattainment in 2015 after implementation of the Clean Air Interstate Rule (CAIR). ${ }^{25}$ Hence,

112 given Steubenville's nonattainment status, the substantial changes that have occurred there since 113 the Six Cities Study, and the recent findings concerning possible health implications of $\mathrm{PM}_{2.5}$ 114 transition metals, a current characterization of $\mathrm{PM}_{2.5}$ trace elements in Steubenville is warranted. 115 This paper provides such an assessment based on elemental analyses of $\mathrm{PM}_{2.5}$ samples 116 collected between May 2000 and May 2002 as part of the Steubenville Comprehensive Air 117 Monitoring Program (SCAMP). Whereas previous $\mathrm{PM}_{2.5}$ studies ${ }^{20-22}$ in Steubenville used X-ray 118 fluorescence spectroscopy (XRF) to determine the elemental composition of $\mathrm{PM}_{2.5}, \mathrm{SCAMP}$ 119 used dynamic reaction cell (DRC) ${ }^{26}$ inductively coupled plasma-mass spectrometry (ICP-MS) 120 for this purpose. ICP-MS has been employed by several recent $\mathrm{PM}_{2.5}$ studies ${ }^{27-28}$ because it 121 exhibits better sensitivity than conventional energy dispersive XRF for determining certain 122 elements that are present in part-per-billion to part-per-trillion amounts. However, the 123 capabilities of conventional low-resolution ICP-MS are limited by polyatomic and isobaric 124 interferences that impede the determination of isotopes such as ${ }^{39} \mathrm{~K},{ }^{40} \mathrm{Ca},{ }^{51} \mathrm{~V},{ }^{52} \mathrm{Cr},{ }^{56} \mathrm{Fe},{ }^{75} \mathrm{As}$, 
125 and ${ }^{80}$ Se. SCAMP is among the first $\mathrm{PM}_{2.5}$ studies to utilize ICP-MS equipped with a DRC in 126 order to minimize these interferences.

127 Also, unlike previous studies in Steubenville, which determined only the elemental 128 composition of the total $\mathrm{PM}_{2.5}$ sample, SCAMP included determinations of the composition of 129 both the water-soluble and acid-digestible $\mathrm{PM}_{2.5}$ fractions, allowing the fractional solubility of $130 \mathrm{PM}_{2.5}$ trace elements to be estimated. These solubility results, presented here, provide some 131 indication of the bioavailability of fine particulate trace metals, and are particularly relevant

132 given the aforementioned toxicological evidence linking soluble metals with pulmonary health 133 endpoints. In addition to data collected at the central SCAMP monitoring site in Steubenville, 134 the elemental composition of the water-soluble $\mathrm{PM}_{2.5}$ fraction was determined at four 135 comparatively remote satellite sites surrounding Steubenville, permitting an assessment of the 136 impact of local sources in Steubenville on soluble $\mathrm{PM}_{2.5}$ trace element concentrations. This 137 paper also presents a recent source apportionment of $\mathrm{PM}_{2.5}$ in Steubenville based on the 138 application of PMF and PSCF to compositional data from the central SCAMP monitoring site; 139 results will be useful in the development of an implementation plan to solve Steubenville's 140 NAAQS nonattainment status.

\section{METHODS}

\section{Sample Collection and Analysis}

144 Details of SCAMP, including results for total $\mathrm{PM}_{2.5}$ mass, major $\mathrm{PM}_{2.5}$ components, gaseous

145 pollutants, and meteorological conditions, have been presented in three previous papers. ${ }^{24,29,30}$

146 Figure 1 shows the locations of the five SCAMP outdoor ambient air monitoring sites. The

147 central site in Steubenville was situated on the campus of Franciscan University of Steubenville $148\left(40.362^{\circ} \mathrm{N}, 80.615^{\circ} \mathrm{W}\right)$ atop a bluff overlooking the Ohio River, which flows from

149 approximately due north to due south in the Steubenville vicinity. Many of the region's major 150 industrial facilities, including iron and steel production facilities, coke plants, coal-fired electric 151 power plants, and other manufacturing facilities, are located along the river's banks. The four 152 satellite sites were located approximately $19 \mathrm{~km}$ to the north near New Manchester, WV; $33 \mathrm{~km}$ 153 to the south in Wheeling, WV; $108 \mathrm{~km}$ to the east in Latrobe, PA; and $22 \mathrm{~km}$ to the west in 154 Hopedale, $\mathrm{OH}$. 
At each site, 24-hr integrated $\mathrm{PM}_{2.5}$ samples were collected daily between May 13, 2000, and May 14, 2002, using an Andersen RAAS2.5-300 Federal Reference Method (FRM) sampler. All samples were collected from 9:00 a.m. to 9:00 a.m. EST on 47-mm Teflon filters at a sampling flow rate of $\sim 16.67 \mathrm{~L} / \mathrm{min}$. The $\mathrm{PM}_{2.5}$ samples collected every fourth day at each site were analyzed to determine the elemental composition of their water-soluble fractions. The Teflon filters containing these samples were transferred into rinsed polypropylene digestion tubes using Teflon-coated forceps and covered with $25 \mathrm{~mL}$ of 18-M $\Omega$ deionized water containing $0.2 \%$ isopropanol as a wetting agent. The tubes were then sonicated for 30 minutes, and an aliquot of the resulting leachate from each sample was submitted for elemental analysis.

164 An internal standard solution containing Ge and In was added to each aliquot so that instrument 165 drift could be monitored and corrected.

In addition, 24-hr integrated $\mathrm{PM}_{2.5}$ samples were collected on a 1-in-4 day frequency at

167 the central site in Steubenville between August 12, 2000, and May 14, 2002, using an Andersen

168 RAAS2.5-400 $\mathrm{PM}_{2.5}$ speciation sampler. To facilitate DRC ICP-MS method development and

169 allow for reanalyses required during this process, $\mathrm{PM}_{2.5}$ samples for acid-digestible elemental

170 analysis were collected in duplicate on 47-mm Teflon filters using separate channels of the 171 speciation sampler. Both channels sampled from 9:00 a.m. to 9:00 a.m. EST at sampling flow 172 rates of $\sim 16.67 \mathrm{~L} / \mathrm{min}$. All filters from the primary channel were digested and analyzed first;

173 however, because of several method-related issues encountered during this succession of

174 analyses, all filters from the backup channel were subsequently digested and analyzed in order to 175 improve valid data capture. In cases where valid results for an element were obtained from both 176 the primary and backup filters for a given day, the arithmetic mean concentration is reported. If 177 a valid result was obtained from only one of the two filters collected on a given day, this single 178 valid result is reported.

179 To prepare the $\mathrm{PM}_{2.5}$ samples for acid-digestible elemental analysis, each exposed filter 180 was placed in a rinsed polypropylene digestion tube, and an acid solution containing $1.39 \mathrm{~mL}$ of 181 Fisher Scientific TraceMetal grade $\mathrm{HNO}_{3}(67-70 \%)$ and $0.11 \mathrm{~mL}$ of an 80:35 mixture of 182 TraceMetal grade $\mathrm{HF}(47-51 \%)$ and $\mathrm{HCl}$ (34-37\%) was added. Although it requires careful 183 handling, the HF is required for more complete digestion ${ }^{31}$ of elements contained in the siliceous 184 matrices commonly encountered in $\mathrm{PM}_{2.5}$. The samples were then digested at $90^{\circ} \mathrm{C}$ for $16-18 \mathrm{hr}$. 185 After cooling, $48.5 \mathrm{~mL}$ of a dilute boric acid solution (used to complex the HF) and $0.5 \mathrm{~mL}$ of an 
186 internal standard solution containing Ge and In were added to each sample. Isopropyl alcohol, a 187 wetting agent, was also added to each digestate during the second sequence of analyses. The 188 digestates were heated to $90^{\circ} \mathrm{C}$ for an additional hour before submittal for elemental analysis. 189 Concentrations of elements in the water extracts and acid digestates were determined 190 using a PerkinElmer ELAN 6100 DRC ICP-MS equipped with a cross-flow nebulizer and HF191 resistant torch. The instrument operates in the same way as a conventional quadrupole ICP-MS 192 except that a reaction cell located between the ion optics system and the analyzing quadrupole is 193 employed to selectively remove species that would otherwise interfere with the determination of 194 the desired analytes. Interferences in ICP-MS can result from isobaric species (e.g., ${ }^{40} \mathrm{Ar}^{+}$, which 195 interferes with the determination of ${ }^{40} \mathrm{Ca}$ ) or polyatomic species (e.g., ${ }^{40} \mathrm{Ar}^{16} \mathrm{O}^{+}$, which interferes 196 with the determination of ${ }^{56} \mathrm{Fe}$ ) that are formed from plasma gases or chemical components of 197 the sample matrix and have the same mass-to-charge ratio $(\mathrm{m} / \mathrm{z})$ as the desired analyte. ${ }^{32}$ In the 198 reaction cell, a gas that readily reacts with the interfering species but not with the desired analyte 199 is introduced when necessary in order to alter the $\mathrm{m} / \mathrm{z}$ of these interfering species. An active 200 filtering quadrupole located in the reaction cell is tuned to eject species falling outside of a 201 specific mass bandpass window, thereby preventing the introduction of new interferants and 202 controlling the $\mathrm{m} / \mathrm{z}$ characteristics of the ion beam that is sent to the analyzing quadrupole. Thus, 203 the reaction gas and active quadrupole in the reaction cell collectively reduce the number of 204 interfering species that pass to the analyzing quadrupole. Additional details concerning the 205 theory and performance of DRC ICP-MS have been presented previously. ${ }^{26,33}$

206 In this study, $\mathrm{CH}_{4}$ and $\mathrm{NH}_{3}$ were used as reaction gases in the DRC when necessary.

207 Table 1 summarizes the general strategy used to determine elements in the water-soluble and 208 acid-digestible $\mathrm{PM}_{2.5}$ fractions. Because of the nature of DRC ICP-MS, the same element at 209 times was determined using different instrumental methods, which included variations in the 210 isotope being determined, the reaction gas (if any) being used, and the reaction gas flow rate. All 211 elemental determinations were validated based upon determinations of quality control standards, 212 including NIST Standard Reference Material (SRM) 1643d or NIST SRM 1640 for water213 soluble elements and NIST SRM 1648 for acid-digestible elements, that were included during 214 the course of each run. Due to the use of multiple methods to determine certain elements, 215 multiple analytical limits of detection (LOD) were obtained for these elements; these LODs have 216 been reported previously. ${ }^{34,35}$ To avoid the introduction of bias, ${ }^{36}$ actual instrument readings for 
217 determinations below the LOD were used in the statistical analyses presented in this paper. As

218 shown in Table 1, most elements had only a small percentage of observations below the LOD,

219 indicating that DRC ICP-MS exhibited sufficient sensitivity for the concentrations being

220 examined in this study.

221 Table 1 also presents statistics describing method performance, as measured by the

222 recovery of elements in NIST standard reference materials. The NIST SRM 2783 was used to

223 assess method performance for the acid-digestible fraction because it allows an evaluation of the

224 success of the digestion procedure for a $\mathrm{PM}_{2.5}$-impregnated filter. Mean recoveries were within

$22515 \%$ of target values for 16 elements in SRM 1643d (analyzed by the water-soluble method) and

22611 elements in SRM 2783 (analyzed by the acid-digestible method), and were within $30 \%$ of

227 target values for all elements having NIST-certified values. The overall imprecision of the

228 method for elements in the acid-digestible fraction, as computed using results from analyses of

229 collocated filters collected during SCAMP, ranged from 15-34\% depending upon the element.

230 Results for $\mathrm{Ti}$ in the water-soluble fraction and $\mathrm{Na}$ in the acid-digestible fraction routinely failed

231 to pass quality control criteria; hence, these results are excluded from Table 1 and the remainder

232 of this paper. Si and Cr were also routinely determined, but are excluded from the analyses

233 presented here because of high blank concentrations (for water-soluble Si and acid-digestible

$234 \mathrm{Cr}$ ), a frequent failure to meet quality control criteria (for acid-digestible $\mathrm{Si}$ ), or a high

235 percentage of observations below the LOD (for water-soluble $\mathrm{Cr}$ ).

\section{Source Apportionment}

237 Source apportionment was performed using Positive Matrix Factorization (specifically, PMF2)

238 and potential source contribution function modeling. PMF, as developed by Paatero, ${ }^{37}$ is a factor 239 analysis algorithm for solving the general receptor modeling problem given by

$$
x_{i j}=\sum_{k=1}^{p} g_{i k} f_{k j}+e_{i j}
$$

241 where $x_{i j}$ is the ambient mass concentration of the $j$ th species from the $i$ th $\mathrm{PM}_{2.5}$ sample collected

242 at the receptor site; $g_{i k}$ is the $\mathrm{PM}_{2.5}$ mass concentration from the $k$ th source contributing to the $i$ th

243 sample; $f_{k j}$ is the mass fraction of the $j$ th species in $\mathrm{PM}_{2.5}$ from the $k$ th source; $e_{i j}$ is the residual

244 associated with $x_{i j}$, and $p$ is the total number of sources contributing to $\mathrm{PM}_{2.5}$ at the receptor site.

245 Because values of both $g_{i k}$ and $f_{k j}$ are unknown, there are an infinite number of solutions to eq 1

246 corresponding to different rotations of the matrix of source contributions, $\mathrm{G}$, and matrix of 
source compositions, F. Hence, the selection of a final solution necessarily involves some subjectivity. PMF imposes non-negativity constraints to help limit the number of possible solutions, and solves for $\mathrm{G}$ and $\mathrm{F}$ by using an iterative weighted least-squares procedure to minimize an objective function, $Q(E)$, which is defined as

$$
Q(E)=\sum_{i=1}^{n} \sum_{j=1}^{m}\left[\frac{x_{i j}-\sum_{k=1}^{p} g_{i k} f_{k j}}{u_{i j}}\right]^{2}
$$

Here, $u_{i j}$ is the uncertainty in the $j$ th species measured in the $i$ th sample; $n$ is the total number of samples, and $m$ is the total number of species. Additional details of PMF have been described extensively in the literature. ${ }^{2-4,37}$

The receptor modeling results presented in this paper are based on the application of PMF to $\mathrm{PM}_{2.5}$ mass, ion, carbon, and acid-digestible elemental data collected at the central monitoring site in Steubenville. Only days for which data were available for mass, ions $\left(\mathrm{NH}_{4}{ }^{+}, \mathrm{SO}_{4}{ }^{2-}, \mathrm{NO}_{3}{ }^{-}\right.$, and $\mathrm{Cl}^{-}$), elemental and organic carbon (EC and $\mathrm{OC}$ ), and at least 10 out of the 18 acid-digestible elements were used; as a result, 115 days were included in the model runs. Because analytical uncertainties were not determined in a consistent manner for all of the included species, uncertainty values for use in PMF were assigned based on the analytical LODs for each species. For determinations above the LOD, concentration-dependent uncertainties were assigned by multiplying each determined concentration by the ratio of its LOD to the overall $25^{\text {th }}$ percentile species concentration. This procedure inherently down-weighted species such as $\mathrm{Cl}^{-}, \mathrm{Co}$, and $\mathrm{Ni}$ for which determined concentrations were often not much greater than the detectable limits of the analytical method being used. For determinations below the LOD, the uncertainty was set equal to 5/6 times the LOD. Any missing values for a species during the 115 days being modeled were replaced with the overall median concentration of that species, and the uncertainties for these missing values were set at four times the median species concentration in order to decrease their weight in the model. To account for possible underestimation of uncertainties according to the procedure above and possible violations of the assumption that the chemical profiles of sources impacting the Steubenville site do not change with time, an extra $5 \%$ uncertainty was added to all observations prior to modeling. 
PMF was run in robust mode to reduce the impact of extreme values, which were defined

275

276

277

278

279

280

281

282

283

284

285

286

287

288

289

as data points for which the model residual was greater than four times the error estimate, on the solution. Instead of employing the normal multiple regression procedure to determine $\mathrm{PM}_{2.5}$ mass apportionment, $\mathrm{PM}_{2.5}$ mass concentration was included as an independent variable in the model runs to directly obtain this apportionment. ${ }^{2}$ PMF was run several times to examine the effects of altering the specified number of sources and the value of the FPEAK parameter, which is used to control rotations of the $\mathrm{F}$ and $\mathrm{G}$ matrices. The final 7-source PMF model that is presented in this paper was selected based on an evaluation of the model goodness-of-fit (e.g., robust $\mathrm{Q}$, scaled residuals) and the physical reasonableness of the source profiles obtained from the various candidate solutions. The robust $\mathrm{Q}$ for this 7-source solution, $\mathrm{Q}=3231$, agreed reasonably well with the theoretical Q of 2875 for the dataset being modeled, and the FPEAK value (FPEAK $=0.0$ ) occurred in a range of FPEAK values for which $Q(E)$ exhibited a minimum and was relatively insensitive to changes in FPEAK (Figure 2). Five different seeds of initial values were used to test the optimality of the PMF solutions. Uncertainties in the elements of the $\mathrm{F}$ and $\mathrm{G}$ matrices were estimated by PMF2 in the standard way from the uncertainties in the ambient concentration values via alternating least squares fits. ${ }^{38}$

Potential source contribution function modeling was employed to help identify probable geographic locations of the sources resolved by PMF. Backward trajectories from the Steubenville site were computed for every hour of each of the 115 days included in the PMF model. All trajectory calculations were performed using the HYSPLIT mode ${ }^{39}$ with NCEP/NCAR Reanalysis data. ${ }^{40}$ Because many sources of $\mathrm{PM}_{2.5}$ in Steubenville are expected to be located within about $100 \mathrm{~km}$ of the monitoring site, 24-hr trajectories with a starting height of $50 \mathrm{~m}$ above model ground level were typically used. These backward trajectories were utilized to compute the PSCF for each of the seven sources resolved by PMF.

The geographical region covered by the backward trajectories was divided into grid cells with a resolution of $0.1^{\circ}$ latitude by $0.1^{\circ}$ longitude. For a given source, the potential source contribution function for the $i j$ th grid cell, $P S C F_{i j}$, is computed as

$$
P S C F_{i j}=\frac{m_{i j}}{n_{i j}}
$$

where $m_{i j}$ is the number of trajectories passing through the cell that are associated with a "high concentration" of $\mathrm{PM}_{2.5}$ from that source observed at the receptor site, and $n_{i j}$ is the total number 
304 of trajectories passing through the cell. Hence, a $P S C F_{i j}$ value close to one indicates a high 305 probability that the $i j$ th cell either contains the source under consideration or is situated along a commonly occurring transport route that results in the source impacting the receptor site. For the

307 analyses presented in this paper, all of the 24 backward trajectories computed for a given day 308 were considered to be associated with the 24-hr average source contributions resolved by PMF 309 for that day. A source was considered to have a "high concentration" at the receptor site on a 310 given day if its estimated contribution to $\mathrm{PM}_{2.5}$ at the receptor site on that day was greater than 311 the overall geometric mean of its estimated daily contributions. To prevent the occurrence of 312 large PSCF values with large uncertainties that result from small values of $n_{i j}$, all PSCF values 313 were multiplied by an arbitrary weight function factor, $W\left(n_{i j}\right)$, which served to down-weight 314 those values for which $n_{i j}$ was less than three times the average $n_{i j}$ :

$$
W\left(n_{i j}\right)= \begin{cases}1.0 & 42<n_{i j} \\ 0.7 & 10<n_{i j} \leq 42 \\ 0.5 & 6<n_{i j} \leq 10 \\ 0.3 & 4<n_{i j} \leq 6 \\ 0.1 & 0<n_{i j} \leq 4\end{cases}
$$

\section{RESULTS AND DISCUSSION}

\section{Ambient Concentrations of Elements in $\mathbf{P M}_{2.5}$ at Steubenville}

319 Table 2 summarizes the 24-hr average concentrations of elements in the acid-digestible $\mathrm{PM}_{2.5}$

320 fraction measured at Steubenville during SCAMP. Based upon the mean concentrations

321 observed during the program, these 18 elements collectively accounted for about $0.8 \mu \mathrm{g} / \mathrm{m}^{3}$ or

$3224.3 \%$ of the total $\mathrm{PM}_{2.5}$ mass at Steubenville. Fe was the most abundant of the elements that

323 were determined, as it alone constituted about $0.3 \mu \mathrm{g} / \mathrm{m}^{3}$ or $1.5 \%$ of the total average $\mathrm{PM}_{2.5}$ mass.

324 Twenty-four-hour average Fe concentrations greater than $1.0 \mu \mathrm{g} / \mathrm{m}^{3}$ were measured nine times 325 during the program.

326 Average concentrations of 11 of the $\mathrm{PM}_{2.5}$ elements ( $\mathrm{Al}, \mathrm{Ca}, \mathrm{Cu}, \mathrm{Fe}, \mathrm{K}, \mathrm{Mn}, \mathrm{Ni}, \mathrm{Pb}, \mathrm{Se}$, $327 \mathrm{~V}$, and $\mathrm{Zn}$ ) measured during SCAMP were also determined in Steubenville between 1979 and 3281988 as part of the Harvard Six Cities Study. ${ }^{22}$ Apart from Ca, elemental concentrations 329 measured during SCAMP were $37 \%(\mathrm{Se})$ to $92 \%(\mathrm{~Pb})$ less than those measured during the Six 330 Cities Study. These differences may in part be due to analytical error; however, the trend of 
331 decreasing ambient concentrations is consistent with trends observed for total $\mathrm{PM}_{2.5}$ mass. ${ }^{24,41}$

332 The large decrease in $\mathrm{Pb}$ concentrations likely reflects the discontinued use of leaded gasoline.

333 The comparatively small decrease in Se concentrations is also reasonable given the continued

334 prevalence of coal combustion and coking plants in the Steubenville region. These plants are a

335 major source of Se, a volatile element that is present in coal and tends to be less effectively controlled by particulate control devices than less-volatile elements. ${ }^{42,43}$

Despite the decreases that have occurred since the Six Cities Study, concentrations of certain $\mathrm{PM}_{2.5}$ transition metals measured in Steubenville during SCAMP remained elevated relative to concentrations reported for other U.S. cities during comparable time periods. For example, although concentrations of Fe and $\mathrm{Zn}$ measured during SCAMP were 50\% and 39\% lower, respectively, than those reported by Laden et al. ${ }^{22}$ for Steubenville, concentrations of 342 these elements at Steubenville during SCAMP were 1.2-3.2 (Fe) and 2.0-7.0 (Zn) times as great 343 as concentrations summarized by Grahame ${ }^{44}$ (using AIRS data) for New York, NY, Baltimore,

344 MD, St. Louis, MO, Boston, MA, and Chicago, IL, for the year 2001. Moreover, mean 345 concentrations of Fe and Zn observed during SCAMP were 2.4-3.0 (Fe) and 5.2-5.3 (Zn) times greater than concentrations measured during recent sampling campaigns in Washington, DC, 45 and Atlanta, GA. ${ }^{46}$ Mean concentrations of Mn measured during SCAMP were 6.6-7.6 times as 348 high as those reported for Washington and Atlanta. Conversely, concentrations of fine particulate $\mathrm{Cu}, \mathrm{Ni}$, and $\mathrm{V}$ at Steubenville during SCAMP were less than the average concentrations reported for most of the seven cities named above. Again, these comparisons

351 likely include some error resulting from differences in the analytical methods used in the various 352 cities, but the consistently observed differences for Fe, Mn, and $\mathrm{Zn}$ are larger than would be 353 expected to result solely from analytical error.

Seven of the 18 elements listed in Table 2 (As, Cd, Co, Pb, Mn, Ni, and $\mathrm{Se}$ ) are defined 356 these elements in $\mathrm{PM}_{2.5}$ at Steubenville during SCAMP were less than the non-cancer chronic 357 inhalation reference concentrations (RfCs), ${ }^{47}$ minimal risk levels (MRLs), ${ }^{48}$ and reference 358 exposure levels (RELs) ${ }^{49}$ established by the U.S. EPA, U.S. Agency for Toxic Substances and 359 Disease Registry, and California EPA. The mean Mn concentration at Steubenville was about $36037 \%$ of the chronic inhalation MRL; concentrations of the other six elements were at least an 361 order of magnitude less than the most stringent reference concentrations. However, total 
ambient concentrations of these elements at Steubenville may be greater than the concentrations

363 reported in Table 2, especially for elements such as Mn that are more abundant in crustal

364 material, ${ }^{50}$ as SCAMP measured $\mathrm{PM}_{2.5}$ rather than total suspended particulate (TSP). Fe and $\mathrm{Zn}$

365 are not classified as HAPs; however, given their high concentrations at Steubenville compared to

366 other U.S. cities and the aforementioned toxicological findings concerning their possible

367 association with pulmonary health endpoints, further study of these metals is warranted to

368 determine whether they play any role in the observed association between $\mathrm{PM}_{2.5}$ and mortality in

369 Steubenville.

Solubility of Elements in $\mathbf{P M}_{2.5}$ at Steubenville

371 Table 2 also shows the median and $25^{\text {th }}$ and $75^{\text {th }}$ percentile daily fractional solubilities for each

372 element that was determined in both the water-soluble and acid-digestible $\mathrm{PM}_{2.5}$ fractions at the

373 Steubenville site. Based on these data, fine particulate As, Ba, Cd, K, and Se tended to be

374 present in predominantly water-soluble forms at Steubenville; each of these elements had a

375 median fractional solubility $>0.8$. This list of highly soluble elements includes three of the

376 seven HAPs discussed above, including the two (As and Cd) that are listed as carcinogens by the

377 U.S. EPA. ${ }^{47}$ Conversely, fine particulate Al, Fe, and Sn were largely present in insoluble forms

378 at Steubenville; these elements had median fractional solubilities $<0.2$.

379 As shown in Table 2, fractional solubilities computed for As and Se at Steubenville were

380 often substantially $>1.0$. This apparent physical incongruity may be the result of a sampling

381 bias, as samples for water-soluble and acid-digestible analyses were collected using separate

382 samplers. It could also be attributable to an analytical error (e.g., ${ }^{75} \mathrm{As}$ and ${ }^{80} \mathrm{Se}$ are prone to

383 interferences by species such as ${ }^{40} \mathrm{Ar}^{35} \mathrm{Cl}^{+}$and ${ }^{40} \mathrm{Ar}_{2}{ }^{+}$, respectively) ${ }^{32}$ or digestion error (e.g.,

384 volatile losses of $\mathrm{AsCl}_{3}$ and $\mathrm{SeOCl}_{2}$ can occur after digestion in hot $\left.\mathrm{HCl}\right){ }^{51}$ These potential

385 errors are guarded against by use of the DRC and a capped digestion procedure with a post-

386 digestion cooling period, though, and are not supported by the performance data presented in

387 Table 1. Pairwise concentrations of As and Se measured in the water-soluble and acid-digestible

$388 \mathrm{PM}_{2.5}$ fractions were well correlated (Spearman correlation coefficients, $\mathrm{r}_{\mathrm{s}}$, were 0.89 for As and

3890.88 for $\mathrm{Se}$ ), indicating that these concentrations are suitable for use in trending and source

390 apportionment analyses. It is noteworthy, however, that the mean concentrations of acid-

391 digestible As and Se reported in Table 2 may be biased low. Mean ambient air concentrations of

392 these elements in the water-soluble $\mathrm{PM}_{2.5}$ fraction were $2.59 \mathrm{ng} / \mathrm{m}^{3}$ for As and $4.73 \mathrm{ng} / \mathrm{m}^{3}$ for Se. 
Given the toxicological findings concerning possible health implications of soluble $\mathrm{PM}_{2.5}$

394 transition metals, there is considerable interest in elucidating factors that affect the solubility of

395 these metals. Figure 3 shows the ratio of the median warm season (April - September) 24-hr

396 average fractional solubility to the median cool season (October - March) solubility for each of

397 the 17 elements for which data were available. Warm-to-cool season ratios are also shown for

398 concentrations of these elements in the water-soluble and acid-digestible $\mathrm{PM}_{2.5}$ fractions. As

399 shown in the figure, fractional solubilities of $\mathrm{Al}, \mathrm{Fe}$, and $\mathrm{Pb}$ were significantly (i.e., at a statistical

400 significance level of $\alpha=0.05$ ) greater during the warm season than during the cool season.

401 Fractional solubilities of the remaining 14 elements did not differ significantly by season.

402 Although Fe is the least soluble of the 17 elements studied as part of SCAMP, its

403 fractional solubility exhibited the greatest variation by season at Steubenville. The fractional

404 solubility of $\mathrm{Fe}$ is of particular interest given evidence ${ }^{52}$ that even a very small amount of soluble

405 iron in particles (i.e., $0.036 \%$ of the total Fe content) may be capable of inducing oxidant

406 generation leading to inflammation. The trend of higher Fe fractional solubility during the warm

407 season than during the cool season at Steubenville could be attributable to seasonal variations in

408 primary emissions of soluble forms of this metal. Alternatively, the increased fractional

409 solubilities observed during the warm season may be related to atmospheric chemistry. Grahame

410 and Schlesinger ${ }^{53}$ recently recommended further research to examine the extent to which ambient

$411 \mathrm{PM}_{2.5}$ metals are made soluble by contact with secondary sulfates. Previous studies ${ }^{54,55}$ have

412 illustrated the photoreduction of $\mathrm{Fe}(\mathrm{III})$ to $\mathrm{Fe}(\mathrm{II})$, which is generally more mobile than Fe(III), ${ }^{56}$

413 in atmospheric aerosols. Ghio et al. ${ }^{57}$ hypothesized that $\mathrm{SO}_{4}{ }^{2-}$ may participate in the

414 solubilization of particulate Fe by serving as a ligand for Fe after its mobilization by

415 photoreduction, and demonstrated via controlled laboratory experiments that aqueous $\mathrm{SO}_{4}{ }^{2-}$

416 (from $\mathrm{CaSO}_{4} \cdot 2 \mathrm{H}_{2} \mathrm{O}$ ) is capable of mobilizing soluble $\mathrm{Fe}$ from $\mathrm{Fe}_{2} \mathrm{O}_{3}$, but only in the presence of

417 light. Results from SCAMP are consistent with the possibility that atmospheric Fe in

418 Steubenville may be solubilized to some extent by interaction with sulfates under suitable

419 photochemical conditions. The fractional solubility of Fe in Steubenville was greatest during the

420 warm season, when photochemical activity and secondary $\mathrm{SO}_{4}{ }^{2-}$ concentrations are maximal.

421 Moreover, as shown in Table 3, 24-hr average Fe fractional solubilities exhibited moderate,

422 positive correlations with $\mathrm{SO}_{4}{ }^{2-}$ and temperature during summertime in Steubenville, whereas

423 correlations among these variables were comparatively weak or negative during other, less 
424 photochemically active seasons. (Correlations of $\mathrm{Cu}, \mathrm{Ni}$, and $\mathrm{Sn}$ with $\mathrm{SO}_{4}{ }^{2-}$ and temperature 425 exhibited similar trends). During the summer, Fe fractional solubility correlated more strongly 426 with $\mathrm{SO}_{4}{ }^{2-}$ than it did with any of the other measured $\mathrm{PM}_{2.5}$ components. These results reinforce 427 the need for further research to investigate possible effects of secondary sulfates on the solubility 428 of $\mathrm{Fe}$ in ambient $\mathrm{PM}_{2.5}$. Such research should also examine whether aerosol acidity, which was 429 not directly measured as part of SCAMP, plays a role in solubilizing Fe. Additional research on 430 the health effects of soluble fine particulate $\mathrm{Fe}$ is also warranted, as several studies ${ }^{58,59}$ have 431 failed to discover any statistically significant associations between $\mathrm{Fe}$ and adverse health 432 endpoints, and another ${ }^{60}$ has suggested that both the soluble and insoluble fractions of PM 433 contain ionizable metals that can catalyze oxidative stress.

$434 \quad$ Although fine particulate $\mathrm{Al}$ and $\mathrm{Pb}$ tended to be more soluble during the warm season 435 than during the cool season at Steubenville, fractional solubilities of these two metals were not 436 well correlated with $\mathrm{SO}_{4}{ }^{2-}$ or temperature during summertime. Conversely, $\mathrm{Al}$ fractional 437 solubilities exhibited moderately strong positive correlations with $\mathrm{SO}_{4}{ }^{2-}$ and temperature during 438 winter. Moreover, fractional solubilities of both $\mathrm{Al}$ and $\mathrm{Zn}$ were well correlated with $\mathrm{SO}_{4}{ }^{2-}$ but 439 not temperature during autumn. Although the results are not shown, $\mathrm{Al}$ and $\mathrm{Zn}$ fractional 440 solubilities in autumn also correlated moderately-to-strongly (i.e., $r_{s}>0.7$ ) with concentrations of 441 a number of other $\mathrm{PM}_{2.5}$ chemical components, including elemental and organic carbon and 442 several trace elements. These results are more suggestive of primary emissions of soluble forms 443 of these metals, perhaps during inversion-driven pollution episodes that have been $\operatorname{shown}^{30}$ to 444 promote buildups in the concentrations of locally-emitted pollutants during non-summer months 445 in Steubenville, than of a photochemically-driven mechanism of solubilization. Soluble Zn may 446 have health implications; Fernandez et al. ${ }^{61}$ recently reported that exposure to $\mathrm{ZnSO}_{4}$ aerosol led 447 to a significant increase in lung permeability in mice, whereas exposure to $\mathrm{ZnO}$ aerosol did not 448 induce such a response.

Spatial Variability of Elements in the Water-Soluble $\mathbf{P M}_{2.5}$ Fraction 451 water-soluble $\mathrm{PM}_{2.5}$ fraction determined at each of the SCAMP monitoring sites between May 4522000 and May 2002. The two-tailed p-values listed for each satellite site indicate whether 453 element concentrations measured at the satellite site differed significantly from those measured 454 at the Steubenville site, based on the application of a Wilcoxon signed rank test to paired 
concentrations measured at the two sites. Ambient concentrations at Steubenville were

456 significantly greater (at $\alpha=0.05$ ) than those measured at all four satellite sites for 10 of the 18

457 elements studied. The northern and western sites are most representative of background $\mathrm{PM}_{2.5}$

458 concentrations in the Steubenville region; ${ }^{24}$ concentrations of 14 elements at the northern site and

45915 elements at the western site were significantly less than corresponding concentrations

460 measured at Steubenville. Water-soluble Fe, Mg, and Mn were particularly enriched at

461 Steubenville; median ambient air concentrations of these elements at the Steubenville site were

462 at least 1.9 times as great as median concentrations at the northern and western satellite sites.

463 This enrichment likely reflects the impact of the local iron and steel industry in the immediate

464 Steubenville vicinity, as elevated airborne concentrations of particulate Fe and Mn are

465 commonly found near steel production facilities. ${ }^{62}$ Ambient concentrations of $\mathrm{Al}$ and $\mathrm{Zn}$ in the

466 water-soluble $\mathrm{PM}_{2.5}$ fraction were also substantially greater at Steubenville than at the

467 background sites.

468 Figure 4 shows Spearman correlation coefficients describing the associations between

469 water-soluble element concentrations measured at Steubenville and corresponding water-soluble

470 element concentrations measured at the satellite sites. Concentrations at the satellite sites were

471 generally moderately correlated with those at Steubenville, and for many of the elements, the

472 strength of association tended to decrease with increasing inter-site distance. These results likely

473 reflect the impact of local sources in Steubenville on $\mathrm{PM}_{2.5}$ trace element concentrations at

474 nearby monitoring sites, as well as the effect of regional-scale meteorology on localized ambient

475 concentrations of trace elements emitted by local sources situated near each satellite site. The

476 weakest correlations were between Mn concentrations at the Steubenville site and Mn

477 concentrations at the southern and eastern sites. This, coupled with the data in Table 4, likely

478 indicates the very localized impact of substantial Mn emissions from sources in Steubenville.

\section{Source Apportionment at Steubenville}

480 Figures 5 and 6, respectively, present the source profiles and source contribution time series for

481 each of the seven sources identified by applying PMF to $\mathrm{PM}_{2.5}$ mass and speciation data

482 collected at the Steubenville site. As shown in Figure 7, which compares daily reconstructed

$483 \mathrm{PM}_{2.5}$ mass concentrations estimated from the PMF source contributions with actual measured

$484 \mathrm{PM}_{2.5}$ concentrations, the model succeeded in accounting for much of the variation in $\mathrm{PM}_{2.5}$ mass

485 at Steubenville. Although results are not presented here, data from the Steubenville site were 
486 also modeled using the EPA Unmix 2.3 receptor model. ${ }^{63}$ Each of the seven sources resolved by 487 PMF resembled a source identified in one or more of the three best 5-source Unmix solutions, 488 and source contributions estimated by the two different models for these pairs of similar sources 489 were moderately-to-strongly correlated $\left(r_{s}=0.58-0.96\right)$, providing further evidence of the 490 validity of the results.

491 Moreover, as discussed earlier, PMF was run a number of times to explore the effects of 492 altering the specified number of sources on the solution. The best eight-source solution, which 493 like the seven-source solution had a robust $Q$ value $(Q=2601)$ near the theoretical $Q$ value of 4942875 , resolved two separate carbon-dominated sources rather than the single source (Source 2) 495 resolved by the seven-source model. However, the identities of these two sources, which also 496 included small amounts of the mass apportioned to Sources 1, 3, 4, 5, and 7 by the seven-source 497 model, were not individually interpretable; one was dominated by EC but contained no OC, and 498 the other was dominated by OC but contained no EC. The six-source solution had a robust Q 499 value that was nearly $50 \%$ greater than the theoretical Q value, and among other problems, it 500 blended various elements of Sources 2, 3, and 6 from the seven-source model into two sources 501 such that the identities of these mixed sources were difficult to ascertain. Overall, the seven502 source solution appeared to have the most appropriate degree of source resolution given the size 503 of the dataset being modeled and known characteristics of $\mathrm{PM}_{2.5}$ sources in the Steubenville area. 504 Among the sources identified by this final seven-source PMF solution, Source 1 is the 505 largest contributor to $\mathrm{PM}_{2.5}$ mass at Steubenville, accounting for $7.4 \mu \mathrm{g} / \mathrm{m}^{3}$, or $\sim 42 \%$, of the total 506 apportioned mass. $\mathrm{SO}_{4}{ }^{2-}$ and $\mathrm{NH}_{4}{ }^{+}$account for $\sim 71 \%$ of the mass associated with this source, 507 whereas the fractional contribution of trace elements to the total source mass is an order of 508 magnitude less than for any other source. The molar ratio of $\mathrm{NH}_{4}{ }^{+}$to $\mathrm{SO}_{4}{ }^{2-}$ is 2.0 for Source 1 509 (the mass of $\mathrm{NO}_{3}{ }^{-}$associated with this source is negligible), suggesting that this source represents 510 the contribution of secondary $\left(\mathrm{NH}_{4}\right)_{2} \mathrm{SO}_{4}$-dominated aerosol to $\mathrm{PM}_{2.5}$ mass at Steubenville. As 511 shown in Figure 6a and Table 5, respectively, the $\mathrm{PM}_{2.5}$ attributed to Source 1 exhibited a 512 pronounced seasonal pattern of higher summertime and lower wintertime concentrations and 513 displayed a moderate, positive correlation with temperature, reflecting the effect of increased 514 summertime photochemical activity on secondary $\mathrm{SO}_{4}{ }^{2-}$ formation. $\mathrm{SO}_{2}$ emitted by coal-fired 515 power plants is expected to be the dominant precursor of secondary $\mathrm{SO}_{4}{ }^{2-}$ in the upper Ohio 516 River valley. PSCF results for Source 1, shown in Figure 8a for 24-hr backward trajectories with 
517 a 50-m starting height, suggest a probable source region to the south of Steubenville, including 518 the Ohio River valley, where several coal-fired power plants are located. For a regional 519 secondary pollutant such as $\left(\mathrm{NH}_{4}\right)_{2} \mathrm{SO}_{4}$, however, a larger PSCF domain is warranted to allow 520 time for atmospheric formation and transport. Figure 8h shows PSCF results calculated for 521 Source 1 using 3-day backward trajectories with a 500-m starting height, which was selected for 522 longer-range transport calculations because it approximately represents the middle of the mixed 523 layer. Although the areas of high probability do not all correspond to locations of major power 524 plants, the results generally suggest transport from the west and southwest of Steubenville, where many such plants are situated.

526 Sources 2 and 3 are the most similar of the seven sources resolved by PMF. The source 527 contributions from these sources correlate more strongly $\left(\mathrm{r}_{\mathrm{s}}=0.63\right)$ than do those from any other 528 pair of sources, and exhibit moderate-to-strong correlations with $\mathrm{CO}, \mathrm{NO}$, and $\mathrm{NO}_{2}$ (Table 5).

529 Source 2, which accounts for $\sim 20 \%$ of the total apportioned $\mathrm{PM}_{2.5}$ mass at Steubenville, is 530 characterized by the largest mass fractions of EC and organic material $(\mathrm{OM}=1.4 \cdot \mathrm{OC})$ of the 531 seven sources. This source also contains more of the total apportioned mass of $\mathrm{Ba}$ and $\mathrm{Cu}$ than 532 any of the other sources. EC is often attributed to diesel emissions, ${ }^{64}$ and Ba, which is used as a 533 smoke suppressant in diesel fuel and as a filler in brake linings, has been suggested as a tracer for 534 heavy-duty diesel trucks. ${ }^{65}$ Moreover, $\mathrm{Cu}$ is found in engine oils and brake linings, ${ }^{65}$ and other 535 elements present in the Source 2 profile, including $\mathrm{Fe}, \mathrm{Ca}$, and $\mathrm{Pb}$, are expected in fine particle 536 emissions from motor vehicles. ${ }^{66}$ The EC/OC ratio for Source $2(0.32)$ is considerably less than 537 the ratio of $\geq 1$ expected for diesel emissions, ${ }^{67}$ but is only slightly less than the average EC/OC 538 ratio of 0.44 reported by Lough et al. ${ }^{66}$ for mixed vehicular emissions in two Milwaukee, WI, 539 tunnels. Hence, given its source profile and its strong correlations with $\mathrm{NO}_{\mathrm{x}}$ and $\mathrm{CO}$, both of 540 which are emitted by motor vehicles, Source 2 likely represents the mixed contribution of local 541 gasoline- and diesel-fueled vehicle emissions to ambient $\mathrm{PM}_{2.5}$ concentrations in Steubenville.

542 The absence of $\mathrm{Zn}$ in the Source 2 profile is unexpected, as $\mathrm{Zn}$ is commonly found in engine oils, 543 tires, and brake linings, ${ }^{65,66}$ however, this may be due to modeling error, especially given the 544 presence of several other strong sources of $\mathrm{Zn}$ affecting the Steubenville site. It is also possible 545 that Source 2, which contains $84 \%$ of the total mass of apportioned EC and $66 \%$ of the total mass 546 of apportioned OM, includes some contribution from non-vehicular sources of fine particulate 547 carbon. Possible other sources include iron and steel facilities, ${ }^{68}$ coke production facilities, ${ }^{69}$ and 
vegetative burning; estimated source contributions for Source 2 were more highly correlated $\left(\mathrm{r}_{\mathrm{s}}=\right.$

549 0.73) with water-soluble $\mathrm{K}$, which is commonly used as a tracer for vegetative burning, ${ }^{70}$ than were contributions for any of the other sources resolved by PMF $\left(r_{s}=0.06-0.70\right)$.

As discussed above, the iron and steel industry is expected to be a major source of $\mathrm{Fe}$ and

$552 \mathrm{Mn}$ in Steubenville. Source 3, which accounts for $\sim 10 \%$ of the total apportioned $\mathrm{PM}_{2.5}$ mass at

553 Steubenville, is characterized by the largest mass fractions of Fe and $\mathrm{Mn}$ of the seven sources

554 resolved by PMF, and likely represents the contribution of local iron and steel emissions to $\mathrm{PM}_{2.5}$

555 in Steubenville. More than half of the total mass of Fe, Mn, and $\mathrm{Zn}$ and more than $40 \%$ of the

556 total mass of $\mathrm{Mg}$ measured at the central Steubenville site were apportioned to this source. Iron

557 oxide emissions are expected from blast furnaces, basic oxygen furnaces, and sintering

558 operations, and magnesium oxide emissions are expected from blast furnaces. ${ }^{71}$ Moreover,

559 based on 2001 Toxics Release Inventory (TRI) data from the U.S. EPA, ${ }^{72}$ the primary metals

560 industry is the largest point source emitter of $\mathrm{Mn}$ and $\mathrm{Zn}$ in Jefferson County, OH, where

561 Steubenville is located. The $\mathrm{Mn} / \mathrm{Zn}$ mass ratio of 0.18 in the Source 3 profile agrees reasonably

562 well with the ratio of 0.16 computed using the Jefferson County TRI data for the primary metals

563 industry. Koutrakis and Spengler ${ }^{21}$ also resolved an iron and steel production source in

564 Steubenville that was characterized by high mass concentrations of Fe, Mn, and Zn; their source

565 accounted for $\sim 9 \%$ of total $\mathrm{PM}_{2.5}$ mass and had a $\mathrm{Mn} / \mathrm{Zn}$ mass ratio of 0.15 , similar to our

566 Source 3. As shown in Table 5, Source 3 exhibited the strongest correlation with CO of the

567 seven sources resolved by PMF. Based on 1999 data from the U.S. EPA, ${ }^{73}$ the ferrous metals

568 processing industry accounts for $\sim 47 \%$ of estimated $\mathrm{CO}$ emissions from point and area sources

569 in the Steubenville-Weirton Metropolitan Statistical Area, consistent with our interpretation of

570 the identity of Source 3.

571 The aforementioned similarities between Sources 2 and 3 may result from the fact that

572 these factors both represent the contribution of emission sources located predominantly in the

573 immediate Steubenville vicinity to the mass of ambient $\mathrm{PM}_{2.5}$ in Steubenville. The correlations

574 presented in Table 6 support this hypothesis. As shown in the table, the estimated daily source

575 contributions for Sources 2 and 3 correlate more strongly than do the source contributions for

576 any other sources with "local source" $\mathrm{PM}_{2.5}$ concentrations estimated by subtracting daily

577 averages of the $\mathrm{PM}_{2.5}$ concentrations measured at the northern and western SCAMP satellite sites

578 from daily $\mathrm{PM}_{2.5}$ concentrations measured at the Steubenville site. Moreover, the source 
contributions for Sources 2 and 3 exhibit the strongest correlations with nighttime maximum

$580 \quad \mathrm{PM}_{2.5}$ concentrations of the seven PMF sources, and correlate much more strongly with

581 nighttime maximum $\mathrm{PM}_{2.5}$ concentrations than with daytime maxima. These correlations are

582 consistent with our interpretation of these two sources, as build-ups in the emissions from

583 vehicles and from iron and steel facilities, which have relatively short stacks, would tend to be

584 promoted by reductions in mixing height overnight and during early morning rush hour. PSCF

585 results for Source 2, shown in Figure 8b, show a high-probability source region surrounding

586 Steubenville in all directions, consistent with the hypothesis that vehicular and other local carbon

587 emissions impacted the Steubenville site regardless of the prevailing transport direction in the

588 surrounding region. The PSCF plot for Source 3 shown in Figure 8c suggests that this source

589 tended to impact the monitoring site when transport was from the south, consistent with the

590 location of major iron and steel production facilities just south of Steubenville.

591 Source 4 accounts for $\sim 15 \%$ of the total apportioned $\mathrm{PM}_{2.5}$ mass and represents the 592 contribution of $\mathrm{NH}_{4} \mathrm{NO}_{3}$-dominated aerosol to $\mathrm{PM}_{2.5}$ in Steubenville during SCAMP. As shown

593 in Figure 6d, the mass contributed by this source exhibited a marked seasonal pattern of higher

594 wintertime and lower summertime concentrations, reflecting the influence of temperature,

595 humidity, and $\mathrm{NH}_{3}$ availability on secondary $\mathrm{NO}_{3}{ }^{-}$formation. The PSCF results shown in Figure

$5968 \mathrm{i}$ (3-day backward trajectories, 500-m starting height) suggest that $\mathrm{NO}_{\mathrm{x}}$ emissions from the

597 Columbus, Dayton, Cincinnati, and Indianapolis areas to the west ${ }^{73}$ likely affect $\mathrm{NH}_{4} \mathrm{NO}_{3}$

598 concentrations in Steubenville.

599 Source 5, which accounts for $\sim 6 \%$ of the total apportioned $\mathrm{PM}_{2.5}$ mass at Steubenville

600 and has a source profile that is characterized by the largest mass fractions of $\mathrm{Al}, \mathrm{Ca}, \mathrm{K}, \mathrm{Mg}$, and

601 Ti of the seven sources resolved by PMF, likely represents the contribution of crustal material to

602 Steubenville's ambient $\mathrm{PM}_{2.5}$. The $\mathrm{Mg} / \mathrm{Al}$ and Ti/Al mass ratios of 0.30 and 0.09 , respectively,

603 computed from the source profile for Source 5 agree well with corresponding ratios of 0.26 and

6040.05 computed from the average composition of the Earth's crust reported by Mason. ${ }^{50}$ The

605 ratios of $\mathrm{Ca} / \mathrm{Al}$ and $\mathrm{K} / \mathrm{Al}$ computed from the Source 5 profile were greater and the ratio of $\mathrm{Fe} / \mathrm{Al}$

606 was less than corresponding ratios computed from Mason's data. These differences may result

607 from disparities between the composition of the crustal material affecting the Steubenville site

608 and the Earth's overall average crustal composition or from modeling or measurement error. As

609 shown in Table 5, daily source contributions for Source 5, like those for the secondary 
$610\left(\mathrm{NH}_{4}\right)_{2} \mathrm{SO}_{4}$ and $\mathrm{NH}_{4} \mathrm{NO}_{3}$ sources, did not correlate strongly with any gaseous pollutants.

611 However, Source 5 daily contributions correlated more strongly with temperature than did

612 contributions from any other source. This may reflect the increased tendency for crustal particles

613 to become airborne during warm periods when dust-producing outdoor activities are common

614 and the ground is dry and free from snow cover.

615 The remaining two sources, Source 6 and Source 7, each accounted for $\sim 0.6 \mu \mathrm{g} / \mathrm{m}^{3}(\sim 3 \%)$

616 of the total apportioned $\mathrm{PM}_{2.5}$ mass at Steubenville. The profile for Source 6 is characterized by

617 the largest mass fractions of $\mathrm{As}, \mathrm{Cu}, \mathrm{Sn}, \mathrm{V}, \mathrm{Zn}$, and especially $\mathrm{Cd}$ and $\mathrm{Pb}$ of the seven sources

618 resolved by PMF, but contains no Fe or Mn. As shown in Figure 8f, PSCF results for this source

619 indicate a probable source region including areas to the east and north of Steubenville. This

620 region is consistent with the locations of a number of metal smelting and processing plants that

621 reported air emissions of $\mathrm{Pb}, \mathrm{Cu}$, and $\mathrm{Zn}$ to the TRI, as well as with the approximate locations of

622 several sources, including a zinc smelter, glass plant, waste incinerator, and resins compounding

623 plant, that reported Cd emissions to the TRI in 2000 through $2002 .^{72}$ In their source

624 apportionment of $\mathrm{PM}_{2.5}$ in Pittsburgh, Pekney et al. ${ }^{74}$ separately resolved a Cd source, a Pb

625 source, and a source characterized by $\mathrm{As}, \mathrm{Cu}$, and $\mathrm{V}$ (as well as $\mathrm{Ga}$, which was not determined as

626 part of SCAMP, and Ni, which was assigned a large uncertainty in our PMF model). The PSCF

627 results reported for these three sources affecting Pittsburgh agree reasonably well with those

628 presented here for Source 6. Hence, Source 6 likely represents the combined impact of various

629 nonferrous metal smelting and processing plants and other industrial point sources located to the

630 east and north of Steubenville on ambient $\mathrm{PM}_{2.5}$ in that city.

631 Source 7 includes $\sim 90 \%$ of the total apportioned mass of Se, which is commonly used as

632 a tracer for primary $\mathrm{PM}_{2.5}$ emitted by coal-fired power plants, ${ }^{64}$ and also correlates well (Table 5)

633 with $\mathrm{SO}_{2}$ and $\mathrm{NO}_{2}$, which are produced in large quantities by these plants. In addition, the

634 profile for Source 7 is characterized by the largest mass fractions of $\mathrm{Ba}, \mathrm{Co}$, and $\mathrm{Ni}$ of the seven

635 sources resolved from the SCAMP data. All of these elements, as well as Al, As, Ca, K, Fe, Mn,

$636 \mathrm{~V}$, and Zn, which also appear in the Source 7 profile (Figure 5f), are expected in PM emissions

637 from coal-fired plants. ${ }^{72,75}$ The largest contributor to the mass associated with Source 7 was

$638 \mathrm{SO}_{4}{ }^{2-}$, likely reflecting some primary sulfate emissions as well as some secondary $\mathrm{SO}_{4}{ }^{2-}$ formed

639 by the atmospheric conversion of $\mathrm{SO}_{2}$ during transport from the stack to the receptor site. As

640 expected for coal-fired power plant emissions, ${ }^{68,75}$ carbon species (i.e., EC + OM) accounted for 
641 very little $(\sim 8 \%)$ of the mass associated with Source 7. PSCF results for Source 7 (Figure 8g) 642 show a probable source area comprising the Ohio River valley to the south of Steubenville, as 643 well as portions of the Ohio River valley to the north of Steubenville and the Monongahela River 644 valley to the south of Pittsburgh, where many of the region's major coal-fired power plants are

645 located. In contrast to the source apportionment modeling conducted by Koutrakis and

646 Spengler ${ }^{21}$ using $\mathrm{PM}_{2.5}$ speciation data collected in Steubenville in 1984, which attributed 8.6

$647 \mu \mathrm{g} / \mathrm{m}^{3}(35 \%)$ of Steubenville's total $\mathrm{PM}_{2.5}$ mass to local coal/oil combustion emissions, our 648 source apportionment results suggest that the contribution of primary coal-fired power plant 649 emissions to ambient $\mathrm{PM}_{2.5}$ in Steubenville is small (i.e., $\sim 0.6 \mu \mathrm{g} / \mathrm{m}^{3}$ or $3 \%$ of the total mass) in

650 spite of the continued prevalence of these plants in the surrounding area. This small contribution 651 reflects the widespread use of particulate control equipment at the plants, ${ }^{43}$ and suggests that 652 whereas reductions in secondary sulfates originating from coal-fired plants (e.g., Source 1) will 653 almost certainly be required if Steubenville is to attain compliance with the $\mathrm{PM}_{2.5} \mathrm{NAAQS}$, 654 further reductions in primary particulate emissions from these plants would be of little aid in 655 attaining a mass-based standard.

\section{CONCLUSIONS}

The source apportionment results presented here suggest that $\sim 70 \%$ of the total mass of

$659 \mathrm{PM}_{2.5}$ in Steubenville during SCAMP resulted from very distinct regional, secondary-source and

660 local, primary-source mechanisms that produced particles with dissimilar chemical

661 compositions. Secondary $\left(\mathrm{NH}_{4}\right)_{2} \mathrm{SO}_{4}$-dominated aerosol, which likely originated from $\mathrm{SO}_{2}$

662 emitted by coal-fired power plants located to the west and southwest of Steubenville, contributed $663 \sim 42 \%$ of the apportioned $\mathrm{PM}_{2.5}$ mass. Correlation analyses presented in Tables 5 and 6 suggest 664 that elevated concentrations of $\mathrm{PM}_{2.5}$ from this source (Source 1), which contained very low 665 amounts of trace metals, typically were observed on a regional scale in the Steubenville area and 666 tended to occur during warm summertime afternoons, when photochemical activity would have 667 been maximal. Conversely, major local sources in the immediate Steubenville vicinity likely 668 accounted for $\sim 30 \%$ of the total apportioned mass. These sources include motor vehicles and 669 other local sources of carbonaceous aerosols (Source 2), which contributed $20 \%$ of the total $670 \mathrm{PM}_{2.5}$ mass and more than half of the mass of fine particulate EC, OM, and Ba observed at the 671 Steubenville site, as well as iron and steel production facilities (Source 3), which contributed 
$672 \sim 10 \%$ of the total $\mathrm{PM}_{2.5}$ mass and more than half of the mass of fine particulate $\mathrm{Fe}, \mathrm{Mn}$, and $\mathrm{Zn}$

673 observed there. Based on correlation analyses, elevated concentrations of $\mathrm{PM}_{2.5}$ from these

674 sources were frequently accompanied by elevated concentrations of $\mathrm{CO}$ and $\mathrm{NO}_{\mathrm{x}}$, and often

675 occurred overnight when mixing heights tend to be minimal. The effect of the iron and steel

676 production source in particular appeared to be very localized in Steubenville; median ambient

677 concentrations of $\mathrm{Fe}$ and $\mathrm{Mn}$ observed in the water-soluble $\mathrm{PM}_{2.5}$ fraction at Steubenville were at

678 least 1.9 times as great as concentrations observed at satellite sites located 19-22 km away. As

679 shown in Figure 1, the overall mean $\mathrm{PM}_{2.5}$ concentration measured at these satellite sites was

$680 \sim 24 \%$ less than that measured at Steubenville, which is reasonably consistent with the $30 \%$ local

681 contribution estimated by PMF for Sources 2 and 3 (assuming that the satellite sites are impacted

682 by local sources from Steubenville or by their own local sources to some extent). In addition to

683 these major regional and local contributors to $\mathrm{PM}_{2.5}$ in Steubenville, $\mathrm{PMF}$ resolved a $\mathrm{NH}_{4} \mathrm{NO}_{3}$

684 source, a crustal source, a mixed nonferrous metals and industrial source, and a primary coal

685 combustion source, which contributed an estimated 15\%,6\%,3\%, and 3\%, respectively, to the

686 total $\mathrm{PM}_{2.5}$ mass observed during SCAMP.

687 Hence, these results suggest that the diverse mechanisms associated with regional and

688 local source contributions to $\mathrm{PM}_{2.5}$ in Steubenville must be carefully considered when

689 developing a SIP to address the city's nonattainment status under the $\mathrm{PM}_{2.5}$ NAAQS. Moreover,

690 the results provide an impetus for further health effects research. As discussed in the

691 introduction, a number of recent toxicology studies have discovered associations between soluble

692 PM transition metals such as Fe, V, and Zn, and pulmonary health endpoints. Trace metal

693 concentrations determined during SCAMP suggest that although ambient levels of these metals

694 have decreased appreciably since the Six Cities Study examined $\mathrm{PM}_{2.5}$ in Steubenville between

6951979 and 1988, concentrations of fine particulate Fe, Mn, and Zn at Steubenville remain

696 substantially higher than concentrations of these elements recently observed in other U.S. cities.

697 The mean fine particulate Mn concentration at Steubenville during SCAMP was about 37\% as

698 great as the U.S. ATSDR's chronic inhalation MRL for total airborne Mn; however, no chronic

699 inhalation RfCs, MRLs, or RELs have been established for Fe or Zn, which were implicated in

700 many of the aforementioned toxicology studies. Hence, further research is warranted to

701 elucidate whether these elements play any role in the health effects that previously ${ }^{19}$ have been

702 attributed to $\mathrm{PM}_{2.5}$ in Steubenville. Whereas fine particulate $\mathrm{Zn}$ in Steubenville is moderately 
703 soluble and appears to be emitted in soluble form by local sources, fine particulate Fe in the city 704 is largely insoluble. These results are consistent with $\mathrm{PM}_{10}$ trace metal solubility observations

705 made in Redcar, UK, before, during, and after the temporary closure of a steel-mill. ${ }^{76}$ However, 706 results from SCAMP are also consistent with the hypothesis that secondary sulfates may play a

707 role in mobilizing soluble fine particulate Fe under suitable photochemical conditions,

708 supporting Grahame and Schlesinger's ${ }^{53}$ recent call for additional research to examine this

709 possibility, as well as additional research to better elucidate the importance of solubility for

710 determining the biological activity of transition metals such as Fe. Ultimately, such research is

711 required to ascertain whether reducing ambient concentrations of particular components of $\mathrm{PM}_{2.5}$

712 might produce a greater public health benefit than reducing total $\mathrm{PM}_{2.5}$ mass.

\section{ACKNOWLEDGMENTS}

715 The authors thank the groups who participated in the collection of data presented here, including

716 Optimal Technologies, Control Analytics, Inc., Franciscan University of Steubenville, Wheeling

717 Jesuit University, and Saint Vincent College. The outdoor ambient air monitoring portion of

718 SCAMP was funded by the United States Department of Energy's National Energy Technology

719 Laboratory. Additional funders of SCAMP include the Ohio Coal Development Office within

720 the Ohio Air Quality Development Authority, Electric Power Research Institute, American

721 Petroleum Institute, National Mining Association, American Iron and Steel Institute, Edison

722 Electric Institute, National Institute of Environmental Health Sciences, U. S. Environmental

723 Protection Agency, and CONSOL Energy Inc.

724 This paper was prepared with the support of the U. S. Department of Energy, under

725 Award No. DE-FC26-00NT40771. However, any opinions, findings, conclusions, or

726 recommendations expressed herein are those of the authors and do not necessarily reflect the

727 views of the DOE.

\section{REFERENCES}

730 1. Lewis, C.W.; Norris, G.A.; Conner, T.L.; Henry, R.C. Source Apportionment of Phoenix $731 \quad \mathrm{PM}_{2.5}$ Aerosol with the Unmix Receptor Model; J. Air \& Waste Manage. Assoc. 2003, 53, $732 \quad 325-338$. 
2. Kim, E.; Hopke, P.K.; Edgerton, E.S. Source Identification of Atlanta Aerosol by Positive Matrix Factorization; J. Air \& Waste Manage. Assoc. 2003, 53, 731-739.

3. Maykut, N.N.; Lewtas, J.; Kim, E.; Larson, T.V. Source Apportionment of $\mathrm{PM}_{2.5}$ at an Urban IMPROVE Site in Seattle, Washington; Environ. Sci. Technol. 2003, 37, 5135-5142.

4. Kim, E.; Hopke, P.K.; Pinto, J.P.; Wilson, W.E. Spatial Variability of Fine Particle Mass, Components, and Source Contributions during the Regional Air Pollution Study in St. Louis; Environ. Sci. Technol. 2005, 39, 4172-4179.

5. Kim, E.; Hopke, P.K.; Kenski, D.M.; Koerber, M. Sources of Fine Particles in a Rural Midwestern U.S. Area; Environ. Sci. Technol. 2005, 39, 4953-4960.

6. Poirot, R.L.; Wishinski, P.R.; Hopke, P.K.; Polissar, A.V. Comparative Application of Multiple Receptor Methods to Identify Aerosol Sources in Northern Vermont; Environ. Sci. Technol. 2001, 35, 4622-4636.

7. U.S. Environmental Protection Agency. National Ambient Air Quality Standards For Particulate Matter: Final Rule; Fed. Regist. 1997, 62, 38651-38760.

8. Pritchard, R.J.; Ghio, A.J.; Lehmann, J.R.; Winsett, D.W.; Tepper, J.S.; Park, P.; Gilmour, M.I.; Dreher, K.L.; Costa, D.L. Oxidant Generation and Lung Injury after Particulate Air Pollutant Exposure Increase with the Concentrations of Associated Metals; Inhal. Toxicol. 1996, $8,457-477$.

9. Frampton, M.W.; Ghio, A.J.; Samet, J.M.; Carson, J.L.; Carter, J.D.; Devlin, R.B. Effects of Aqueous Extracts of $\mathrm{PM}_{10}$ Filters from the Utah Valley on Human Airway Epithelial Cells; Am. J. Physiol. 1999, 277, L960-L967.

10. Molinelli, A.R.; Madden, M.C.; McGee, J.K.; Stonehuerner, J.G.; Ghio, A.J. Effect of Metal Removal on the Toxicity of Airborne Particulate Matter from the Utah Valley; Inhal. Toxicol. 2002, 14, 1069-1086.

11. Gavett, S.H.; Haykal-Coates, N.; Copeland, L.B.; Heinrich, J.; Gilmour, M.I. Metal Composition of Ambient $\mathrm{PM}_{2.5}$ Influences Severity of Allergic Airways Disease in Mice; Environ. Health Perspect. 2003, 111, 1471-1477.

12. Zelikoff, J.T.; Schermerhorn, K.R.; Fang, K.; Cohen, M.D.; Schlesinger, R.B. A Role for Associated Transition Metals in the Immunotoxicity of Inhaled Ambient Particulate Matter; Environ. Health Perspect. 2002, 110 (suppl. 5), 871-875. 
13. Maciejczyk, P.; Chen, L.C. Effects of Subchronic Exposures to Concentrated Ambient Particles (CAPs) in Mice: VIII. Source-Related Daily Variations in In Vitro Responses to CAPs; Inhal. Toxicol. 2005, 17, 243-253.

14. Carter, J.D.; Ghio, A.J.; Samet, J.M.; Devlin, R.B. Cytokine Production by Human Airway Epithelial Cells After Exposure to an Air Pollution Particle is Metal-Dependent; Toxicol. Appl. Pharmacol. 1997, 146, 180-188.

15. Ghio, A.J.; Carter, J.D.; Dailey, L.A.; Devlin, R.B.; Samet, J.M. Respiratory Epithelial Cells 276, L933-L940.

16. Huang, Y.C.; Ghio, A.J.; Stoneheurner, J.; McGee, J.; Carter, J.D.; Grambow, S.C.; Devlin, R.B. The Role of Soluble Components in Ambient Fine Particles - Induced Changes in Human Lungs and Blood; Inhal. Toxicol. 2003, 15, 327-342.

17. Fernandez, A.; Davis, S.B.; Wendt, J.O.L.; Cenni, R.; Young, R.S.; Witten, M.L. Particulate Emission from Biomass Combustion; Nature 2001, 409, 998.

18. Adamson, I.Y.; Prieditis, H.; Hedgecock, C.; Vincent, R. Zinc is the Toxic Factor in the Lung Response to an Atmospheric Particulate Sample; Toxicol. Appl. Pharmacol. 2000, 166, 111119.

19. Dockery, D.W.; Pope, C.A.; Xu, X.; Spengler, J.D.; Ware, J.H.; Fay, M.E.; Ferris, B.G.; Speizer, F.E. An Association Between Air Pollution and Mortality in Six U.S. Cities; $N$. Engl. J. Med. 1993, 329, 1753-1759.

20. Spengler, J.D.; Thurston, G.D. Mass and Elemental Composition of Fine and Coarse Particles in Six U.S. Cities; J. Air Pollution Control Assoc. 1983, 33, 1162-1171.

21. Koutrakis, P.; Spengler, J.D. Source Apportionment of Ambient Particles in Steubenville, OH Using Specific Rotation Factor Analysis; Atmos. Environ. 1987, 21, 1511-1519.

22. Laden, F.; Neas, L.M.; Dockery, D.W.; Schwartz, J. Association of Fine Particulate Matter from Different Sources with Daily Mortality in Six U.S. Cities; Environ. Health Perspect. 2000, 108, 941-947.

23. Grahame, T.; Hidy, G. Using Factor Analysis to Attribute Health Impacts to Particulate Pollution Sources; Inhal. Toxicol. 2004, 16(suppl. 1), 143-152. 
24. Connell, D.P.; Withum, J.A.; Winter, S.E.; Statnick, R.M.; Bilonick, R.A. The Steubenville

793 Comprehensive Air Monitoring Program (SCAMP): Overview and Statistical

794 Considerations; J. Air \& Waste Manage. Assoc. 2005, 55, 467-480.

25. U.S. Environmental Protection Agency. Technical Support Document for the Final Clean Air Interstate Rule - Air Quality Modeling. Office of Air Quality Planning and Standards: Research Triangle Park, NC, 2005. Available: http://www.epa.gov/interstateairquality/pdfs/ finaltech02.pdf (accessed 11/18/05).

26. Tanner, S.D.; Baranov, V.I. Theory, Design, and Operation of a Dynamic Reaction Cell for ICP-MS; Atomic Spectroscopy, 1999, 20(2), 45-52.

27. Graney, J.R.; Landis, M.S.; Norris, G.A. Concentrations and Solubility of Metals from Indoor and Personal Exposure $\mathrm{PM}_{2.5}$ Samples; Atmos. Environ. 2003, 38, 237-247.

28. Pekney, N.J.; Davidson, C.I. Determination of Trace Elements in Ambient Aerosol Samples; Anal. Chim. Acta 2005, 540, 269-277.

29. Connell, D.P.; Withum, J.A.; Winter, S.E.; Statnick, R.M.; Bilonick, R.A. The Steubenville Comprehensive Air Monitoring Program (SCAMP): Associations among Fine Particulate Matter, Co-Pollutants, and Meteorological Conditions; J. Air \& Waste Manage. Assoc. 2005, 55, 481-496.

30. Connell, D.P.; Withum, J.A.; Winter, S.E.; Statnick, R.M.; Bilonick, R.A. The Steubenville Comprehensive Air Monitoring Program (SCAMP): Analysis of Short-Term and Episodic Variations in $\mathrm{PM}_{2.5}$ Concentrations Using Hourly Air Monitoring Data; J. Air \& Waste Manage. Assoc. 2005, 55, 559-573.

31. Kingston, H.M.; Jassie, L.B.; In Introduction to Microwave Sample Preparation: Theory and Practice; Kingston, H.M., Jassie, L.B., Eds.; American Chemical Society: Washington, DC, 1988; pp. 93-154.

32. May, T.W.; Wiedmeyer, R.H. A Table of Polyatomic Interferences in ICP-MS; Atomic Spectroscopy 1998, 19(5), 150-155.

33. Conrad, V.B.; Winter, S.E.; Krofcheck, D.S. ICP-MS and X-Ray Fluorescence: A Comparative Study for the Elemental Analysis of Fine Particulate Matter; Presented at the International Symposium on Measurement of Toxic and Related Air Pollutants, Research Triangle Park, NC, September 2000. 
34. Connell, D.P.; Winter, S.E.; Conrad, V.B. The Elemental Composition of $\mathrm{PM}_{2.5}$ Collected During the Steubenville Comprehensive Air Monitoring Program (SCAMP); In Proceedings of A\&WMA's 98th Annual Conference \& Exhibition, Minneapolis, MN, June 21-24, 2005; A\&WMA: Pittsburgh, PA, 2005; Paper 582.

35. Connell, D.P.; Winter, S.E.; Conrad, V.B. Characterization of $\mathrm{PM}_{2.5}$ Trace Elements in Steubenville, Ohio, Using Dynamic Reaction Cell ICP-MS; In Proceedings of Air Quality V, Arlington, VA, September 19-21, 2005.

36. Gilbert, R.O. Statistical Methods for Environmental Pollution Monitoring; Van Nostrand Reinhold: New York, 1987; pp. 177-178.

37. Paatero, P. Least Square Formulation of Robust Nonnegative Factor Analysis; Chemomet. Intell. Lab. Systems 1997, 37, 23-35.

38. Paatero, P. User's Guide for Positive Matrix Factorization Programs PMF2 and PMF3, Part 2: Reference; December 12, 2002.

39. Draxler, R.R.; Rolph, G.D. HYSPLIT (Hybrid Single-Particle Lagrangian Integrated Trajectory) Model. NOAA Air Resources Laboratory: Silver Spring, MD, 2003. Available: http://www.arl.noaa.gov/ready/hysplit4.html (accessed 12/27/05).

40. NOAA ARL - Gridded Meteorological Data Archives; http://www.arl.noaa.gov/ss/transport/ archives.html (accessed 12/27/05).

41. Lipfert, F.W. Trends in Airborne Particulate Matter in the United States; Appl. Occup. Environ. Hyg. 1998, 13, 370-384.

42. Yan, R.; Gauthier, D.; Flamant, G.; Peraudeau, G.; Lu, J.; Zheng, C. Fate of Selenium in Coal Combustion: Volatilization and Speciation in the Flue Gas; Environ. Sci. Technol. 2001, $35,1406-1410$.

43. Brown, T.D.; Smith, D.N.; Hargis, R.A.; O’Dowd, W.J. Mercury Measurement and Its Control: What We Know, Have Learned, and Need to Further Investigate; J. Air \& Waste Manage. Assoc. 1999, 49, 628-640.

44. Grahame, T.J. What Types of $\mathrm{PM}_{2.5}$ (Or Associated Pollutants) May Be More (Or Less) Likely to Cause Premature Mortality? In Proceedings of the Valuing Externalities Workshop, McLean, VA, February 20-21, 2003. Available: http://www.netl.doe.gov/publications/ proceedings/03/valuing-ext/v-ext03.html (accessed 12/27/05). 
852 45. Begum, B.A.; Hopke, P.K.; Zhao, W. Source Identification of Fine Particles in Washington, 853 DC, by Expanded Factor Analysis Modeling; Environ. Sci. Technol. 2005, 39, 1129-1137.

46. Marmur, A.; Unal, A.; Mulholland, J.A.; Russell, A.G. Optimization-Based Source Apportionment of $\mathrm{PM}_{2.5}$ Incorporating Gas-to-Particle Ratios; Environ. Sci. Technol. 2005, $39,3245-3254$.

47. U.S. Environmental Protection Agency, Technology Transfer Network, Air Toxics Website,

858 Sources of Chronic Dose-Response Information. http://www.epa.gov/ttn/atw/toxsource/ chronicsources.html (accessed 12/1/05).

48. Agency for Toxic Substances and Disease Registry, Minimal Risk Levels (MRLs) for Hazardous Substances. http://www.atsdr.cdc.gov/mrls.html (accessed 12/1/05).

49. California Office of Environmental Health Hazard Assessment, Air - Chronic RELs. http://www.oehha.ca.gov/air/chronic_rels/AllChrels.html (accessed 12/1/05).

50. Mason, B. Principles of Geochemistry; John Wiley \& Sons: New York, 1966; pp 45-46.

51. Skoog, D.A.; West, D.M.; Holler, F.J. Fundamentals of Analytical Chemistry, $7^{\text {th }}$ ed.; Harcourt: Fort Worth, 1996; p 750.

52. Lay, J.C.; Bennett, W.D.; Ghio, A.J.; Bromberg, P.A.; Costa, D.L.; Kim, C.S.; Koren, H.S.; Devlin, R.B. Cellular and Biochemical Response of the Human Lung After Intrapulmonary Instillation of Ferric Oxide Particles; Am. J. Respir. Cell Mol. Biol. 1999, 20, 631-642.

53. Grahame, T.J.; Schlesinger, R.B. Evaluating the Health Risk from Secondary Sulfates in Eastern North American Regional Ambient Air Particulate Matter; Inhal. Toxicol. 2005, 17, $15-27$.

54. Faust, B.C.; Hoigne, J. Photolysis of Fe(III)-Hydroxy Complexes as Sources of OH Radicals in Clouds, Fog and Rain; Atmos. Environ. 1990, 24A, 79-89.

55. Zhu, X.; Prospero, J.M.; Savoie, D.L.; Millero, F.J.; Zika, R.G.; Saltzman, E.S. Photoreduction of Iron(III) in Marine Mineral Aerosols; J. Geophys. Res. [Atmos.] 1993, 98, 9039-9046.

56. Majestic, B.J.; Schauer, J.J.; Shafer, M.M.; Turner, J.R.; Fine, P.M.; Singh, M.; Sioutas, C. Development of a Wet-Chemical Method for the Speciation of Iron in Atmospheric Aerosols; Environ. Sci. Technol. 2006, 40, 2346-2351.

57. Ghio, A.J.; Stoneheurner, J.; McGee, J.K.; Kinsey, J.S. Sulfate Content Correlates with Iron Concentrations in Ambient Air Pollution Particles; Inhal. Toxicol. 1999, 11, 293-307. 
58. Lay, J.C.; Zeman, K.L.; Ghio, A.J.; Bennett, W.D. Effects of Inhaled Iron Oxide Particles on Alveolar Epithelial Permeability in Normal Subjects; Inhal. Toxicol. 2001, 13, 1065-1078.

59. Sackner, M.A.; Dougherty, R.L.; Chapman, G.A.; Cipley, J.; Perez, D.; Kwoka, M.; Reinhart, M.; Brito, M.; Schreck, R. Effects of Brief and Intermediate Exposures to Sulfate Submicron Aerosols and Sulfate Injections and Cardiopulmonary Function of Dogs and Tracheal Mucous Velocity of Sheep; J. Toxicol. Environ. Health; 1981, 7, 951-972.

60. Ghio, A.J.; Stonehuerner, J.; Dailey, L.A.; Carter, J.D. Metals Associated with Both the Water-Soluble and Insoluble Fractions of an Ambient Air Pollution Particle Catalyze an Oxidative Stress; Inhal. Toxicol. 1999, 11, 37-49.

61. Fernandez, A.; Wendt, J.O.L.; Witten, M.L. Health Effects Engineering of Coal and Biomass Combustion Particulates: Influence of Zinc, Sulfur and Process Changes on Potential Lung Injury from Inhaled Ash; Fuel 2005, 85, 1320-1327.

62. Dusseldorp, A.; Kruize, H.; Brunekreef, B.; Hofschreuder, P.; de Meer, G.; van Oudvorst, A.B. Associations of $\mathrm{PM}_{10}$ and Airborne Iron with Respiratory Health of Adults Living Near a Steel Factory; Am. J. Respir. Crit. Care Med. 1995, 152, 1932-1939.

63. Henry, R.C.; Norris, G.A. EPA Unmix 2.3 User Guide; March 2002.

64. Suarez, A.E.; Ondov, J.M. Ambient Aerosol Concentrations of Elements Resolved by Size and Source: Contributions of Some Cytokine-Active Metals from Coal- and Oil-Fired Power Plants; Energy \& Fuels 2002, 16, 562-568.

65. Chellam, S.; Kulkarni, P.; Fraser, M.P. Emissions of Organic Compounds and Trace Metals in Fine Particulate Matter from Motor Vehicles: A Tunnel Study in Houston, Texas; J. Air \& Waste Manage. Assoc. 2005, 55, 60-72.

66. Lough, G.C.; Schauer, J.J.; Park, J.-S.; Shafer, M.M.; Deminter, J.T.; Weinstein, J.P.

Emissions of Metals Associated with Motor Vehicle Roadways; Environ. Sci. Technol. 2005, 39, 826-836.

67. Coutant, B.W.; Holloman, C.H.; Swinton, K.E.; Hafner, H.R. Eight-Site Source Apportionment of PM $M_{2.5}$ Speciation Trends Data; Final Report to the U.S. EPA Office of Air Quality Planning and Standards, Emissions, Monitoring, and Analysis Division; Contract No. 68-D-02-061, September 2003. 
68. Cabada, J.C.; Pandis, S.N.; Robinson, A.L. Sources of Atmospheric Carbonaceous Particulate Matter in Pittsburgh, Pennsylvania; J. Air \& Waste Manage. Assoc. 2002, 52, 732-741.

69. Weitkamp, E.A.; Lipsky, E.M.; Pancras, P.J.; Ondov, J.M.; Polidori, A.; Turpin, B.J.; Robinson, A.L. Fine Particle Emission Profile for a Large Coke Production Facility Based on Highly Time-Resolved Fence Line Measurements; Atmos. Environ. 2005, 39, 6719-6733.

70. Gordon, G.E. Receptor Models; Environ. Sci. Technol. 1988, 22, 1132-1142.

71. U.S. Environmental Protection Agency; Compilation of Air Pollutant Emission Factors, Volume 1: Stationary Point and Area Sources, $5^{\text {th }}$ ed. Available: http://www.epa.gov/ttn/ chief/ap42/index.html (accessed 12/29/05).

72. U.S. Environmental Protection Agency, Toxics Release Inventory (TRI) Program, Get TRI Data. http://www.epa.gov/tri/tridata/index.htm (accessed 12/29/05).

73. U.S. Environmental Protection Agency, AirData: Access to Air Pollution Data. http://www.epa.gov/air/data/index.html (accessed 12/29/05).

74. Pekney, N.J.; Davidson, C.I.; Zhou, L.; Hopke, P.K. Identifying Sources of PM $_{2.5}$ in Pittsburgh Using PMF and PSCF; Presented at the AAAR Specialty Conference: Particulate Matter, Supersites Program \& Related Studies, Atlanta, GA, February 7-11, 2005.

75. Lee, S.W. Source Profiles of Particulate Matter Emissions from a Pilot-Scale Boiler Burning North American Coal Blends; J. Air \& Waste Manage. Assoc. 2001, 51, 1568-1578.

76. Hutchinson, G.R.; Brown, D.M.; Hibbs, L.R.; Heal, M.R.; Donaldson, K.; Maynard, R.L.; Monaghan, M.; Nicholl, A.; Stone, V. The Effect of Refurbishing a UK Steel Plant on PM 10 937 is a Research Group Leader, all with CONSOL Energy Inc. Research \& Development.

938 Myoungwoo Kim is a Research Manager with the Center for Air Quality at Ohio University, and

939 Kevin C. Crist, Ph.D., is an Associate Professor of Chemical Engineering and Director of the 940 Center for Air Quality at Ohio University. Please direct correspondence to Daniel P. Connell, 941 CONSOL Energy Inc. Research \& Development, 4000 Brownsville Road, South Park, PA

94215129 , or send email to danielconnell@ consolenergy.com. 
Table 1. Summary of methods and method performance for the determination of elements in the water-soluble and acid-digestible $\mathrm{PM}_{2.5}$ fractions by DRC ICP-MS.

\begin{tabular}{|c|c|c|c|c|c|c|c|}
\hline \multirow[b]{2}{*}{ Element } & \multicolumn{3}{|c|}{ Water-Soluble $\mathrm{PM}_{2.5}$ Fraction } & \multicolumn{4}{|c|}{ Acid-Digestible $\mathrm{PM}_{2.5}$ Fraction } \\
\hline & Methods ${ }^{a}$ & $\begin{array}{l}\% \text { of } \\
\text { Obs. } \\
<\text { LOD }^{b}\end{array}$ & $\begin{array}{l}\text { Recovery of } \\
\text { NIST SRM 1643d } \\
\text { (Mean } \pm \text { SD, \%) }\end{array}$ & Methods ${ }^{a}$ & $\begin{array}{l}\% \text { of } \\
\text { Obs. } \\
<\text { LOD }^{b}\end{array}$ & $\begin{array}{c}\text { Recovery of } \\
\text { NIST SRM } 2783 \\
\text { (Mean } \pm \text { SD, \%) }\end{array}$ & $\begin{array}{c}\text { Method } \\
\text { Imprecisionc } \\
(\%)\end{array}$ \\
\hline $\mathrm{Al}$ & $27\left(\mathrm{NH}_{3}\right)$ & 0 & $94 \pm 4$ & $27\left(\mathrm{NH}_{3}\right)$ & 0 & $99 \pm 34$ & 20.8 \\
\hline As & $75\left(\mathrm{CH}_{4}\right)$ & 0 & $90 \pm 9$ & $75,75\left(\mathrm{CH}_{4}\right), 75\left(\mathrm{NH}_{3}\right)$ & 7 & $110 \pm 7$ & 21.9 \\
\hline $\mathrm{Ba}$ & 138 & 0 & $102 \pm 4$ & 138 & 1 & $104 \pm 11$ & NA \\
\hline $\mathrm{Ca}$ & $40\left(\mathrm{CH}_{4}\right), 40\left(\mathrm{NH}_{3}\right), 44$ & 0 & $98 \pm 24$ & $40\left(\mathrm{CH}_{4}\right), 44$ & 6 & $104 \pm 6$ & 24.2 \\
\hline $\mathrm{Cd}$ & 111,114 & 0 & $97 \pm 1$ & 111,114 & 1 & NA & 21.5 \\
\hline Co & 59 & 1 & $99 \pm 2$ & 59 & 22 & $115 \pm 12$ & NA \\
\hline $\mathrm{Cu}$ & 63 & 0 & $95 \pm 10$ & $63\left(\mathrm{CH}_{4}\right), 63\left(\mathrm{NH}_{3}\right), 65\left(\mathrm{CH}_{4}\right)$ & 2 & $79 \pm 21$ & 17.9 \\
\hline $\mathrm{Fe}$ & $54\left(\mathrm{CH}_{4}\right), 56\left(\mathrm{CH}_{4}\right)$ & 4 & $121 \pm 18$ & $54\left(\mathrm{CH}_{4}\right), 56\left(\mathrm{CH}_{4}\right), 56\left(\mathrm{NH}_{3}\right)$ & 0 & $97 \pm 12$ & 19.2 \\
\hline $\mathrm{K}$ & $39\left(\mathrm{CH}_{4}\right), 39\left(\mathrm{NH}_{3}\right)$ & 5 & $115 \pm 13$ & $39\left(\mathrm{CH}_{4}\right), 39\left(\mathrm{NH}_{3}\right)$ & 1 & $99 \pm 11$ & 15.1 \\
\hline $\mathrm{Mg}$ & 24,25 & 0 & $100 \pm 9$ & 24,25 & 0 & $97 \pm 5$ & 22.1 \\
\hline $\mathrm{Mn}$ & $55\left(\mathrm{CH}_{4}\right)$ & 9 & $111 \pm 7$ & $55\left(\mathrm{CH}_{4}\right), 55\left(\mathrm{NH}_{3}\right)$ & 1 & 106 & 22.6 \\
\hline $\mathrm{Na}$ & $23,23\left(\mathrm{NH}_{3}\right)$ & 0 & $105 \pm 23$ & - & - & - & - \\
\hline $\mathrm{Ni}$ & 58,60 & 2 & $98 \pm 3$ & $58,58\left(\mathrm{NH}_{3}\right), 60\left(\mathrm{CH}_{4}\right)$ & 27 & $119 \pm 20$ & NA \\
\hline $\mathrm{Pb}$ & 208 & 1 & $101 \pm 5$ & 207,208 & 0 & $101 \pm 5$ & 21.8 \\
\hline $\mathrm{Se}$ & $80\left(\mathrm{CH}_{4}\right), 82$ & 1 & $92 \pm 8$ & $78\left(\mathrm{CH}_{4}\right), 80\left(\mathrm{CH}_{4}\right)$ & 1 & NA & 16.8 \\
\hline Sn & 118 & 5 & NA & 118,120 & 1 & NA & 24.0 \\
\hline $\mathrm{Ti}$ & - & - & - & 48 & 2 & $71 \pm 14$ & 21.3 \\
\hline V & $51\left(\mathrm{CH}_{4}\right)$ & 3 & $99 \pm 9$ & $51\left(\mathrm{NH}_{3}\right)$ & 1 & $84 \pm 10$ & 33.6 \\
\hline $\mathrm{Zn}$ & 66,68 & 0 & $100 \pm 6$ & $64\left(\mathrm{NH}_{3}\right), 66,68$ & 0 & $108 \pm 8$ & 18.7 \\
\hline
\end{tabular}

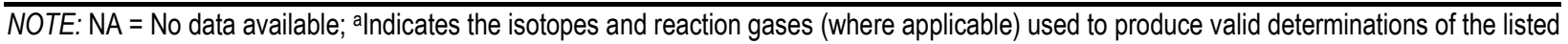
element by DRC ICP-MS; ' Percentage of observations that were less than the analytical limit of detection; ${ }^{c}$ Method imprecision $=100$. $(\mathrm{RMSD} / \sqrt{2})$ / mean, where RMSD is the root mean square difference between duplicate determinations (i.e., from separate analyses of collocated filters) of a given element, and mean is the overall mean concentration of that element measured at Steubenville during SCAMP. 
Table 2. Summary statistics for 24 -hr average ambient air concentrations and fractional solubilities of elements in $\mathrm{PM}_{2.5}$ collected at Steubenville during SCAMP.

\begin{tabular}{|c|c|c|c|c|c|c|c|c|c|c|}
\hline \multirow[b]{2}{*}{ Element } & \multicolumn{7}{|c|}{ Concentration $\left(\mathrm{ng} / \mathrm{m}^{3}\right)$} & \multicolumn{3}{|c|}{ Fractional Solubility ${ }^{a}$} \\
\hline & $\mathbf{N}$ & Mean & SD & Q25 & Q50 & Q75 & Max & Q25 & Q50 & Q75 \\
\hline $\mathrm{Al}$ & 135 & 97.7 & 56.6 & 62.2 & 80.8 & 123.3 & 411.7 & 0.09 & 0.14 & 0.23 \\
\hline As & 139 & 1.64 & 1.64 & 0.67 & 1.20 & 1.88 & 10.56 & 1.29 & 1.60 & 1.88 \\
\hline $\mathrm{Ba}$ & 124 & 2.3 & 1.5 & 1.1 & 2.0 & 3.2 & 8.5 & 0.69 & 0.82 & 1.00 \\
\hline $\mathrm{Ca}$ & 137 & 136 & 61 & 93 & 118 & 167 & 310 & 0.37 & 0.53 & 0.71 \\
\hline $\mathrm{Cd}$ & 139 & 0.46 & 0.58 & 0.19 & 0.30 & 0.51 & 5.89 & 0.86 & 1.04 & 1.23 \\
\hline Co & 122 & 0.065 & 0.047 & 0.030 & 0.061 & 0.091 & 0.209 & 0.38 & 0.55 & 0.77 \\
\hline $\mathrm{Cu}$ & 130 & 3.2 & 1.8 & 1.9 & 2.8 & 4.0 & 9.8 & 0.55 & 0.73 & 0.94 \\
\hline $\mathrm{Fe}$ & 139 & 272 & 308 & 87 & 173 & 294 & 1530 & 0.03 & 0.06 & 0.11 \\
\hline $\mathrm{K}$ & 134 & 91 & 55 & 55 & 73 & 114 & 261 & 0.76 & 1.00 & 1.32 \\
\hline $\mathrm{Mg}$ & 138 & 47 & 48 & 20 & 32 & 57 & 389 & 0.47 & 0.56 & 0.70 \\
\hline $\mathrm{Mn}$ & 139 & 14.6 & 15.4 & 5.0 & 9.6 & 17.4 & 90.5 & 0.40 & 0.51 & 0.64 \\
\hline $\mathrm{Ni}$ & 121 & 1.1 & 1.5 & 0.3 & 0.7 & 1.5 & 8.1 & 0.29 & 0.44 & 0.86 \\
\hline $\mathrm{Pb}$ & 139 & 15.3 & 20.7 & 7.0 & 10.5 & 16.2 & 218.3 & 0.37 & 0.47 & 0.60 \\
\hline $\mathrm{Se}$ & 132 & 3.30 & 3.21 & 1.49 & 2.40 & 4.20 & 24.69 & 1.14 & 1.38 & 1.69 \\
\hline Sn & 137 & 1.36 & 1.19 & 0.62 & 0.97 & 1.55 & 5.97 & 0.07 & 0.13 & 0.23 \\
\hline $\mathrm{Ti}$ & 121 & 16.9 & 20.6 & 8.9 & 11.6 & 17.7 & 159.0 & NA & NA & NA \\
\hline V & 132 & 1.50 & 1.49 & 0.57 & 1.06 & 1.99 & 11.02 & 0.47 & 0.66 & 0.85 \\
\hline $\mathrm{Zn}$ & 139 & 84.4 & 81.4 & 40.9 & 57.6 & 89.8 & 448.6 & 0.39 & 0.49 & 0.60 \\
\hline
\end{tabular}

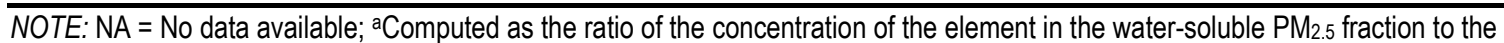
concentration of the element in the acid-digestible $\mathrm{PM}_{2.5}$ fraction for a given day. 
Table 3. Spearman correlations between 24-hr average $\mathrm{PM}_{2.5}$ trace element fractional solubilities and 24-hr sulfate concentrations or temperatures at Steubenville, by astronomical season.

\begin{tabular}{|c|c|c|c|c|c|c|c|c|}
\hline \multirow[b]{2}{*}{ Element } & \multicolumn{4}{|c|}{ Sulfate } & \multicolumn{4}{|c|}{ Temperature } \\
\hline & Winter & Spring & Summer & Fall & Winter & Spring & Summer & Fall \\
\hline $\mathrm{Al}$ & 0.75 & 0.59 & -0.01 & 0.68 & 0.64 & 0.63 & 0.17 & 0.28 \\
\hline As & 0.05 & 0.02 & -0.01 & -0.11 & -0.17 & -0.24 & 0.32 & -0.45 \\
\hline $\mathrm{Ba}$ & -0.26 & -0.06 & -0.13 & -0.06 & -0.37 & 0.21 & -0.29 & -0.48 \\
\hline $\mathrm{Ca}$ & 0.46 & -0.15 & -0.01 & 0.34 & 0.63 & 0.14 & -0.25 & 0.12 \\
\hline $\mathrm{Cd}$ & 0.47 & 0.26 & -0.15 & 0.18 & 0.34 & 0.05 & 0.07 & -0.13 \\
\hline Co & 0.32 & 0.02 & 0.11 & -0.15 & 0.19 & -0.13 & -0.18 & -0.09 \\
\hline $\mathrm{Cu}$ & 0.25 & -0.07 & 0.83 & -0.18 & 0.07 & 0.29 & 0.82 & 0.43 \\
\hline $\mathrm{Fe}$ & 0.17 & 0.33 & 0.66 & 0.07 & -0.21 & 0.39 & 0.72 & -0.34 \\
\hline $\mathrm{K}$ & 0.24 & 0.19 & -0.52 & 0.24 & -0.06 & 0.10 & -0.37 & -0.41 \\
\hline $\mathrm{Mg}$ & 0.13 & 0.43 & -0.36 & 0.33 & 0.02 & 0.47 & -0.51 & -0.31 \\
\hline $\mathrm{Mn}$ & 0.30 & 0.40 & 0.39 & 0.02 & 0.21 & 0.30 & 0.47 & -0.13 \\
\hline $\mathrm{Ni}$ & 0.08 & -0.11 & 0.46 & 0.14 & -0.07 & -0.05 & 0.60 & -0.53 \\
\hline $\mathrm{Pb}$ & 0.27 & 0.42 & -0.06 & 0.02 & 0.21 & 0.45 & 0.18 & -0.16 \\
\hline $\mathrm{Se}$ & 0.31 & -0.31 & -0.32 & 0.33 & 0.18 & 0.01 & 0.25 & -0.04 \\
\hline Sn & -0.22 & -0.17 & 0.51 & -0.43 & -0.34 & 0.27 & 0.79 & -0.49 \\
\hline V & 0.12 & 0.11 & -0.05 & 0.12 & 0.24 & -0.10 & 0.39 & -0.31 \\
\hline $\mathrm{Zn}$ & 0.50 & 0.55 & 0.32 & 0.73 & 0.47 & 0.17 & -0.02 & 0.16 \\
\hline
\end{tabular}


Table 4. Median 24-hr ambient air concentrations of elements in the water-soluble $\mathrm{PM}_{2.5}$ fraction at the five SCAMP monitoring sites, as well as significance of differences between concentrations at each Satellite site and concentrations at the Steubenville site.

\begin{tabular}{|c|c|c|c|c|c|c|c|c|c|}
\hline \multirow[b]{2}{*}{ Element } & \multirow{2}{*}{$\begin{array}{c}\text { Steubenville } \\
\text { Median } \\
\left(\mathrm{ng} / \mathrm{m}^{3}\right)\end{array}$} & \multicolumn{2}{|c|}{ Northern Site } & \multicolumn{2}{|c|}{ Southern Site } & \multicolumn{2}{|c|}{ Eastern Site } & \multicolumn{2}{|c|}{ Western Site } \\
\hline & & $\begin{array}{l}\text { Median } \\
\left(\mathrm{ng} / \mathrm{m}^{3}\right)\end{array}$ & P-value ${ }^{a}$ & $\begin{array}{l}\text { Median } \\
\left(\mathrm{ng} / \mathrm{m}^{3}\right)\end{array}$ & P-value ${ }^{a}$ & $\begin{array}{l}\text { Median } \\
\left(\mathrm{ng} / \mathrm{m}^{3}\right)\end{array}$ & P-value ${ }^{a}$ & $\begin{array}{l}\text { Median } \\
\left(\mathrm{ng} / \mathrm{m}^{3}\right)\end{array}$ & P-value ${ }^{a}$ \\
\hline $\mathrm{Al}$ & 13.2 & 6.9 & $0.000(<)$ & 9.9 & $0.001(<)$ & 6.7 & $0.000(<)$ & 7.4 & $0.001(<)$ \\
\hline As & 1.95 & 1.52 & $0.000(<)$ & 1.73 & $0.009(<)$ & 1.51 & $0.000(<)$ & 1.29 & $0.000(<)$ \\
\hline $\mathrm{Ba}$ & 1.6 & 0.9 & $0.000(<)$ & 2.8 & $0.000(>)$ & 1.5 & 0.116 & 1.1 & $0.000(<)$ \\
\hline $\mathrm{Ca}$ & 61 & 42 & $0.000(<)$ & 50 & $0.003(<)$ & 43 & $0.000(<)$ & 54 & $0.000(<)$ \\
\hline $\mathrm{Cd}$ & 0.36 & 0.24 & $0.000(<)$ & 0.28 & $0.011(<)$ & 0.25 & $0.002(<)$ & 0.25 & $0.000(<)$ \\
\hline Co & 0.035 & 0.029 & $0.007(<)$ & 0.038 & 0.285 & 0.035 & 0.407 & 0.033 & 0.361 \\
\hline $\mathrm{Cu}$ & 2.0 & 1.6 & $0.000(<)$ & 2.2 & 0.756 & 1.9 & 0.427 & 1.7 & $0.020(<)$ \\
\hline $\mathrm{Fe}$ & 12.4 & 6.7 & $0.000(<)$ & 11.9 & $0.000(<)$ & 7.0 & $0.000(<)$ & 6.4 & $0.000(<)$ \\
\hline $\mathrm{K}$ & 80 & 70 & $0.000(<)$ & 71 & $0.007(<)$ & 77 & 0.557 & 58 & $0.000(<)$ \\
\hline $\mathrm{Mg}$ & 19 & 10 & $0.000(<)$ & 9 & $0.000(<)$ & 8 & $0.000(<)$ & 10 & $0.000(<)$ \\
\hline $\mathrm{Mn}$ & 5.3 & 2.5 & $0.000(<)$ & 2.0 & $0.000(<)$ & 2.0 & $0.000(<)$ & 2.0 & $0.000(<)$ \\
\hline $\mathrm{Na}$ & 69 & 46 & $0.000(<)$ & 52 & $0.013(<)$ & 53 & $0.000(<)$ & 47 & $0.000(<)$ \\
\hline $\mathrm{Ni}$ & 0.5 & 0.5 & 0.077 & 0.5 & 0.564 & 0.5 & 0.131 & 0.5 & 0.319 \\
\hline $\mathrm{Pb}$ & 5.3 & 3.8 & $0.000(<)$ & 3.8 & $0.000(<)$ & 3.4 & $0.000(<)$ & 3.5 & $0.000(<)$ \\
\hline $\mathrm{Se}$ & 3.43 & 3.72 & 0.963 & 3.28 & 0.100 & 3.48 & 0.278 & 2.83 & $0.003(<)$ \\
\hline Sn & 0.11 & 0.11 & 0.215 & 0.14 & 0.129 & 0.19 & $0.000(>)$ & 0.14 & 0.225 \\
\hline V & 0.66 & 0.55 & 0.068 & 0.66 & 0.126 & 0.50 & $0.000(<)$ & 0.46 & $0.000(<)$ \\
\hline $\mathrm{Zn}$ & 28.0 & 16.4 & $0.000(<)$ & 15.6 & $0.000(<)$ & 15.7 & $0.000(<)$ & 14.1 & $0.000(<)$ \\
\hline
\end{tabular}

aTwo-tailed p-value resulting from a Wilcoxon signed rank test applied to paired differences in concentrations measured at the satellite site and at the Steubenville site. For P-values indicating statistically significant differences at $\alpha=0.05$, the parenthetical indicates whether concentrations measured at the satellite site tended to be greater than $(>)$ or less than $(<)$ those measured at Steubenville. 
Table 5. Spearman correlations between 24-hr PMF-estimated source contributions and 24-hr average gaseous pollutant concentrations and meteorological conditions at Steubenville.

Source 1 Source 2 Source 3 Source 4 Source 5 Source 6 Source 7

\begin{tabular}{lccccccc}
\hline $\mathrm{SO}_{2}$ & 0.33 & 0.54 & 0.50 & -0.05 & 0.34 & 0.26 & 0.71 \\
$\mathrm{NO}$ & 0.03 & 0.71 & 0.65 & 0.06 & 0.11 & 0.55 & 0.54 \\
$\mathrm{NO}_{2}$ & 0.12 & 0.77 & 0.65 & -0.08 & 0.45 & 0.56 & 0.70 \\
$\mathrm{CO}$ & 0.27 & 0.73 & 0.76 & 0.05 & 0.35 & 0.49 & 0.54 \\
$\mathrm{O}_{3}$ & 0.17 & -0.14 & -0.05 & -0.37 & 0.35 & -0.16 & -0.30 \\
$\mathrm{WS}$ & -0.21 & -0.52 & -0.32 & 0.07 & -0.08 & -0.47 & -0.29 \\
$\mathrm{Temp}$ & 0.51 & 0.35 & 0.37 & -0.54 & 0.58 & 0.30 & 0.28 \\
$\mathrm{RH}$ & 0.31 & -0.36 & -0.39 & 0.10 & -0.32 & 0.03 & -0.10 \\
$\mathrm{BP}$ & 0.07 & 0.40 & 0.47 & -0.28 & 0.37 & 0.25 & 0.26 \\
\hline
\end{tabular}

$\overline{\text { Note: } \text { WS = wind speed; Temp = temperature; } \mathrm{RH}=\text { relative humidity; } \mathrm{BP}=\text { barometric }}$ pressure. 
Table 6. Spearman correlation coefficients between 24-hr PMF-estimated source contributions and measures of the intraday timing of $\mathrm{PM}_{2.5}$ episodes and impact of local vs. regional sources on $\mathrm{PM}_{2.5}$ concentrations in Steubenville.

\begin{tabular}{|c|c|c|c|c|}
\hline & 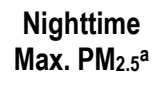 & $\begin{array}{c}\text { Daytime } \\
\text { Max. } \mathrm{PM}_{2.5} \mathrm{~b}\end{array}$ & $\begin{array}{l}\text { Local } \\
\mathrm{PM}_{2.5^{\mathrm{C}}}\end{array}$ & $\begin{array}{c}\text { Regional } \\
\mathrm{PM}_{2.5^{\mathrm{d}}}\end{array}$ \\
\hline Source 1 & 0.35 & 0.71 & 0.44 & 0.76 \\
\hline Source 2 & 0.73 & 0.27 & 0.63 & 0.38 \\
\hline Source 3 & 0.65 & 0.09 & 0.67 & 0.06 \\
\hline Source 4 & -0.13 & -0.06 & 0.06 & 0.22 \\
\hline Source 5 & 0.42 & 0.37 & 0.36 & 0.24 \\
\hline Source 6 & 0.36 & 0.08 & 0.50 & 0.15 \\
\hline Source 7 & 0.45 & 0.38 & 0.44 & 0.45 \\
\hline
\end{tabular}

aMaximum 1-hr concentration measured between 2:00 a.m. and 9:00 a.m. EST; bMaximum 1-hr concentration measured between 12:00 p.m. and 7:00 p.m. EST; 'Difference between 24-hr concentration measured at Steubenville and average of 24-hr concentrations measured at the northern and western sites; dAverage of 24-hr concentrations measured at the northern and western sites. 


\section{FIGURE CAPTIONS}

Figure 1. Average $\mathrm{PM}_{2.5}$ concentrations $\left(\mu \mathrm{g} / \mathrm{m}^{3}\right)$ measured at the five SCAMP monitoring sites between May 2000 and May 2002.

Figure 2. Sensitivity of robust $\mathrm{Q}$ to changes in FPEAK for final 7-source PMF model.

Figure 3. Ratio of warm season (April - September) to cool season (October - March) median concentrations (in both the water-soluble and acid-digestible $\mathrm{PM}_{2.5}$ fractions) and fractional solubilities measured at the Steubenville site. Solid symbols indicate statistically significant (at $\alpha=0.05$ ) seasonal differences, based on the results of Wilcoxon rank sum tests.

Figure 4. Spearman correlations between concentrations measured at Steubenville and concentrations measured at each satellite site for elements in the water-soluble $\mathrm{PM}_{2.5}$ fraction.

Figure 5. Source profiles (with $1 \sigma$ uncertainties) estimated by applying PMF to $\mathrm{PM}_{2.5}$ mass and composition data measured at Steubenville during SCAMP.

Figure 6. Time series of source contributions $\left(\mu \mathrm{g} \mathrm{PM}_{2.5} / \mathrm{m}^{3}\right)$ at Steubenville estimated by the seven-factor PMF model. The overall mean contribution from each source is also indicated.

Figure 7. $\mathrm{PM}_{2.5}$ concentrations predicted by the seven-factor PMF model vs. $\mathrm{PM}_{2.5}$ concentrations measured at Steubenville, with parity line and linear regression line (bold).

Figure 8. PSCF plots showing possible source regions for each of the seven factors resolved by PMF. Subplots (a) through (g) show results obtained for each of the factors using 24-hr backward trajectories with starting heights of $50 \mathrm{~m}$; subplots (h) and (i) show results obtained for the sulfate and nitrate sources, respectively, using 72-hr backward trajectories with starting heights of $500 \mathrm{~m}$. 


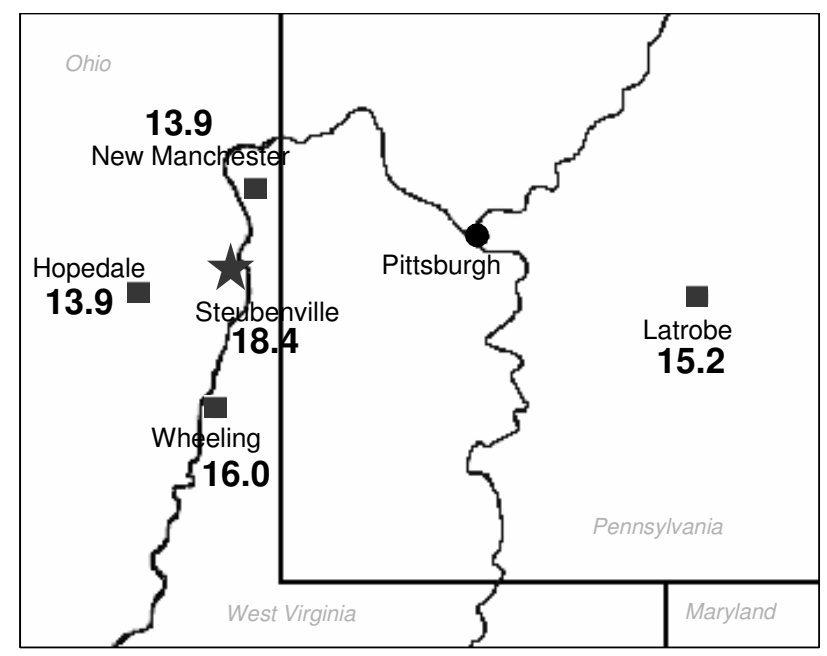




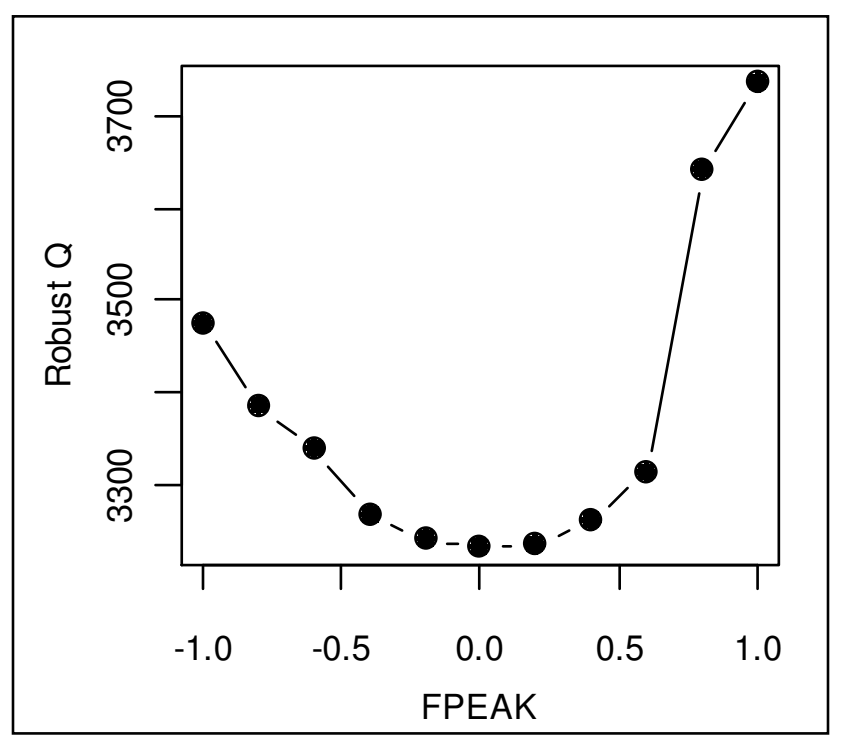




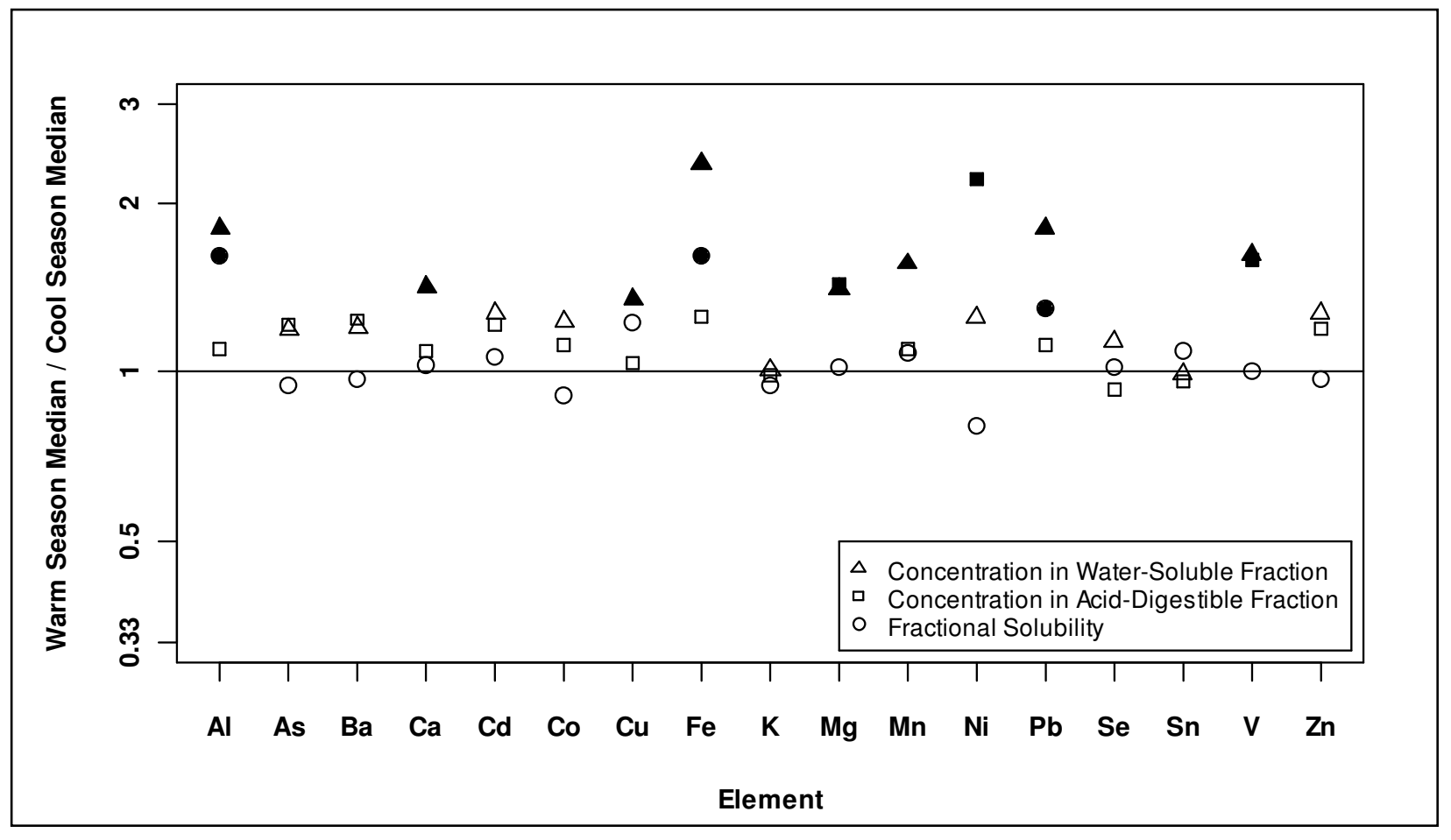




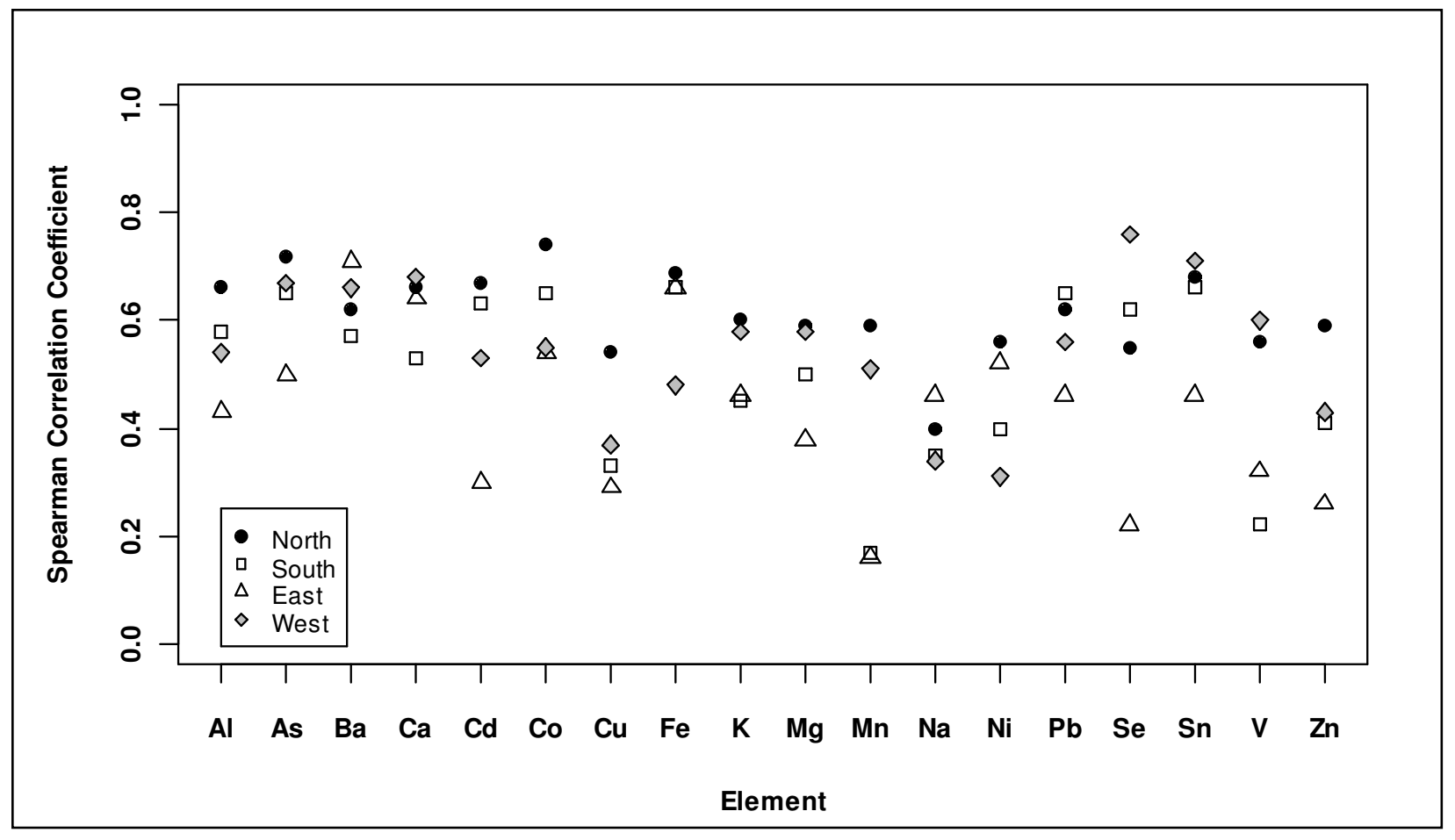




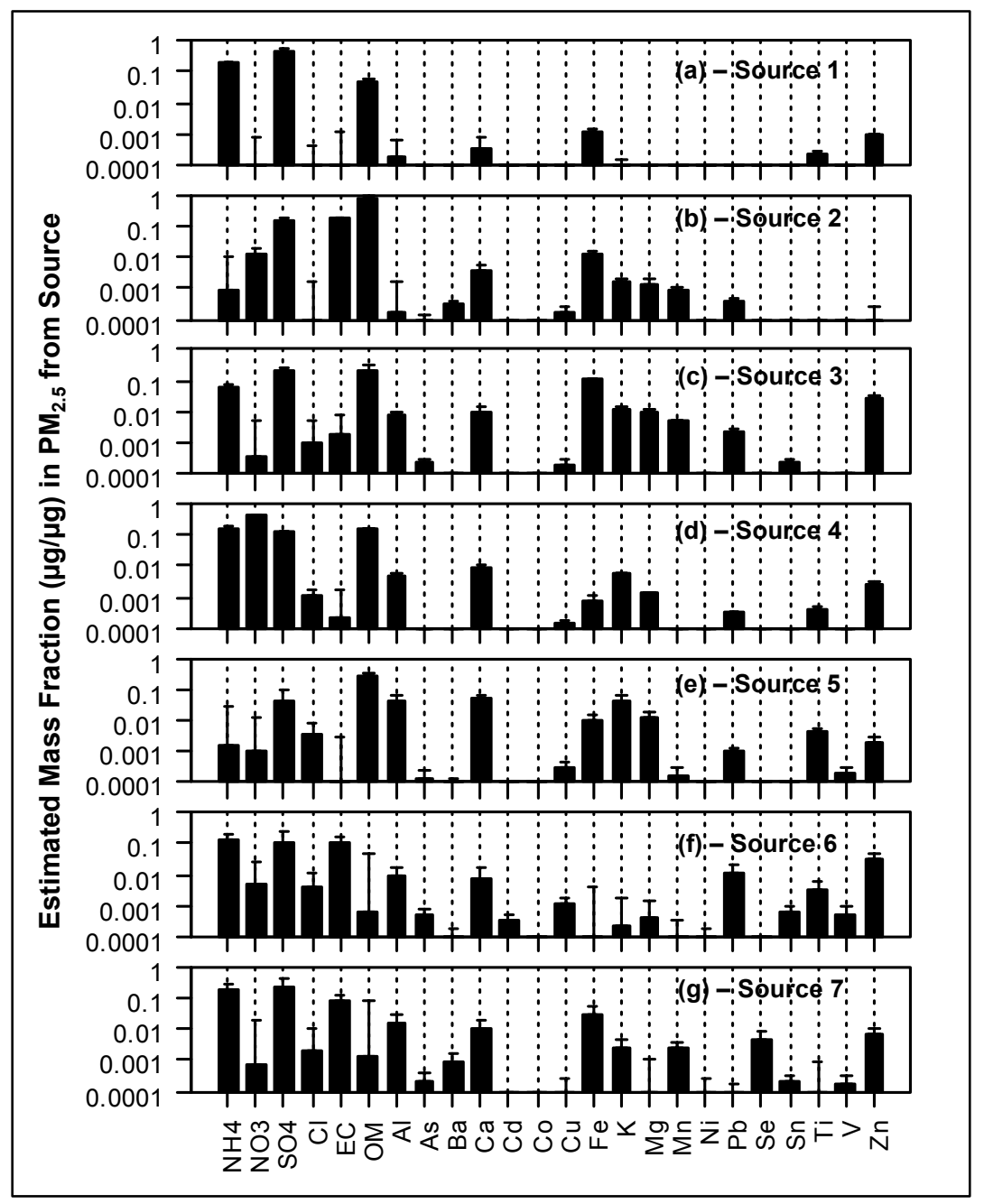




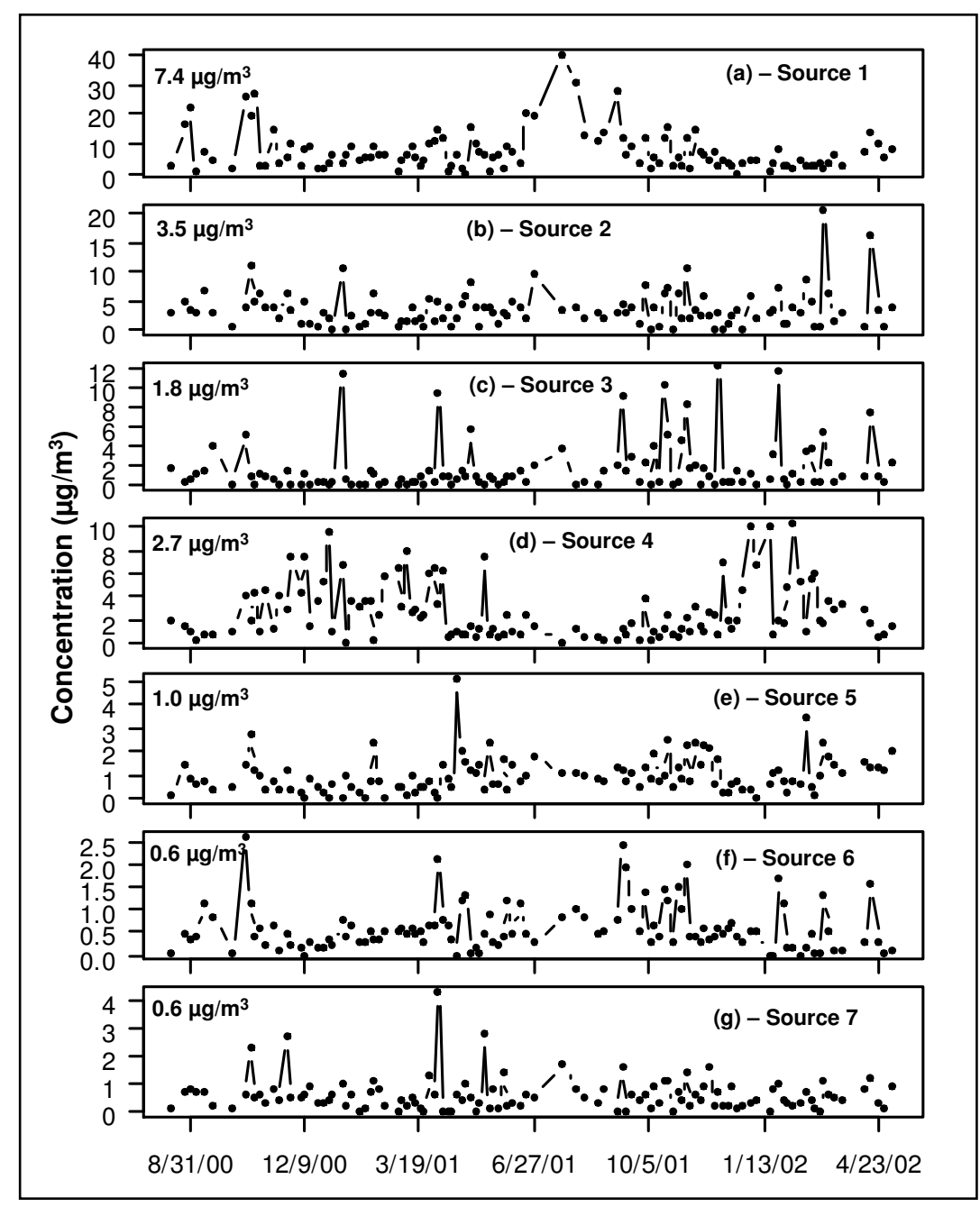




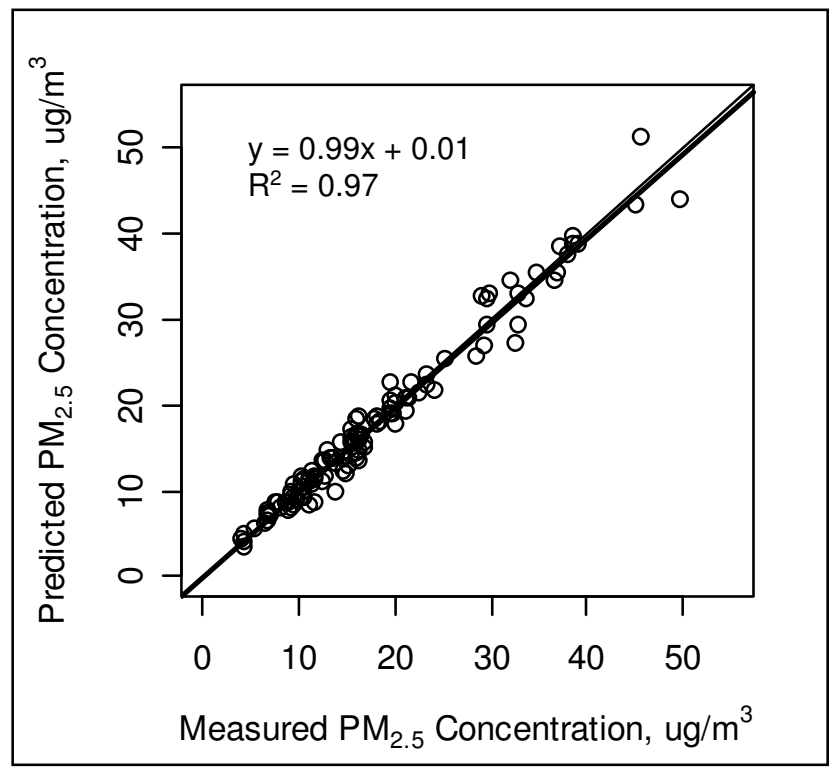




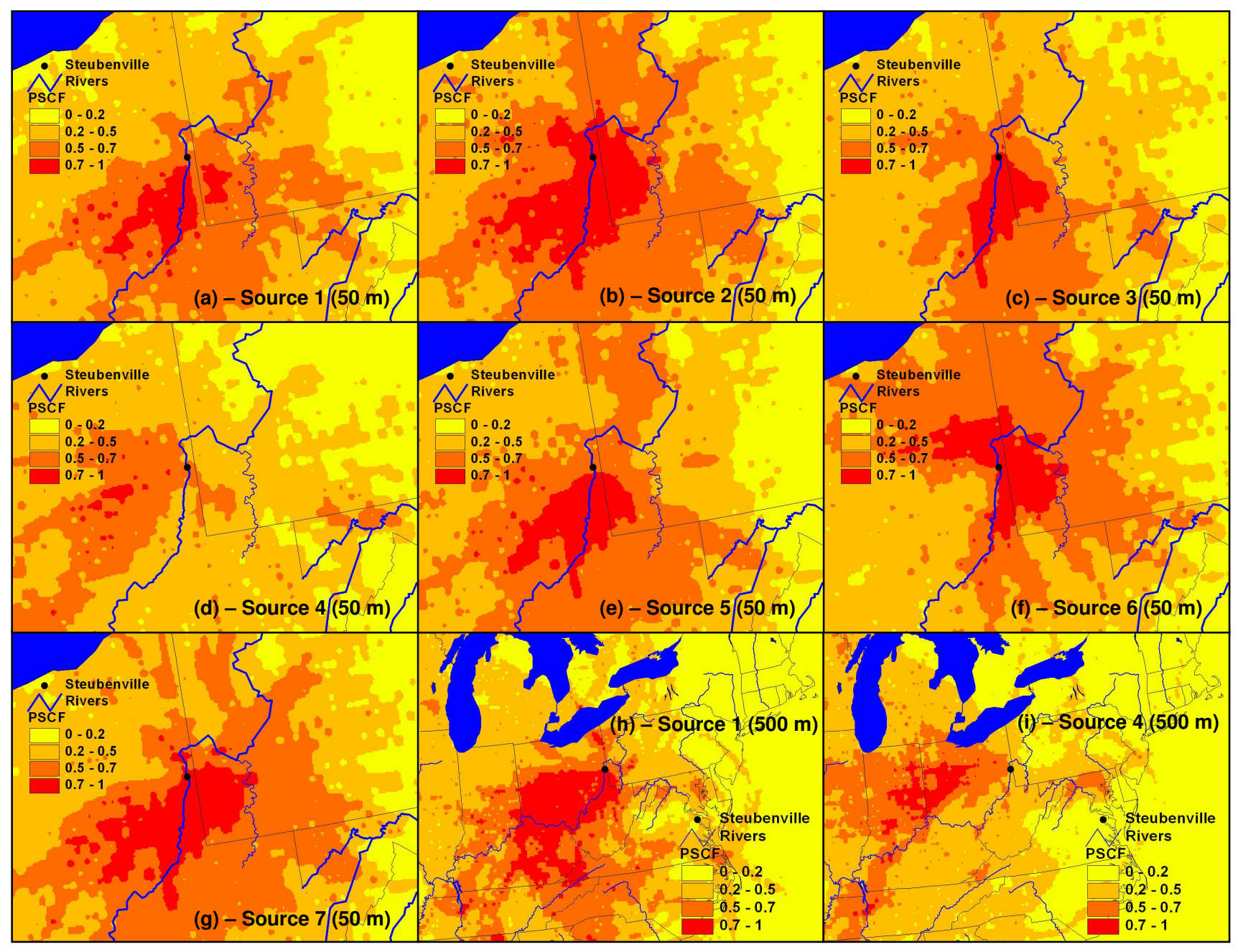




\section{APPENDIX E}

\section{AMBIENT PARTICULATE AIR POLLUTION AND CARDIAC ARRHYTHMIA IN A PANEL OF OLDER ADULTS IN STEUBENVILLE, OHIO}

MANUSCRIPT SUBMITTED TO OCCUPATIONAL AND ENVIRONMENTAL MEDICINE 
Ambient particulate air pollution and cardiac arrhythmia in a panel of older adults in Steubenville, Ohio

\author{
Stefanie Ebelt Sarnat ${ }^{1}$ \\ Helen $\mathrm{H} \mathrm{Suh}^{2}$ \\ Brent A Coull ${ }^{3}$ \\ Joel Schwartz ${ }^{2}$ \\ Peter H Stone ${ }^{4}$ \\ Diane R Gold ${ }^{2,5}$
}

\footnotetext{
${ }^{1}$ Department of Environmental and Occupational Health, Rollins School of Public Health, Emory University, Atlanta, USA

${ }^{2}$ Department of Environmental Health, Harvard School of Public Health, Boston, USA

${ }^{3}$ Department of Biostatistics, Harvard School of Public Health, Boston, USA

${ }^{4}$ Cardiovascular Division, Brigham and Women's Hospital, Harvard Medical School, Boston, USA

${ }^{5}$ The Channing Laboratory, Department of Medicine, Brigham and Women's Hospital, Harvard Medical School, Boston, USA
}

\title{
Corresponding Author:
}

Stefanie Ebelt Sarnat

Department of Environmental and Occupational Health

Rollins School of Public Health of Emory University

1518 Clifton Road, N.E.

Atlanta, GA 30322

Phone: 404-712-9636

Fax: 404-727-8744

E-mail: sebelt@sph.emory.edu

Word count: text $=4312$ (including tables), abstract $=296$

Running Title: Ambient air pollution and cardiac arrhythmia

Keywords: Air pollution, epidemiology, cardiovascular disease, arrhythmia 


\begin{abstract}
Objectives: Ambient particulate air pollution has been associated with increased risk of cardiovascular morbidity and mortality. Pathways by which particles may act involve autonomic nervous system dysfunction or inflammation, which can affect cardiac rate and rhythm. The importance of these pathways may vary by particle component or source. In an eastern U.S. location with significant non-traffic pollution, we examine the association of air pollution and odds of cardiac arrhythmia in older adults.
\end{abstract}

Methods: We evaluated 32 non-smoking older adults on a weekly basis for 24-weeks during the summer and fall of 2000 with a standardized 30-minute protocol that included continuous electrocardiogram measurements. A central ambient monitoring station provided daily concentrations of fine particles $\left(\mathrm{PM}_{2.5}\right.$, sulfate, elemental carbon) and gases. Sulfate was used as a marker of regional, non-traffic pollution. We used logistic mixed effects regression to examine the odds of having any supraventricular ectopy (SVE) or ventricular ectopy (VE) in association with increases in air pollution for moving average pollutant concentrations up to ten days prior to the health assessment.

Results: Participant-specific mean counts of arrhythmia over the protocol varied between 0.1 - 363 for SVE and 0 - 350 for VE. We observed odds ratios for having SVE over the length of the protocol of 1.42 (95\% CI: 0.99, 2.04), 1.70 (95\% CI: 1.12, 2.57) and 1.78 (95\% CI: $0.95,3.35)$ for $10.0 \mu \mathrm{g} / \mathrm{m}^{3}, 4.2 \mu \mathrm{g} / \mathrm{m}^{3}$ and $14.9 \mathrm{ppb}$ increases in 5-day moving average $\mathrm{PM}_{2.5}$, sulfate and ozone concentrations, respectively. The other pollutants, including elemental carbon, showed no effect on arrhythmia. Participants reporting cardiovascular conditions (e.g., previous myocardial infarction or hypertension) 
were the most susceptible to pollution-induced SVE. We found no association of pollution with VE.

Conclusion: Increased levels of ambient particulate air pollution from non-traffic sources may increase the risk of supraventricular arrhythmia in the elderly. 


\section{INTRODUCTION}

Several recent studies provide evidence of the relationship between ambient particle concentrations and cardiovascular morbidity[1][2][3][4] and mortality.[5][6][7]

Autonomic nervous system dysfunction, as well as inflammation, may be pathways by which particles affect cardiac rate and rhythm.

Findings from recent panel studies suggest that particulate air pollution can affect the risk of ectopy,[8][9][10][11] defined as extra cardiac depolarizations within either the atria (i.e., supraventricular ectopy [SVE]) or the ventricles (i.e., ventricular ectopy [VE]). For example, a study examining chronic obstructive pulmonary disease (COPD) patients in Vancouver found a $22 \%$ increased rate of SVE for each $5.8 \mu \mathrm{g} / \mathrm{m}^{3}$ increase in fine particles $\left(\mathrm{PM}_{2.5}\right)$.[11] Riediker and colleagues (2004) found $23.0 \%$ and $19.1 \%$ increased rates of SVE and VE, respectively, for $10 \mu \mathrm{g} / \mathrm{m}^{3}$ increases in $\mathrm{PM}_{2.5}$ in a study of North Carolina highway patrolmen.[10] In contrast to these two studies, where the primary sources of air pollution were traffic, this paper reports the effects particle pollution on the risk of ectopy in a population of older adults in the small town of Steubenville, $\mathrm{OH}$. Steubenville is located in an industrial area of the Ohio River Valley, characterized by coal-fired power plants and steel mills.

\section{METHODS}

\section{Study design and recruitment}

We recruited 32 non-smoking older adults to participate in a cardiovascular health and air pollution exposure study in Steubenville, $\mathrm{OH}$. Most participants lived in one of three centrally located apartment buildings. Sampling was conducted over two 12-week 
sampling sessions during the summer (June 4 - August 18) and fall (September 25 December 15) of 2000. Of the 32 participants, 28 participated in both seasons. Prior to the study, we held screening appointments to obtain information on the health status of each participant and baseline resting electrocardiograms (ECG) (12-lead MAC6, Marquette Medical Systems Inc.). Since heart rate variability (HRV) was an endpoint of interest, exclusion criteria for this study included having a pacemaker, a recent acute coronary syndrome, atrial flutter or atrial fibrillation. The research protocol was approved by Institutional Review Boards of the Harvard School of Public Health and the Brigham and Women's Hospital in Boston, MA. Informed consent was obtained from all individuals prior to their participation in the study.

\section{Health measurements}

Participants visited one of two clinic rooms, set-up in rooms of two main apartment buildings where subjects resided, on a weekly basis following a regular schedule (Monday-Friday, 8am-4pm). During each visit, we administered a questionnaire regarding symptoms, doctor and hospital visits, changes in medication and participant medication use that morning. Holter monitoring (SEER MC, GE Medical Systems) with electrodes in a modified V5 and AVF position provided continuous ECG data throughout a 30-minute protocol, comprised of: (1) five minutes of rest in a supine position; (2) three supine blood pressure (BP) measurements (NIBP Vital Signs Monitor, Welch Allyn); (3) five minutes of standing with three standing BP measurements taken after two minutes; (4) five minutes of exercise (walking) outdoors (weather and health permitting); 
(5) five minutes of rest in a supine position and; (6) two minutes and 20 seconds of paced breathing.

Research technicians downloaded the ECG recordings onto a Sparq station in the field. Cardiology technicians at the Brigham \& Women's Hospital analyzed the ECG files using a MARS Marquette Workstation. For each clinic visit, we obtained data on heart rate and counts of SVE and VE, as compiled over the whole protocol and for each separate interval.

\section{Exposure measurements}

We measured 24-hour integrated fine particulate $\left(\mathrm{PM}_{2.5}\right.$, sulfate $\left[\mathrm{SO}_{4}{ }^{2-}\right]$, elemental carbon $[\mathrm{EC}]$ ) and gaseous (ozone $\left[\mathrm{O}_{3}\right]$, nitrogen dioxide $\left[\mathrm{NO}_{2}\right]$, sulfur dioxide $\left[\mathrm{SO}_{2}\right]$ ) pollutant concentrations at a central ambient site at the Franciscan University of Steubenville beginning at 9am each day (except Saturday) using a Harvard multipollutant monitor (HMPM). CONSOL Energy Inc. Research \& Development analyzed the $\mathrm{SO}_{4}{ }^{2-}, \mathrm{O}_{3}, \mathrm{NO}_{2}$ and $\mathrm{SO}_{2}$ filters using ion chromatography and $\mathrm{EC}$ filters using thermal optical transmission. A complete description of the HMPM and its performance in the current study has been described previously.[12][13] Due to the high number of HMPM $\mathrm{SO}_{2}$ samples below the limit of detection,[13] these data were not used in the current analysis.

The HMPM data were supplemented with continuous measurements of $\mathrm{PM}_{2.5}(\mathrm{R} \& \mathrm{P}$, TEOM 1400A [50 $\mathrm{C}]$ ), $\mathrm{SO}_{2}$ (API, Model 100UV Fluorescent), carbon monoxide (CO)(API, Model 300 GFC) and meteorological variables (Met-1, 10 meter station) collected by CONSOL Energy Inc. Research \& Development as part of a broader 
monitoring effort in Steubenville.[14][15] The $\mathrm{PM}_{2.5}$ data were used in sensitivity analyses only, to fill in missing Saturday values in the HMPM $\mathrm{PM}_{2.5}$ data series. The $\mathrm{SO}_{2}$ and $\mathrm{CO}$ data supplemented the pollutants measured with the HMPM sampler. Using the meteorological variables, we calculated apparent temperature as: $-2.653+(0.994 \mathrm{x}$ $\mathrm{Ta})+\left(0.0153 \times \mathrm{Td}^{2}\right)$, where $\mathrm{Ta}$ is the air temperature and $\mathrm{Td}$ is the dew point.

\section{Data analysis}

We excluded one participant who dropped out of the study after four weeks due to the limited number of samples, and another participant who had atrial fibrillation. Intervals or sessions with less than $50 \%$ valid ECG data were invalidated.

We used logistic regression to examine the odds of having at least one arrhythmia (i.e., during the 30-minute protocol or for specific protocol intervals) associated with increases in air pollution. In these analyses, we excluded participants who experienced no change in their binomial $(0 / 1)$ outcome, as they would have no variation in the outcome. Excluded from primary analyses were participants who experienced a) ectopic beats during all clinic visits, or b) no ectopic beats during any clinic visit. Sensitivity analyses were conducted that included all participants regardless of their binomial outcomes.

We additionally examined the relative rate of arrhythmia (e.g. \# beats/30-minute protocol) associated with increases in air pollution by fitting overdispersed Poisson regression models, otherwise known as negative binomial regression, to the arrhythmia counts. These analyses included the entire cohort. 
We conducted all analyses using PROC NLMIXED (SAS Release 8.02; SAS Institute, Cary, NC), controlling for a random subject effect and the fixed effects of apparent temperature, season (summer vs. fall), day of week, hour of day, age and body mass index (BMI). We chose 'current hour of the clinic visit', a priori, as the most appropriate exposure window for apparent temperature since participants went outside during the ECG protocol. A sensitivity analysis, conducted by including a categorical "building of residence" variable, did not affect model results.

We created separate models to examine the relative effects of particles $\left(\mathrm{PM}_{2.5}\right)$, particle components $\left(\mathrm{SO}_{4}{ }^{2-}\right.$ and $\left.\mathrm{EC}\right)$ and gases $\left(\mathrm{O}_{3}, \mathrm{NO}_{2}, \mathrm{SO}_{2}\right.$ and $\left.\mathrm{CO}\right)$ on cardiac arrhythmia. Based on autonomic nervous system dysfunction, which may be acute, and inflammation, which may take several days to develop, as potential mechanisms by which particles could influence cardiac arrhythmia, we examined the relative effects of 1day to 5-day moving average concentrations of each pollutant prior to the health assessment. Moving averages up to 10-days prior to the health assessment were examined in sensitivity analyses. Effect estimates are presented for interquartile range (IQR) increases in pollutant concentrations at each exposure period evaluated.

Finally, we explored the potential for heterogeneity in response across the cohort by including participant characteristics, medications use (recorded at each clinic visit) and participant-specific mean ectopy levels as potential effect modifiers of the $\mathrm{PM}_{2.5}$ associations. These factors were included as main effects and interaction terms with $\mathrm{PM}_{2.5}$ in the models. 


\section{RESULTS}

\section{Participant characteristics and arrhythmia occurrence}

Participants (mean age: 71.2 years, range: 53.5 - 90.3 years) were predominantly female $(n=28)$ and over the age of $60(n=27)$ (Table 1$)$. The majority of participants $(n$ =29) reported at least one of the listed cardiovascular or respiratory illnesses. 23 participants reported multiple diagnoses. Of the 6 participants that reported angina, for example, 4 also reported having at least one of the respiratory diseases. Similarly, of the 9 participants that reported having asthma, 6 also reported having COPD. Participants with cardiovascular conditions (e.g., previous myocardial infarction (MI), heart failure and/or hypertension) reported taking cardiovascular medications more frequently than those without the condition. For example, of the 22 subjects who reported ever having had hypertension, $80 \%$ were on beta-blockers, $\mathrm{Ca}^{2+}$ channel blockers and/or ACE inhibitors compared to only $5 \%$ in those without hypertension. Similarly, participants with respiratory illness (bronchitis, COPD and/or asthma) reported taking respiratory medications (bronchodilators, beta-agonists and/or steroids) more frequently (43-57\%) than those without the condition (7-12\%).

Over the 24-week study period, 623 clinic visits provided valid ECG data. The mean duration of the structured ECG protocol session was $33( \pm 3)$ minutes and mean counts of arrhythmia for the whole cohort were $27.2( \pm 87.8)$ beats/protocol session (or $50.0 \pm$ 162.8 beats/hr) for SVE and $28.0( \pm 93.3)$ beats/protocol session (or $52.6 \pm 173.5$ beats/hr) for VE. There was considerable variability in participant-specific SVE and VE counts, as participant-specific mean counts (over the whole protocol) varied between 0.1 - 363 for SVE and $0-350$ for VE. The correlation between the two arrhythmia 
measures was low, with counts of SVE and VE over the whole protocol showing a

Spearman correlation coefficient (r) of 0.03 .

Table 1. Participant characteristics, disease diagnoses and medications use.

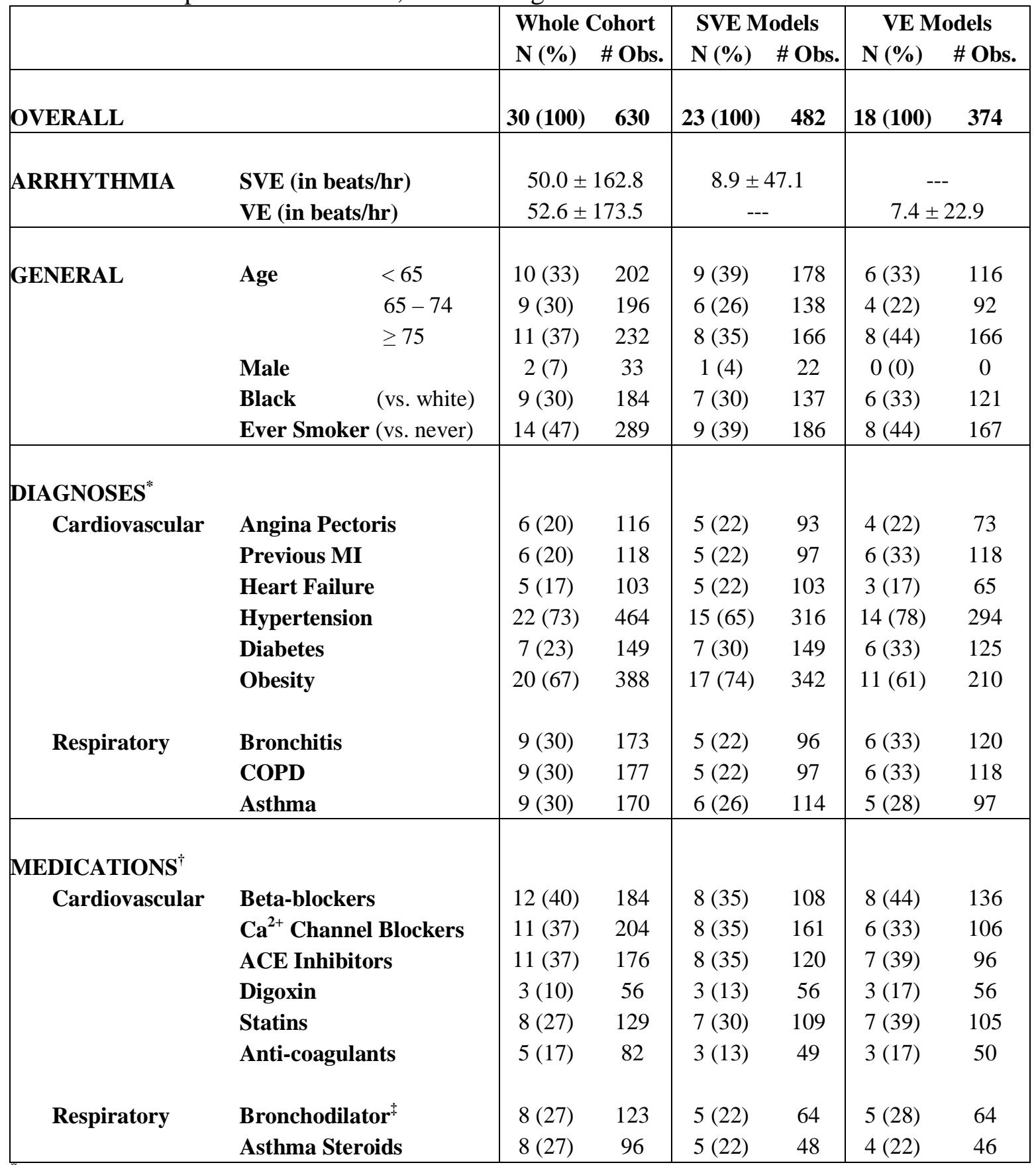

"Diagnoses are self-reported doctor's diagnoses except for: COPD and asthma are self-reported; diabetes determined via diabetic medications use, obesity defined as BMI > 30, bronchitis defined as chronic cough or phlegm on most days for 3 consecutive months or more during the year.

${ }^{\dagger}$ Medications use lists participants who reported taking the medication at least once throughout the study on the day of their clinic visit.

${ }^{\sharp}$ Bronchodilator grouping includes beta-agonist and atrovent medications. 


\section{Air quality data}

Table 2 and Table 3 present descriptive statistics and correlations for air pollutants, respectively. During the study, 24-hr $\mathrm{PM}_{2.5}$ concentrations averaged approximately 19 $\mu \mathrm{g} / \mathrm{m}^{3}$ and ranged from 3.6 to $48.4 \mu \mathrm{g} / \mathrm{m}^{3}$. The correlations between pollutants showed similar patterns whether examining 1-day or 5-day moving averages. Ambient $\mathrm{PM}_{2.5}$ and $\mathrm{SO}_{4}{ }^{2-}$ were highly correlated ( $\mathrm{r}=0.90$ for 5 -day moving averages), with slightly lower correlations between $\mathrm{PM}_{2.5}$ and the other pollutants (range of $\mathrm{r}=0.33-0.75$ for 5-day moving averages). Correlations were also relatively strong between apparent temperature (at current hour) and $\mathrm{SO}_{4}{ }^{2-}$ and $\mathrm{O}_{3}$ concentrations ( $\mathrm{r}=0.57$ and 0.77 , respectively), likely due to the direct influence of meteorology on the formation of these secondary pollutants. In contrast, correlations were weaker between apparent temperature and $\mathrm{EC}, \mathrm{NO}_{2}, \mathrm{SO}_{2}$ and $\mathrm{CO}$, which are all primary pollutants $(\mathrm{r}=0.40,0.10,-0.19$ and -0.32 , respectively). $\mathrm{SO}_{4}{ }^{2-}$ comprised approximately $50 \%$ of the ambient $\mathrm{PM}_{2.5}$ mass, similar to other locations in the eastern U.S.; this suggests that the regional influence on $\mathrm{PM}_{2.5}$ in Steubenville was relatively high. EC comprised approximately $6 \%$ of the ambient $\mathrm{PM}_{2.5}$ mass, which also compares well to other areas of the country.

Table 2. Summary of air pollutant concentrations from the central monitoring site for 1and 5-day moving average concentrations prior to the first participant visit each clinic day.

\begin{tabular}{|cl|c|c|cccccc|}
\hline Average & Pollutant & $\mathbf{N}$ & Mean \pm SD & Min & 25th & 50th & 75th & Max & IQR $^{*}$ \\
\hline 1-day & $\mathrm{PM}_{2.5}\left(\mu \mathrm{g} / \mathrm{m}^{3}\right)$ & 113 & $19.6 \pm 10.4$ & 3.6 & 11.7 & 17.7 & 25.0 & 48.4 & 13.3 \\
& $\mathrm{SO}_{4}{ }^{2-}\left(\mu \mathrm{g} / \mathrm{m}^{3}\right)$ & 109 & $6.8 \pm 4.7$ & 0.0 & 3.3 & 5.7 & 8.5 & 25.0 & 5.2 \\
& $\mathrm{EC}\left(\mu \mathrm{g} / \mathrm{m}^{3}\right)$ & 103 & $1.1 \pm 0.6$ & 0.3 & 0.7 & 1.0 & 1.3 & 3.6 & 0.6 \\
& $\mathrm{O}_{3}(\mathrm{ppb})$ & 111 & $21.8 \pm 12.6$ & -0.8 & 12.0 & 20.2 & 28.5 & 74.8 & 16.5 \\
& $\mathrm{NO}_{2}(\mathrm{ppb})$ & 111 & $10.7 \pm 6.7$ & -0.9 & 6.3 & 9.6 & 14.0 & 37.9 & 7.7 \\
& $\mathrm{SO}_{2}(\mathrm{ppb})$ & 106 & $10.4 \pm 8.3$ & 1.8 & 5.2 & 8.1 & 12.4 & 58.3 & 7.2 \\
& $\mathrm{CO}(\mathrm{ppm})$ & 110 & $0.2 \pm 0.3$ & -0.1 & 0.0 & 0.1 & 0.3 & 1.5 & 0.3 \\
& & & & & & & &
\end{tabular}




\begin{tabular}{|c|c|c|c|c|c|c|c|c|c|}
\hline \multirow[t]{7}{*}{ 5-day } & $\mathrm{PM}_{2.5}\left(\mu \mathrm{g} / \mathrm{m}^{3}\right)$ & 107 & $19.8 \pm 7.5$ & 4.9 & 13.9 & 19.0 & 23.9 & 38.7 & 10.0 \\
\hline & $\mathrm{SO}_{4}^{2-}\left(\mu \mathrm{g} / \mathrm{m}^{3}\right)$ & 97 & $6.7 \pm 3.1$ & 1.5 & 4.2 & 6.1 & 8.4 & 14.8 & 4.2 \\
\hline & $\mathrm{EC}\left(\mu \mathrm{g} / \mathrm{m}^{3}\right)$ & 80 & $1.0 \pm 0.4$ & 0.4 & 0.7 & 0.9 & 1.2 & 2.2 & 0.5 \\
\hline & $\mathrm{O}_{3}(\mathrm{ppb})$ & 101 & $22.2 \pm 9.1$ & 6.5 & 14.2 & 20.7 & 29.1 & 44.0 & 14.9 \\
\hline & $\mathrm{NO}_{2}(\mathrm{ppb})$ & 98 & $10.5 \pm 4.2$ & 4.5 & 7.4 & 9.2 & 12.9 & 20.4 & 5.5 \\
\hline & $\mathrm{SO}_{2}(\mathrm{ppb})$ & 103 & $10.7 \pm 5.5$ & 2.4 & 7.4 & 9.1 & 12.8 & 31.3 & 5.4 \\
\hline & $\mathrm{CO}$ (ppm) & 106 & $0.2 \pm 0.2$ & 0.0 & 0.1 & 0.2 & 0.3 & 1.3 & 0.2 \\
\hline
\end{tabular}

*IQR: interquartile range $\left(75^{\text {th }}-25^{\text {th }}\right.$ percentile).

Table 3. Spearman correlations between all air parameters using 5-day moving average concentrations prior to first participant visit each clinic day.

\begin{tabular}{|l|ccccccc|}
\hline & $\mathbf{P M}_{2.5}$ & $\mathbf{S O}_{4}{ }^{2-}$ & $\mathbf{E C}$ & $\mathbf{O}_{3}$ & $\mathbf{N O}_{2}$ & $\mathbf{S O}_{2}$ & $\mathbf{C O}$ \\
\hline App Temp $^{\dagger}$ & $0.46^{\dagger}$ & $0.57^{\dagger}$ & $0.40^{*}$ & $0.77^{\dagger}$ & 0.10 & -0.19 & $-0.32^{*}$ \\
\hline $\mathbf{P M}_{2.5}$ & & $0.90^{\dagger}$ & $0.75^{\dagger}$ & $0.33^{*}$ & $0.46^{\dagger}$ & $0.51^{\dagger}$ & $0.47^{\dagger}$ \\
$\mathbf{S O}_{4}{ }^{2-}$ & & & $0.60^{\dagger}$ & $0.53^{\dagger}$ & $0.37^{*}$ & $0.35^{*}$ & $0.26^{*}$ \\
$\mathbf{E C}$ & & & & 0.15 & $0.66^{\dagger}$ & $0.46^{\dagger}$ & $0.55^{\dagger}$ \\
$\mathbf{O}_{3}$ & & & & & -0.19 & -0.21 & $-0.35^{*}$ \\
$\mathbf{N O}_{2}$ & & & & & & $0.40^{*}$ & $0.50^{\dagger}$ \\
$\mathbf{S O}_{2}$ & & & & & & & $0.66^{\dagger}$ \\
\hline
\end{tabular}

${ }^{*} \mathrm{p}<0.05 ;{ }^{\dagger} \mathrm{p}<0.0001 ;{ }^{\ddagger}$ Apparent temperature at current hour of clinic visit.

\section{Associations between air pollution and cardiac arrhythmia}

Results of the logistic regression models showed that air pollution increased the odds of having at least one SVE, but not VE, over the entire protocol (Table 4). The results for SVE were greatest for $\mathrm{PM}_{2.5}, \mathrm{SO}_{4}{ }^{2-}$ and $\mathrm{O}_{3}$, while $\mathrm{EC}, \mathrm{NO}_{2}, \mathrm{SO}_{2}$ and $\mathrm{CO}$ demonstrated weaker and null effects. The impacts of air pollution on the odds of SVE and VE did not differ when examining individual protocol intervals (i.e., resting, standing, exercise, etc.) in separate models. 
Table 4. Odds ratios for SVE and VE for IQR increases in 5-day mean pollutant concentrations. ${ }^{*}$

\begin{tabular}{|c|c|c|c|c|c|c|c|}
\hline \multirow[b]{2}{*}{ Pollutant } & \multirow[b]{2}{*}{ 5-day IQR } & \multicolumn{3}{|c|}{ SVE } & \multicolumn{3}{|c|}{ VE } \\
\hline & & $\mathbf{N}$ & Odds Ratio (95\% CI) & p-value & $\mathbf{N}$ & Odds Ratio (95\% CI) & p-value \\
\hline \multicolumn{8}{|l|}{ Particles } \\
\hline $\mathrm{PM}_{2.5}$ & $10.0 \mu \mathrm{g} / \mathrm{m}^{3}$ & 400 & $1.42(0.99,2.04)$ & 0.07 & 314 & $1.02(0.63,1.65)$ & 0.93 \\
\hline $\mathrm{SO}_{4}{ }^{2-}$ & $4.2 \mu \mathrm{g} / \mathrm{m}^{3}$ & 356 & $1.70(1.12,2.57)$ & 0.02 & 286 & $1.08(0.65,1.80)$ & 0.78 \\
\hline $\mathrm{EC}$ & $0.5 \mu \mathrm{g} / \mathrm{m}^{3}$ & 310 & $1.15(0.73,1.81)$ & 0.57 & 243 & $1.00(0.57,1.75)$ & 0.99 \\
\hline \multicolumn{8}{|l|}{ Gases } \\
\hline $\mathrm{O}_{3}$ & $14.9 \mathrm{ppb}$ & 387 & $1.78(0.95,3.35)$ & 0.09 & 304 & $1.43(0.63,3.27)$ & 0.41 \\
\hline $\mathrm{NO}_{2}$ & $5.5 \mathrm{ppb}$ & 379 & $0.89(0.61,1.28)$ & 0.53 & 296 & $0.61(0.36,1.03)$ & 0.08 \\
\hline $\mathrm{SO}_{2}$ & $5.4 \mathrm{ppb}$ & 397 & $1.04(0.78,1.39)$ & 0.78 & 306 & $1.28(0.85,1.92)$ & 0.25 \\
\hline $\mathrm{CO}$ & $0.2 \mathrm{ppm}$ & 410 & $0.99(0.76,1.29)$ & 0.93 & 317 & $1.05(0.75,1.46)$ & 0.80 \\
\hline
\end{tabular}

*Models control for apparent temperature at hour of clinic visit, season, day of week, hour of day, age and BMI.

Over the entire protocol, the OR for having at least one air pollution-related SVE was greatest at long-term moving average concentrations prior to the health assessment (Figure 1). For example, the OR for SVE was 1.42 (95\% CI: 0.99, 2.04) for a $10 \mu \mathrm{g} / \mathrm{m}^{3}$ increase in 5-day $\mathrm{PM}_{2.5}$ as compared to 1.04 (95\% CI: $0.73,1.47$ ) for a $13.3 \mu \mathrm{g} / \mathrm{m}^{3}$ increase in 1-day $\mathrm{PM}_{2.5}$. The observed particle effects remained elevated or increased at moving average concentrations longer than 5-days. In these analyses, the effects of $\mathrm{PM}_{2.5}$ on the odds of SVE were not different when the HMPM $\mathrm{PM}_{2.5}$ time-series was filled in for missing Saturday data using regressions with 24-hour averaged TEOM data.

Including heart rate in the models resulted in more precise estimation of effects, with the 5-day moving average $\mathrm{PM}_{2.5}$ effect on the odds of SVE (OR: 1.48, 95\% CI: 1.02, 2.15) becoming significant. Inclusion of 5-day $\mathrm{O}_{3}$ in models together with either 5-day $\mathrm{PM}_{2.5}$ or $\mathrm{SO}_{4}{ }^{2-}$ reduced the effects of both pollutants slightly. For example, with 5-day 
$\mathrm{SO}_{4}{ }^{2-}$ in the model, the 5-day $\mathrm{O}_{3}$ effect fell to 1.57 (95\% CI: $\left.0.74,3.35\right)$ and the $\mathrm{SO}_{4}{ }^{2-}$ effect fell to 1.54 (95\% CI: 1.00, 2.36).

In sensitivity analyses, the logistic model results were similar when all 30 participants were included in the analyses. In order to use the information provided by the counts of SVE and VE in our dataset, we additionally modeled the outcome as a count variable using negative binomial regression. Estimated associations between pollution levels and the rate of arrhythmias per 30-minute interval from this model were not significantly different from zero (results not shown).

\section{Examination of effect modification}

Figure 2 presents the results of interactions between 5-day moving average $\mathrm{PM}_{2.5}$ concentrations and participant characteristics on the odds of SVE. Pollution effects were greatest for participants with cardiovascular conditions. Participants who reported a previous MI, for example, had an OR for SVE of 2.35 (95\% CI: 1.03, 5.39) as compared to an OR of $1.31(95 \% \mathrm{CI}: 0.89,1.91)$ in those without a previous MI, each for a 10.0 $\mu \mathrm{g} / \mathrm{m}^{3}$ increase in 5-day $\mathrm{PM}_{2.5}$ (test of significant difference, $\mathrm{p}=0.20$ ). In addition, participants who reported ever having hypertension showed a significantly higher effect (OR: $1.88,95 \%$ CI: $1.21,2.92)$ compared to those without hypertension (OR: $0.94,95 \%$ CI: $0.56,1.59$ ) (test of significant difference, $\mathrm{p}=0.04$ ). Medications use showed collinear effects with diagnosis; participants on medications for cardiac conditions, such as beta blockers or $\mathrm{Ca}^{2+}$ channel blockers, experienced greater air pollution effects than those not on cardiac medications (corresponding to those without diagnosed cardiac disease). In contrast, participants with respiratory conditions (e.g. bronchitis, asthma) did 
not influence the effect of $\mathrm{PM}_{2.5}$ on the odds of SVE. The null effect of $\mathrm{PM}_{2.5}$ on participants with angina is likely influenced by the fact that a majority of these participants (4 of 6) also had respiratory disease.

The temporal association between $\mathrm{PM}_{2.5}$ and SVE noted above was similar when considering only those participants with cardiac diagnoses. For example, subsetting the analyses only on those participants with hypertension, the OR for having at least one air pollution-related SVE was greater at 5-day moving average concentrations (2.07 [95\% CI: 1.29, 3.32] for a $10 \mu \mathrm{g} / \mathrm{m}^{3}$ increase in 5-day $\mathrm{PM}_{2.5}$ ) prior to the health assessment as compared to 1-day moving average concentrations (1.28 [95\% CI: $0.82,1.99]$ for a 13.3 $\mu \mathrm{g} / \mathrm{m}^{3}$ increase in 1-day $\mathrm{PM}_{2.5}$ ).

We also examined whether pollution effects were greater in participants with higher levels of ectopy. We observed that 5-day $\mathrm{PM}_{2.5}$ effects on the odds of SVE were significantly higher for participants with mean SVE rates greater than the population median rate of 1.5 beats/hr (OR: 1.99, 95\% CI: 1.20, 3.29) as compared to participants with mean rates $<1.5$ beats/hr (OR: $1.03,95 \%$ CI: $0.65,1.64$ ) (test of significant difference, $\mathrm{p}=0.05)$.

\section{DISCUSSION}

In a community with significant industrial sources for air pollution, our study demonstrates an association of particle pollution with increased odds of supraventricular arrhythmia in a cohort of older adults, with findings of $42 \%, 70 \%$ and $78 \%$ increases in odds of SVE associated with IQR increases in 5-day moving average $\mathrm{PM}_{2.5}, \mathrm{SO}_{4}{ }^{2-}$ and $\mathrm{O}_{3}$, respectively. Air pollution effects were greatest for participants with a history of 
clinically significant cardiac disease. Since two-pollutant models demonstrated stability in the effects of both particles and $\mathrm{O}_{3}$, collectively our results may provide evidence of the combined effect of the secondary pollutant mix in Steubenville on cardiac arrhythmia. Specifically, the strong effects found with $\mathrm{SO}_{4}{ }^{2-}$ are interesting as Steubenville is located in an industrial area of the Ohio River Valley, with little traffic but with a number of coal-fired power plants, which are the major source of $\mathrm{SO}_{2}, \mathrm{a} \mathrm{SO}_{4}{ }^{2-}$ precursor. A previous study conducted in Boston, reporting on patients with implantable cardioverter defibrillators (ICD), found that traffic-related pollutants, particularly $\mathrm{NO}_{2}$, showed the greatest odds of arrhythmia.[16] Our data suggest that pollution in an industrial location may also contribute to the risk of arrhythmia and they indicate the potential for varying impacts of air pollution by geographical location and source contributions.

Recent air pollution health effects studies have suggested mechanisms to support the association between ambient particle levels and SVE occurrence.[8][9][10][11] A leading hypothesis regarding the biological mechanism of air pollution health effects centers on the relationship between increased air pollution levels and autonomic nervous system imbalance,[17][18][19][20] which is known to aggravate SVE.[21] Our observation that long-term moving average pollutant concentrations exerted the greatest impact on the odds of SVE is consistent with the previous ICD patient studies,[16] [22] and the results may suggest the presence of an inflammatory mechanism as well.[23] Stone and Godleski suggest that elevated circulating cytokine levels as part of the systemic response can act to impair cardiac myocyte and electrophysiologic function,[24][25] which could cause cardiac irritability, thus increasing SVE occurrence. 
We identified several factors that increased the odds of air pollution-related SVE within our cohort. Participants reporting previous cardiovascular conditions, including MI or hypertension, or individuals with mean SVE rates $>1.5$ beats/hr were most susceptible to pollution-induced SVE. Participants on cardiac medications, including beta blockers or $\mathrm{Ca}^{2+}$ channel blockers, also showed sensitivity to air pollution mediated SVE. The association of these cardiac medications and increased sensitivity to air pollution is likely due to these medications serving as a surrogate for the presence of the clinical cardiovascular conditions and due not to the pharmacologic effect of the drug per se.

It has also been hypothesized that individuals with chronic lung disease comprise a susceptible subgroup, given their tendency for loss of vagal restraint, thereby leading to an increased heart rate and conditions suitable for ectopic tachycardias.[26] However, air pollution did not influence the odds of SVE in these participants. Our results differ from previous studies reporting significant effects of air pollution on SVE for groups of COPD patients.[8] [9] [11] A study of 16 COPD patients in Vancouver, whose mean rate of SVE was 33 beats $/ \mathrm{hr}$, reported a $22 \%$ increased rate of SVE for each $5.8 \mu \mathrm{g} / \mathrm{m}^{3}$ increase in $\mathrm{PM}_{2.5}$.[11] Since the number of participants with bronchitis, COPD and/or asthma (n= $5-6$ ) in our analyses was low, the lack of observed effects for these groups is likely a function of weak statistical power. Moreover, the small size $(n=23)$ of the cohort used in the SVE models may limit the generalizability of our findings regarding effect modification by diagnosis.

This study has several limitations. We recognize that the occurrence of at least one SVE or VE is a subclinical outcome. While we were able to detect associations between 
pollution levels and the occurrence of at least one SVE during the protocol, we did not detect significant associations between pollution levels and the actual counts of arrhythmias. Thus, incorporating this extra information did not improve our ability to detect effects over the binary analysis. The large amount of overdispersion in the nonzero counts could have reduced our power to detect associations between pollution levels and the arrhythmia counts.

Effect sizes of air pollution on the odds of VE were extremely small. The lack of observed effects may have been due to a lack of vulnerability of our small $(\mathrm{n}=18)$, and therefore limited, study population. Dockery and colleagues (2004) demonstrated in their study of ICD patients that ventricular arrhythmias within three days of a prior event presented significantly higher effects (OR: $1.60,95 \%$ CI: 1.25, 2.04) for 2-day mean $\mathrm{PM}_{2.5}$ than those more than three days since a previous event (OR: 0.98, 95\% CI: 0.84 , 1.14).[22] In a discussion of their findings, the authors suggest that air pollution may act in combination with acutely predisposing conditions, which increase ventricular electrical instability and that could lead to arrhythmia occurrence.[22] It is plausible that our study population did not experience such acutely predisposing conditions that would enhance the effects of air pollution on VE.

Our results are consistent with a previous study examining the effects of air pollution on both SVE and VE in the elderly, where significant effects were found with SVE but not VE. [8] In contrast, Riediker and colleagues (2004) found a significant effect of air pollution on both SVE and VE in their study of highway patrolmen, reporting a 19.1\% increased rate of VE for each $10 \mu \mathrm{g} / \mathrm{m}^{3}$ increase in $\mathrm{PM}_{2.5 .}$.110] Studies of associations of $\mathrm{PM}_{2.5}$ with risk of VE require a sufficient number of observations on a vulnerable study 
population, and may, as in the case of the patrolman, require stress during the period of observation.

The relatively brief period of observation (i.e., 30-minute ECG recording per participant-visit) may have further limited our ability to capture the air pollution effect on the odds of VE, a relatively rare outcome. Recordings of longer length (e.g. 24-hour) as conducted in other panel studies[8][9][10] may provide outcome data for which associations with air pollution are better detected.

\section{CONCLUSION}

In summary, our results suggest that increased levels of ambient particulate air pollution associated with non-traffic sources may increase the risk of supraventricular arrhythmia in the elderly. Findings of long-term air pollution effects $(\geq 5$-day moving average concentrations prior to the health assessment) as the highest and most significant, may suggest that a long-acting mechanism promoted the ectopic beats in our population. Furthermore, the results suggest that individuals with a history of clinically significant cardiac disease may be at particular risk of particle health effects. 


\section{ACKNOWLEDGEMENTS}

The authors wish to thank all of the participants of the study as well as those involved in project coordination (Monique Verrier, Meghan Syring, Marisa Barr), data collection (field team members from the Franciscan University of Steubenville) and data processing (Bruce Nearing, Gail McCallum, Marina Jacobson-Canner). The authors are also grateful for CONSOL Energy Inc. Research \& Development's laboratory analysis of air pollutant samples and for the provision of continuous ambient monitoring data. Finally, the authors are appreciative of the insightful comments provided by Jeremy Sarnat and Petros Koutrakis.

\section{FUNDING AND COMPETING INTEREST STATEMENT}

This work is supported by funding from the National Institute of Environmental Health Sciences (ES-09825), the U.S. Environmental Protection Agency (R826780-01-0, R827353-01-0), the Ohio Coal Development Office within the Ohio Air Quality Development Authority (CDO/D-98-2), the Electric Power Research Institute (EPP4464/C2166), the American Petroleum Institute (\#78142), and the United States Department of Energy's National Energy Technology Laboratory (DE-FC2600NT40771). These sponsors did not play a role in the study design, collection, analysis, nor interpretation of the data, writing of the report, nor the decision to submit the paper for publication. Any opinions, findings, conclusions, or recommendations expressed herein are those of the authors and do not necessarily reflect the views of these funding sources. The authors have no competing financial interests to declare. 


\section{COPYRIGHT}

The Corresponding Author has the right to grant on behalf of all authors and does grant on behalf of all authors, an exclusive licence on a worldwide basis to the BMJ Publishing Group Ltd and its licensees, to permit this article (if accepted) to be published in OEM and any other BMJPG products and to exploit all subsidiary rights, as set out in our licence (http://oem.bmjjournals.com/misc/ifora/licenceform.shtml). 


\section{REFERENCES}

1. Schwartz J. Air pollution and hospital admissions for heart disease in eight U.S. counties. Epidemiology 1999;10:17-22.

2. Zanobetti A, Schwartz J, Gold D. Are there sensitive subgroups for the effects of airborne particles? Environ Health Perspect 2000;108:841-845.

3. Mann JK, Tager IB, Lurmann F, et al. Air pollution and hospital admissions for ischemic heart disease in persons with congestive heart failure or arrhythmia. Environ Health Perspect 2002;110:1247-1252.

4. Metzger KB, Tolbert PE, Klein M, et al. Ambient air pollution and cardiovascular emergency department visits. Epidemiology 2004;15:46-56.

5. Samet JM, Dominici F, Curriero FC, et al. Fine particulate air pollution and mortality in 20 U.S. cities, 1987-1994. N Engl J Med 2000;343:1742-1749.

6. Hoek G, Brunekreef B, Fischer P, et al. The association between air pollution and heart failure, arrhythmia, embolism, thrombosis, and other cardiovascular causes of death in a time series study. Epidemiology 2001;12:355-357.

7. Pope CA, 3rd, Burnett RT, Thurston GD, et al. Cardiovascular mortality and long-term exposure to particulate air pollution: Epidemiological evidence of general pathophysiological pathways of disease. Circulation 2004;109:71-77.

8. Linn WS, Gong H, Jr., Clark KW, et al. Day-to-day particulate exposures and health changes in Los Angeles area residents with severe lung disease. J Air Waste Manage Assoc 1999;49:108-115. 
9. Brauer M, Ebelt ST, Fisher TV, et al. Exposure of chronic obstructive pulmonary disease patients to particles: Respiratory and cardiovascular health effects. J Expo Anal Environ Epidemiol 2001;11:490-500.

10. Riediker M, Cascio WE, Griggs TR, et al. Particulate matter exposure in cars is associated with cardiovascular effects in healthy young men. Am J Respir Crit Care Med 2004;169:934-940.

11. Ebelt ST, Wilson WE, Brauer M. Exposure to ambient and nonambient components of particulate matter: A comparison of health effects. Epidemiology 2005;16:396-405.

12. Demokritou P, Kavouras IG, Ferguson ST, et al. Development and laboratory performance evaluation of a personal multipollutant sampler for simultaneous measurements of particulate and gaseous pollutants. Aerosol Sci Technol 2001;35:741-752.

13. Sarnat SE, Coull BA, Schwartz J, et al. Factors affecting the association between ambient concentrations and personal exposures to particles and gases. Environ Health Perspect 2006; In press.

14. Connell DP, Withum JA, Winter SE, et al. The Steubenville Comprehensive Air Monitoring Program (SCAMP): Analysis of short-term and episodic variations in $\mathrm{PM}_{2.5}$ concentrations using hourly air monitoring data. J Air Waste Manage Assoc 2005;55:559-573.

15. Connell DP, Withum JA, Winter SE, et al. The Steubenville Comprehensive Air Monitoring Program (SCAMP): Associations among fine particulate matter, co- 
pollutants, and meteorological conditions. J Air Waste Manage Assoc 2005;55:481-496.

16. Peters A, Liu E, Verrier RL, et al. Air pollution and incidence of cardiac arrhythmia. Epidemiology 2000;11:11-17.

17. Pope CA, 3rd, Verrier RL, Lovett EG, et al. Heart rate variability associated with particulate air pollution. Am Heart J 1999; 138:890-899.

18. Gold DR, Litonjua A, Schwartz J, et al. Ambient pollution and heart rate variability. Circulation 2000;101:1267-1273.

19. Creason J, Neas L, Walsh D, et al. Particulate matter and heart rate variability among elderly retirees: The Baltimore 1998 PM study. J Expo Anal Environ Epidemiol 2001;11:116-122.

20. Liao DP, Duan YK, Whitsel EA, et al. Association of higher levels of ambient criteria pollutants with impaired cardiac autonomic control: A population-based study. Am J Epidemiol 2004;159:768-777.

21. Ho JE, Stevenson WG, Strichartz GR, et al. Mechanisms of cardiac arrhythmias. In: Lilly LS, ed. Pathophysiology of heart disease: A collaborative project of medical students and faculty, 3rd Edition. Baltimore, MD: Lippincott Williams \& Wilkins 2003:253-268.

22. Dockery DW, Luttmann-Gibson H, Rich DQ, et al. Particulate air pollution and nonfatal cardiac events. Part II: Association of air pollution with confirmed arrhythmias recorded by implanted defibrillators. Health Effects Institute Research Report Number 124 2005:83-126. 
23. Seaton A, MacNee W, Donaldson K, et al. Particulate air pollution and acute health effects. Lancet 1995;345:176-178.

24. Stone PH, Godleski JJ. First steps toward understanding the pathophysiologic link between air pollution and cardiac mortality. Am Heart J 1999;138:804-807.

25. Brook RD, Brook JR, Rajagopalan S. Air pollution: The "heart" of the problem. Curr Hypertens Rep 2003;5:32-39.

26. Levine PA, Klein MD. Mechanisms of arrhythmias in chronic obstructive lung disease. Geriatrics 1976;November:47-56. 


\section{FIGURE LEGENDS}

Figure 1. Odds ratios for SVE for IQR increases in pollutant concentrations at 1 to 5-day moving average concentrations $(\mathrm{N}=310-421)$. Models control for apparent temperature at hour of clinic visit, season, day of week, hour of day, age and BMI. Error bars indicate 95\% confidence intervals.

Figure 2. Participant characteristics as effect modifiers of the 5-day moving average PM2.5 SVE association. 0=participants without the characteristic, 1=participants with the characteristic. Difference in pollution effect is significant at ${ }^{*} \mathrm{p} p<0.05,{ }^{*} \mathrm{p}<0.10$. Models control for apparent temperature at hour of clinic visit, season, day of week, hour of day, age and BMI. Error bars indicate 95\% confidence intervals. 


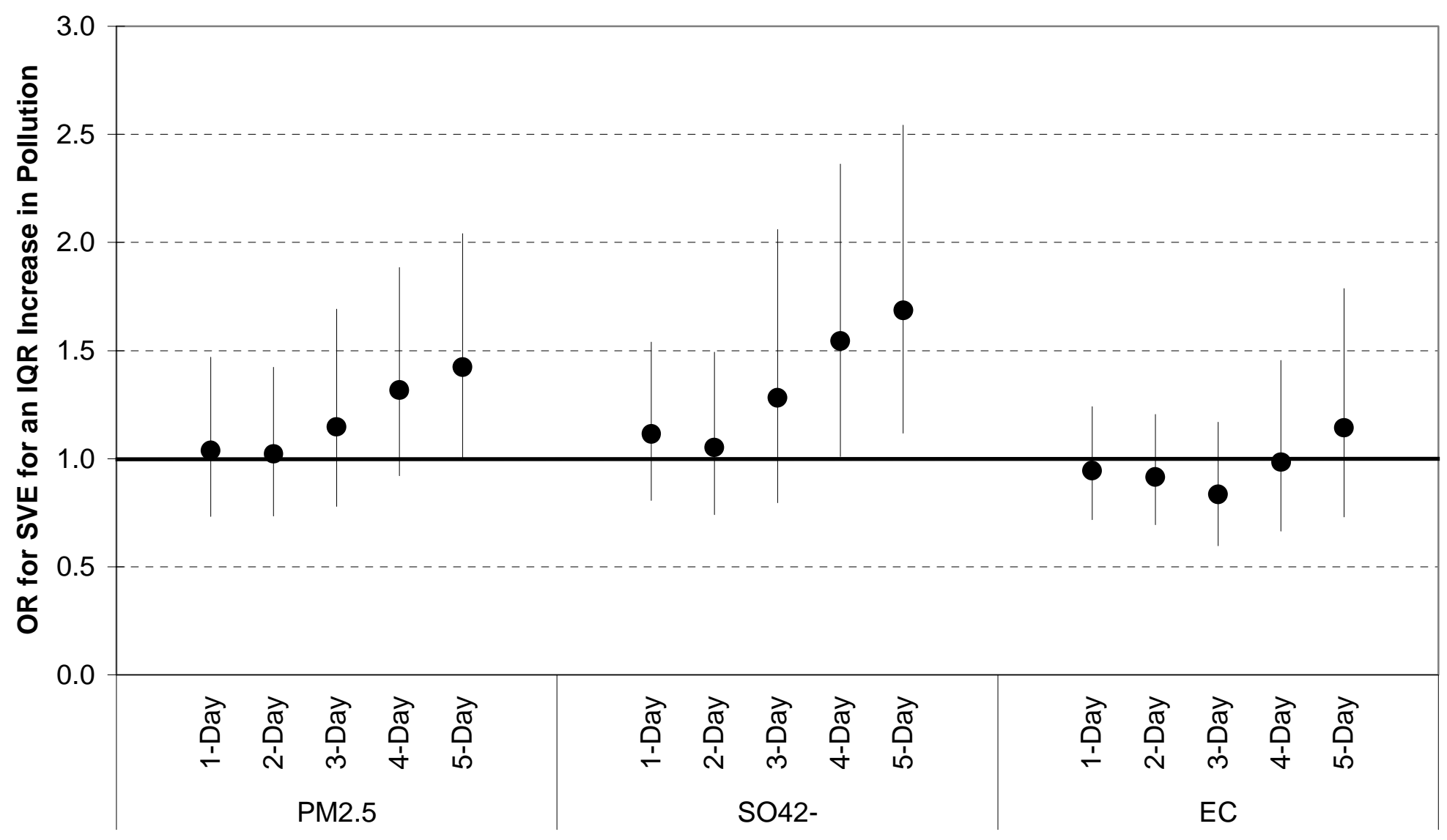




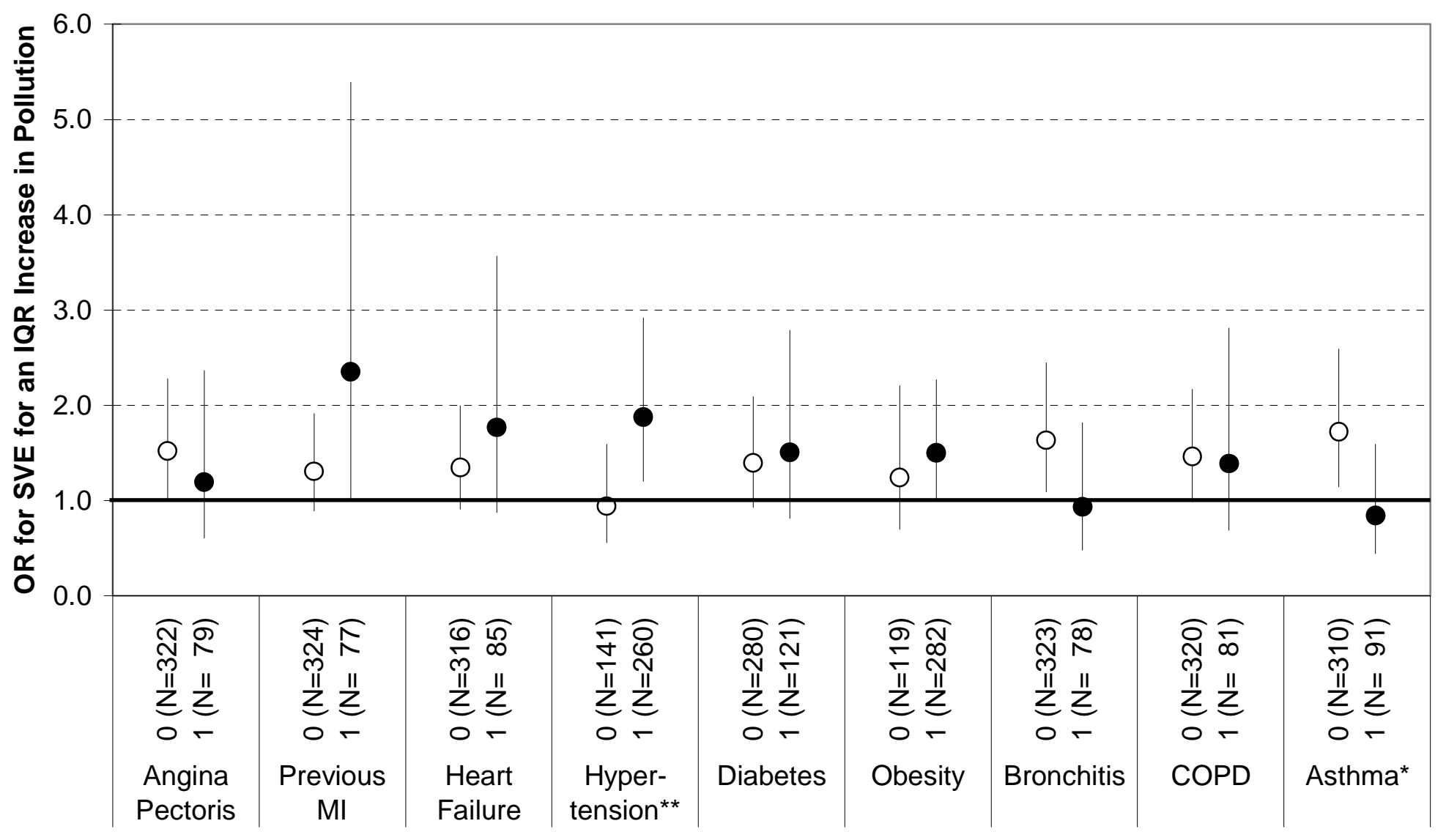




\section{APPENDIX F}

\section{SHORT-TERM EFFECTS OF AIR POLLUTION ON HEART RATE VARIABILITY IN SENIOR ADULTS IN STEUBENVILLE, OH}

MANUSCRIPT SUBMITTED TO JOURNAL OF OCCUPATIONAL AND ENVIRONMENTAL MEDICINE 


\title{
Short-term Effects of Air Pollution on Heart Rate Variability in Senior Adults in Steubenville, $\mathbf{O H}$
}

\author{
Heike Luttmann-Gibson ${ }^{1}$, Helen H. Suh ${ }^{1}$, Brent A. Coull ${ }^{2}$, Douglas W. Dockery ${ }^{1,3}$, \\ Stefanie E. Sarnat ${ }^{4,1}$, Joel Schwartz ${ }^{1,3}$, Peter H. Stone ${ }^{5}$, Diane R. Gold ${ }^{1,3}$ \\ ${ }^{1}$ Department of Environmental Health, Harvard School of Public Health, Boston, MA \\ ${ }^{2}$ Department of Biostatistics, Harvard School of Public Health, Boston, MA \\ ${ }^{3}$ Channing Laboratory, Harvard Medical School, Boston, MA \\ ${ }^{4}$ Department of Environmental and Occupational Health, Emory University, Atlanta, GA \\ ${ }^{5}$ Cardiovascular Division, Brigham and Women's Hospital, Harvard Medical School, Boston, MA
}

\section{Corresponding Author:}

Heike Luttmann-Gibson, $\mathrm{PhD}$

Harvard School of Public Health

401 Park Drive, Suite 415

Boston, MA 02215

Phone: 617.384 .8742

Fax: 617.384.8745

Email: hgibson@hsph.harvard.edu

\section{Acknowledgements}

This work is supported by funding from the National Institute of Environmental Health Sciences (ES-09825 and ES-00002), the U.S. Environmental Protection Agency (R826780-01-0, R827353-01-0), the Ohio Coal Development Office (CDO/D-98-2) and the United States Department of Energy's National Energy Technology Laboratory Award No. DE-FC2600NT40771. Any opinions, findings, conclusions, or recommendations expressed herein are those of the authors and do not necessarily reflect the views of the U.S. Department of Energy. The authors are also grateful for CONSOL Energy Inc. Research and Development's laboratory analysis of air pollutant samples and for the provision of continuous ambient monitoring data. 


\section{Short-term Effects of Air Pollution on Heart Rate Variability in Senior Adults in Steubenville, $\mathrm{OH}$}

Key words: Air Pollution, short-term effects, autonomic function, heart rate variability, fine particles, sulfates

Running Title: Short-term Effects of Air Pollution on Autonomic Function
Abbreviations:
$\mathrm{BC}=$ Black Carbon
$\mathrm{CI}=$ confidence interval
$\mathrm{CO}=$ carbon monoxide
$\mathrm{EC}=$ elemental carbon
$\mathrm{HF}=$ high frequency power
$\mathrm{HRV}=$ heart rate variability
$\mathrm{IQR}=$ interquartile range
$\mathrm{LF}=$ low frequency power
$\mathrm{NO}_{2}=$ nitrogen dioxide
$\mathrm{O}_{3}=$ ozone

$\mathrm{PM}_{2.5}=$ particulate matter $<2.5 \mu \mathrm{m}$ aerodynamic diameter

PNN50 $=$ percent of adjacent RR intervals more than $50 \mathrm{msec}$ different from each other

r-MSSD $=$ square root of the mean of the squared differences between adjacent normal NN intervals

SDNN = standard deviation of normal RR Intervals 
$\mathrm{SO}_{2}=$ sulfur dioxide

$\mathrm{SO}_{4}{ }^{2-}=$ sulfate

$\mathrm{Ta}=$ air temperature

$\mathrm{Td}=$ dew point temperature

Page 2 


\section{Abstract}

Objective: We examined the association between ambient air pollution levels and heart rate variability (HRV) in a panel study of 32 subjects.

Methods: We used linear mixed models to analyze the effects of fine particles $\left(\mathrm{PM}_{2.5}\right)$, sulfate $\left(\mathrm{SO}_{4}{ }^{2-}\right)$, elemental carbon (EC), and gases on log-transformed standard deviation of normal $\mathrm{RR}$ intervals (SDNN), mean square of differences between adjacent RR intervals (r-MSSD), and high and low frequency power (HF, LF).

Results: An interquartile range (IQR) increase of $5.1 \mu \mathrm{g} / \mathrm{m}^{3}$ in $\mathrm{SO}_{4}{ }^{2-}$ on the previous day was associated with a decrease of $-3.3 \% \operatorname{SDNN}(95 \% \mathrm{CI}:-6.0 \%,-0.5 \%),-5.6 \% \mathrm{r}-\mathrm{MSSD}(-10.7 \%,-$ $0.2 \%)$, and $-10.3 \%$ HF $(-19.5 \%,-0.1 \%)$. Associations with total $\mathrm{PM}_{2.5}$ were similar. HRV was not associated with $\mathrm{EC}, \mathrm{NO}_{2}, \mathrm{SO}_{2}$ or $\mathrm{O}_{3}$.

Conclusion: In addition to traffic-related particles, elevated levels of sulfate particles may also adversely affect autonomic function. 


\section{Introduction}

Acute exposure to increases in ambient air pollution have been associated with increased cardiovascular mortality $^{1-4}$ and morbidity ${ }^{5,6}$ including increased subclinical indicators such as heart rate $^{7-10}$ and blood pressure, ${ }^{11-14}$ increased risk of cardiac arrhythmias ${ }^{15,16}$ and myocardial infarction, ${ }^{17-20}$ ST-segment depression, ${ }^{21}$ and decreased HRV. ${ }^{8,10,22-28} \mathrm{HRV}$ varies with autonomic tone, and reduced HRV is believed to be either in the pathway leading to increased cardiac risk or, alternatively, a marker of poor health.

Reduced HRV as a patient characteristic has been prospectively associated with the development of clinically significant cardiovascular disease, ${ }^{29-31}$ and short-term HRV changes may also have clinical significance. HRV was decreased in patients in the period immediately preceding ischemic sudden death, ${ }^{32}$ and increased LF/HF ratios have been reported immediately preceding the onset of ventricular tachycardias, ${ }^{33-35}$ suggesting that shorter-term increased sympathetic and reduced parasympathetic activity may trigger cardiac arrhythmias.

While some studies investigating the relation of ambient pollution with HRV have specifically connected traffic-associated particle pollution with reduced HRV, ${ }^{10}$ less is known about the specific effects of non-traffic related pollution on HRV. In a study of elders living near a major inner city roadway in Boston, the effect of traffic-related black carbon (BC) on reduced HRV predominated. ${ }^{10}$ In this study of elders in the small industrial town of Steubenville, $\mathrm{OH}$ we examined the association of acute non-traffic as well as traffic-related air pollution exposures with repeatedly measured $\mathrm{HRV}$, using sulfate $\left(\mathrm{SO}_{4}{ }^{2-}\right)$ as a marker of non-traffic pollution. ${ }^{36}$ 


\section{Subjects and Methods}

\section{Study Population and Protocol}

Thirty-two non-smoking senior adults from Steubenville, $\mathrm{OH}$ were recruited to participate in a study on air pollution and cardiovascular health during the summer and fall of 2000. Most participants lived in one of three centrally located, subsidized apartment buildings. Prior to inclusion in the study, a screening appointment was held to collect information on cardiovascular and respiratory health and medications and to obtain baseline electrocardiogram (12-lead MAC6, Marquette Medical Systems Inc.) recordings. Exclusion criteria included smoking, having a pacemaker, a recent acute coronary syndrome, atrial flutter or atrial fibrillation.

The study design was reviewed and approved by the Human Subjects Committees of the Brigham and Women's Hospital and the Harvard School of Public Health.

Study participants were seen weekly on the same day of the week and at the same time during summer (June 4 - August 18) and fall (September 25 - December 15) of 2000. A short questionnaire on recent symptoms, hospital or doctor's visits and medication use was administered, followed by Holter electrocardiogram monitoring (SEER MC, GE Medical Systems) with electrodes in a modified V5 and AVF position. The Holter monitoring protocol included: (1) five minutes of rest in a supine position; (2) three supine blood pressure (BP) measurements (NIBP Vital Signs Monitor, Welch Allyn); (3) five minutes of standing with three standing BP measurements taken after two minutes; (4) five minutes of exercise (walking) outdoors (weather and health permitting); (5) five minutes of rest in a supine position and; (6) two minutes and 20 seconds of paced breathing. 
The Holter tapes were analyzed using a Marquette MARS Workstation (GE Medical Systems), with a 125 samples/second sampling rate following HRV guidelines ${ }^{37}$. The Holter tapes were analyzed for time domain HRV measures including the standard deviation of normal RR intervals (SDNN), the mean square of differences between adjacent RR intervals (r-MSSD), and the percent of RR intervals more than $50 \mathrm{msec}$ different from the prior interval (PNN50), and frequency domain HRV measures including low frequency power (LF) and high frequency power (HF). HRV and average heart rate was obtained for the whole protocol and for each separate interval.

\section{Air Pollution Concentration and Meteorological Measurements}

Hourly $\mathrm{PM}_{2.5}$ (TEOM 1400A, Rupprecht and Patashnick, East Greenbush, NY), ozone $\left(\mathrm{O}_{3}\right.$; API, Model $\left.400 \mathrm{UV}\right)$, nitrogen dioxide $\left(\mathrm{NO}_{2}\right.$; API, Model 200A Chemiluminescent), sulfur dioxide ( $\mathrm{SO}_{2}$; API, Model 100UV Fluorescent), and carbon monoxide (CO; API, Model 300 GFC) concentrations, temperature, relative humidity, and dew point were obtained from a centrally located ambient monitoring site at the Franciscan University of Steubenville operated by CONSOL Energy Inc. Research \& Development.

We calculated apparent temperature as: $-2.653+(0.994 \times \mathrm{Ta})+\left(0.0153 \times \mathrm{Td}^{2}\right)$, where Ta is the air temperature and $\mathrm{Td}$ is the dew point.

We also collected 24-hour integrated $\mathrm{PM}_{2.5}, \mathrm{SO}_{4}{ }^{2-}, \mathrm{EC}$ and gaseous pollutant $\left(\mathrm{O}_{3}, \mathrm{NO}_{2}\right.$, $\mathrm{SO}_{2}$ ) samples beginning at 9 a.m. each day (except Saturday) using a Harvard multi-pollutant monitor ${ }^{38}$. $\mathrm{PM}_{2.5}$ was measured gravimetrically. CONSOL analyzed the $\mathrm{SO}_{4}{ }^{2-}, \mathrm{O}_{3}, \mathrm{NO}_{2}$ and $\mathrm{SO}_{2}$ filters using ion chromatography and EC filters using thermal optical transmission. The 
concentration of non-sulfate $\mathrm{PM}_{2.5}$ was calculated as the difference between the measured $\mathrm{PM}_{2.5}$ and sulfate concentrations, with sulfate assumed to in the form of ammonium sulfate $\left(\left(\mathrm{NH}_{4}\right)_{2} \mathrm{SO}_{4}\right)$, that is: non-sulfate $\mathrm{PM}_{2.5}=\mathrm{PM}_{2.5}-\left(\mathrm{SO}_{4}{ }^{2-} \cdot 132 / 96\right)$.

\section{Statistical Methods}

We examined the associations between air pollution and log-transformed HRV parameters and HR over the entire 30-minute protocol with linear mixed models including random subject effects, fixed effects of pollution, age, gender, race, obesity (defined as Body Mass Index $>30$ ), season, time of day, apparent temperature, and a first-order auto-regressive process for the within-subject residuals. ${ }^{39}$ In the main analysis 24-hour integrated pollution measurements (ending at 9 a.m. on the day of the electrocardiogram recording) were used as the exposure variable. Exposures also were assessed using moving averages ( 4 to 72 hours) of $\mathrm{PM}_{2.5}$ and gaseous pollutant hourly concentrations before the electrocardiogram.

We assessed effect modification by medical conditions and medication intake in regression models including interaction terms between air pollution effects and potential effect modifiers. Results are restricted to r-MSSD as an outcome and $\mathrm{PM}_{2.5}$ and $\mathrm{SO}_{4}{ }^{2-}$ as exposure variables. Hypertension, coronary artery disease (angina or myocardial infarction), and congestive heart failure were defined as subject-specific conditions. Medication intake was defined as a time-varying condition. Results were similar when we defined medication intake as subject-specific (subject defined as "on medication" when medication was taken on most days). 
Results are reported as estimated percent differences and $95 \%$ confidence interval (CI) in HRV or heart rate associated with an IQR increase in each pollutant. All analyses were done with SAS software version 9.1 (SAS Institute, Inc; Cary, NC). 


\section{Results}

\section{Study Population}

Of 53 subjects screened, thirty-two were recruited for the study. There were 645 health visits, with an average of 20 (range 4-24) per subject (Table 1). The mean age at screening was 71 years; $91 \%$ of the participants were female, and 69\% were white. Most participants (84\%) had one or more cardiovascular condition, and two thirds were on one or more medications (Table 1). Twenty subjects $(63 \%)$ with body mass index greater than $30 \mathrm{~kg} / \mathrm{m}^{2}$ were classified as obese. Average HRV and heart rate measurements are listed in Table 2.

\section{Ambient Air Pollutant Concentrations}

Daily mean ambient air pollution concentrations are summarized in Table 3 for $\mathrm{PM}_{2.5}$, $\mathrm{SO}_{4}{ }^{2-}$, non-sulfate $\mathrm{PM}_{2.5}, \mathrm{EC}, \mathrm{NO}_{2}, \mathrm{SO}_{2}$, and $\mathrm{O}_{3}$ during the study period. Ambient concentrations of the measured criteria gases were moderate in Steubenville while ambient fine particle concentrations were relatively high, with some daily means approaching the 24-h National Ambient Air Quality Standards $\left(65 \mu \mathrm{g} / \mathrm{m}^{3}\right.$ for $\left.\mathrm{PM}_{2.5}\right)$. On six of the 118 days $(5 \%)$ the daily mean $\mathrm{PM}_{2.5}$ (based on the hourly data averaged over the day) exceeded $50 \mu \mathrm{g} / \mathrm{m}^{3}$ (maximum $\left.50.7 \mu \mathrm{g} / \mathrm{m}^{3}\right)$. The correlation coefficients between daily particulate and gas concentrations are shown in Table 4.

\section{Associations between Air Pollution and Heart Rate Variability Measures}

Time and frequency domain HRV parameters including SDNN, r-MSSD, HF and LF were negatively associated with the mean $\mathrm{PM}_{2.5}$ concentration during the day before the HRV 
measurement (Table 5). For example, R-MSSD was $-6.5 \%$ (CI $-12.1 \%$ to $-0.6 \%$, p=0.03) lower with each IQR range increase in mean $\mathrm{PM}_{2.5}\left(13.4 \mu \mathrm{g} / \mathrm{m}^{3}\right)$ on the day prior to the measurement. We found no suggestion of an association of $\mathrm{HRV}$ with mean $\mathrm{NO}_{2}, \mathrm{SO}_{2}$, or $\mathrm{O}_{3}(\mathrm{p}>0.10)$. For PNN50, the results were similar in magnitude but with wider confidence intervals (data not shown). In contrast to HRV, we found that heart rate was elevated with increased $\mathrm{PM}_{2.5}$. For example, heart rate was elevated by $1.1 \%$ (CI $0.2 \%$ to $2.1 \%, \mathrm{p}=0.02$ ) with each IQR range increase in $\mathrm{PM}_{2.5}$ on the day before the measurement.

We compared the associations of $\mathrm{PM}_{2.5}$ with those for its major components $\left(\mathrm{EC}, \mathrm{SO}_{4}{ }^{2-}\right.$ and non-sulfate $\mathrm{PM}_{2.5}$ ). We found that $\mathrm{SO}_{4}{ }^{2-}$ was significantly associated with decreased SDNN, r-MSSD, HF, and LF and increased heart rate, while non-sulfate $\mathrm{PM}_{2.5}$ was moderately associated $(\mathrm{p}<0.10)$ with decreased SDNN, r-MSSD, and increased heart rate. In contrast, we found no associations with HRV for the EC fraction of $\mathrm{PM}_{2.5}$ or for any of the gaseous pollutants $(\mathrm{p}>0.10)$.

We compared the association between $\mathrm{HRV}$ and ambient $\mathrm{PM}_{2.5}$ for averaging periods at 4, 6, 12, 24, 48 and 72 hours prior to the electrocardiogram recordings. For all HRV measures, the associations between the daily mean $\mathrm{PM}_{2.5}$ and HRV were similar to those for the 24- and 48hour moving averages (Figure 1).

\section{Effect Modification}

We found no consistent effect modification of the air pollution effect by congestive heart failure, coronary artery disease, or statin intake (Table 6). However, we did find that subjects with hypertension showed very little response to increased levels of $\mathrm{PM}_{2.5}$, while subjects without hypertension showed a change of $-17.8 \%$ in $\mathrm{r}-\mathrm{MSSD}$ [CI -25.8 to -8.9 ] associated with increased 
$\mathrm{PM}_{2.5}$ (p-value of interaction $=0.002$ ). We also found stronger effects of $\mathrm{PM}_{2.5}$ on days when subjects were not on beta-blocker medication ( $-10.0 \%$ r-MSSD [CI -16.0 to -3.4 ] for a $\mathrm{PM}_{2.5}$ increase of $\left.13.4 \mu \mathrm{g} / \mathrm{m}^{3}\right)$ as compared to no effect (1.6\%, [CI -7.6 to 11.9$\left.]\right)$ on days when subjects were on beta-blockers (interaction p-value $=0.03$ ). Similarly, we found higher $\mathrm{PM}_{2.5}$ effects on days when subjects were not on statins ( $-8.4 \%$ r-MSSD [CI -14.4 to -2.0$])$ as compared to days when they were (interaction p-value $=0.15$ ). While $52 \%$ of those with hypertension and $0 \%$ of those without hypertension were on beta blockers, the effect modification by hypertension remained significant $(\mathrm{p}<0.05)$ in the 20 subjects not on beta-blockers. Associations between sulfates and HRV were similarly modified by hypertension and beta blocker intake, with slightly higher interaction p-values. 


\section{Discussion}

We found reduced HRV in a group of elderly subjects living in Steubenville, $\mathrm{OH}$ associated with increased total $\mathrm{PM}_{2.5}$ and $\mathrm{SO}_{4}{ }^{2-}$ during the previous day. Reduced $\mathrm{HRV}$ was more weakly related to the non-sulfate component of $\mathrm{PM}_{2.5}$, and was not related to increases in pollutants generally associated with traffic sources such as $\mathrm{EC}, \mathrm{O}_{3}$, or $\mathrm{NO}_{2}$. Increases in overall $\mathrm{PM}_{2.5}$ and $\mathrm{SO}_{4}{ }^{2-}$ were associated not only with decreased r-MSSD and HF, suggesting reduction in vagal tone, but also with decreased LF and increased heart rate, suggesting increases in sympathetic tone.

Our sulfate effects suggest that in an environment where non-traffic sources of pollution (e.g. coal combustion at power plants and steel mills) contribute significantly to ambient pollution in the community, elevated levels of particles from these sources may also adversely affect cardiac autonomic function and clinical cardiac outcomes. This conclusion is consistent with the American Cancer Society's cohort study ${ }^{40}$ in which sulfate concentrations were a significant predictor of cardiovascular mortality, the time-series results within the Six-Cities Study (which included Steubenville) by Laden et al., ${ }^{41}$ who found sulfur was predictive of shortterm mortality, and the findings by O'Neill et al., ${ }^{42}$ who found increased sulfate concentrations to be a significant predictor of decreased vascular reactivity in diabetics.

Within the framework of the 2000-2002 Steubenville Comprehensive Air Monitoring Program (SCAMP), Connell et $\mathrm{al}^{43}$ studied fine particulate matter concentration and composition and found that $\mathrm{SO}_{4}{ }^{2-}$ is the major constituent of $\mathrm{PM}_{2.5}$ in Steubenville, accounting for approximately $31 \%$ of total mass. Within the period of this study, ambient $\mathrm{SO}_{4}{ }^{2-}$ comprised between $52 \%$ and $43 \%$ of the total $\mathrm{PM}_{2.5}$ mass $\left(\right.$ as $\left.\left(\mathrm{NH}_{4}\right)_{2} \mathrm{SO}_{4}\right){ }^{44}$ The SCAMP analyses ${ }^{43}$ suggest 
that local sources in Steubenville contribute only approximately $4.6 \mu \mathrm{g} / \mathrm{m}^{3}$ (25\% of the annual mean $18.4 \mu \mathrm{g} / \mathrm{m}^{3}$ ) to the city's $\mathrm{PM}_{2.5}$ concentrations. The main source of $\mathrm{PM}_{2.5}$ and sulfate in Steubenville is fossil fuel (primarily coal) combustion, ${ }^{36}$ most likely produced by the steel mills and power plants located in the Ohio River Valley.

Traffic pollutant effects predominated in our two previous Boston studies conducted with a similar study design in a community of elders living next to a city roadway. ${ }^{8,10}$ In the first study, $\mathrm{SO}_{4}{ }^{2-}$ and $\mathrm{BC}$ measurements were not available, but we found associations of ozone as well as overall $\mathrm{PM}_{2.5}$ with reduced HRV. ${ }^{8}$ In the second study, reduced HRV was most strongly and consistently associated with increased $\mathrm{BC}$, which is a marker for traffic exposure ${ }^{10}$. Mean air pollution levels during the study period from June to December 2000 show that $\mathrm{PM}_{2.5}$ and $\mathrm{SO}_{4}{ }^{2-}$ were twice as high in Steubenville than in Boston $\left(\mathrm{PM}_{2.5}: 20\right.$ vs. $10 \mu \mathrm{g} / \mathrm{m}^{3}, \mathrm{SO}_{4}{ }^{2-}: 6.9$ vs. 3.0 $\mu \mathrm{g} / \mathrm{m}^{3}$ ) whereas the traffic-related pollutant $\mathrm{NO}_{2}$ was lower in Steubenville (10.0 vs. $21.5 \mathrm{ppb}$ ) (Steubenville: Table 3, Boston: data not shown).

Our results for Steubenville and Boston elders, suggesting pollution-associated decreases in vagal stimulation and/or increases in sympathetic tone, are consistent with findings from many other studies that did not separate out components of $\mathrm{PM}_{2.5}$ that might enable the investigators to distinguish traffic from non-traffic $\mathrm{PM}_{2.5}$ effects (Table 7).

Elevation of overall particle pollution $\left(\mathrm{PM}_{2.5}\right.$ or $\left.\mathrm{PM}_{10}\right)$ has been related to reduction in HRV or increases in heart rate in repeated measures elders studies from Baltimore, ${ }^{23,24}$ Utah Valley, ${ }^{22,25}$ and Mexico City. ${ }^{26}$ While studies have not consistently found that elevated pollution levels increase $\mathrm{HR}$ at the same time as they reduce $\mathrm{HRV}$, it has been proposed that the association of increased pollution with reduced HRV may be mediated, in part, through the 
increase in heart rate that results from increased sympathetic tone. For all HRV parameters in our study, controlling for heart rate led to small changes in the magnitude of the effect estimates (Figure 2), suggesting that a portion, but not all, of the HRV associations related to the pathways reflected by heart rate.

Similar associations of particle mass with HRV have been reported in a chamber study on elderly volunteers exposed for two hours to concentrated air pollution particles, in which significant decrements in HRV in both time and frequency domain were found immediately and 24 hours after exposure. ${ }^{45}$ While the majority of the studies point to a significant association of particle pollution with reduced HRV, effects of $\mathrm{PM}_{2.5}$ on HRV have not been found in panel studies conducted in Northwestern US and Canada, perhaps because of differences in particle composition or, alternatively, low power. ${ }^{46-48}$ Also, in contrast to the negative associations noted above, increases in traffic pollution were associated with increased HRV in a study of a younger healthy population of traffic police in North Carolina. ${ }^{49}$ The investigators hypothesize that the nature of the pollution-related autonomic dysfunction may depend on the age and underlying disease states of the study participants.

Between-person comparisons of HRV show that reduced HRV may be a marker for overall ill health. ${ }^{29}$ While the significance of within-person short-term changes in HRV is somewhat less well established, a study of ischemic events showed that they were preceded by decreased high frequency HRV in the hour before the event, and in low frequency HRV in the 4 minutes before the event. ${ }^{50}$ Similarly, a significant decrease in heart HRV has been reported to precede paroxysmal atrial fibrillation. ${ }^{51}$ 
We found effect modification of hypertension and beta-blocker intake in this study, with stronger associations between particles and HRV among the "healthier" subjects (no hypertension, not on beta-blocker). These findings contrast with several previous studies which showed stronger adverse effects of air pollution on HRV in subjects with preexisting cardiovascular conditions, ${ }^{23}$ previous myocardial infarction, ${ }^{10}$ or hypertension. ${ }^{26-28}$ Two of those studies were cross-sectional analyses of large cohorts, with much larger numbers of subjects. ${ }^{27,28}$ The small numbers of subjects in panel studies such as this one make examination of effect modification difficult, and this result may be a chance finding. Alternatively, it is possible that in sicker populations other influences on HRV (for example medication) predominate, making it more difficult to detect pollution effects. In support of our findings, a panel study of elderly subjects in Seattle also found associations between particles and heart rate primarily in healthy subjects. $^{52}$

Personal exposures to particles and gases were measured in a subset of the study population. Associations between ambient particle concentrations and corresponding personal exposures were strong, whereas associations between ambient gases and their corresponding personal exposures were much weaker. ${ }^{44} \mathrm{We}$ conclude that $\mathrm{PM}_{2.5}$ and $\mathrm{SO}_{4}{ }^{2-}$ ambient concentrations are very good proxies for the personal exposure of the study participants.

Recently, the scientific and regulatory communities have focused their attention on the adverse cardiac effects of ambient particles from mobile sources. This study supports the hypothesis that in an environment such as Steubenville, Ohio, where non-traffic sources of pollution contribute significantly to ambient pollution in the community, particle pollution from these sources, particularly sulfate particles, can also have adverse effects on autonomic function. 


\section{Acknowledgements}

The authors wish to thank all of the participants of the study as well as Monique Verrier, Meghan Syring, Bruce Nearing, Gail McCallum, Marisa Barr and Marina Jacobson-Canner. We also thank the field team members from Franciscan University of Steubenville, in particular Kim Agnew, Michelle Bellini, Karen Gay, Sara Krilich, Debra Santarelli, Steven Shea, and Teresa Sobie The authors are also grateful for CONSOL Energy Inc. Research and Development's laboratory analysis of air pollutant samples and for the provision of continuous ambient monitoring data. This work is supported by funding from the National Institute of Environmental Health Sciences (ES-09825 and ES-00002), the U.S. Environmental Protection Agency (R826780-01-0, R827353-01-0), the Ohio Coal Development Office (CDO/D-98-2) and the United States Department of Energy's National Energy Technology Laboratory Award No. DEFC26-00NT40771. Any opinions, findings, conclusions, or recommendations expressed herein are those of the authors and do not necessarily reflect the views of the U.S. Department of Energy. 


\section{References}

1. Schwartz J, Dockery DW. Particulate air pollution and daily mortality in Steubenville, Ohio. Am J Epidemiol 1992;135:12-9.

2. Dockery DW, Pope CA, 3rd, Xu X, et al. An association between air pollution and mortality in six U.S. cities. N Engl J Med 1993;329:1753-9.

3. Pope CA, 3rd, Thun MJ, Namboodiri MM, et al. Particulate air pollution as a predictor of mortality in a prospective study of U.S. adults. Am J Respir Crit Care Med 1995;151:66974.

4. Samet JM, Dominici F, Curriero FC, Coursac I, Zeger SL. Fine particulate air pollution and mortality in 20 U.S. cities, 1987-1994. N Engl J Med 2000;343:1742-9.

5. Zanobetti A, Schwartz J. The effect of particulate air pollution on emergency admissions for myocardial infarction: a multicity case-crossover analysis. Environ Health Perspect 2005;113:978-82.

6. Wellenius GA, Schwartz J, Mittleman MA. Air pollution and hospital admissions for ischemic and hemorrhagic stroke among medicare beneficiaries. Stroke 2005;36:2549-53.

7. Peters A, Perz S, Doring A, Stieber J, Koenig W, Wichmann HE. Increases in heart rate during an air pollution episode. Am J Epidemiol 1999;150:1094-8.

8. Gold DR, Litonjua A, Schwartz J, et al. Ambient pollution and heart rate variability. Circulation 2000;101:1267-1273. 
9. Pope CA, 3rd, Dockery DW, Kanner RE, Villegas GM, Schwartz J. Oxygen Saturation, Pulse Rate, and Particulate Air Pollution. A Daily Time-Series Panel Study. American Journal of Respiratory \& Critical Care Medicine 1999;159:365-372.

10. Schwartz J, Litonjua A, Suh H, et al. Traffic related pollution and heart rate variability in a panel of elderly subjects. Thorax 2005;60:455-61.

11. Ibald-Mulli A, Stieber J, Wichmann HE, Koenig W, Peters A. Effects of air pollution on blood pressure: a population-based approach. Am J Public Health 2001;91:571-7.

12. Ibald-Mulli A, Timonen KL, Peters A, et al. Effects of particulate air pollution on blood pressure and heart rate in subjects with cardiovascular disease: a multicenter approach. Environ Health Perspect 2004;112:369-77.

13. Zanobetti A, Canner MJ, Stone PH, et al. Ambient pollution and blood pressure in cardiac rehabilitation patients. Circulation 2004;110:2184-9.

14. de Paula Santos U, Braga AL, Giorgi DM, et al. Effects of air pollution on blood pressure and heart rate variability: a panel study of vehicular traffic controllers in the city of Sao Paulo, Brazil. Eur Heart J 2005;26:193-200.

15. Peters A, Liu E, Verrier RL, et al. Air pollution and incidence of cardiac arrhythmia. Epidemiology 2000;11:11-7.

16. Dockery DW, Luttmann-Gibson H, Rich DQ, et al. Association of air pollution with increased incidence of ventricular tachyarrhythmias recorded by implanted cardioverter defibrillators. Environ Health Perspect 2005;113:670-4. 
17. Peters A, Dockery DW, Muller JE, Mittleman MA. Increased particulate air pollution and the triggering of myocardial infarction. Circulation 2001;103:2810-5.

18. Grazuleviciene R, Maroziene L, Dulskiene V, et al. Exposure to urban nitrogen dioxide pollution and the risk of myocardial infarction. Scand J Work Environ Health 2004;30:293-8.

19. Peters A, von Klot S, Heier M, et al. Exposure to traffic and the onset of myocardial infarction. N Engl J Med 2004;351:1721-30.

20. D'Ippoliti D, Forastiere F, Ancona C, et al. Air pollution and myocardial infarction in Rome: a case-crossover analysis. Epidemiology 2003;14:528-35.

21. Gold DR, Litonjua AA, Zanobetti A, et al. Air pollution and ST-segment depression in elderly subjects. Environ Health Perspect 2005;113:883-7.

22. Pope CA, 3rd, Verrier RL, Lovell EG, et al. Heart rate variability associated with particulate air pollution. American Heart Journal 1999;138:890-899.

23. Liao D, Creason J, Shy C, Williams R, Watts R, Zweidinger R. Daily variation of particulate air pollution and poor cardiac autonomic control in the elderly. Environ Health Perspect 1999;107:521-5.

24. Creason J, Neas L, Walsh D, et al. Particulate matter and heart rate variability among elderly retirees: the Baltimore 1998 PM study. J Expo Anal Environ Epidemiol 2001;11:116-22. 
25. Pope CA, 3rd, Hansen ML, Long RW, et al. Ambient particulate air pollution, heart rate variability, and blood markers of inflammation in a panel of elderly subjects. Environ Health Perspect 2004;112:339-45.

26. Holguin F, Tellez-Rojo MM, Hernandez M, et al. Air pollution and heart rate variability among the elderly in Mexico City. Epidemiology 2003;14:521-7.

27. Liao D, Duan Y, Whitsel EA, et al. Association of higher levels of ambient criteria pollutants with impaired cardiac autonomic control: a population-based study. Am J Epidemiol 2004;159:768-77.

28. Park SK, O'Neill MS, Vokonas PS, Sparrow D, Schwartz J. Effects of air pollution on heart rate variability: the VA normative aging study. Environ Health Perspect 2005;113:304-9.

29. Tsuji H, Larson MG, Venditti FJ, Jr., et al. Impact of reduced heart rate variability on risk for cardiac events. The Framingham Heart Study. Circulation 1996;94:2850-5.

30. La Rovere MT, Bigger JT, Jr., Marcus FI, Mortara A, Schwartz PJ. Baroreflex sensitivity and heart-rate variability in prediction of total cardiac mortality after myocardial infarction. ATRAMI (Autonomic Tone and Reflexes After Myocardial Infarction) Investigators. Lancet 1998;351:478-84.

31. Schroeder EB, Liao D, Chambless LE, Prineas RJ, Evans GW, Heiss G. Hypertension, blood pressure, and heart rate variability: the Atherosclerosis Risk in Communities (ARIC) study. Hypertension 2003;42:1106-11. 
32. Pozzati A, Pancaldi LG, Di Pasquale G, Pinelli G, Bugiardini R. Transient sympathovagal imbalance triggers "ischemic" sudden death in patients undergoing electrocardiographic Holter monitoring. J Am Coll Cardiol 1996;27:847-52.

33. Lombardi F, Porta A, Marzegalli M, et al. Heart rate variability patterns before ventricular tachycardia onset in patients with an implantable cardioverter defibrillator. Participating Investigators of ICD-HRV Italian Study Group. Am J Cardiol 2000;86:959-63.

34. Pruvot E, Thonet G, Vesin JM, et al. Heart rate dynamics at the onset of ventricular tachyarrhythmias as retrieved from implantable cardioverter-defibrillators in patients with coronary artery disease. Circulation 2000;101:2398-404.

35. Huikuri HV, Valkama JO, Airaksinen KE, et al. Frequency domain measures of heart rate variability before the onset of nonsustained and sustained ventricular tachycardia in patients with coronary artery disease. Circulation 1993;87:1220-8.

36. Koutrakis P, Spengler JD. Source Apportionment of Ambient Particles in Steubenville, OH using Specific Rotation Factor Analysis. Atmospheric Environment 1987;21:1511-1519.

37. Task Force of the European Society of Cardiology and the North American Society of Pacing and Electrophysiology. Heart rate variability. Standards of measurements, physiological interpretation, and clinical use. Circulation 1996;93:1043-1065.

38. Demokritou P, Kavouras IG, Ferguson ST, Koutrakis P. Development and Laboratory Performance Evaluation of a Personal Multipollutnant Sampler for Simultaneous 
Measurements of Particulate and Gaseous Pollutants. Aerosol Science and Technology 2001;35:741-752.

39. Diggle P, Heagerty P, Liang K-Y, Zeger S. Analysis of Longitudinal Data, 2nd ed. New York: Oxford University Press; 2002.

40. Pope CA, 3rd, Burnett RT, Thun MJ, et al. Lung cancer, cardiopulmonary mortality, and long-term exposure to fine particulate air pollution. Jama 2002;287:1132-41.

41. Laden F, Neas LM, Dockery DW, Schwartz J. Association of fine particulate matter from different sources with daily mortality in six U.S. cities. Environ Health Perspect 2000;108:941-7.

42. O'Neill MS, Veves A, Zanobetti A, et al. Diabetes enhances vulnerability to particulate air pollution-associated impairment in vascular reactivity and endothelial function. Circulation 2005;111:2913-20.

43. Connell DP, Withum JA, Winter SE, Statnick RM, Bilonick RA. The Steubenville comprehensive air monitoring program (SCAMP): overview and statistical considerations. J Air Waste Manag Assoc 2005;55:467-80.

44. Sarnat SE, Coull BA, Schwartz J, Gold DR, Suh HH. Factors affecting the association between ambient concentrations and personal exposures to particles and gases. Environ Health Perspect 2006;114:649-54. 
45. Devlin RB, Ghio AJ, Kehrl H, Sanders G, Cascio W. Elderly humans exposed to concentrated air pollution particles have decreased heart rate variability. Eur Respir $J$ Suppl 2003;40:76s-80s.

46. Brauer M, Ebelt ST, Fisher TV, Brumm J, Petkau AJ, Vedal S. Exposure of chronic obstructive pulmonary disease patients to particles: respiratory and cardiovascular health effects. J Expo Anal Environ Epidemiol 2001;11:490-500.

47. Sullivan JH, Schreuder AB, Trenga CA, et al. Association between short term exposure to fine particulate matter and heart rate variability in older subjects with and without heart disease. Thorax 2005;60:462-6.

48. Ebelt ST, Wilson WE, Brauer M. Exposure to ambient and nonambient components of particulate matter: a comparison of health effects. Epidemiology 2005;16:396-405.

49. Riediker M, Cascio WE, Griggs TR, et al. Particulate matter exposure in cars is associated with cardiovascular effects in healthy young men. Am J Respir Crit Care Med 2004;169:934-40.

50. Kop WJ, Verdino RJ, Gottdiener JS, O'Leary ST, Bairey Merz CN, Krantz DS. Changes in heart rate and heart rate variability before ambulatory ischemic events. J Am Coll Cardiol $2001 ; 38: 742-9$.

51. Bettoni M, Zimmermann M. Autonomic tone variations before the onset of paroxysmal atrial fibrillation. Circulation 2002;105:2753-9. 
52. Mar TF, Koenig JQ, Jansen K, et al. Fine particulate air pollution and cardiorespiratory effects in the elderly. Epidemiology 2005;16:681-7. 


\section{Legends}

Figure 1: Estimated percent changes [95\% Confidence intervals] in SDNN and r-MSSD associated with an interquartile range increase in $\mathrm{PM}_{2.5}$ mean air pollution for different exposure metrics: moving averages for 4, 6, 12, 24, 48, and 72 hours (based on continuous data) and 1-day lag (based on filter data, 9 a.m. to 9 a.m.)

IQRs are: $17.7,17.5,16.6,15.2,12.6,11.4$, and $13.4 \mu \mathrm{g} / \mathrm{m}^{3}$, respectively.

Figure 2: Estimated percent changes [95\% Confidence intervals] in HRV parameters associated with an interquartile range increase in $\mathrm{PM}_{2.5}$ and $\mathrm{SO}_{4}{ }^{2-}$ (previous day) in the base model and adjusted for heart rate. 
Table 1: Participant Characteristics $(n=32)$

\begin{tabular}{lrr} 
Characteristic & Mean & range \\
\hline Number of visits & 20.2 & $4-24$ \\
Age (years) & 70.8 & $54-90$ \\
Body Mass Index $\left(\mathrm{kg} / \mathrm{m}^{2}\right)$ & 31.4 & $21-47$ \\
& & \\
Characteristic & $\mathrm{N}$ & $\%$ \\
\hline Gender & & \\
Male & 3 & 9 \\
Female & 29 & 91 \\
Race/Ethnicity & & \\
Black & 10 & 31 \\
White & 22 & 69 \\
Diagnoses & & \\
Angina & 6 & 19 \\
Myocardial Infarct & 7 & 22 \\
Coronary Artery Disease & \\
Congestive Heart Failure & 11 & 34 \\
Diabetes & 6 & 19 \\
Hypertension & 7 & 22 \\
Chronic Obstructive Pulmonary Disease & 23 & 72 \\
& 9 & 28
\end{tabular}

Medications Use ${ }^{\mathrm{b}}$

$\begin{array}{lll}\text { Beta Blocker } & 12 & 38\end{array}$

Calcium Channel Blocker $\quad 11 \quad 34$

$\begin{array}{lrr}\text { Statin } & 9 & 28\end{array}$

Angiotensin Converting Enzyme Inhibitors $\quad 11 \quad 34$

Digoxin $\quad 3 \quad 9$

Any of the above listed medications $\quad 21 \quad 66$

${ }^{a}$ Angina or Myocardial Infarct

${ }^{\mathrm{b}}$ Medication use is defined as reported at least once during the study 
Table 2: Average Heart Rate Variability (HRV) and average Heart Rate during 30-minute protocol for 32 subjects (638 valid measurements)

\begin{tabular}{lcc}
\hline & N & Mean (standard deviation) \\
\hline SDNN (ms) & 638 & $86.4(32.6)$ \\
r-MSSD (ms) & 638 & $36.3(37.4)$ \\
PNN50 (\%) & 638 & $7.7(13.5)$ \\
HF (ms $\left.{ }^{2}\right)$ & 634 & $239(425)$ \\
LF (ms ${ }^{2}$ ) & 635 & $355(589)$ \\
Heart Rate (beats/min) & 638 & $79.7(12.0)$
\end{tabular}


Table 3: Average air pollution concentrations during the two study periods (Jun $01-$ Aug 25, 2000, Sep 20 - Dec 15, 2000)

\begin{tabular}{|c|c|c|c|c|c|c|}
\hline & Pollutant & $\mathbf{N}$ & Mean & \multicolumn{2}{|c|}{ percentile } & IQR \\
\hline Daily data & $\mathrm{PM}_{2.5}\left(\mu \mathrm{g} / \mathrm{m}^{3}\right)$ & 137 & 19.7 & 11.6 & 25.0 & 13.4 \\
\hline \multirow[t]{6}{*}{9 a.m. to 9 a.m. } & $\mathrm{SO}_{4}{ }^{2-}\left(\mu \mathrm{g} / \mathrm{m}^{3}\right)$ & 133 & 6.9 & 3.3 & 8.5 & 5.1 \\
\hline & Non-sulfate $\mathrm{PM}_{2.5}\left(\mu \mathrm{g} / \mathrm{m}^{3}\right)$ & 133 & 10.0 & 6.3 & 11.5 & 5.3 \\
\hline & $\mathrm{EC}\left(\mu \mathrm{g} / \mathrm{m}^{3}\right)$ & 127 & 1.1 & 0.7 & 1.3 & 0.6 \\
\hline & $\mathrm{NO}_{2}(\mathrm{ppb})$ & 133 & 10.5 & 6.0 & 13.4 & 7.3 \\
\hline & $\mathrm{SO}_{2}(\mathrm{ppb})$ & 134 & 4.1 & 0.4 & 4.7 & 4.3 \\
\hline & $\mathrm{O}_{3}(\mathrm{ppb})$ & 134 & 22.2 & 12.1 & 28.5 & 16.4 \\
\hline Hourly data & $\mathrm{PM}_{2.5}(\mu \mathrm{g} / \mathrm{m} 3)$ & 118 & 20.0 & 11.3 & 26.5 & 15.2 \\
\hline averaged over & $\mathrm{NO}_{2}(\mathrm{ppb})$ & 113 & 10.9 & 7.4 & 14.7 & 7.3 \\
\hline \multirow[t]{2}{*}{ Calendar days } & $\mathrm{SO}_{2}(\mathrm{ppb})$ & 151 & 10.8 & 5.4 & 13.2 & 7.8 \\
\hline & $\mathrm{O}_{3}(\mathrm{ppb})$ & 144 & 27.3 & 15.7 & 36.3 & 20.6 \\
\hline
\end{tabular}


Table 4: Pearson correlation coefficients between daily air pollution concentrations during the two study periods (Jun 01 - Aug 25, 2000, Sep 20 - Dec 15, 2000)

\begin{tabular}{|c|c|c|c|c|c|c|}
\hline & $\mathrm{SO}_{4}^{2-}$ & $\begin{array}{c}\text { non-sulfate } \\
\mathrm{PM}_{2.5}\end{array}$ & $\mathrm{EC}$ & $\mathrm{NO}_{2}$ & $\mathrm{SO}_{2}$ & $\mathrm{O}_{3}$ \\
\hline $\mathrm{PM}_{2.5}$ & 0.90 & 0.87 & 0.59 & 0.40 & 0.33 & 0.23 \\
\hline $\mathrm{SO}_{4}^{2-}$ & & 0.57 & 0.47 & 0.24 & 0.31 & 0.36 \\
\hline non-sulfate $\mathrm{PM}_{2.5}$ & & & 0.62 & 0.54 & 0.31 & 0.01 \\
\hline $\mathrm{EC}$ & & & & 0.54 & 0.38 & -0.10 \\
\hline $\mathrm{NO}_{2}$ & & & & & 0.26 & -0.29 \\
\hline $\mathrm{SO}_{2}$ & & & & & & -0.03 \\
\hline
\end{tabular}


Table 5: Estimated percent changes [95\% Confidence intervals] in HRV and HR associated with an interquartile range increase in mean air pollution on the day before ${ }^{\mathrm{a}}$ the HRV measurement.

\begin{tabular}{|c|c|c|c|c|c|c|c|c|c|c|c|c|}
\hline & \multirow[b]{2}{*}{ IQR } & \multirow[b]{2}{*}{$\mathbf{n}$} & \multicolumn{2}{|c|}{ SDNN } & \multicolumn{2}{|c|}{ r-MSSD } & \multicolumn{2}{|r|}{ HF } & \multicolumn{2}{|r|}{$\mathbf{L F}$} & \multicolumn{2}{|c|}{ Heart Rate } \\
\hline & & & $\begin{array}{c}\% \\
\text { change }\end{array}$ & $95 \%$ CI & $\begin{array}{c}\% \\
\text { change }\end{array}$ & $95 \%$ CI & $\begin{array}{c}\% \\
\text { change }\end{array}$ & $95 \%$ CI & $\begin{array}{c}\% \\
\text { change }\end{array}$ & $95 \%$ CI & $\begin{array}{c}\% \\
\text { change }\end{array}$ & $95 \%$ CI \\
\hline $\mathbf{P M}_{2.5}$ & $\begin{array}{l}13.4 \\
\mu \mathrm{g} / \mathrm{m}^{3}\end{array}$ & 559 & $-4.0^{*}$ & {$[-7.0,-0.9]$} & $-6.5^{*}$ & {$[-12.1,-0.6]$} & $-11.4^{*}$ & {$[-21.5,-0.1]$} & $-10.7 *$ & {$[-20.1,-0.3]$} & $1.1^{*}$ & {$[0.2,2.1]$} \\
\hline $\mathrm{SO}_{4}{ }^{2-}$ & $\begin{array}{l}5.1 \\
\mu \mathrm{g} / \mathrm{m}^{3}\end{array}$ & 538 & $-3.3^{*}$ & {$[-6.0,-0.5]$} & $-5.6^{*}$ & {$[-10.7,-0.2]$} & $-10.3^{*}$ & {$[-19.5,-0.1]$} & $-8.4^{+}$ & {$[-17.0,1.2]$} & $0.8^{+}$ & {$[-0.02,1.7]$} \\
\hline $\begin{array}{l}\text { non- } \\
\text { sulfate } \\
\mathbf{P M}_{2.5}\end{array}$ & $\begin{array}{l}5.3 \\
\mu \mathrm{g} / \mathrm{m}^{3}\end{array}$ & 538 & $-2.1^{+}$ & {$[-4.3,0.1]$} & $-3.8^{+}$ & {$[-8.0,0.5]$} & -5.9 & {$[-13.7,2.6]$} & -7.2 & {$[-14.3,0.5]$} & $0.7^{+}$ & {$[-0.01,1.31]$} \\
\hline $\mathbf{E C}$ & $\begin{array}{l}0.6 \\
\mu \mathrm{g} / \mathrm{m}^{3}\end{array}$ & 511 & 1.5 & {$[-1.1,4.1]$} & -1.1 & {$[-5.8,3.9]$} & 3.1 & {$[-6.4,13.5]$} & -4.7 & {$[-12.7,4.0]$} & -0.2 & {$[-0.9,0.6]$} \\
\hline $\mathbf{N O}_{2}$ & $\begin{array}{l}7.3 \\
\mathrm{ppb}\end{array}$ & 552 & 0.1 & {$[-2.2,2.4]$} & -1.3 & {$[-5.6,3.2]$} & -1.3 & {$[-9.4,7.7]$} & -2.9 & {$[-10.4,5.2]$} & 0.0 & {$[-0.7,0.7]$} \\
\hline $\mathrm{SO}_{2}$ & $\begin{array}{l}4.3 \\
\mathrm{ppb}\end{array}$ & 558 & 0.7 & {$[-1.0,2.5]$} & 0.5 & {$[-2.8,4.0]$} & 1.7 & {$[-4.9,8.7]$} & 4.9 & {$[-1.4,11.5]$} & 0.3 & {$[-0.2,0.8]$} \\
\hline $\mathbf{O}_{3}$ & $\begin{array}{l}16.4 \\
\text { ppb }\end{array}$ & 552 & -1.1 & {$[-4.2,2.1]$} & -2.5 & {$[-8.4,3.9]$} & -3.8 & {$[-14.9,8.7]$} & -3.9 & {$[-14.2,7.6]$} & 0.7 & {$[-0.3,1.6]$} \\
\hline
\end{tabular}


Table 6: Effect modification of association of r-MSSD with $\mathrm{PM}_{2.5}\left(13.4 \mu \mathrm{g} / \mathrm{m}^{3}\right)$ and $\mathrm{SO}_{4}{ }^{2-}\left(5.1 \mu \mathrm{g} / \mathrm{m}^{3}\right)$ on the previous day by chronic cardiovascular diagnoses and medication intake

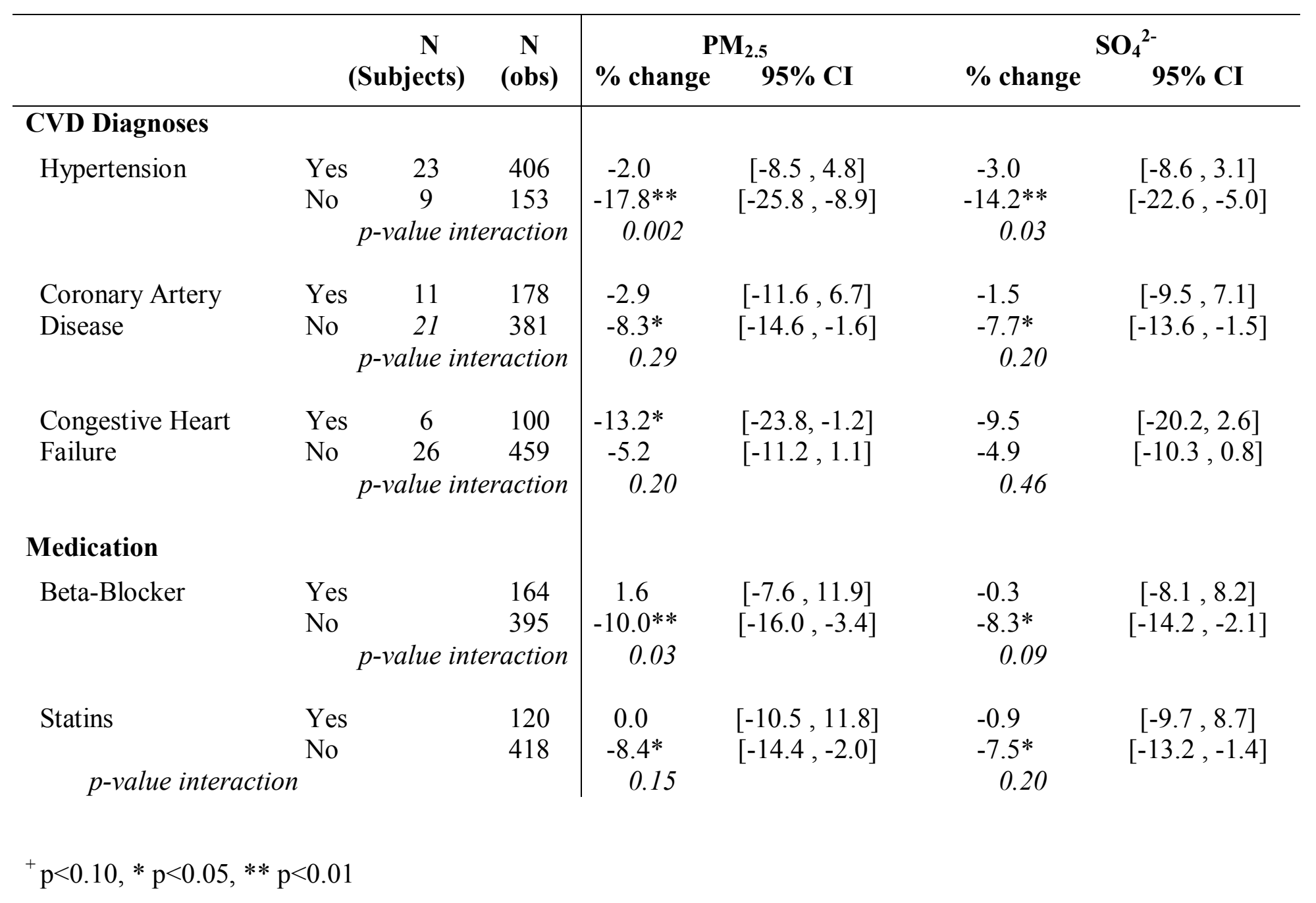




\begin{tabular}{|c|c|c|c|c|c|c|c|c|c|c|c|}
\hline \multirow[b]{2}{*}{ Study } & \multirow{2}{*}{$\begin{array}{c}\mathrm{N} \\
\text { Subjects }\end{array}$} & \multirow{2}{*}{$\underset{\text { observations }}{\mathrm{N}}$} & \multirow[b]{2}{*}{ metric } & \multicolumn{2}{|c|}{ SDNN } & \multicolumn{2}{|c|}{ r-MSSD } & \multicolumn{2}{|r|}{ HF } & \\
\hline & & & & $\begin{array}{c}\% \\
\text { change }\end{array}$ & $95 \%$ CI & $\begin{array}{c}\% \\
\text { change }\end{array}$ & $95 \%$ CI & $\begin{array}{c}\% \\
\text { change }\end{array}$ & $95 \%$ CI & $\begin{array}{c}\% \\
\text { change }\end{array}$ & $95 \% \mathrm{CI}$ \\
\hline $\begin{array}{l}\text { Boston Elders, } 1997 \\
\text { (Gold et al. 2000) }^{8}\end{array}$ & 20 & 163 & $4 \mathrm{hrs}$ & -2.8 & $(-6.4,0.8)$ & -10.0 & $(-15.4,-4.6)$ & & & & \\
\hline $\begin{array}{l}\text { Baltimore PM Study, } 1998 \\
(\text { Creason et al. 2001) }\end{array}$ & 56 & $\begin{array}{c}\text { up to } 12 \\
\text { per subject }\end{array}$ & 1 day & & & & & -14.9 & $(-25.9,-2.3)$ & -12.9 & $(-20.6,-4.5)$ \\
\hline $\begin{array}{l}\text { Vancouver } 1998 \\
(\text { Ebelt et al. 2005) }\end{array}$ & 19 & 76 & 1 day & -8.0 & $(-23.0,6.9)$ & -13.4 & $(-42.6,15.9)$ & & & & \\
\hline $\begin{array}{l}\text { Boston Elders, } 1999 \\
(\text { Schwartz et al. 2005) }\end{array}$ & 28 & 310 & $24 \mathrm{hrs}$ & -2.6 & $(-6.0,0.8)$ & -10.1 & $(-16.9,-2.8)$ & & & & \\
\hline $\begin{array}{l}\text { Utah, 1990-2001 } \\
(\text { Pope et al. 2004) }\end{array}$ & 88 & 250 & 1 day & -2.7 & $(-3.9,-1.4)$ & -6.1 & $(-9.3,-3.0)$ & & & & \\
\hline $\begin{array}{l}\text { Mexico City, } 2002 \\
\text { (Holguin et al. 2003) }^{26}\end{array}$ & 34 & 384 & 1 day & & & & & -19.3 & $(-29.2,-8.0)$ & -8.4 & $(-19.3,4.0)$ \\
\hline $\begin{array}{l}\text { Normative Aging Study, 2000-03 } \\
(\text { Park et al. 2005) }\end{array}$ & 497 & 497 & $24 \mathrm{hrs}$ & -2.7 & $(-9.5,4.5)$ & & & -16.2 & $(-28.9,-1.2)$ & 0.8 & $(-12.0,15.3)$ \\
\hline Steubenville 2000 & 32 & 638 & 1 day & -4.0 & $(-7.0,-0.9)$ & -6.5 & $(-12.1,-0.6)$ & -11.4 & $(-21.5,-0.1)$ & -10.7 & $(-20.1,-0.3)$ \\
\hline
\end{tabular}


Figure1

Click here to download high resolution image

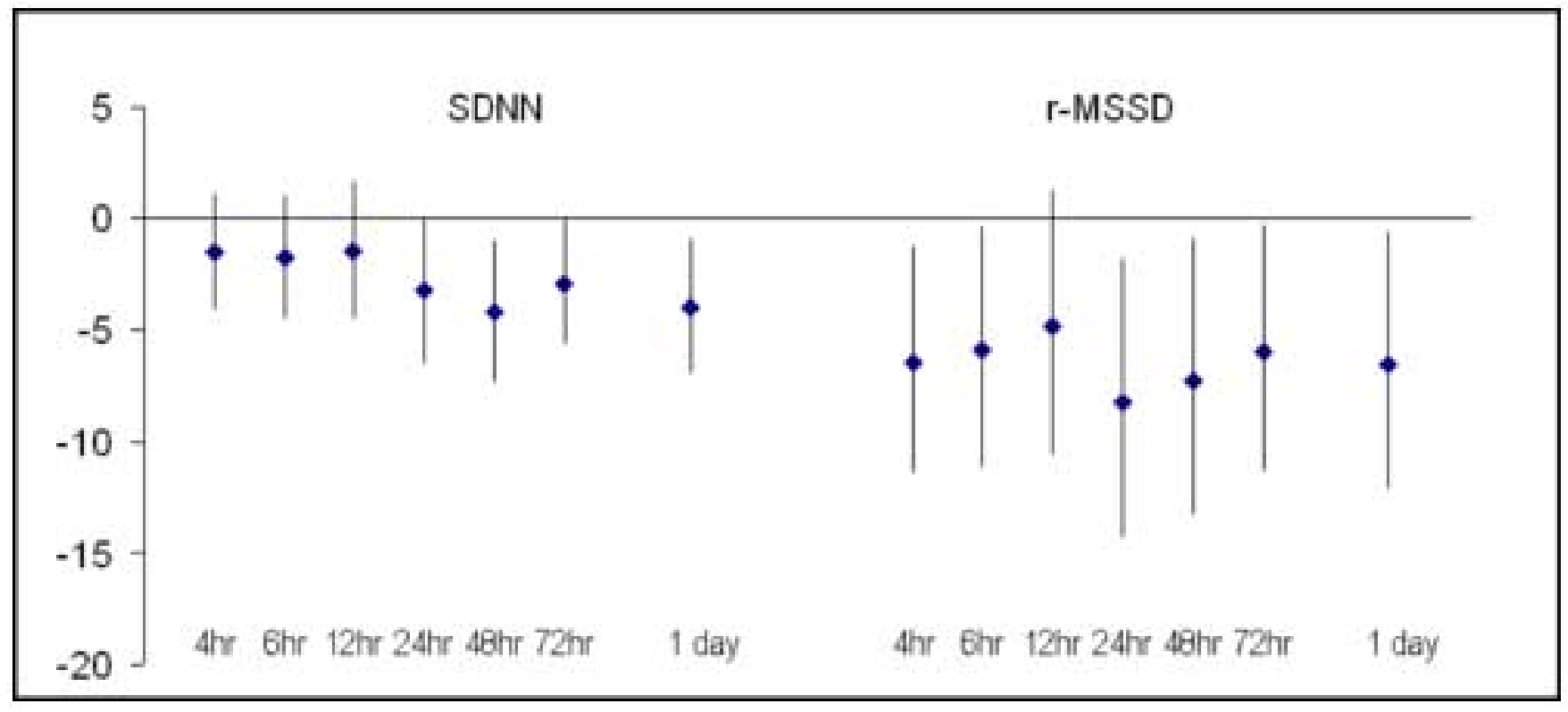


Figure 2
Click here to download high resolution image

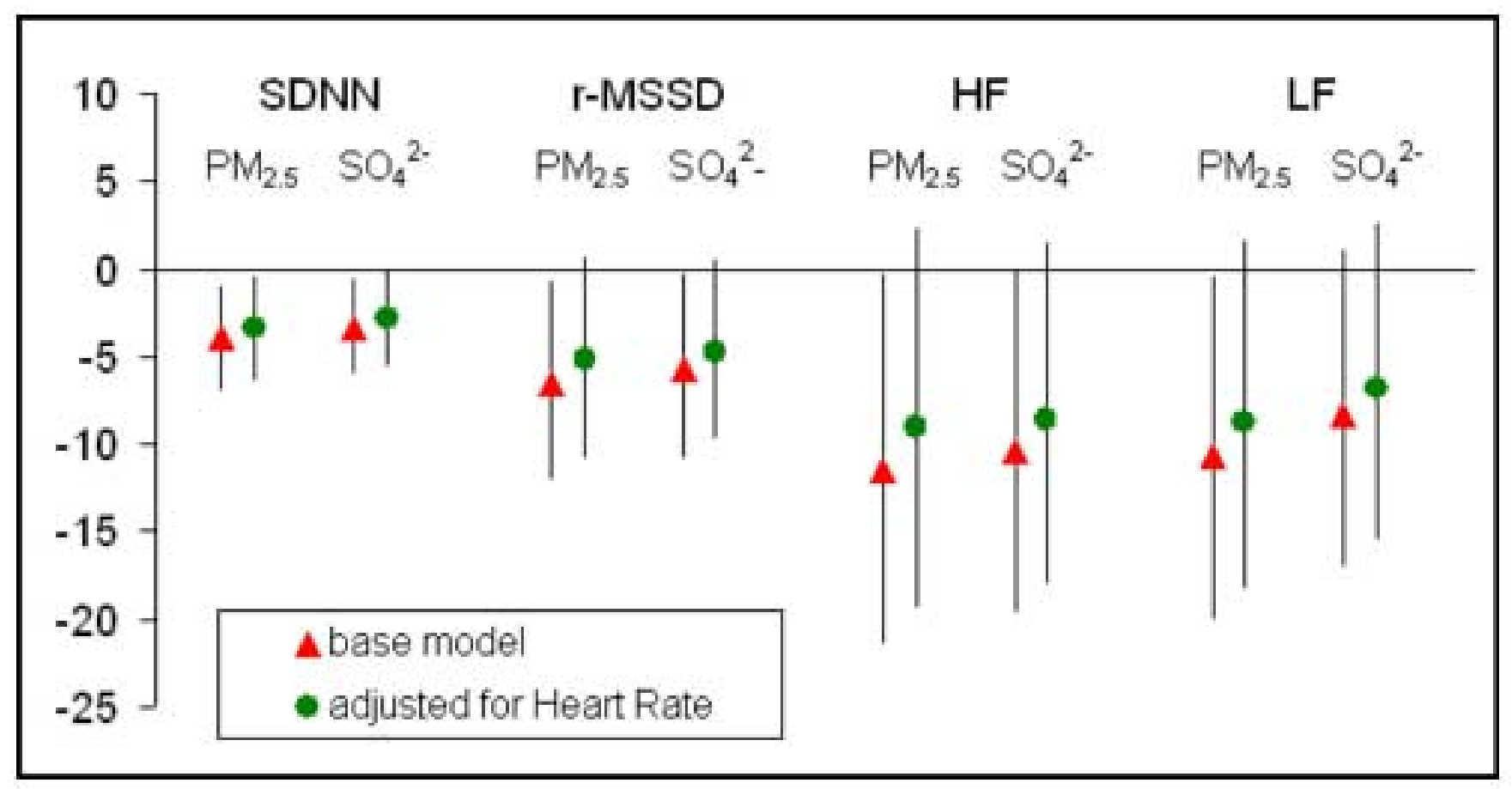

